$$
\text { الأثار الخارجية الاقتصادية: }
$$

Economic Externalities: Theory and Solutions

$$
\begin{aligned}
& \text { د. عيد عشري جابر } \\
& \text { مدرس بقسم الاقتصاد و المالية العامة } \\
& \text { كلية الحقوق - جامعة حلو ان } \\
& 2020
\end{aligned}
$$




\section{مُلذّص البحث}

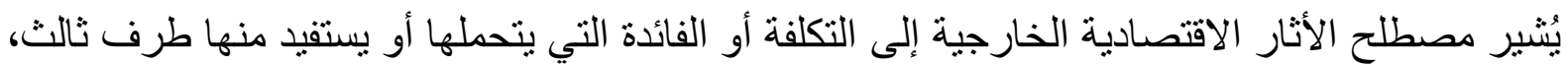

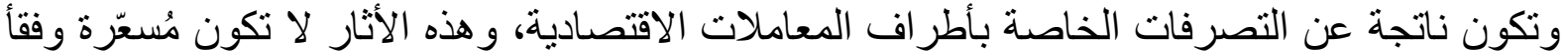

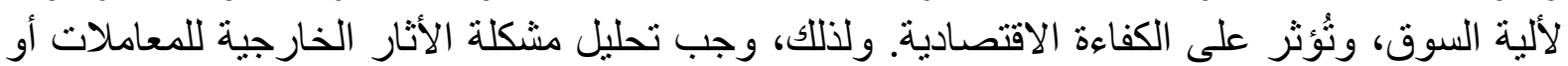

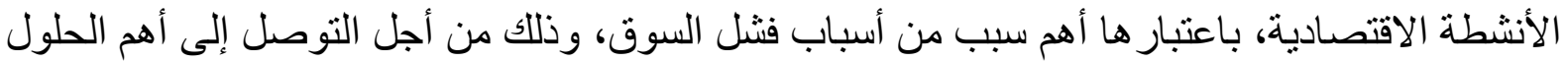

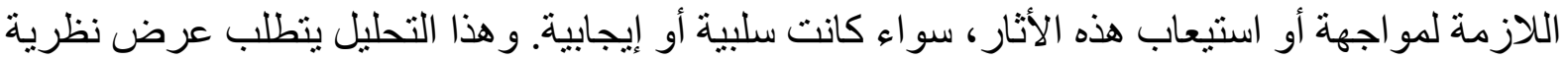

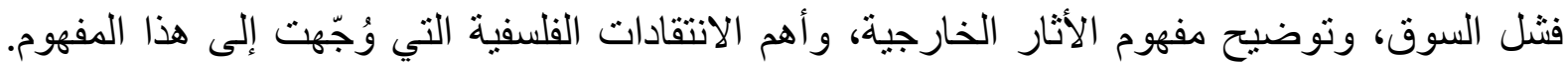

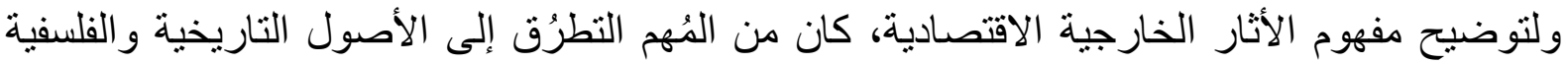

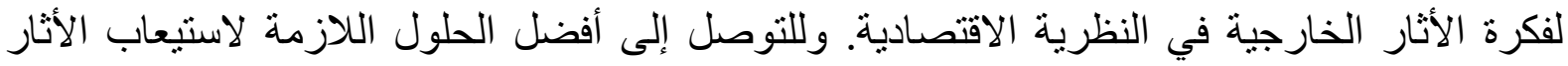

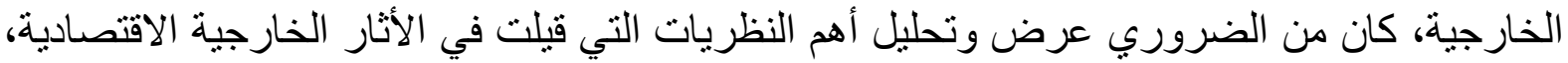
وخصوصًا أهم الحلول التي قدمتها هذه النظريات.

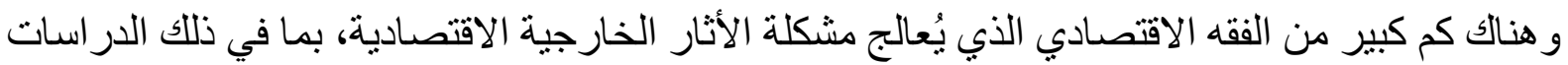

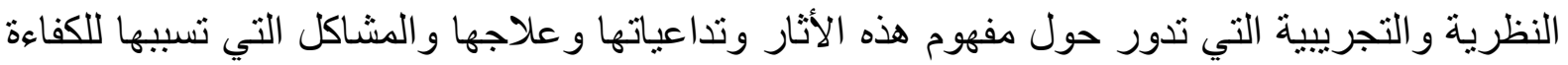

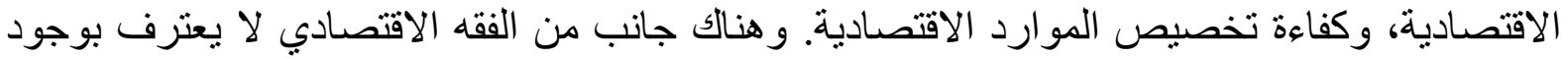

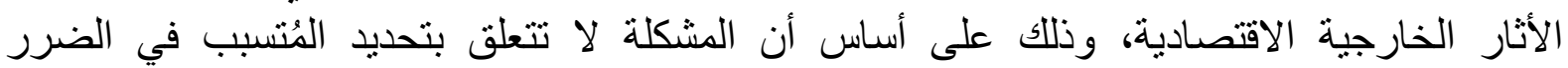

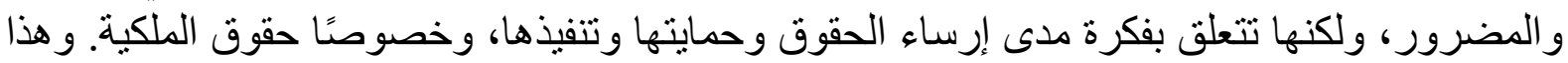

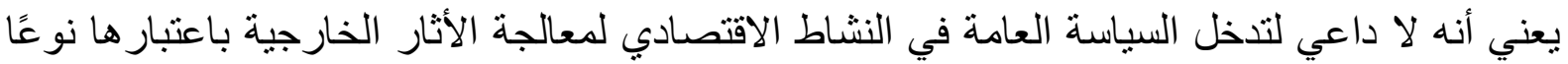

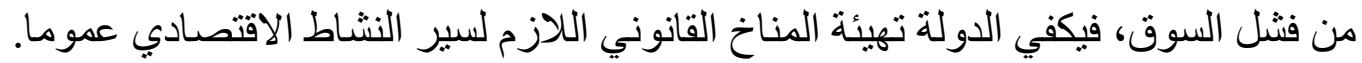

أما بالنسبة للجانب الفقهي الأخر، وهو الجانب الأكبر، فيعترف بوجود الأثار الخارجية. ولكن يظهر الأبران

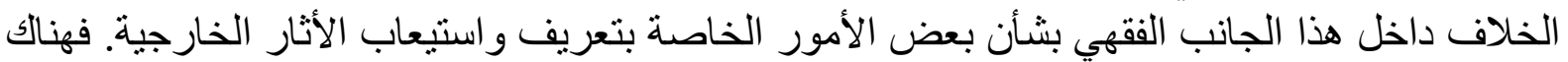

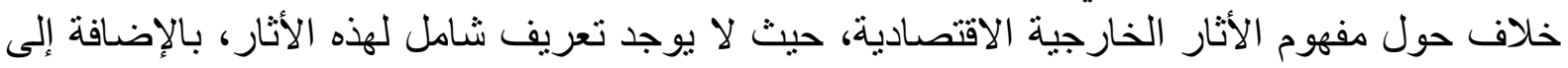

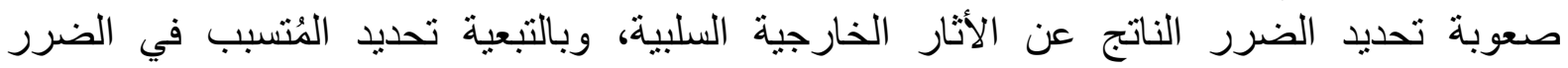

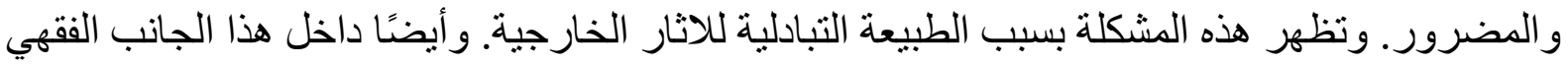

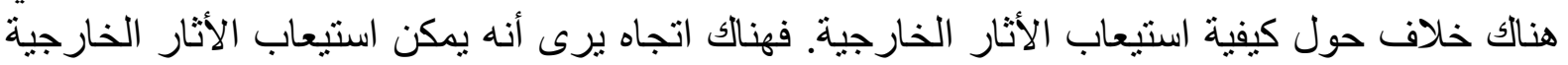

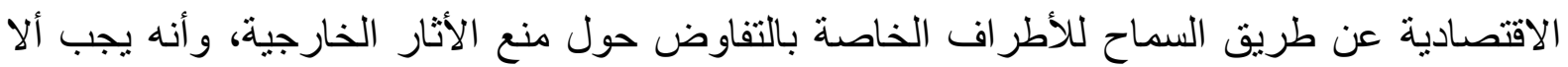

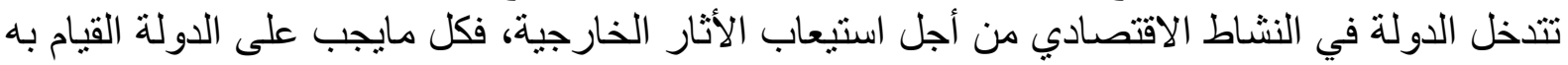

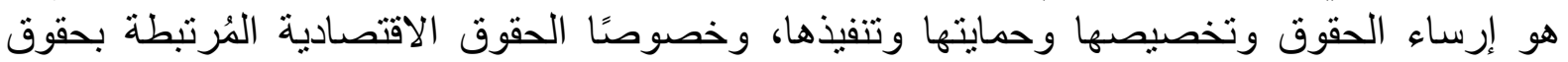

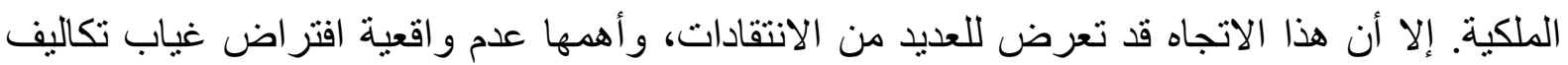

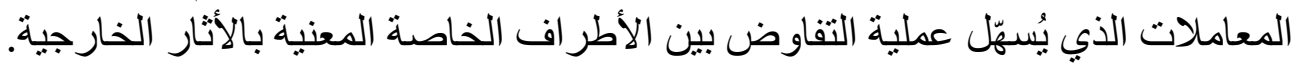

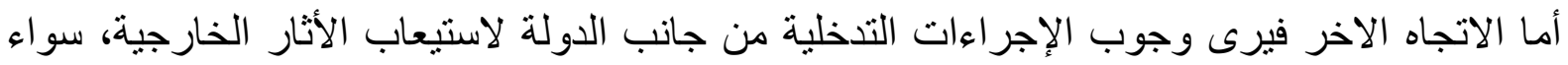

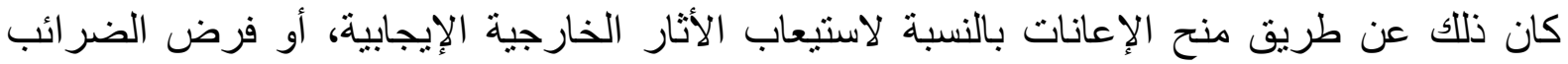

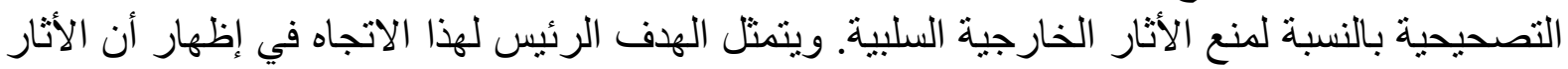

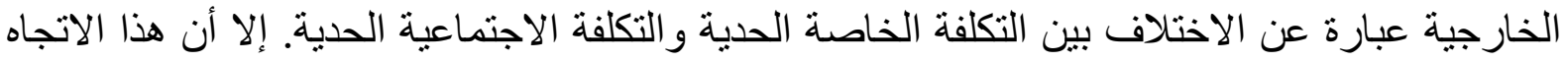

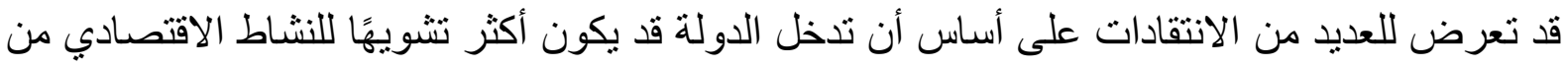

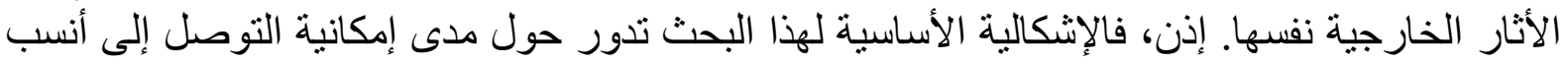

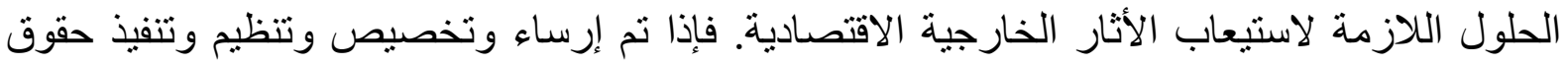


الملكية العامة والخاصة، وأيضًا تنظيم الجوانب الأخلاقية للمعاملات الاقتصادية، فإن ذلك سيساهم في استيعاب العديد من أنو اع الأثار الخارجية الإقتصادية. 


\begin{abstract}
The term 'economic externality' refers to the cost or benefit that is borne or benefited by a third party. These cost or benefit result from the acts of the parties to economic transactions, and these effects are not priced according to the market mechanism, though it affects the economic efficiency and resource allocation. Therefore, it is necessary to analyze the problem of economic externalities, as it is one of the main causes of market failure. This analysis would be critical to reach effective solutions needed to internalize these externalities, whether they are negative or positive externalities. This analysis requires presenting the theory of market failure, clarifying the concept of externality, and the philosophical criticisms directed at this concept. To clarify the concept of economic externalities, it is crucial to present the historical and philosophical origins of externalities in economic theory. In order to reach appropriate solutions needed to internalize economic externalities, it was necessary to describe and analyze the essential economic theories that deal with the economic externalities, especially the most adequate solutions presented by these theories.
\end{abstract}

There is a large amount of economic literature that deals with the problem of economic externalities, including theoretical and empirical studies that revolve around the concept of externalities and their consequences and internalization, and the problems they cause to the efficient allocation of economic resources. However, on the one hand, there is a part of this economic literature does not recognize the existence of economic externalities, on the grounds that the problem is not related to determining who caused the harm and who is the injured, but rather related to the extent to which rights are established, protected and implemented, especially property rights. This means that there is no need for public policy to intervene in economic activity to address externalities as a type of market failure. It is sufficient for the state to create the legal environment necessary for conducting economic activity in general.

On the other hand, the significant part of economic literature admits the existence of economic externalities. However, within this part, there are certain controversial issues regarding the definition and internalization of economic externalities. There is disagreement about the concept of economic externalities, as there is no comprehensive definition of externality concept, and it is difficult to determine the damage resulting from negative externalities and accordingly to determine the cause of the damage and the injured party. This problem appears due to the reciprocal nature of externalities. Moreover, there is a disagreement about how to internalize economic externalities. Some economists advocate that economic externalities can be dealt with by allowing private parties to negotiate about preventing externalities, and that the state should not interfere in economic activity in order to eliminate externalities. Accordingly, 
all that the state should do is to establish, allocate, protect and implement rights, especially economic rights associated with property rights. However, this philosophy has been criticized, as it is based on the unrealistic assumption of the absence of transaction costs, which facilitates the negotiation process between private parties concerned with externalities.

Other economists argue that the intervention measures by the state are necessary to prevent externalities, whether that is by granting subsidies in relation to internalizing the positive externalities, or imposing corrective taxes in relation to preventing negative externalities. The main objective of this argument is to show that externalities are the difference between marginal private cost and marginal social cost. However, this argument has been criticized on the grounds that the state intervention may be more distorting to economic activity than externalities itself. Therefore, the main problem of this research revolves around the extent to which it is possible to reach the most appropriate solutions for internalizing the economic externalities. One appropriate solution for eliminating externalities states that if public and private properties rights are established, allocated, organized and implemented, as well as the ethical aspects of economic transactions are regulated, this will contribute to preventing many types of economic externalities. 
في اقتصاد السوق، يُعرَّف السوق بأنه أهم مكان للتنسيق بين المنتجين و المستهلكين بشأن تتفيذ معاملاتهم الاقتصادية. وبعبارة أخرى، السوق هو البيئة التي يلتقي فيها مجموعة من المشترين والبائعين لتبادل

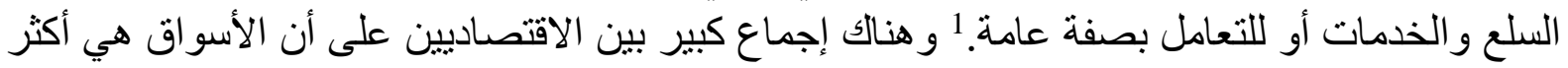
الآليات فعالية من حيث تخصيص الموارد بين الوحدات الاقتصادية المُختلفة. فإذاذا كان نظام السوق

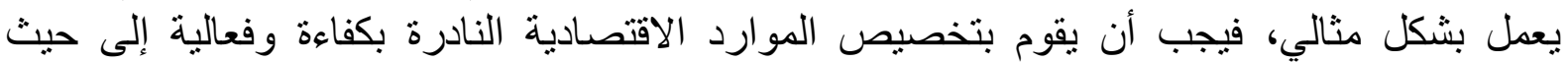
الاستخدام الأفضل لهذه الموارد. ففي الأسواق، يتم اتخاذ قرار ات تخدئ تخصيص الموارد بطريقة لامركزية،

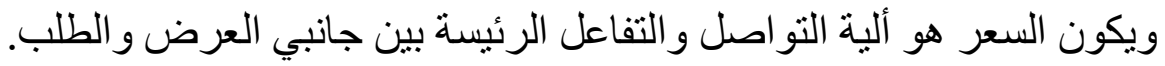

ولكن، غالبًا ما تعمل بعض الأسواق بشكل غير فعّال، ففي بعض الأسواق حيث يوجد عدد كبير جدًا من

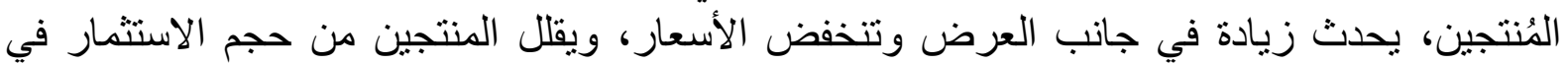

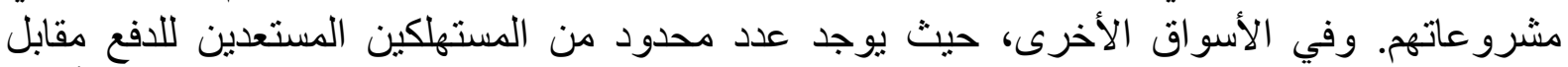

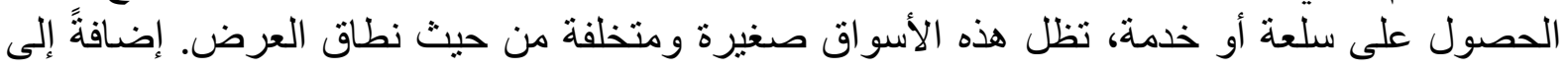

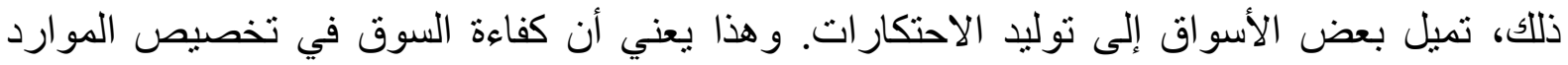

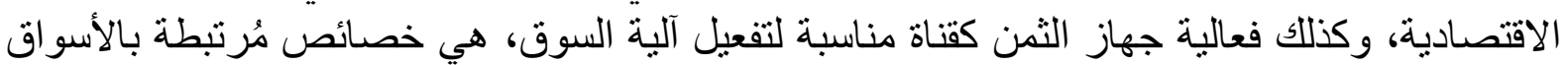

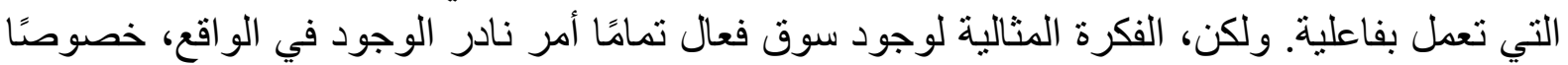

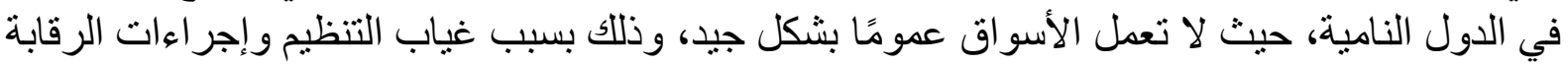

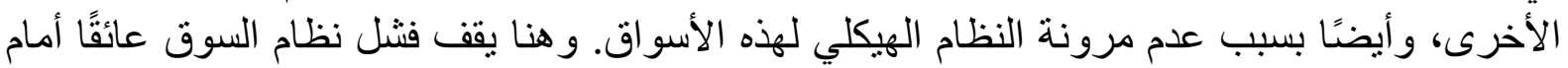

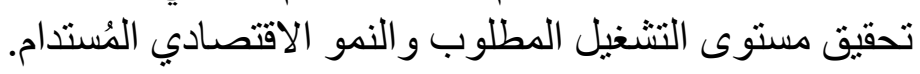

لذللك، يمكن القول أن فثنل السوق يحدث في الحالات التي لا تقوم فيها الأسواق بالدور الفعّال في عملية

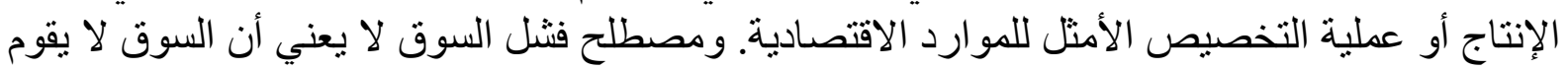

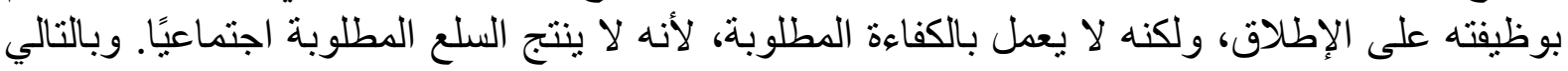

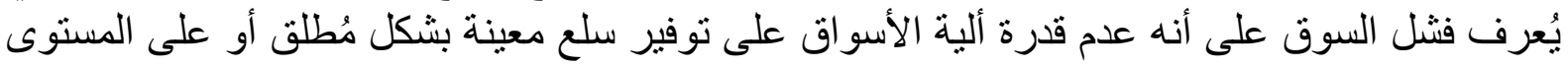

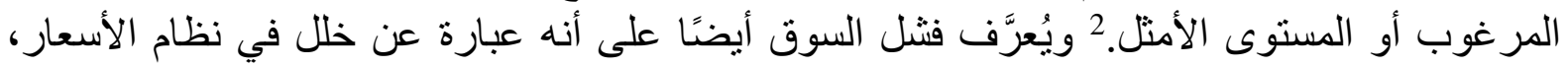

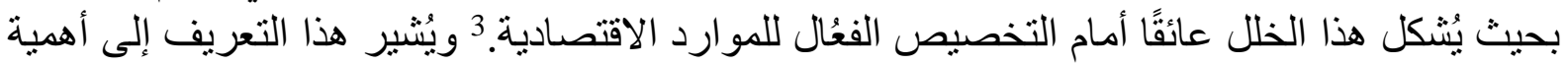
أن يكون نظام الأسعار قادرًا على أن يعكس التكاليف و القيمة الحقيقية للمنتج.

ويجب الإشارة إلى أن هنالك العديد من الحالات المُختلفة لفثل السوق، وقد تغيرت أهمية هذه الحالات،

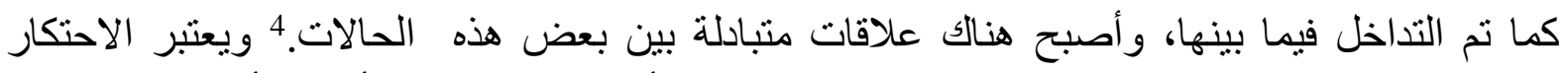

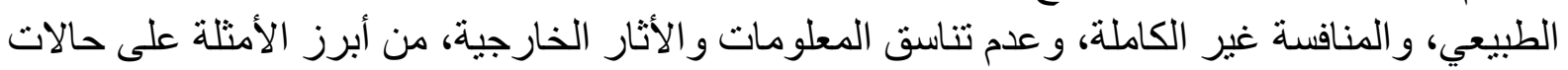
فنثل السوق. 5 ويتمثل السبب الأهم و السائد لفتش السوق في ما يسمى بالأثنار الخارجية. ويطلق على الأثار

${ }^{1}$ Cunningham, S., (2011). Understanding Market Failures in an Economic Development Context. Pretoria, South Africa: Mesopartner Monograph 4, P.11.

${ }^{2}$ Pearce, D.W., (1986). Market Failure. In Macmillan dictionary of modern economics. Pearce, D.W. (Ed.), P.264.

${ }^{3}$ Samuelson, P.A. \& Nordhaus, W.D., (1992). Economics. 14th ed. New York, NY: McGraw-Hill., P.131.

${ }^{4}$ Wolf, C., (1979). “A Theory of Nonmarket Failure: Framework for Implementation Analysis". Journal of Law and Economics, Vol. 22(April), P. 107.

5 Kneese, A. and R. Ayres., (1969). "Production, Consumption, and Externalities," American Economic Review 59, P. 282. 
الخارجية اسم العو امل الخارجية، أو الجو انب الاقتصادية الخارجية، أو اللاوفورات الاقتباديادية، أو الأثار

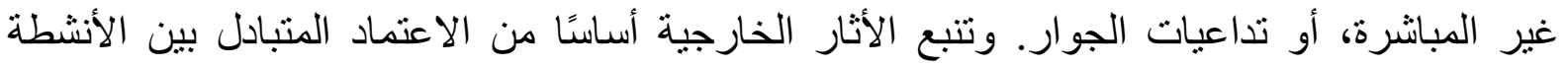

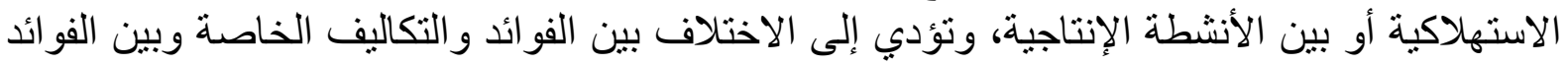

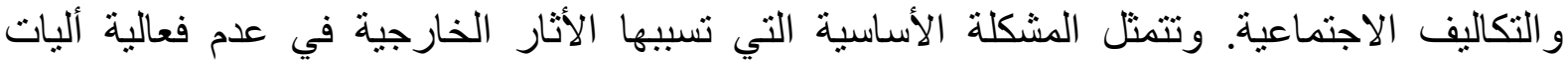

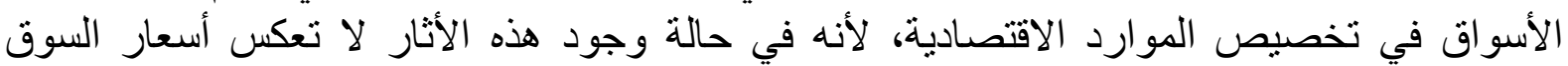

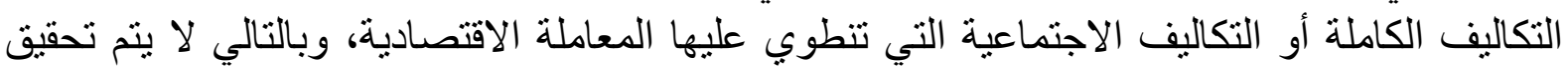

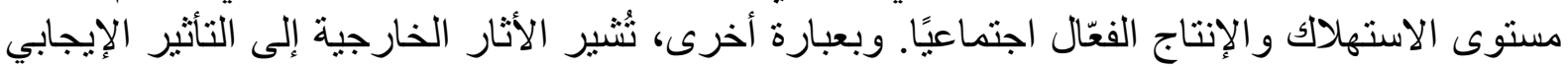

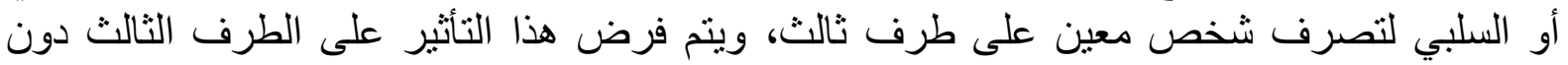

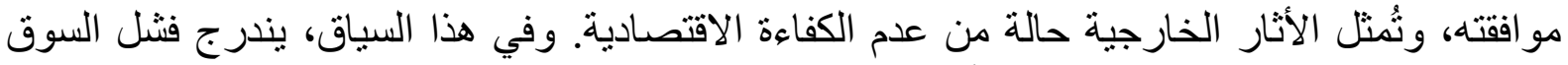
ضمن فئة عامة من أسباب فثل السوق تُسمى الأثار الخارجية الاقتصادية.

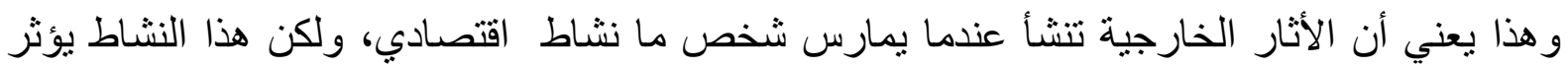

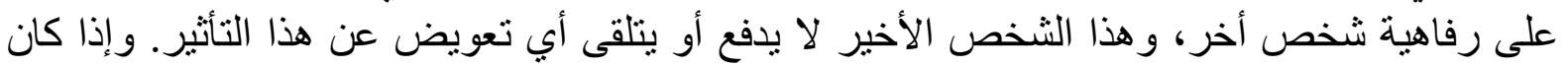

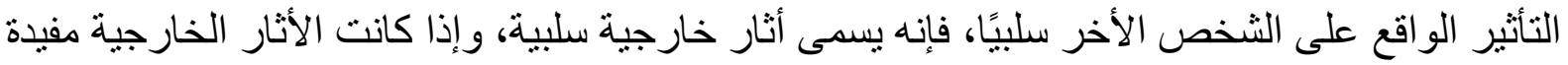

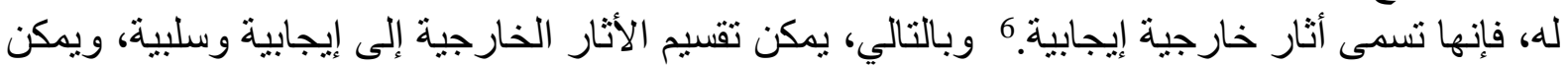

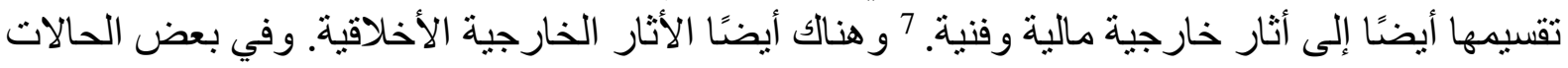

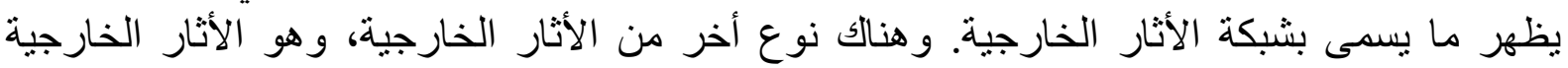

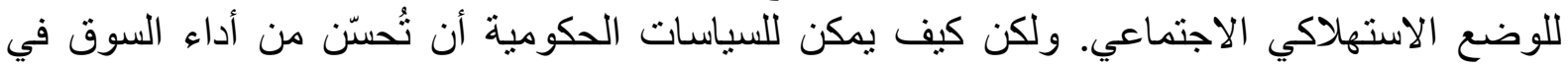
تخصيص الموارد الاقتصادية، وما هي أنواع السياسات التي يمكن أن تعمل بشكل أفضل في في هذا النيات المجال.

ومن المُلاحظ أن هناك توسع كبير وانتشار واسع للكتابات الفقهية والأكاديمية حول الأثار الخارجية

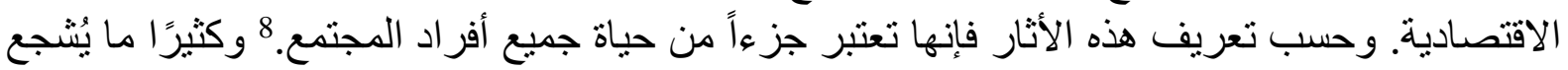

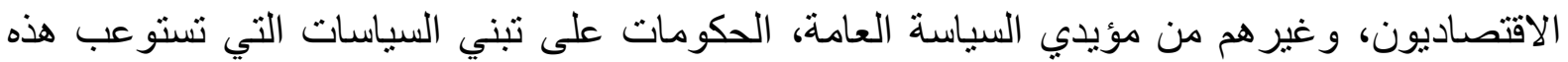

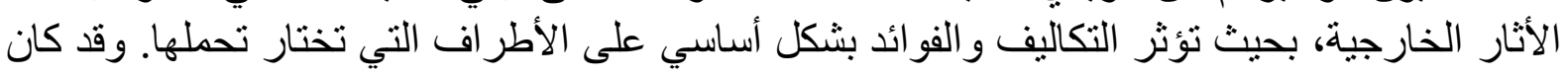

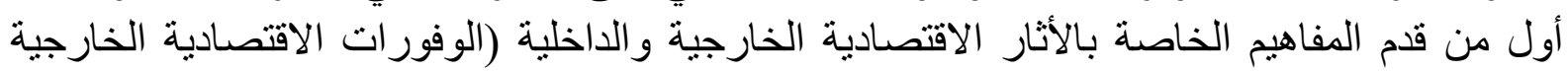
و الداخلية) هم ألفريد مارشال، وآرثر سيسيل بيجو.

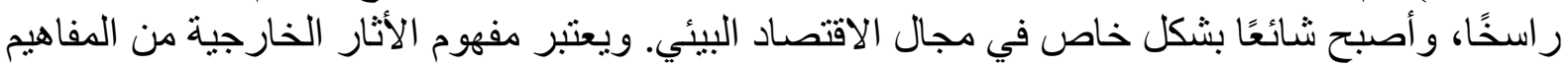

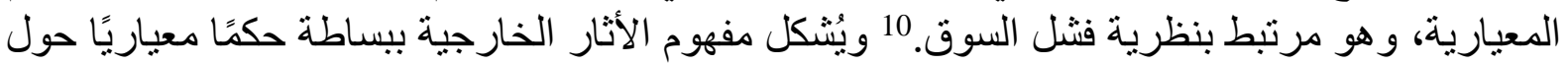

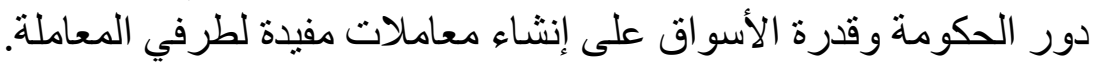

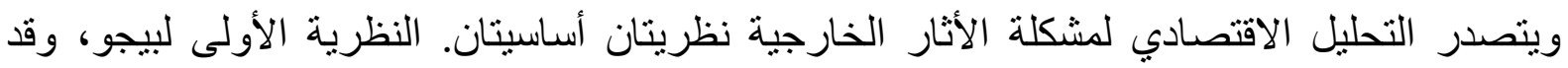

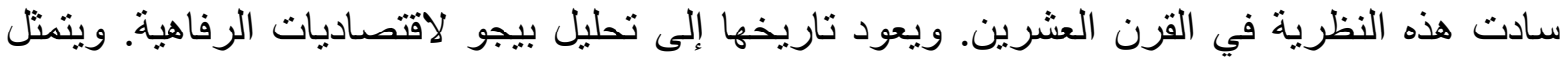

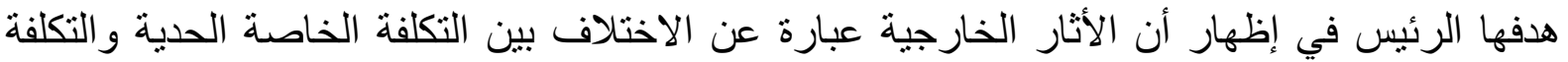

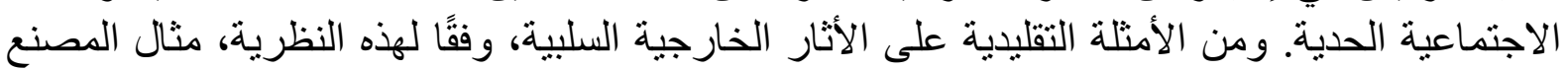

\footnotetext{
${ }^{6}$ Meade, J. E., (1973). The Theory of Economic Externalities: The Control of Environmental Pollution and Similar Social Costs. Leiden: Sijthoff, P.15.

${ }^{7}$ Bryan Caplan, Externalities, Libr. Econ. and Liberty, available at:

$<$ https://www.econlib.org/library/Enc/Externalities.html?highlight=\%5B \%22externality\%22\%5D >.

8 Roger Meiners, (2017). Externalities: Bad Economics, Good Law, in Exploration in public sector economics: Essays by prominent economists (J. Hall ed., 2017), P.61.

${ }^{9}$ Edwin S. Mills \& Philip E. Graves, (1986). The Economics of Environmental Quality, 2 (2d ed.).

${ }^{10}$ Carl Dahlman, (1979). The Problem of Externality, 22 J. L. \& ECON., P. 141.
} 
الذي ينبعث منه الأدخنة أو يتخلص من النفايات في نهر معين، وفي كلتا الحالتين يتسبب في الإضرار

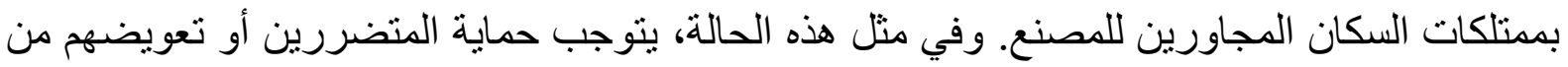

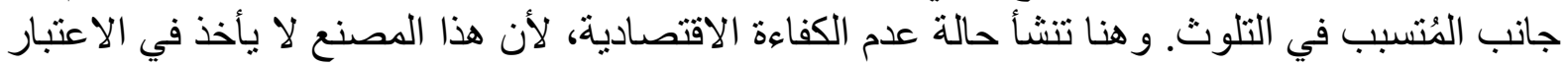

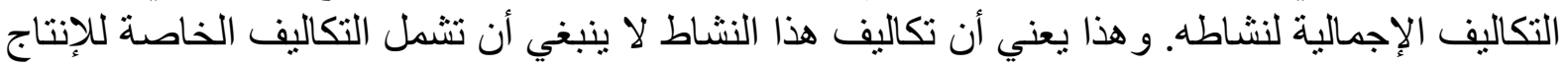

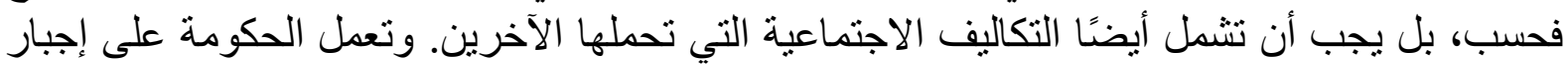

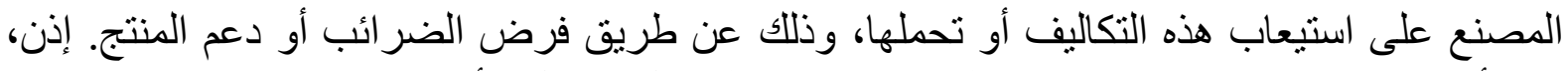
يبدو أن نظرية بيجو لديها نظرة متفائلة لقدر ات الدولئ وذلة على حل مشاكل الأثار الخارجية.

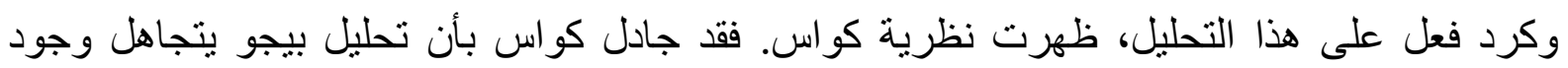

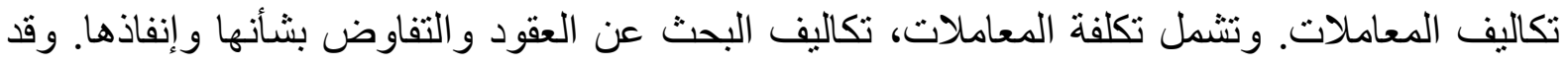

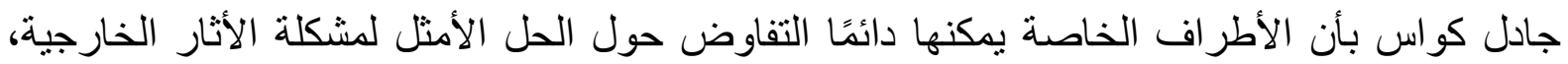

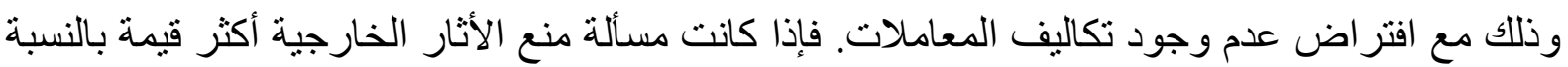

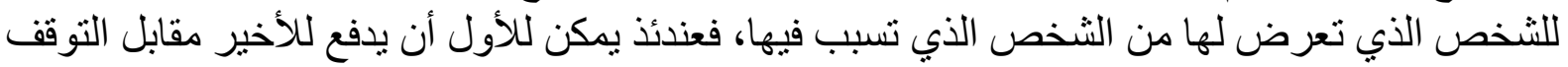

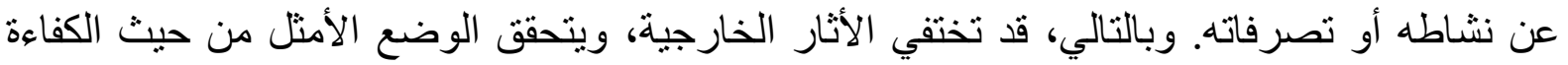

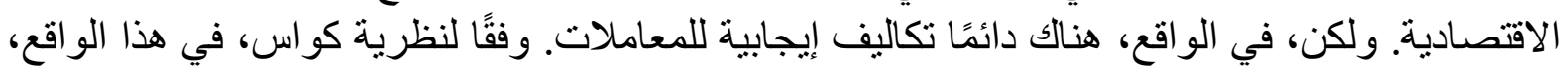

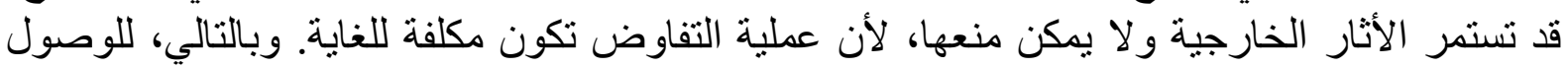

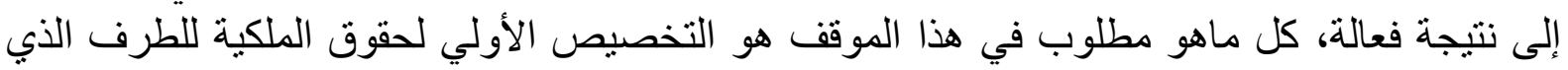

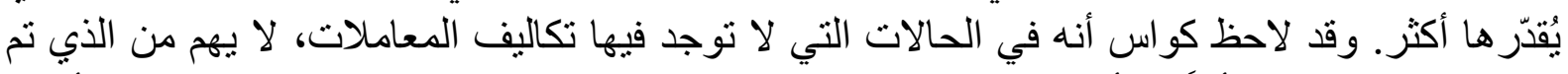

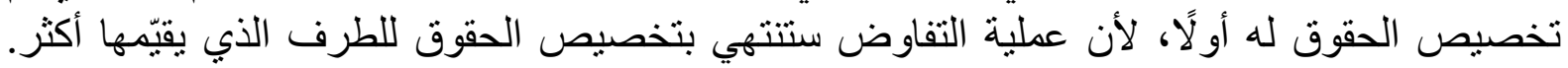

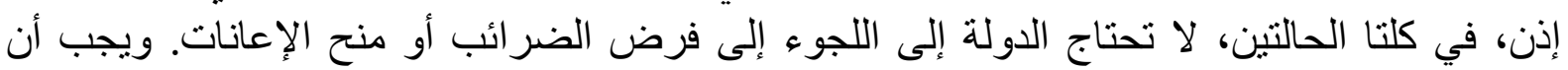

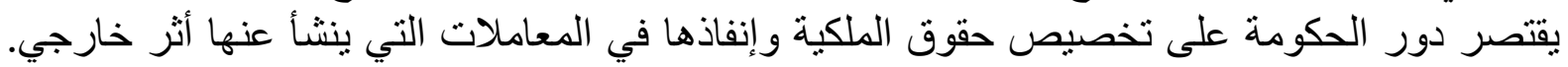
ويمكن للسوق القيام بباقي الأمر.

ومن أحدث النظريات التي قيلت في تفسير وتحليل الأثار الخارجية الاقتصادية هي نظرية التوقعات.

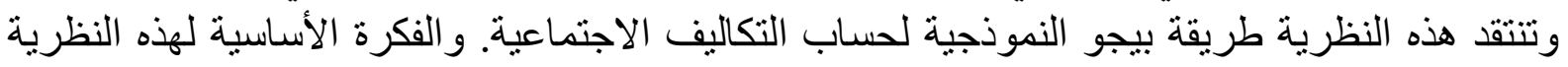

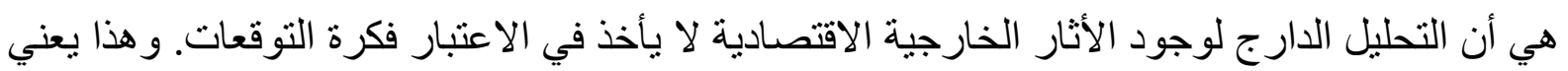

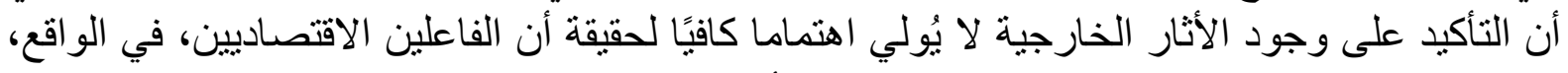

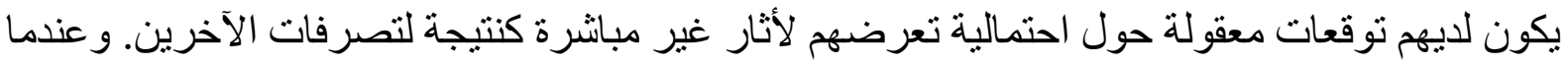

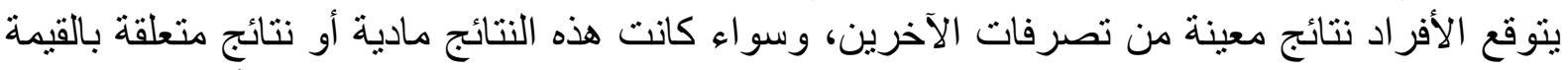

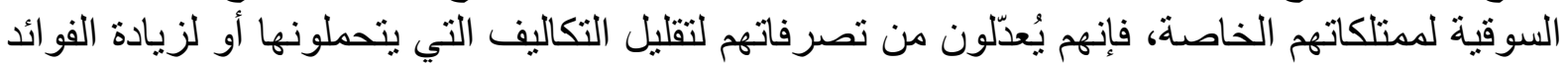

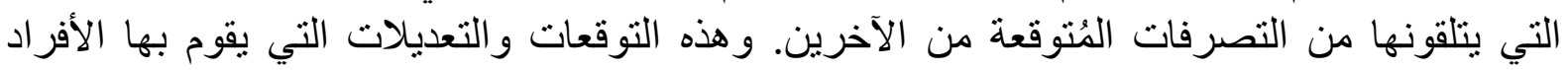

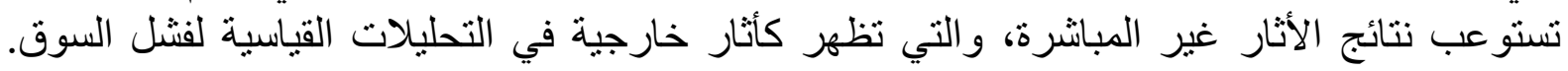

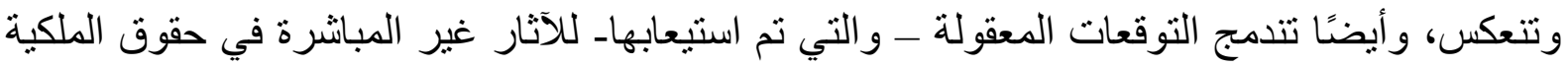

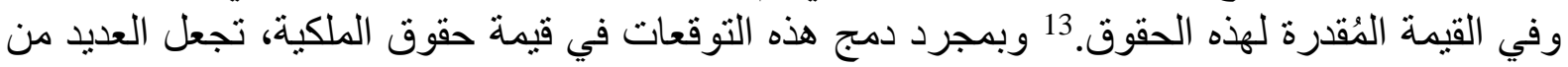

\footnotetext{
${ }^{11}$ Claassen, Rutger., (2016). Externalities as a basis for regulation: a philosophical view. Journal of Institutional Economics, 1, P. 15.

${ }^{12}$ Coase, R. H., (1960). 'The Problem of Social Cost', The Journal of Law and Economics, 3, P. 22.

${ }_{13}$ M. Rahmatian \& L. Cockerill, (2004). Airport Noise and Residential Housing Valuation in Southern California: A Hedonic Pricing Approach 1 INT'L J. ENVTL. SCI. \& TECH., PP. 17- 18.
} 
الأثار غير المباثرة، والتي تظهر من خلال الملاحظة العرضية على أنها أثنار خارجية، لتكون في الواقع جزءاً من هيكل حقوق الملكية.

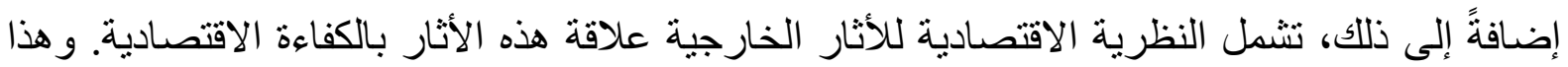

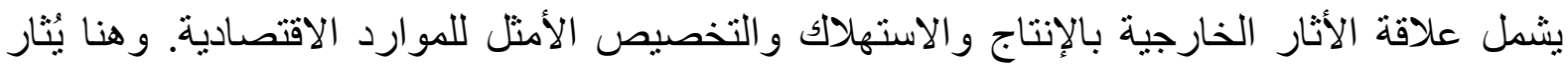

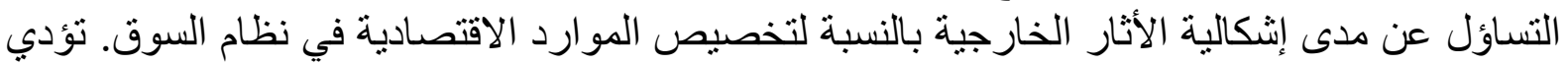

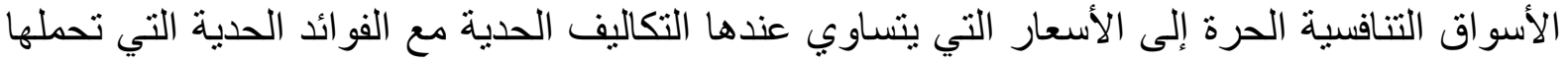

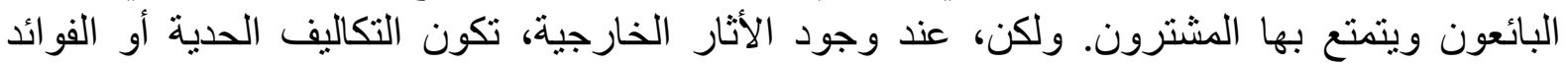

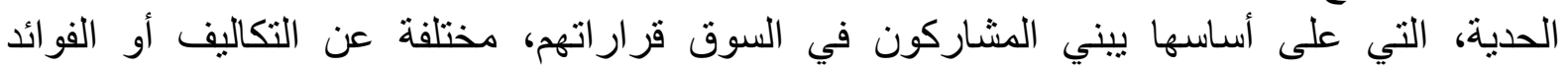

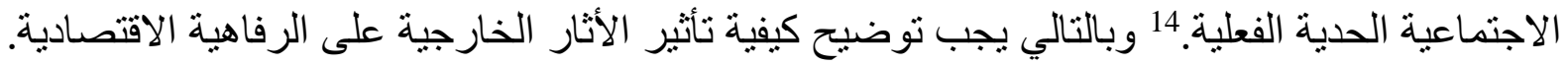
ويوضح هذا التحليل على وجه التحديد كيف أن الأثار الخارجية تتسبب في قيأي التار الأسواق بتخصيص

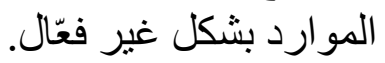

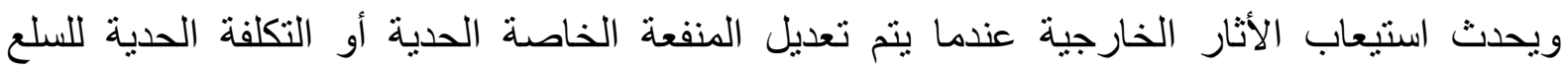

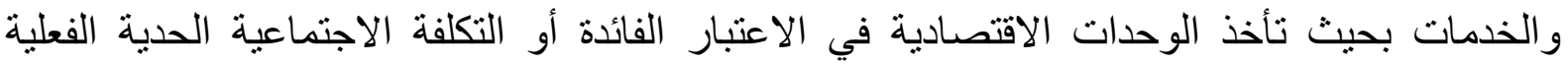

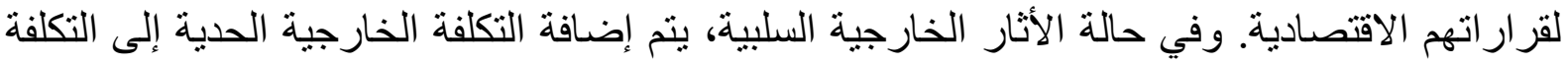

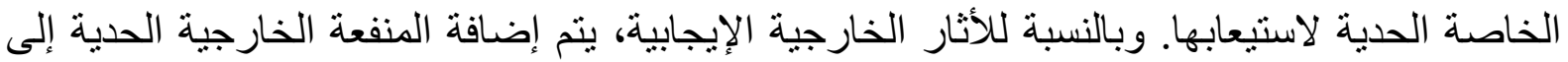

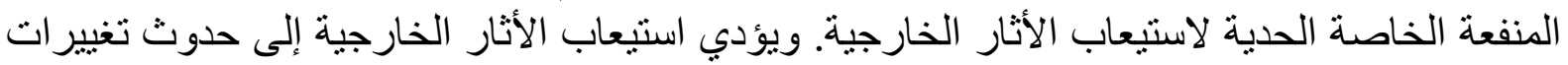

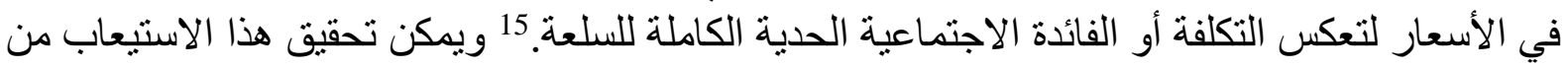

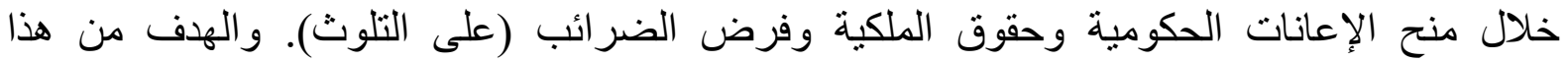

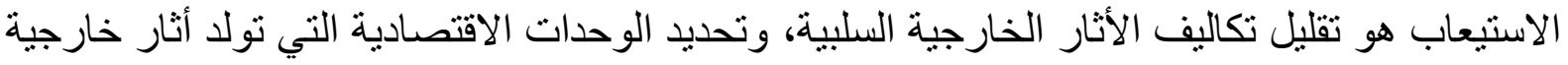

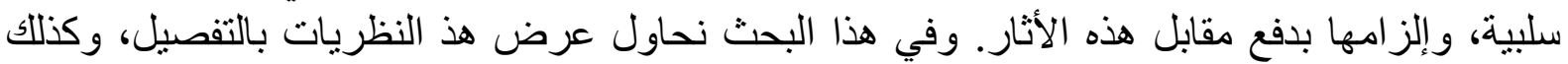
الحلول الممكنه لاستيعاب الأثار الخارجية الانتارية وفتصادية.

\footnotetext{
${ }^{14}$ Heller, Walter P., and David A. Starrett, (1976). "On the Nature of Externalities." In Steven A. Y. Lin, ed., Theory and Measurement of Economic Externalities. New York: Academic Press, PP. 9-21.

${ }^{15}$ Berta, Nathalie, and Elodie Bertrand, (2014). "Market Internalization of Externalities: What Is Failing?" Journal of the History of Economic Thought 36 (3), P. 331.
} 
يزخر الفقه الاقتصادي بكم هائل من الكتابات التي تُعالج مشكلة الأثنار الخارجية الاقتصادية، بما في ذلك

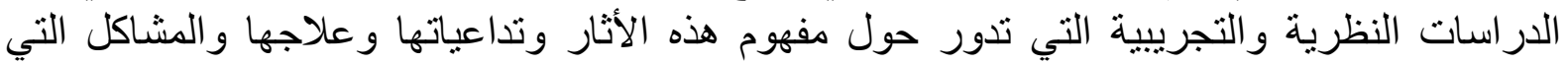

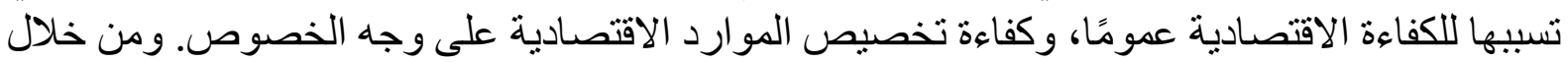

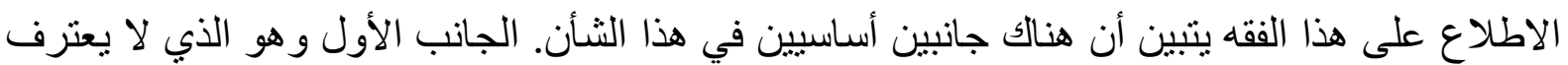

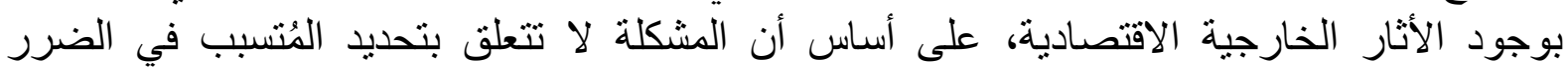
و المضرور، ولكنها تتعلق بفكرة مدى إرساء الحقوق وحمايتها وتنفيذها، وخصوصيًا حقوق الملكية. وهذا لإنة

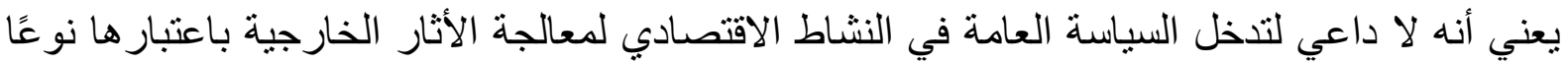
من فثل السوق، فيكفي الدولة تهيئة المناخ القانوني اللازم لسير النشاط الاقتهادي لهي عمومًا.

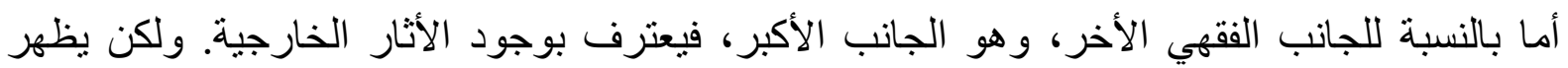

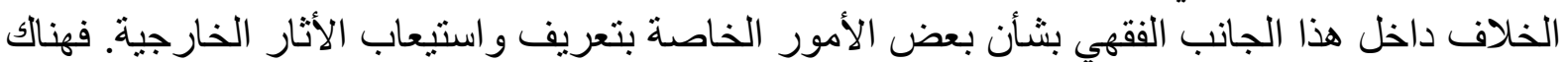

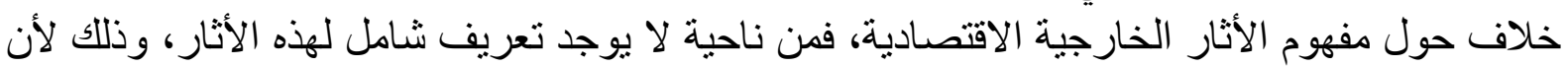

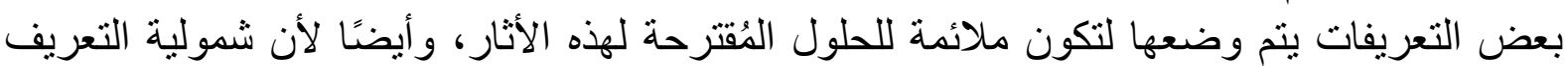

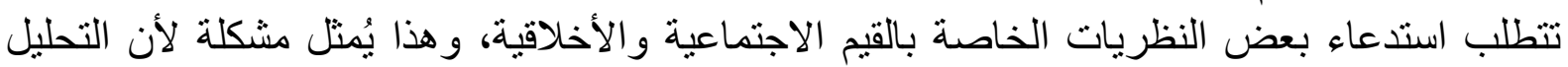

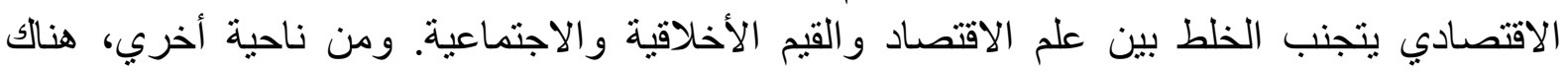

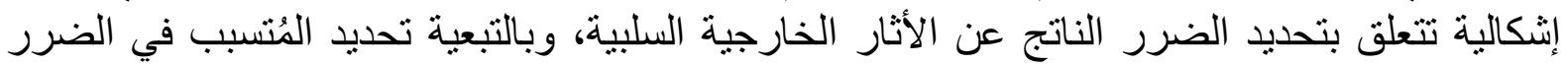
و المضرور ـ وتظهر هذه المشكلة بسبب الطبيعة التبادلية للاثار الخارجية، فقد يدعي المُتسبب في الضرر

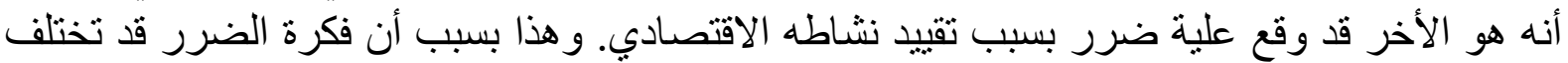

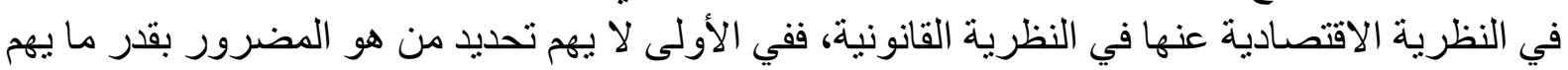

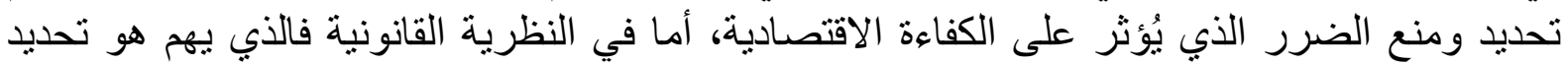

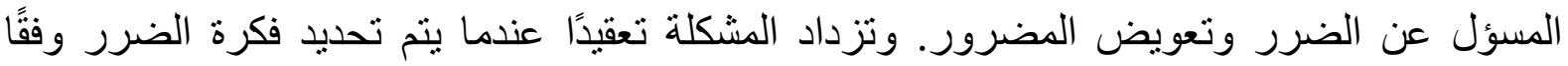
للمعايير القانونية السائدة، وهذه المعايير قد تكون تحكمية وشخصية، وقد يُساء استخدامها لصالح

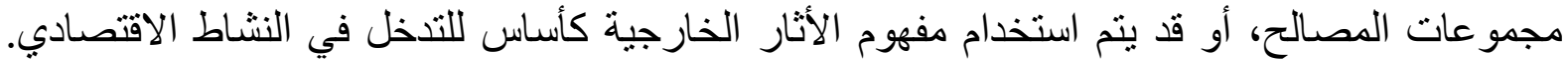
و هنا يمكن القول أنه يجب البحث عن معيار موضوعي كأساس لتحديد الضرر، بشرط أنسا أن يكون هذا

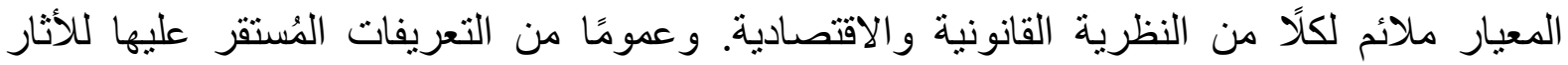
الخارجية الاقتصادية في الفقه الحالى، هي أنها عبارة عن التكلفة أو الفائدة التي يتحملها أو يستفيد منها التها

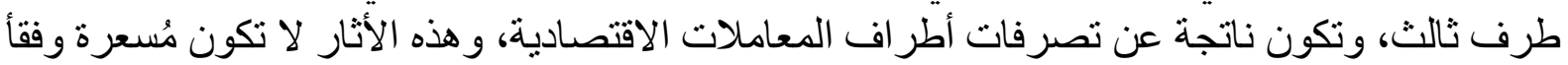

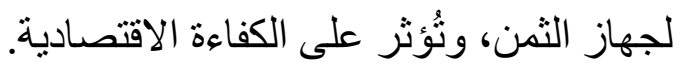

وتظهر الإشكالية الأخرى لهذا البحث في الخلاف حول كيفية استيعاب الأثنار الخارجية. فهناك اتجاه،

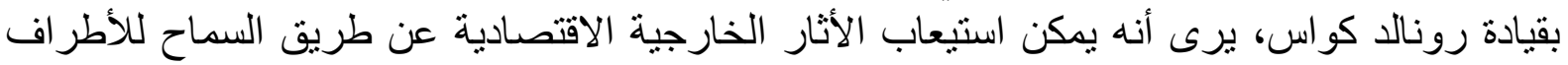

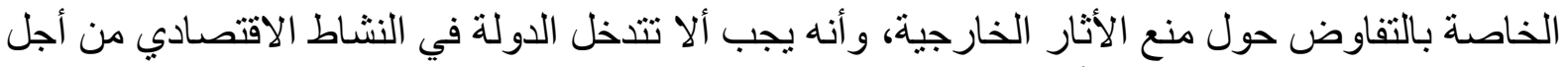

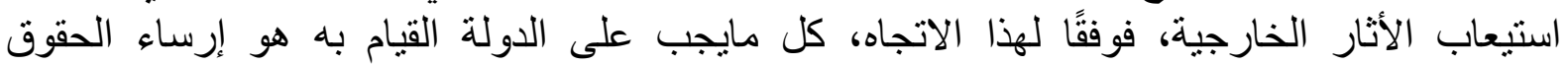

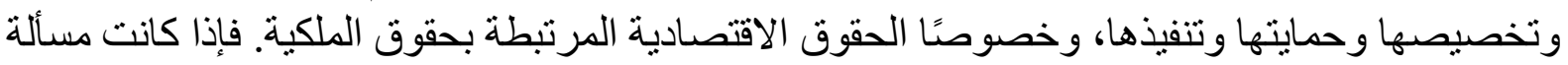

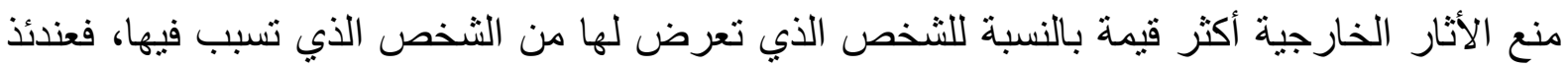

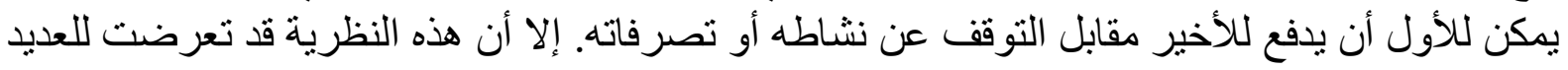

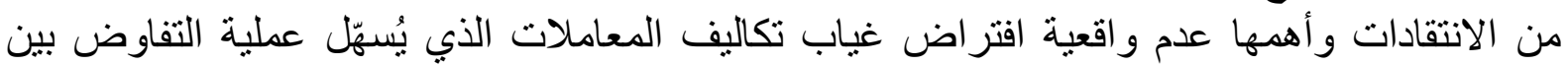

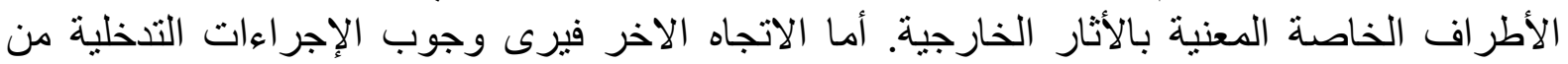

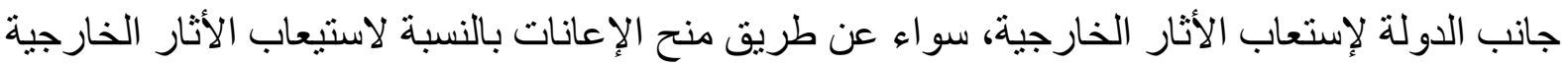


الإيجابية أو فرض الضر ائب التصحيحية بالنسبة لمنع الأثار الخارجية السلبية. ويتمثل الهدف الرئيس لهذا

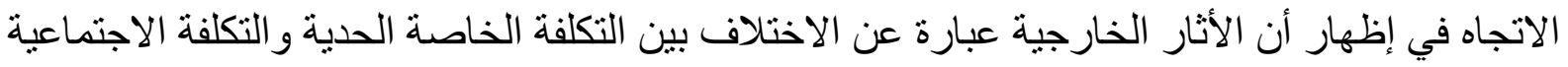

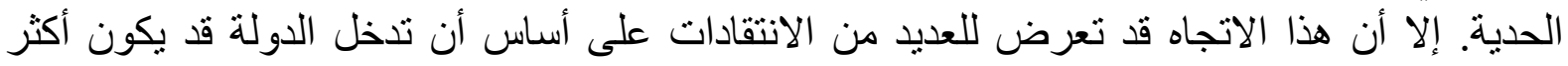
تشويهًا للنشاط الاقتصادي من الأثار الخارجية نفسها. إذن فالإشكالية الأساسية لهذا البحث تدور حول مدى إمكانية التوصل إلى أنسب الحلول اللازمة لاستيعاب

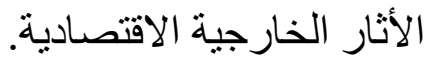

أسئلة البحث البث يدور السؤال الرئيس لهذا البحث حول ماهية الحل الملائم أو الأفضل لمواجهة أو استيعاب الأثار

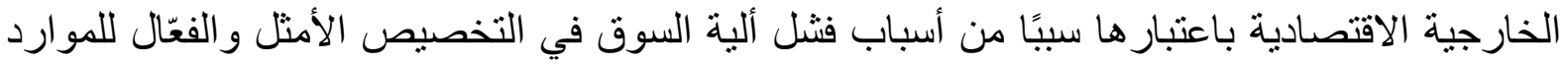

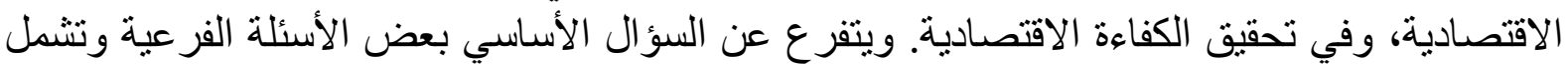
ما يلي: - n

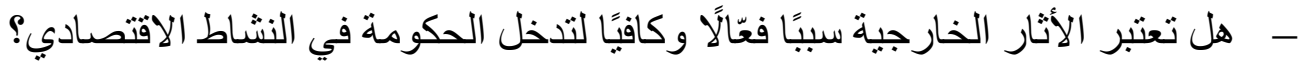

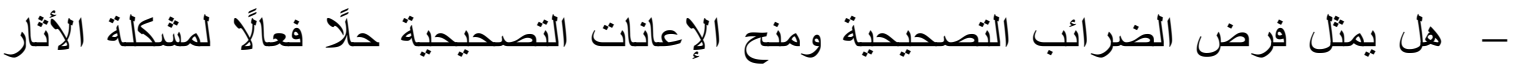

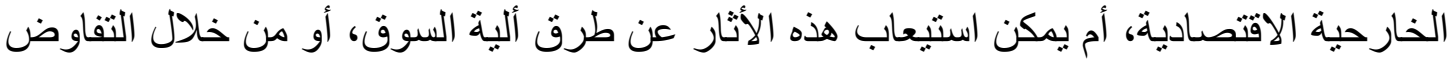

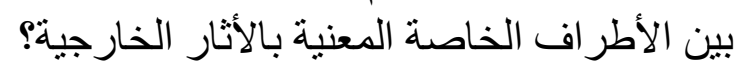

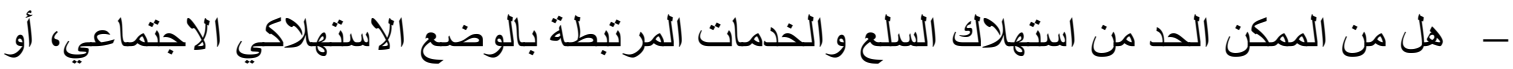

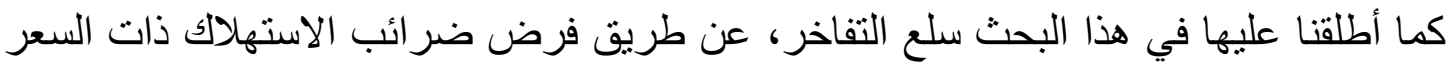

$$
\text { التصاعدي؟ }
$$

أهداف البحث يتمثل الهدف الرئيس لهذا البحث في تحليل مشكلة الأثار الخارجية للمعاملات أو الأنشطة الاقتصادية،

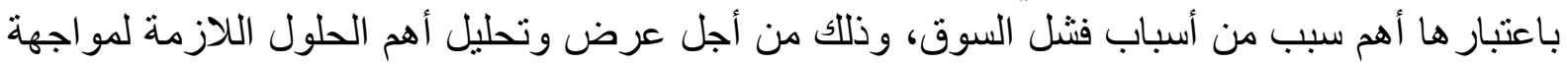

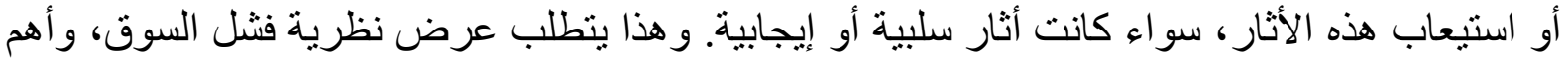

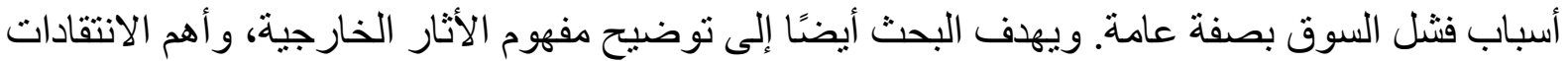

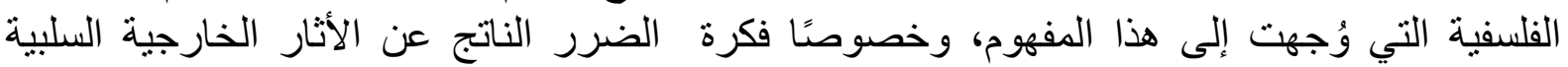

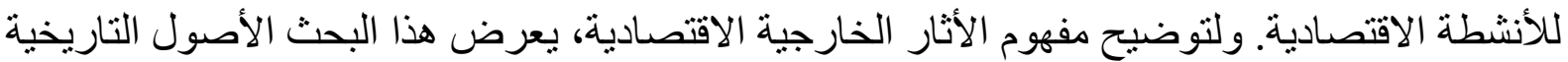

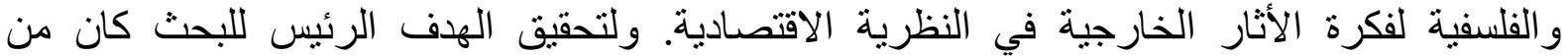

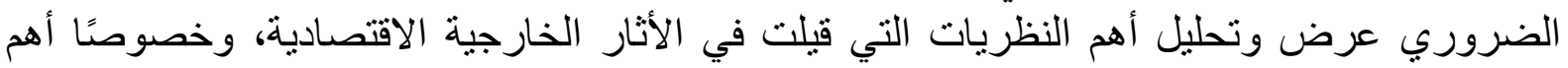
الحلول التي قدمتها هذه النظريات.

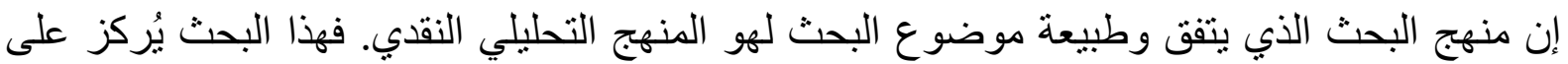

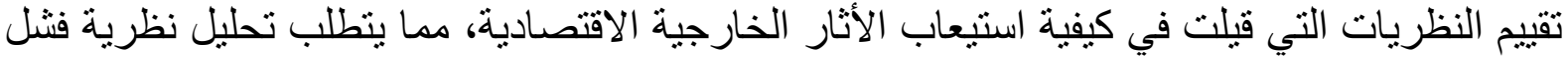

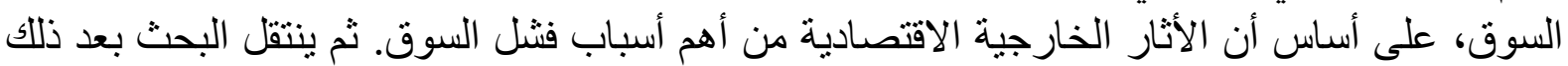

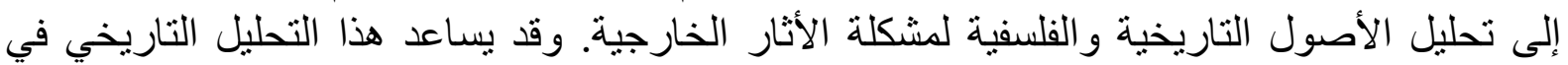

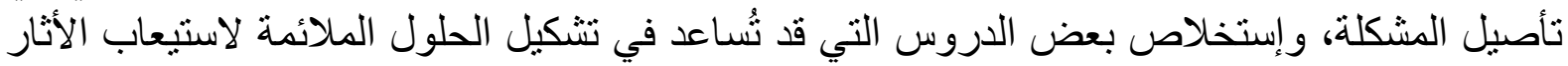

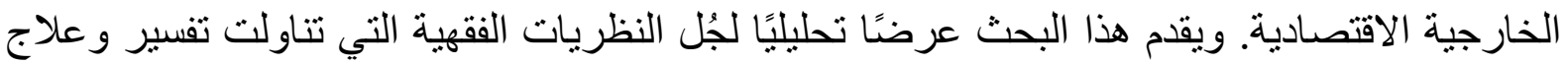
الأثار الخارجية الاقتصادية. إضافة إلى ذلك، قدم هذا البحث تحليلًا بالرسوم البيانية لكيفية تأثير الأثار 
الخارجية على الكفاءة الاقتصادية، وكذلك التحليل البياني لكيفية استيعاب الأثار الخارجية من خلال

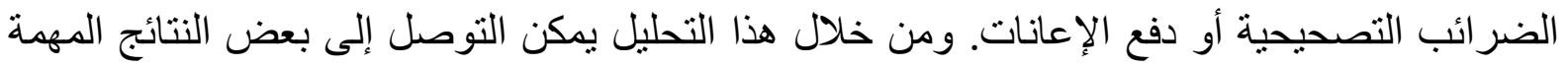
بشأت استبعاب الأثار الخارجية الاقتصادية.

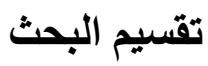
بما أن مشكلة الأثار الخارجية الاقتصادية هي سبب رئيس من أسباب فثل السوق، كما هو متفق عليه في

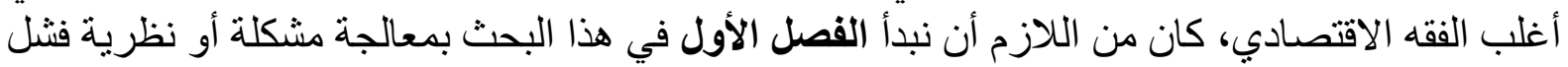

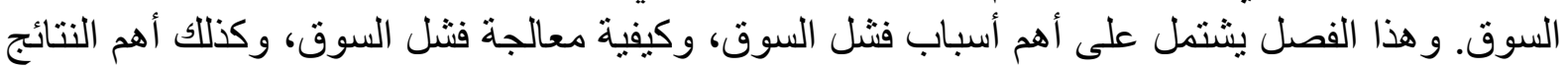

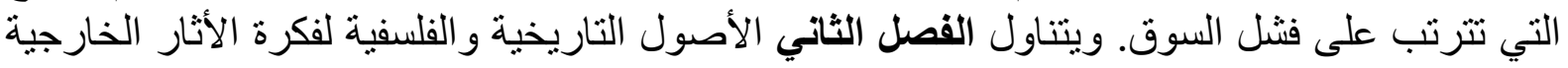

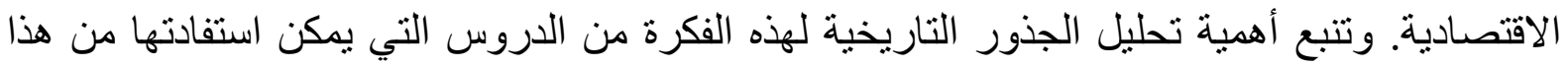

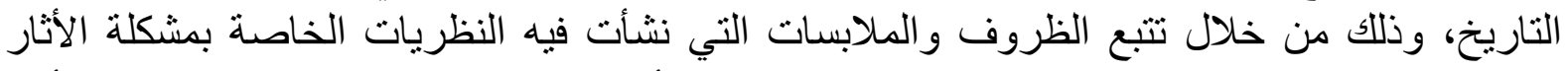

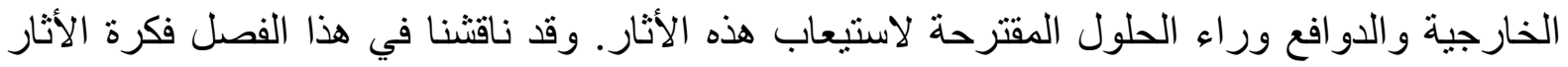

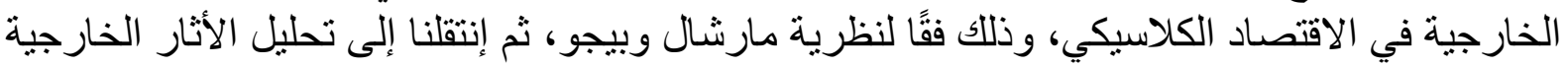
في الفقه الاقتصادي الكلاسيكي الجديد، بما في ذللك أفكار رونالد كواس في تحليل التاليل الأثار الخارجية السلبية والإيجابية.

وقد تم تخصيص الفصل الثالث لمفهوم وأنواع الأثار الخارجية الاقتصادية، وذللك لأن مفهوم الأثار

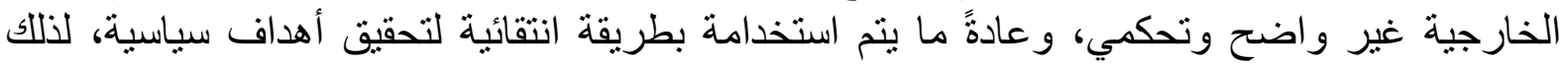

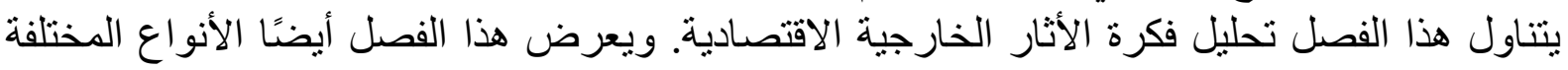

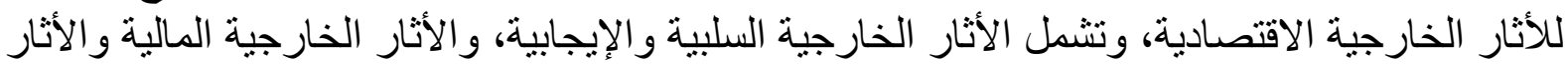

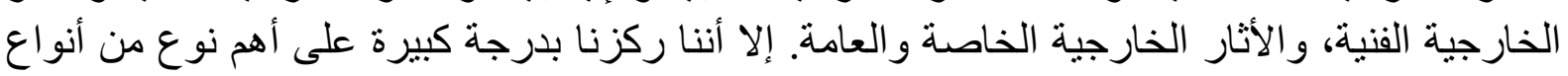

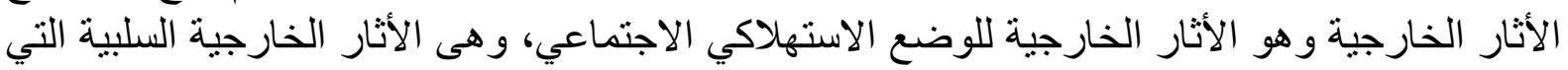

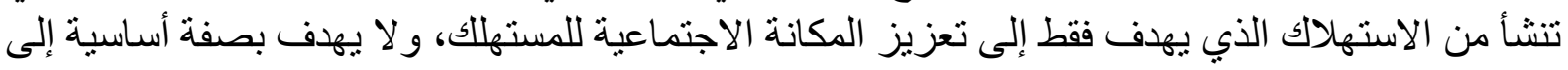

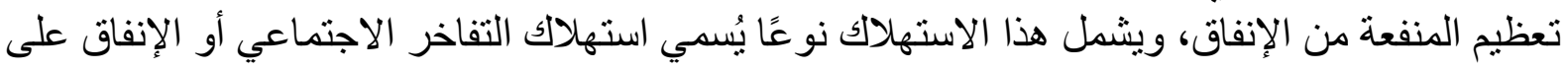

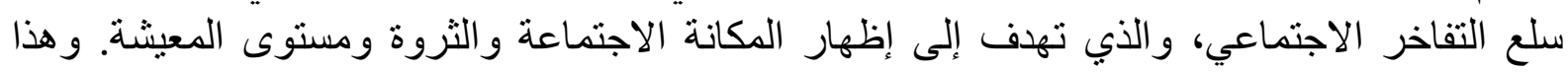

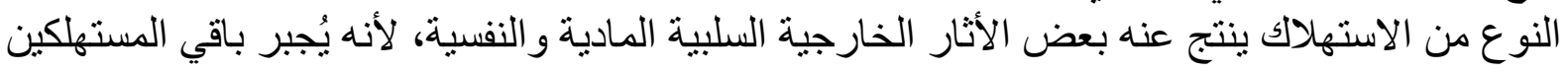

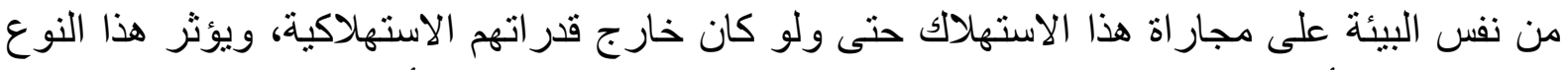

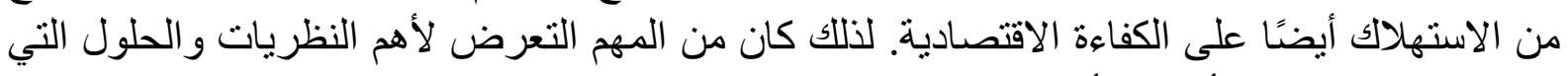
قيلت في هذا النوع من أنواع الأثار الخارجية.

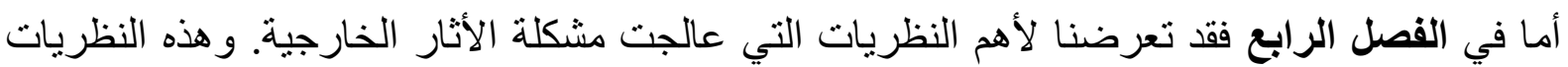

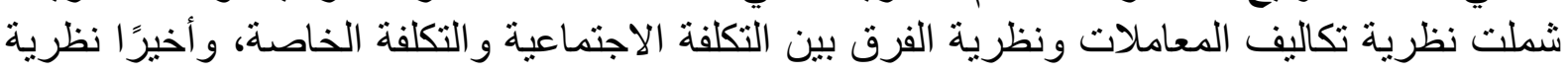

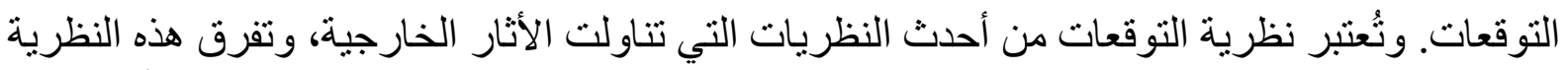

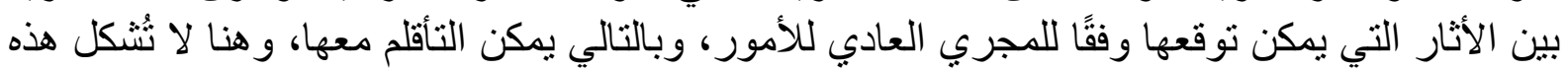

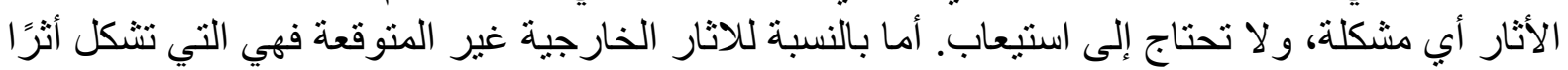

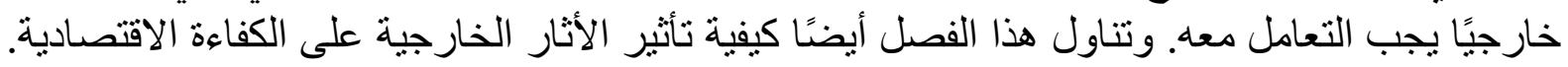

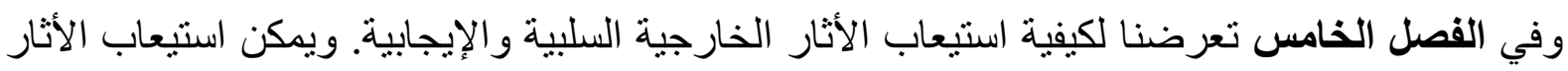

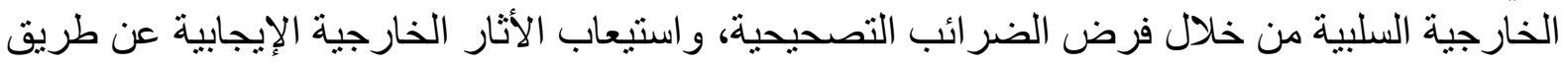




$$
\text { والفصل الأول: ينقسم هذا البحث إلى الفصول الأتية: }
$$

الفصل الثاني: تاريخ وفلسفة الأثار الخارجية الاقتصادية.

الفصل الثالث: مفهوم وأنواع الأثار الخارجية الاقتصادية.

الفصل الرابع: النظريات الاقتصادية للأثار الخارجية.

الفصل الخامس: استيعاب الأثار الخارجية الاقتصادية. 


\section{1 \\ مقدمة}

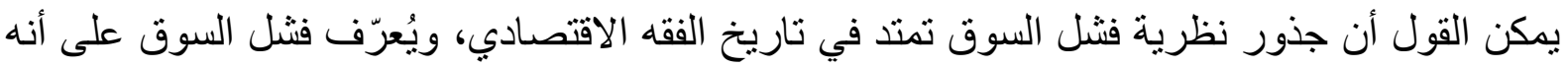

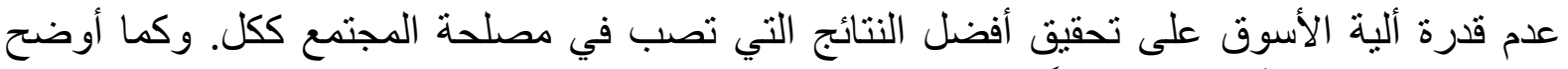

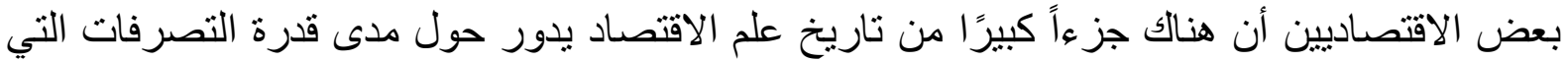

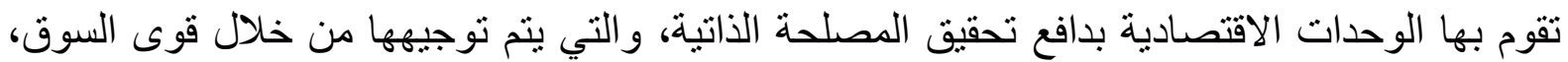

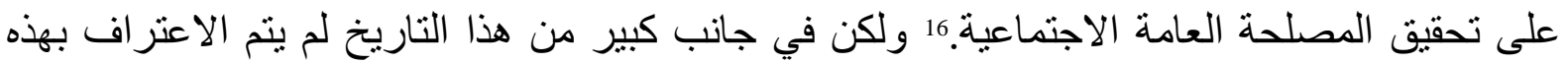

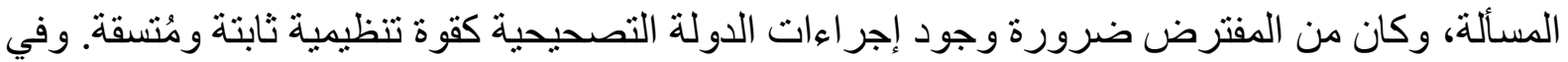

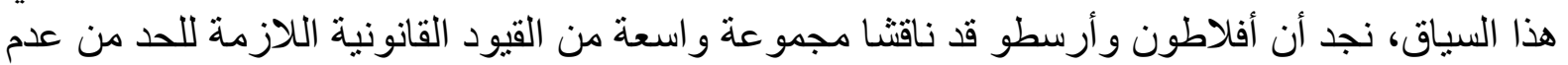

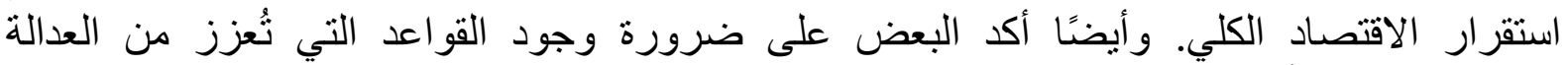

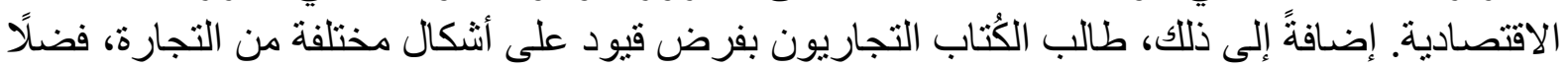

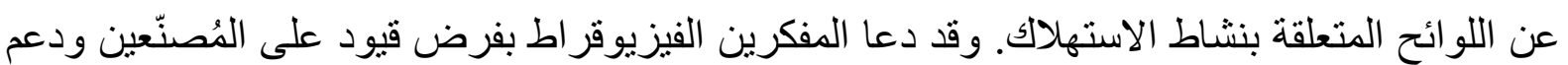

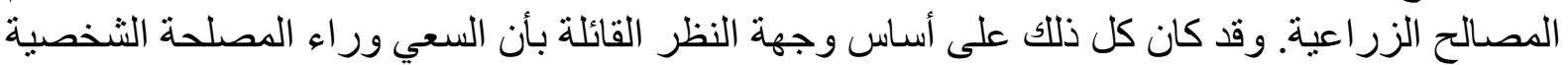

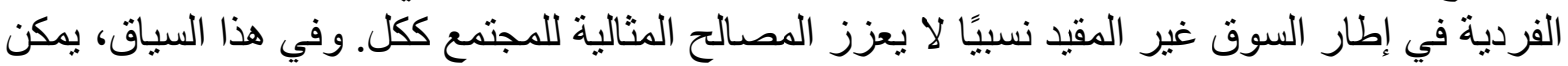

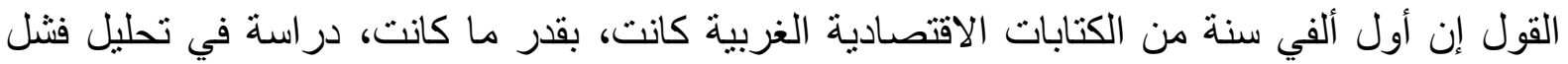

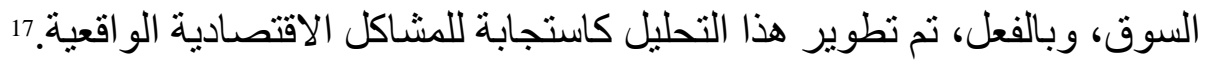

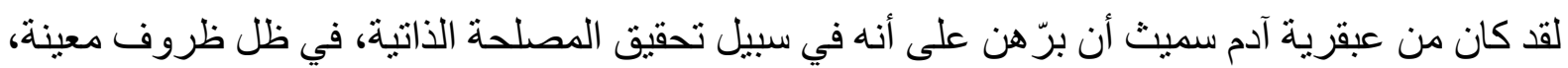

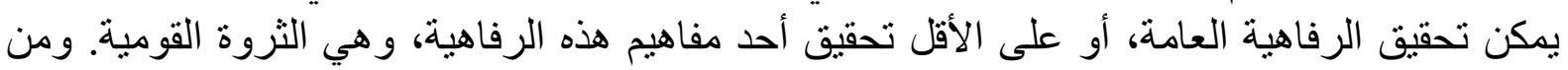

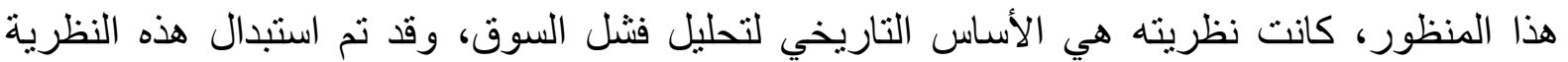

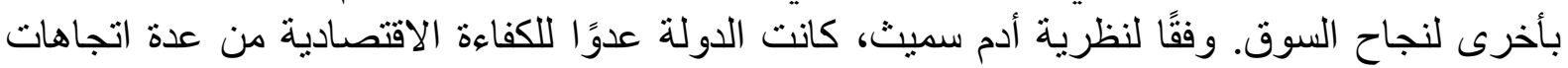

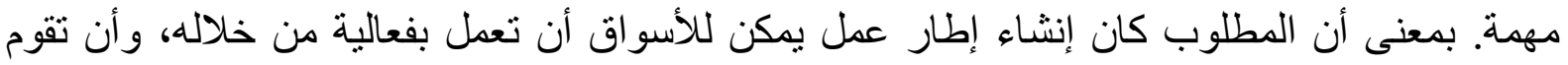

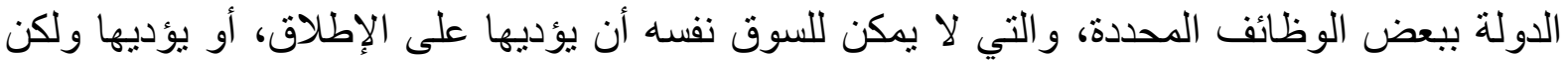

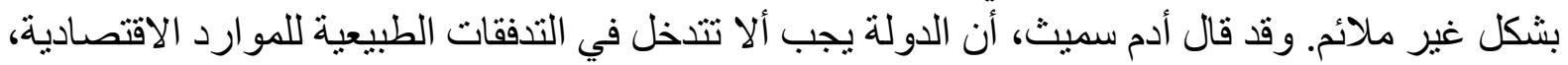

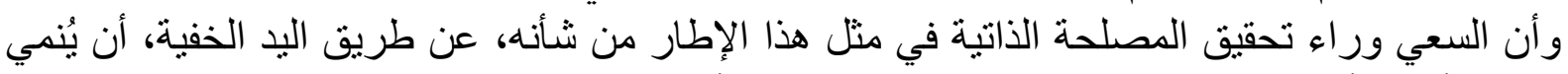
ثروة الأمة، و أن يوزع تللك الثروة بمقياس مناسب حتى لألأدنى مر اتب الثعب.

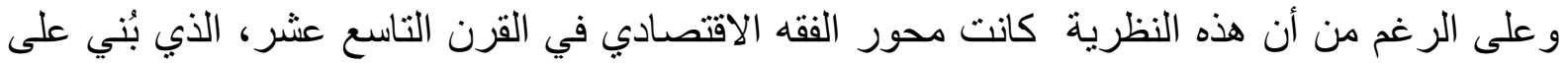

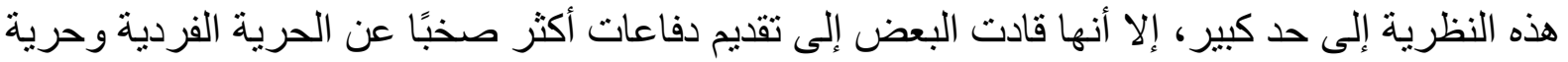

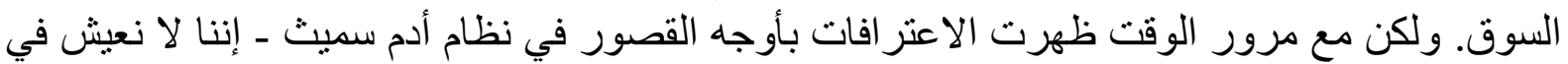

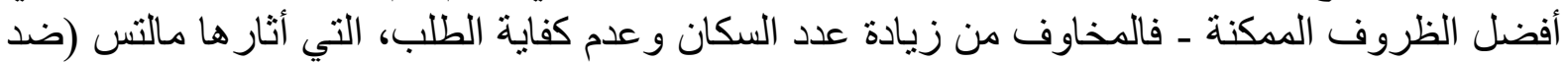

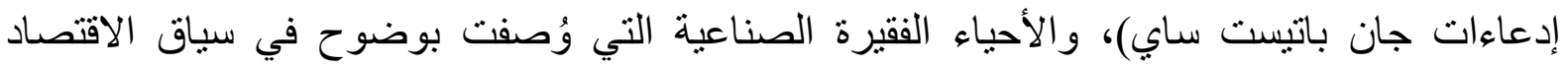

\footnotetext{
${ }^{16}$ Medema, Steven G., (2009). The Hesitant Hand: Taming Self-Interest in the History of Economic Ideas. Princeton University Press, Jstor, P.54.

${ }^{17}$ Alain Marciano \& Steven G. Medema, (2015). "Market Failure in Context: Introduction," History of Political Economy, Duke University Press, vol. 47(5), PP. 1-19.

${ }^{18}$ Smith, A., (1776) 1976. An Inquiry into the Nature and Causes of the Wealth of Nations. General editors: R. H. Campbell and A. S. Skinner. Textual editor: W. B.Todd. Oxford: Oxford University Press.
} 


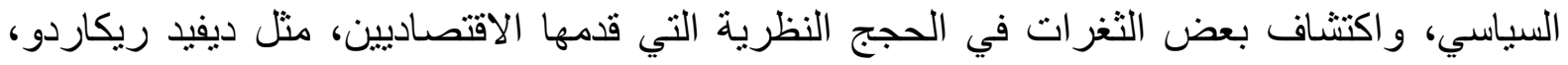

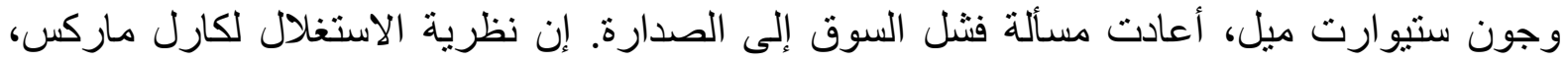

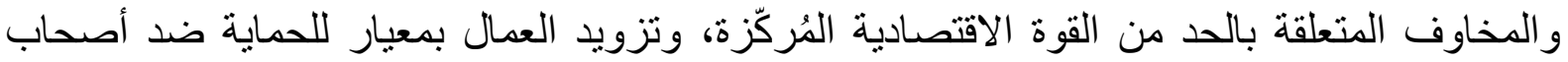
العمل، وتأثثر التقلبات الصناعية على الظروف الاقتصادية الوطنية، وسبل العيش الفردية قد دعموا

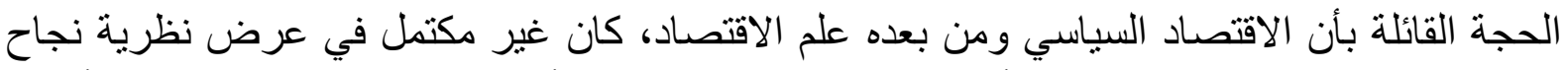

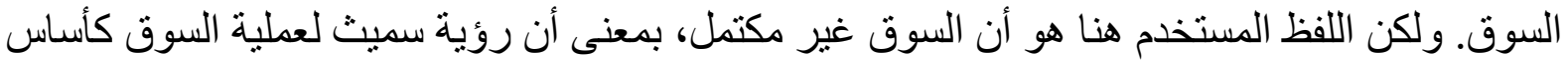

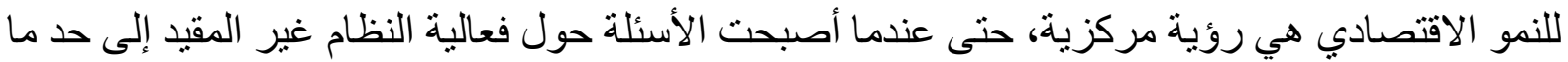
أكثر أو أقل عددًا وأعلى صوتًا. إذن، ترجع أصول التحليل الحديث لنظرية فنشل السوق إلى عدم قدرة ألية

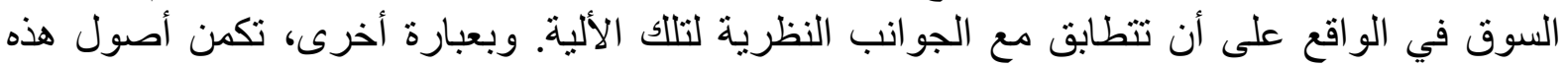
النظرية في تللك السياقات التي عاش فيها المعلقون الاقتصاديون و عملو ا فيها.

من الناحية الاقتصادية، ظهر مفهوم فنثل السوق في البداية كوسيلة لتبرير وجود النفقات الحكومية أو

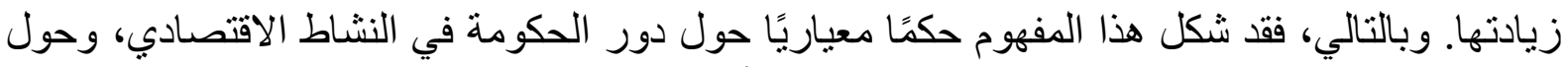

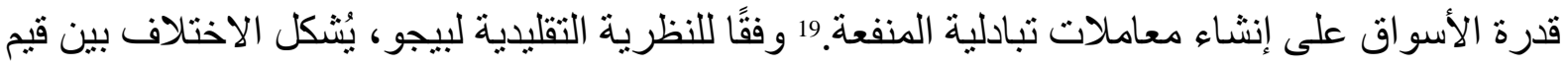

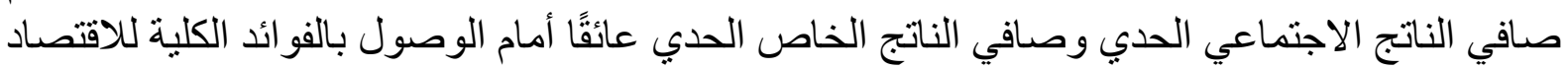

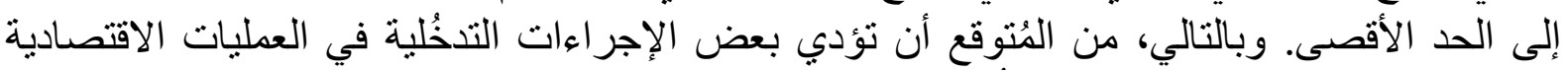

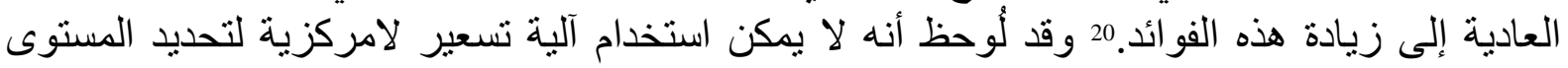
الأمثل لإنتاج السلع التي تتميز بالاستههلاك الجماعي.21 وفي مثل هذه وفئ الحالات، ليس أمام السوق خيار

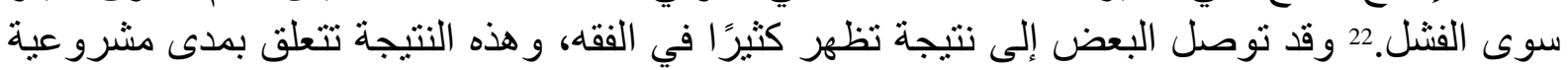

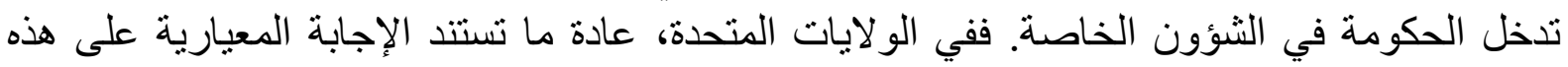

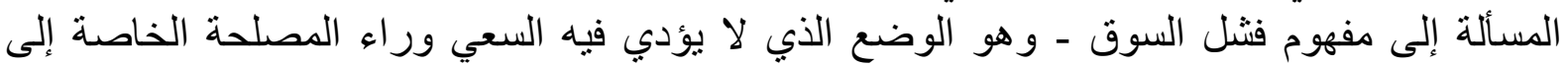

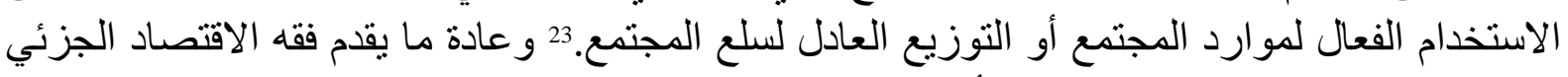

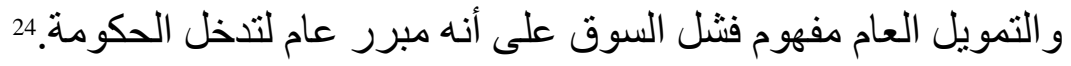

ومع تبلور مفهوم فثل السوق اكتسب خاصية إضافية، وهذه الخاصية هي استخدام هذا المفهوم كأداة لتشخيص أسباب فثل السوق، وعن طريق هذا التشخيص يستطيع صانعوا السياسة كيفية التحديد الموضوعي لنطاق التدخل في السوق، وكذلك نوع التدخل أيضًا. 25 وقد تم التوسع في استخدام هذا المفهوم

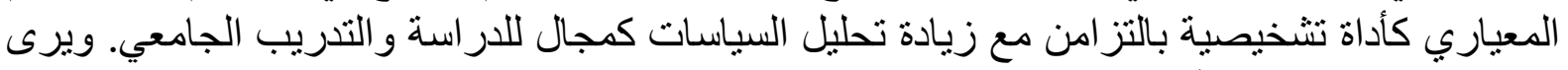

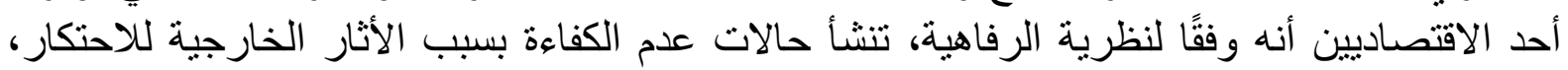

\footnotetext{
${ }^{19}$ Dahlman, C.J., (1979, April). The problem of externality. Journal of Law and Economics, 22, P.150. ${ }^{20}$ Pigou, A.G. (1932). The economics of welfare (4th ed.). London: Macmillan, P. 173.

${ }^{21}$ Samuelson, P.A., (1954, November). The pure theory of public expenditure. Review of Economics and Statistics, 36, P.386.

${ }^{22}$ Skaggs, N.T., \& Carlson, J.L., (1996). Microeconomics: Individual choice and its consequences (2nd ed.). Cambridge, MA: Blackwell Publishers, P. 543.

23 Weimer, D.L., \& Vining, A.R., (1992). Policy analysis: Concepts and practice (2nd ed.). Englewood Cliffs, NJ: Prentice Hall, P. 13.

${ }^{24}$ Boardman, A.E., Greenberg, D.H., Vining, A.R., \& Weimer, D.L., (1996). Cost-benefit analysis: Concepts and practice. Upper Saddle River, NJ: Prentice Hall, P. 99.

${ }^{25}$ Hyman, D.N., (1990). Public finance: A contemporary application of theory to policy. Chicago: Dryden Press.
} 
والأسباب الأخرى لفثل السوق. وهذا يساعد في فهم أوجه القصور وربما حلها تمامًا مثل تشخيص

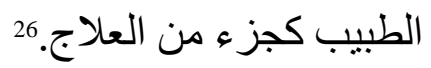

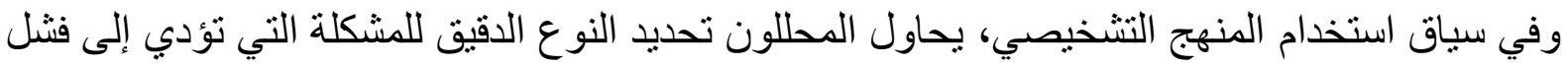

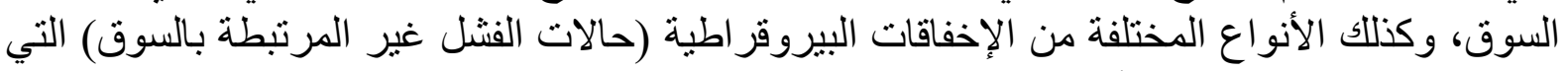

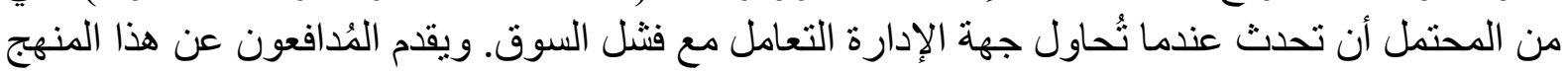

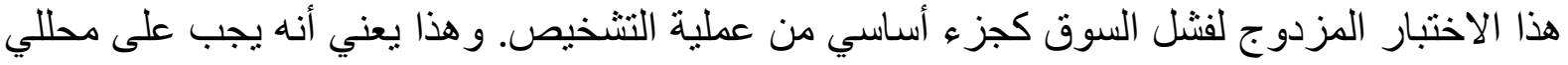

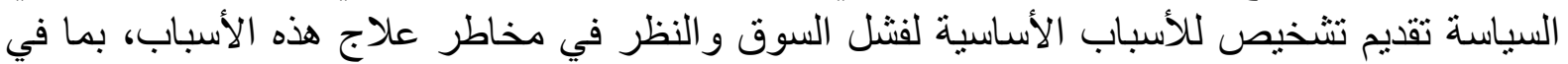

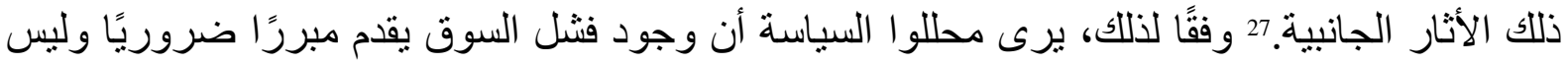

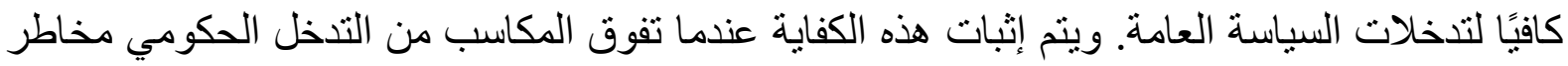
هذا التنخل.28

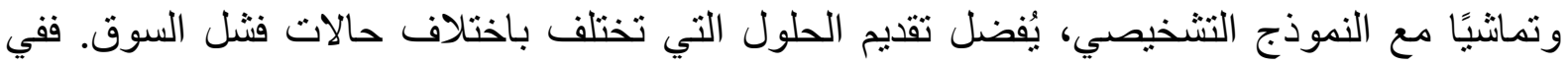

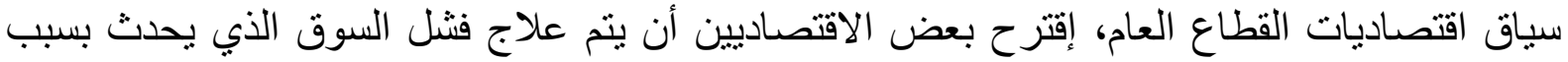

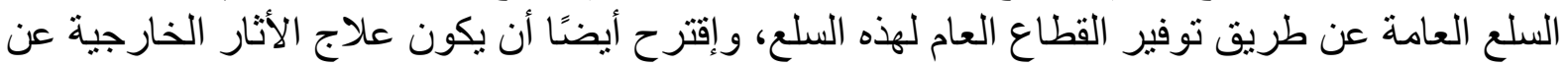

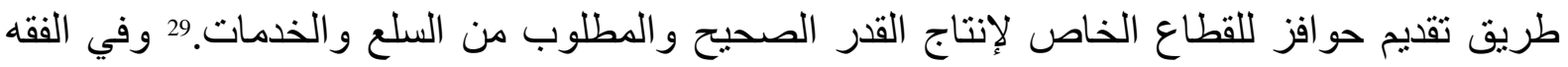

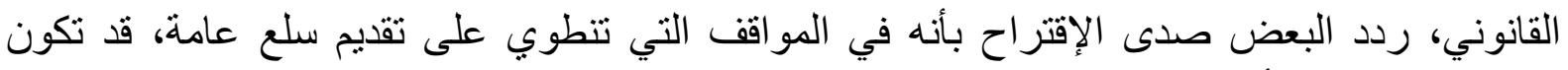

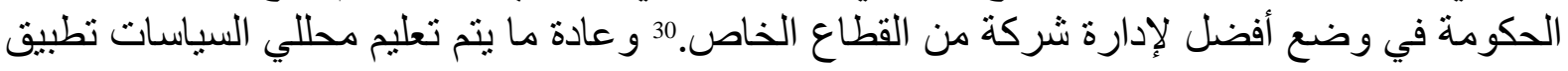

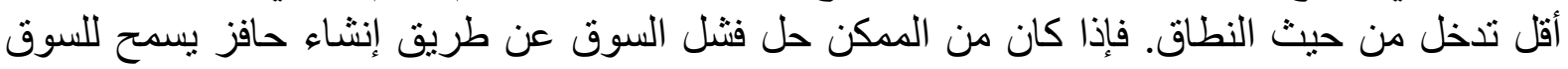

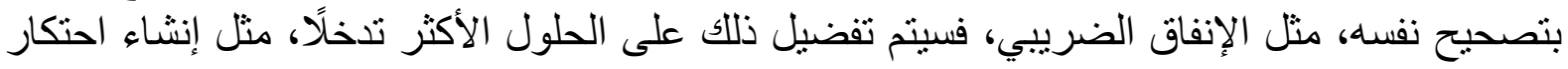

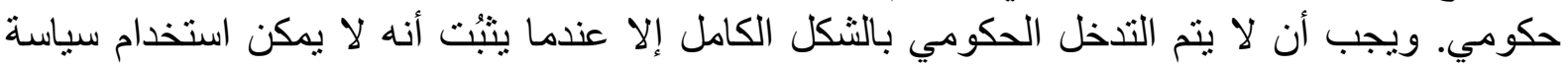

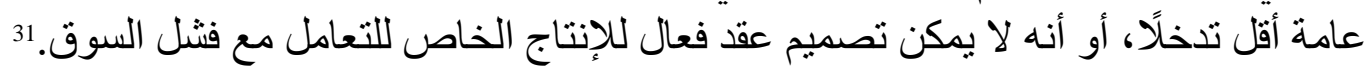

و هكذا بدأ مفهوم فثل السوق كمحاولة بسيطة لتقديم تفسير معياري لوجود النفقات الحكومية، ثم تتطور

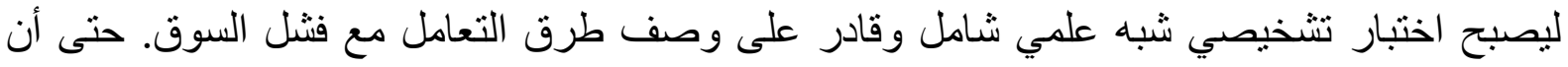

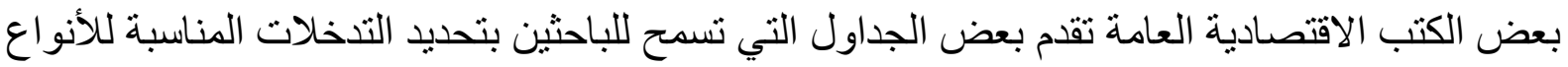

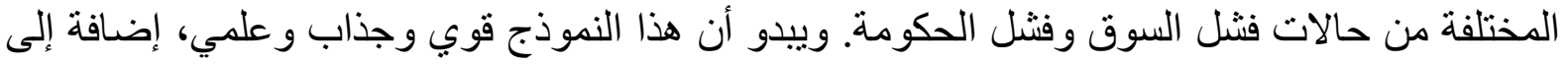
أنه يقدم اختبارًا موضو عيًا للتنخل الحكومي.

\footnotetext{
${ }^{26}$ Farrell, J., (1987, Fall). Information and the Coase theorem. Journal of Economic Perspectives, 1, P.113.

27 Weimer, D.L., \& Vining, A.R., (1992). Policy analysis: Concepts and practice (2nd ed.). Englewood Cliffs, NJ: Prentice Hall, P. 179.

${ }^{28}$ Wolf, C., (1979, April). A theory of nonmarket failure: Framework for implementation analysis. Journal of Law and Economics, 22, P. 138.

${ }^{29}$ Boadway, R.W., \& Wildasin, D.W., (1984). Public sector economics (2nd ed.). Toronto: Little Brown and Company, P. 61.

${ }^{30}$ Frankel, T., (1995). Foreword Symposium: A recipe for effecting institutional changes to achieve privatization. Boston University International Law Journal, 13, 295-311. P. 295.

${ }^{31}$ Zerbe, Richard \& McCurdy, Howard, (1999). The Failure of Market Failure. Journal of Policy Analysis and Management. 18, P. 558.

${ }^{32}$ Hyman, D.N., (1990). Public finance: A contemporary application of theory to policy. Chicago: Dryden Press, P.251.
} 
ويجب الإشارة إلى أن مثل هذه المفاهيم والتعاليم تجد لها صدى في ممارسات السياسة العامة. فقد

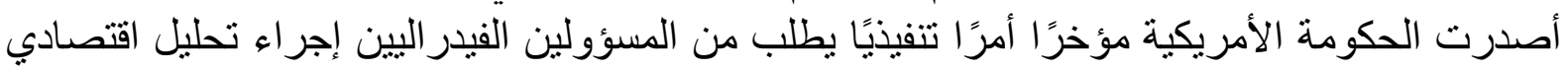

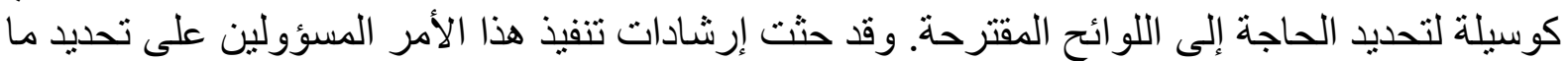

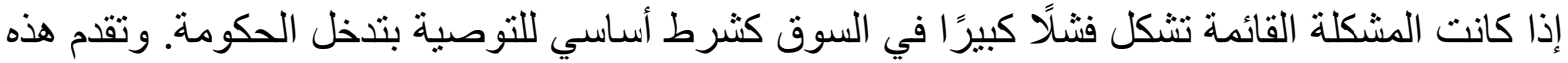

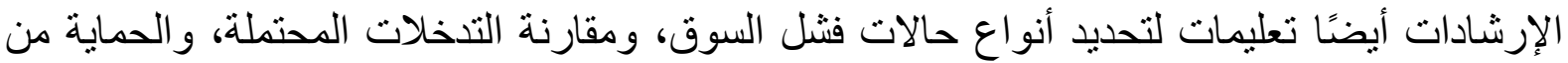

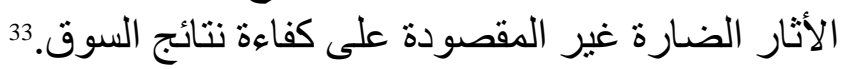

وفي ضوء هذه المقدمة، ينقسم هذا الفصل إلى المباحث التالية:

المبحث الأول: ماهية فثل السوق.

المبحث الثاني: بعض الأنواع الشائعة لفشل السوق.

المبحث الثالث: معالجة فشل السوق.

\section{المبحث الأول: ماهية فشل السوق}

أولًا: تعريف السوق

في اقتصاد السوق، يُعرَّف السوق بأنه المكان الأكثر أهمية للتنسيق بين المنتجين و المستهلكين، وذلك من

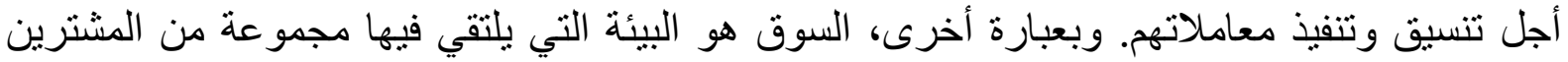

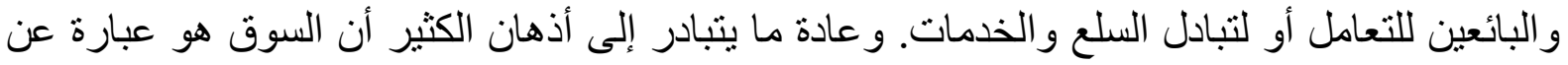

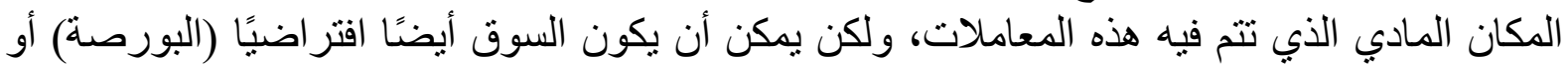

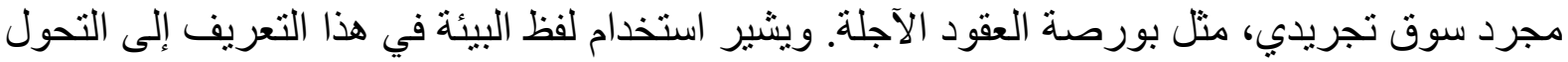

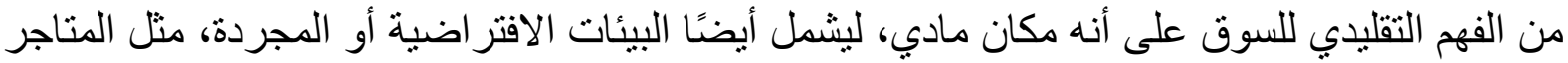

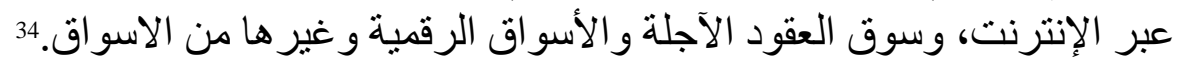

و الأسواق هي أكثر الآليات فعالية لتخصيص الموارد بين الوحدات الاقتصادية المختلفة. وبعبارة أخرى،

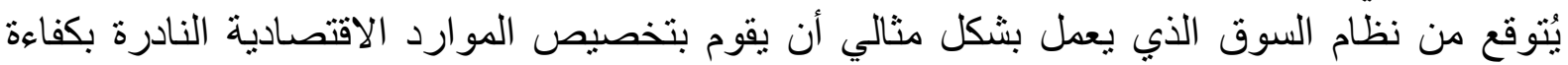

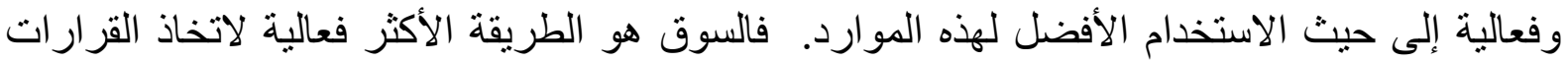

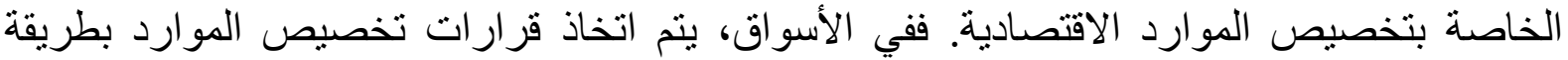

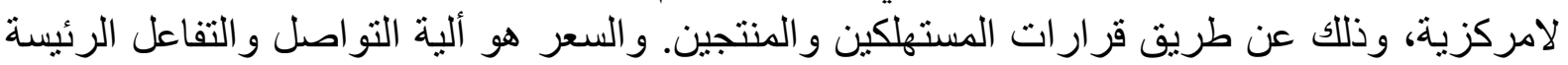

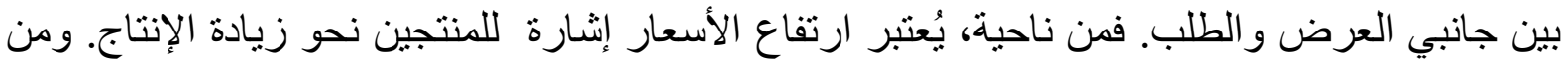
ناحية أخرى، يتطلب إنخفاض الأسعار من المنتجين تقليص الإنتاج. وتعتبر الأسعار مؤشر للمستهلكين عن الجودة أو حتى عن القيمة.

ولكن غالبًا ما تعمل الأسواق بشكل غير صحيح. ففي بعض الأسواق يوجد عدد كبير جدًا من المنتجين،

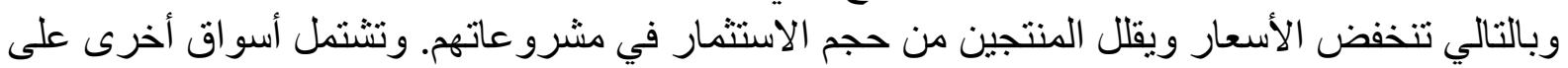

\footnotetext{
${ }^{33}$ De Alessi, L., (1996). Error and bias in benefit-cost analysis: HUD's case for the wind rule. Cato Journal, 16, P.129.

${ }^{34}$ Cunningham, S., (2011). Understanding Market Failures in an Economic Development Context. Pretoria, South Africa: Mesopartner Monograph 4, P.13.
} 


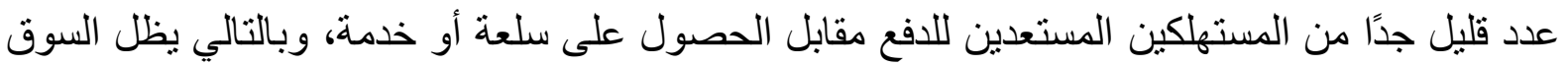

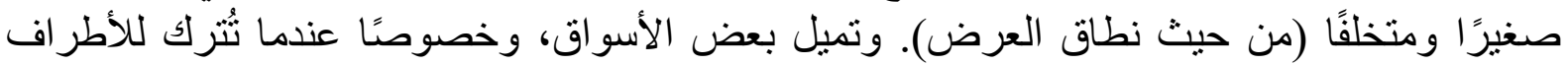

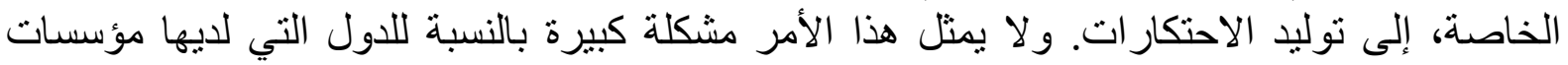

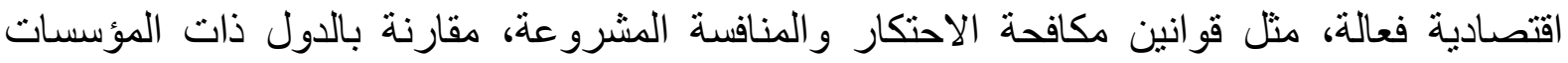

الاقتصادية الضعيفة.

و هذا يعني أن كفاءة السوق في تخصيص الموارد الاقتصادية، وكذللك فعالية آلية السعر كقناة مناسبة

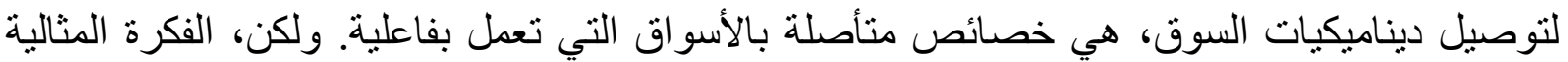

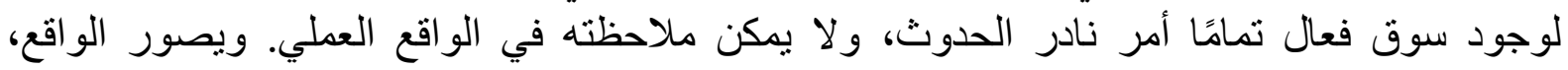

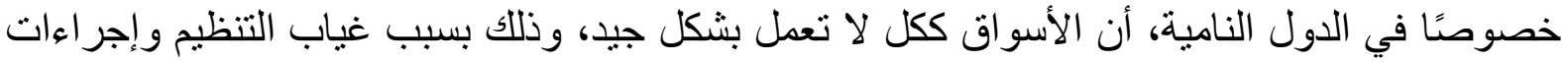

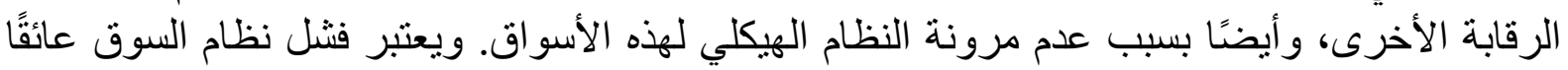

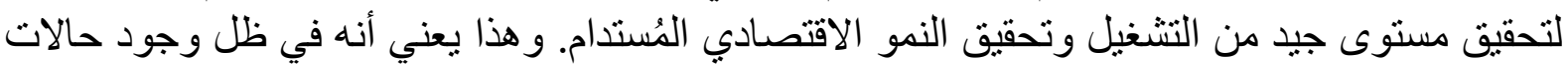

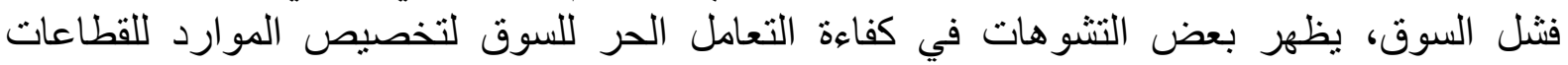

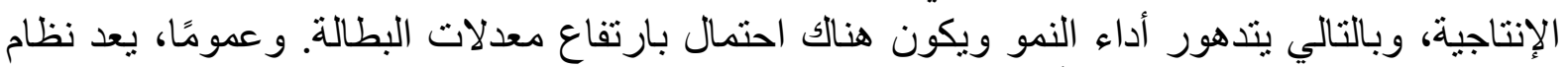

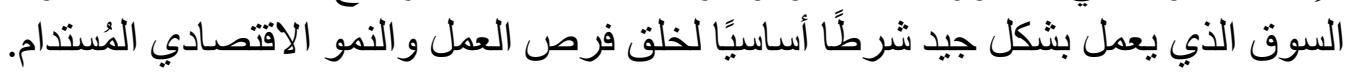

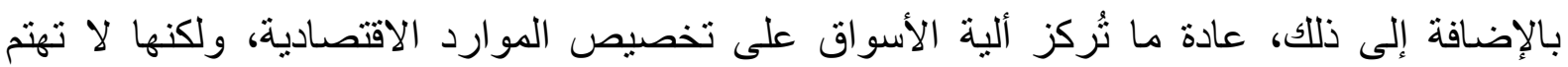

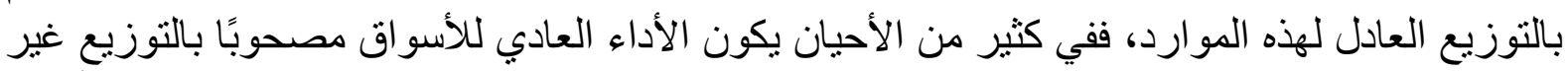

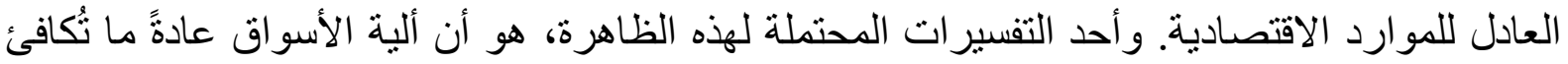

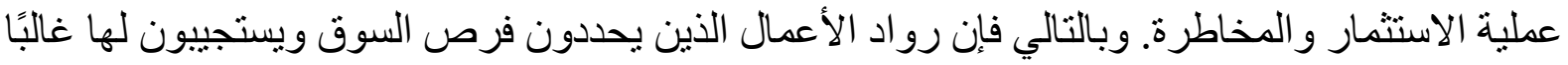

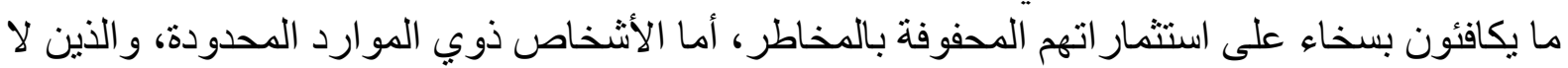

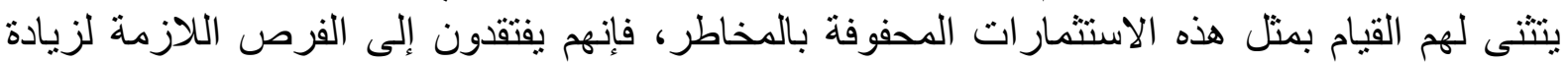

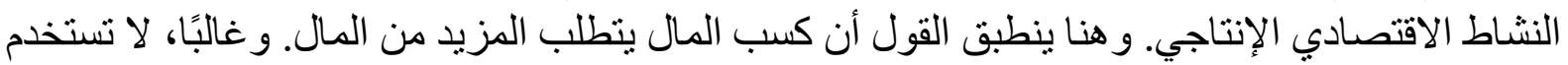

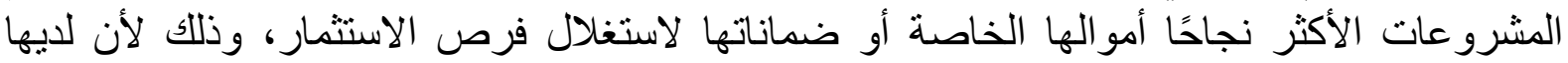

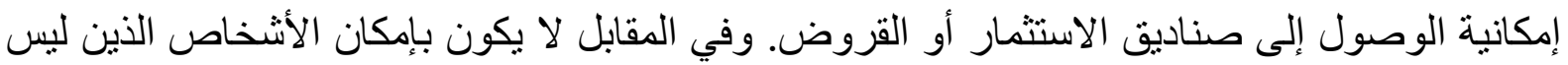

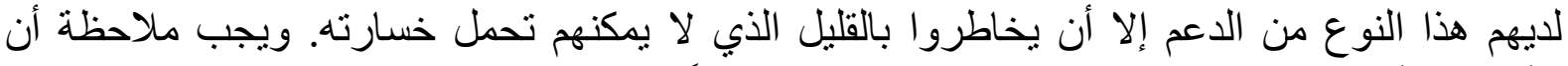

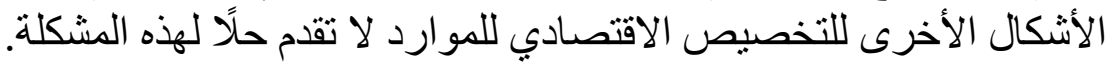

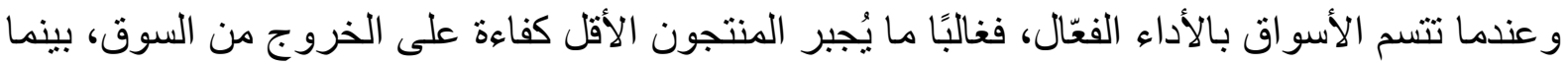

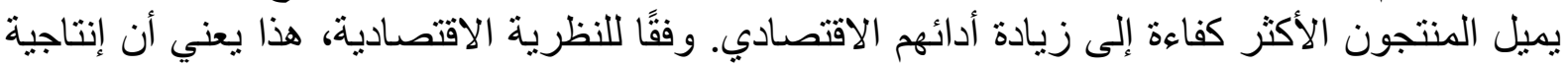

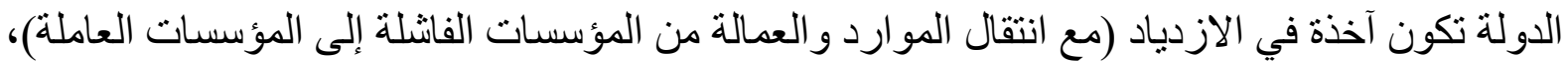

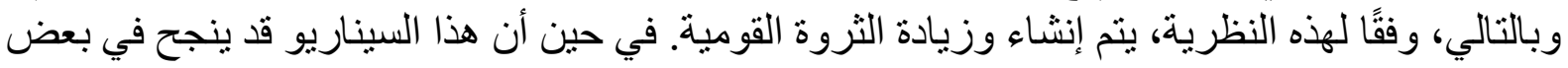

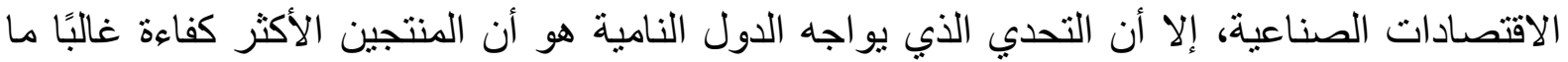

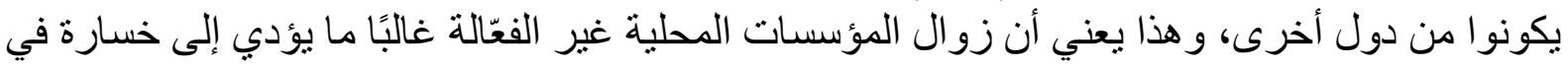

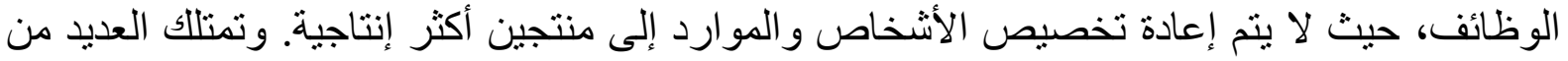

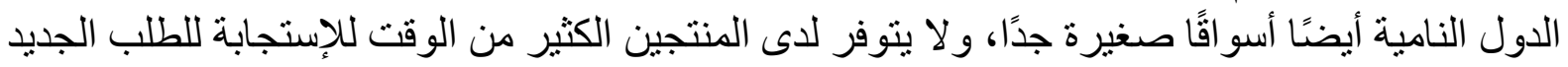

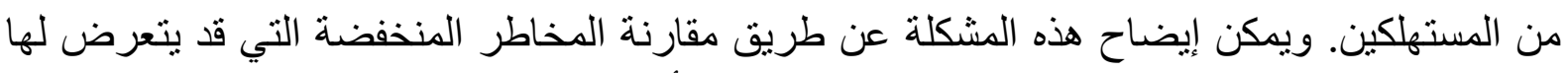

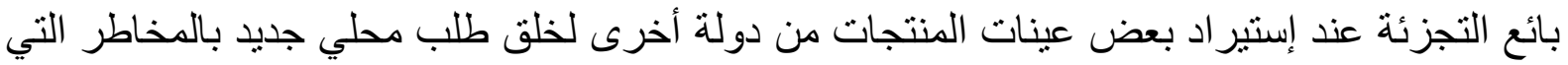
قد يتعرض لها المصنع لتطوير منتج جديد لإنشاء سوق جديد. وفي هذه الحالة، يواجه تجار التجزئة 
مخاطر أقل بكثير ، ويمكنهم أيضًا الاستجابه للاتجاهات الجديدة في السوق (التي يمكن لهم إنشائها) بشكل أسرع بكثير من الثركة المصنعة لمنتج جديد.

وقد فنثلت الجهود المبذولة لاستبدال ألية الأسواق بطرق أخرى من طرق التسيق بين العرض و الطلب.

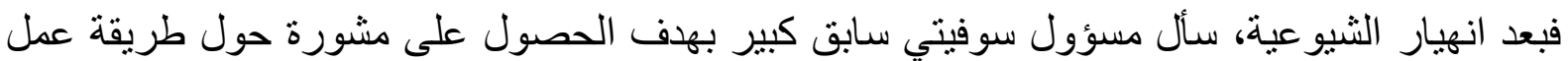

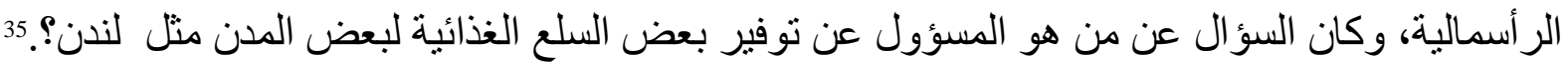

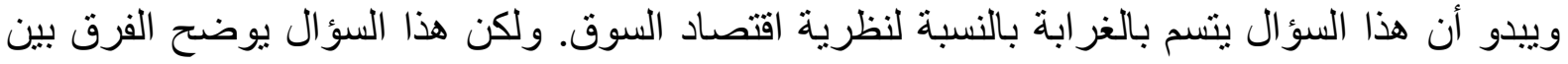

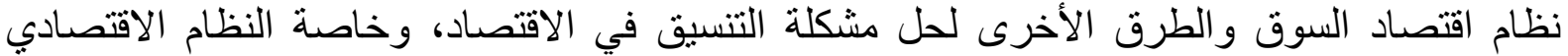

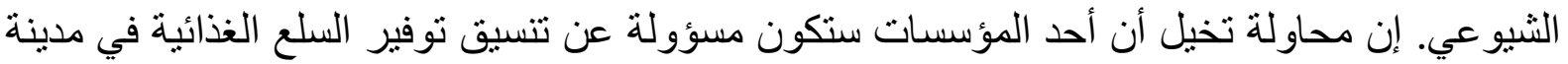

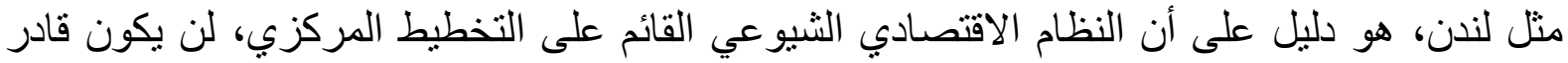

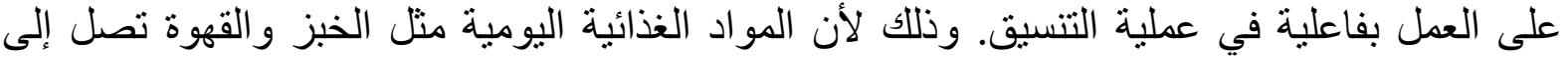

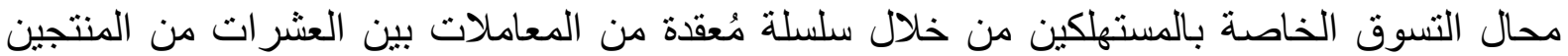

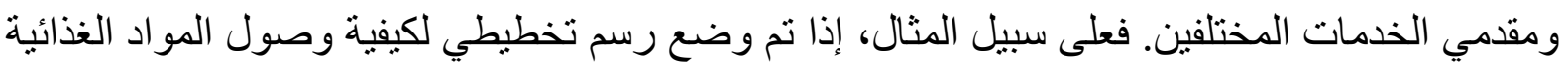

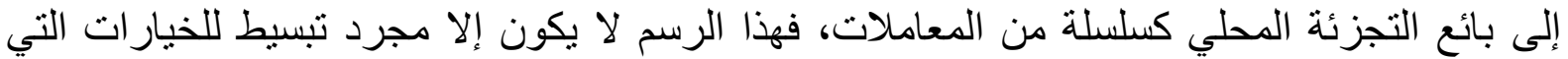

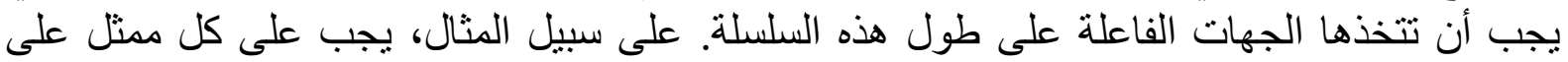

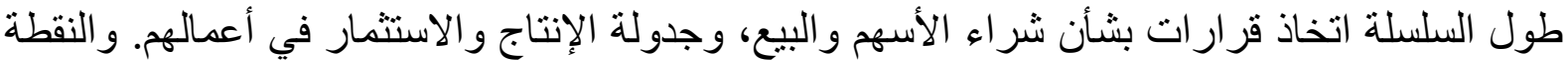

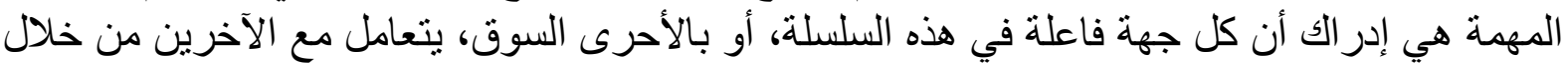

اتخاذ القرار ات بطريقة لامركزية.

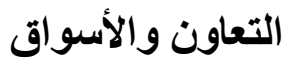

يمكن القول أن التتسيق بين التصرفات والقرارت الاقتصادية للأعداد الكبيرة من الأفراد ليس بالأمر

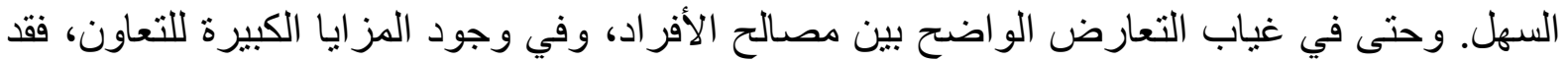

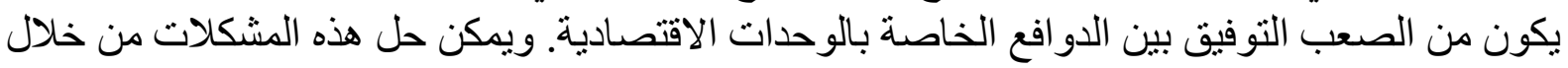

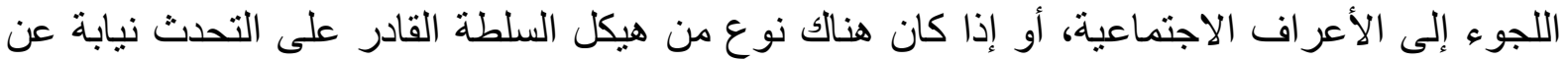

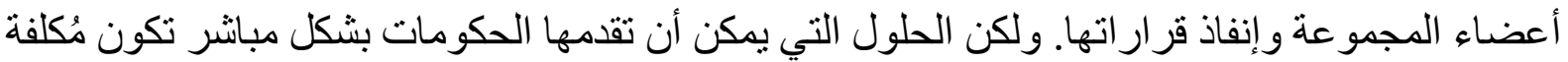

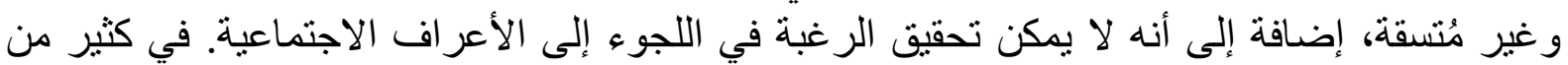

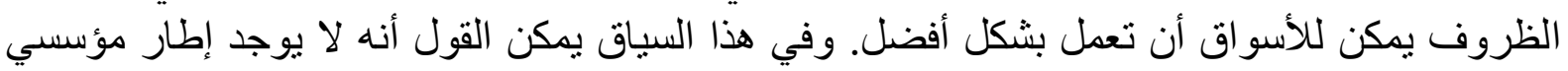

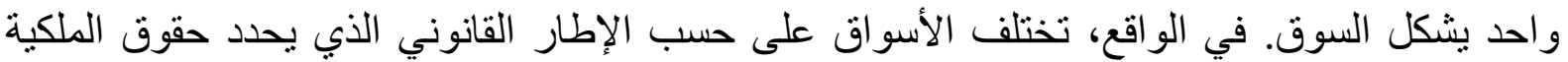

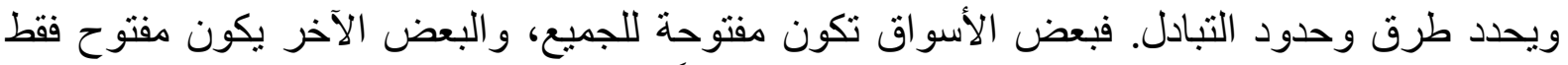

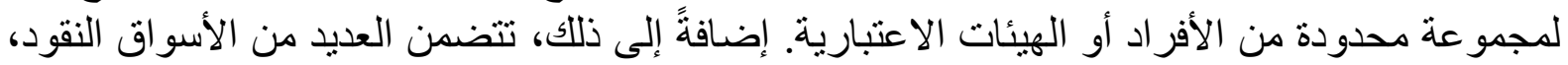

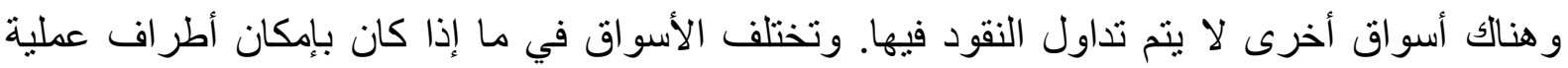

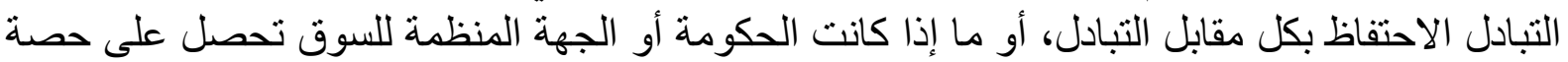

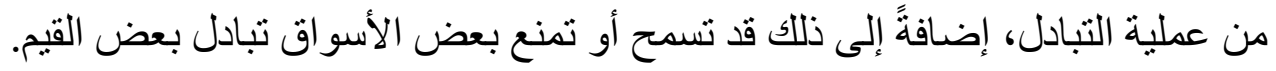

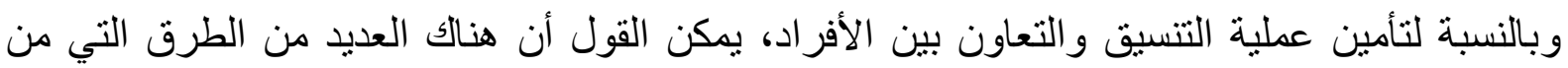

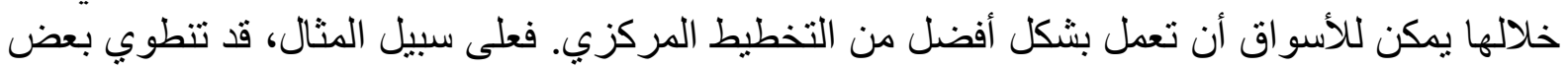

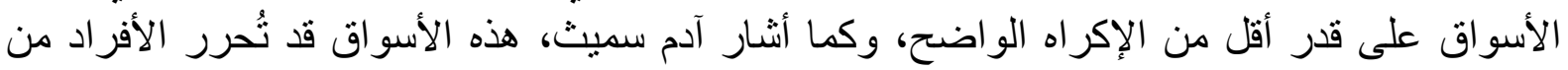

${ }^{35}$ Harford, T., (2006). The undercover economist. London: Little Brown Book Group, P.150. 
الإذعان التقليدي.36 و هناك أيضًا بعض الطرق التي من خلالها يمكن للأسواق أن تعمل بشكل غير جيد، أنسا

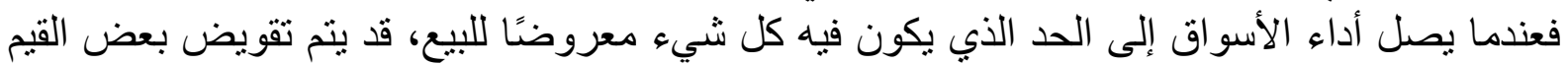

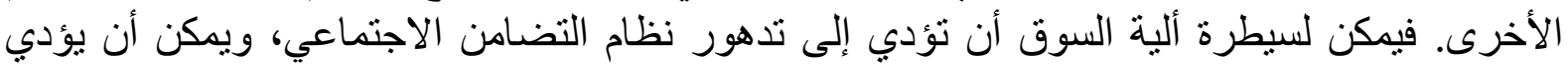

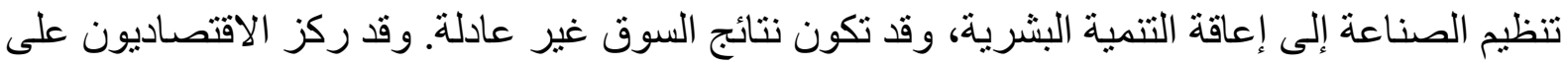

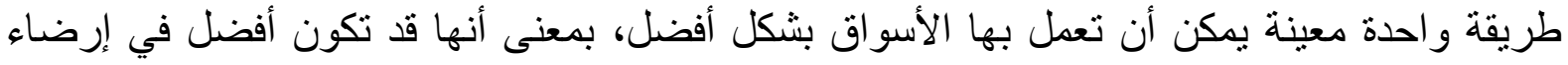

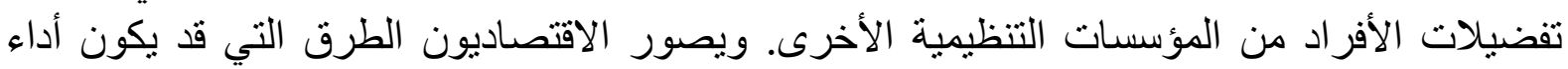

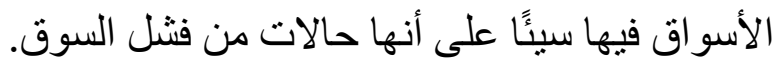

ولكن لماذا لا تعمل الأسواق بكفاءة في بعض الأحيان؟ أولًا، هنالك حالات لفشل السوق، وهنالك أسباب

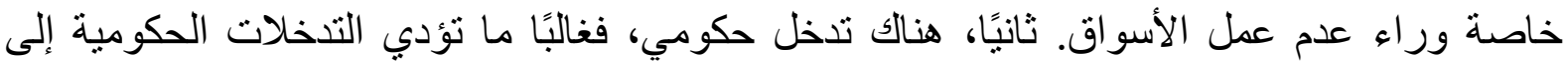

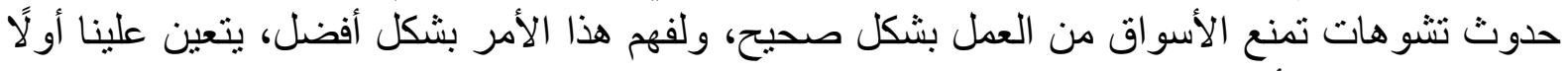
النظر في طبيعة الأسواق.

ثانيًا: الثروط الضرورية لوجود وعمل السوق

هنالك العديد من الثروط أو المتطلبات اللازمة لتحقيق الكفاءة في عمل الأسواق. ولكن من المهم ملاحظة

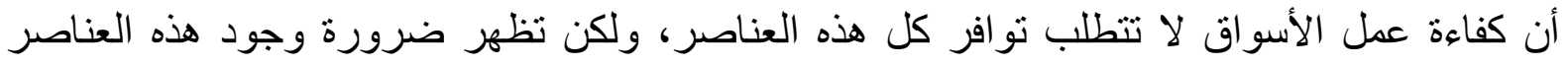

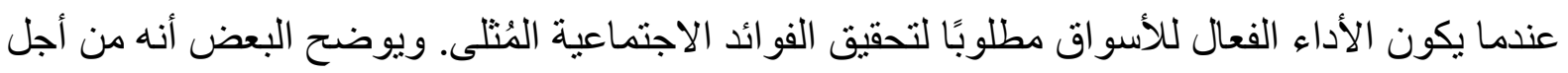

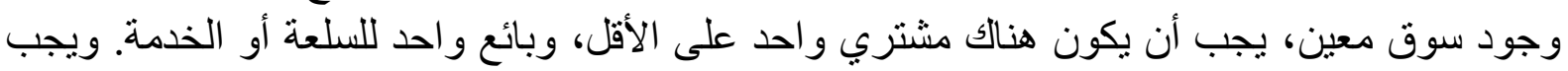

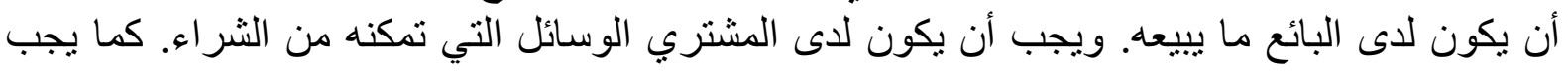

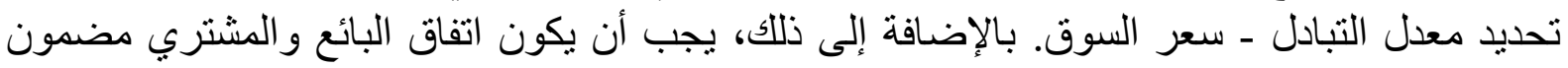
النفاذ بموجب القانون أو العرف.

ويبدو أن هذه الثروط هي عبارة عن وصف لقدرة الأطر اف المختلفة على التعامل مع بعضها البعض.

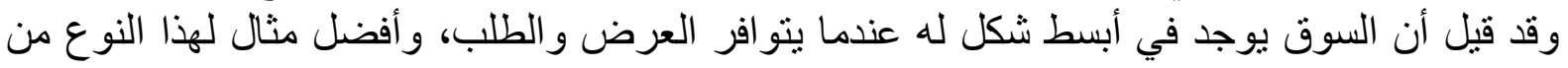

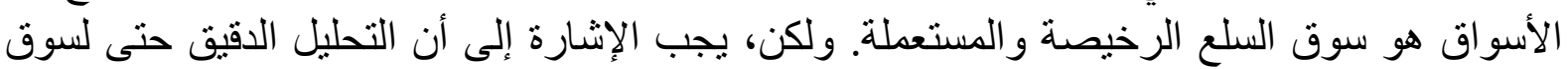

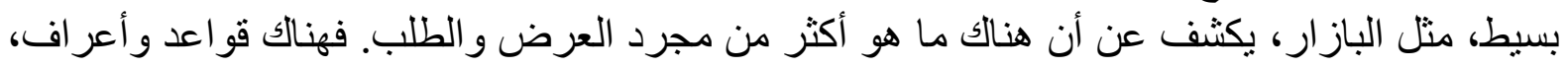

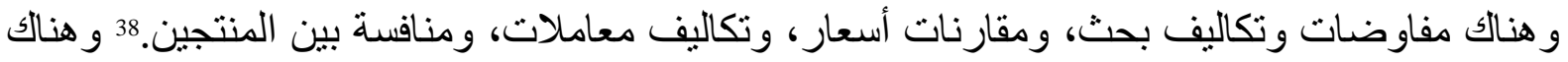

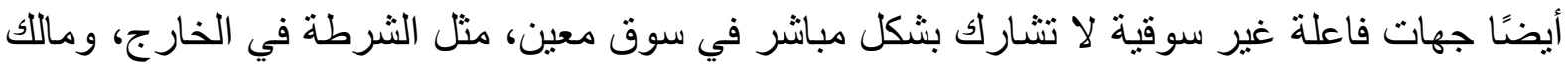

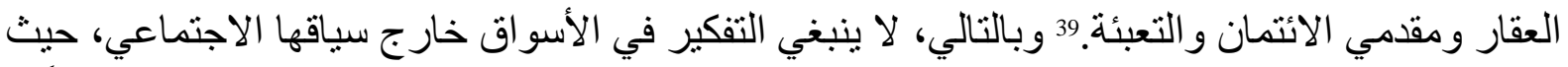

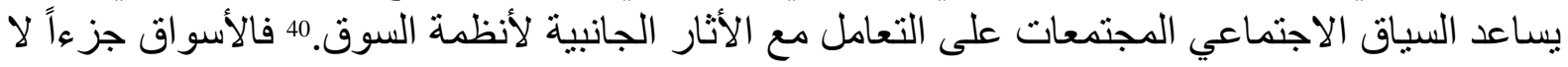

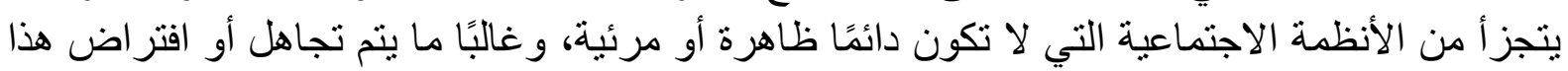

\footnotetext{
${ }^{36}$ Smith, Adam.,(1982). An Inquiry into the Nature and Causes of the Wealth of Nations. 1776. Rpt. Oxford: Oxford University Press, P.277.

${ }^{37}$ Mohr, P. \& Fourie, L., (2007). Economics for South African students. 4th ed. Pretoria: Van Schaik, P.44.

${ }^{38}$ Mcmillan, J., (2002). Reinventing the bazaar: a natural history of markets. 1st Ed. New York, NY: Norton, P.267.

${ }^{39}$ Lindblom, C.E., (2001). The market system: what it is, how it works, and what to make of it. New Haven, CT: Yale University Press, P.241.

${ }^{40}$ White, H.C., (2002). Markets from networks: socioeconomic models of production. Princeton, NJ:

Princeton University Press, P.122.
} 
الاندماج بين السوق والنظم الاجتماعية من قبل الاقتصـاديين والنماذج الاقتصادية القياسية. وذللك لأن التركيز يكون فقط على العرض و الطلب على المنتجات و الخدمات.

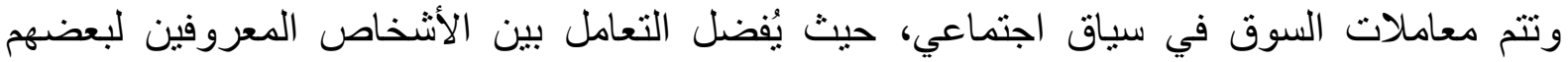

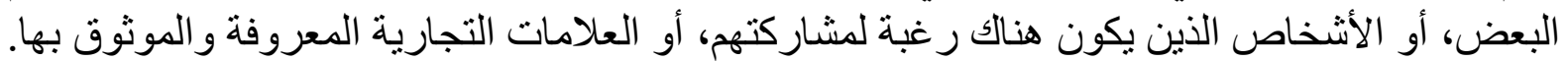

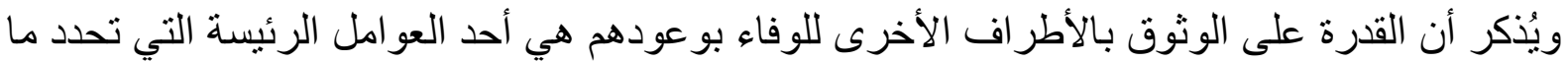

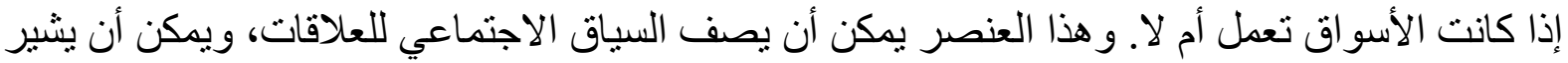

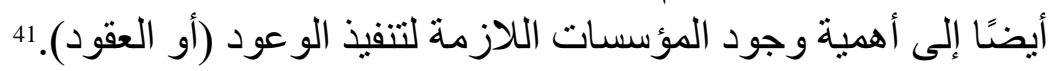

وقد أوضح البعض أنه لكي يعمل السوق بكفاءة، فيجب نوافر خمسة عناصر أساسية، وهذه العناصر

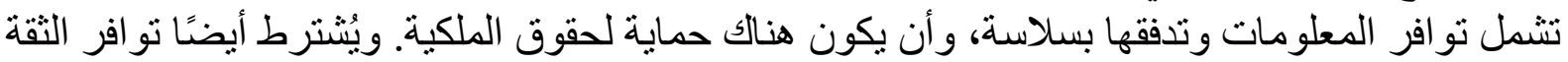

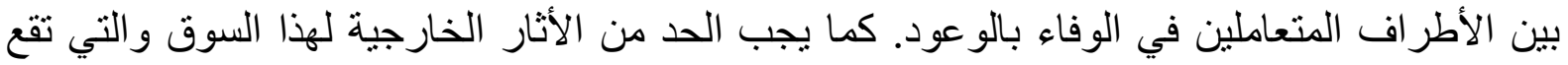

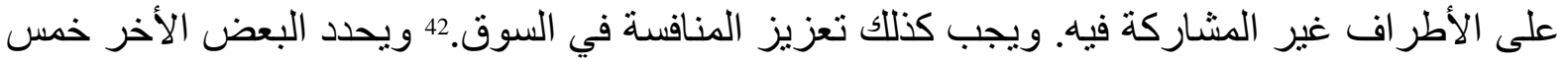

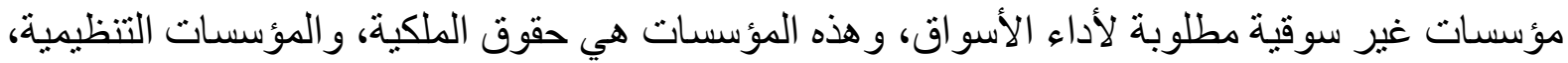

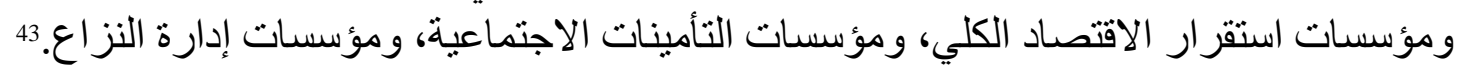
ونتيجة لأن السياق الاجتماعي ينعكس في الأسواق، فإنه لا يمكن بسهولة نقل مكونات التنظيم المؤسسي التئي

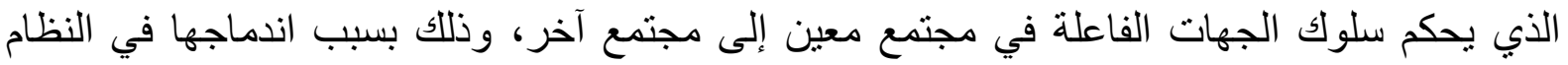

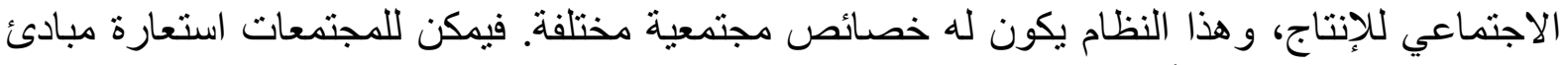

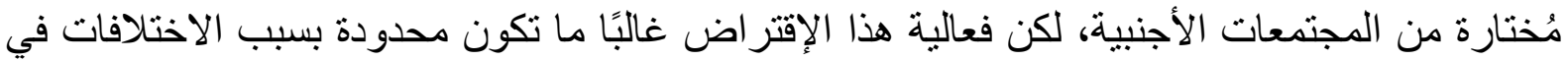

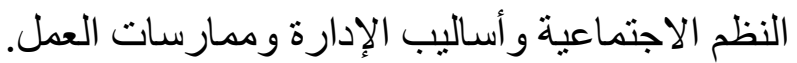

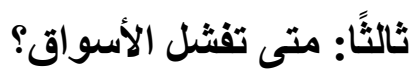

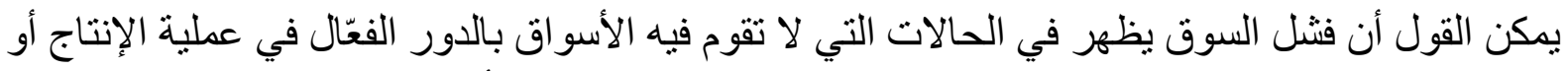

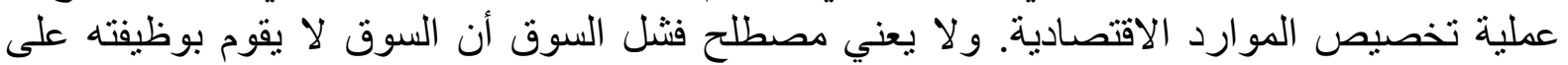

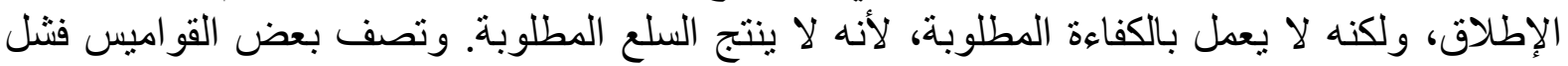

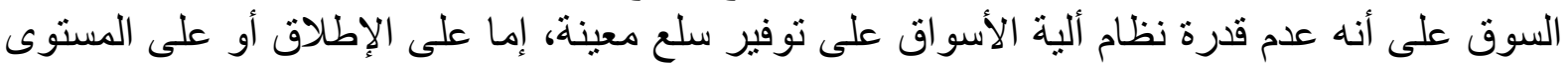

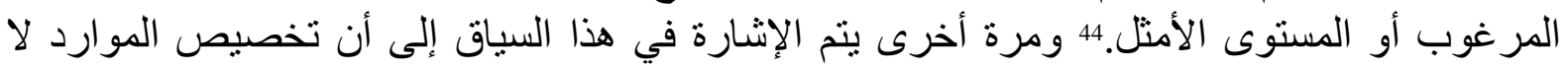

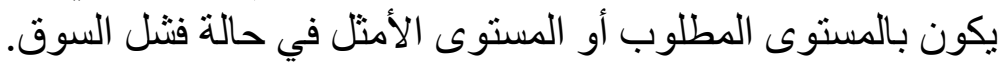

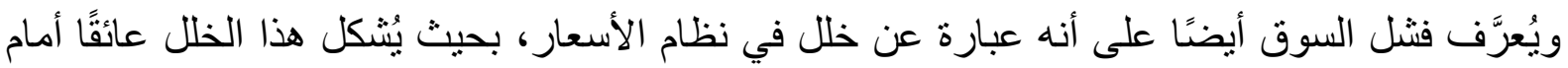

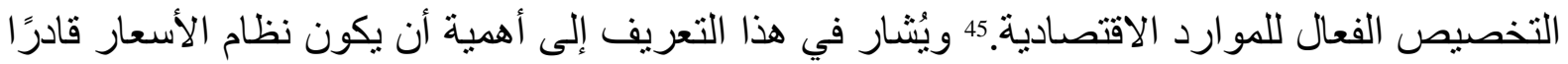

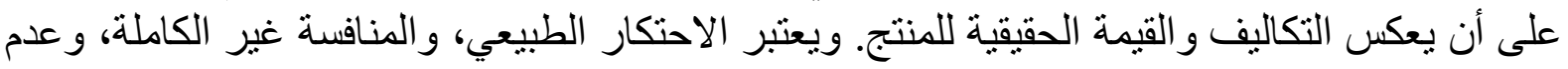

${ }^{41}$ Mcmillan, J., (2002). Reinventing the bazaar: a natural history of markets. 1st ed. New York, NY: Norton, P.268.

${ }^{42}$ Cunningham, S., (2009). The role of market failure in the utilisation of Quality Management services by the tooling industry. Ph.D Thesis, North West University, P.65.

${ }^{43}$ Rodrik, D., (2000). Institutions for high-quality growth: What they are and how to acquire them. Studies in Comparative International Development, 35(3), PP.3-31.

${ }^{44}$ Pearce, D.W., (1986). Market Failure. In Macmillan dictionary of modern economics. Pearce, D.W. (Ed.).

${ }^{45}$ Samuelson, P.A. \& Nordhaus, W.D., (1992). Economics. 14th ed. New York, NY: McGraw-Hill., P.250. 
تناسق المعلومات والأثار الخارجية من أبرز الأمثلة على حالات فثل السوق. ويحدث فثل في السوق

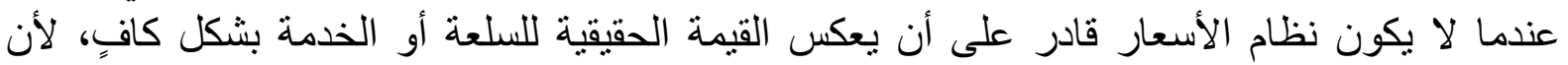

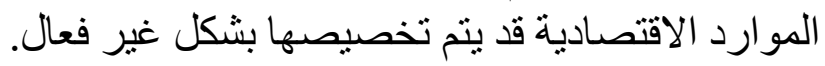

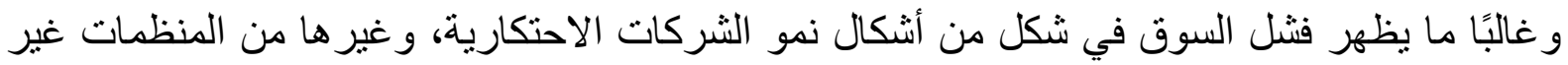

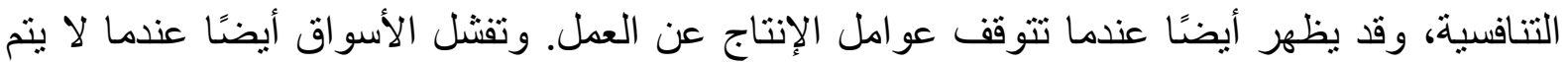

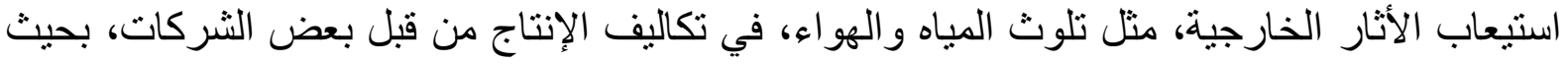

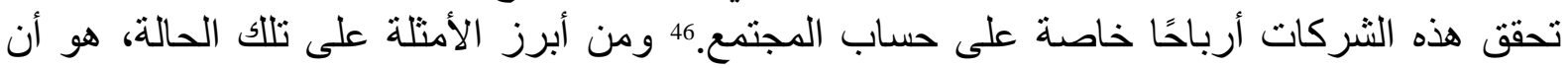

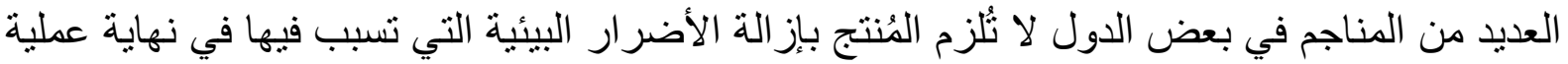

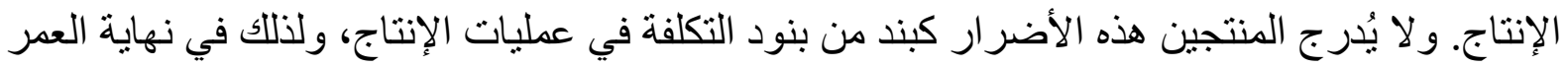

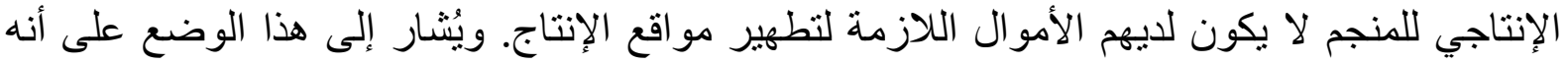

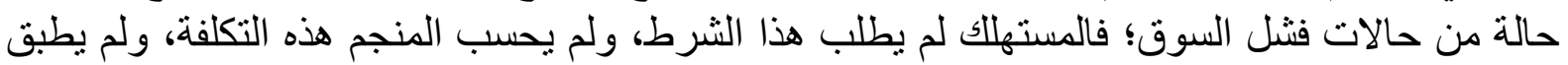

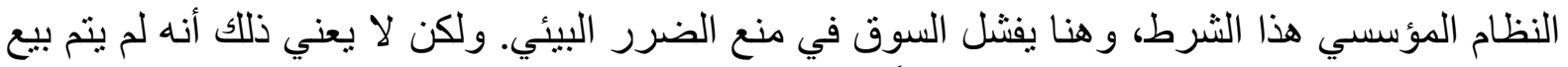

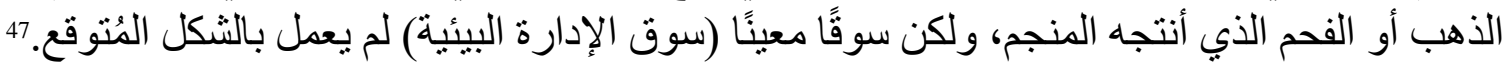
و عندما يحدث فثل في السوق، يكون السبب الفعلي في ذلك هو فنشل النظام المؤسسي في دعم السوق.

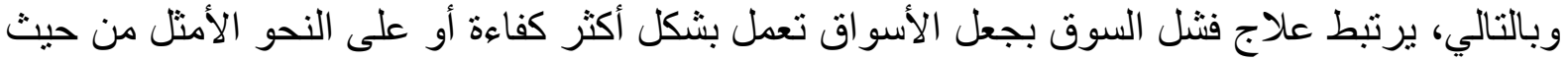

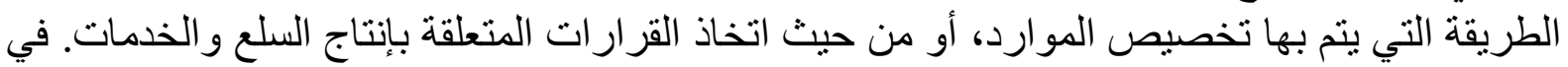

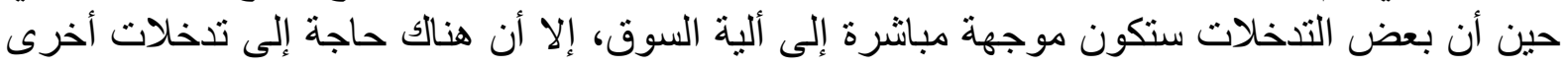

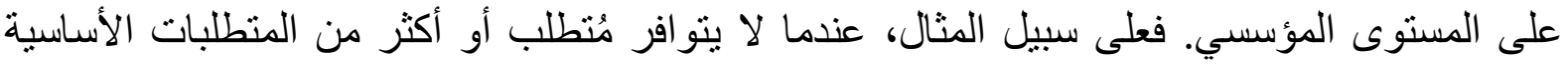

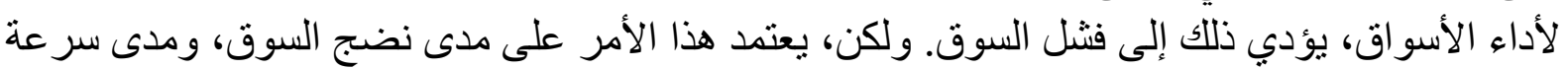

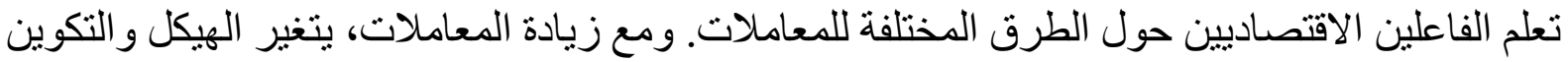

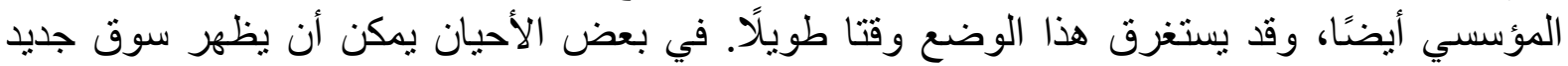

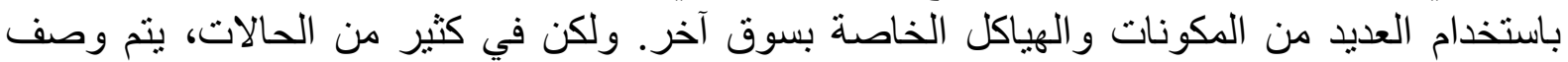

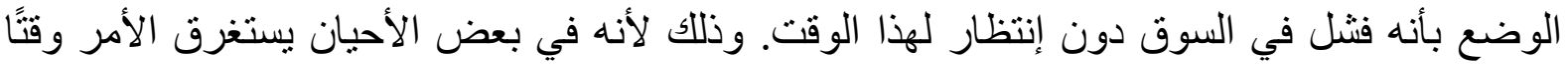

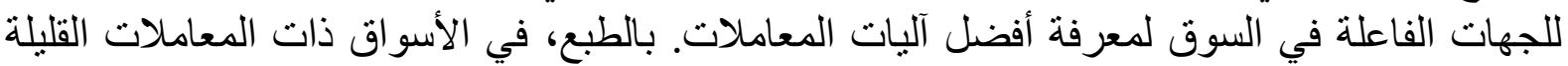
جدًا، قد لا يحدث ذللك أبدًا. و هذا يعني أن الحكم على أداء السوق بالفنشل قد يكون مبكرًا.

وعلى الرغم من تعريف فثل السوق من حيث كفاءة تخصيص الموارد الاقتصادية فقط، وأن هذا

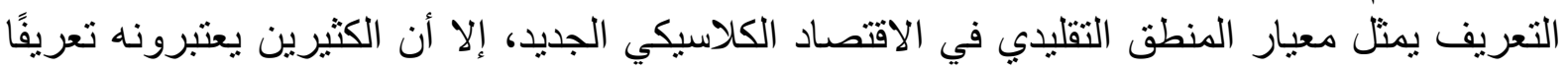

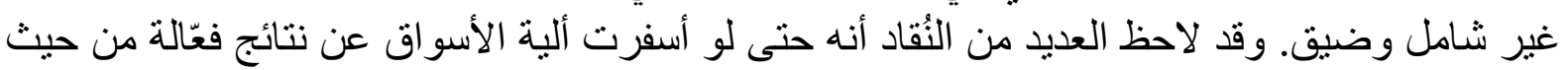

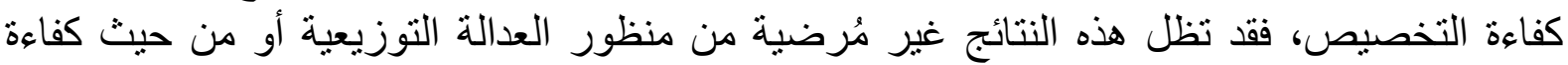

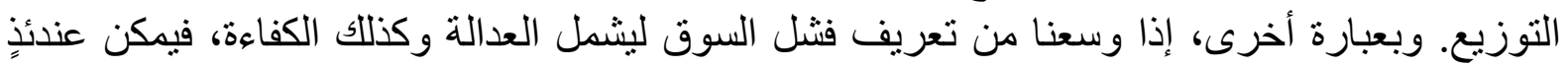

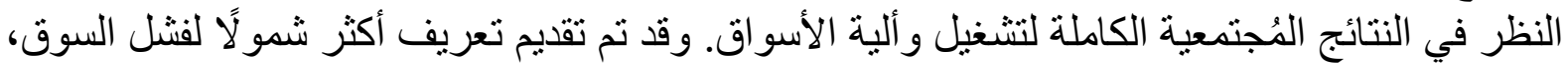

${ }^{46}$ Kneese, A. and R. Ayres., (1969). "Production, Consumption, and Externalities," American Economic Review 59, P. 282.

${ }^{47}$ Lines, D., Marcouse, I. \& Martin, B., (2006). The complete AZ business studies handbook. 5th ed. London: Hodder Arnold, P.302. 


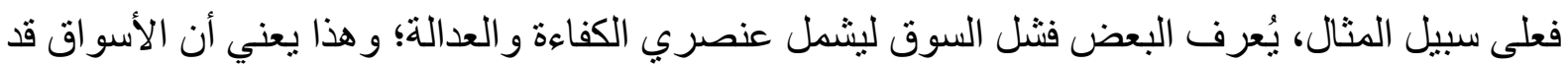

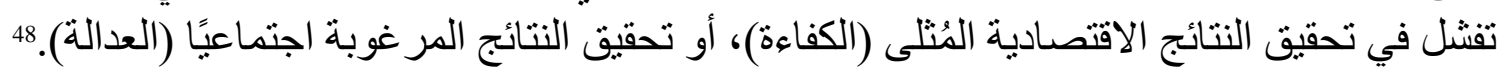
ويمكن القول، أن إدخال مسائل العدالة أو المساواة في التحليل الاقتصادي يجلب معه بعض الاعتبار ات المعقدة، ليس أقلها حقيقة وجود مجموعة لا تنتهي تقريبًا من المعايير الأخلاقية المعقولة لتقبيم العدالة. 49

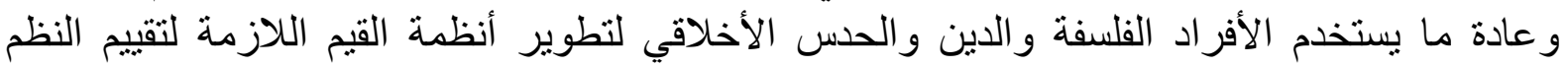

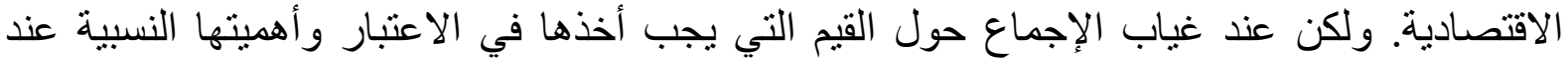
تعارضها، يجب أن تلعب المؤسسات السياسية دورًا لا مفر منه في اختيار القيم المحددة اللازمة لتقييم النظم الاقتصسادية.

لهذه الأسباب وغيرها، تحفّظ الاقتصاديون على الإدخال المحدد للمعايير الأخلاقية في التحليل

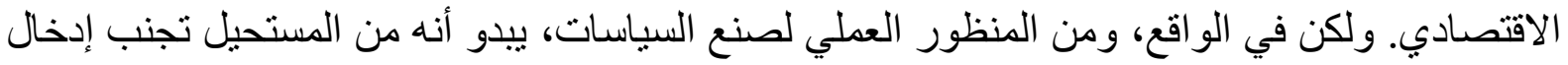

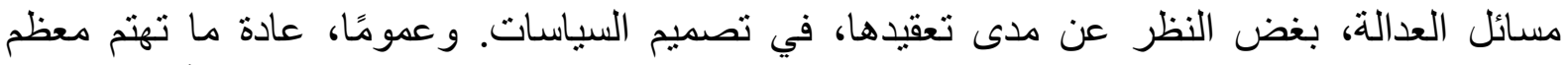

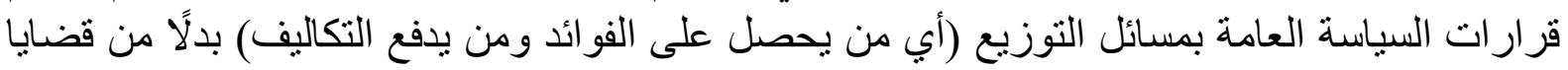
الكفاءة (أي حجم الفو ائد و التكاليف).

ويتسبب فنثل السوق في صعوبة تحقيق حالة الكفاءة الاقتصادية، وذللك لأنه يؤدي إلى تشويه آليات

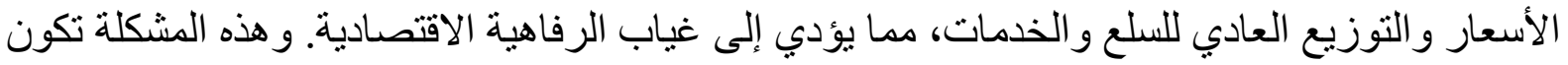

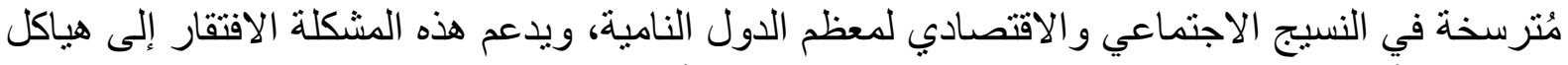
السوق والأنظمة الاقتصادية الفعالة، والتي من المُفترض أن تجعل اقتصاد السوق قادر على إمتصاص مثل هذه المشاكل الاقتصادية.

وفقًا للفكر التقليدي، تتحمل الحكومات مسؤولية ضمان عمل الأسواق بالشكل الأمثل من خلال دور ها في

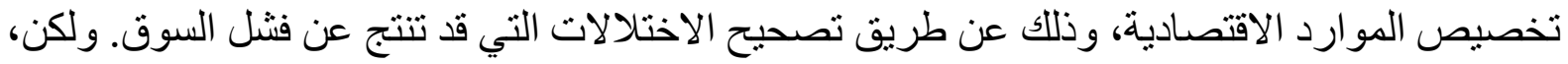

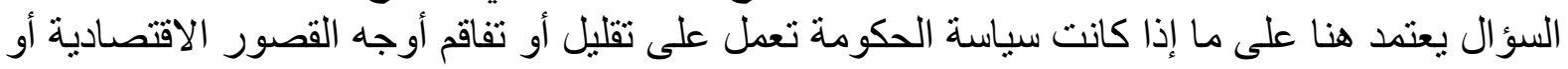

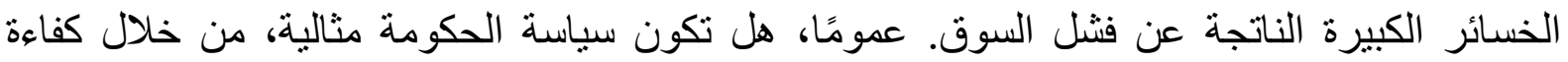

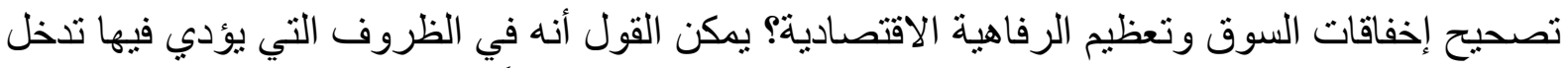

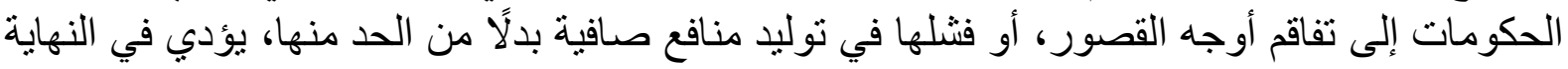
إلى فثل الحكومة.

فقد تجد الحكومات صعوبة في التحديد الدقيق لمدى انحر اف نتائج السوق عن مستواها الأمثل، وبالتالي

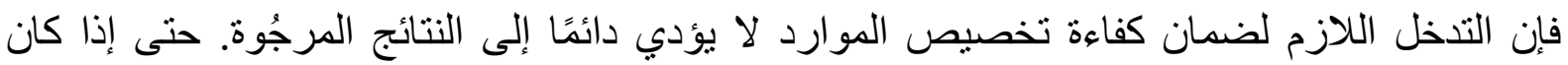
بإمكان صانعي السياسات تحديد درجة فثل السوق بالكامل، وبالتالي التدخل بكفاءة، فإن نتيجة التهة سياسة

\footnotetext{
${ }^{48}$ Klaus Mathis, (2009). Efficiency instead of justice: Searching for the Philosophical Foundations of the Economic Analysis of Law, Springer Science+Business Media B.V, P.51.

${ }^{49}$ Kolm, S. C., (1977), Modern Theories of Justice, (Cambridge, MIT Press).

${ }^{50}$ Weimer, D. L. and Vining, A. R., (1999). Policy Analysis (third edition), (Upper Saddle River, N. J., Prentice Hall), P.134.

${ }^{51}$ Winston, C., (2006). Government Failure versus Market Failure: Macroeconomics Policy Research and Government Performance. AEI-Brookings Joint Center for Regulatory Studies, the American Enterprise Institute for Public Policy Research, Washington, D.C., and the Brookings Institution, Washington, D.C., P.20.
} 
التدخل قد لا نز ال غير قادرة على تحفيز كفاءة تخصيص الموارد.52 فقد يكون هنالك فثل في السوق

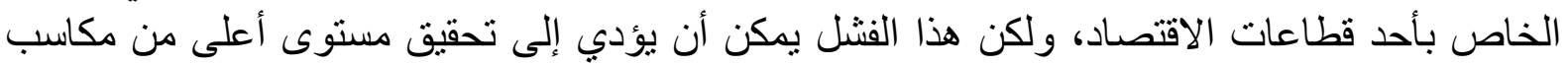

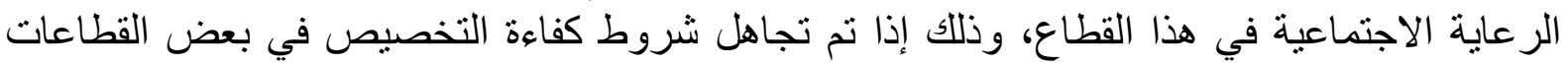

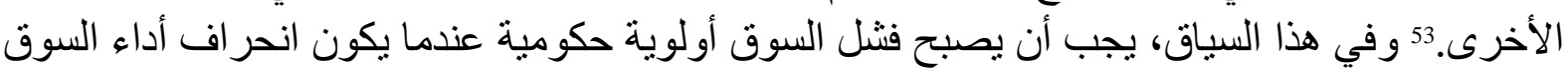

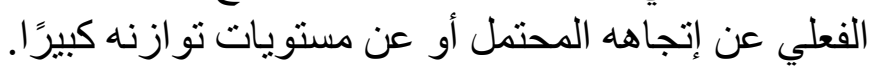

وهناك تركيز عالمي كبير على ضمان الاستخدام الرشيد للموارد الاقتصادية الفردية، وذلك لتحسين الإنتاجية، مما سيؤثر في النهاية على فرص العمل بشكل إيجابي. ومن المُعتقد أن يكون هذا التركيز أيضًا

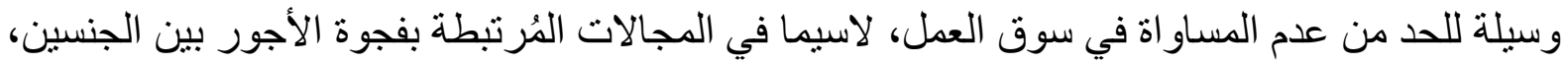

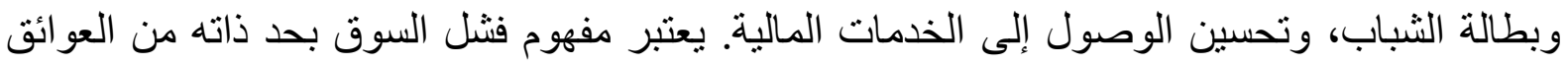

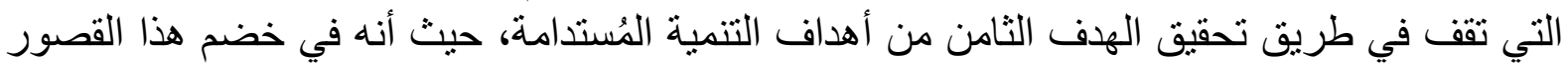
الاقتصادي، لا يعمل النظام الاقتصادي عادة بشكل جيد لضمان نمو اقتصادي مُستدام وشامل في قطاعات الاقتصاد التي تشتد الحاجة إليها.

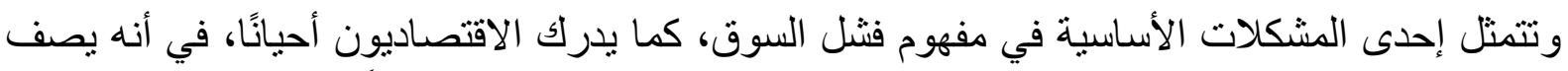

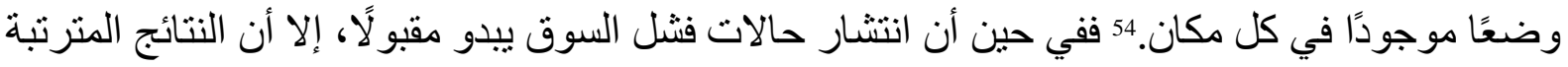

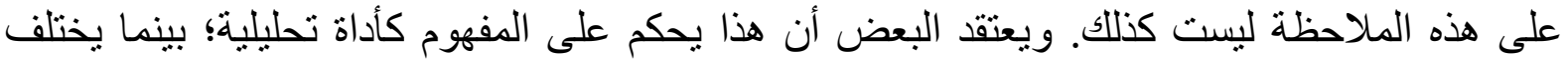
الآخرون في ذلك. فيُعتقد أن حالات فنثل السوق تحدث عندما يفشل السوق في إنتاج سلع عامة، أو يُنتج

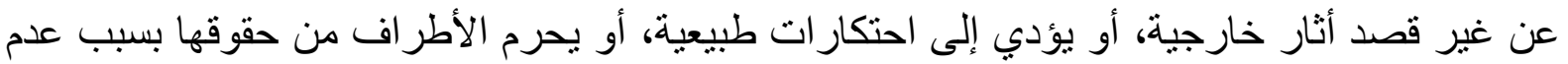

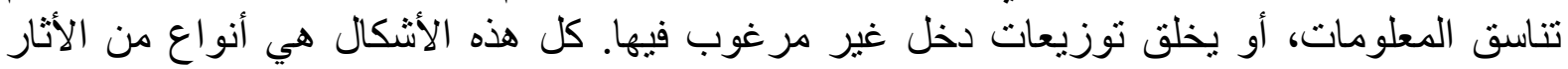

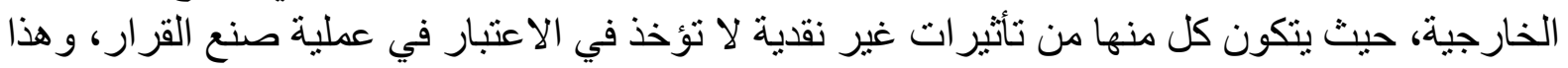

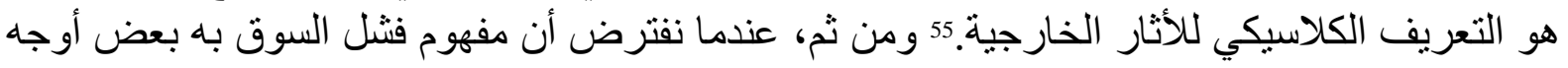

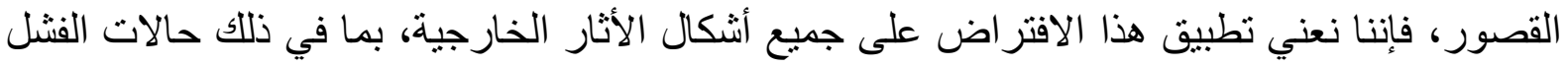
غير السوقية من قبل المؤسسات الحكومية.

والحجة الأساسية ضد تحليل فنشل السوق تكون مُستمدة من دراسة تكاليف المعاملات، وتنشأ الأثار

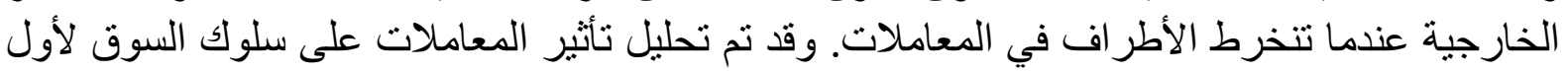
مرة في ثلاثينيات القرن الماضي، بدءً من تحليل رسوم السمسرة وتكاليف المعاملات الأخرى.

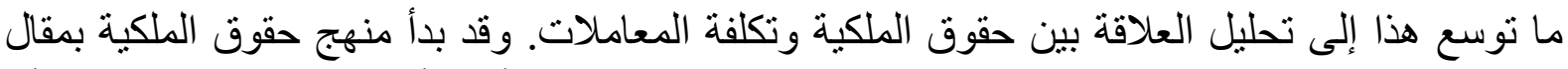

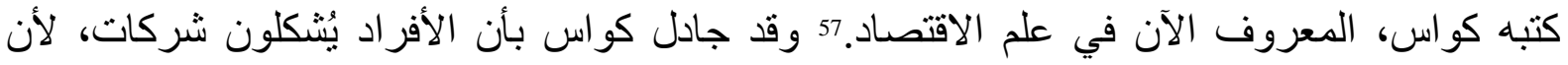

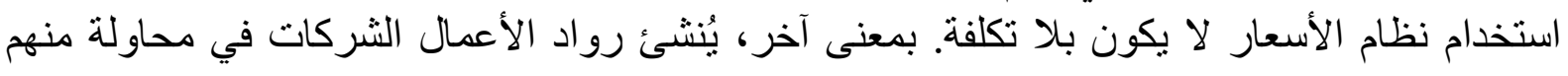

${ }^{52}$ Lipsey, R. G. and Lancaster, K., (1956). The General Theory of the Second Best, Review of Economic Studies, Vol.24 (1), PP.11-23.

${ }^{53}$ B. Dollery \& J. Wallis, (2001). The Theory of Market Failure and Equity-Based Policy Making in Contemporary Local Government, Local Government Studies, 27:4, P.59.

${ }^{54}$ Nelson, R., (1987, summer). Roles of government in a mixed economy. Journal of Policy Analysis and Management, 6, P.541.

${ }^{55}$ Baumol, W.J., \& Oates, W.E., (1975). The theory of environmental policy. Englewood Cliffs, NJ: Prentice Hall, P.14.

56 Allen, D., (1999). Transactions costs. In S. Medema, G. Bouckaert, \& G. DeGeest (Eds.), Encyclopedia of law and economics. Aldershot, UK: Edward Elgar, P.250.

${ }^{57}$ Coase, R.H., (1937). The nature of the firm. Reprinted in R. Coase, The firm, the market, and the law. Chicago: University of Chicago Press, 1988, P.66. 
لتقليل تكاليف المعاملات المرتبطة باستخدام نظام الأسعار. وقد تم تطوير هذا المنهج بشكل أساسي بعد مقالة كو اس حول مشكلة التكلفة الاجتماعية.58

وتظهر أهمية منهج تحليل حقوق الملكية من حيث أنه يحدد الحالة التي بموجبها تختفي الأثار الخارجية

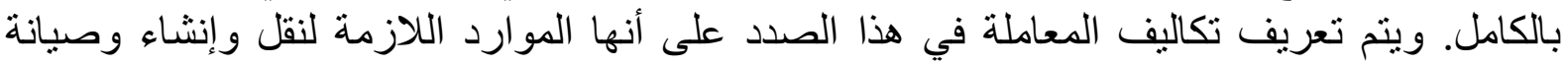
حقوق الملكية. 59 ونظرًا لأن حقوق الملكية أصبحت أكثر شمولًا و إكتمالًا، فإن تكاليف المعاملات تكاد تكاد تقترب من الصفر. وبطريقة مماثلة، مع إنخفاض تكاليف المعاملات، تصبح حقوق الملكية أكثر إكتمالا، حيث يكون من الأرخص الدفاع عنها أو نقلها. و عندما تكون حقوق الملكية مثالية، تتلاشى تكاليف المعاملات. و عندما لا يكون هنالك تكاليف للصفقات التجارية، و عندما يكون حقوق الملكية محددة جيدًا،

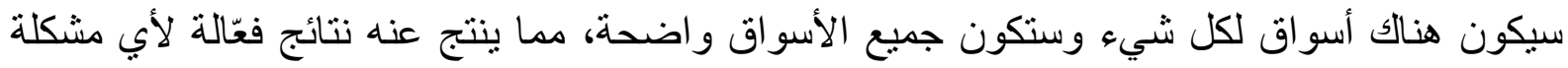

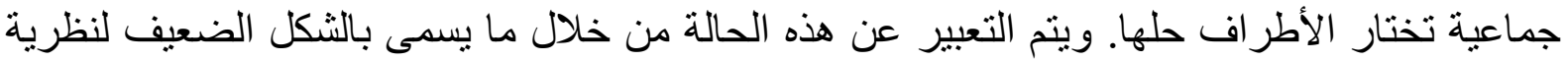
كواس. وهذه النظرية تتص على أنه عند تحديد حقوق الملكية بالكامل، وحيث تكون تكاليف المعاملات صفرًا، سيكون تخصيص الموارد فعَّاًا. ${ }^{60}$ ولكن في الواقع، لا يوجد مثل هذا الافتر اض على فلى الإطلاق و هذه النتيجة مهمة لفهم سبب عدم نجاح نموذج فنشل السوق.

\section{المبحث الثاني: بعض الأنواع الثائعة لفشل السوق}

هنالك العديد من الحالات المُختلفة لفتل السوق التي تم وصفها في الفقه الاقتصادي. ولكن مع مرور

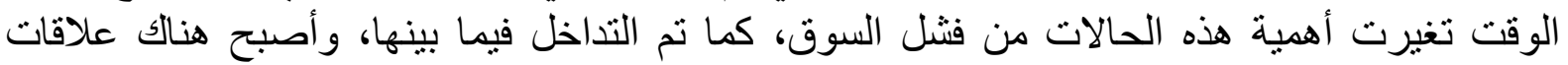

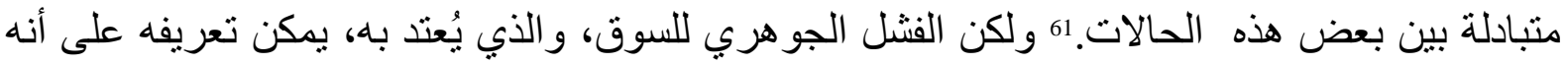
الوضع الذي تفنل فيه الأسواق، حتى في ظل اقتصاد نشط وبه هيئة قوية لمكافحة الاحتكار.

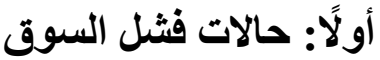

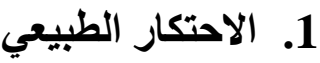

هنالك بعض المنتجات و الخدمات التي لا يتم تقديمها من خلال الأسواق أو لا تخضع لألية اقتصاد السوق،

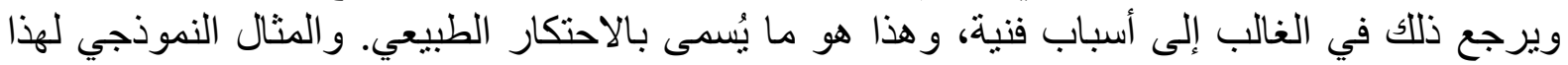

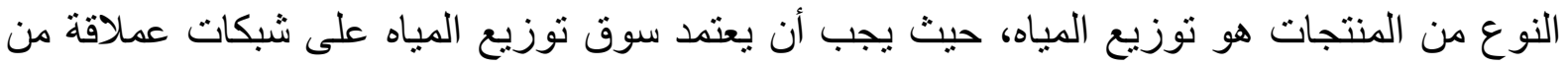

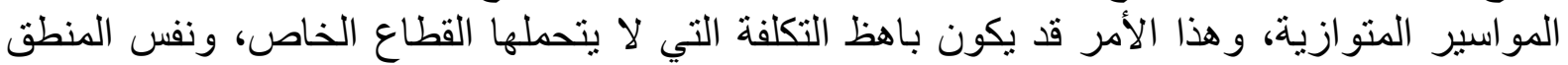

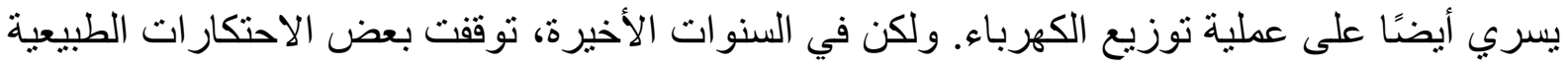

${ }^{58}$ Coase, R.H., (1960, October). The problem of social cost. Journal of Law and Economics, 3, PP.144.

59 Allen, D.W., (1991). What are transaction costs? In R.O. Zerbe and V.P. Goldberg (Eds.), Research in law and economics (Volume 14, PP. 1-8). Greenwich, CN: JAI Press, P.4.

${ }^{60}$ Medema, S.G., \& Zerbe, R.O. Jr. (1999). The Coase theorem. In S. Medema, G. Bouckaert, \& G.

DeGeest (Eds.), Encyclopedia of law and economics. Aldershot, UK: Edward Elgar.

${ }^{61}$ Wolf, C., (1979). "A Theory of Nonmarket Failure: Framework for Implementation Analysis". Journal of Law and Economics, Vol. 22(April), P. 107.

${ }^{62}$ Alan Randall, (1983). The Problem of Market Failure, 23 Nat. Resources J., P. 131. 
عن كونها طبيعية بسبب التغير التكنولوجي، ويظهر ذلك على سبيل المثال في مجال الاتصالات السلكية و اللاسلكية. ويجب ملاحظة أن الاحتكار الطبيعي يكون مختلف عن السلوك الاحتكاري للشركات.

\section{2. الأثار الخارجية للمعاملات الاقتصادية}

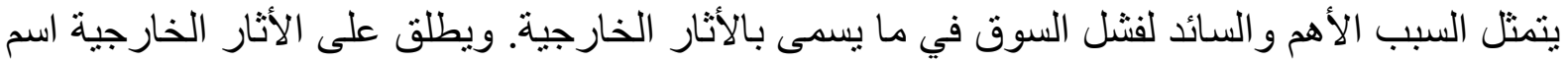

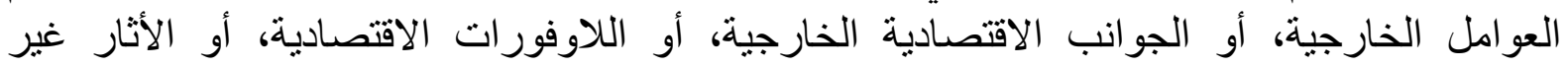

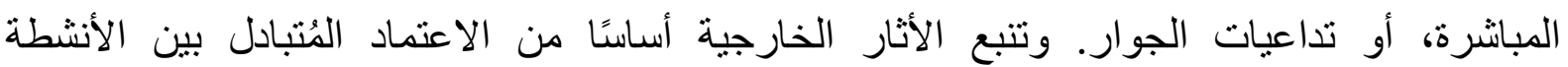

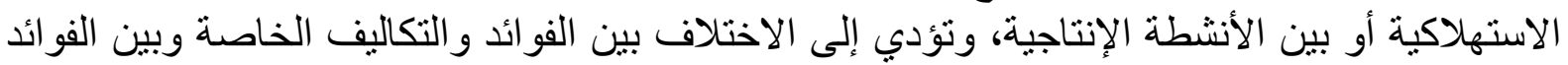

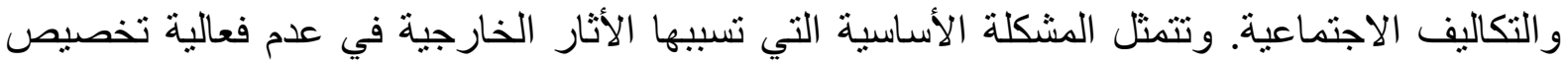

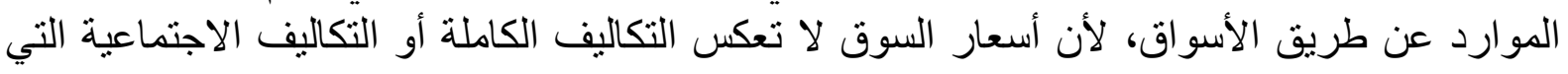

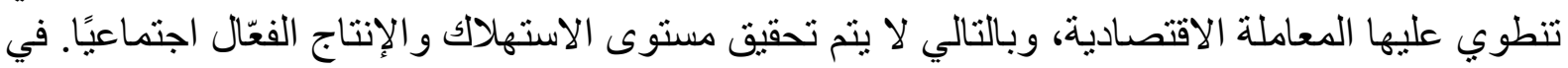

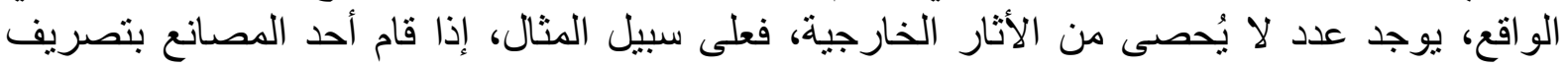

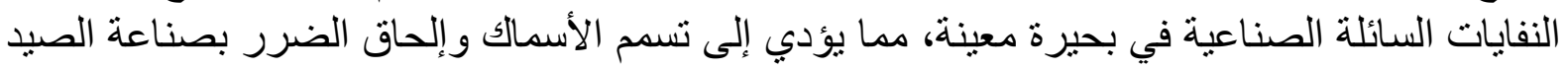

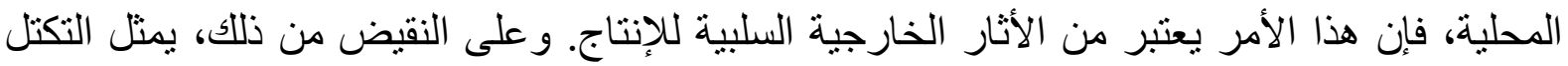

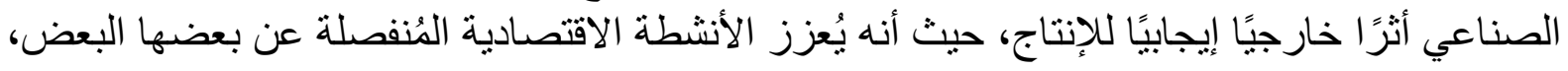

$$
\text { ويُخفض من تكاليف الإنتاج. }
$$

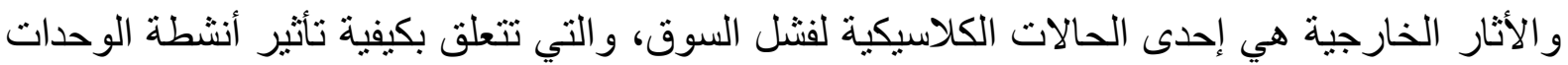

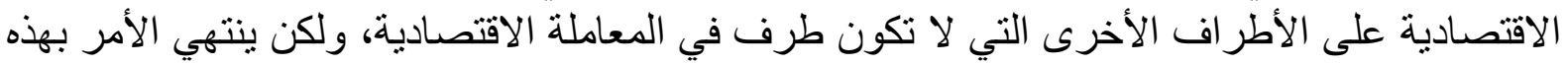

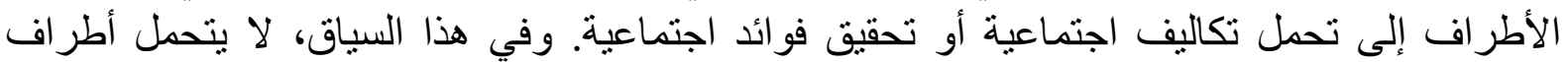

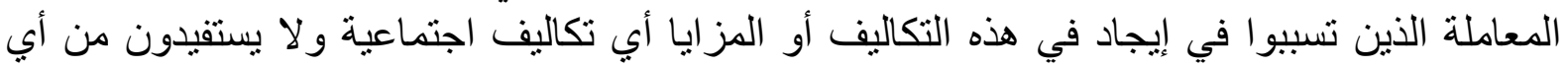

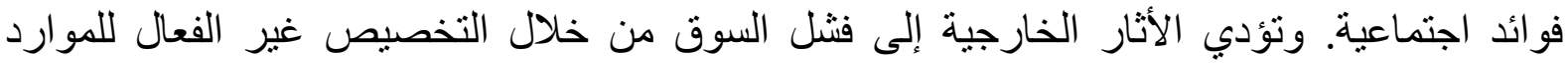

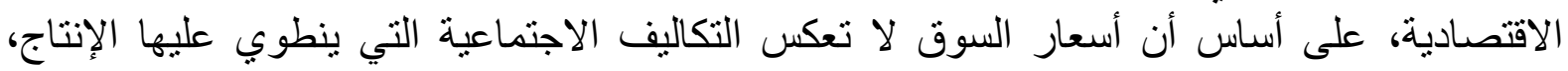

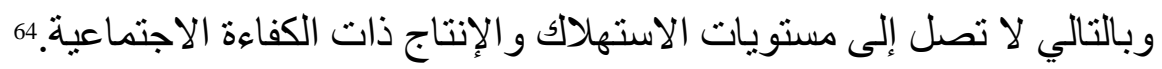

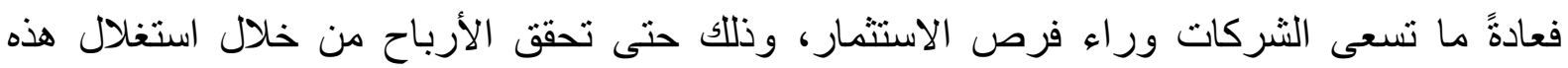

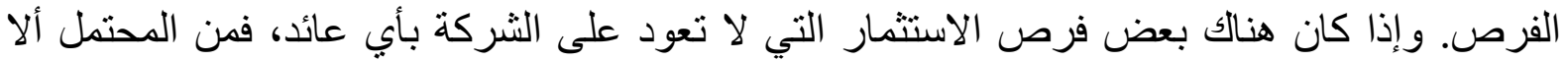

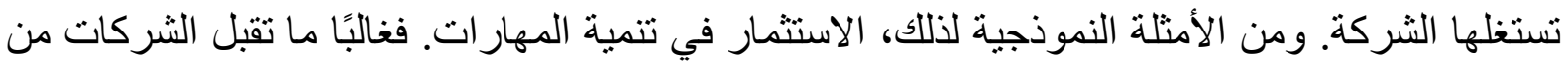

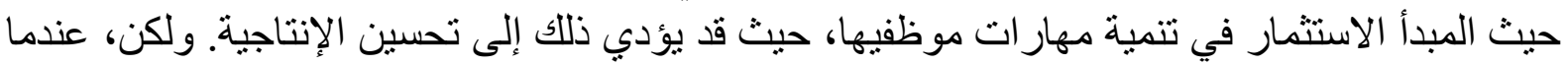

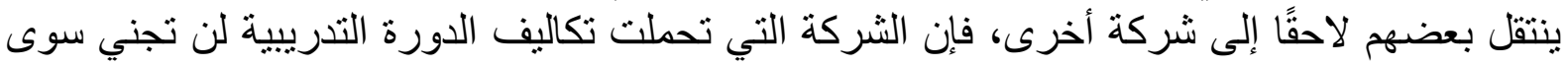

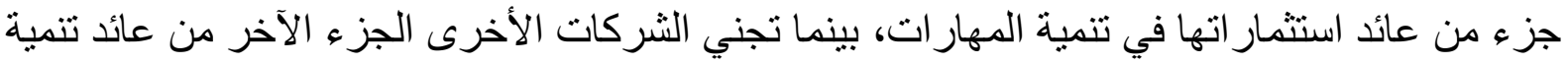

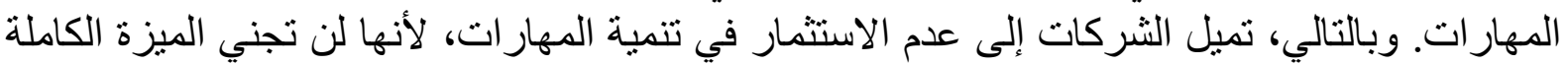

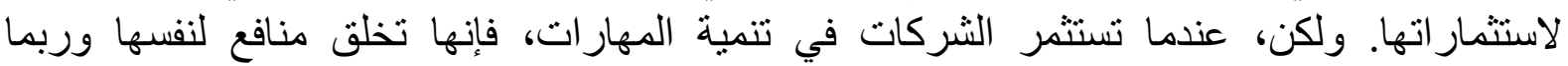

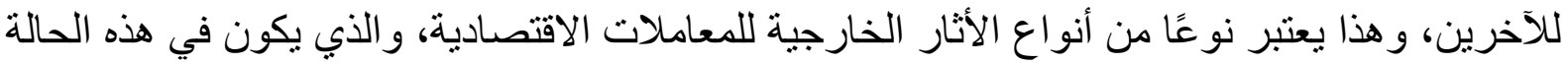

${ }^{63}$ Cunningham, S., (2011). Understanding Market Failures in an Economic Development Context. Pretoria, South Africa: Mesopartner Monograph 4, P.15.

${ }^{64}$ B. Dollery \& J. Wallis, (2001). The Theory of Market Failure and Equity-Based Policy Making in Contemporary Local Government, Local Government Studies, 27:4, PP.59-70. 
من ضمن الأثار الخارجية الإيجابية. و هناك أيضًا أثار خارجية سلبية، على سبيل المثال الأضرار البيئية

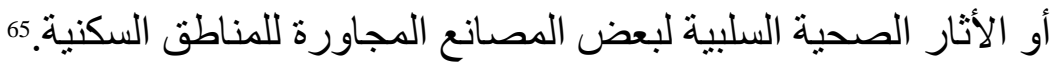

وفي جميع حالات الأثار الخارجية، يمكن حل هذه المشكلة عن طريق مُساواة التكاليف والفوائد

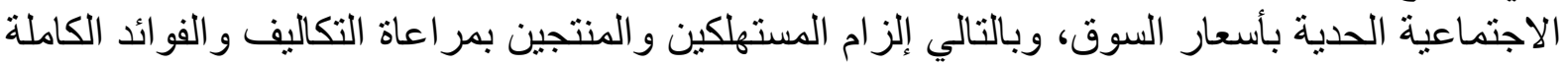

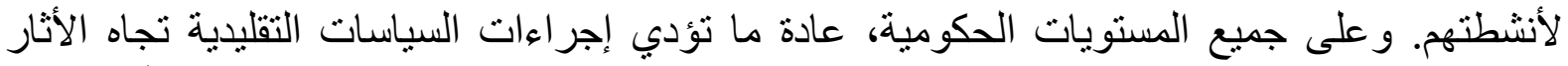

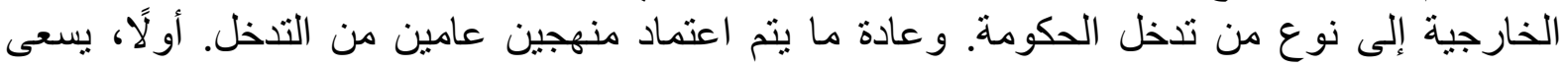

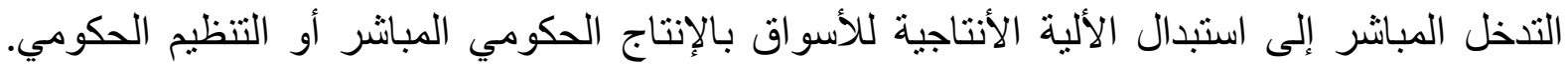

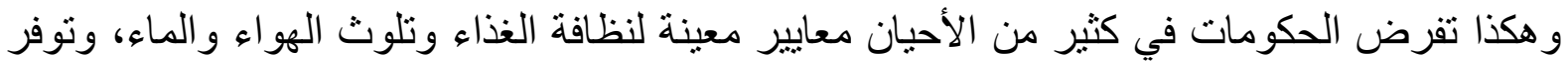

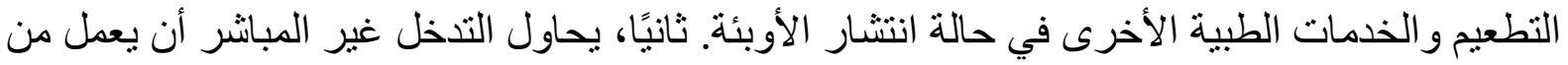

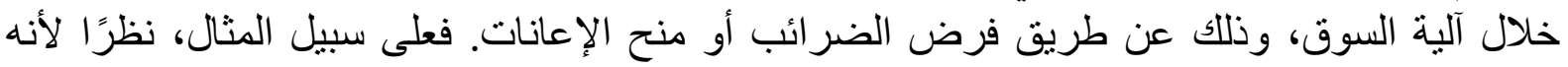

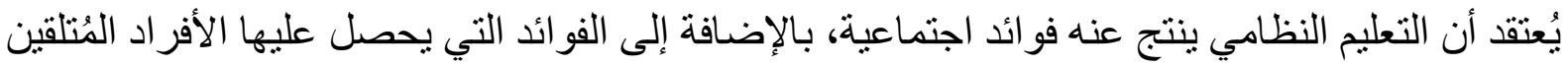

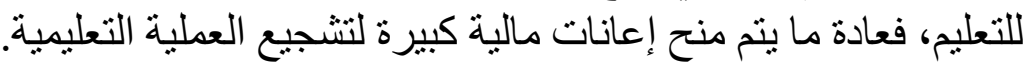

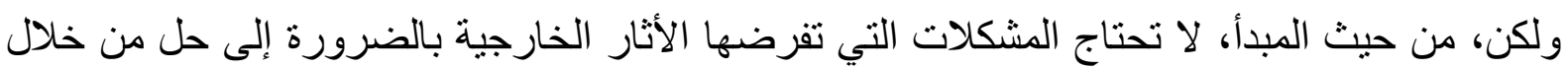

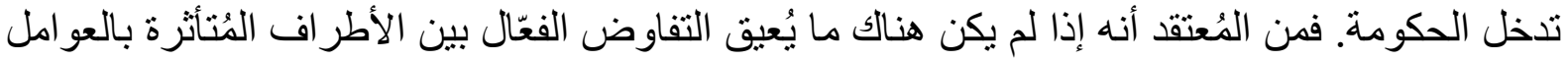

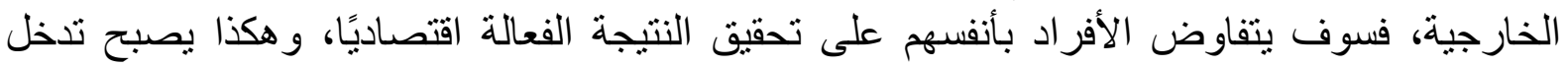

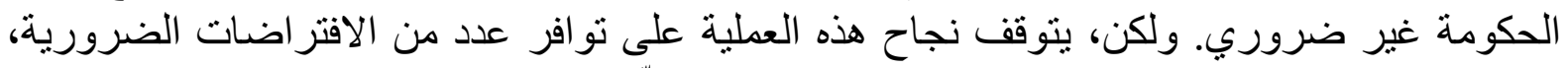

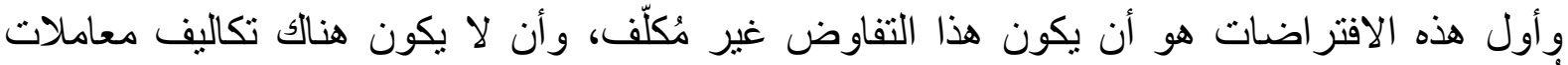
أُخرى

\section{3. عدم القابلية للتجزئة أو اقتصاديات الحجم الكبير}

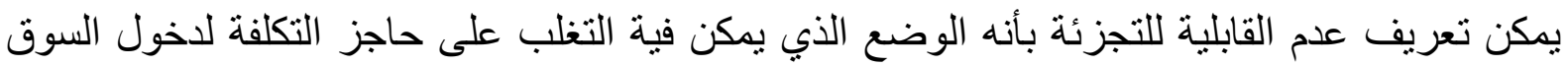

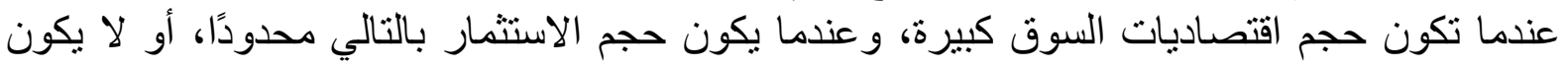

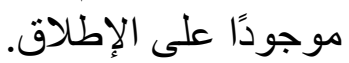

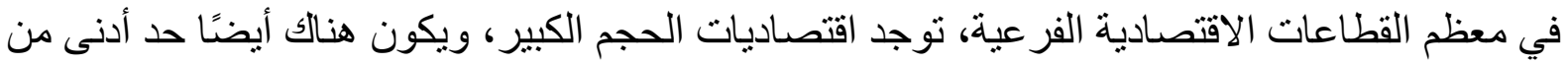

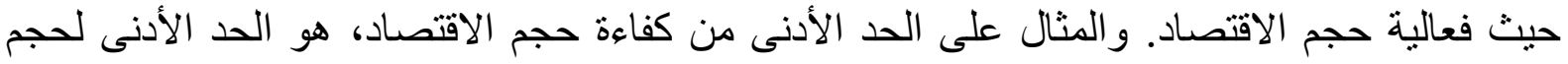

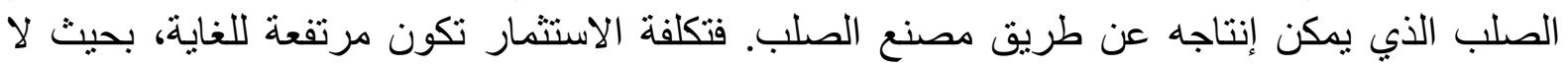

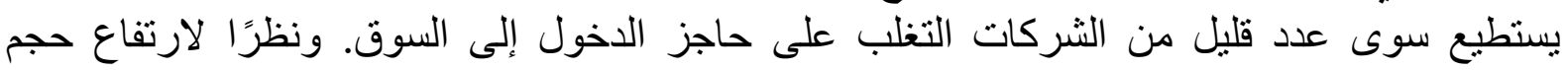

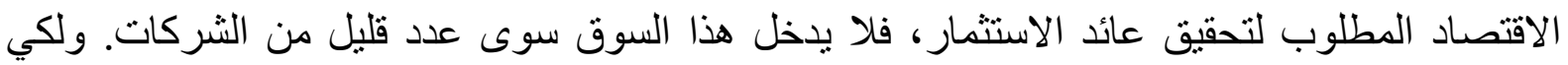

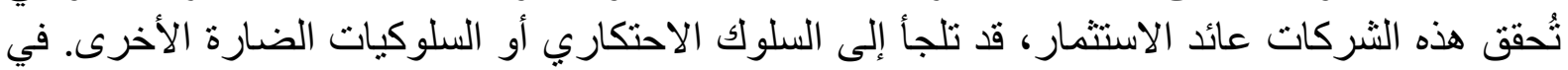

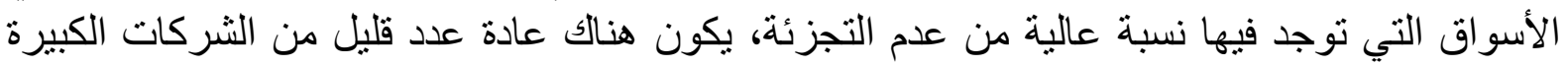

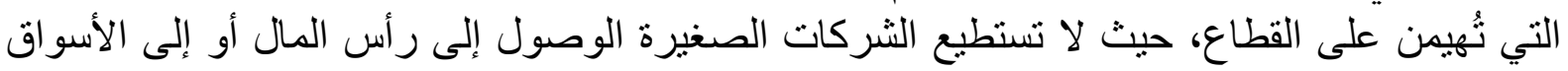

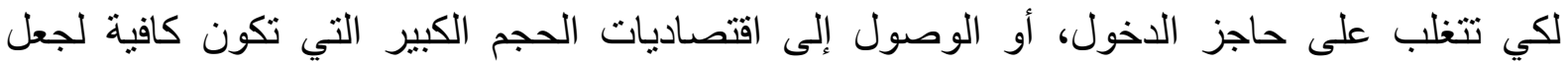

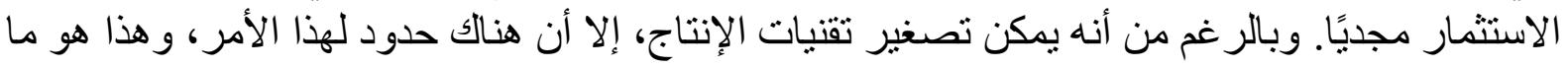
يدور حوله مبدأ عدم التجزئة.

${ }^{65}$ Papandreou, Andreas A., (1994). Externality and Institutions. Oxford: Oxford University Press, P.111. 


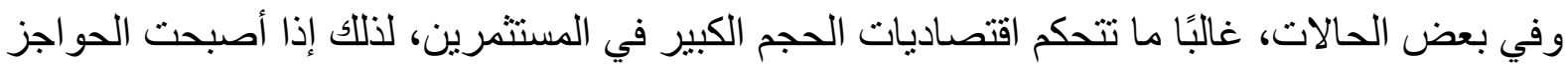

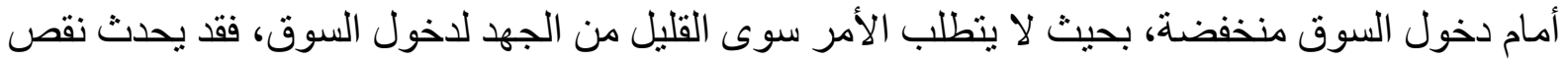
في الاستثمار. وغالبًا ما يحدث هذا الأمر مع التجار غير الرسميين، وفي مجال التصنيع محدود النطاق.

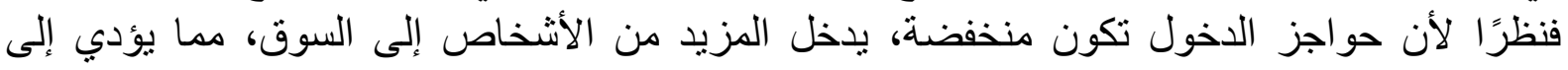
إنخفاض عائد الاستثمار و الفتشل في النهاية.

و ون المهم أن نلاحظ أنه في حين ترتبط عدم القابلية للتجزئة في الغالب بالاستثمار ات الكبيرة، فإن عدم

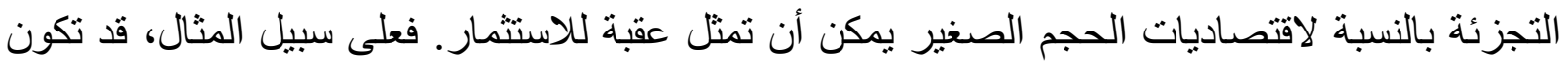
التكلفة التي تتحملها شركة صغيرة لتوظيف محاسب أو شر اء كمبيوتر إضافي أو سيارة توصيل باديل باهظة

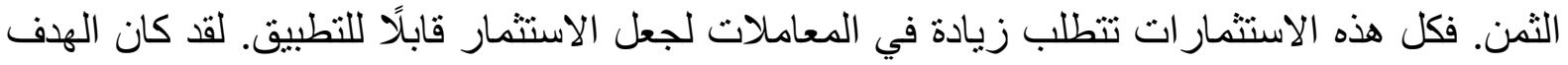

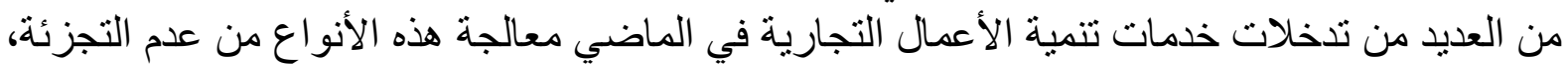

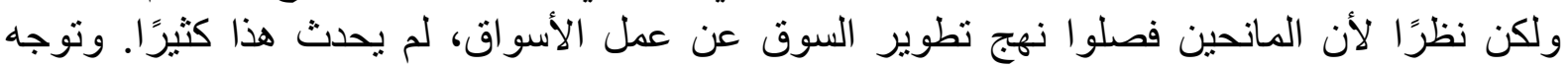

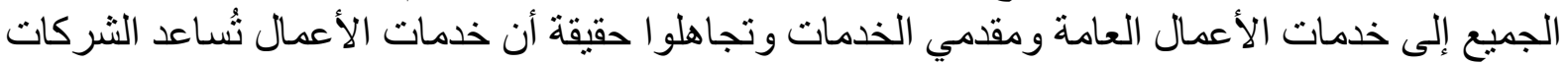

$$
\text { على التغلب على أوجه عدم التجزئة. }
$$

وقد تو اجه الثركات التي تمكنت دن التغلب على حاجز الدخول إلى السوق تحديًا آخر، و هذا التحدي هو التها

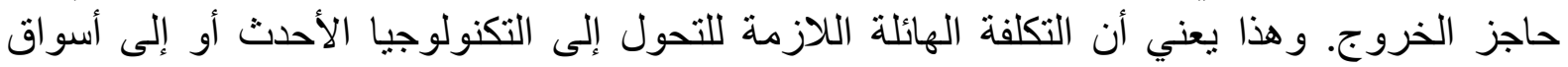

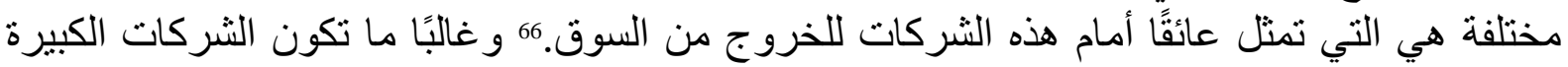

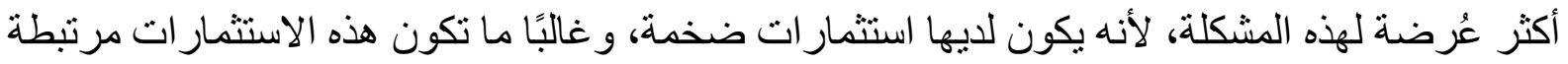

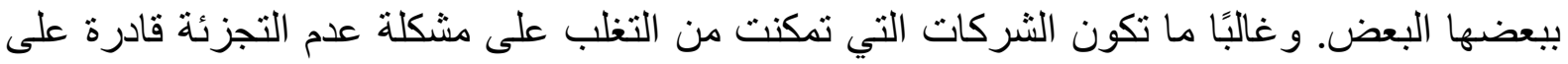

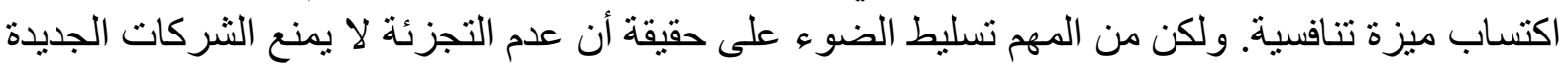

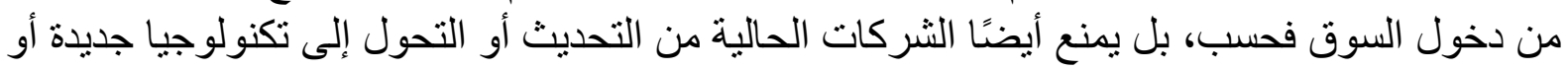
من تنفيذ نماذج مشرو عات جديدة.

و عادةً ما يتم التغلب على مشكلة عدم التجزئة من خلال مجموعات جديدة من التكنولوجيا، أو من خلال

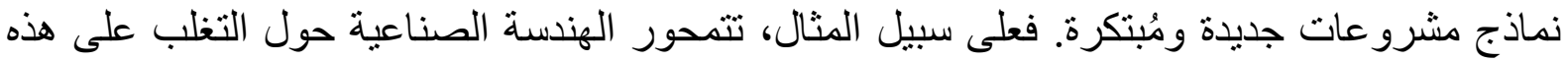

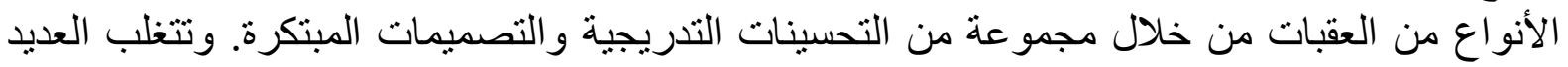

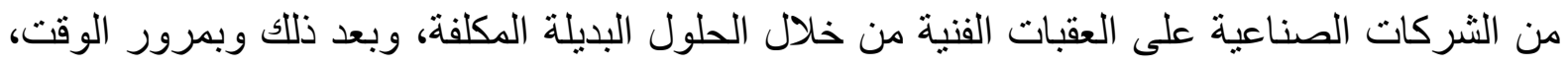

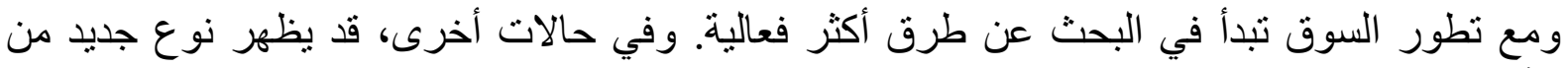

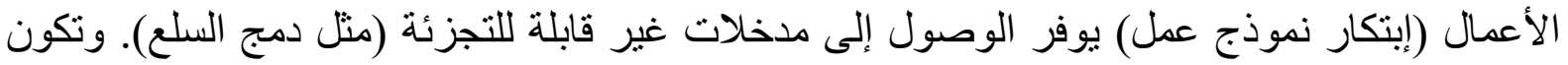
العديد من الشركات الصغيرة غير قادرة ببساطة على القيام بذللك، ومن ثم تعاني من عدم القابلية للتجزئة.

\section{4. عدم تماثل أو تناسث المعلومات}

يظهر المثال الكلاسيكي للمعلومات غير المتماثلة في عملية بيع سيارة مُستعملة. وهنا بعرف البائع

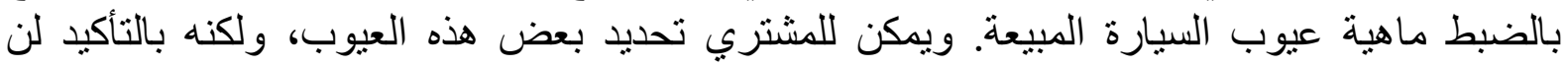

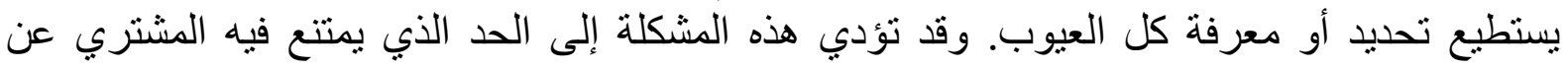

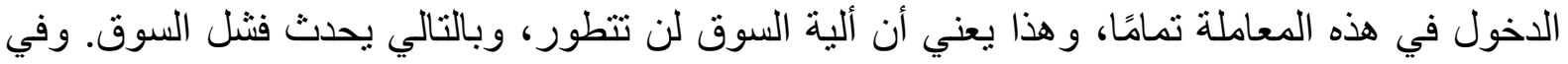

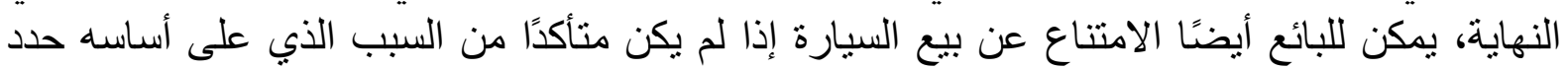

${ }^{66}$ David, Paul., (2007). Path Dependence: A Foundational Concept for Historical Social Science. Cliometrica, Journal of Historical Economics and Econometric History. 1, P. 91. 


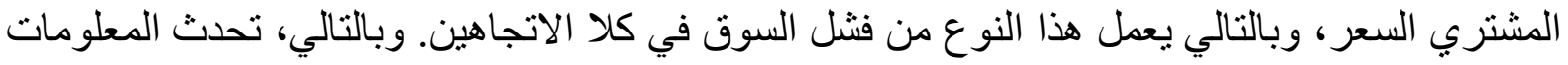

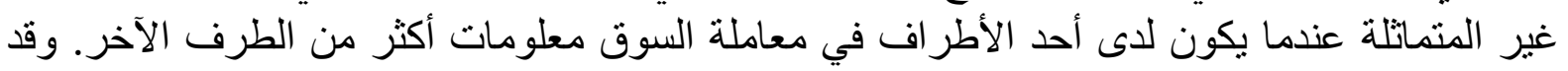

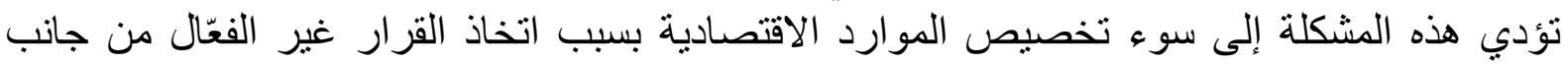
المنظمات أو الأفر اد، أو انهيار الأسواق المئه بأكملها.

و هذا لا يعني أنه يجب أن تكون جميع المعلومات الخاصة بالبائعين أو المشترين معروفة تمامًا حتى تتم

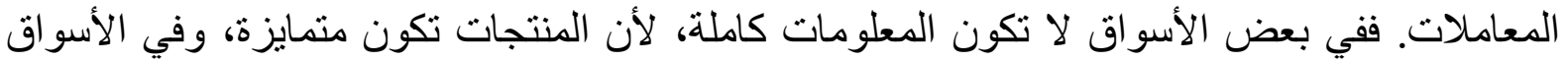

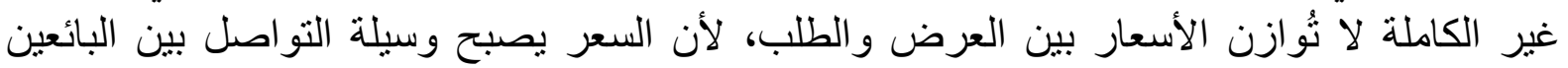

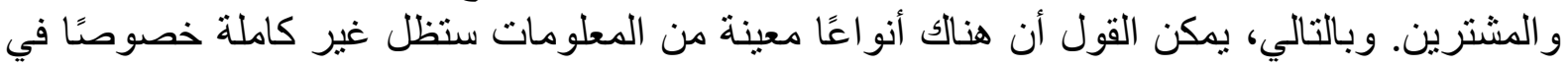

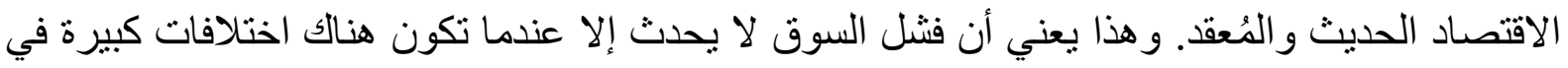

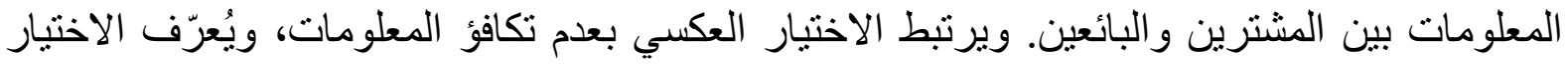

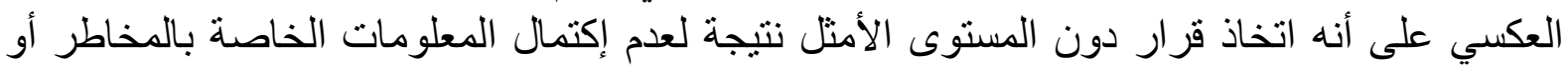
الجودة.

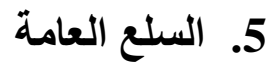

تنبيع أهمية السلع العامة كمصدر لفشل السوق من عدم قدرة الأسواق الخاصة على تقديم السلع العامة،

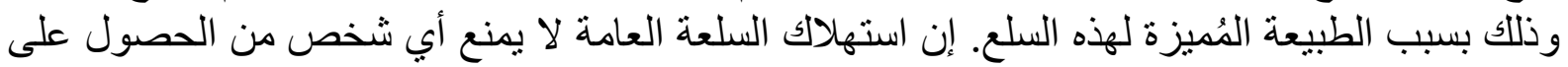

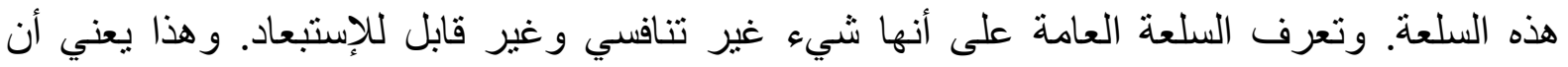

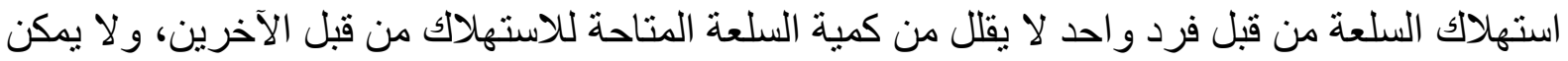

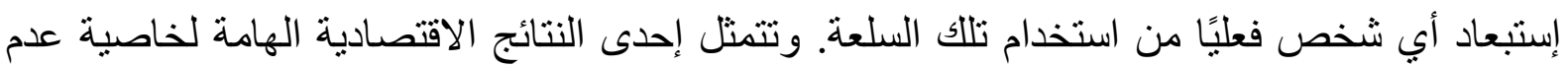

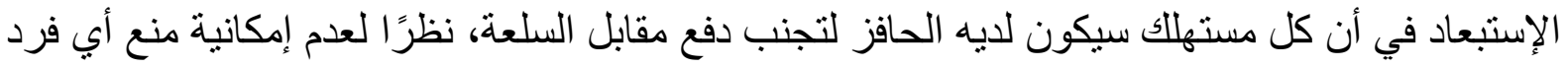
من استهلاك السلعة، أي أن مشكلة الانتفاع المجاني تعني أنه لا يمكن توفير السلعة من خلائل الألئ ألية الأسو اق.

ويحدث فثل السوق بسبب السلع العامة عندما يتم توفير هذه السلع بطريقة لا تفيد سوى عدد محدود من

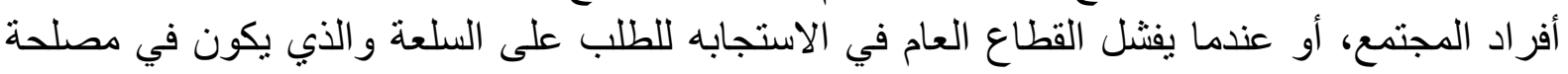

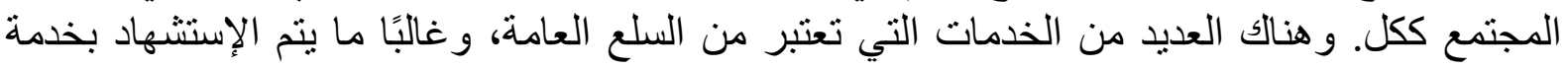

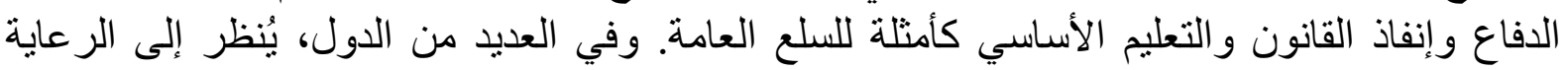
الصحية، وحتى التعليم الثانوي أو العالي، على التى أنها سلع عامة.

و هناك بعض السلع، وخصوصيًا الخدمات، حيث يكون من الصعب أو المستحيل تحصبل رسوم من

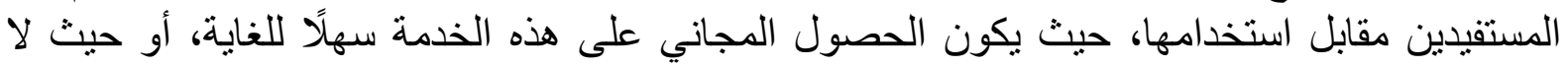

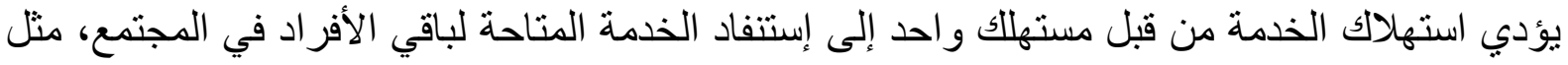

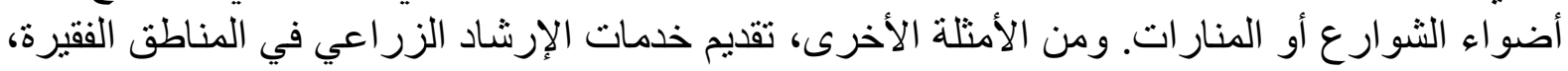

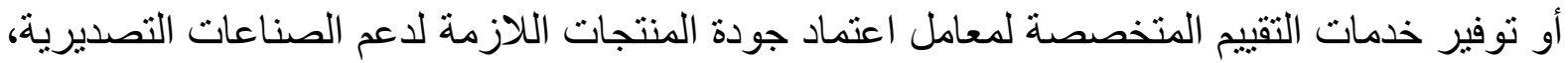
وذللك للإلتز ام بالمعايير الدولية. ويمكن أن يلعب البحث و التطوير من قبل مؤسسات التعليم العالي و غيرها

${ }^{67}$ Johnson, Marianne. (2015). "Public Goods, Market Failure, and Voluntary Exchange." In Market Failure in Context, edited by Alain Marciano and Steven G. Medema. History of Political Economy 47, P. 174. 
من المؤسسات الممولة من القطاع العام دورًا مهمًا في الإبتكار و الإنتاج في منطقة معينة، وهو شكل آخر

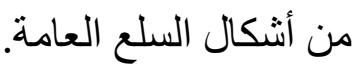

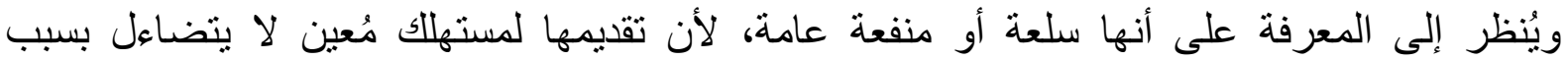

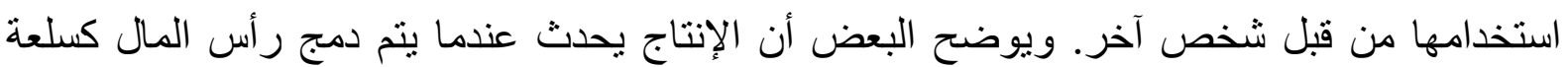

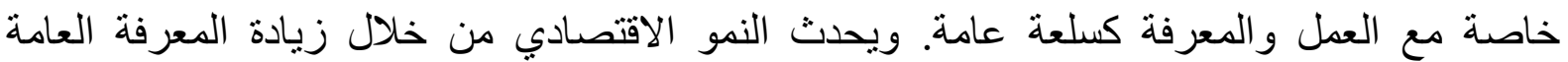
المتاحة. ولكن، عندما يتم توفير المعرفة كسلعة خاصة، تزدة اد تكلفة النمو الاقتصادي بالنسبة للمجتمع.68

\section{6. علدم وجود أو تحديد حقوق الملكية}

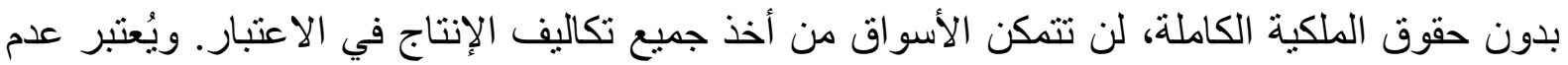

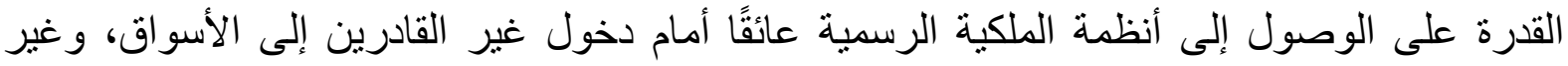

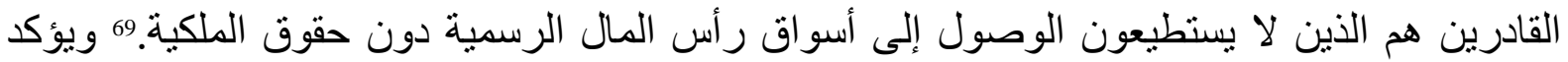

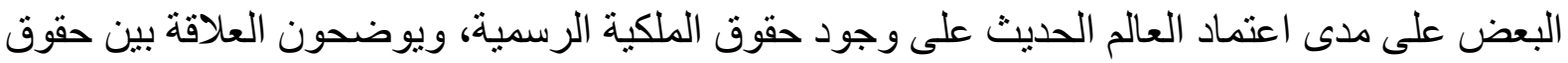

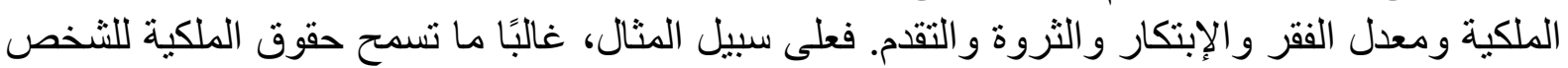

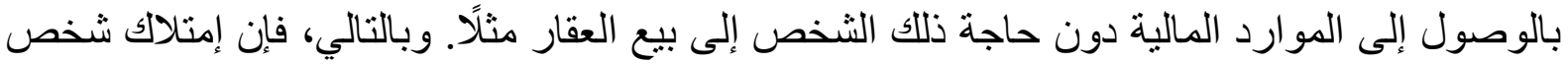

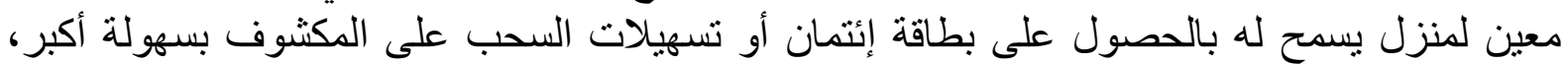

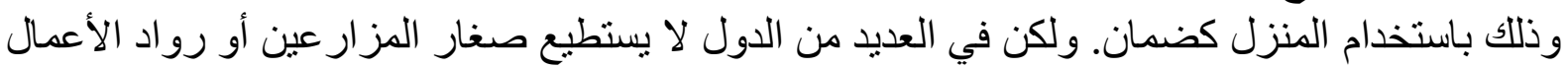

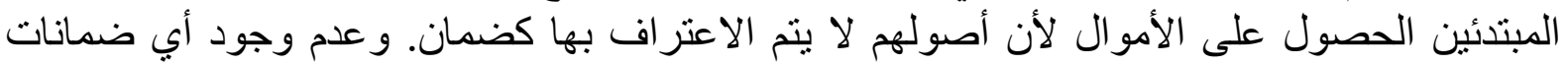

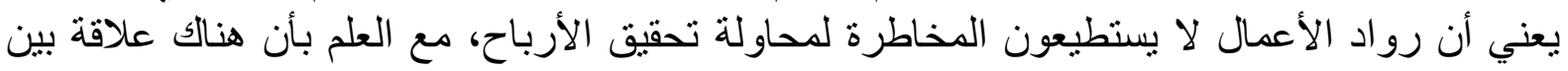

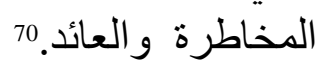

و هناك وجهة نظر أخرى لحقوق الملكية، وهي أنها العنصر الأساسي لتحديد من يمتلاك الأرباح ومن يقرر

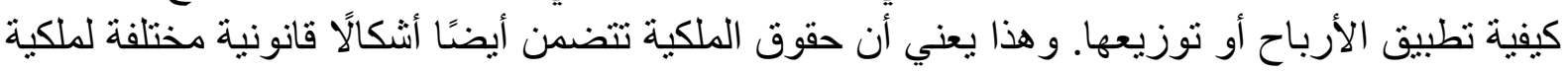

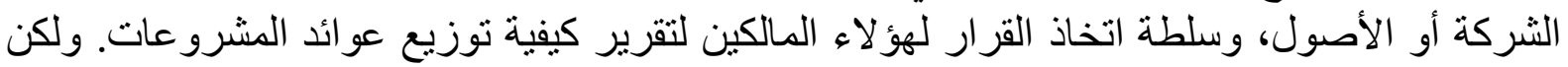

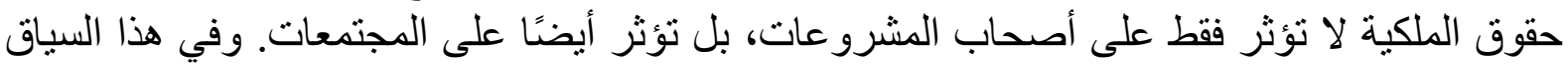

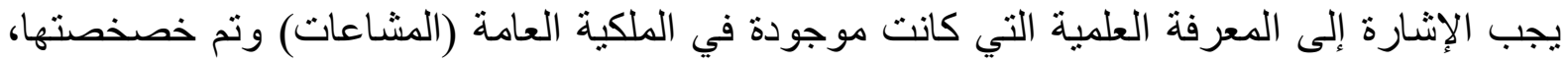

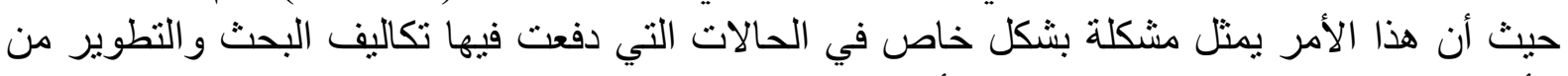

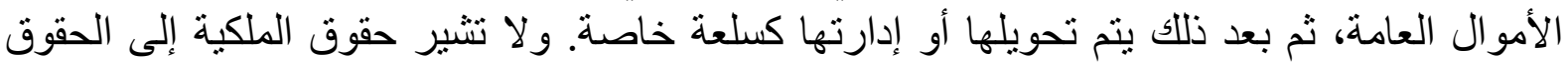

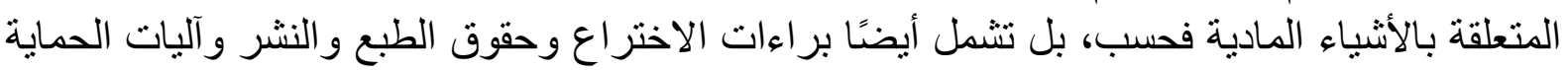

\footnotetext{
${ }^{68}$ Arrow, K., (1999). Knowledge as a factor of production. In Annual World Bank Conference on Development Economics. Stiglitz, J.E. \& Pleskovic, B. (Eds.), Washington, DC: The World Bank, PP. 15-20.

${ }^{69}$ De Soto, H., (2000). The mystery of capital: why capitalism triumphs in the West and fails everywhere else. New York, NY: Basic Books, P.66.

${ }^{70}$ Prahalad, C.K., (2005). The fortune at the bottom of the pyramid. Upper Saddle River, NJ: Wharton School Publishing, P.43.
} 
الأخرى. وجدير بالذكر أن القدرة على استخدام الممتلكات للحصول على التمويل، أو التبادل أو التجارة

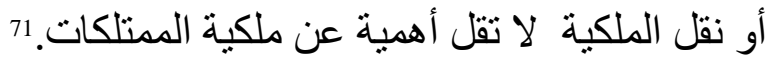

في حين أن حقوق الملكية وبر اءات الاختراع وحقوق التأليف والنشر ضرورية لعمل الأسواق، إلا أن

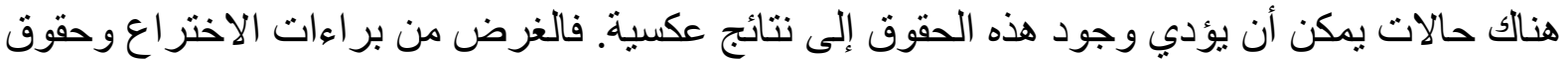

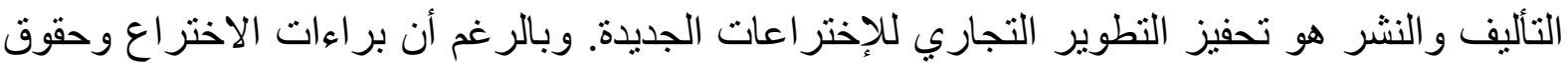

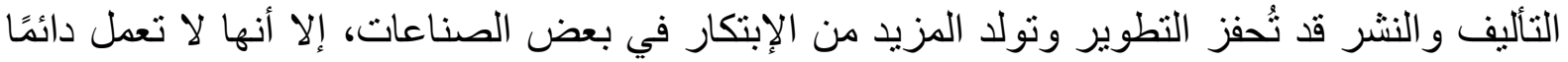

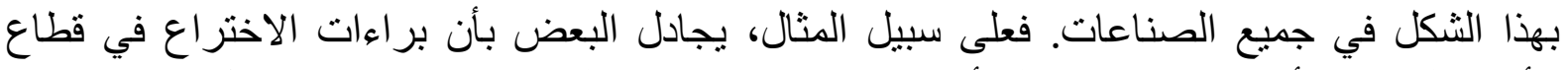

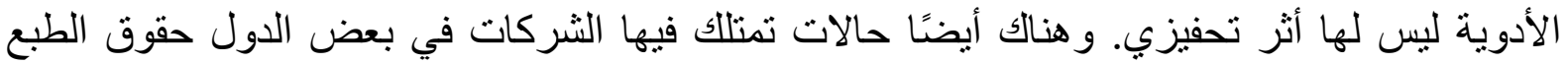
و النشر لأشياء، مثل الجينات أو النباتات أو الوصفات التئ التقليدية، ومن ثم تمنع هذه الحقوق الثركات

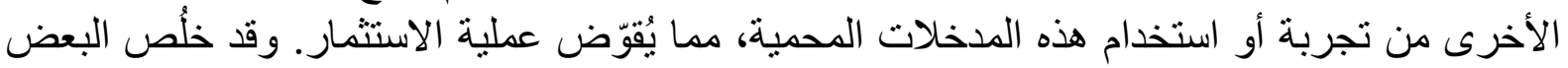

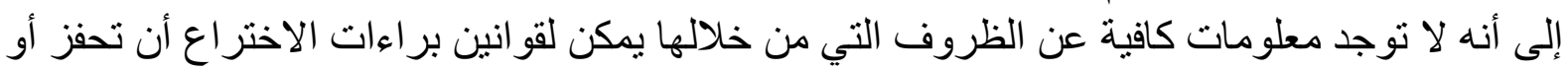
تقوض التتمية التجارية.72

\section{7. هياكل السوق دون المستوى الأمثل: الاحتكارات واحتكار القّة}

عندما يكون تنظيم الأسواق دون المستوى الأمثل، يمكن أن تحدث المنافسة غير الكاملة والتمبيز السعري

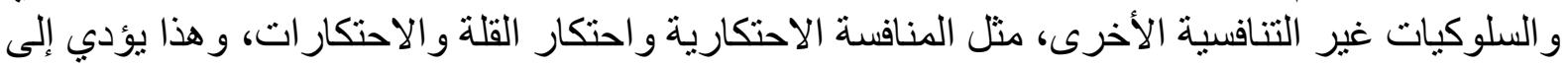

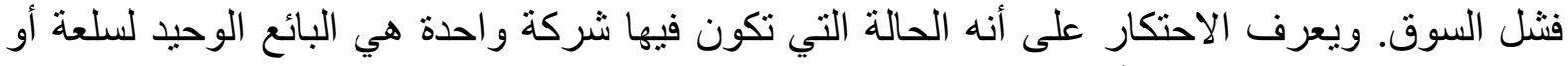

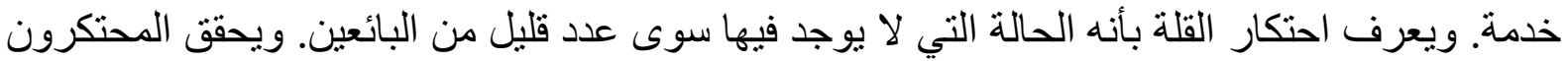

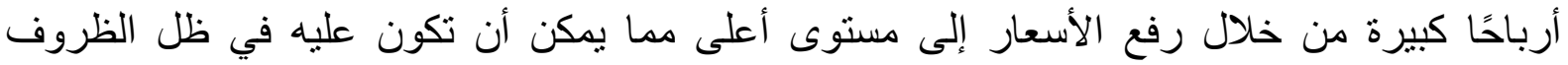

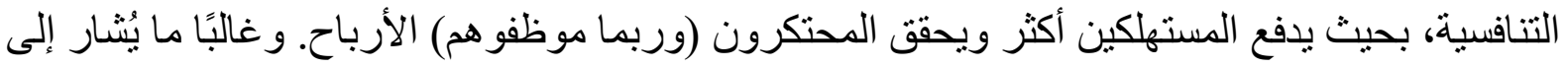

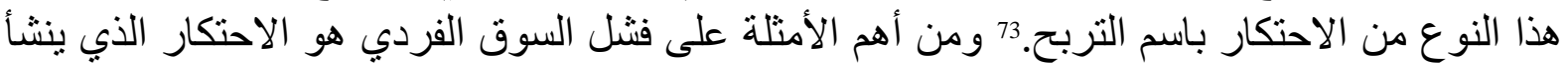

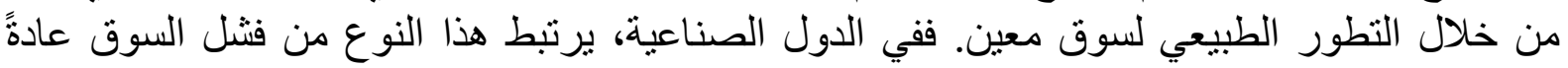

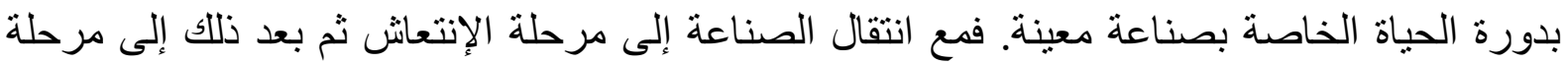

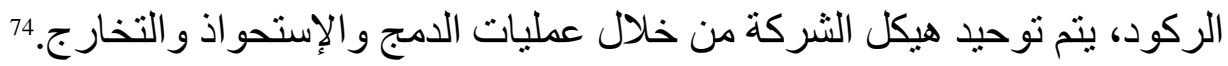

ورن حالات فثن السوق الأقل حدوثًا، هو مايحدث في بعض قطاعات صناعة البرمجيات، حيث ظهرت

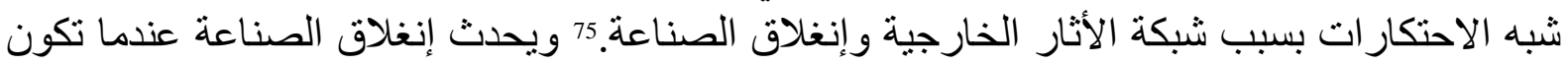

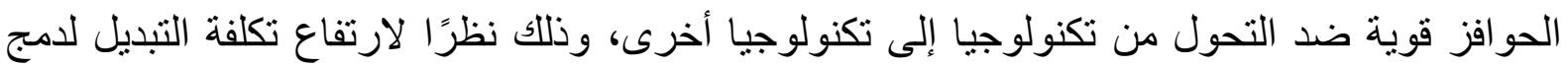

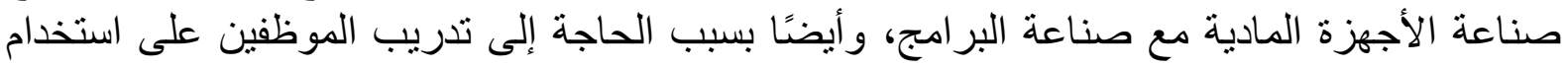

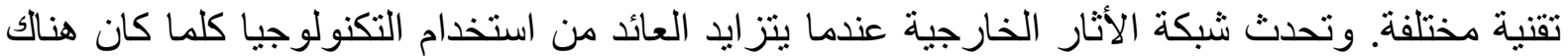

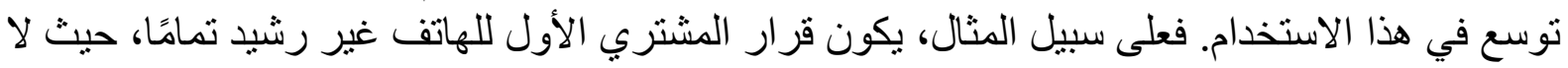

71 Nelson, R.R., (2003). The advance of technology and the scientific commons. Philosophical Transactions: Mathematical, Physical and Engineering Sciences, 361(1809), P.1691.

${ }^{72}$ Mazzoleni, R. \& Nelson, R.R., (1998). Economic theories about the benefits and costs of patents. Journal of Economic Issues, 32(4), P.1031.

${ }^{73}$ Stigler, G.J. (2002). Monopoly. In The Concise Encyclopedia of Economics. Henderson, D.R.E.

(Ed.), available at <http://www.econlib.org/library/Enc/Monopoly.html >.

${ }^{74}$ Baumol, W. J., Panzar, J. C. and Willig, R. D., (1982). Contestable Markets and the Theory of Industrial Structure, (New York, Harcourt Brace), P.70.

${ }^{75}$ Cantner, Uwe; Vannuccini, Simone, (2016). Innovation and lock-in, JenaEconomic Research Papers, No. 2016-018, Friedrich Schiller University Jena, Jena, P.15. 
يوجد شخص يمكنه الاتصال به، في حين أن كل مشتري لاحق للهاتف يتمتع بميزة استخدام التكنولوجيا منذ تلك اللحظة.

وفي الدول النامية، تكون الاحتكار ات، في بعض الأحيان، نتيجة لتدخل الحكومة، أو نتيجة للامتياز ات

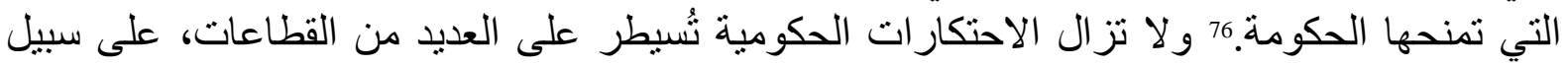

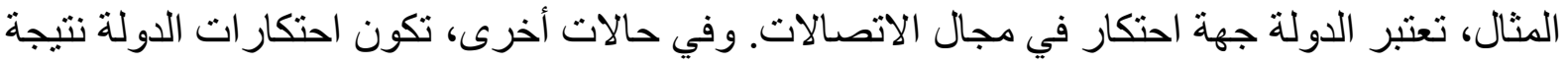

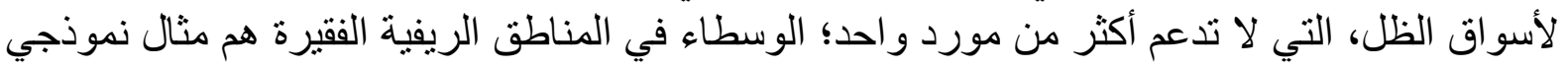

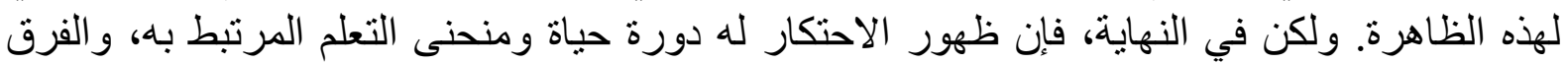

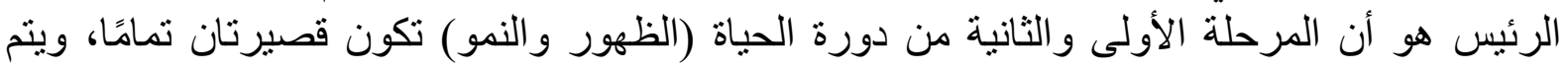
الوصول إلى مرحلة الاندماج بسر عة كبيرة.

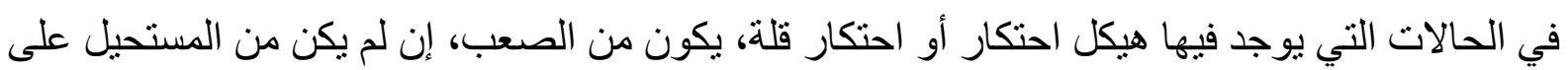
المنافسين الجدد دخول السوق، وبالتالي يتم زيادة الحواجز أمام دخول السوق.

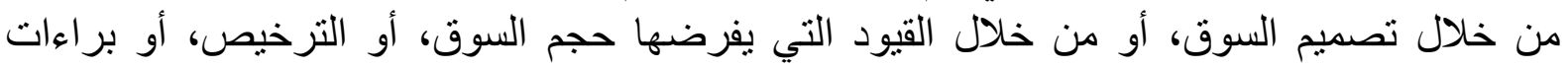
الاختر اع، أو حقوق الملكية، أو حتى الحصول من خصول إلى المو اد الخام.

في بعض الأحيان تصبح الثركات مُسيطرة بسبب عمليات السوق العادية، وهذه القوة الاحتكارية لا

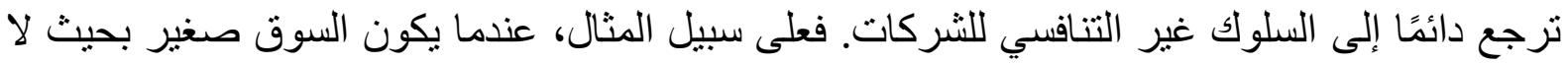
يدعم العديد من المنافسين، مما يعني أن السوق لا يمكنه دعم سوى فاعلئ فاعل واحد أو اثنين. وفي الحالات

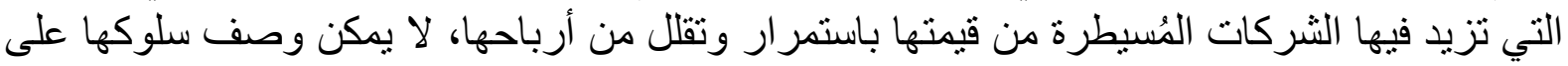

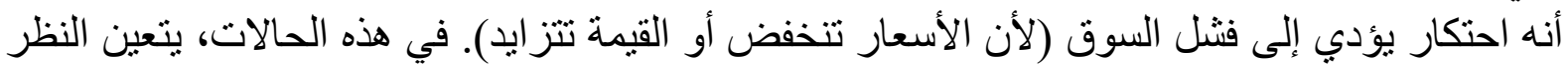

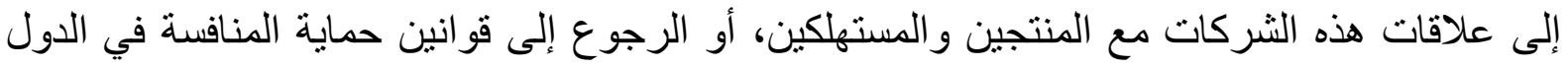

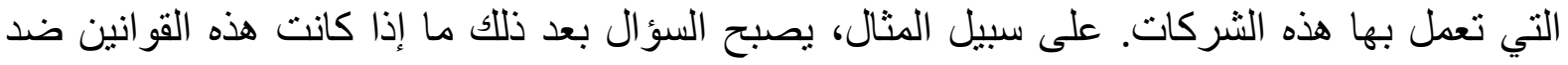

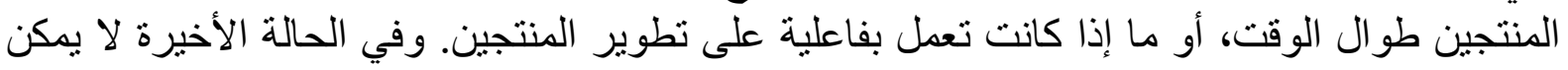

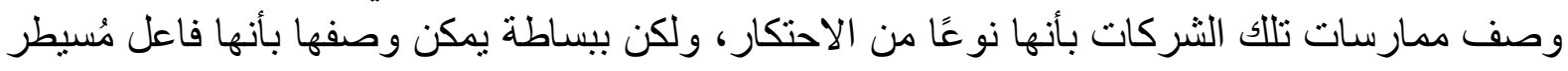

$$
\text { في السوق. }
$$

و هناك نوع آخر من الاحتكار وهو الذي يقوم على الإبتكار التكنولوجي. إن العلاقة بين هيكل السوق دون الإن

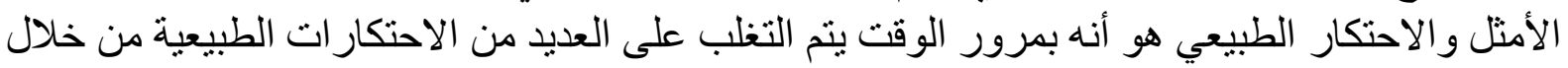

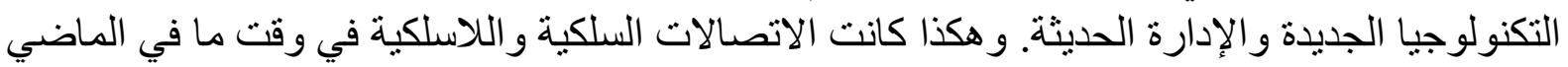

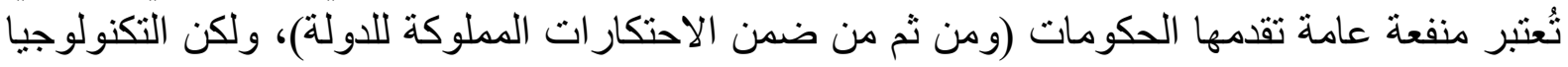

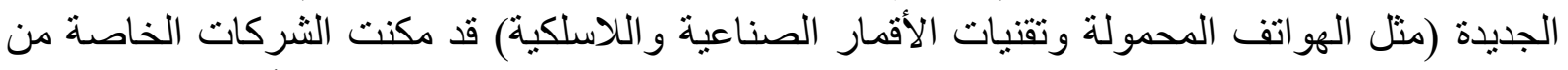

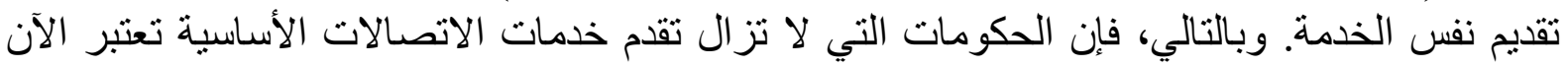

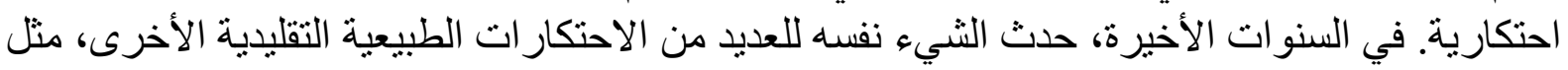

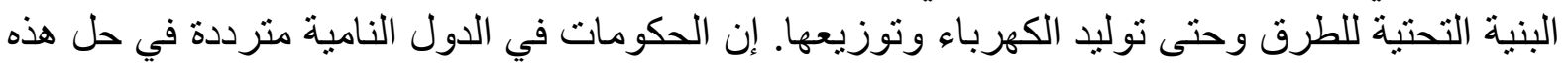

\footnotetext{
${ }^{76}$ Oates, W. E., (1972). Fiscal Federalism, (New York, Harcourt Brace Jovanovich).

${ }^{77}$ Moher, P. \& Fourie, L., (2007). Economics for South African students. 4th ed. Pretoria: Van Schaik, P. 243.

${ }^{78}$ Moher, P. \& Fourie, L., (2007). Economics for South African students. 4th ed. Pretoria: Van Schaik, P. 244.
} 
الاحتكار ات التي تجيزها الدولة، و التي تُحقق منها إيرادات ضخمة، لأن تكلفة التزويد إنخفضت كثيرًا،

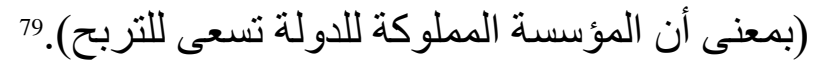

\section{ثانيًا: النتائج التي تترتب على فثل السوق}

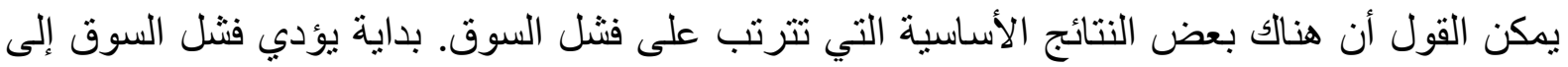

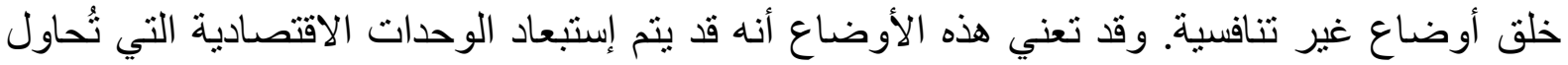

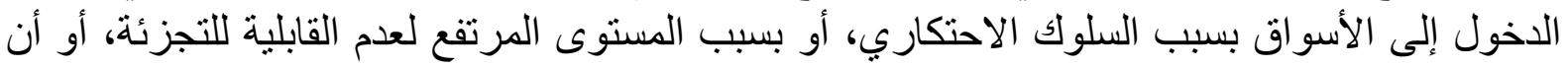

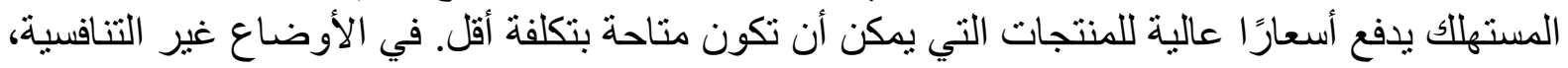

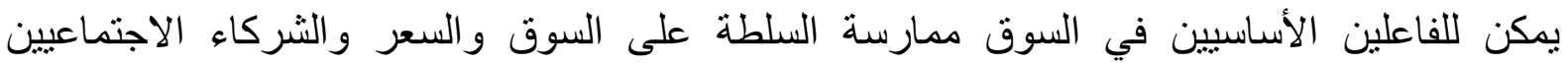

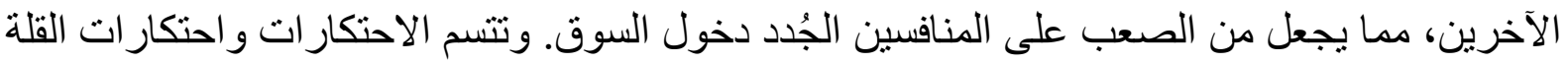

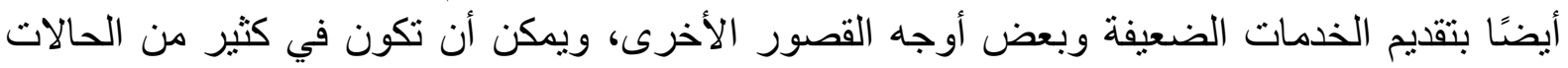

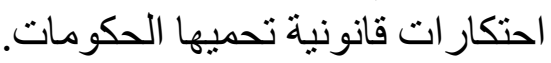

قد يتسبب فنثل السوق في خلق توازن منخفض المستوى. يمكن لنتائج فنشل السوق أن تعزز بعضها

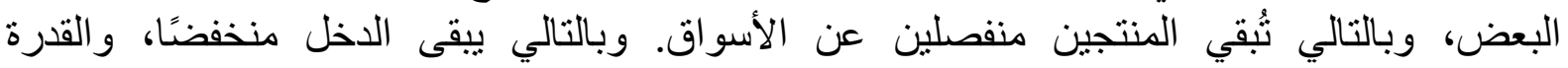

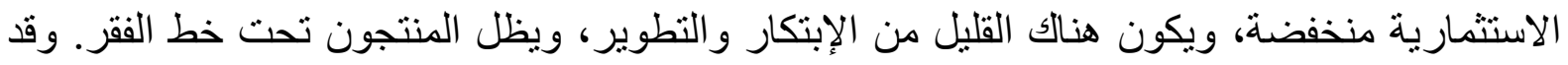

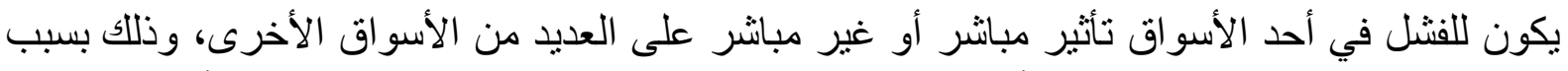

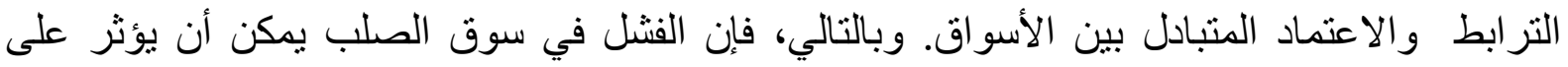

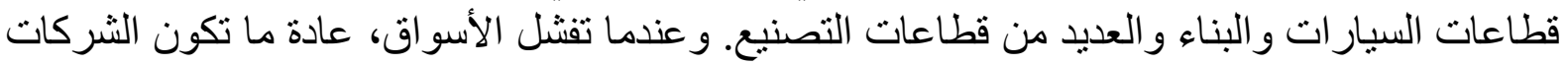

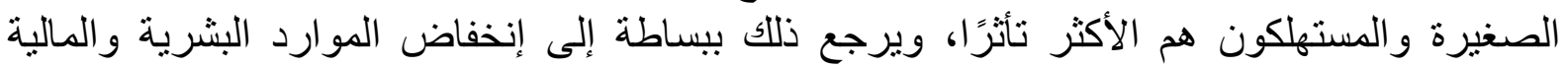
اليُتاحة لإيجاد طرق للتغلب على الحواجز أو العقبات.

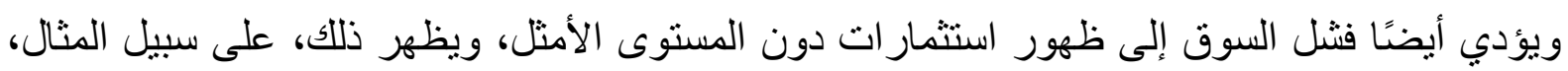

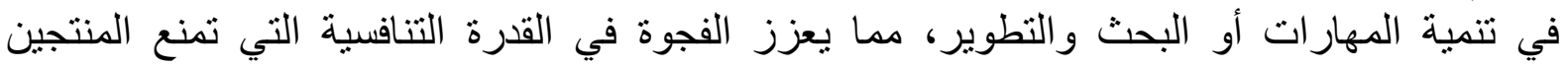

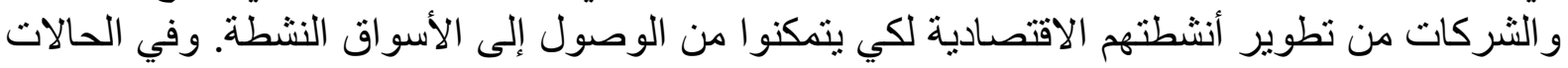

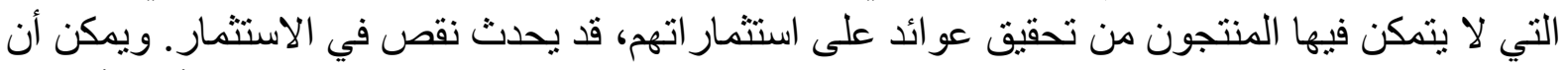

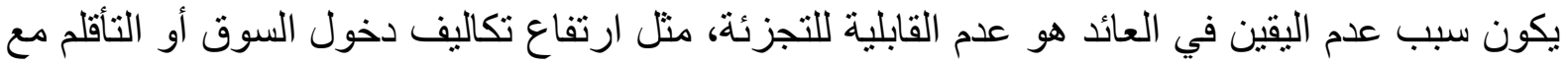

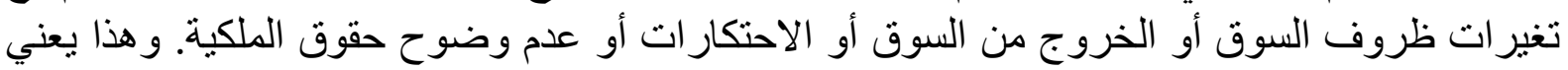

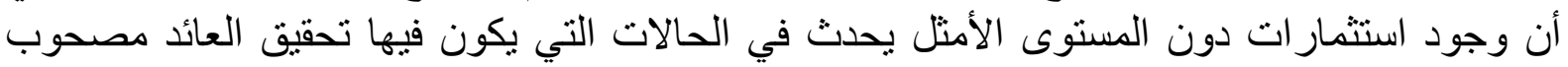

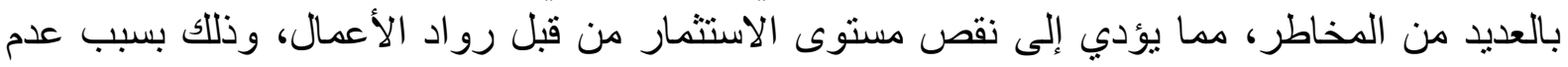

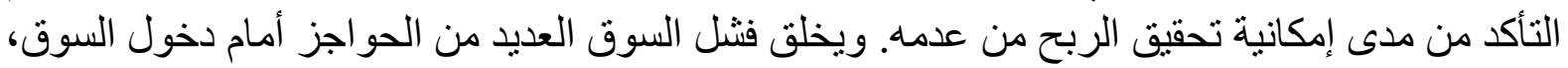

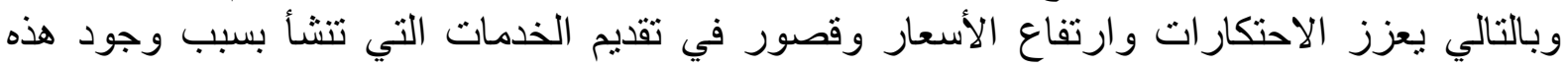

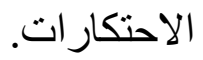

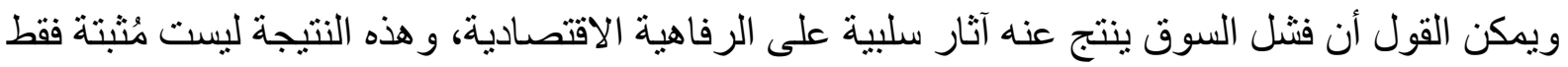

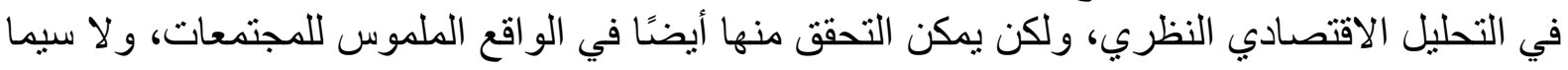

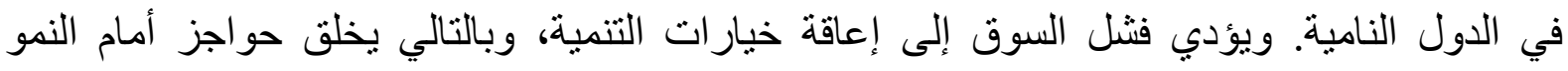

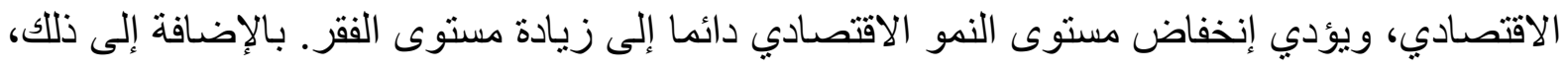

${ }^{79}$ Cunningham, S., (2011). Understanding Market Failures in an Economic Development Context. Pretoria, South Africa: Mesopartner Monograph 4, P.44. 
تضع حالات فنثل السوق مزيدًا من المسؤولية على عاتق الحكومة، حيث تشعر الحكومة غالبًا بأنها

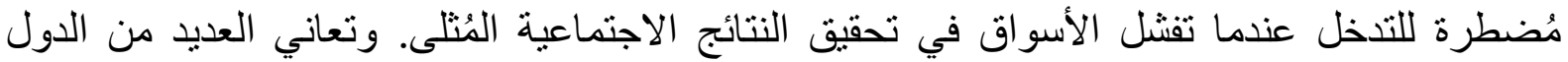

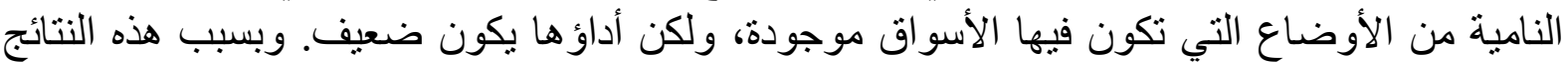

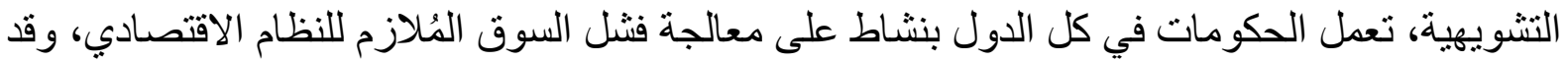
أنثأت العديد من الحكومات بعض هيئات مكافحة الاحتكار وذلك لمكافحة الاحتكار ات الخاصة. 80

وقد يكون من الخطأ الافتر اض أن فنثل السوق هو ظاهرة مُرتبطة باقتصاديات الدول النامية و المناطق

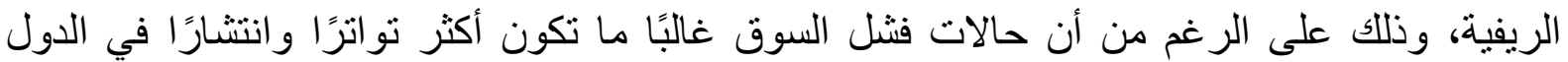

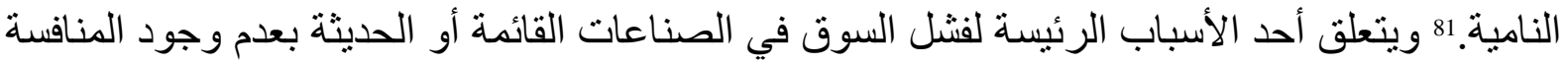

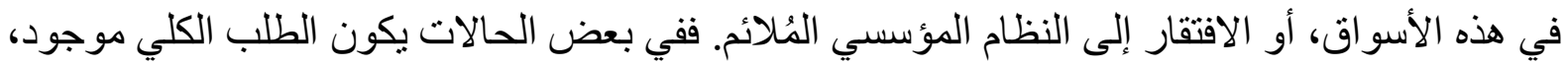

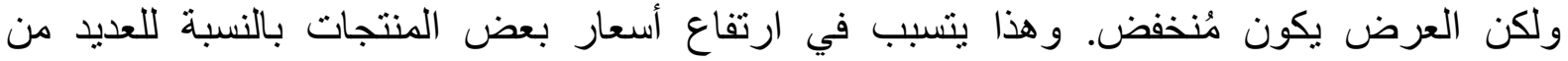

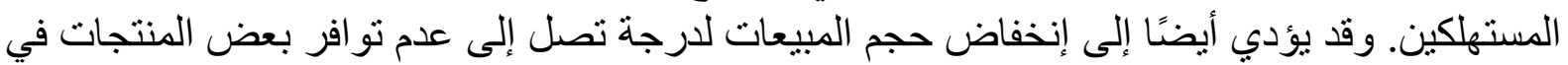
بعض المناطق. وفي بعض الحالات الأخرى، قد يتو افر العرض، ولكن ولكن يكون مستوى الطلب منخفض.

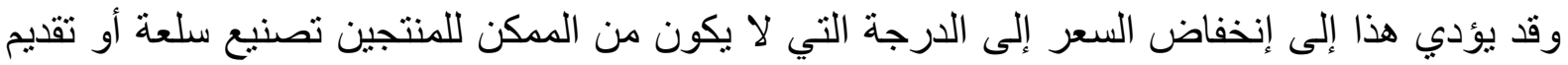

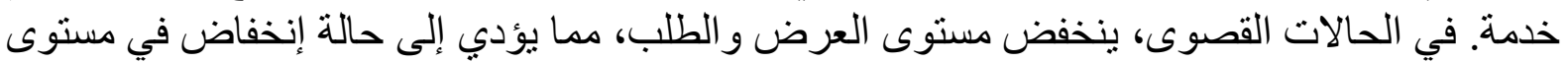
التوازن. ومن الأمثلة على ذلك قطاعات البرمجيات أو الأدوية في العديد من الدول المتقدمة التي لا تعمل على النحو الأمثل.

ويجادل بعض الاقتصاديين ضد النظرية التقليدية القائلة بأن المشكلة في العرض، ويؤكد أن المشكلة تكمن

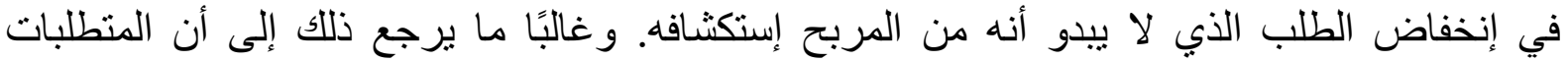
و المو اصفات أو التفضيلات الخاصة بجانب الطلب تكون غير واضحة المعالم أو يصعب مر اعاتها من قبل معظم الشركات.83

ثالثًا: العلاقة بين فثل السوق وفشل الحكومة

على الرغم من أن مصطلح فثل السوق قد تم مناقشته على نطاق واسع خلال القرن الماضي، إلا أن

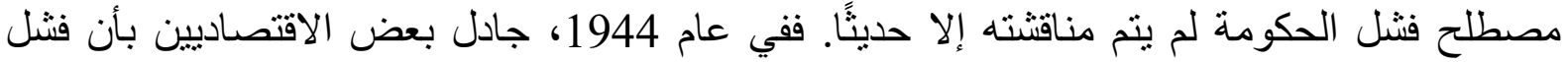

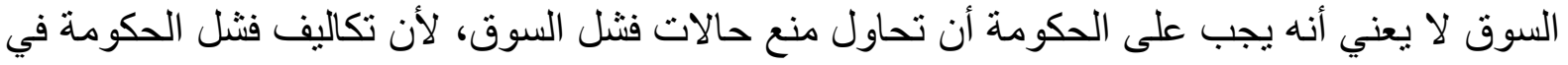

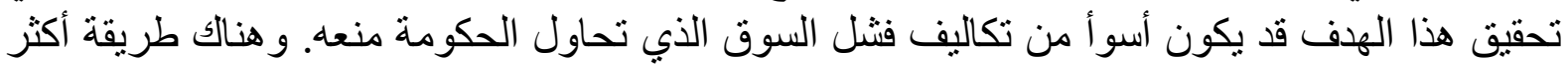

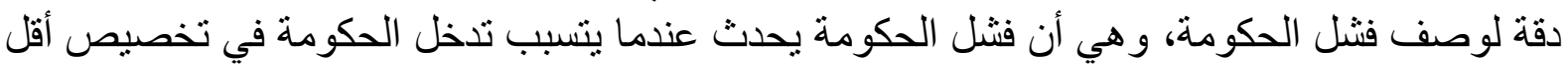

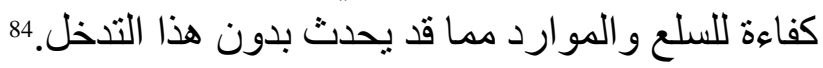

\footnotetext{
${ }^{80}$ Wolf, C., (1987). Market and Non-Market Failures: Comparison and Assessment. Journal of Public Policy 7(1), P.43.

${ }^{81}$ Rodrik, D., (2008). Second-best institutions. Working Paper 14050, Cambridge: National Bureau of Economic Research (NBER), P.22.

82 Stiglitz, J.E., (1998). Markets, market failures and development. Perspectives on economic development. American Economic Review, 79(2), P.197.

${ }^{83}$ Rodrik, D., (2007). Industrial policy for the twenty-first century, In: One economics, many recipes: globalisation, institutions, and economic growth. Rodrik, D. (Ed.), Princeton, NJ: Princeton University Press, P.99.

${ }^{84}$ Von Hayek, F.A., (2001). The road to serfdom. London: Routledge Classics, P.67.
} 
وفي هذا السياق من المهم تحليل التفاعل بين الأنواع الثلاثة من الفشل. على سبيل المثال، غالبَّا ما يؤدي

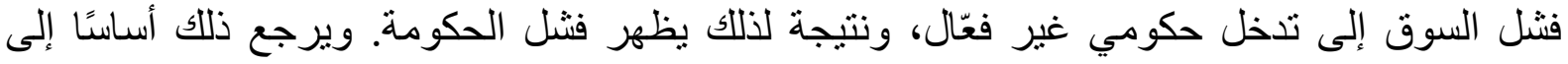

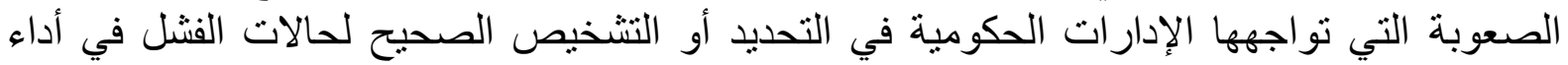

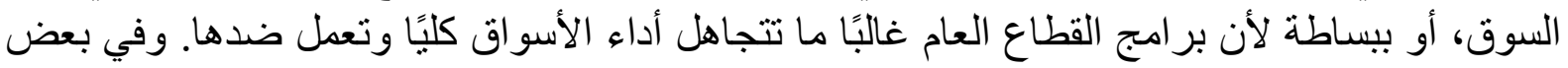

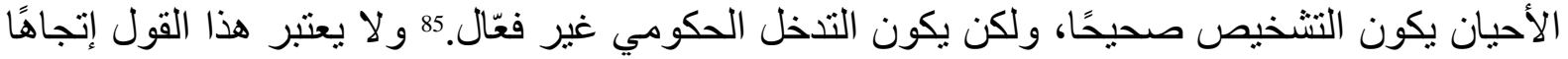

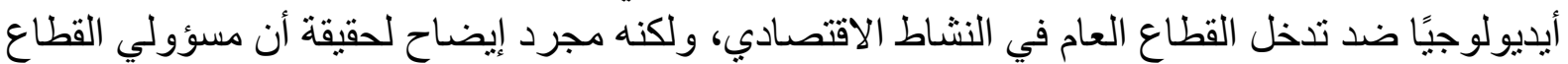

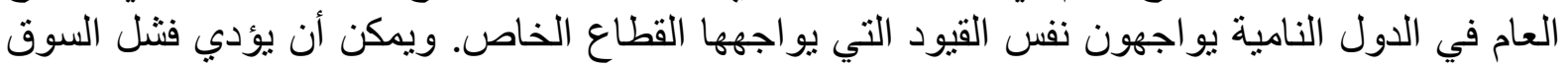

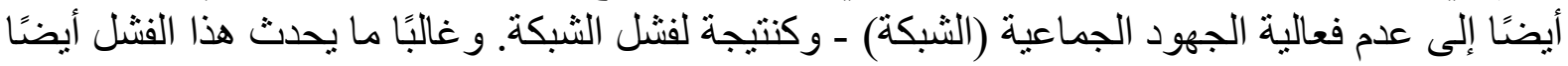
بسبب الأساليب التي تعتمد بشكل مُفرط على التنسيق بين مختلف الجهات الفاعلة ذات الأهداف المختلفة،

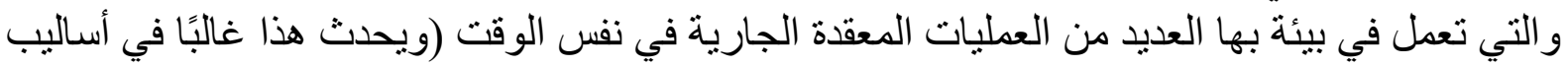

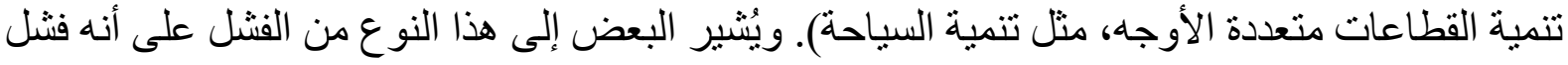
في التنسيق. وكما هو الحال مع فثل السوق، لا يمكن حل فثل التنسيق بمزيد من التنسيق.

ويتطلب وجود الأسواق القوية وجود حكومات قوية. 87 ففي كثير من الدول النامية، يكون فثل الحكومات أكبر بكثير من فنثل السوق. 88 ويعتبر دور الحكومة في تطوير الأسواق أكثر أهمية في الدول الأو الأقل تقدمًا،

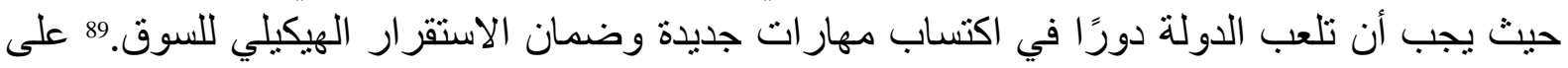

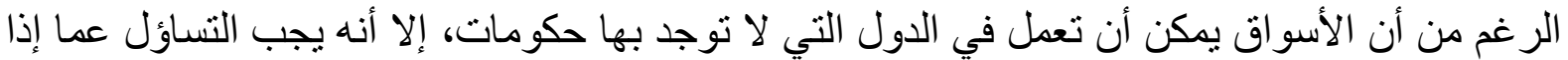

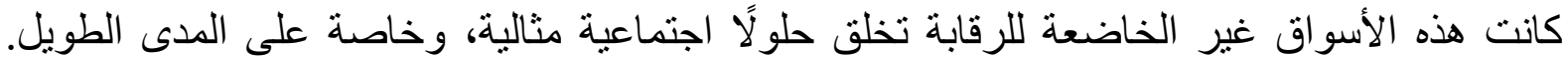

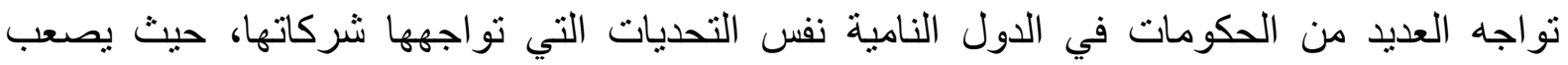

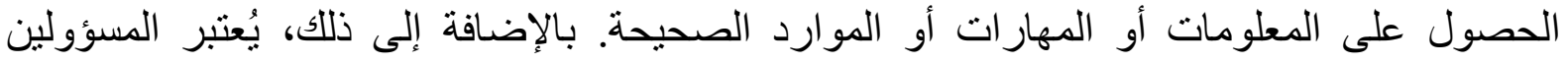

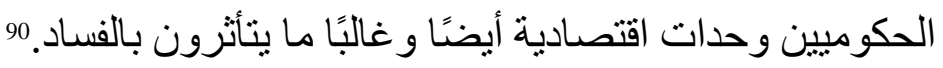

وفي هذا السياق، لا يمكن أن يقتصر النقاش على الموازنة بين ألية الأسواق وبين التذخل الحكومي، لأن

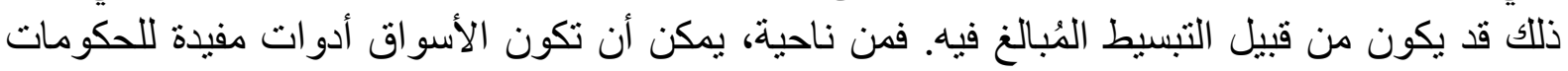

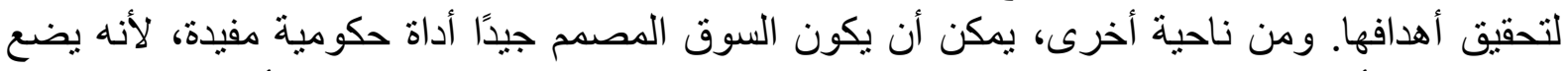

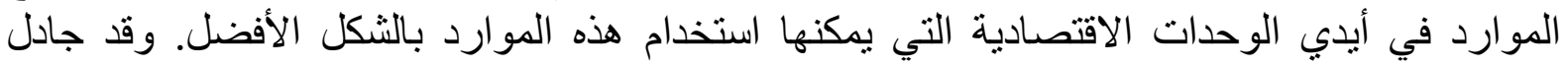

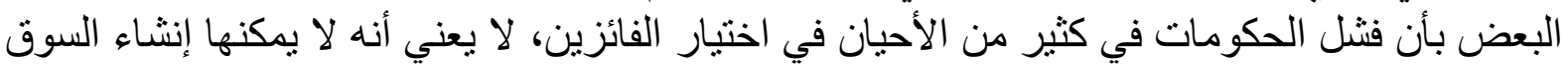

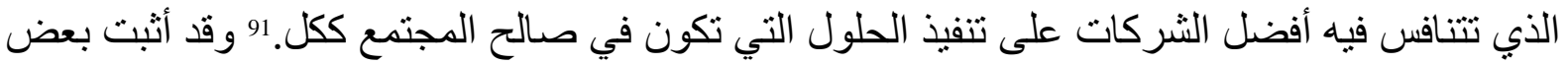
الاقتصاديين أنه في السنوات الأخيرة، تحولت السياسة الصناعية من التركيز على الحصول على فلى فئل

${ }^{85}$ Julian Le Grand, (1991). The Theory of Government Failure. British Journal of PoliticalScience, 21, P. 423.

${ }^{86}$ Brennan, Geoffrey and James Buchanan., (1985). The Reason of Rules. Cambridge: Cambridge University Press.

${ }^{87}$ Mcmillan, J., (2002). Reinventing the bazaar: a natural history of markets. 1st ed. New York, NY: Norton.

${ }^{88}$ Fligstein, N., (2001). The architecture of markets: an economic sociology of twenty-first century capitalist societies. Princeton, NJ: Princeton University Press, P.36.

${ }^{89}$ Hosseini, H., (2001). Uncertainty and perceptual problems causing government failures in less advanced nations. The Journal of Socio-Economics, 33(2001), P.263.

90 Stiglitz, J.E., (1998). Markets, market failures and development. Perspectives on economic development. American Economic Review, 79(2), P.197.

${ }^{91}$ Mcmillan, J., (2002). Reinventing the bazaar: a natural history ofmarkets. 1st Ed. New York, NY: Norton, P. 195. 
مخرجات السياسة بشكل صحيح إلى ضمان نجاح عملية السياسة. وبالتالي فإن بعض الاقتصاديين يشجعون عملية الإكتشاف التي تسمح بالتكيف و التفاعل بين القطاعين العام و الخاص.

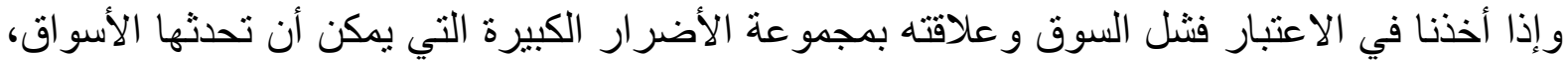

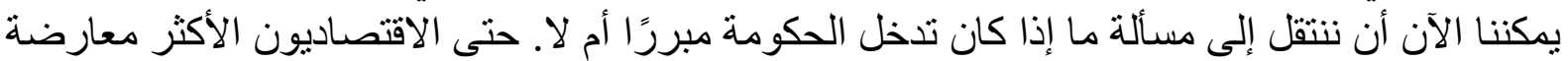

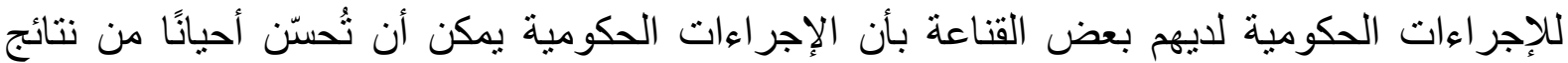

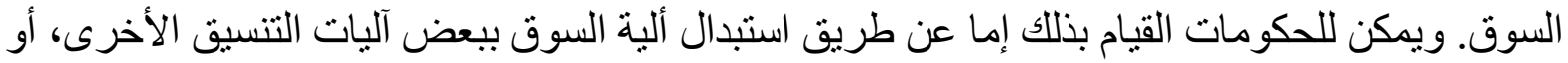

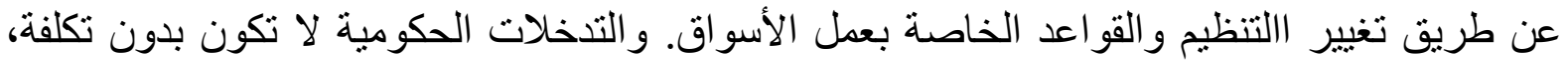
و هنالك العديد من الحالات التي يكون من الأفضل فيها التعايش مع حالات فئل التهل السوق بدلًا من التدخل

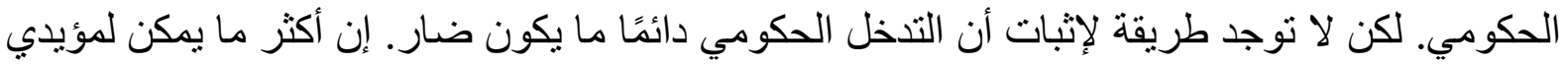

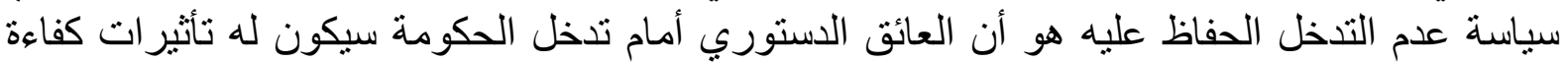

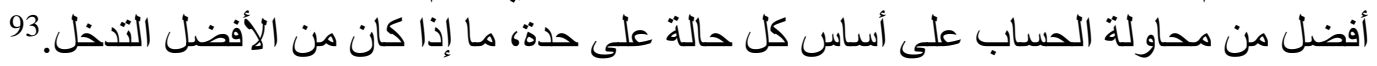

وحتى هذه الحالة تكون غير مُستدامة، خاصة عندما يتم النظر في الطرق العديدة التي يمكن أن تسبب

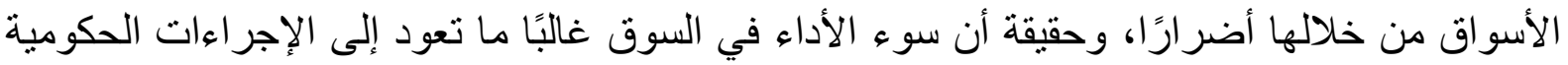

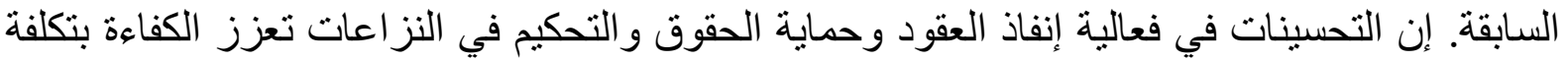

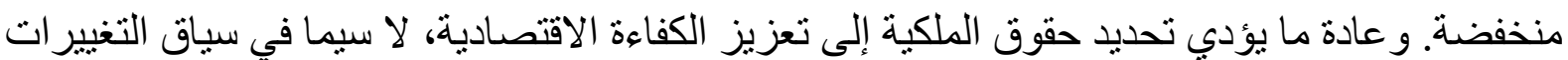

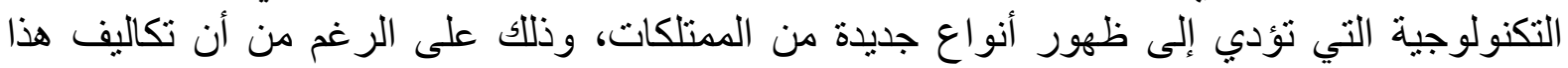

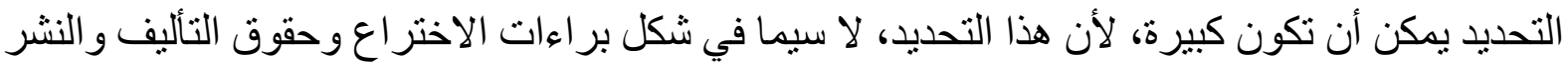
و اللوائح الحكومية المختلفة هو المسؤول عن العديد من الاحتكار ات.94 94

ويمكن القول أن التذخل الحكومي في سوق معين يواجه مشاكل كبيرة. وتشمل هذه المشاكل التكاليف

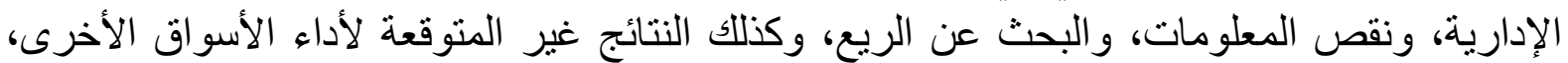

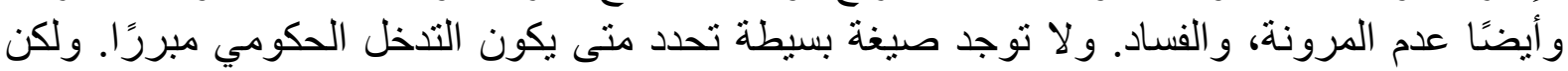

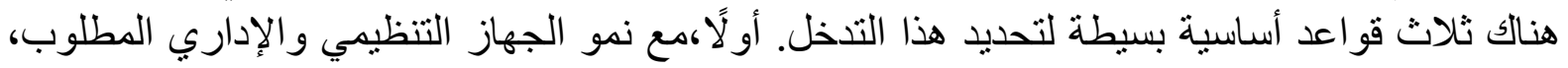

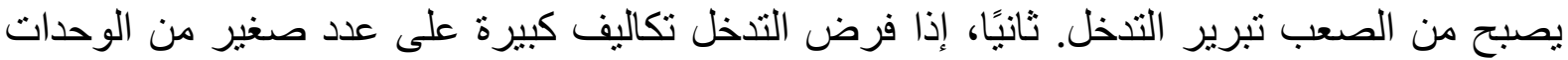

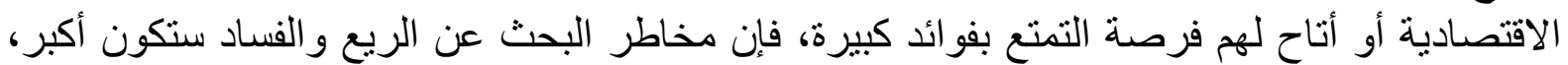

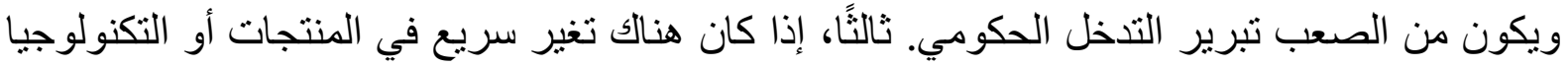

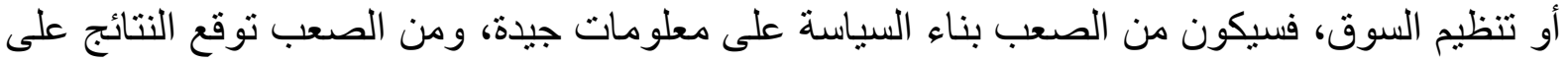
الأسو اق الأخرى، ويكون من الصعب التحلي بالمرونة، وبالتالي يصعب تبرير تبرئ تدخل الحكومة. 95

\footnotetext{
${ }^{92}$ Rodrik, D., (2007). Industrial policy for the twenty-first century. In One economics, many recipes: globalisation, institutions, and economic growth. Rodrik, D. (Ed.), Princeton, NJ: Princeton University Press, P. 3.

${ }_{93}$ Brennan, Geoffrey and James Buchanan. (1985). The Reason of Rules. Cambridge: Cambridge University Press, P.120.

${ }^{94}$ Winston, C., (2006). Government Failure versus Market Failure: Macroeconomics Policy Research and Government Performance. AEI-Brookings Joint Center for Regulatory Studies, the American Enterprise Institute for Public Policy Research, Washington, D.C., and the Brookings Institution, Washington, D.C.

${ }^{95}$ Hausman, Daniel M., (2008). "Market Failure, Government Failure, and the Hard Problems of Cooperation," Ethics and Economics, CREUM, Université de Montréal, vol. 6(1), PP. 1-6.
} 


\section{المبحث الثالث: معالجة فثل السوق}

يمكن تقديم حلول لفشل السوق من خلال ألية الأسواق أو فكرة التسلسل الهرمي أو الشبكات. و غالبًا ما التا

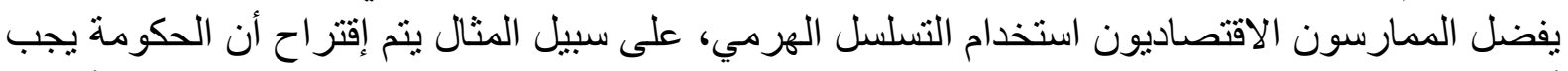

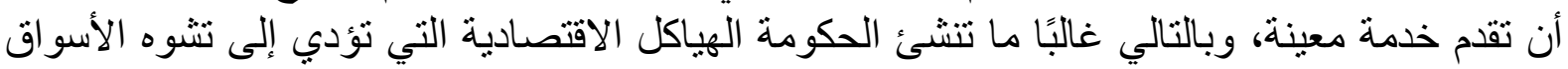

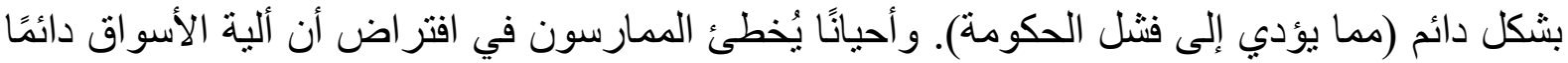

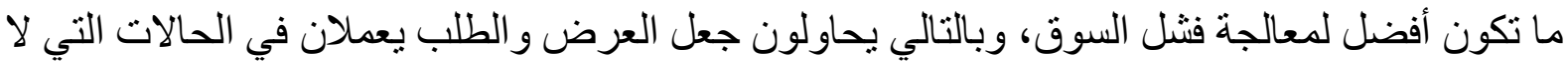

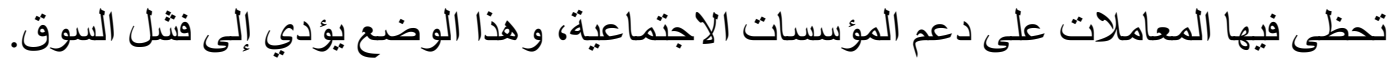

و عادة ما يتم فهم والتعامل مع العديد من حالات فثل السوق بشكل حدسي من قبل الممارسين

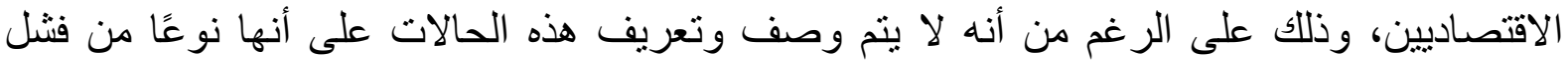

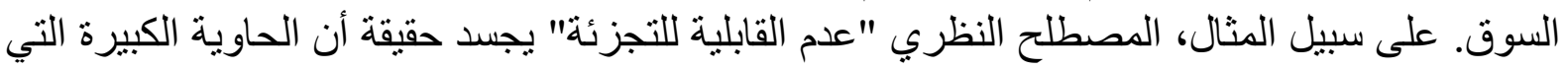

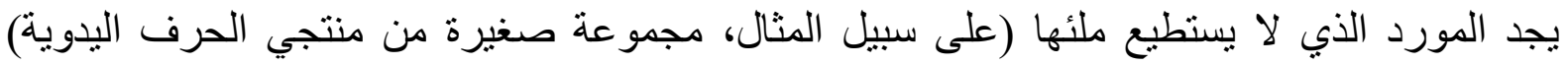

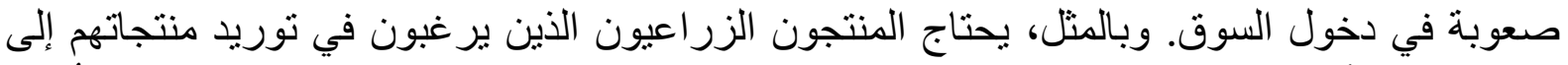

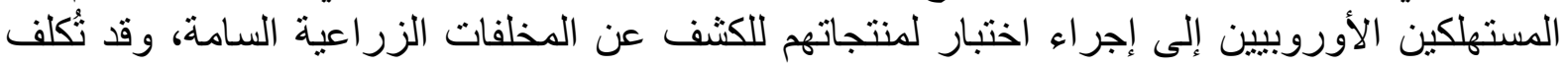

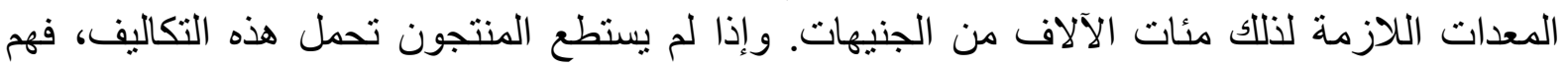

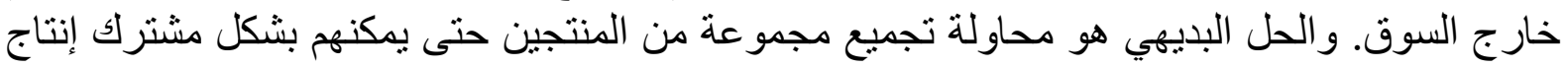

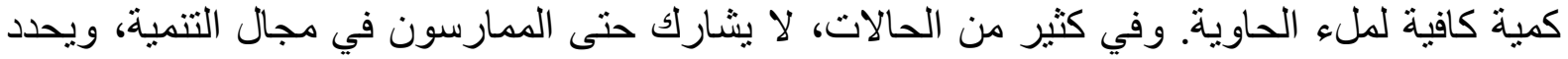

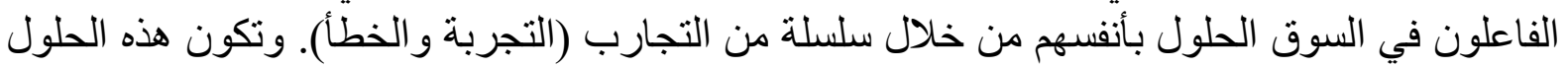

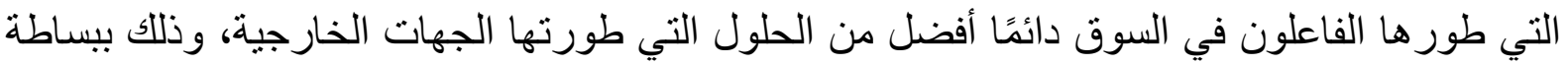
لأن الجهات الفاعلة المعنية بشكل مباثر تفهم المعايير و القيود الاجنماعية بشكل الفئ أفضل.

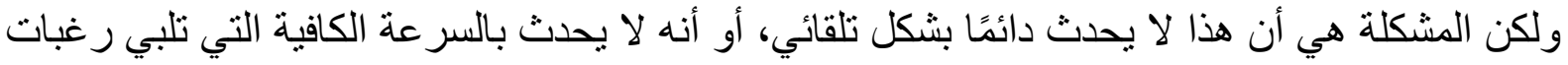

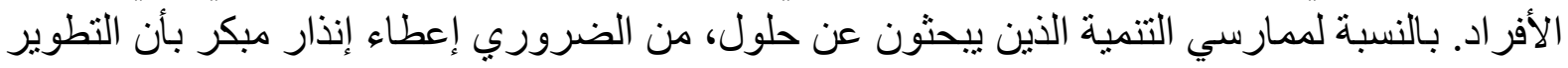

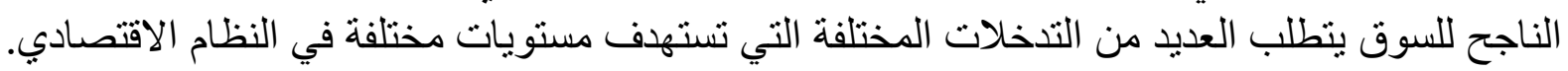

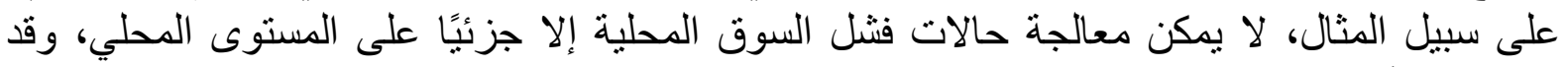

تتطلب تنخلًا وطنيًا أيضًا.

\section{أولاً: معالجة فشل السوق على المستوى المحلي أو الإقليمي}

على المستوى المحلي أو الإقليمي، غالبًا ما يواجه الممارسون في مجال التتمية الاقتصادية التحدي

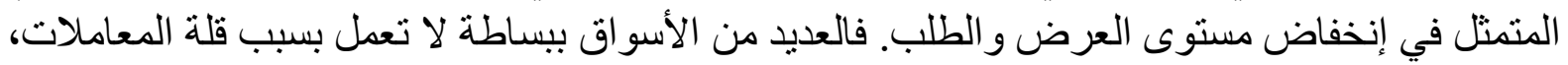

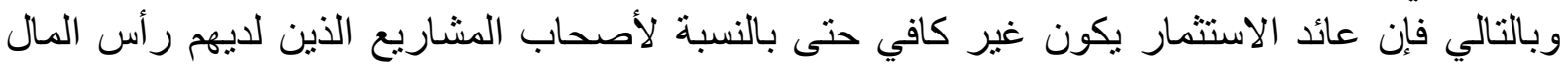

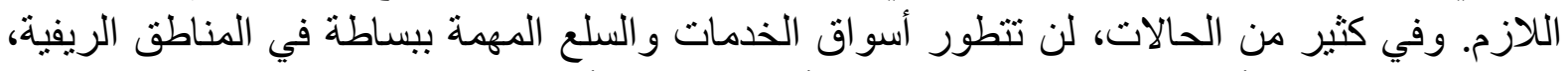

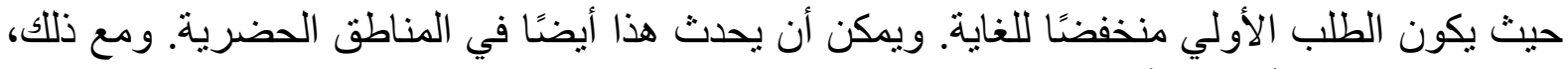

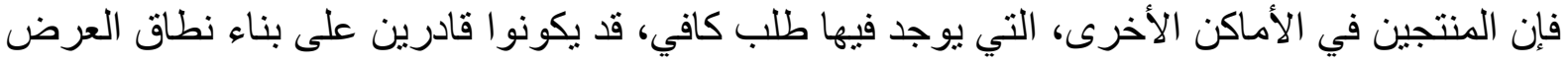

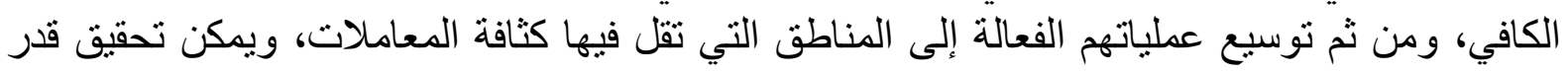

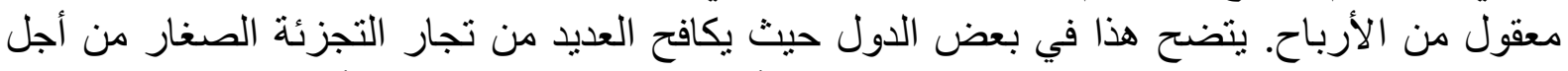

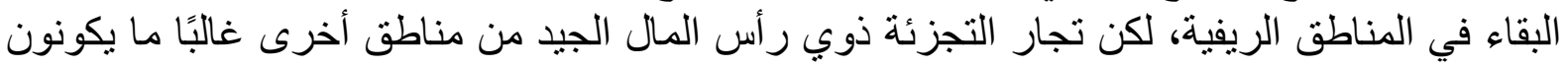

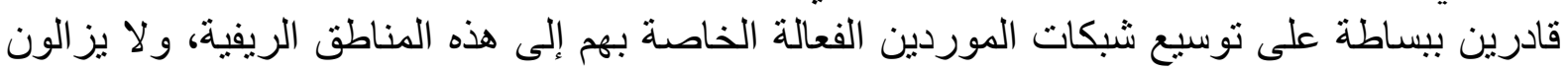
يُحققون دخلًا أعلى من المتوسط. 
وهناك ظاهرة أخرى لتطوير السوق من منظور محلي، وهي أن مشتري الخدمات المتطورة، الذين

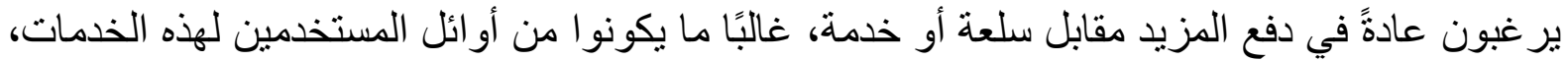

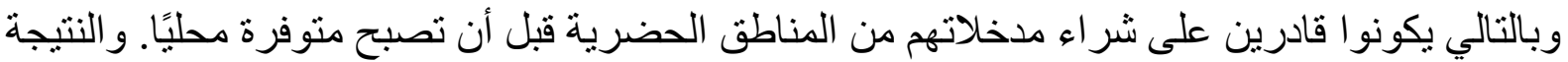

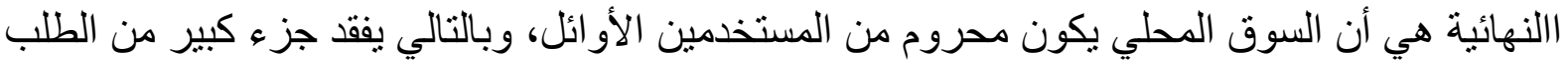

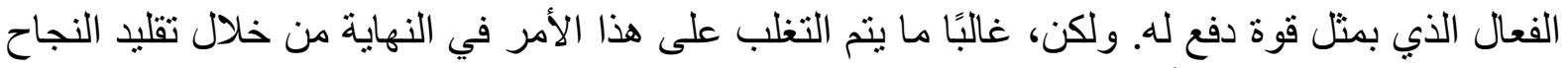

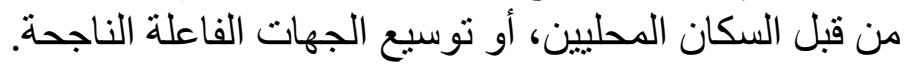

ربما يكون التحدي الأكبر الذي يواجه ممارسي التنمية العاملين على المستوى المحلي هو الوقت. فعادةً ما

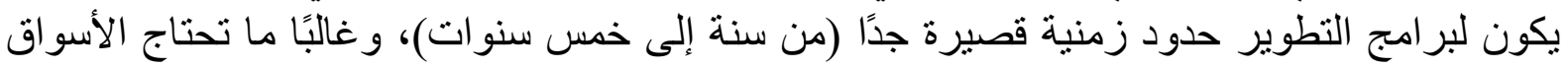

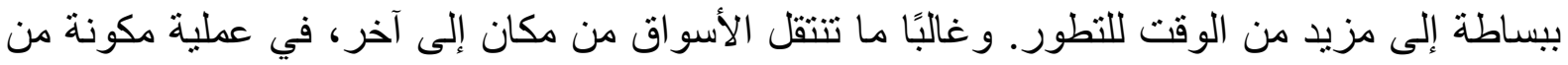

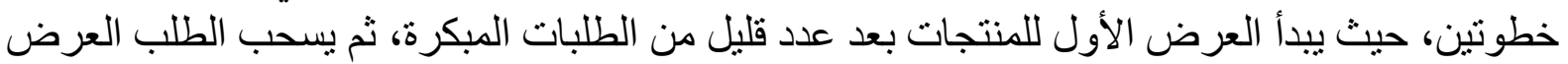

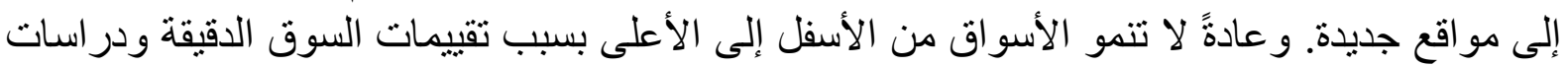

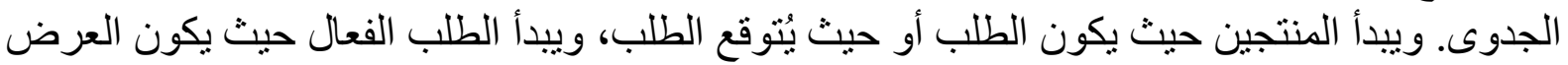

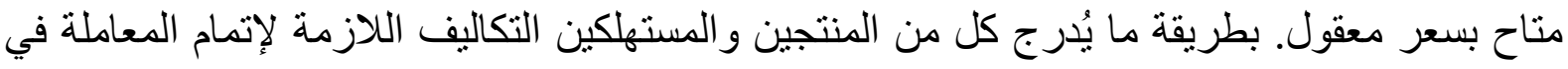

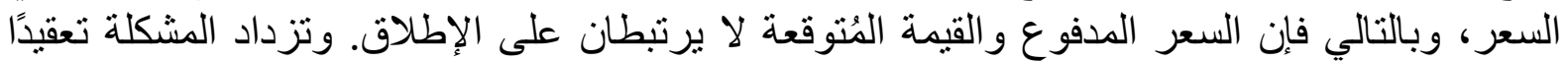

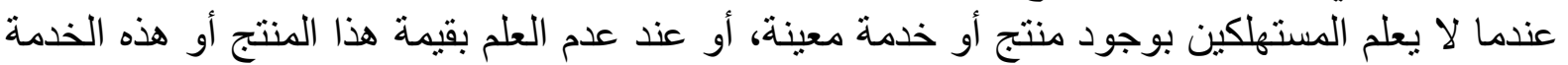
بالنسبة لهم. وفي هذه الحالات، يمكن القول أن هناك صعوبة في بداية أو ظهور الأسواق.

وبالتالي، فإن تطوير السوق على المستوى المحلي يعد مهمة صعبة. وفي هذا السياق، تتمثل إحدى أهم

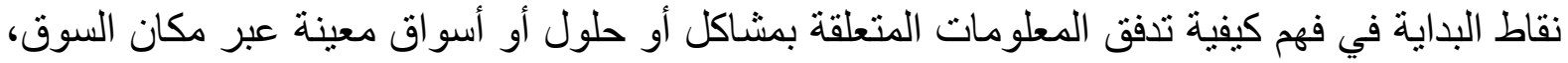

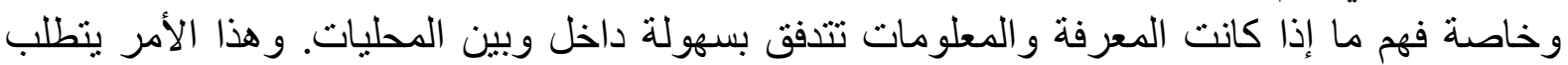

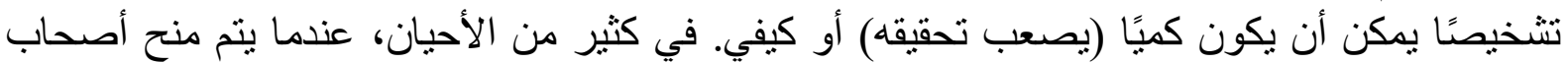

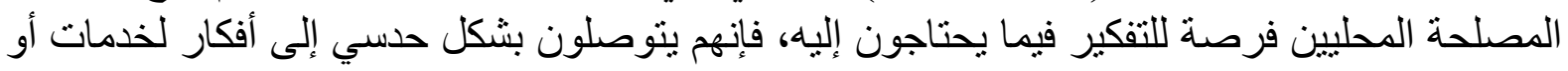

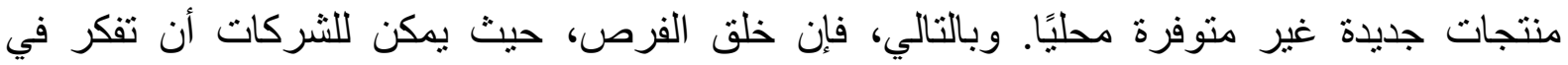

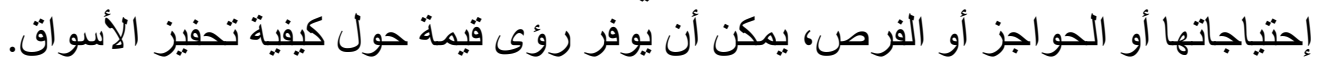

ورع ذلك، فإن الخطوة الأولى هي اكتساب الفهم الأفضل لشروط الأداء المحددة لنظام سوق معين. وهنا

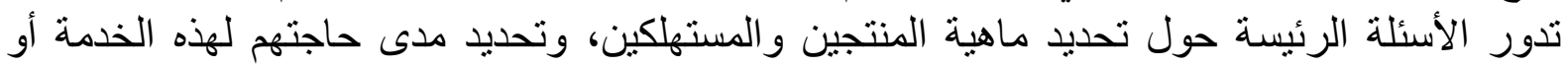

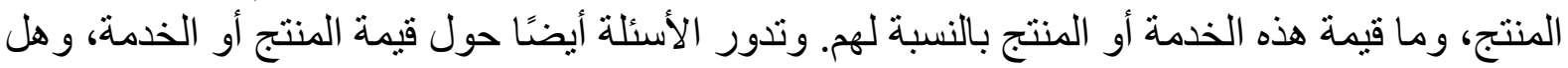

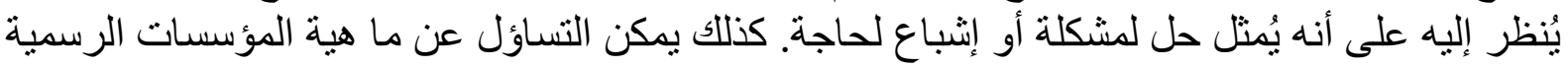

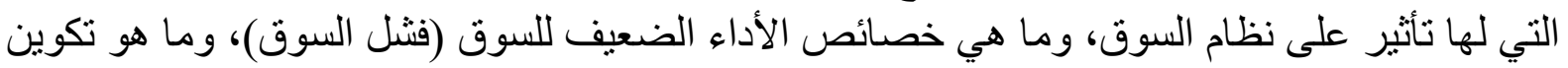
المؤسسات (الرسمية وغير الرسمية) الأنسب لمعالجة هذه القضية المحددة، وما هي المي العلاقة المتبادلة بين هذا النظام للسوق وبين أنظمة السوق الأخرى. وتتعلق بعض الأسئلة عن وجود مستخدمين محليين لهذا

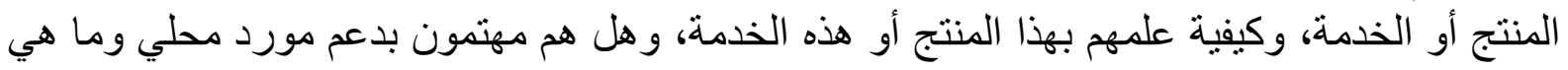

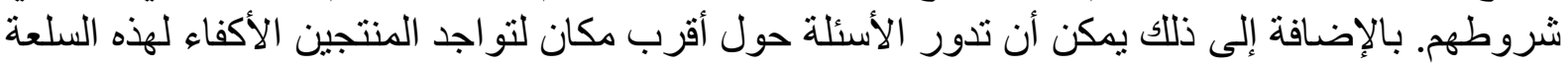
أو الخدمة، وهل هم على علم بطلب السوق، وهل هم قادرون على تقديم خدمات أو منتجات للاتلى للمنطقة

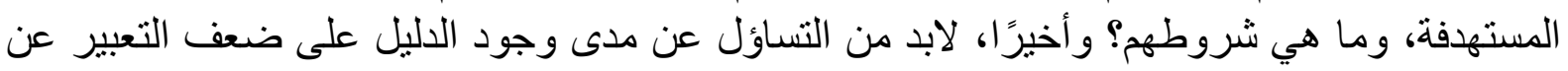
الطلب (حجم السوق، الإحتياجات المحددة) أو العرض (القيمة، التوفير في التكاليف، الفو ائد).

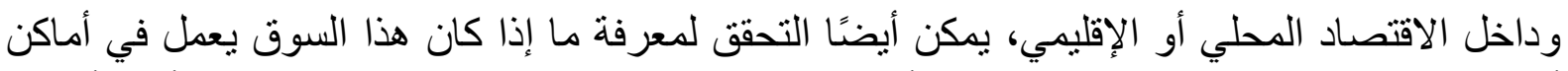

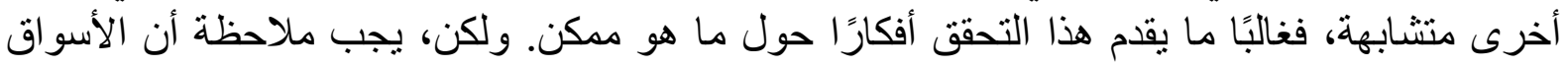


تتطور في علاقة وثيقة مع الأسواق الأخرى. وهذا يعني أن فهم الاعتماد المنبادل بين الأسواق لا يقل

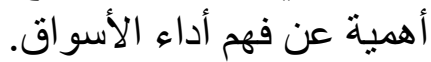

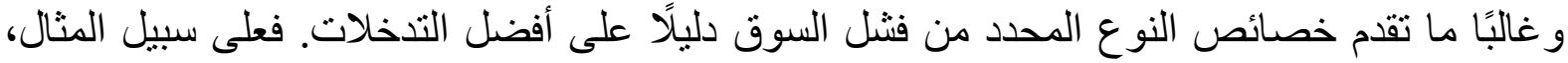

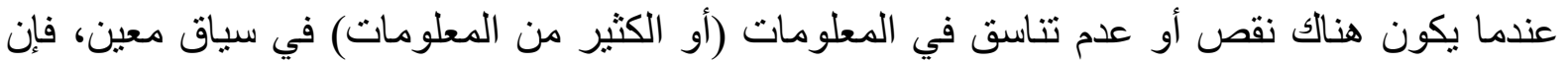

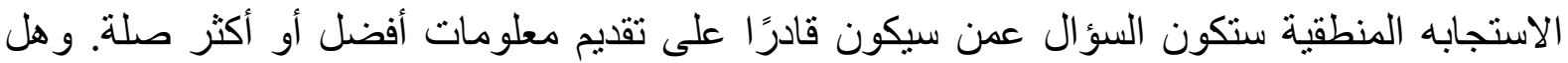

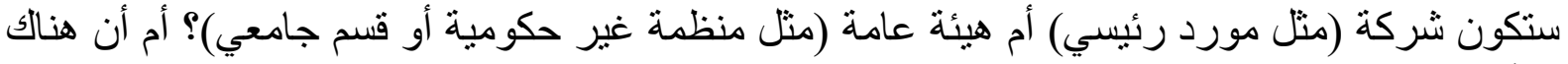

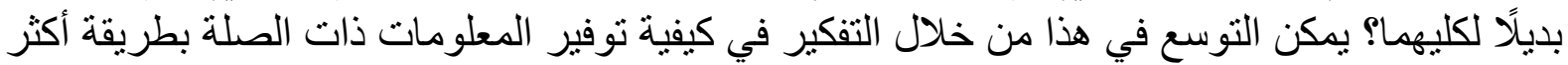

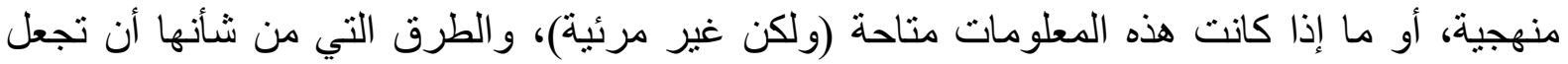
الوصول إلى المعلومات أكثر سهولة.

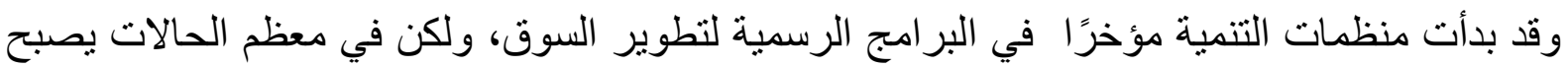

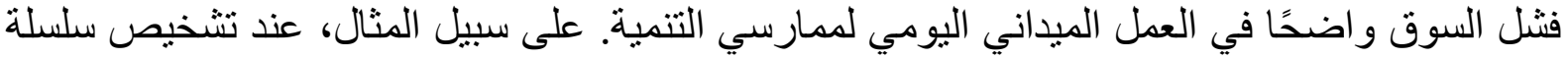

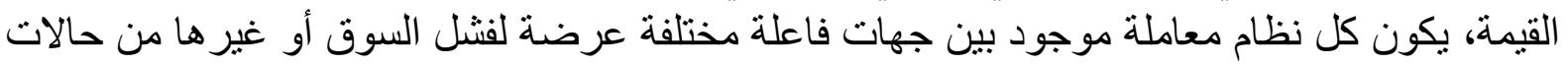

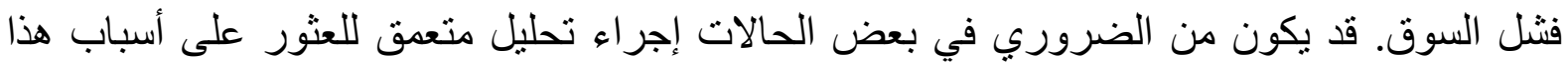

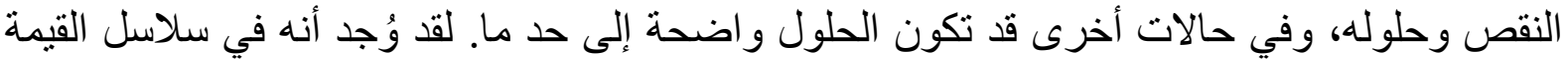
غالبًا ما يكون هناك تعبير ضعيف للطلب وضلات ألبعف في التعبير عن قيمة أو منافع الخدمات و السلع. تفثل الأسو اق المختلفة لأسباب مختلفة، الأمر الذي يتطلب حلو لَا أو تكوينات مختلفة يجب أن تكون دائمًا محددة السياق. لقد وُجد أنه حتى داخل نظام سوق واحد يمكن الأن الن يكون هناك إخفاقات متعددة في السوق تؤثر على نفس السوق بطرق مختلفة.

\section{ثانيًا: المحددات الأساسية لمعالجة حالات فثل السوق}

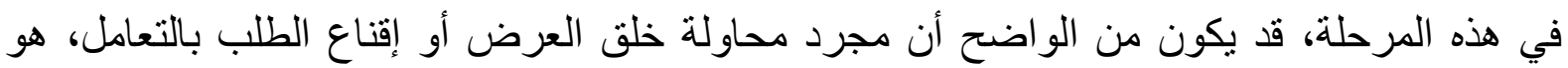

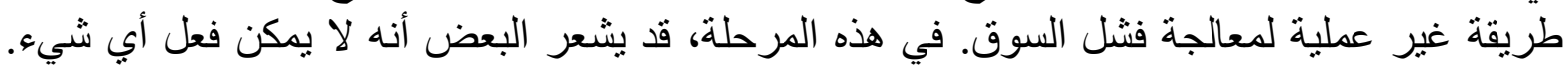

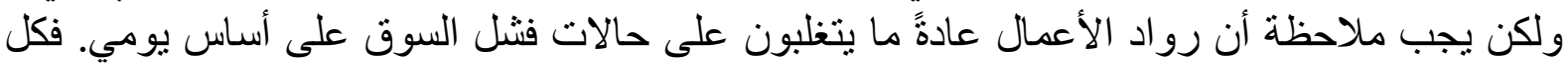

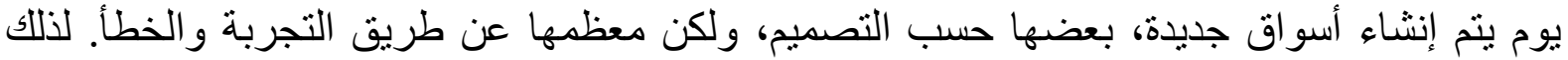
عندما يكون تحديد وصف معين على أنه فثل في السوق، يتعين مر اعاة بعض النق النقاط و هي كالتالي:

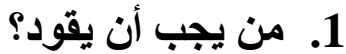

ويجب التساؤل هنا عن المسؤول عن قيادة عملية علاج فثل السوق. فهل تقود الحكومة و المنظمات غير الهير

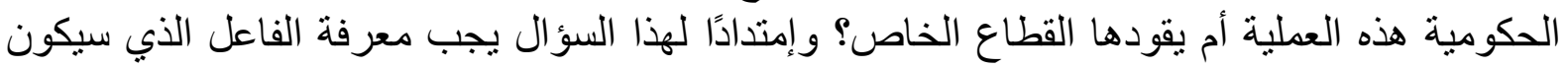

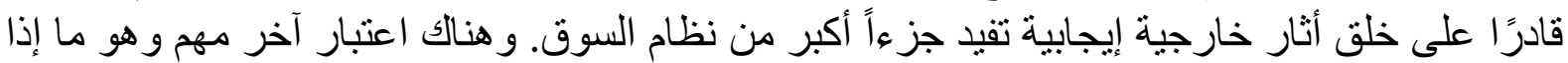
كان يمكن تقديم الحل بطريقة تجارية، مع تقديم حوافز لفز لمقدمي الخدمات المحتملين للاستثمار في الحل.

\section{2. الدور المناسب للحكومة في معالجة فثل السوق}

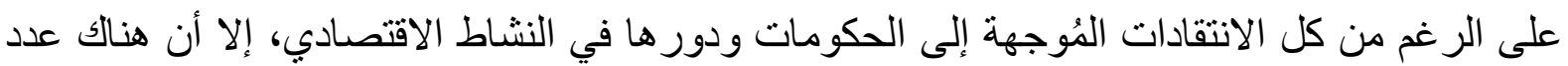

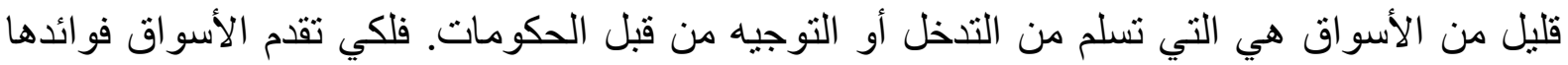

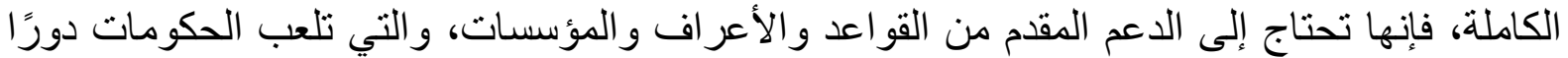

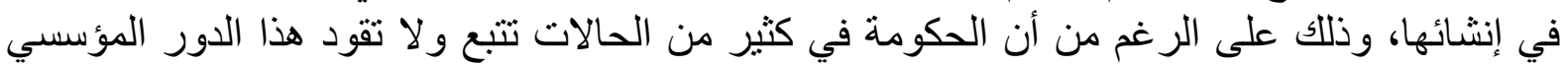


المُنشئ. وقد أصبح هذا الأمر أكثر صعوبة بسبب التوسع في الدور الاقتصادي للحكومة، خصوصًا في النظام الاقتصادي المُختلط. وقد صف بعض الاقتصاديين العديد من التدخلات الهامة للحكومات في الدول الدول النامية. وقد قدم بعض الاقتصاديين بعض التوجيهات الخاصة بمعالجة الحكومة لفتشل السوق، وذللك من

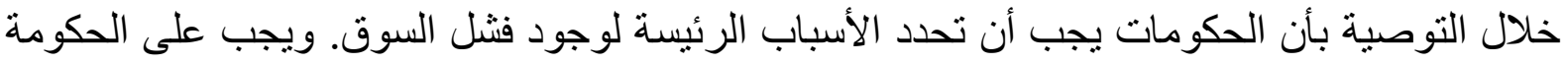

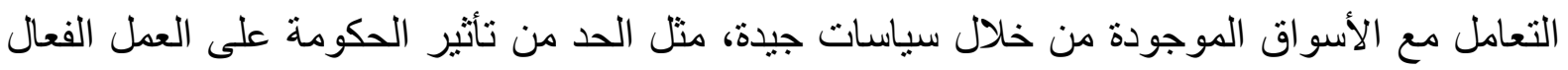

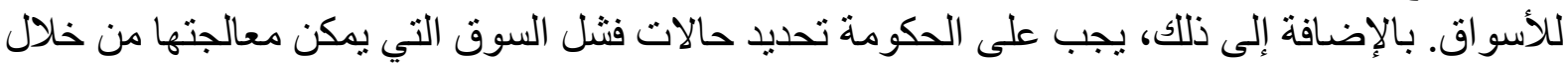
المؤسسات غير السوقية، ويجب أن تلعب الحكومة الدور الفعال في إنشاء مثل هذه المؤسسات غير

ويشير البعض إلى أنه من المهم التعرف على حدود ونقاط القوة في الأسواق، فضلَ عن نقاط القوة وحدود التدخلات الحكومية التي تهدف إلى تصحيح حالات فنثل السوق. بالنسبة للممارسين في مجال

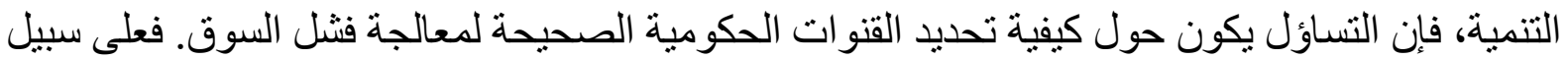

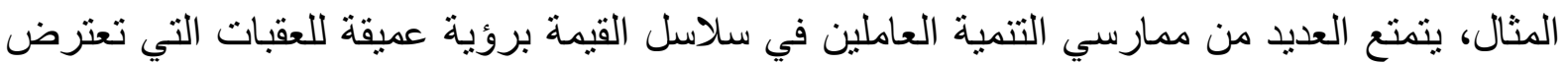

المعاملات، ولكن لا يتم تغذية هذا دائمًا في النظام الأوسع.

\section{3. يمكن أن تكون المشكلة في النظام المؤسسي}

عندما تكون حالات فنل السوق موجودة على نطاق واسع في أسواق محددة و غير ها من الأسواق ذات

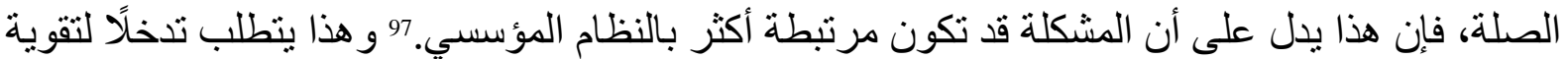

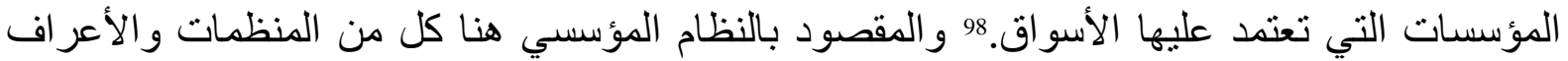
الأساسية والقيمة والقواعد والاتفاقيات و العادات. ويصف البعض البع الترنيبات المؤسسية بأنها التنسيق بين مختلف الفاعلين الاقتصاديين، مثل منتجي المواد الخام، وعملية المعالجة، وتدفق المواد واد و التمويل و المعلومات و المعرفة والعملاء والمنتجات النهائية والحكومات. وهذا يعني أن المجتمع بطور النظام

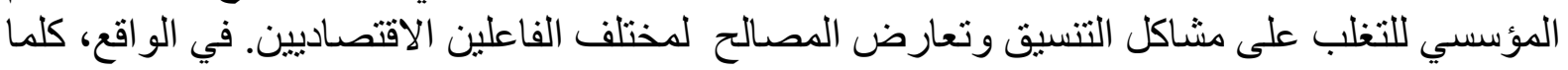
كان السوق أكثر حرية، كلما زاد اعتماده على الترثيبات المؤسسية لتنسيق المعاملات الاقتصادية. من المهم ملاحظة أن فنثل السوق غالبًا ما يكون نتيجة لعدم الكفاءة في تصميم و أداء المؤسسات التي تدعم السوق.

\section{4. تصميم أسواق جديدة}

غالبًا ما يكون هذا الحل أسهل مع المنتجات أو الخدمات الجديدة تمامًا مقارنة بالأسواق الحالية. ورهنا سيتعين أولًا تصميم السوق، وبعد ذللك يجب أن يجعل قو اعد السوق و اضحة للغاية، وبعد ذلك يجب الكب تحفيز

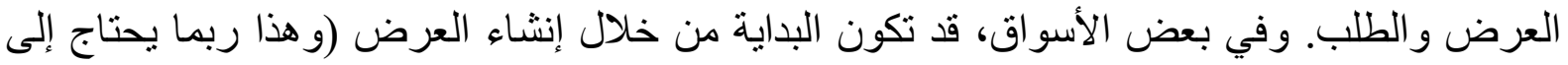

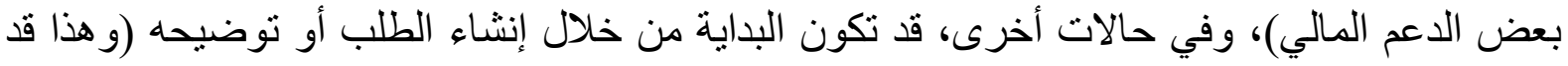

\footnotetext{
96 Stiglitiz, J.E., (1998). Markets, market failures and development. Perspectives on economic development. American Economic Review, 79(2), P. 202.

${ }^{97}$ Papandreou, Andreas. (2000). Externality, convexity and institutions. Economics and Philosophy. 19, P. 281.

${ }^{98}$ Rodrik, D., (2000). Institutions for high-quality growth: What they are and how to acquire them. Studies in Comparative International Development, 35(3), P.3.

99 J. Rogers Hollingsworth (2000). Doing institutional analysis: implications for the study of innovations, Review of International Political Economy, 7:4, P.595.
} 
يجذب المستثرين في جانب العرض). ومن الأمثلة على الأسواق الثهيرة التي تم إنشاؤها في السنوات القليلة الماضية موقع إيباي و أمازون.

\section{5. الضغوط الاولية لإصلاح الأسواق}

في بعض الأحيان، تمارس المؤسسات الدولية، مثل المفوضية الأوروبية والبنك الدولي أو الثركاء التجاريين، ضغوطًا على الدول لإصلاح أسواق معينة. ومن الجدير بالذكر أن هذه المؤسسات لم تكن الأن

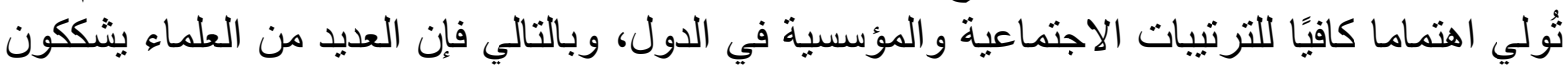

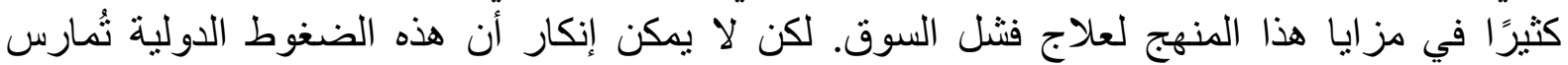

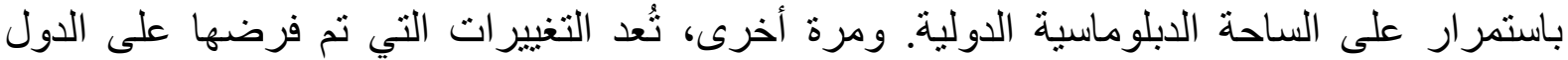

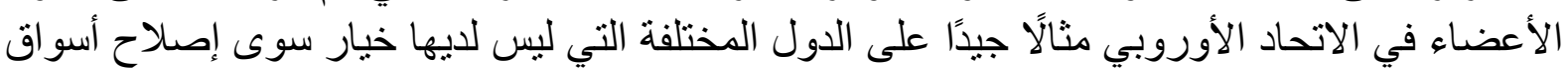

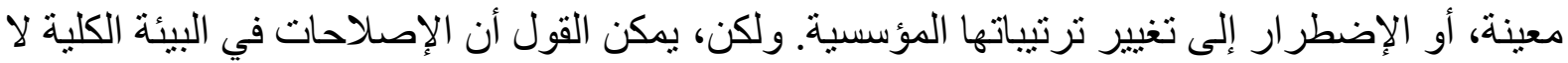

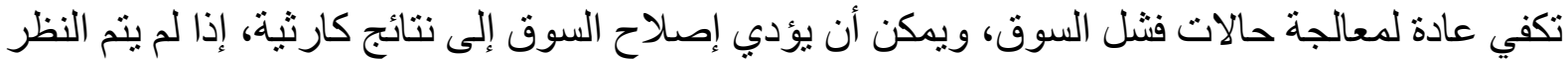
بعناية في السياق المؤسسي المحلي.

\section{6. في بعض الأحيان يتطلب الأمر بعض التطور للأسواق}

في بعض الأحيان، يستغرق الأمر وقتًا لتنطور الأسواق، ويحتاج العرض والطلب إلى المنتجات المناسبة

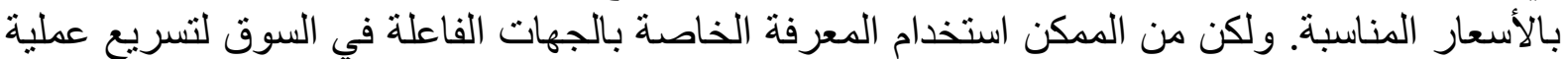

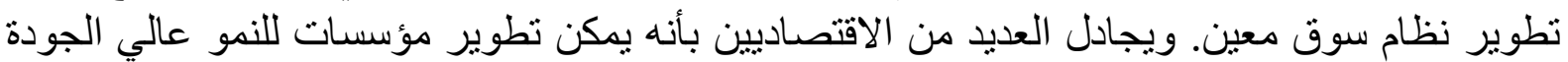

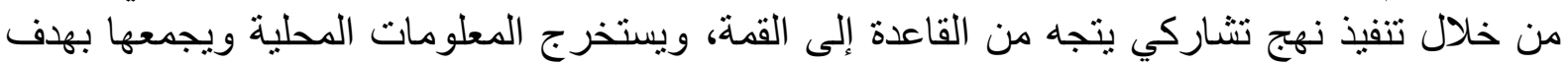
إنشاء المؤسسات.101 و هذا يكون عكس المخططات التي تتجه من أعلى إلى أسفل، و التي غالبًا ما يتم

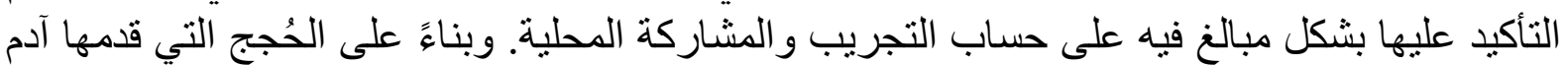

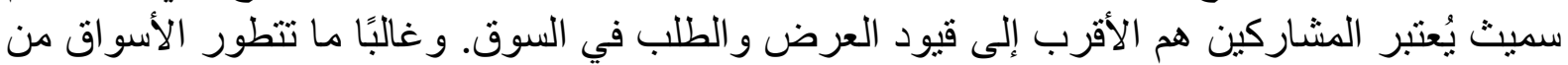

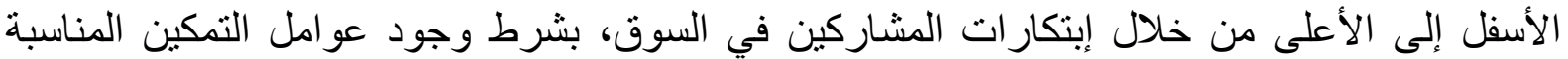

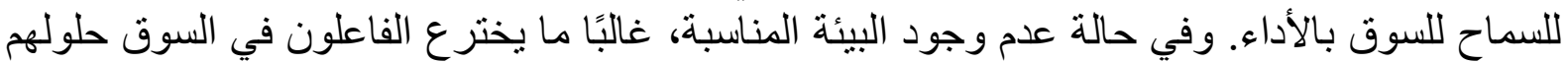

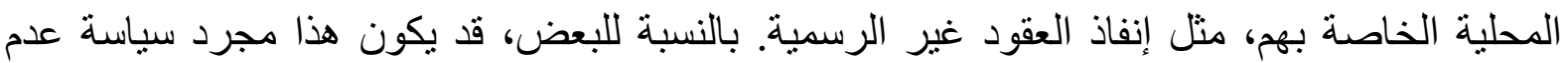

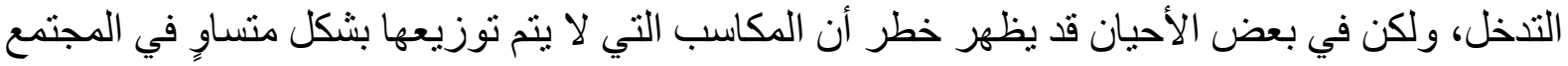
يمكن أن تؤدي إلى إضطر ابات اجتماعية.

\section{7. يمكن للتكنولوجيا أحيانًا التظلب على إخفاقات السوق}

غالبًا ما تلعب التكنولوجيا الجديدة دورًا في التغلب على حالات فنثل السوق. في كثير من الحالات، غيرت

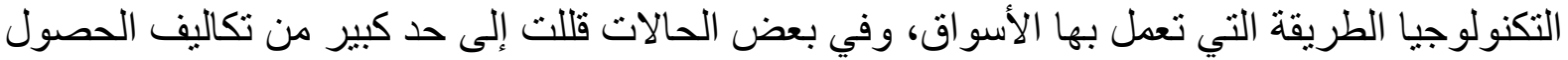

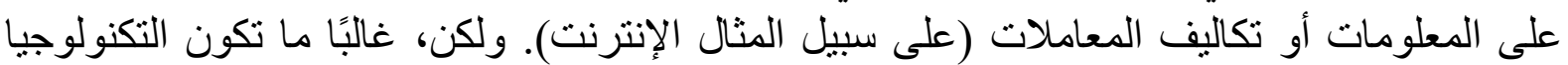

\footnotetext{
${ }^{100}$ Cunningham, S., (2009). The role of market failure in the utilisation of Quality Management services by the tooling industry. Ph.D Thesis, North West University, P.191.

${ }^{101}$ Klinger, B. \& Lederman, D., (2006). Diversification, innovation, and imitation inside the global technological frontier. Policy Research Working Paper Series. World Bank Policy Research Discussion Paper No. 3872, Washington, DC: The World Bank, P.2.

102 Hausmann, R. \& Rodrik, D., (2003). Economic development as self-discovery. Journal of Development Economics, 72(2), P.610.
} 
الجديدة عرضة لحالات فثل السوق نفسها، بسبب المنافسة غير الكاملة أو المعلومات غير المتماثلة أو

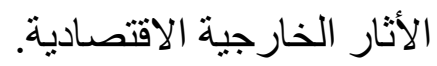

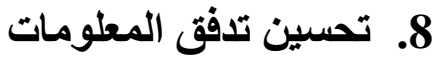

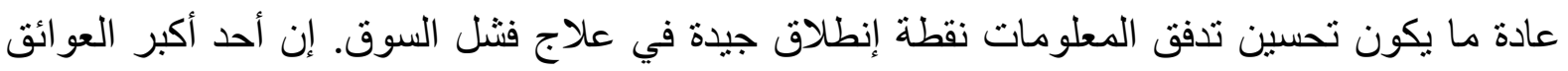

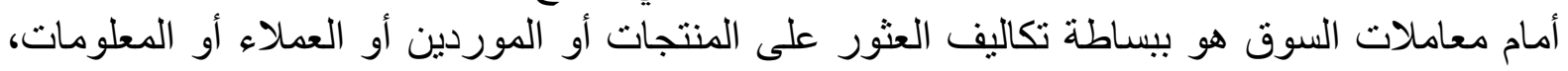

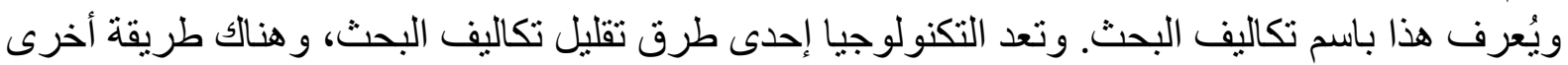

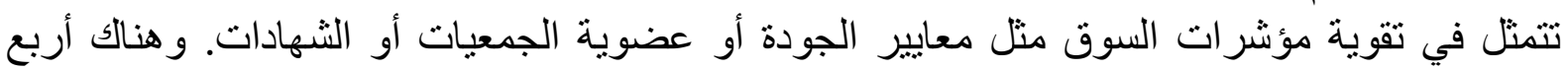

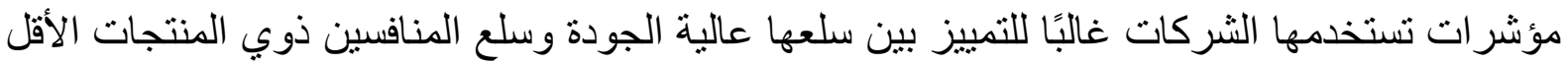

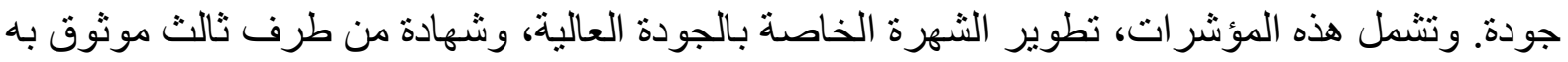

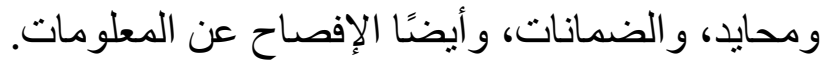

وتواجه الدول النامية بعض المخاطر الجديدة والتي تتمثل في أن أجزاء كبيرة من مجتمعاتها يمكن أن أن النياء

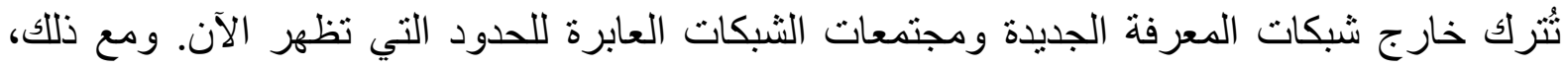

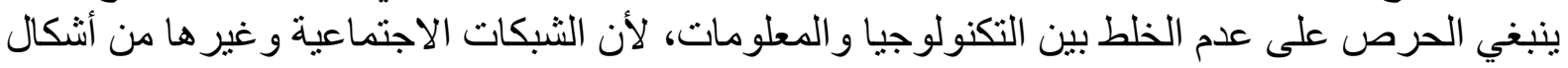
الاتصنال مهمة أيضًا في تدفق المعلومات.

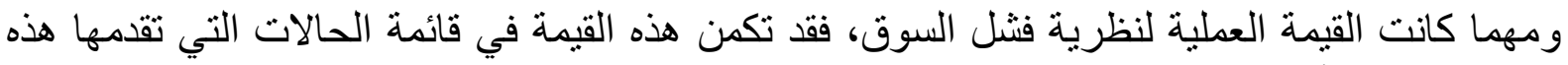

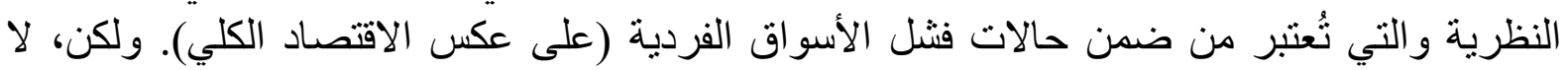

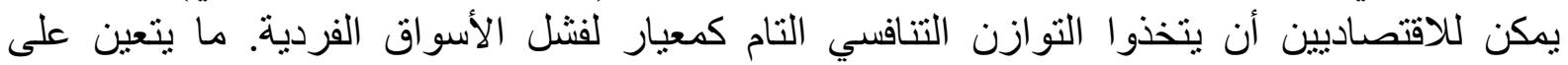

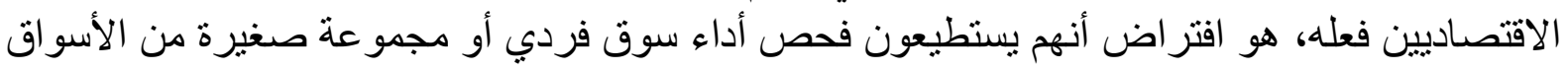

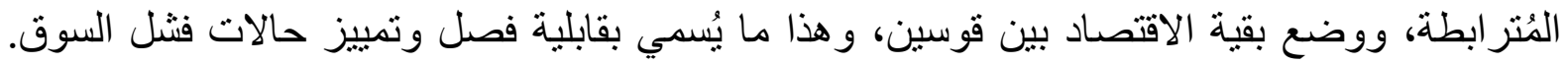

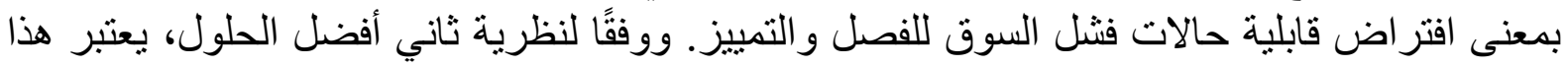

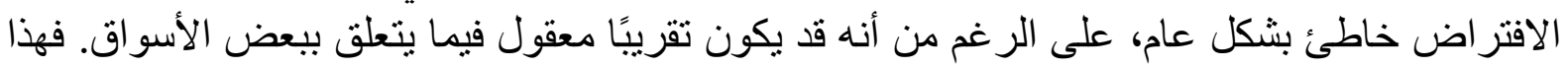

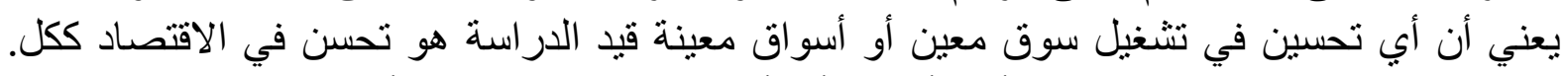

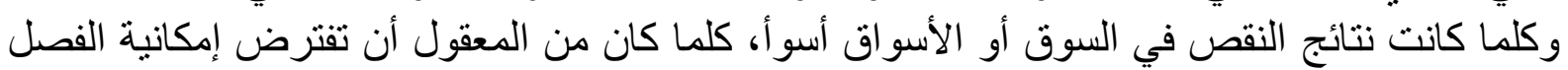

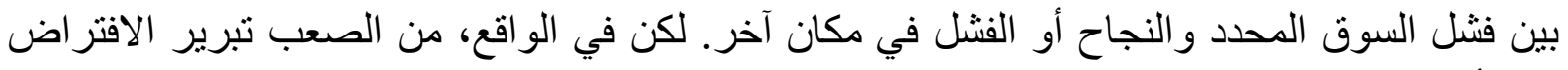

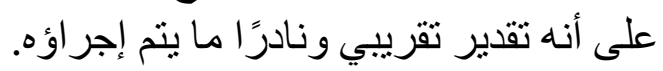

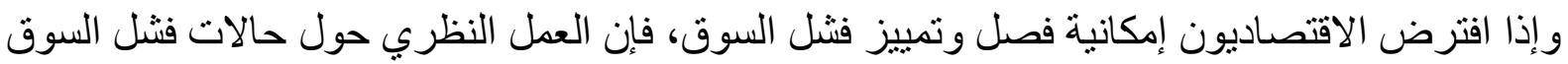

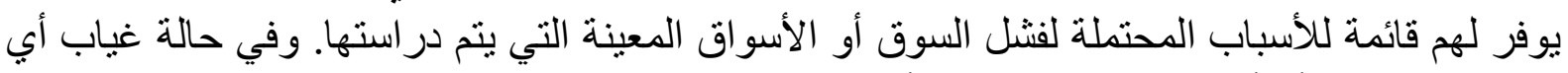

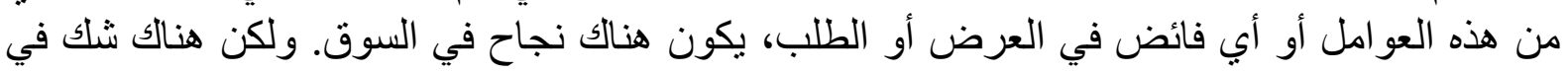

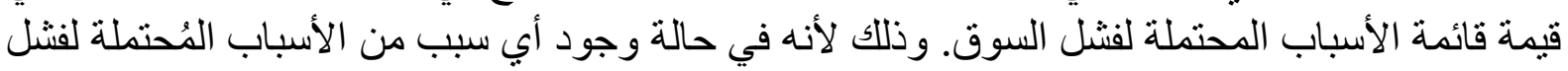

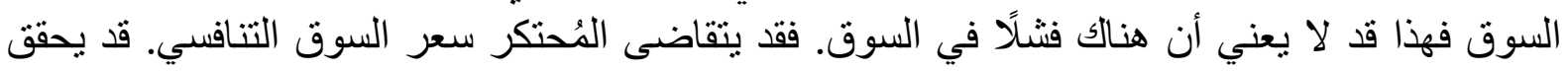

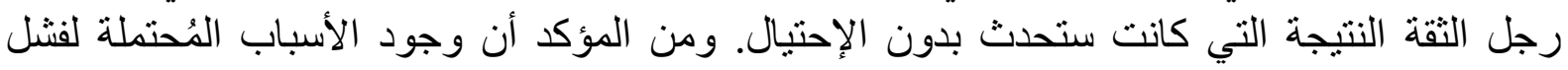

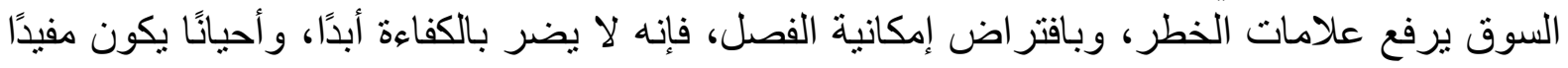

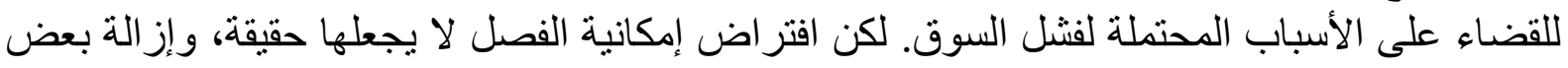

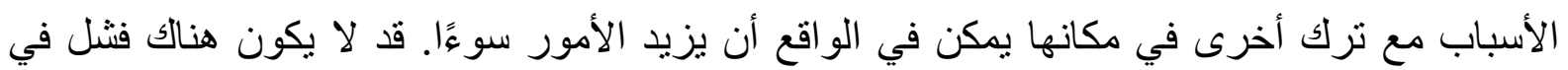
السوق، و إذا كان هنالك سبب محتمل لفتشل السوق يمكن الني أن يحيد الآخر. 


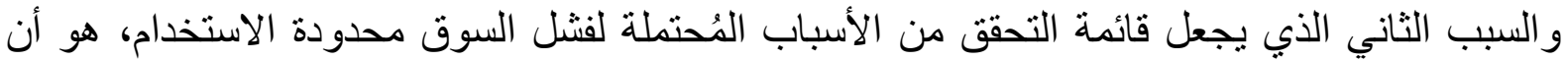

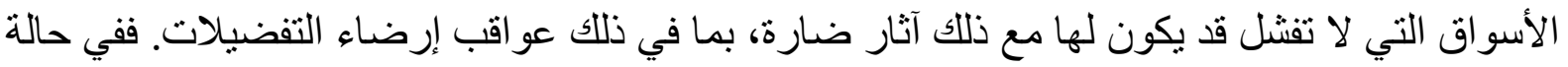

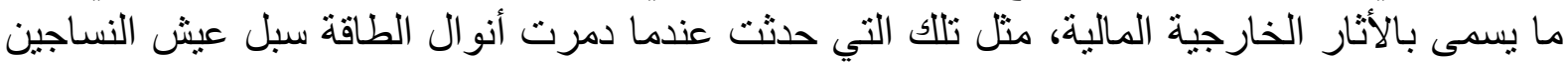

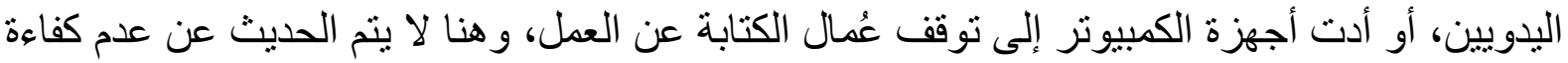

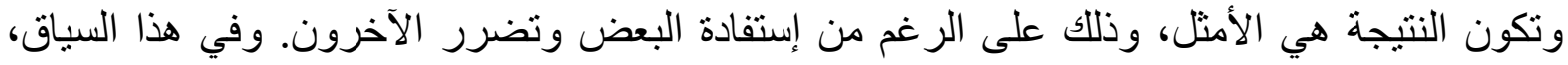
تكون الأسئلة الأخلاقية حول ما إذا كان يجب الإن محاولة تحسين نتائج السوق في محلها.

${ }^{103}$ Hausman, Daniel, (1992). "When Jack and Jill Make a Deal," Social Philosophy and Policy 9, P. 95. 


\section{2}

من المُلاحظ أن هناك توسع كبير وانتشار واسع للكتابات الفقهية والأكاديمية حول الأثار الخارجية الاقتصادية. وحسب تعريف هذه الأثار، فإنها تعتبر جزعاً من حياة جميع أفراد المجتمع. 104 والأثار الخارجية الإيجابية هي الفوائد التي يتعذر تحصيل مقابل تقديمها أو توفيرها، والأنثار الخارجية السلبية

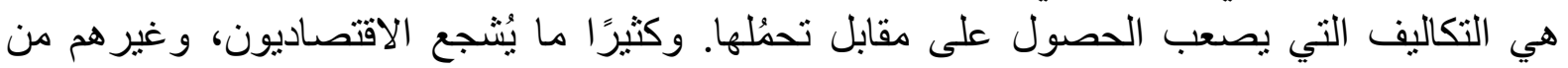

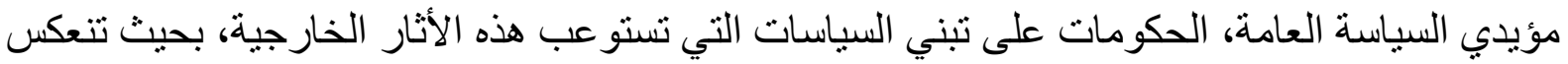
التكاليف و الفو ائد بشكل أساسي في المعاملات التي تنتج عنها هذه الأثار.

وبصفة عامة، تؤثر قرارات الأفراد وحقائق الطبيعة علينا ماديًا ونفسيًا، وبطرق إيجابية وسلبية.

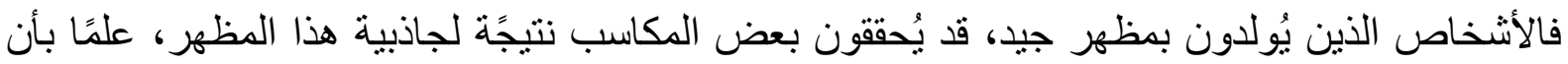

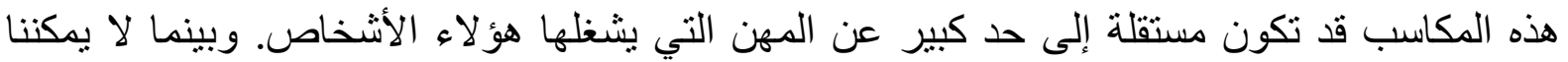

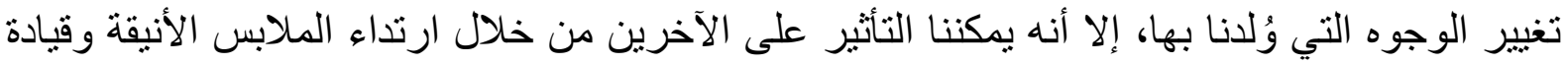

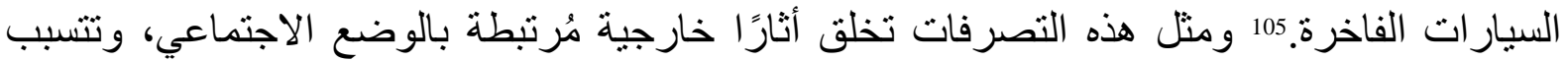

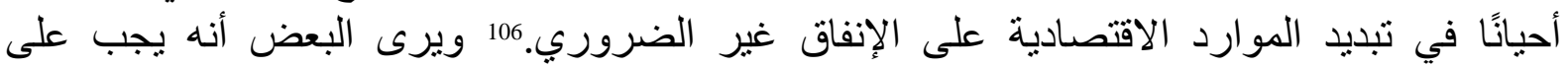
السياسات العامة أن تنظر في التعامل مع مثل هذه النود التهائل من الأنثار الخارجية.

وتُركز الكتابات الاقتصادية أيضًا على الأثنار الخارجية للاستهلاك، فمثلًا، في كثير من الأحيان، تسود الأني

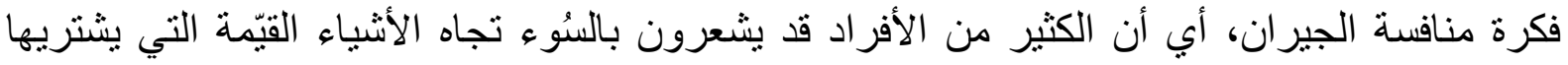

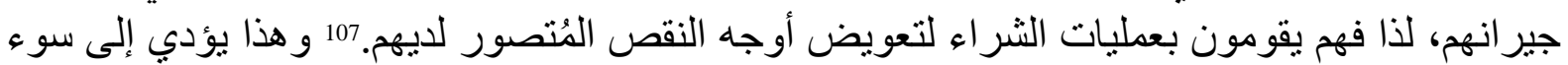

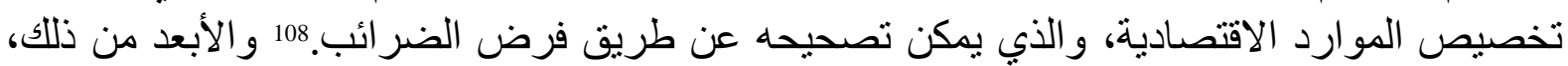

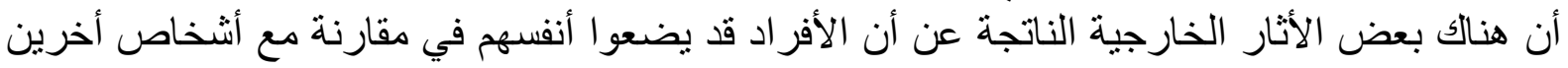

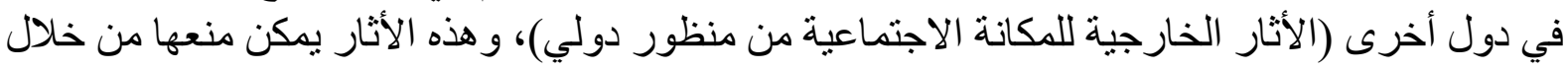
تبني سياسة ضريبية فحّالة، وفي إطار تعاوني من شأنه أن يحقق فائدة كبيرة من حيث الرفارة الرفاهية

\footnotetext{
${ }^{104}$ Roger Meiners, (2017). Externalities: Bad Economics, Good Law, in Exploration in public sector economics: Essays by prominent economists 61-91 (J. Hall ed.,), P.61.

${ }^{105}$ Daniel S. Hamermesh \& Jeff E. Biddle, (1994). Beauty and the Labour Market, 84 AM. ECON. REV., P. 1174; Chris Warhurst et al., (2009). Lookism: The New Frontier of Employment Discrimination?, 51 J. INDUS. REL., P. 131.

106 Michael A. Lewis, (2012). The Spending Explosion: Positional Externalities and Exponential Consumption Growth, 7 J. Applied Quantitative Methods, P.25.

107 Thomas Aronsson \& Olof Johansson-Stenman, (2015). Keeping Up with the Joneses, the Smiths, and the Tanakas: On International Tax Coordination and Social Comparisons, 131 J. PUB. ECON., P. 71.

${ }^{108}$ Paul Eckerstorfer \& Ronald Wendner, (2013). Asymmetric and Non-Atmospheric Consumption Externalities, and Efficient Consumption Taxation, 106 J. PUB. ECON., P. 42.
} 
الاقتصادية.109 وفي هذا السياق، يمكن أن يؤدي التنافس بين الجيران إلى الإفراط في الاستهلاك، مما قد يؤدي إلى أمر اض السمنة، وهو أيضًا من ضمن النئ بودي الأثار الخارجية السلبية.

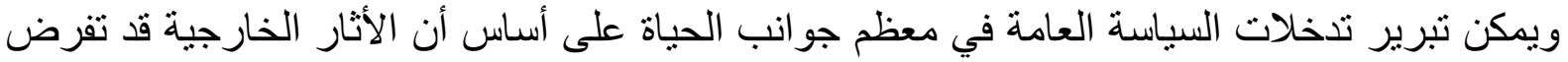

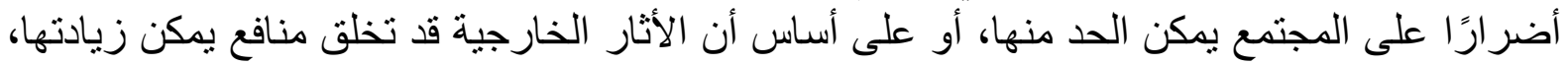

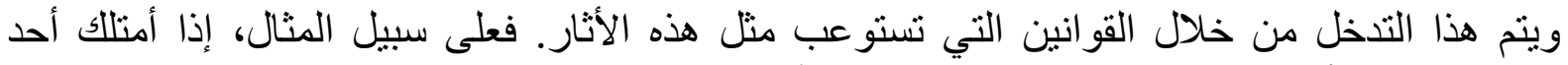

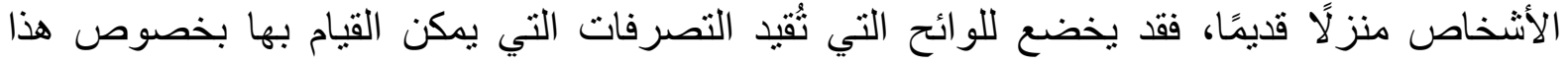

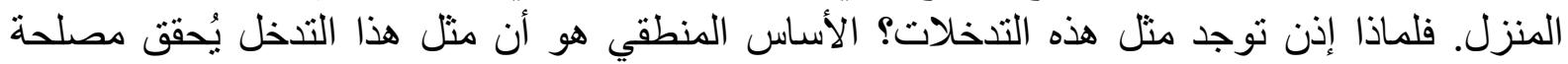

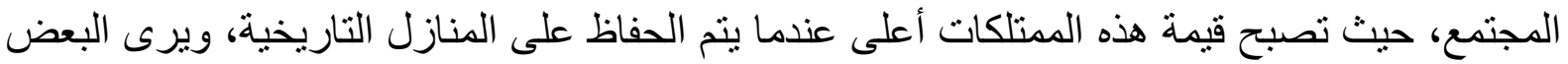
أن هذا التدخل يُحقق أثنار خارجية إيجابية.

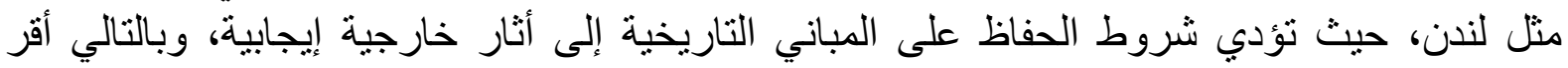

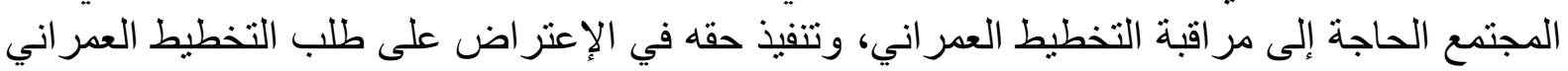

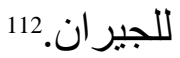

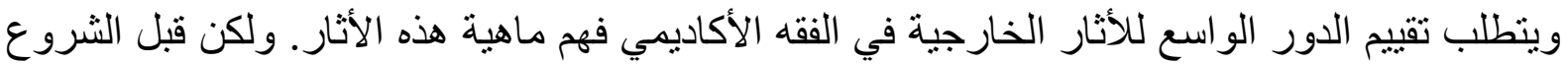

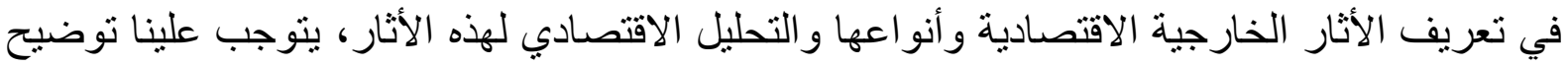

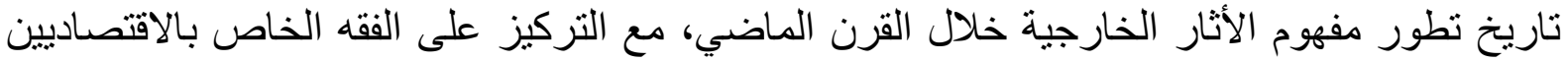

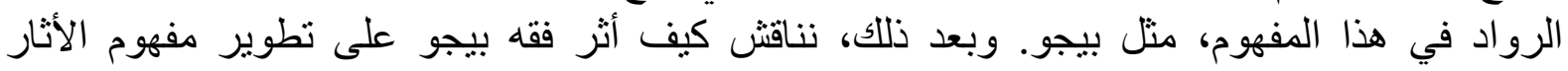

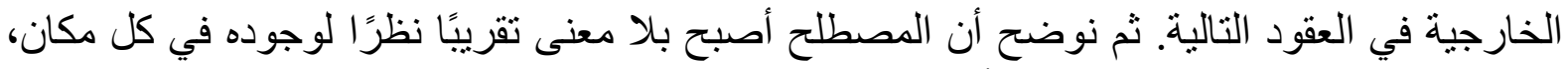

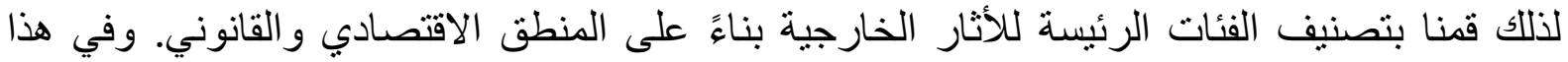

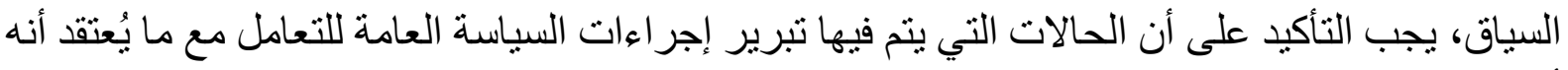
أثار خارجية هي حالات قليلة جدًا. وينقسم هذا الفصل إلى المباحث الأتية: المبحث الأول: الأصول التاريخية للأثار الخارجية وتطورها: نظرية مارشال وبيجو. المبحث الثاني: الطابع الرسمي لتحليل الأثار الخارجية. المبحث الثالث: مفهوم الأثار الخارجية في الفقه الحالى.

\footnotetext{
${ }^{109}$ Frank, R., (2008), 'Should Public Policy Respond to Positional Externalities?', Journal of Public Economics, 92(8-9), P. 1779.

${ }^{110}$ Roberta Mann, (2017). Controlling the Environmental Costs of Obesity, 47 ENVTL. L., P. 697.

111 Andrew J. Narwold, (2008)."Estimating the value of the historical designation externality", International Journal of Housing Markets and Analysis, Vol. 1, Iss. 3 P. 288.

112 Abilene, Texas. N. Edward Coulson \& Robin M. Leichenko, (2001). The Internal and External Impact of Historical Designation of Property Values, 23 J. REAL EST. FIN. \& ECON., P. 113.
} 


\section{المبحث الأول: الأصول التاريخية للأثار الخارجية وتظورها: نظرية مارشال وبيجو}

كان أول من قدم مفاهيم الأثار الاقتصادية الخارجية والداخلية (الوفورات الاقتصادية الخادية الخارجية و الداخلية)

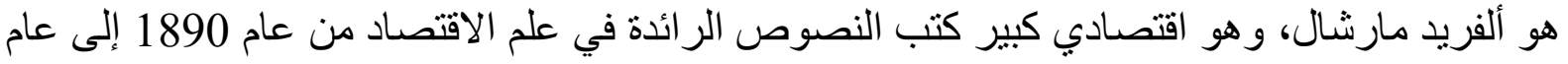

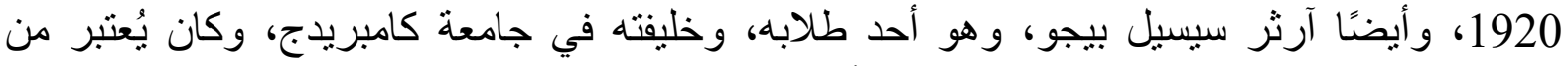
الثخصيات الرئيسة في الاقتصاد في النصف الأول من القرن العشرين. 113

ولكن في هذا السياق يرى بعض الاقتصاديين أن أصول مفهوم الأثار الخارجية لا تعود إلى بيجو، بل

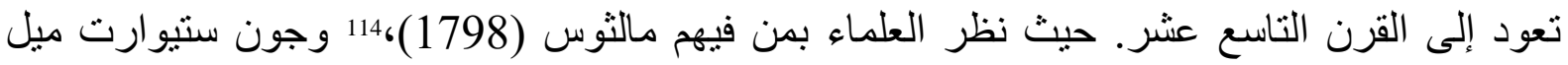

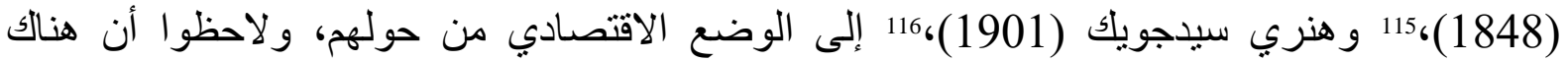

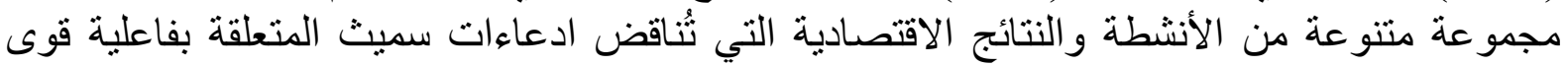

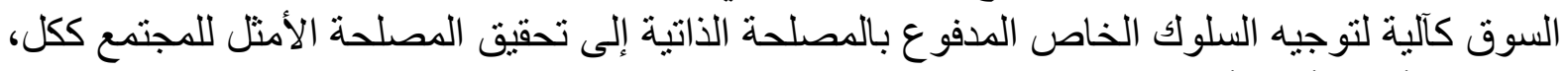

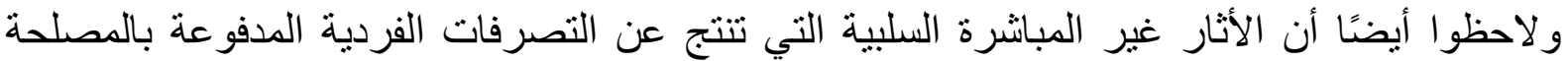
الذاتية بدأت تلوح في الأفق بشكل متز ايدا

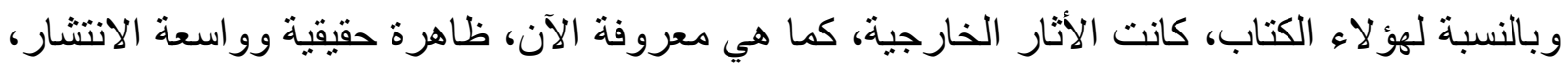

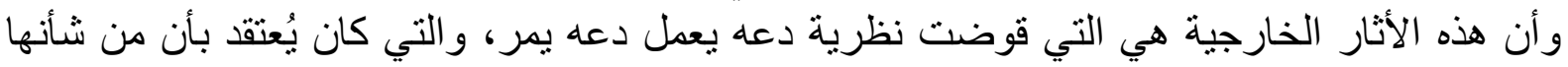

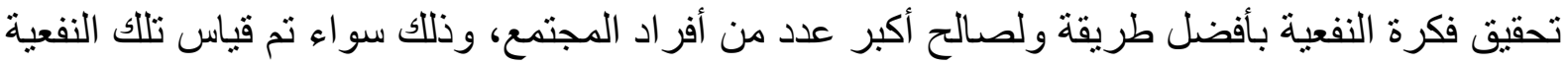

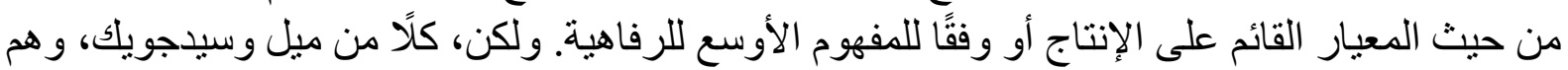

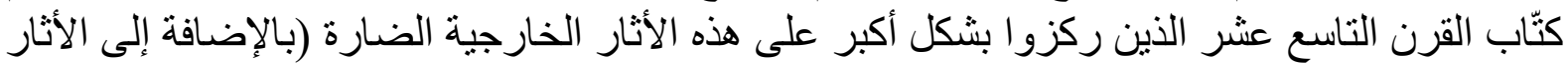

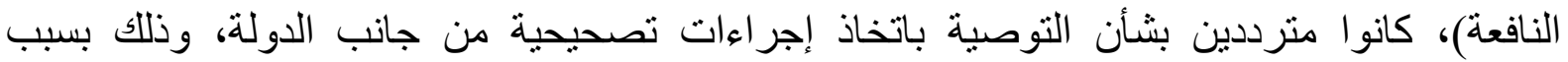

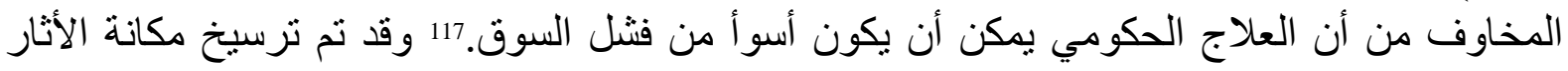
الخارجية في التفكير الاقتصادي من قبل بيجو في الثروة والرفي الرفاهية، واقتصاديات الرفان الرفاهية.

اولًا: نظرية مارشال: الوفورات الاقتصادية الاخلية والخارجية

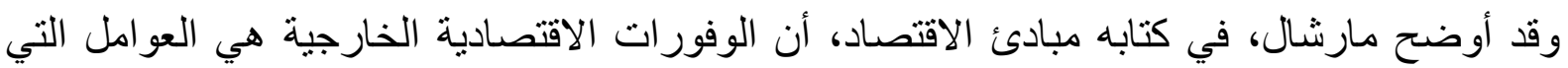

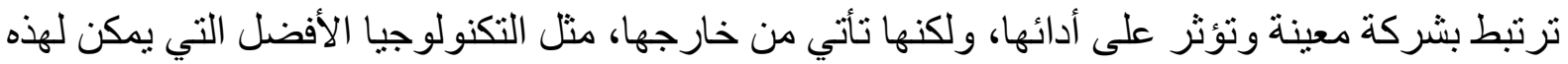

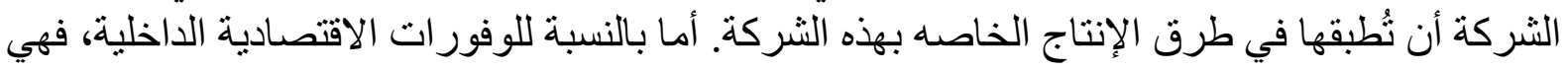

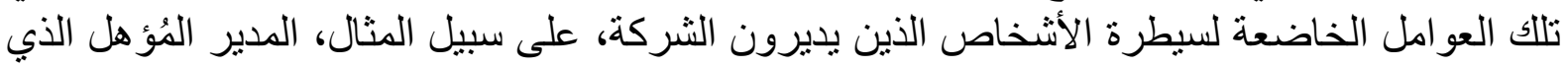

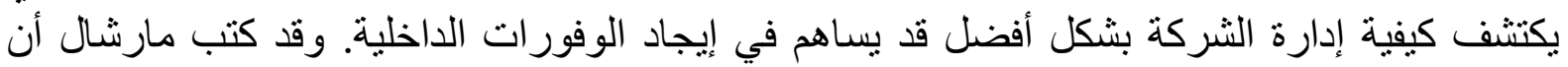

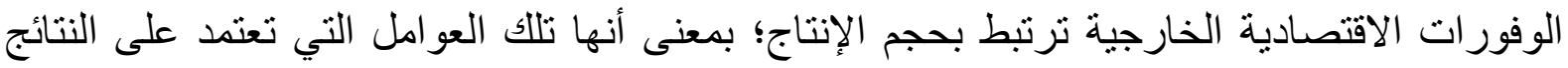

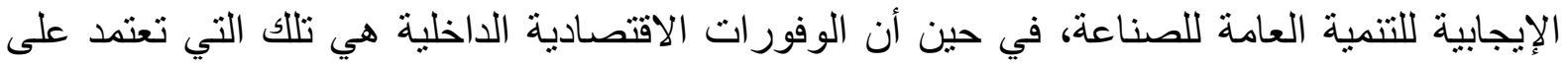

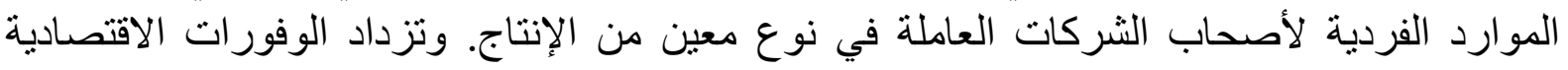

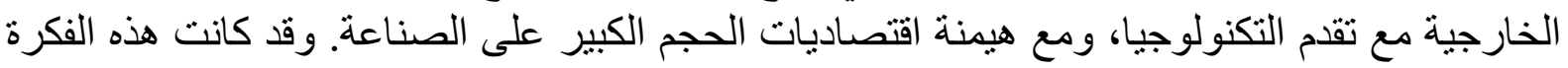

\footnotetext{
${ }^{113}$ Edwin S. Mills \& Philip E. Graves, (1986). The Economics of Environmental Quality, 2 (2d ed.).

114 Malthus, Thomas Robert. (1798). An Essay on the Principle of Population. London: Joseph Johnson, P.75.

${ }^{115}$ Mill, John Stuart. (1848). Principles of Political Economy. London: Longmans, Green and Co.

${ }^{116}$ Sidgwick, Henry. (1901). Principles of Political Economy, 3rd ed. London: Macmillan.

${ }_{117}$ Medema, Steven G., (2009). The Hesitant Hand: Taming Self-Interest in the History of Economic Ideas. Princeton, N.J.: Princeton University Press, P.54.
} 
نوعًا من المعرفة ذات القيمة العالية، والتي كانت بعيدة عن متناول أب شخص لا يستطيع تحمل تكاليف

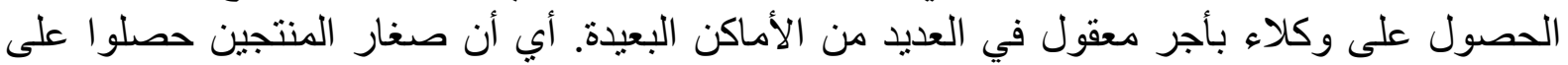

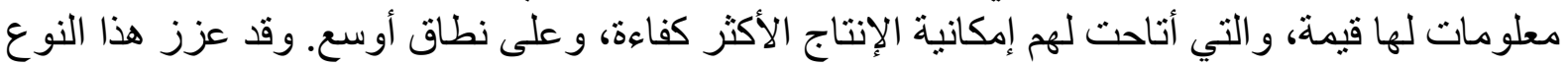
من المعرفة كفاءة رأس المال و العمل.

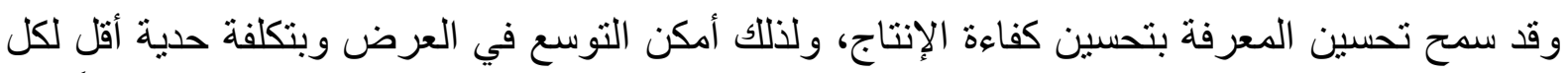

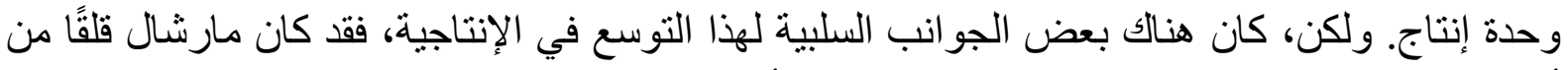

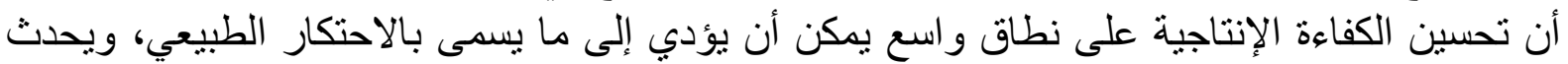

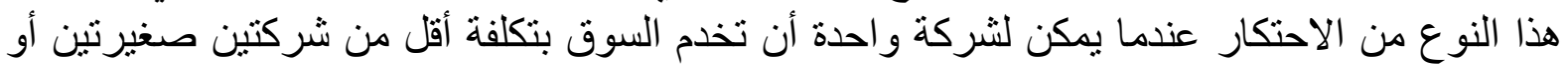

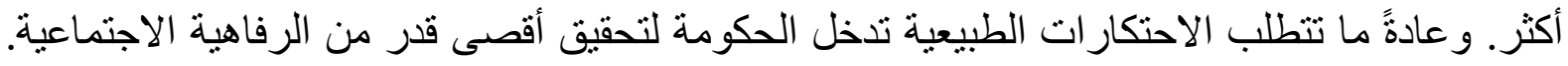

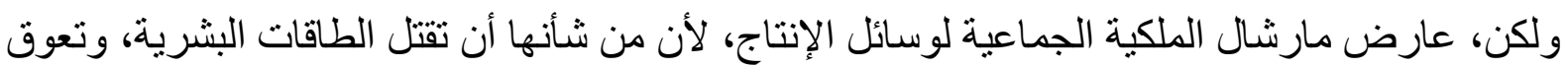

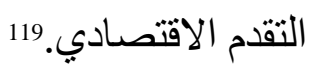

وبالر غم من أن مارشال لم يناقش مشكلة التلوث صر احةً، إلا أنه أثشار إلى عملية تقليل النفايات ـ الأشياء

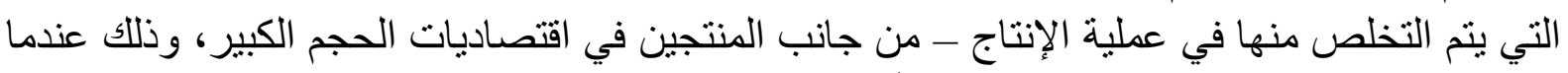

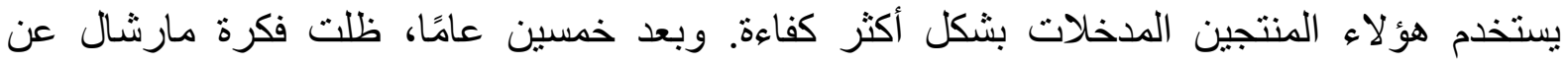

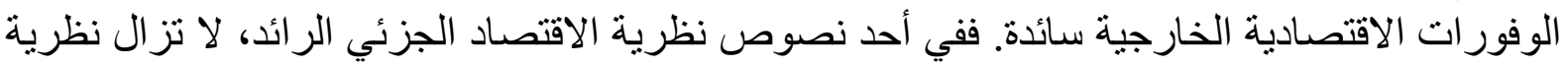

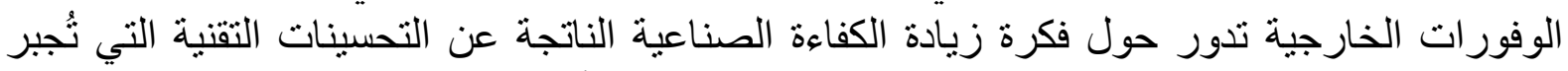

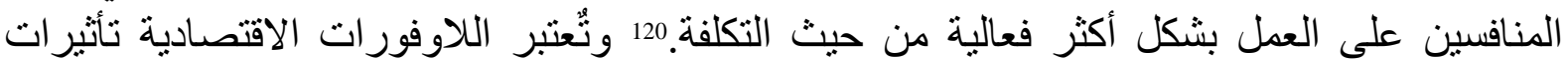

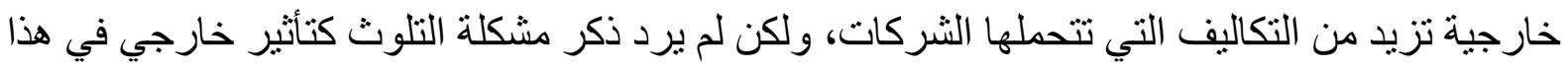

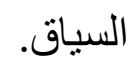

بالرغم من أن مارشال وضح فكرة الأثار الخارجية (الوفورات الاقتصادية) على الإنتاج، إلا أن الثنكل

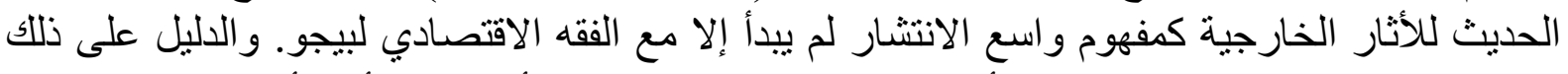

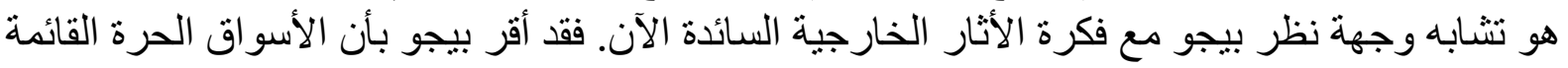

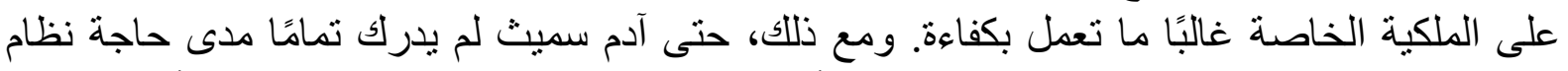

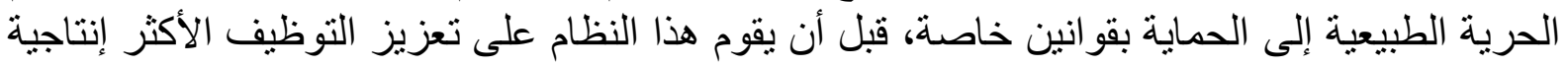
لموارد الدولة. 121

\section{ثانيًا: نظرية بيجو: عدم تطابق الناتج الحدي الخاص مع الناتج الحدي الاجتماعي}

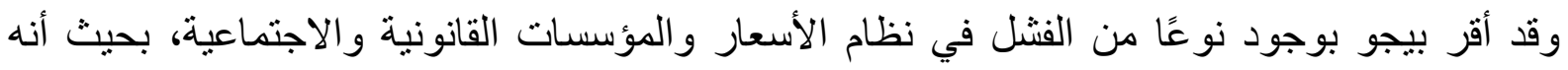

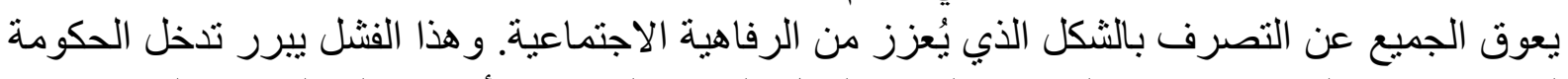

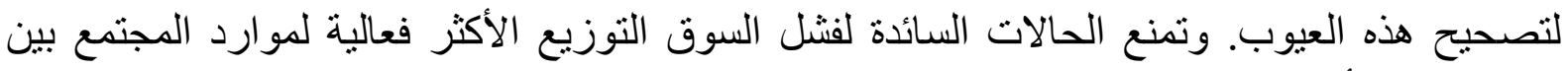

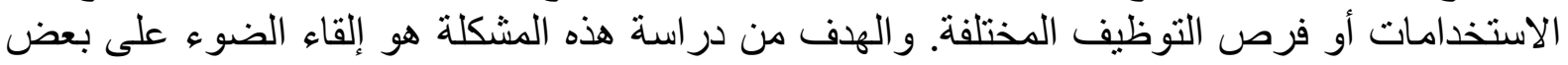

\footnotetext{
118 Alfred Marshall, (1920). Principles of Economics 266 (8th ed), P. 314; Ellis, Howard S., and William Fellner. (1943). "External Economies and Diseconomies." American Economic Review 33 (3), P. 493.

119 Alfred Marshall, (1920). Principles of Economics 266 (8th ed.), P. 713.

120 James M. Henderson \& Richard E. Quandt, (1971). Microeconomic Theory: a Mathematical approach (McGraw-Hill, 2d ed.), P.113.

${ }^{121}$ Arthur Cecil Pigou, (1932). The Economics of Welfare (4th ed.), P. 130.
} 
الطرق التي يمكن للحكومات من خلالها التحكم في دور القوى الاقتصادية، وذللك لتعزيز الرفاهية الاقتصادية، وبالتالي، الرفاهية الكاملة لكل أفر اد المجتمع.

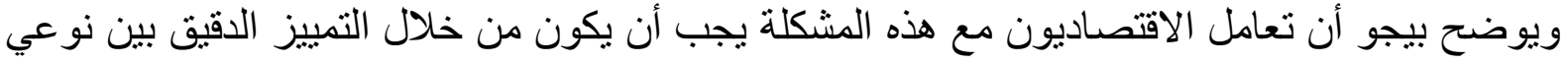

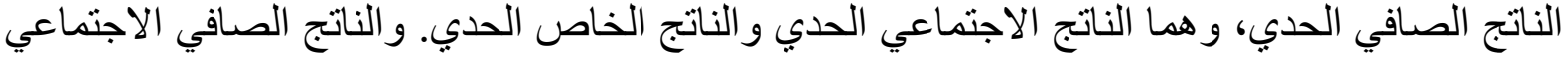

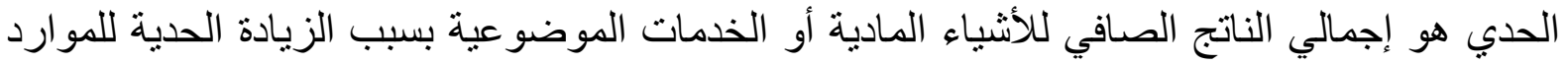

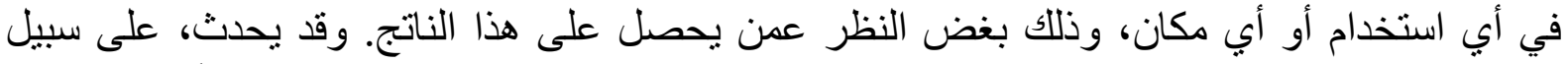

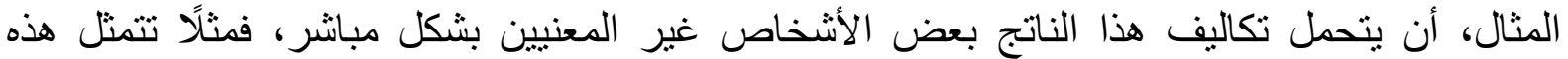

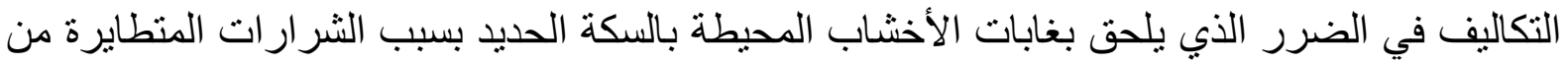

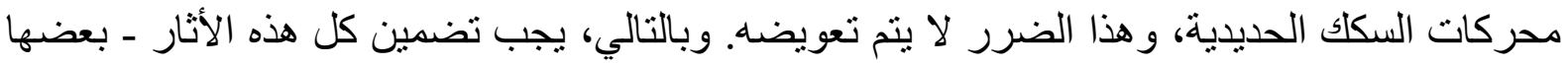

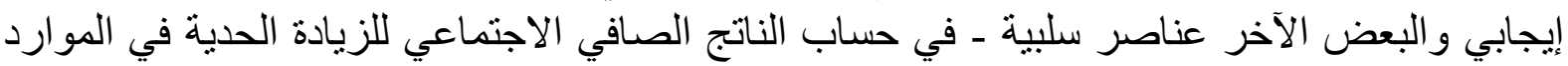

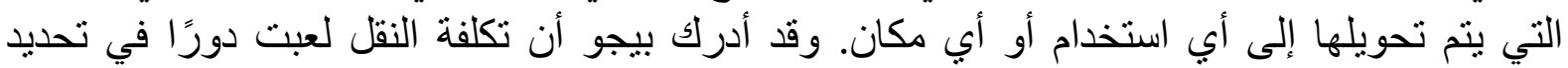

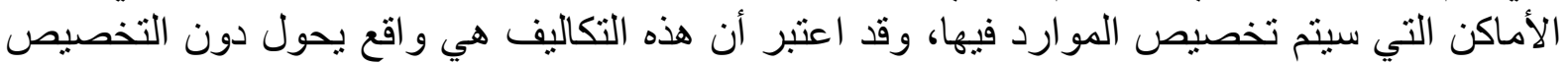

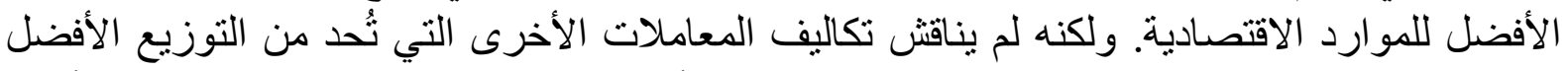

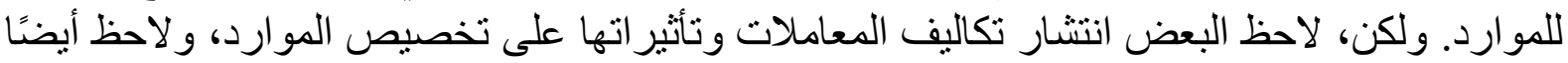
أن جز ءاً من عبقرية المنظمات الناجحة هو التقليل من هذه التكاليف.122

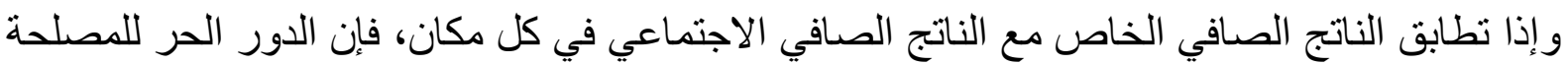

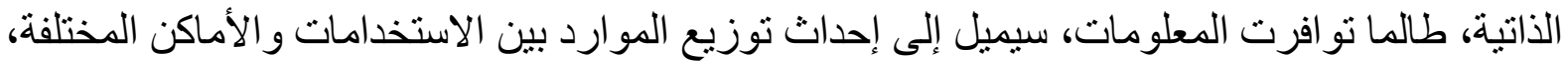

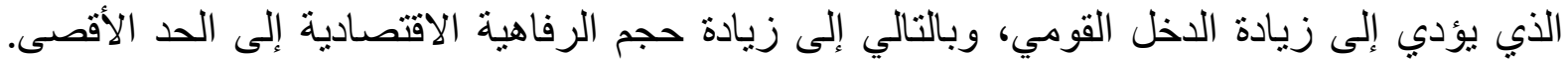

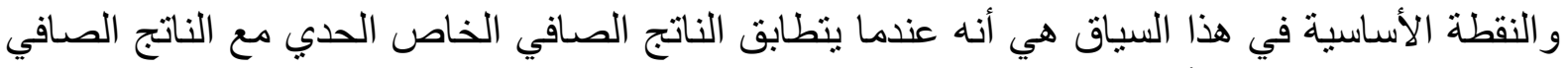

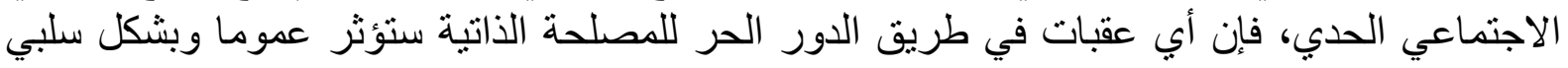

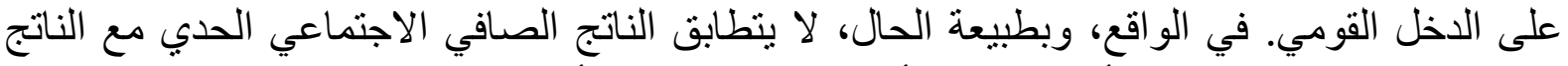

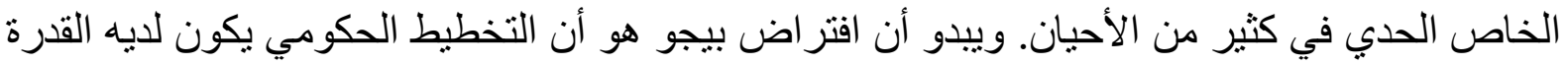

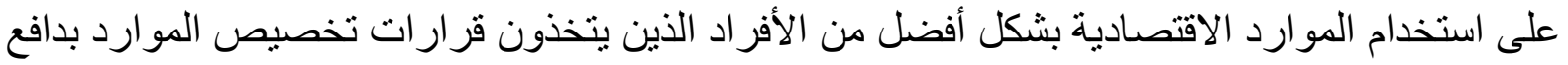

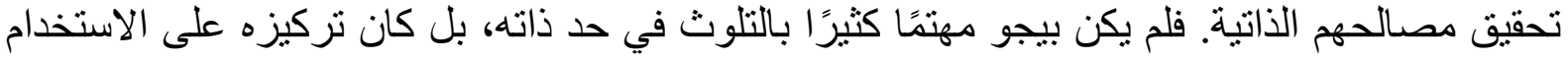
الأمثل للموارد لتعظيم القيمة الإنتاجية لموارد معينة.

ويظهر فثل السوق في إنتاج الحد الأقصى من الدخل القومي بسبب نقص المعرفة لدى الجهات القادرة

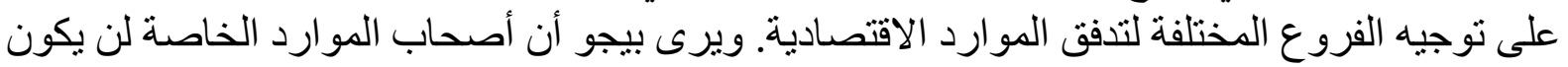

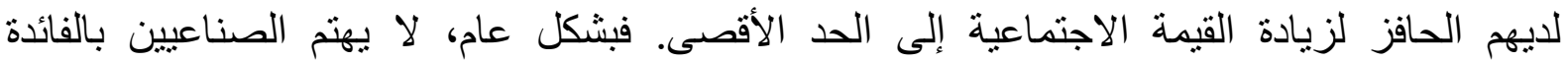

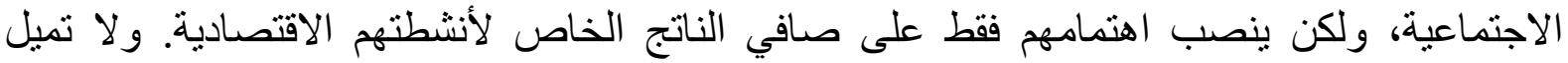

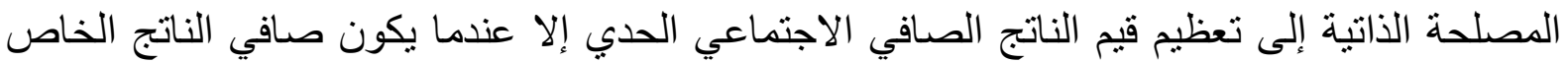

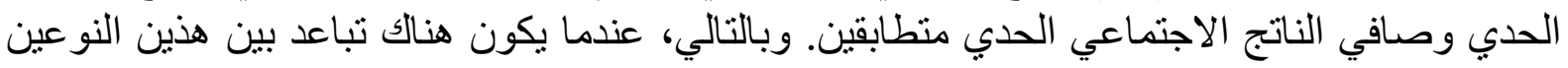

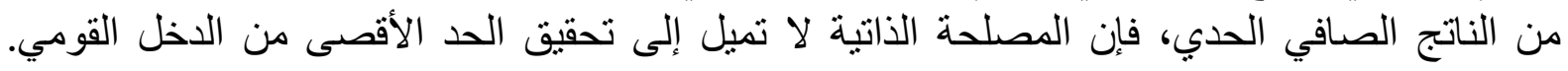

${ }^{122}$ Ronald H. Coase, (1937). The Nature of the Firm, Economica, New Series, Vol. 4, No. 16, PP. 386-405; see also Williamson, O. E., (1985). The economic institutions of capitalism: Firms, markets, relational contracting. New York: Free Press, P.15. 
وبالتالي، يُتوقع أن تتسبب بعض الإجراءات المحددة للتدخل في الأنشطة الاقتصسادية العادية إلى زيادة الاخل القومي، ولا لتوفع ان تشبب في نقصانه.

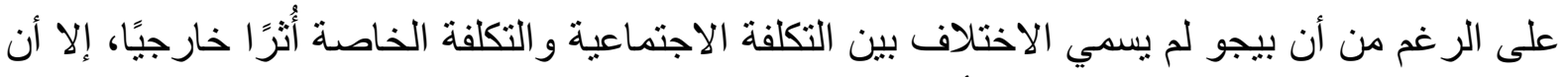

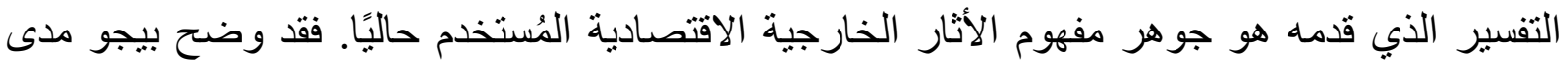

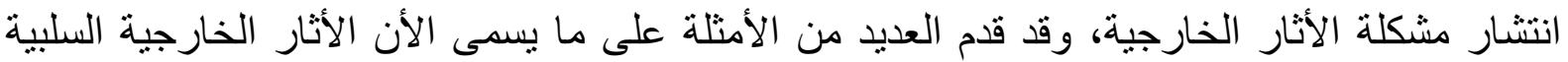

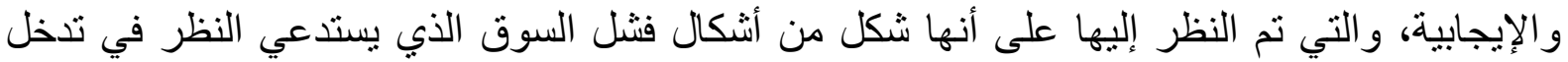

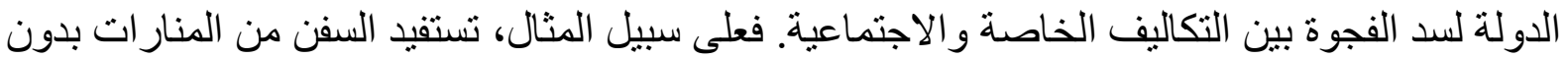

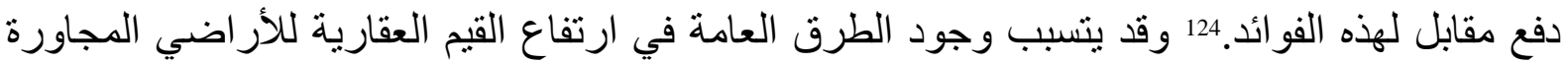

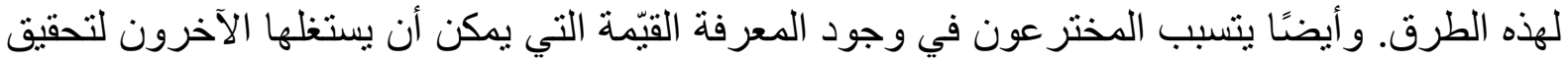

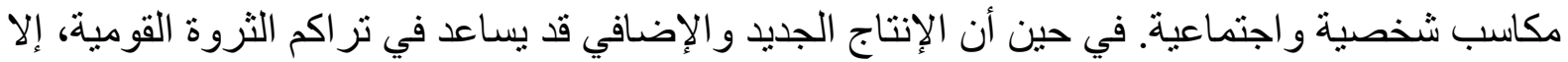

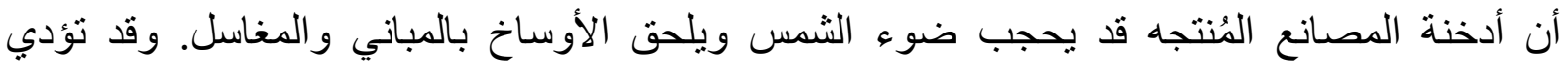

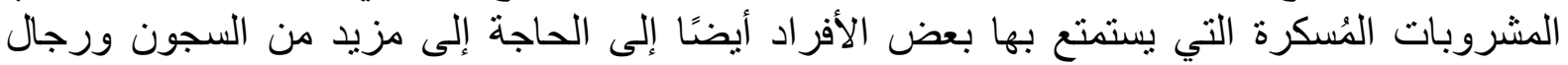

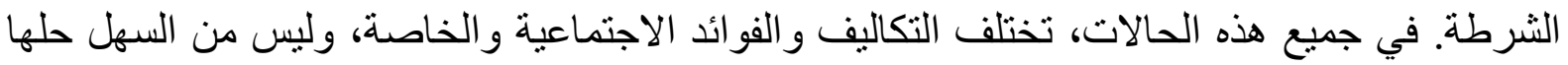
بسبب الصعوبة الفنية في إنفاذ التعويض عن الأضرار العرضية.

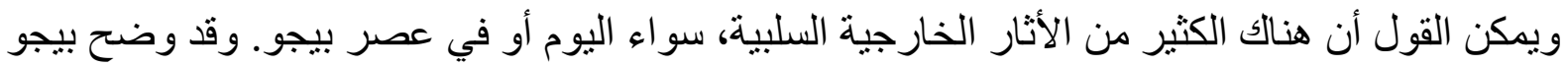

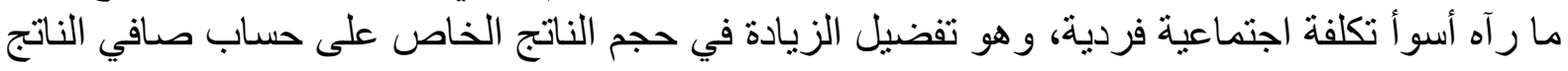

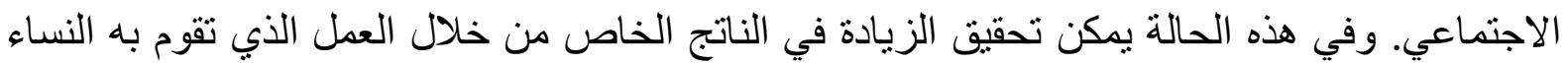

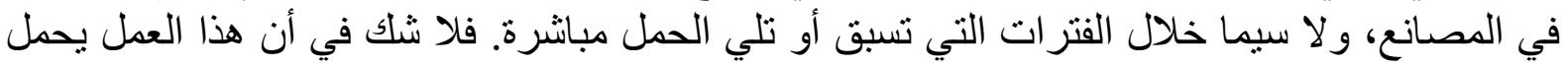

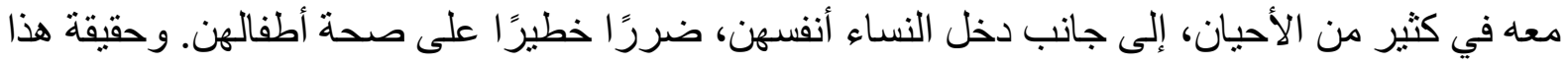

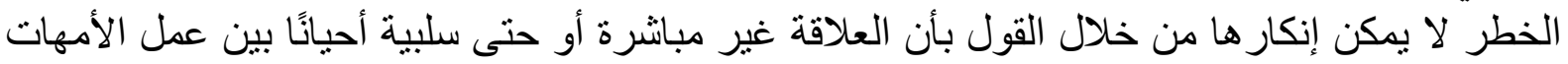

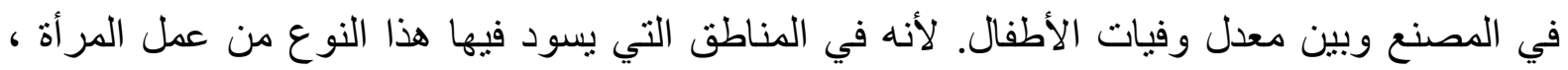

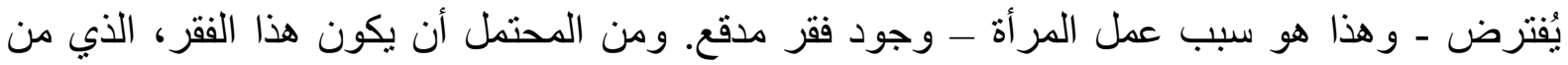

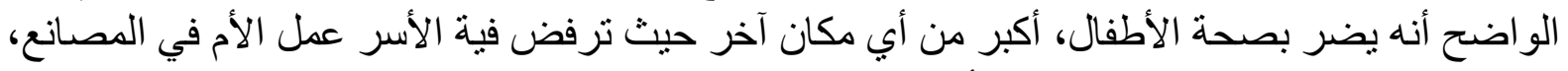

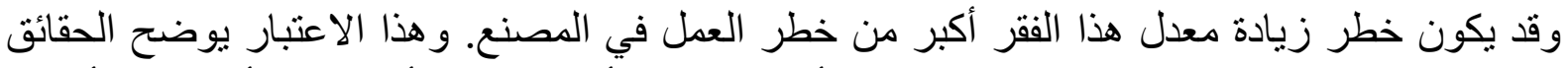

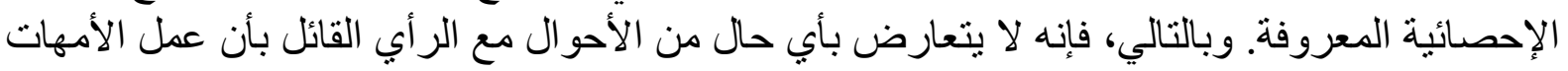

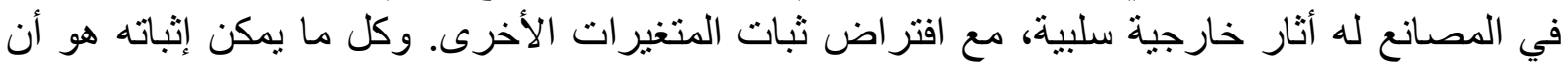

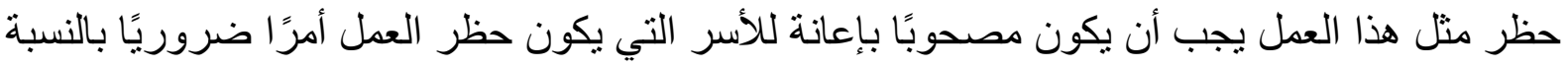

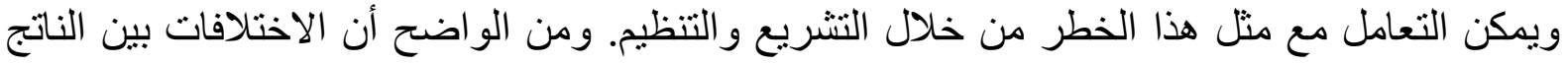

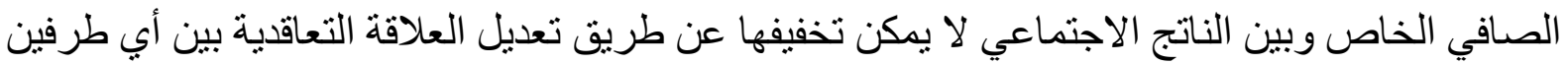

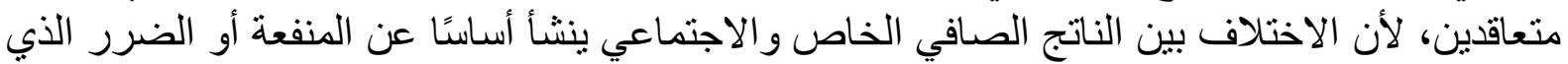

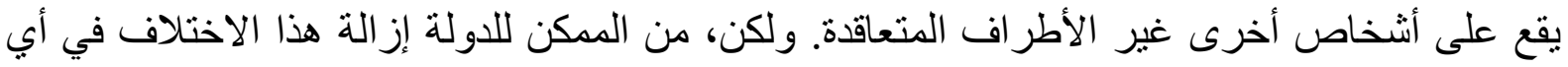

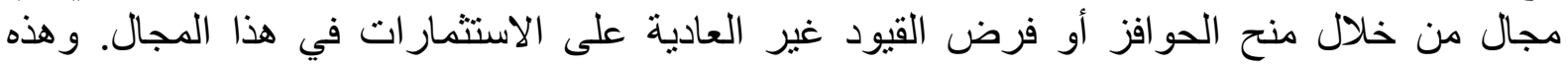

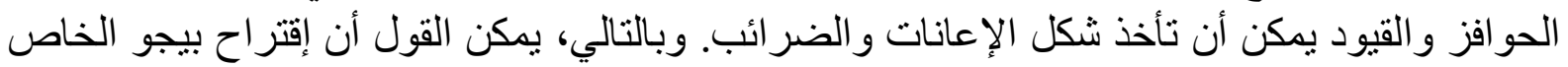

\footnotetext{
${ }^{123}$ Arthur Cecil Pigou, (1932). The Economics of Welfare (4th ed.), P. 172.

124 Sidgwick, H., (2011). The Principles of Political Economy (Cambridge Library Collection Philosophy). Cambridge: Cambridge University Press.
} 
بمنح الإعانات أو فرض الضرائب لتقليص الفجوة بين التكاليف الاجتماعية والخاصة هو حجر الأساس في تحليل الأثار الخارجية الحديثة.

\section{المبحث الثاني: الطابع الرسمي لتحليل الأثار الخارجية}

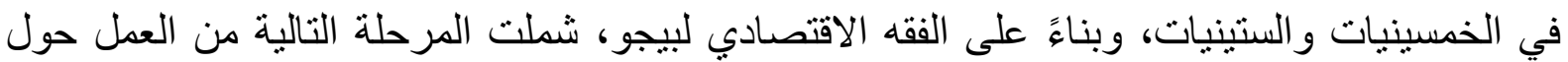

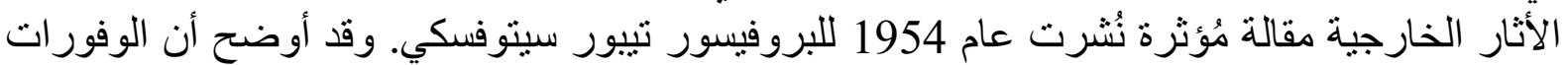

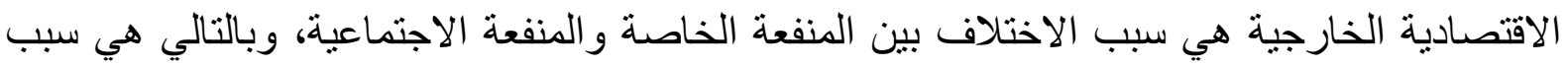
فثنل المنافسة الكاملة في الوصول هي إلى إلى الوضع الأمثل.126

أولًا: تصنيف الاثار الخارجية

وفي سياق شرح الحالات التي تظهر فيها الأثار الخارجية، تم تحديد أربعة أنواع من الاعتماد المتبادل

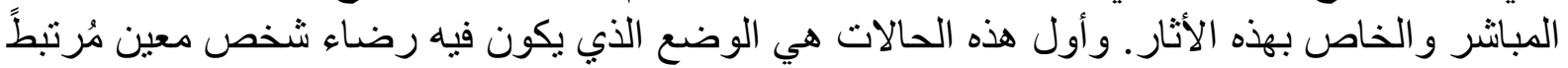

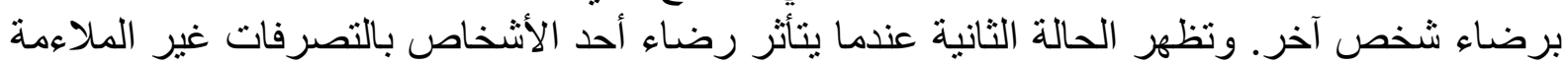
لثخص أخر، مثل الدخان الناتج عن الإنتاج. والحالة الثالثة تظهر عندماء عنداء يتعلم المنتجون تقديم السلع

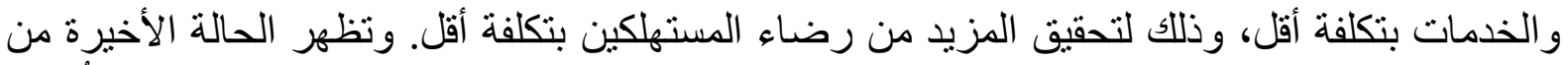

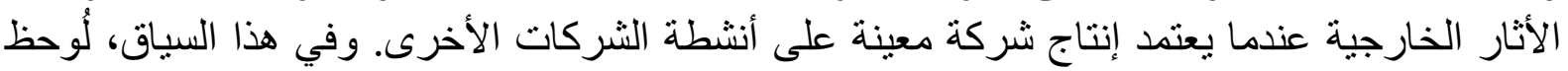

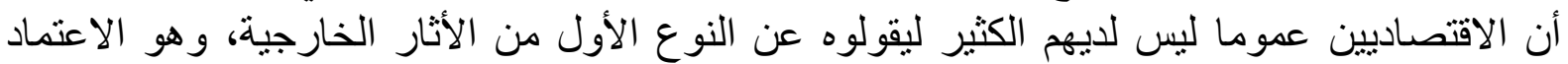

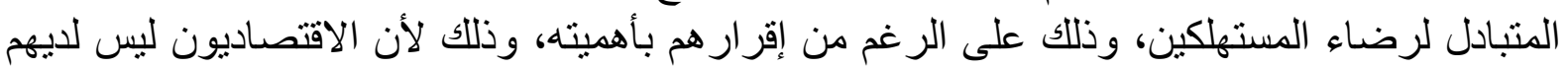
اهتمام لفهم المنفعة الثخصية أو الرضاء وضئ.

ويُعتقد أن النوع الثاني من الأنثار الخارجية، مثل الانبعاثات المرتبطة بالإنتاج، غير مهم لأنه يمكن

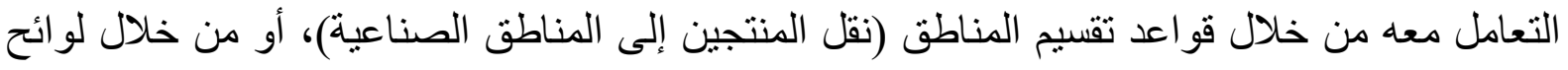
الصحة و السلامة العامة.

وبالنسبة للنوع الثالث من الأثار الخارجية، و الذي لاحظه مارشال وبيجو، وهو النوع الذي بظهر عندما

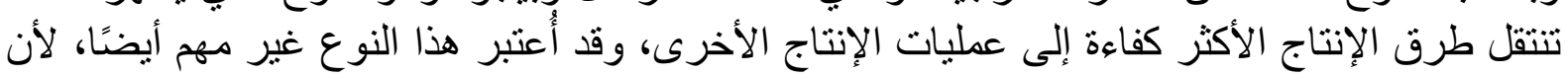

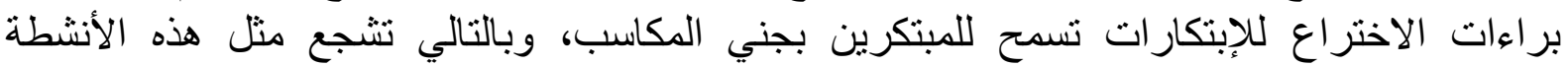
الإنتاجية. ويبيع المبتكرون إنتاجهم للمشترين الذين بستفيدون من استخدام التكنولوجيا لإنيا الجديدة في إنتاجهم.

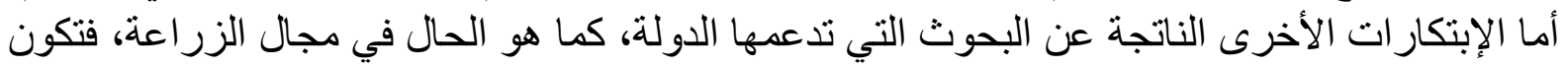
نتائج البحوث مناحة للجميع.127

وييدو أن النوع الرابع من الأثار الخارجية، وهو الاعتماد المتبادل بين المنتجين، غير مُنتشر، وبالتالي التيا فهو قليل الأهمية. ولكن في الفترة الأخيرة، تم عمل الكثير من الأثنار الخارجية التكتلية التي تنشأ عندما

${ }^{125}$ Donald J. Boundreaux \& Roger Meiners, (2019). Externality: Origins and Classifications, 59 Nat. Resources J. 1, P.15.

126 Tibor Scitovsky, (Apr., 1954). Two Concepts of External Economies, Journal of Political Economy, Vol. 62, No. 2, P.151.

127 Tibor Scitovsky, (Apr., 1954). Two Concepts of External Economies, Journal of Political Economy, Vol. 62, No. 2, P. 143. 
تستفيد بعض الأطر اف من بعضهم البعض. بيد أن الاعتر اف بصحة هذا الأمر لا يُيرر تدخل الحكومة. 128

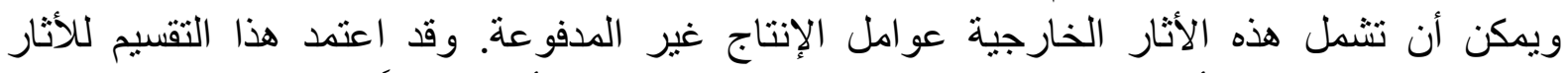

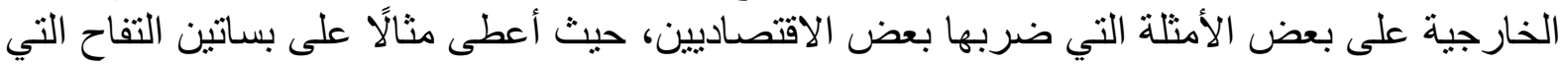

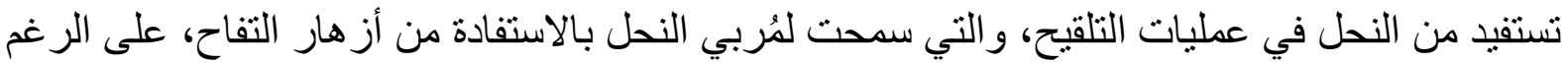

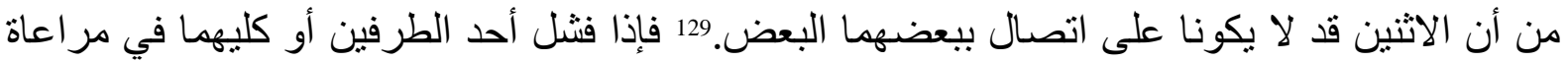
آثار تصرفاته على إنتاج الطرف الآخر، فسيكون هناك إنتاج دون المستوى الأمنل للتفاح و العسل. وهذا

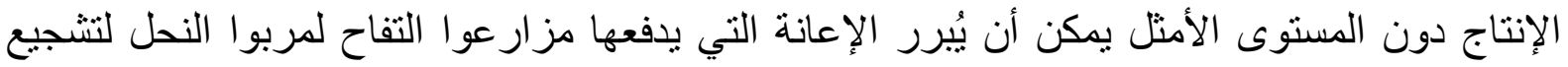

$$
\text { النحالين على إنتاج المزيد من العسل. }
$$

وبالمثل، تلعب العلاقة بين بعض المنتجات، كالمعرفة الخاصة بشركة معينة أو أحد منتجاتها، والتي يكون

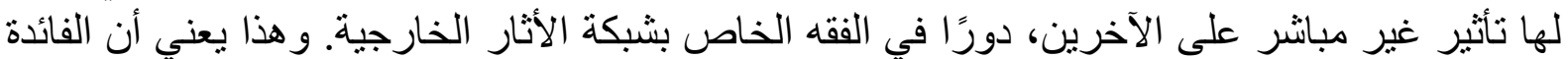
التي يحصل عليها شخص معين من سلعة معينة، مثل الهاتف أو الإنترنت، تعتمد على عدى عدد المستخدمين

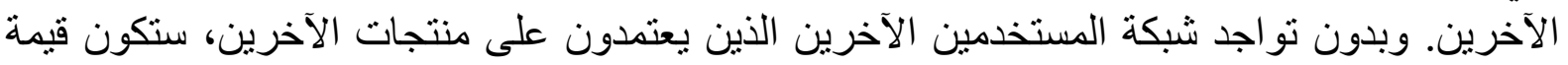

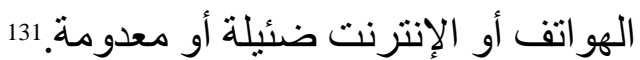

\section{ثانيًا: الأثار الخارجية القنية والأثثار الخارجية المالية}

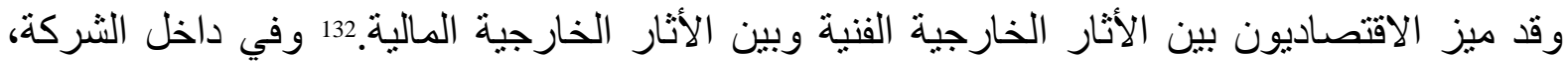

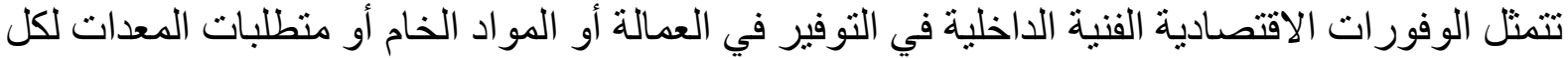

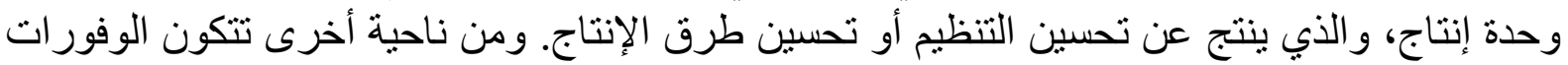
الاقتصادية الداخلية المالية من المزايا الموجودة في عمليات الثراء، مثل الخصومات ومن الات في عمليات الثراء

وبالرغم دن التمييز الفقهي بين الوفورات الاقتصادية الفنية والمالية، إلا أن هذا التمبيز الثكلى لا يهم

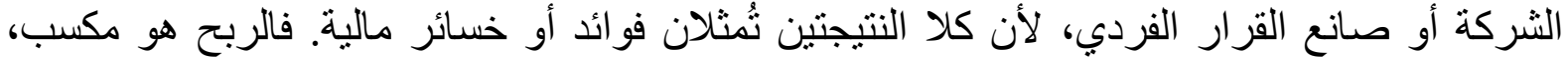

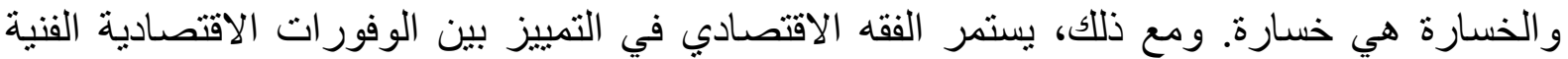

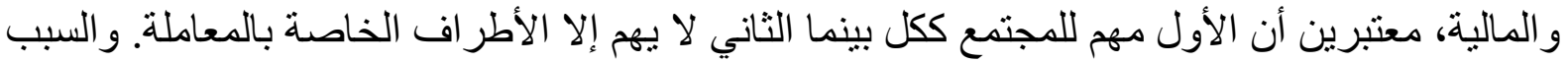
في ذلك هو الاعتقاد بأن الأثار الخارجية الفنية قد تُقلل أو نزيد من الرئية الرفاهية الاجتماعية، بينما الأثار

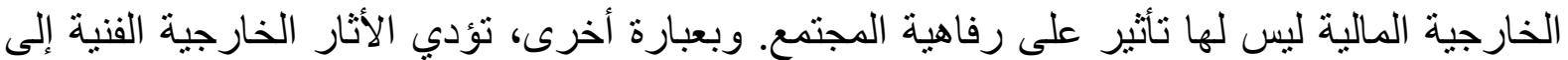

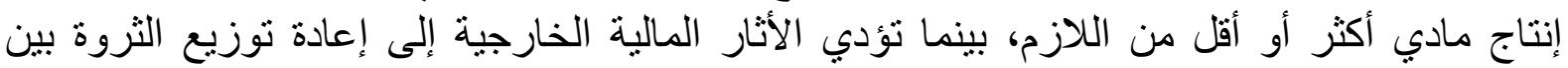
الفاعلين الاقتصاديين دون تقليصها.

${ }^{128}$ Edward L. Glaeser \& Joshua D. Gottlieb, (2009). The Wealth of Cities: Agglomeration Economies and Spatial Equilibrium in the United States, Journal of Economic Literature, Vol. 47, No., P. 983.

129 James E. Meade, (1952). External Economies and Diseconomies in a Competitive Situation, The Economic Journal, Vol. 62, No. 245, PP. 54-67

${ }^{130}$ Stephen N. S. Cheung. Stephen N. S. Cheung, (1973). The Fable of the Bees: An Economic Investigation, The Journal of Law \& Economics, Vol. 16, No. 1, P. 11.

${ }^{131}$ S. J. Liebowitz \& Stephen E. Margolis, (1994). Network Externality: An Uncommon Tragedy, The Journal of Economic Perspectives, Vol. 8, No. 2, P. 133.

${ }^{132}$ Randall G. Holcombe \& Russell S. Sobel, (2001). Public Policy Toward Pecuniary Externalities, 29 PUB. FIN. REV, P. 304. 


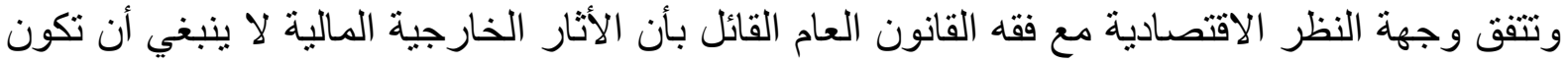

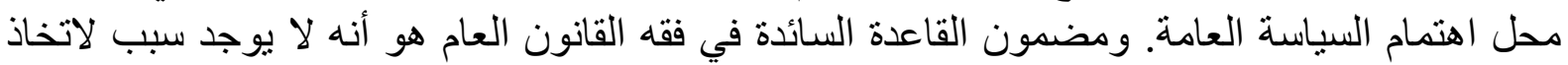

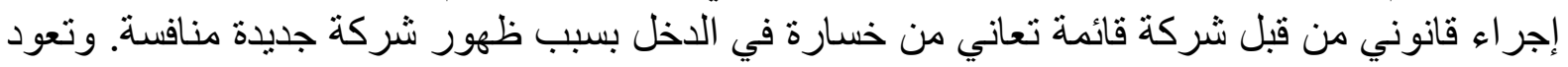

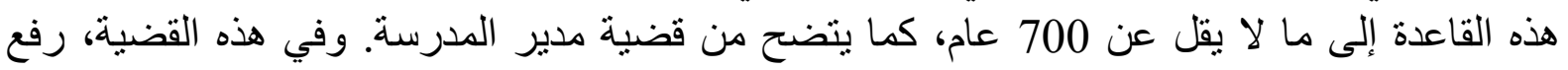

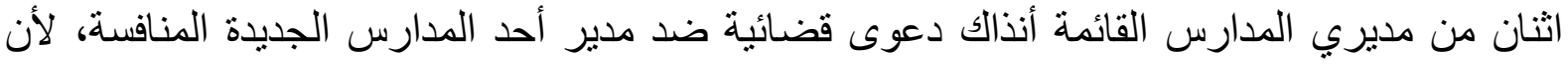

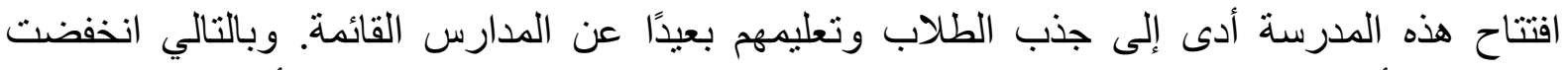

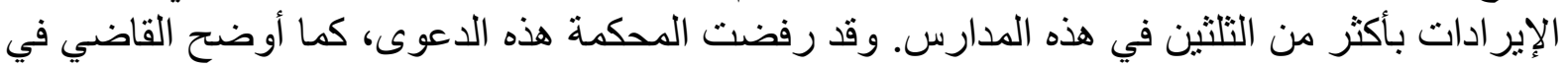

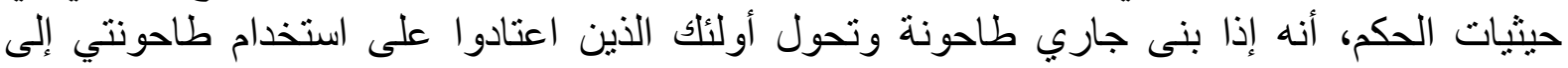

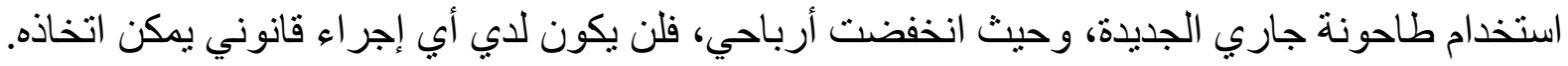

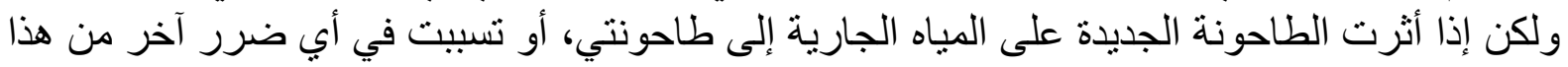
النوع، فسيكون لي حق اللجوء إلى القضاء الطئ وفقًا للقانون.

\section{ثالثًا: الأثار الخارجية ومفهوم الكفاءة الاقتصادية}

وقد تلى الفقه السابق134 حول مفهوم الأثار الخارجية بعض الكتابات حول الأثار الخارجية، وقد شكلت هذه التابه

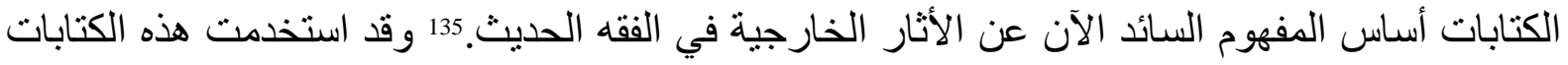

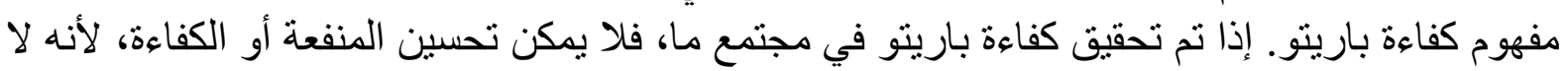

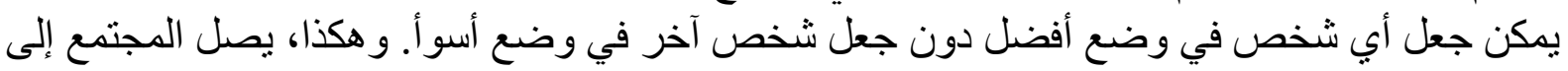
نقطة الإثباع.

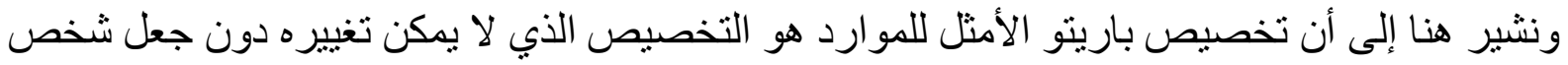

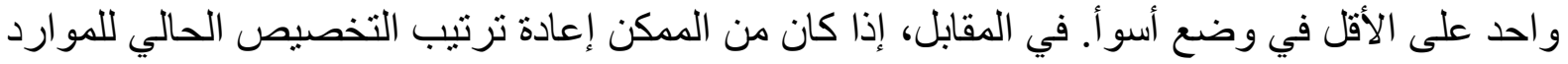

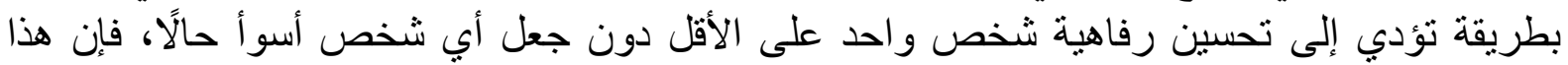

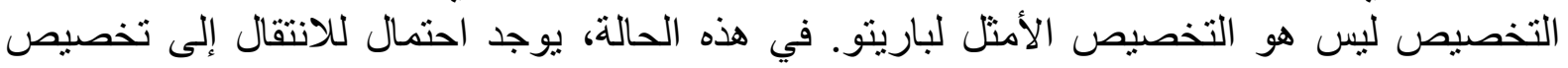

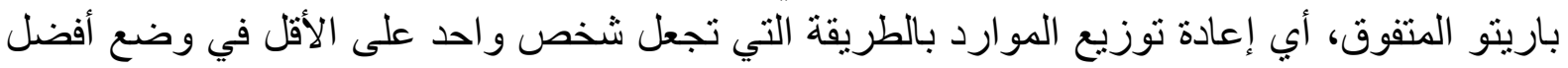

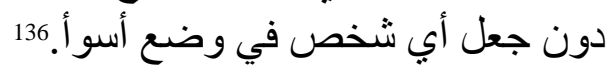

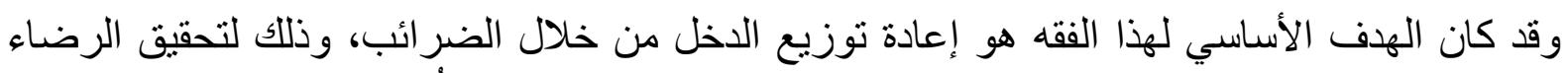

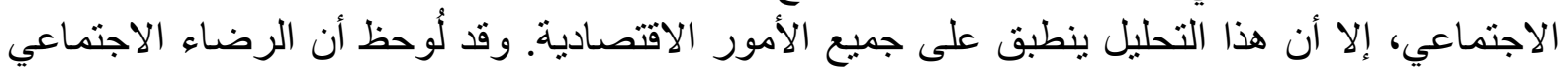

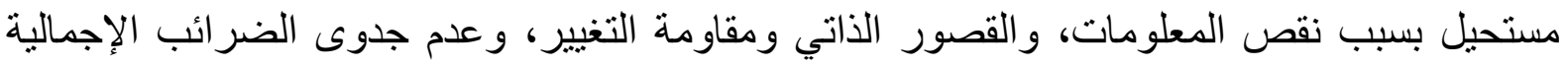

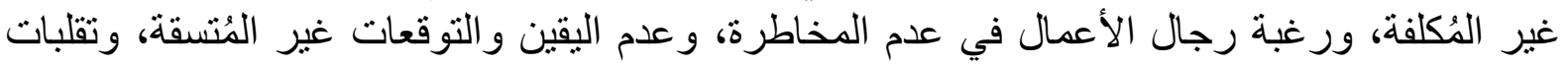

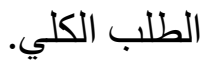

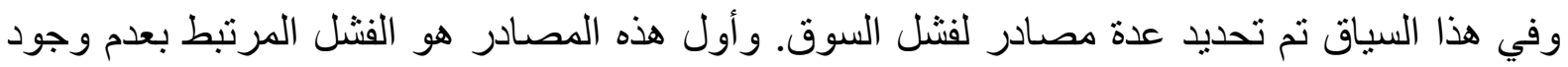
السوق بسبب نقص المعدلات الحدية المثالية للإحلال فيما ينعلق بنقاط المدخلات و المخرجات المات الو أو الإنتاج

\footnotetext{
${ }^{133}$ Hawk, Barry E., (2018). English Competition Law Before 1900, (February 2,). Antitrust Bulletin, Fordham Law Legal Studies Research Paper, P.6.

134 Tibor Scitovsky, (Apr., 1954), Two Concepts of External Economies, Journal of Political Economy, Vol. 62, No. 2, P. 141.

${ }^{135}$ Francis M. Bator, (1958). The Anatomy of Market Failure, 72 Q.J. ECON. 35, P.352.

136 Sidgwick, H. (2011). The Principles of Political Economy (Cambridge Library Collection Philosophy). Cambridge: Cambridge University Press, P. 255.
} 


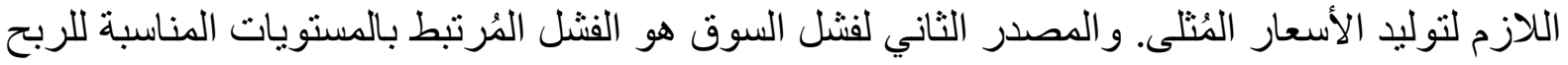

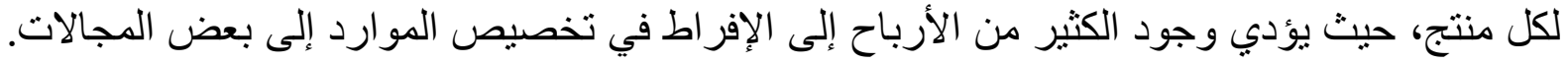

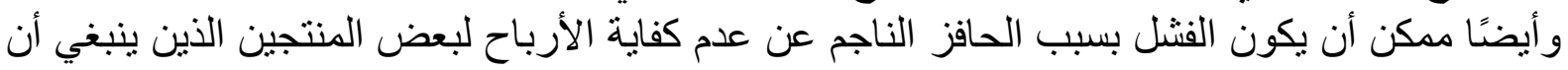

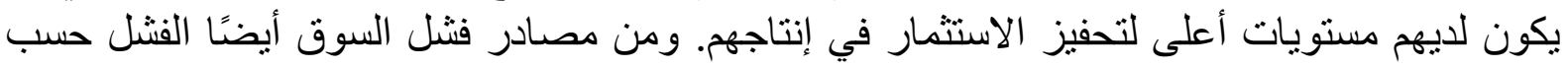

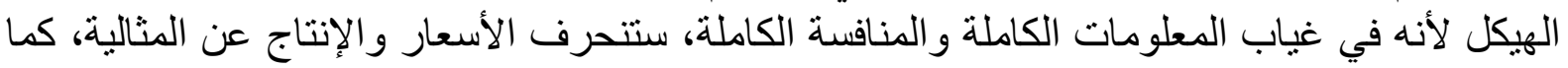

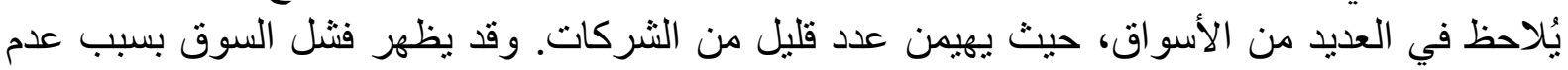
التنفيذ الر اجع إلى الثغر ات القئل القانونية والتنظيمية.

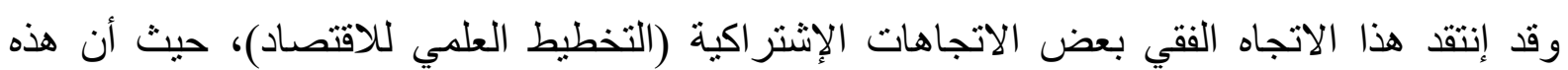

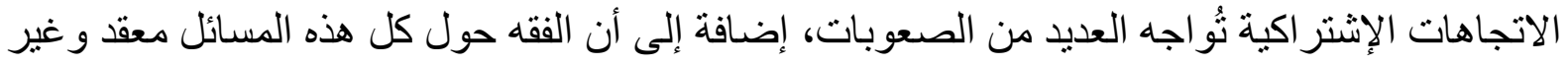

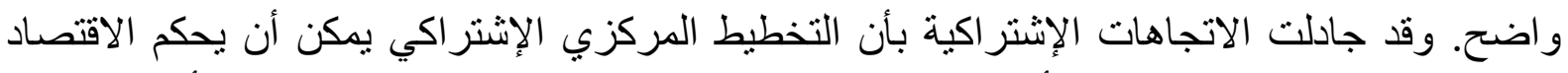

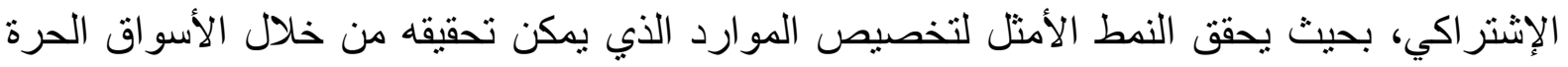

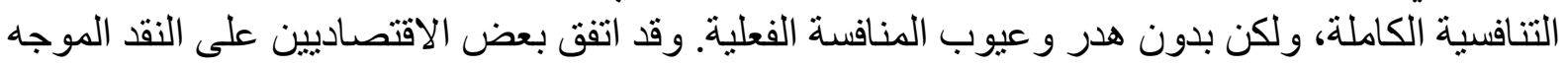

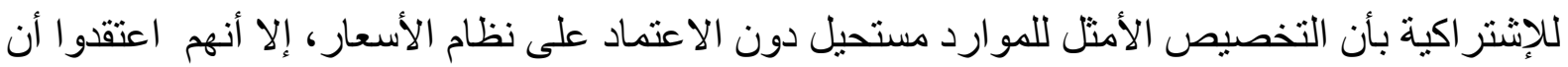

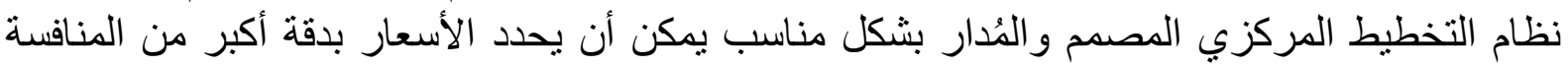
الو اقعية بين البائعين و المشترين في القطاع الخاص.

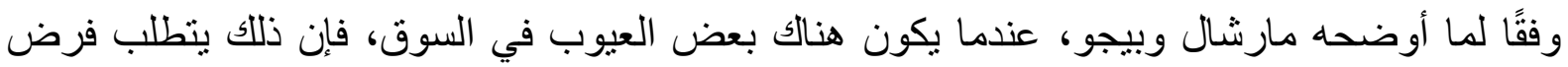

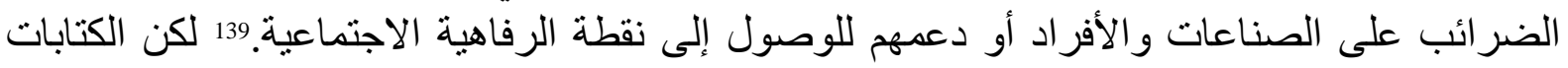

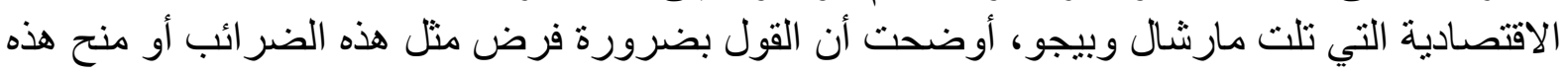

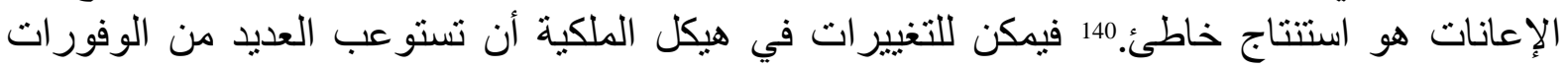

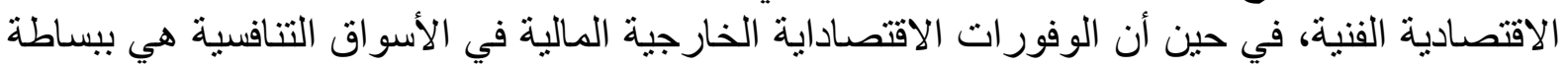

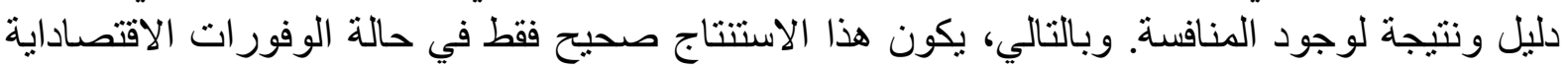

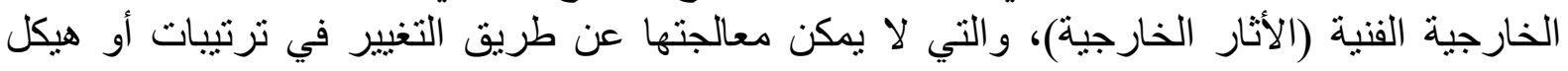

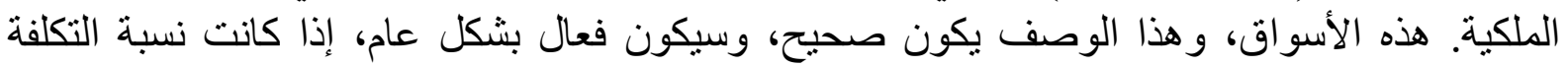

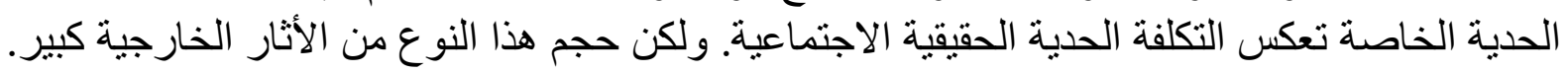

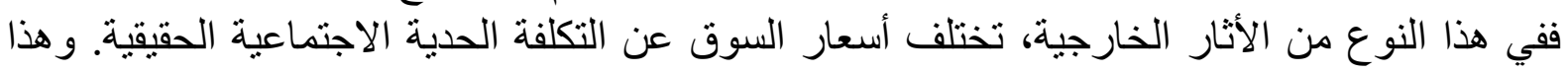

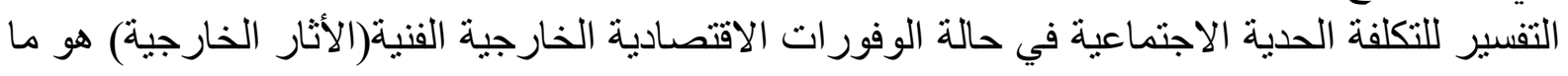
يجذب اهتمام الاقتصاديون منذ ذلك الوقت التان.

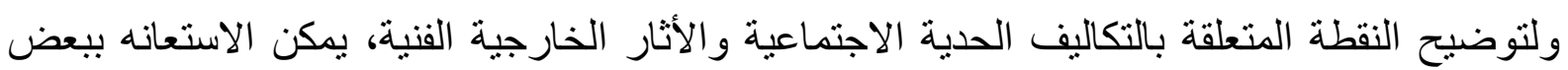

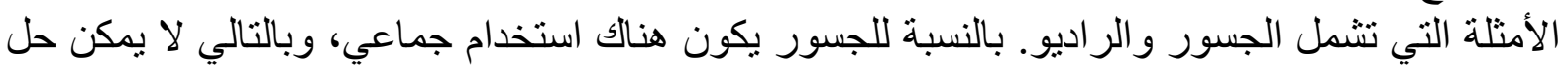

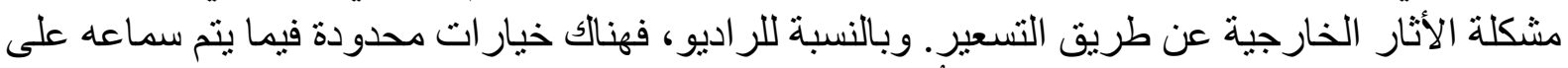

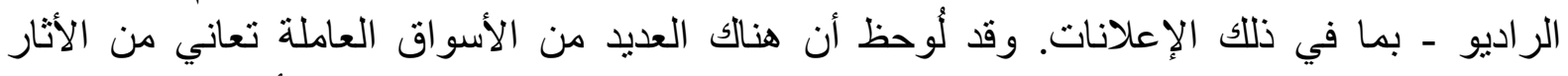

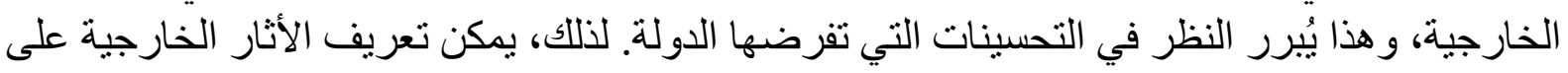

\footnotetext{
${ }^{137}$ Francis M. Bator, (1958). The Anatomy of Market Failure, 72 Q.J. ECON., P. 354.

138 Don Lavoie, (1985). Rivalry and Central Planning: The Socialist Calculation Debate Reconssidered, New York: Cambridge University Press, P. 152.

${ }^{139}$ Francis M. Bator, (1958). The Anatomy of Market Failure, 72 Q.J. ECON., P. 357.

${ }^{140}$ Frank H. Knight, (1924). Some Fallacies in the Interpretation of Social Cost, 38 Q.J. ECON., P. 582.
} 
أنها أي موقف تظل فيه بعض التكاليف والفوائد خارجة عن حسابات الأسعار اللامركزية للتكلفة

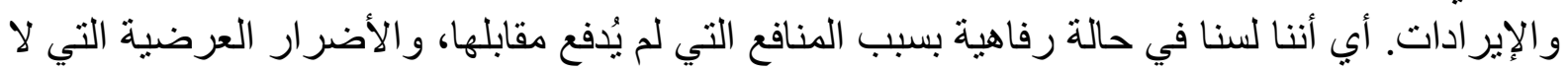
يتم تعويضها، و التي تشكل جو هر فنشل السوق.

ووفقًا لهذا الفقه، فقد تم تقسيم الأثار الخارجية إلى ثلاث فئات، وأحيانًا تكون هذه الفئات متداخلة. أولاً،

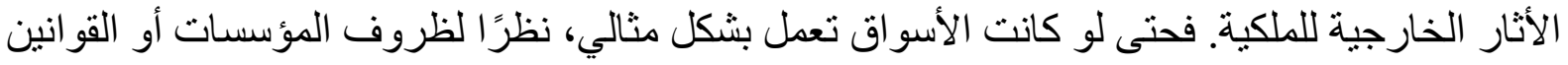

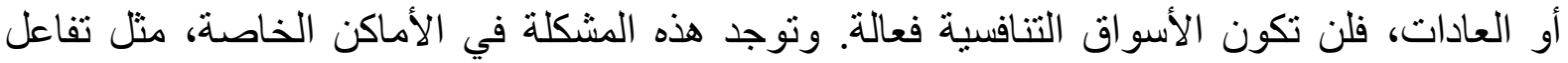

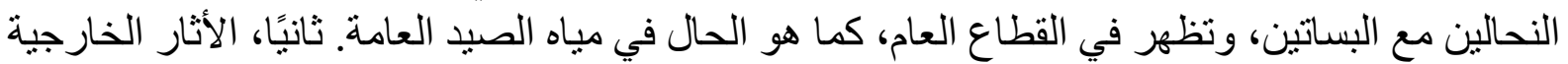

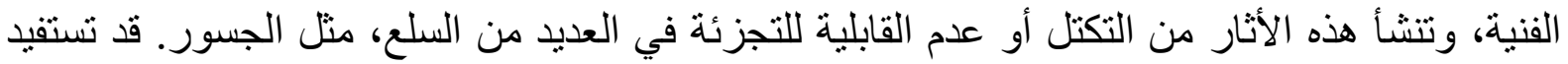

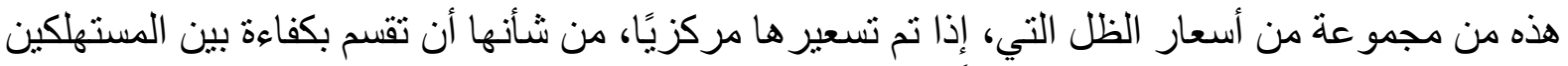

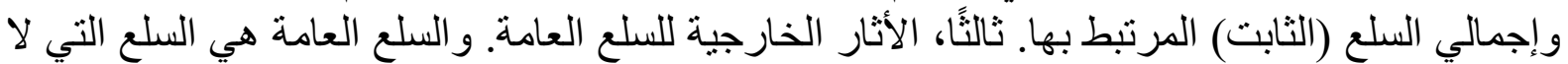
يؤثر فيها استهلاك شخص ما على استهلاك شخص آخر.

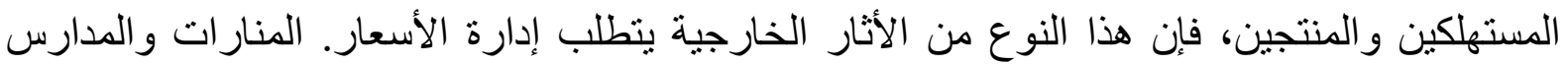

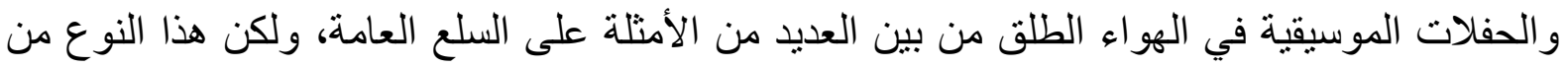

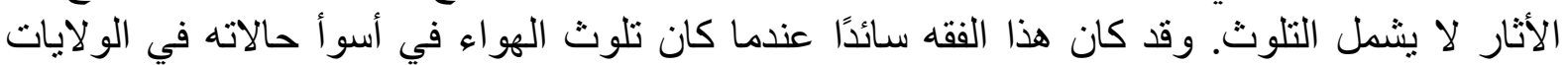

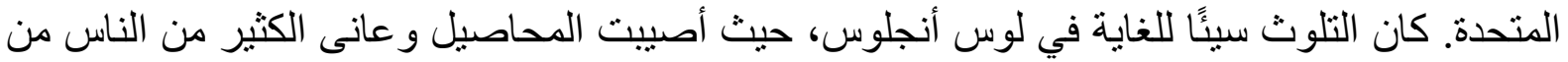

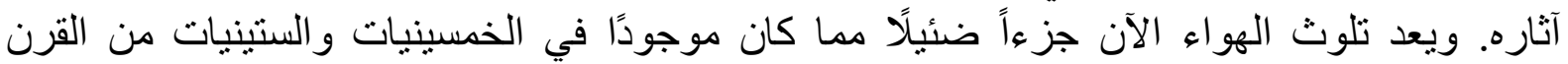

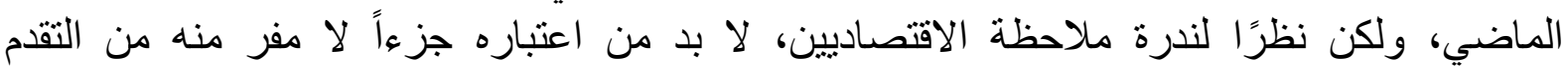

\section{رابعًا: مفهوم الأثار الخارجية وفقًا لققه كواس}

وبعد هذه المرحلة الفقهية التي تم فيها تعريف الأثار الخارجية وتقسيمها إلى عدة أنواع، ظهر الفقه

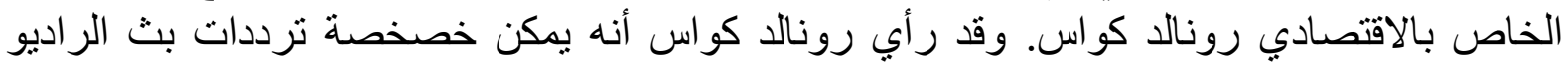

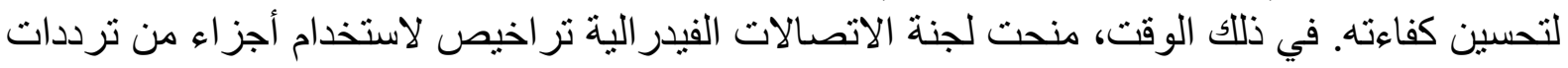

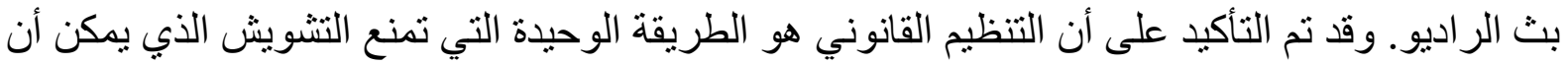

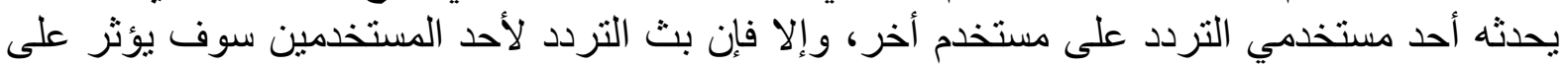

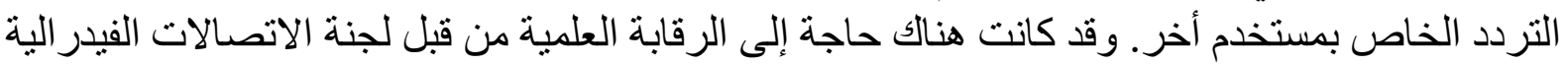

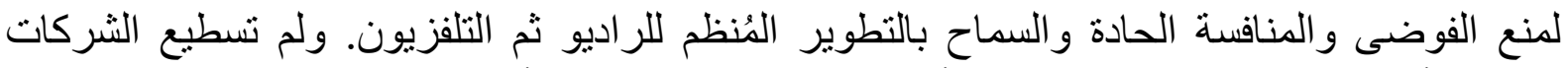

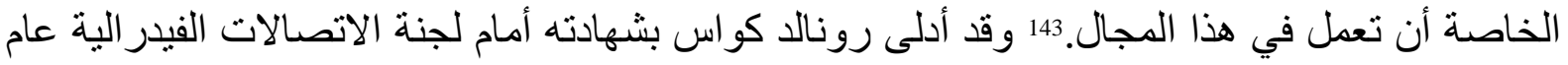
1959، ور أى أنه يمكن خصخصة في هذه ترددات الر اديو بكفاءة. هذه الفكرة الغريبة التي اقترحها كواس، حتى أن أحد المفوضين سأله عما إذا كان الإقتر اح مزحة كبيرة المفئ

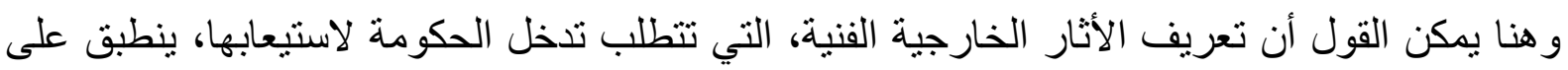
مضمون الأثنار الخارجية المتعلقة ببث تردد الراديو. وما لاحظه رونالد كواس هو أن الحكومة كانت

\footnotetext{
${ }^{141}$ Francis M. Bator, (1958). The Anatomy of Market Failure, 72 Q.J. ECON., P. 357.

${ }^{142}$ Paul Samuelson, (1955). Diagrammatic Exposition of a Theory of Public Expenditure, 37 REV. ECON. \& STAT, P. 350.

${ }^{143}$ Ronald H. Coase, (1959). The Federal Communications Commission, 2 J. L. \& ECON. 1, P.13.

${ }^{144}$ Ronald H. Coase, (2015). Testimony to the Federal Communications Commission, 2 MAN \& ECON. 1, P.22.
} 
تسيطر على منح التراخيص، وبالتالي لم يتم تسليم التراخيص القيّمة بشكل عشوائي؛ كانت هذه أنه التراخيص تذهب إلى أصحاب المصالح، مما سمح لهم بالحصول على مكاسب غير عادية. وقد أوضح

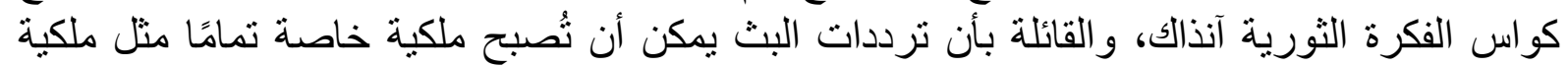

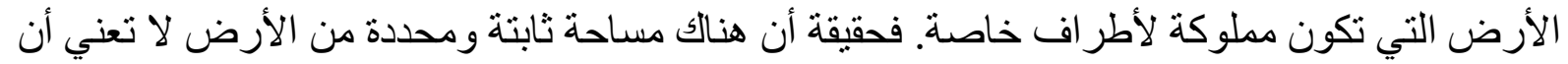

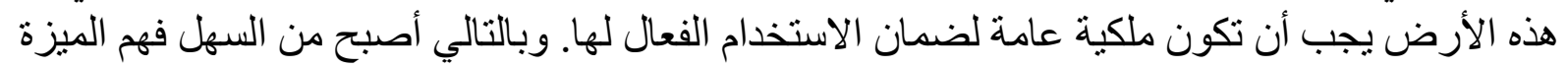

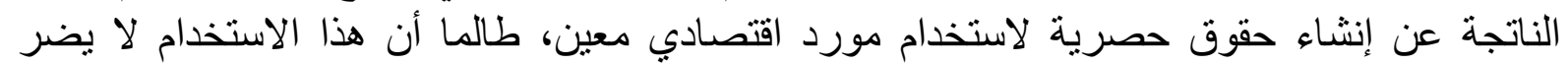

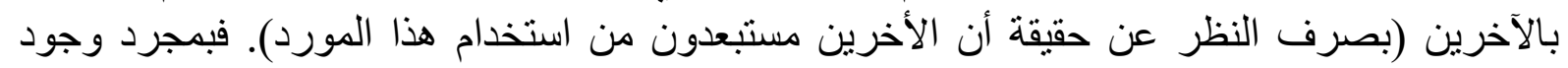
حقوق الملكية الخاصة، قد تتفاوض الأطر اف المالكة لهذه الحقوق حول كيفية استخدام الممتلكات، حيث الاثن ينتهى الأمر بالطرف الذي يُعطي أعلى قيمة لجزء من الملكية إلى إمتلاك هذا الجزء الأهو

وفي الأوراق التي قُدمت للجنة الاتصالات الفيدرالية، أوضح كواس نظريته، والتي تتضمن أنه في

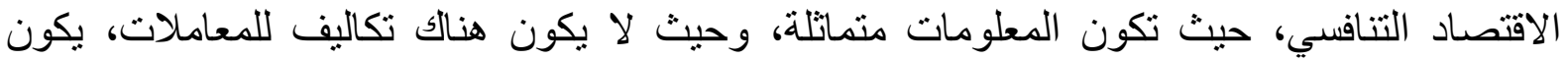

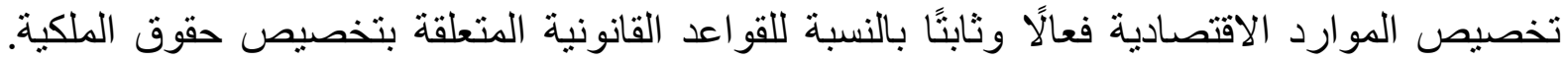

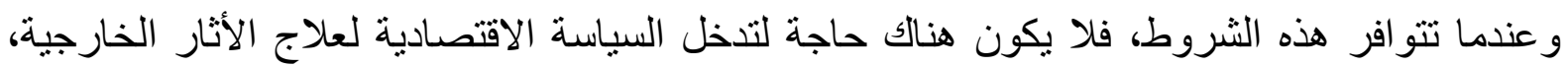
وذللك باستثناء التنخل لضمان أن حقوق الملكية محددة بوضوح وندان ومحية.145 ولتوضيح هذه النظرية استخدم كو اس وقائع بعض القضايا.146 وتتضمن هذه الوقائع استخدم صاحب مصن مصنع الحلو ايات لممتلكاته

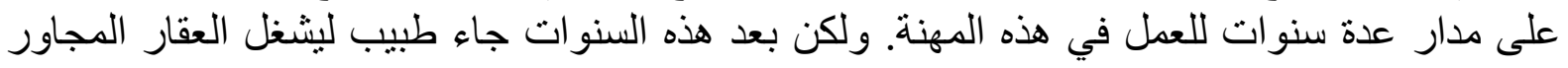

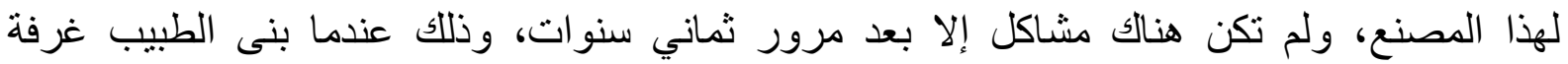

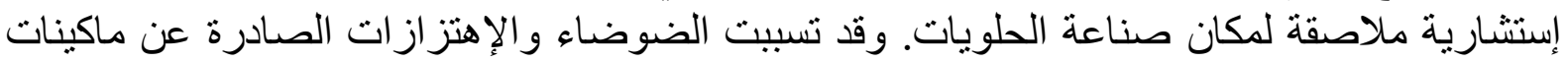

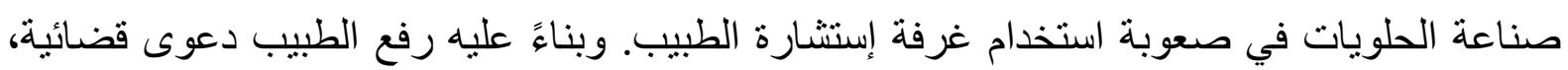
وحصل على أمر قضائي ضد هذا النوع من استخدام الملكية. 147

ولم ثُركز هذه النظرية على فنثل السوق الناتج عن التكتل الاقتصادي أو هيمنة الثركات أو الأثار

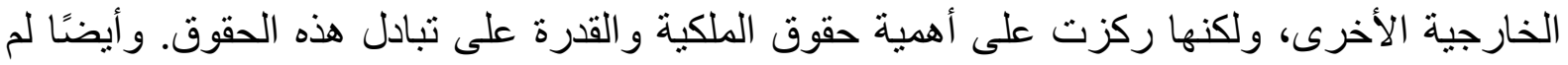

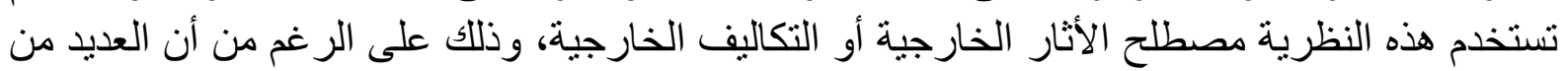

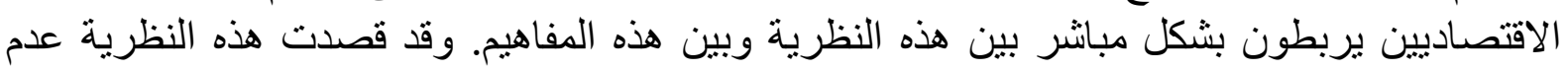

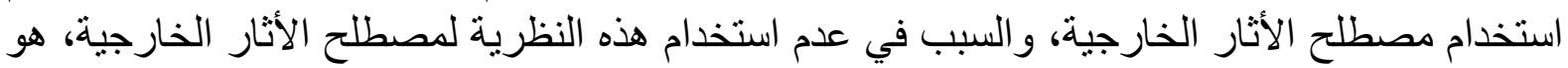

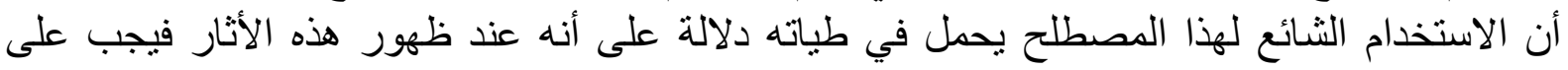
الحكومة أن تتخذ بعض الإجر اءات لمنعها. و السبب الوحيد لعدم الحاجة إلى اتخاذ أي إجر اء لـاء لمنع الأنار

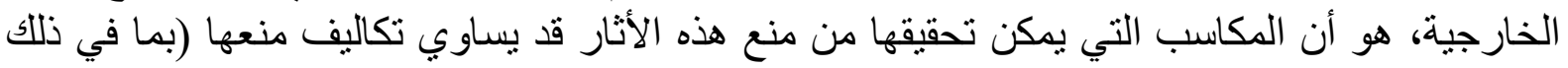

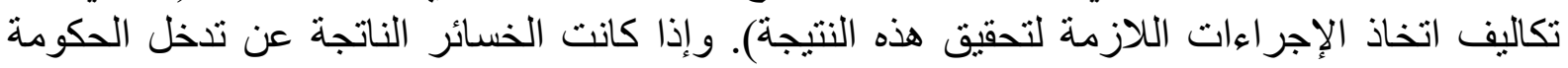
للقضاء على الأثار الخارجية تتجاوز المكاسب الناتجة عن هذا التدخل، فمن الأفضل عدم استيعاب الأثار

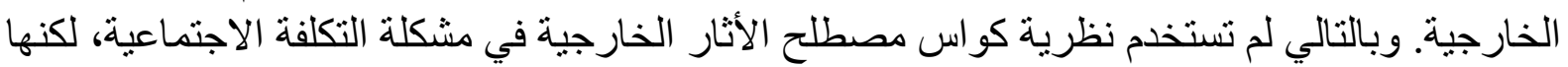
تحدثت عن الأثار الضارة دون تحديد ما إذا كان صانع القرار يأخذها في الاعتبار أم لا. 148

\footnotetext{
${ }^{145}$ Coase Theorum, A Dictionary of Econ. (3d ed., 2013); see Henry Mohrman, (2015). Coase on the Coase Theorem, 'The Social Cost Controversy, 2 MAN \& ECON. 215.

${ }^{146}$ Sturges v. Bridgman, 11 Ch. D. 852 (1879).

${ }^{147}$ Ronald H. Coase, (1959). The Federal Communications Commission, 2 J. L. \& ECON., P.26.

${ }^{148}$ Ronald H. Coase, (1988). The Firm, The Market, and the Law 26-27; Herbert Hovenkamp, (2009).

The Coase Theorem and Arthur Cecil Pigou, 51 ARIZ. L. REV, P.634.
} 
وقد تناولت نظرية كواس بشكل مباثر اقتصاديات الرفاهية لبيجو، والتي تُركز على الفرق بين التكاليف

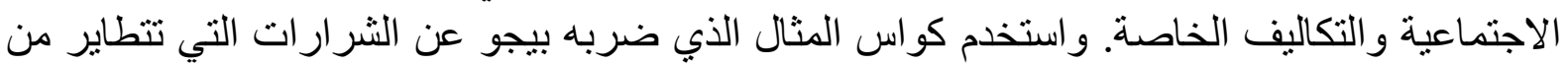

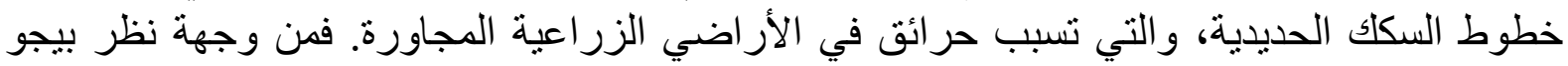

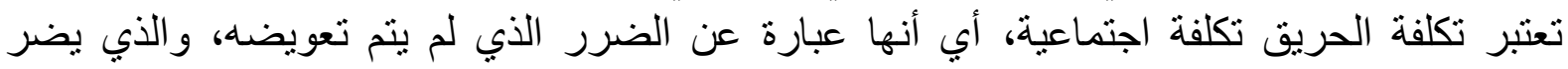

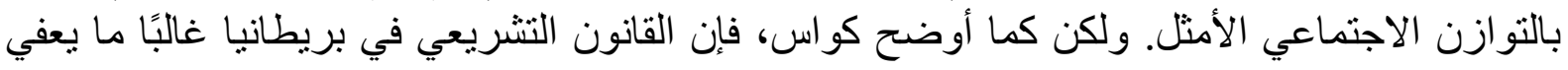

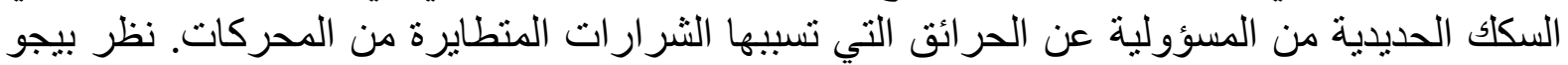

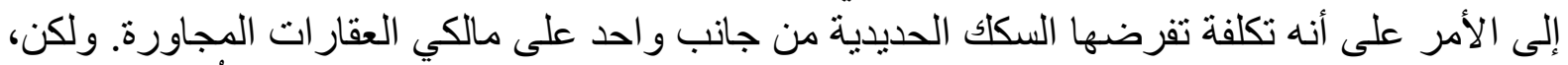

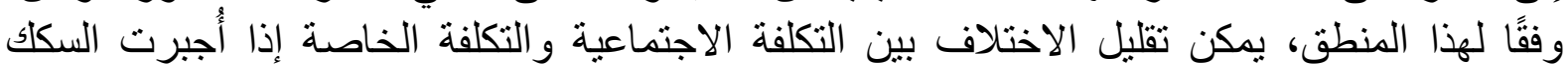

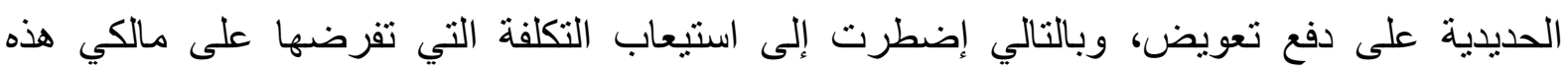
الأراضي.

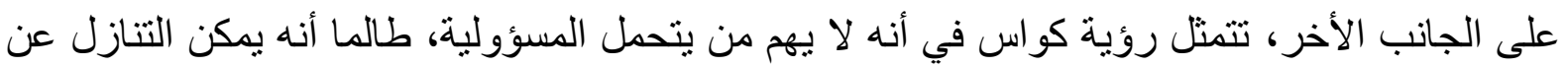

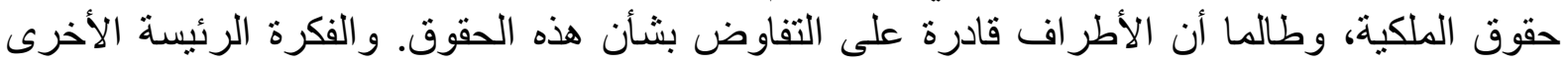

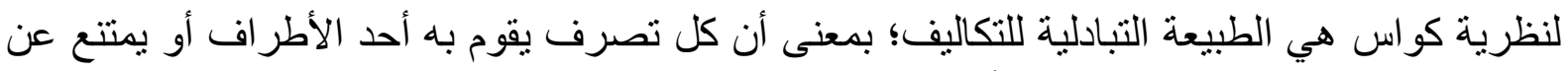

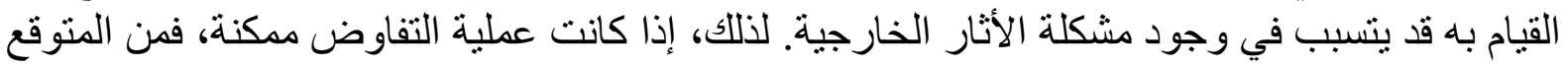

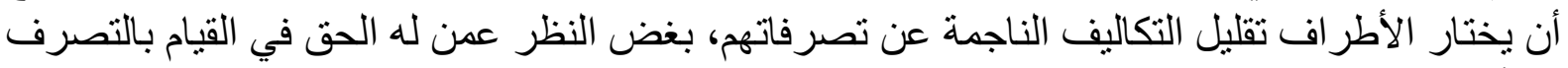

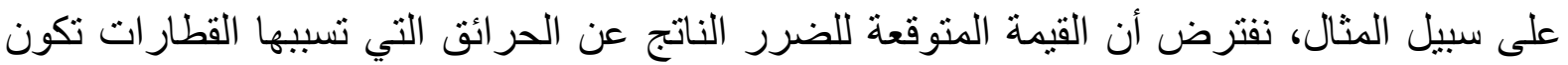

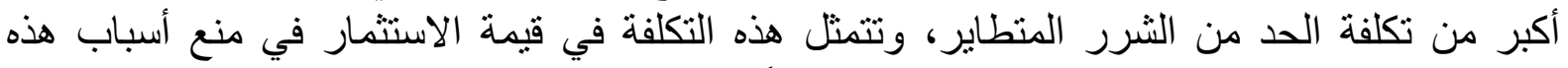

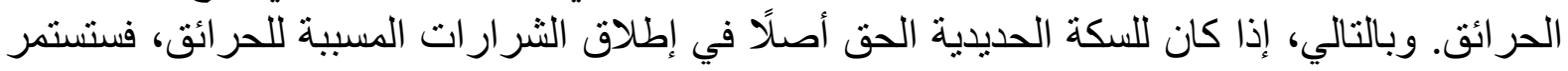

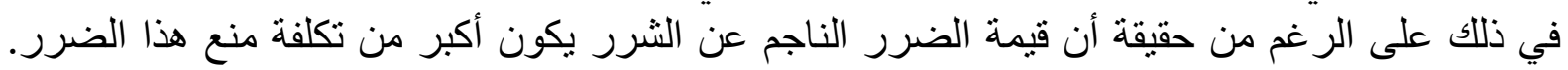

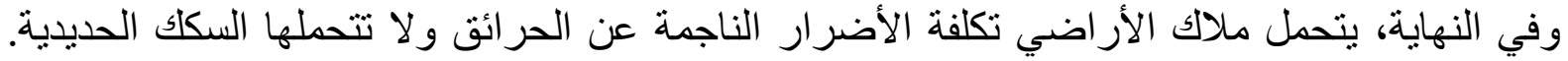

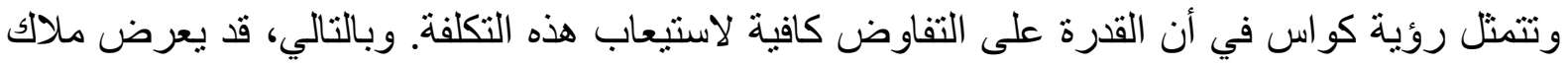

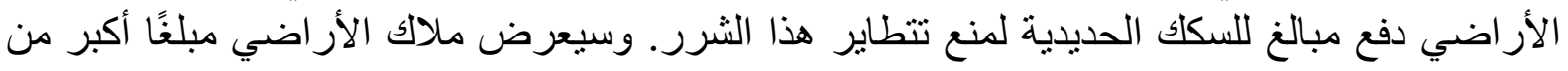

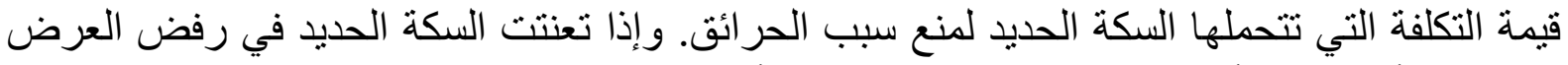

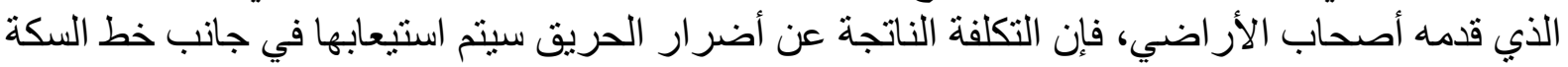

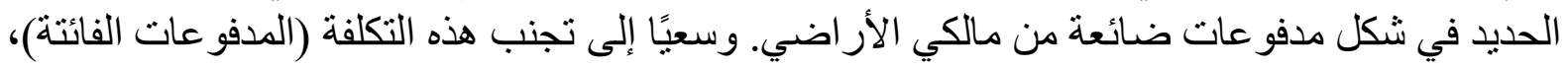

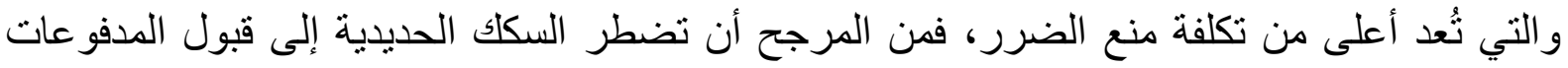

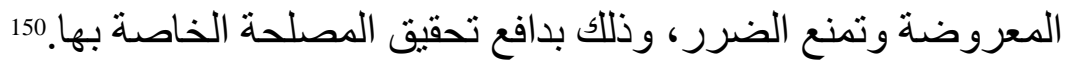

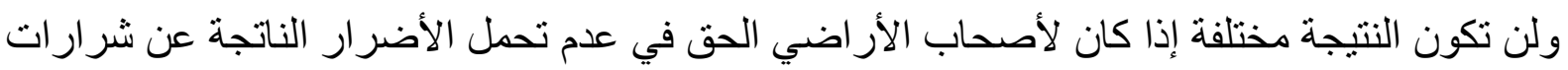

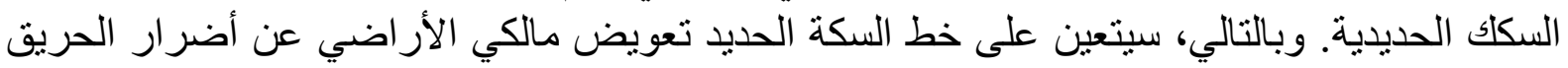

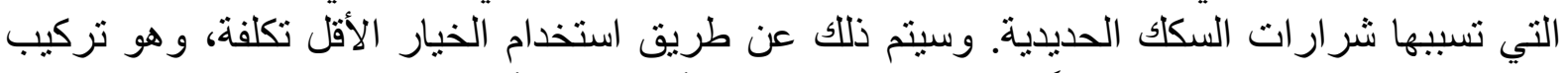

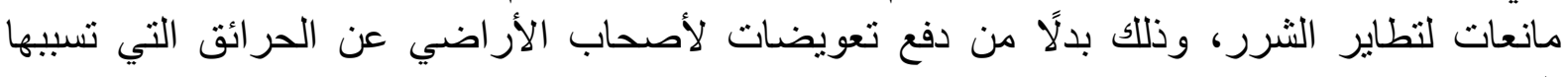

${ }^{149}$ Ronald H. Coase, (1960). The Problem of Social Cost, 3 J. L. ECON. 1, P.29.

${ }^{150}$ Ronald H. Coase, (1960). The Problem of Social Cost, 3 J. L. ECON. 1, P.34. 
وقد إنتقد كواس بيجو لعدم تحققه من القانون المتعلق بمسؤولية السكك الحديدية قبل شجب ما خلص إليه

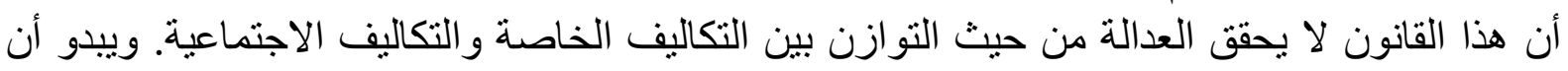

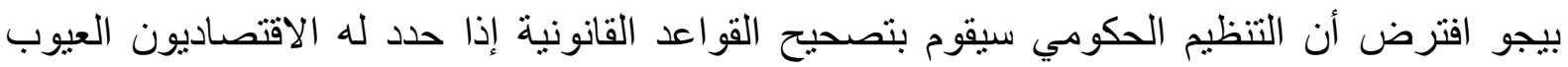

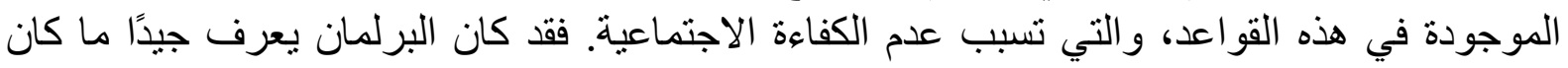

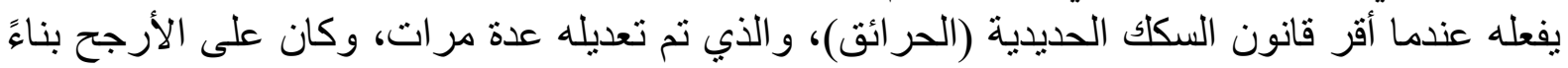

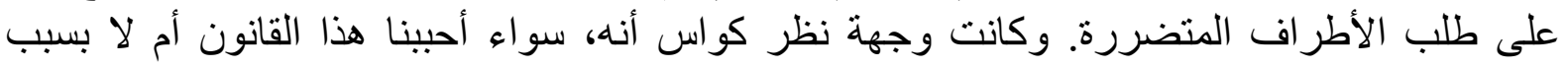
أصوله التشريعية، و الذي قد بعكس مصالح سياسية خاصة، فقد أسست هذ القانون حقوق الملكية، وكان للأطر اف الحرية في أخذه في الاعتبار عند تأسيس وتنظيم نشاطهم الاقتصـادي.

وقد رفض كواس تحذير بيجو من ضعف أداء الوكالات الحكومية، ووصفه بأنه لا بعكس ثقة بيجو في مثل هذه الوكالات. وقد استشهد كواس بتفاؤل بيجو بشأن التحسينات في الديمقر اطبة والإدارة العامة، لوفية وخاصة ظهور لجنة تنظيمية مستقلة في بعض الدول، مثل الو لايات المتحدة الأمريكية و المملكة المتحدة، وأن هذه التحسينات كافية لضمان أن الحكومة ستنفذ مهام تصحيح فنش السوق بطريقة غير سياسية

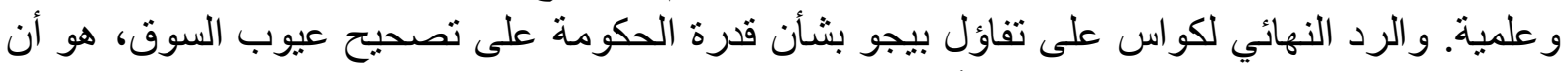
الاقتصاديين و المسؤولين الحكوميين لا يأخذون على محمل الجد بلدئ بائل التدخل التنظيمي.

إن القول بأن السياسيين وغيرهم من المسؤولين الحكوميين سوف يبتكرون الحل الأمثل لتصحيح

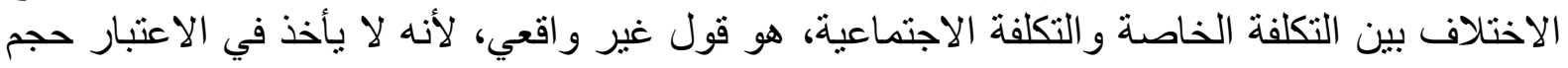

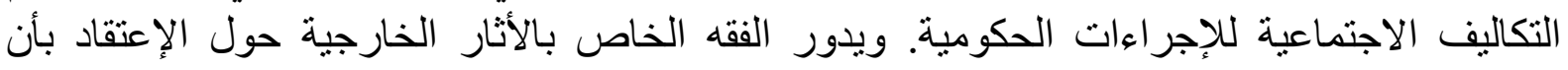

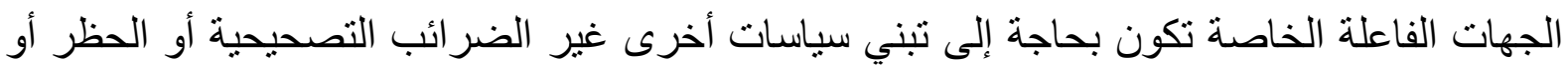

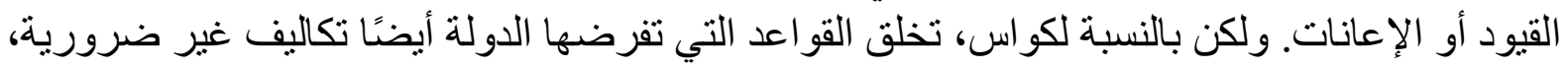
وخصوصًا عند تقييم هذه التكاليف من خلال نموذج مثنالي لا يأخذ في الاعتبار التكاليف الحقيقة

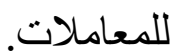

ووجهة نظر كواس هي أن القواعد التي تفرضها الدولة تكون غير فعالة عندما يُحكم عليها بنفس المعيار

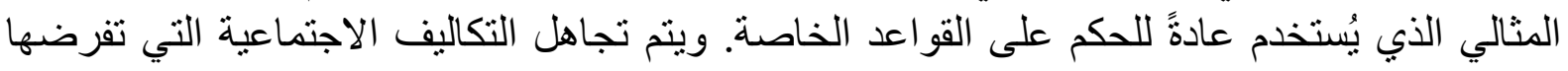

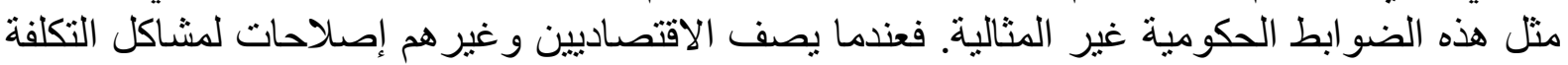

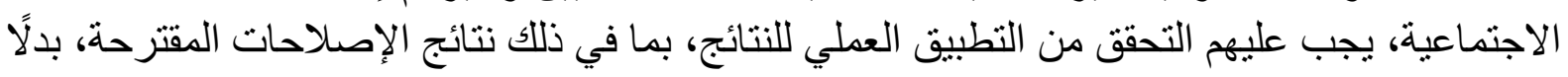

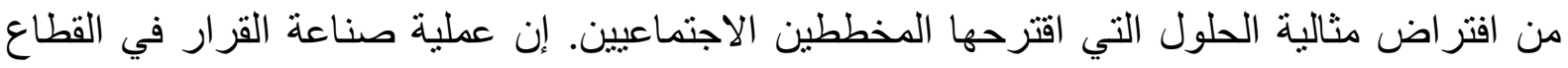
العام يشوبها العديد من الحوافز الضارة من وجهة نظر الكفاءة الاقتصادية. فعادة ما تقوم هذه العملية

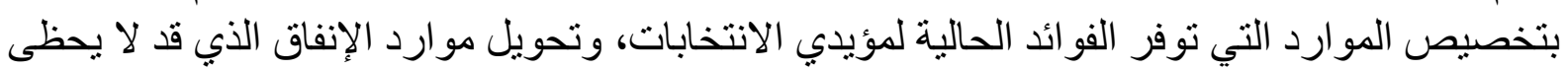
بدعم كبير حاليَّا، حيث أن فو ائد هذا الإنفاق لن تتحقق إلا على النى المدى البعيد.152

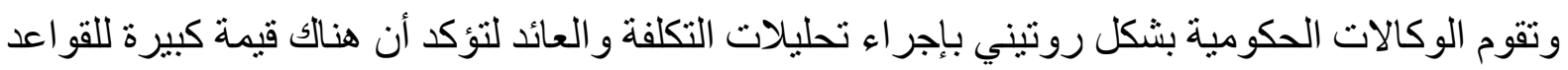
المفروضة، ولكن هذه التحليلات غالبًا ما تكون غير واقعية. 153 ويمكن أن يكون هنالك اختلاف كبير بين

151 Coase, R. H., (1990). "The Firm, the Market, and the Law," University of Chicago Press Economics Books, University of Chicago Press, PP.26-27.

${ }^{152}$ Donald J. Boundreaux \& Roger Meiners, (2019). Externality: Origins and Classifications, 59 Nat. Resources J. 1, P.16.

${ }^{153}$ Roger Meiners \& Rafal Czajkowski, (2014), Making Cost-Benefit a Political Tool, 3 LA. ST. U. J. ENERGY L. RESOURCES 225, P. 226. 
تقدير ات الاقتصاديين حول تكاليف الأحداث الاقتصادية وبين تقدير ات البر امج الحكومية لهذه الأحداث.154 يتم إجر اء الأرقام الخيالية بشكل روتيني لأيني لتعزيز القيم المزعومة.

وقد اعتقد العديد من الاقتصاديين، ومن بينهم بيجو، أن الضر ائب التصحيحية يمكن أن توفق بين التكاليف

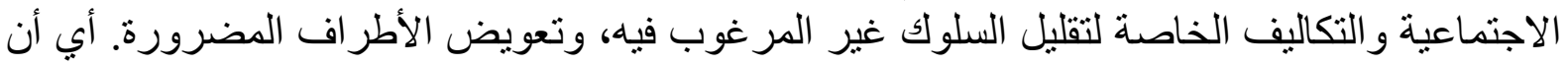

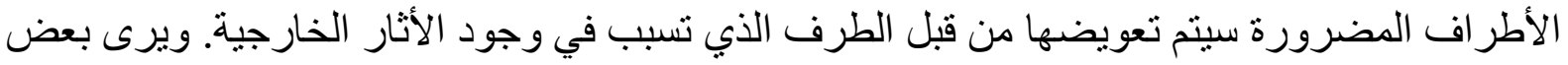

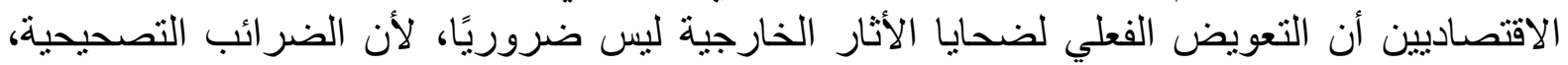
المحددة بدقة، كافية لتعديل سلوك الطرف المُنخرط في العمل غير المر غوب فئن فيه لتحسين الإنتاجية

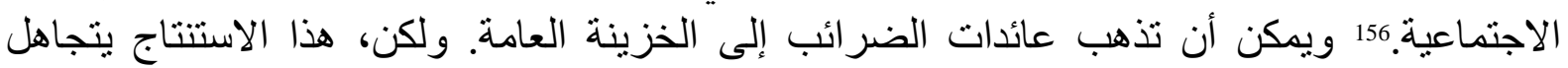
التكاليف الاجتماعية الناتجة عن استخدام الحكومة للموارد. ويرى بعض الإن الاقتصاديين أن هذه المشكلة

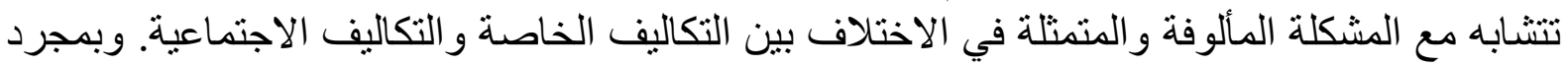

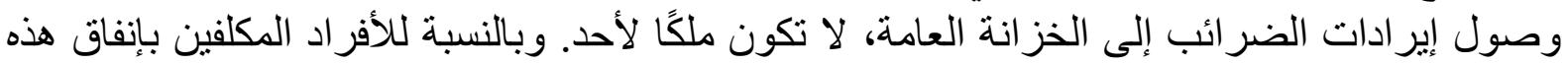

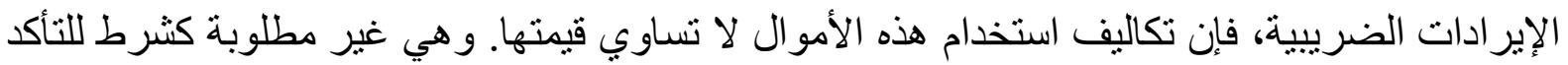

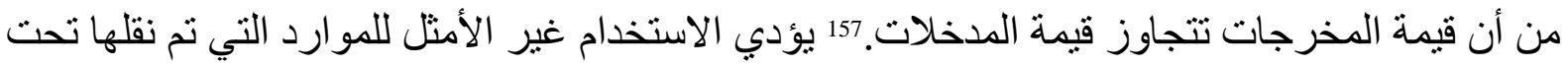

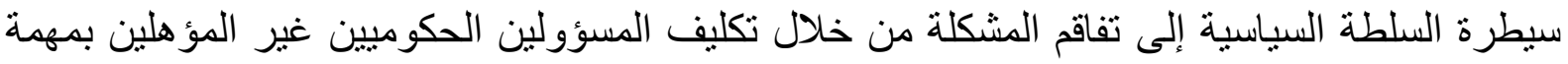

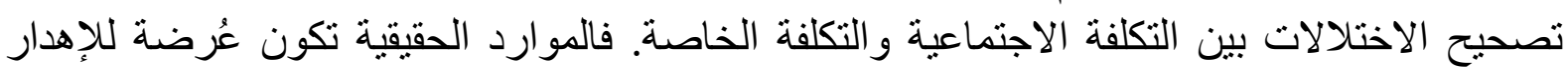

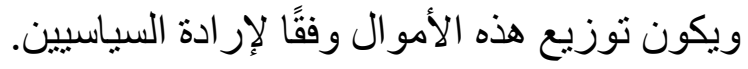

\section{خامسًا: الجدل التاريخي حول استيعاب الأثنار الاقتصادية الخارجية}

وبالعودة إلى تطور الفكر الاقتصادي حول الأثار الخارجية، في مرحلة لاحقة بدأ أحد الكُتاب (بوكانان)

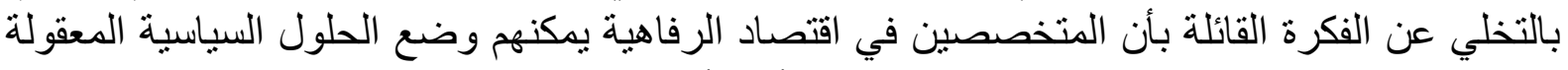

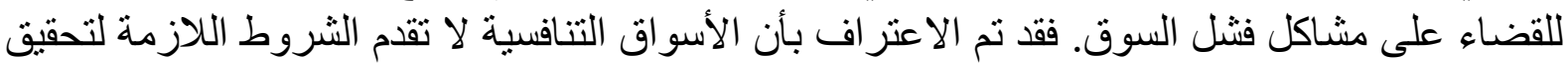

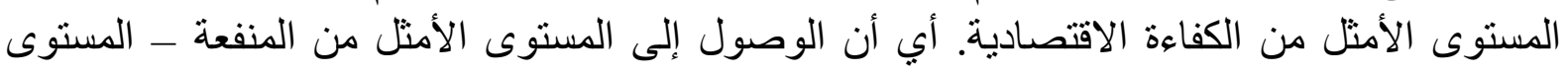

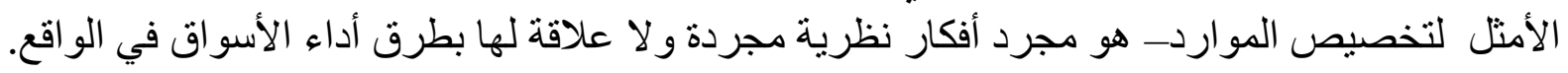

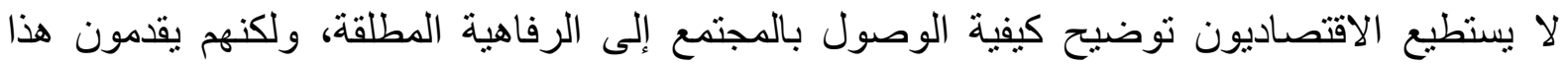

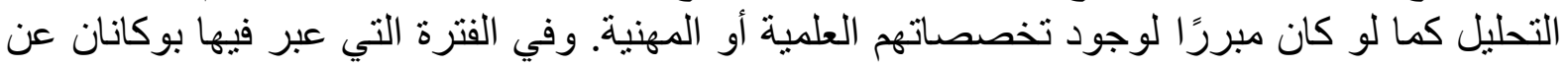

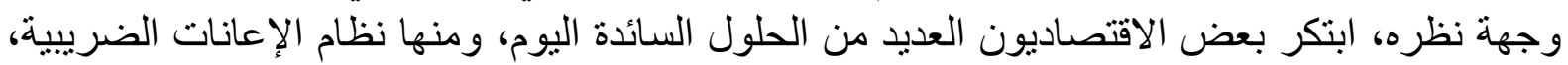

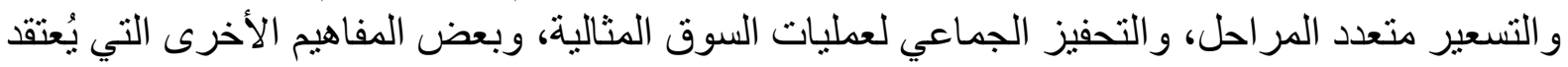
أنها تعزز الكفاءة الاقتصادية.

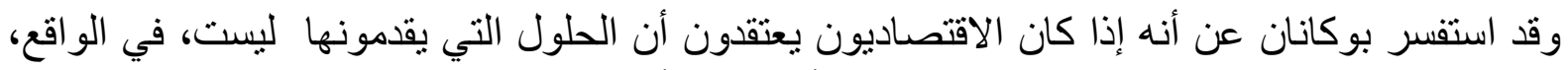
ذات صلة بالسياسة الاقتصادية، فلماذا إذن يجب أن يكلفوا أنفسهم عناء تطوير الأن مثل هذه المفاهيم؟ فليس

${ }^{154}$ Richard Bishop et al., (2017). Putting a Value on Injuries to Natural Assets: The BP Oil Spill, 356 SCI., P.253.

${ }^{155}$ Donald Boudreaux, Roger Meiners \& Todd Zywicki, (1999). Talk Is Cheap: The Existence Value Fallacy, 29 ENVTL. L. 765.

${ }^{156}$ Eytan Shekhinski, (2002). On Atmosphere Externality and Corrective Taxes, 88 J. PUB. ECON., P. 727.

${ }^{157}$ William Meckling \& Armen A. Alchian, (1960). Incentives in the United States, 59 AM. ECON. REV., P. 55.

158 James M. Buchanan, (1962). Politics, Policy and the Pigouvian Margins, 29 ECONOMICA 17, P. 18. 


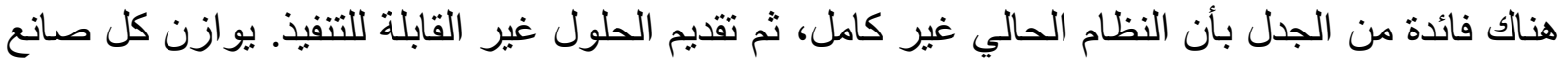

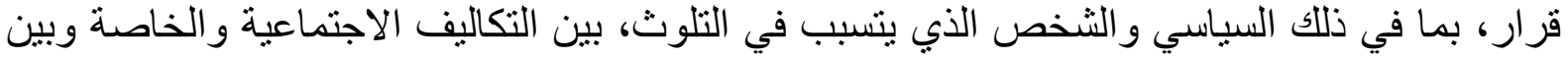

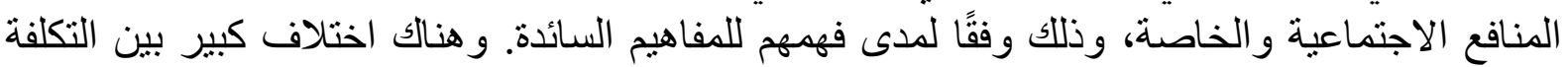

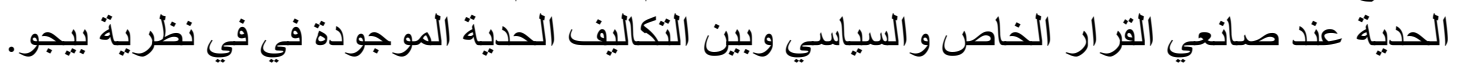

وقد قال بوكانان إنه لو افترضنا مجتمع معين يتم فيه تنظيم جميع الأنشطة بشكل خاص، باستثناء الأنشطة

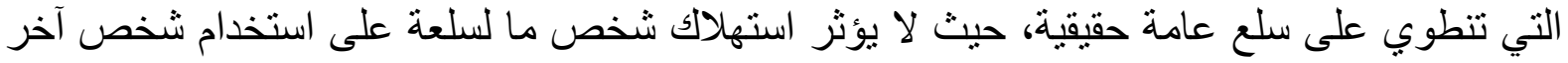

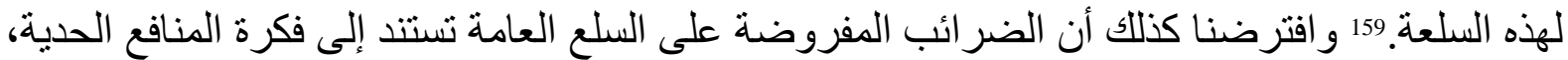

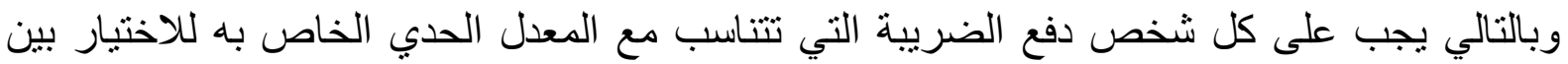

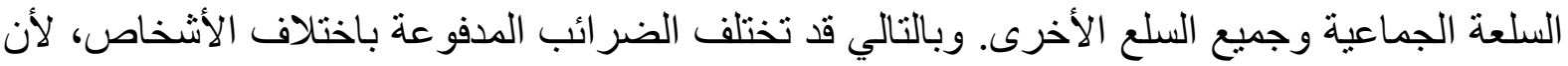

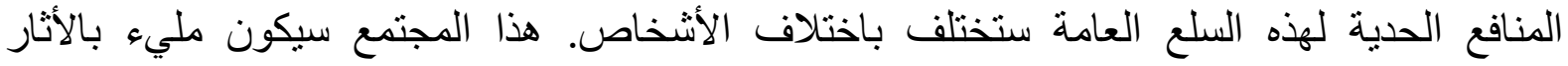

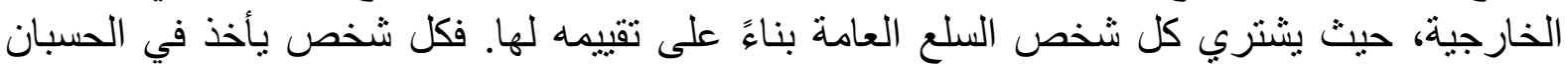

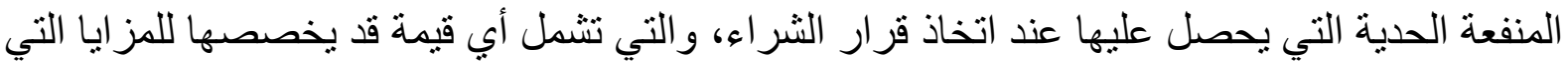

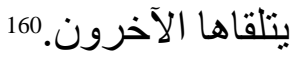

وبعد عدة سنوات، تحدث بوكانان عن كيفية استيعاب الأثار الخارجية، أو حلها، من خلال استخدام

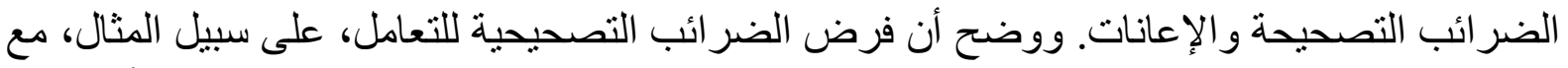

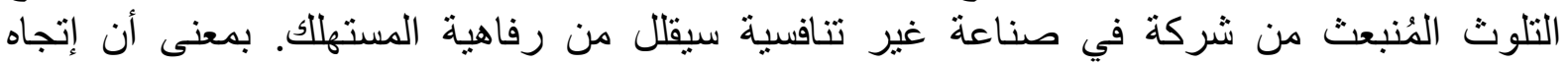

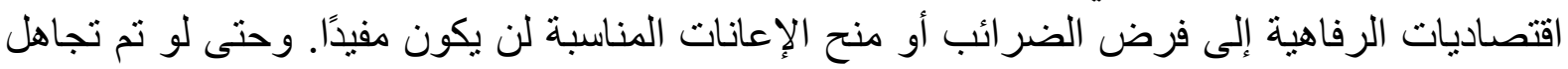

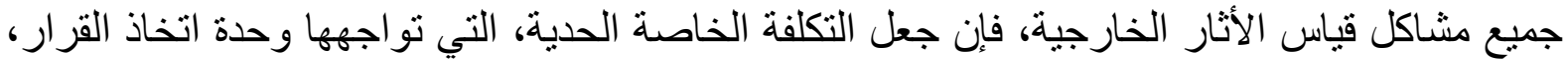
مساوية للتكلفة الاجتماعية الحدية، لا يوفر الحل السحري بانية بالنسبة لاقتصاد الرفاهية. 161

ولكن كان رد الاقتصاديين المؤيدين لنظرية بيجو على وجهة نظر بوكانان السابقة هو أنها تعتبر تشويه

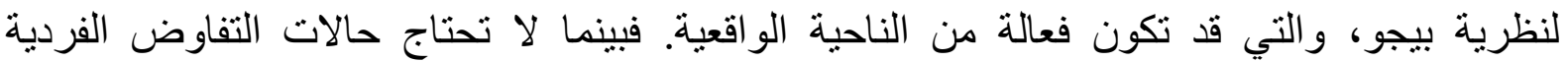

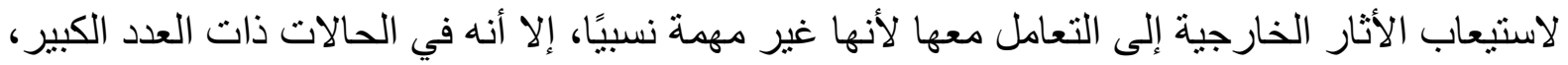

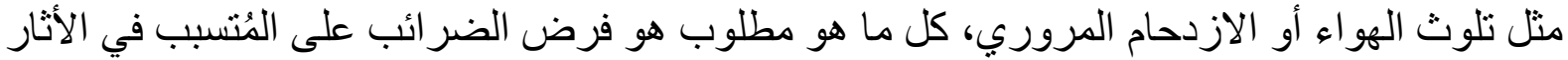

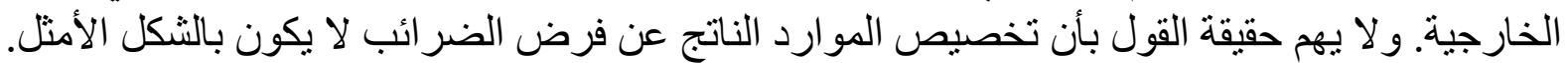
لأن الضر ائب و الإعانات على الأقل تُحسن من الوضع القائم، حتى لو لم تحقق مستوى الكفاءة الأمثل.

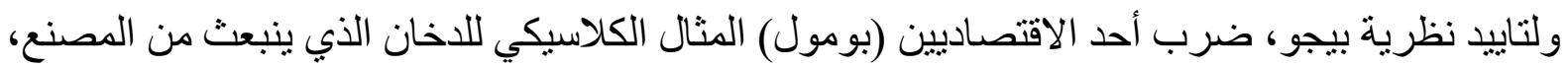

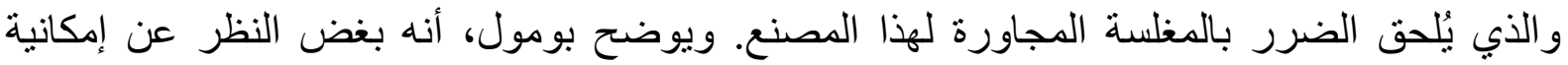

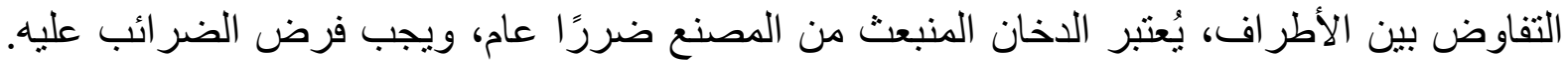

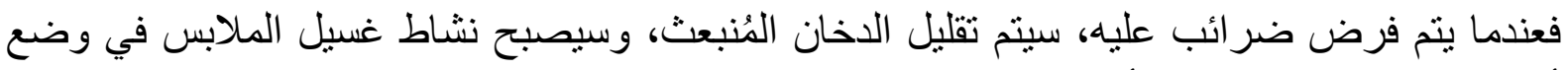

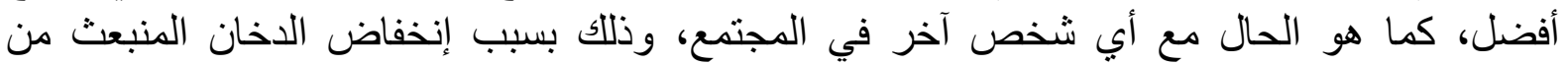

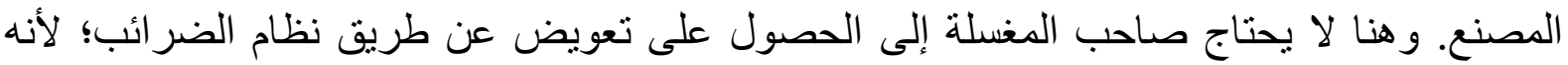

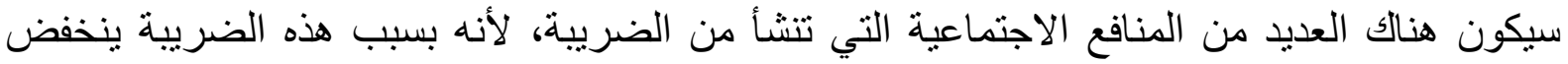

${ }^{159}$ Paul A. Samuelson, (1954). The Pure Theory of Public Expenditure, 36 REV. ECON. \& STAT.,P. 387.

${ }^{160}$ James M. Buchanan, (1962).Politics, Policy and the Pigouvian Margins, 29 ECONOMICA 17, P. 26.

${ }^{161}$ James M. Buchanan, (1969). External Diseconomies, Corrective Taxes, and Market Structure, The American Economic Review, Vol. 59, No. 1, PP. 174-177 
الدخان إلى المستوى المعقول. وفي المقابل، إذا كنا نريد زيادة إنتاج المصانع التي ينبعث منها الدخان

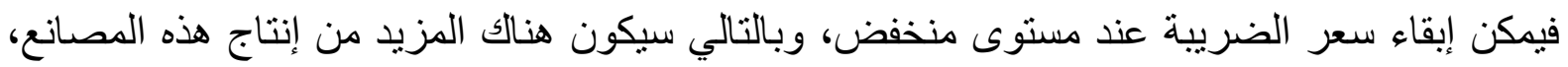

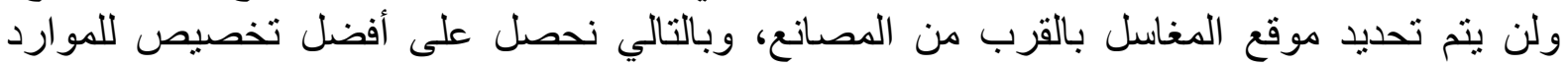

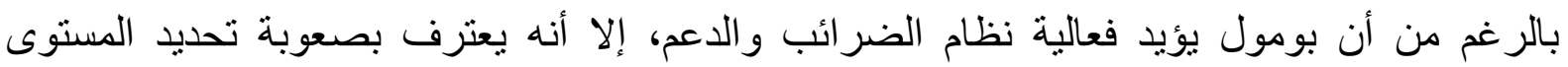

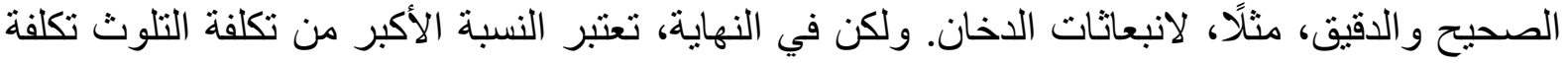

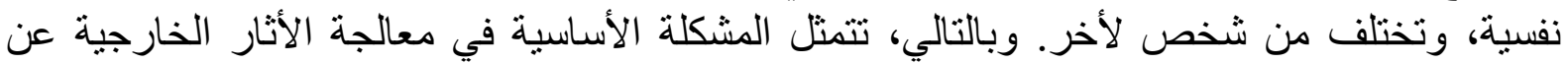

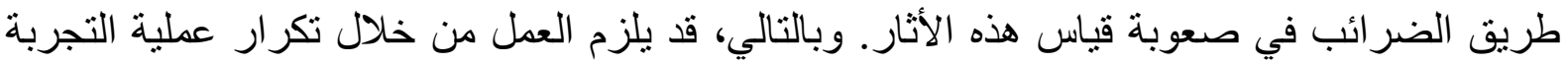
و الخطأ لمعدلات الضر ائب المختلفة للوصول إلى مستوى الإنتاج الأمثل من الناحية الاجتماعية.

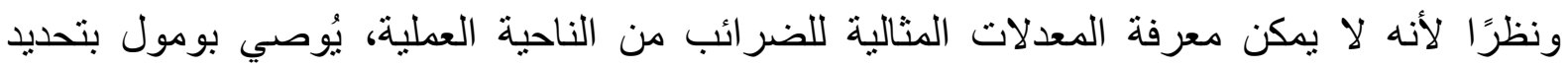

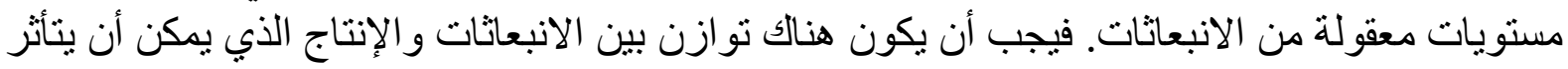

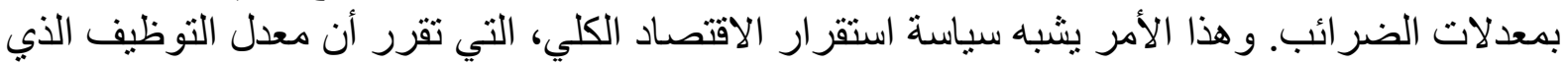

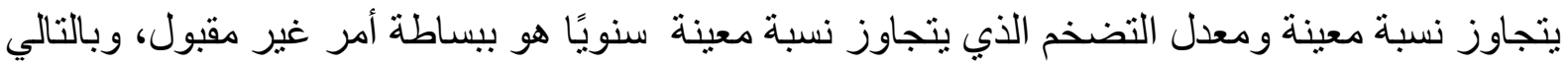

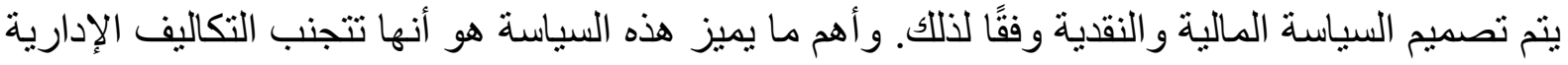

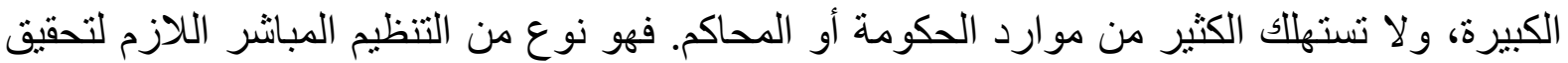

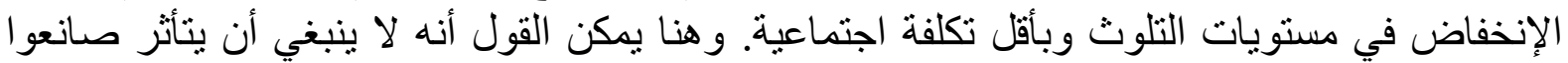

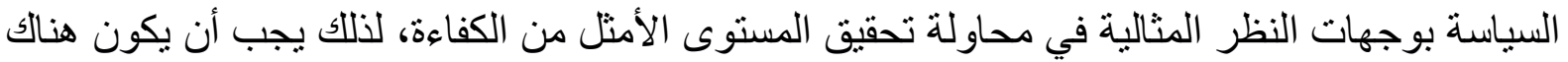
قو اعد مرنة تقود إلى الاتجاه الصحيح لمعالجة الأثار الخارجية.

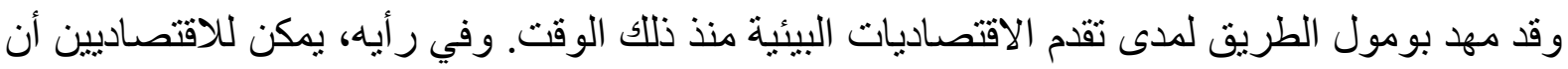

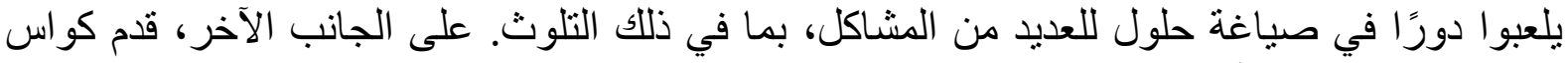

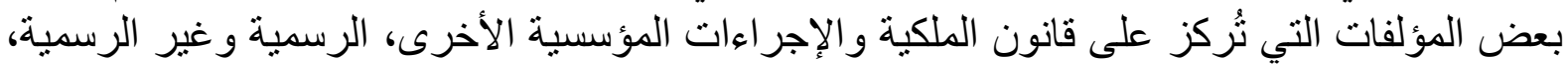
التي تعمل على حل النزاعات حول استخدام الموارد دون الحاجة إلى مر اسيم السلطة الهرمية. 164

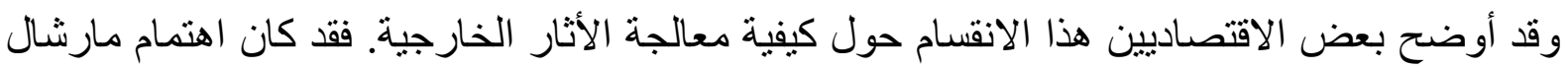

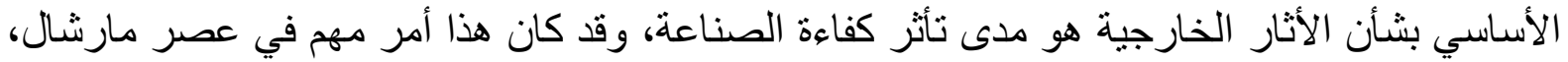

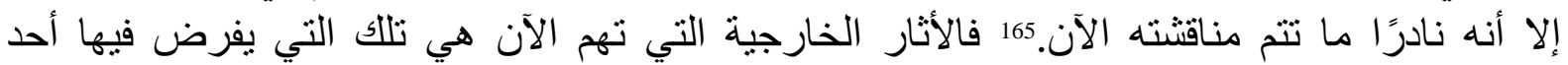

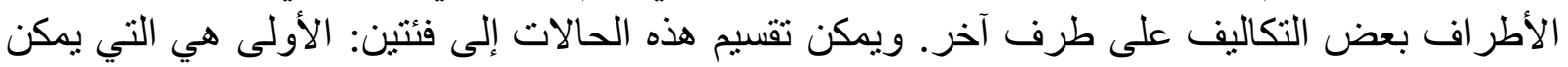

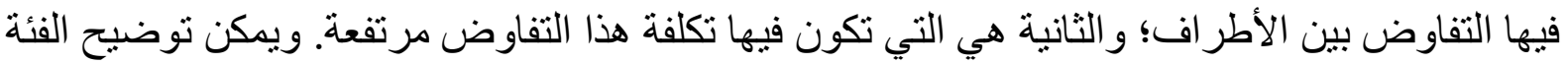

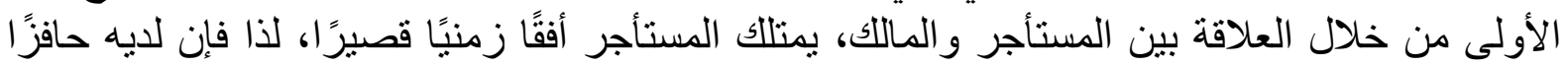

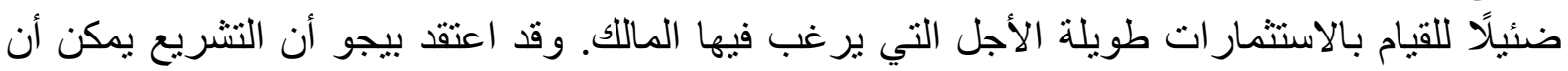

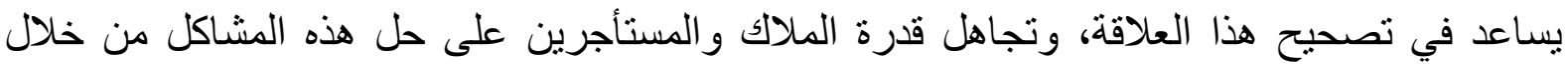

${ }^{162}$ William J. Baumol, (1972). On Taxation and the Control of Externalities, The American Economic Review, Vol. 62, No. 3, P. 307.

${ }^{163}$ William J. Baumol, (1972). On Taxation and the Control of Externalities, 62 AM. ECON. REV. 307, P. 319.

164 Ostrom, E. (1990). Governing the Commons: The Evolution of Institutions for Collective Action (Political Economy of Institutions and Decisions). Cambridge: Cambridge University Press, P.126.

${ }^{165}$ Harold Demsetz, (1996). The Core Disagreement between Pigou, the Profession, and Coase in the Analyses of the Externality Question, 12 EUR. J. POL. ECON. 565, P. 568. 
العقود التي يبرمونها مع بعضهم البعض. ولكن أصبح واضح الأن بثكل عام أن التفاوض، وفقًا لنظرية

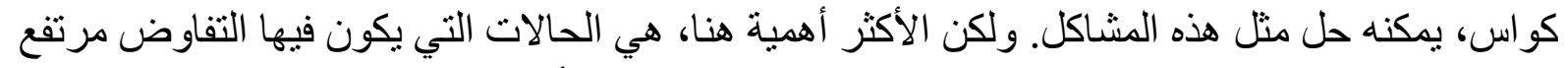

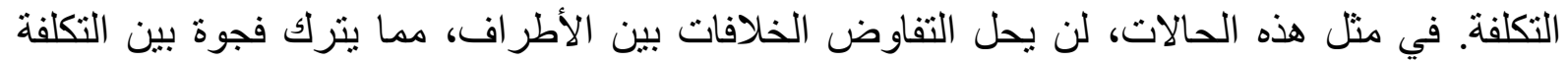

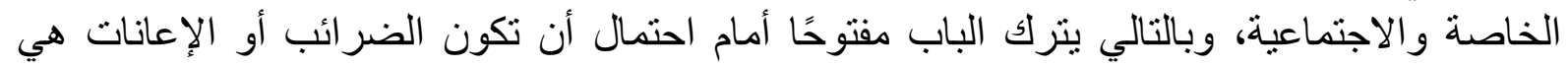
أفضل وسيلة لتحقيق النتائج المثلى. 166

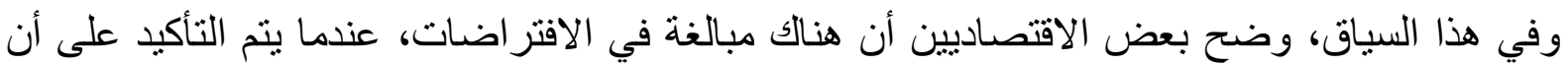

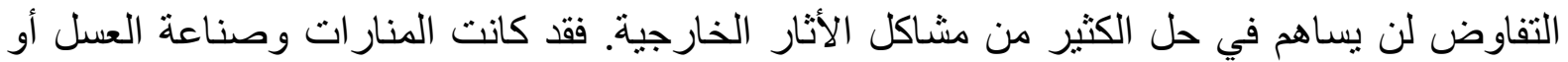

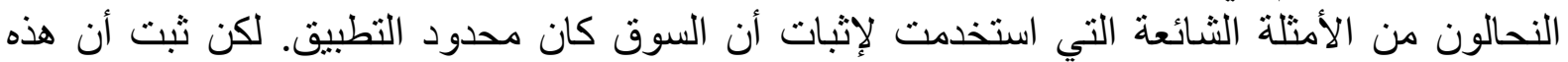
الأمثلة لم تستخدم لوصف الواقع. فقد توصلت الأطر اف الخاصة إلى كيفية إبرام صفقات مفيدة للطرفين أو تصميم إجر اءات مؤسسية لتعزيز الكفاءة. 167

عادةً ما تتطوى المعاملات على العديد من التكاليف، لكن غالبًا ما يُؤكد الاقتصاديون على أن نظريات

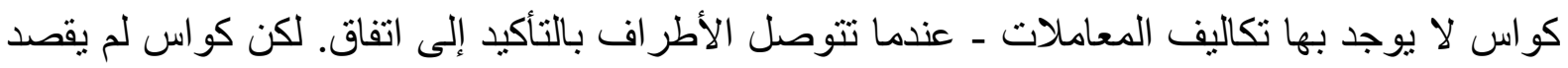

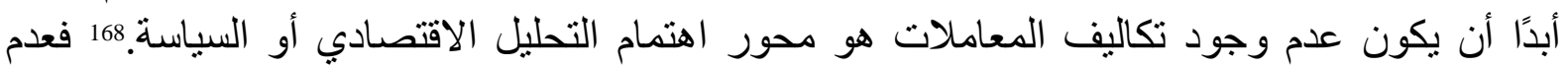

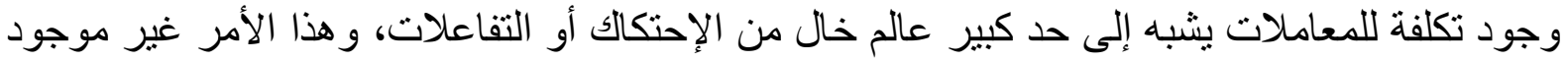
في الواقع. ولكن المهم في هذه النظريه هو فهم كيفية وصول الأطر اف لحل لحن المشاكل في العالم الحقيقي

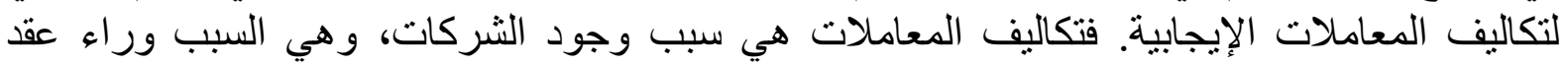
الصفقات طو ال الوقت وفي كل مكان. وقد استند مؤيدي التدخل التنظيمي إلى حقيقة انتشار تكاليف وهيف المعاملات كمبرر لتوسيع دور الحكومة في تخصيص كل فلوف الموارد الاقتصسادية. 169

و الخلاصة، أطلق مارشال وبيجو، فكرة التكاليف الخارجية باعتبار ها مصدر اهتمام للتحليل الاقتصادي.

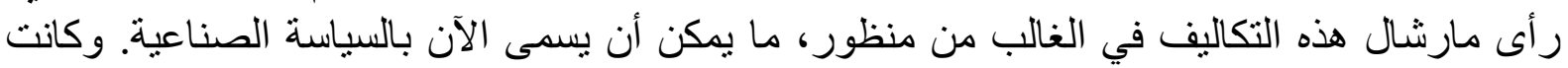

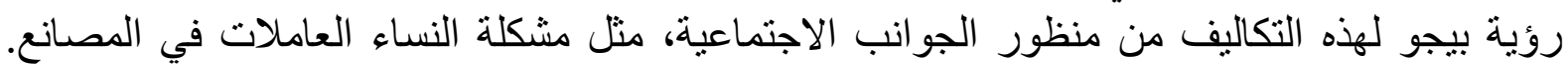
ولكن في خمسينيات وستينيات القرن الماضي، تم إضفاء الطابع الرسمي على تحليل الأثنار الخارجية

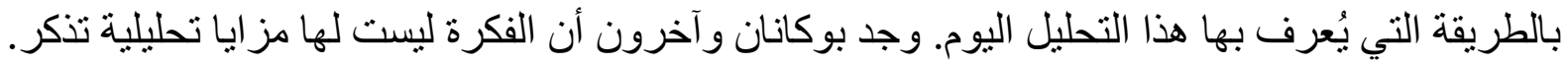
في المقابل، رأى بومول وآخرون أنها أداة لدفع السياسات لتصحيح المشاكل الاجتماعية.

\footnotetext{
${ }^{166}$ Harold Demsetz, (1996). The Core Disagreement between Pigou, the Profession, and Coase in the Analyses of the Externality Question, 12 EUR. J. POL. ECON. 565, PP. 569-70.

${ }^{167}$ Ronald H. Coase, (1974). The Lighthouse in Economics, 17 J. L. \& ECON. 357.

${ }^{168}$ Henry Mohrman, (2015). Coase on the Coase Theorem, 'The Social Cost Controversy, 2 MAN \& ECON. 215, P.221.

${ }^{169}$ Harold Demsetz, (1996). The Core Disagreement between Pigou, the Profession, and Coase in the Analyses of the Externality Question, 12 EUR. J. POL. ECON. 565, P.573.
} 


\section{المبحث الثالث: مفهوم الأثار الخارجية في الفقه الحالى}

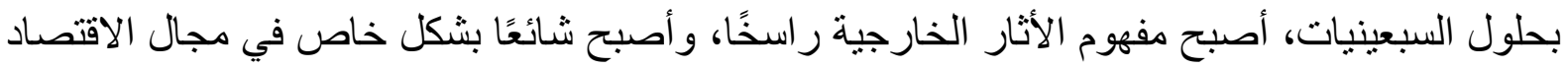

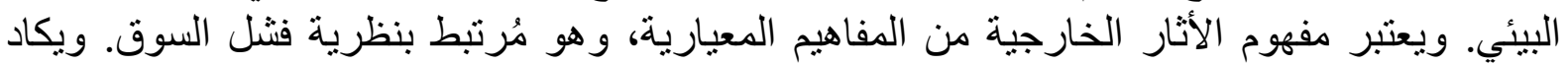

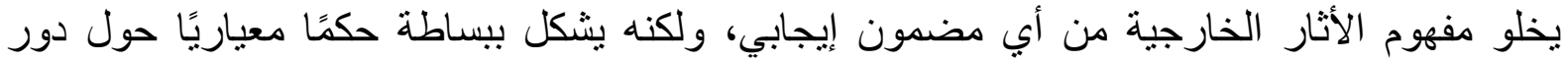

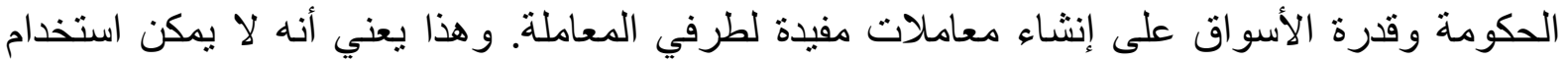

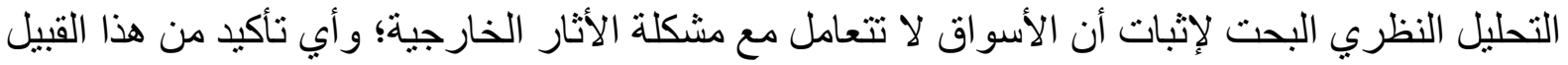

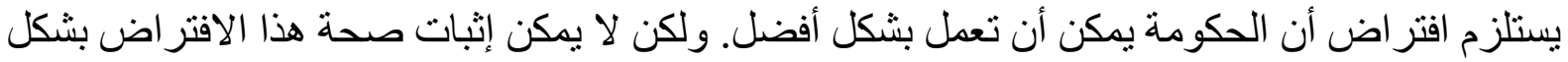

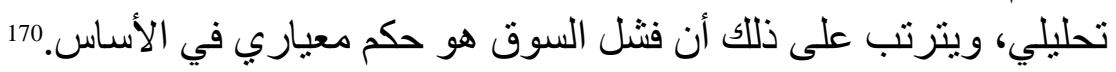

وفنشل السوق يعني أن هناك إعادة تخصيص للموارد، منل التغيير الذي يحدث في هيكل أنشطة السوق،

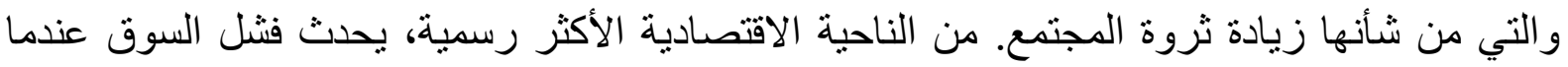

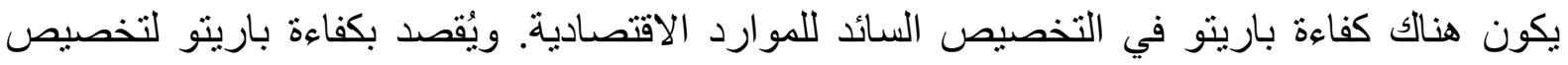

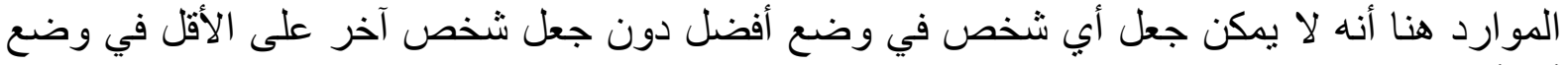

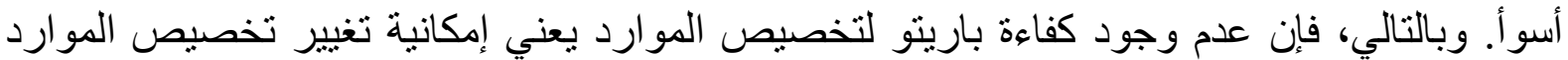

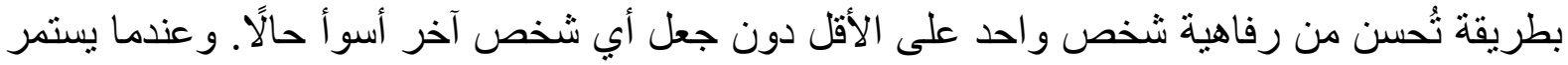

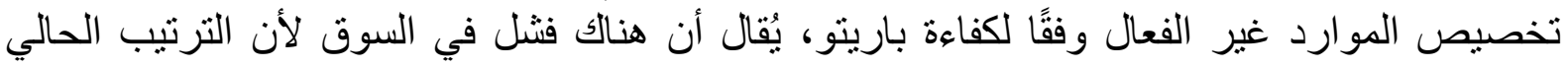
للسوق يترك حالة من عدم الاستقرار في المكاسب الاجتماعية المحتملة. 171

ويمكن القول أن أي حالة من حالات فثل السوق تحتوي بالضرورة على فرص لتحقيق الربح؛ أي إمكانية

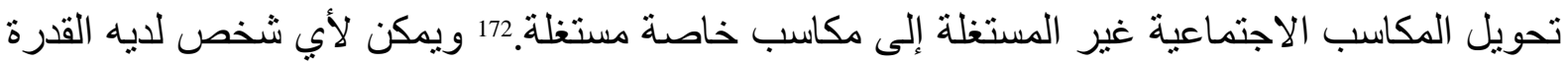

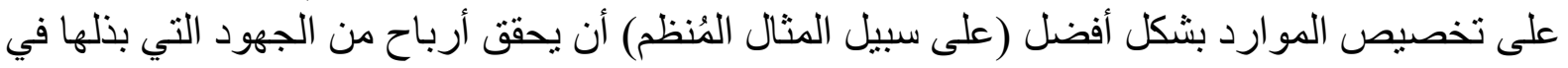

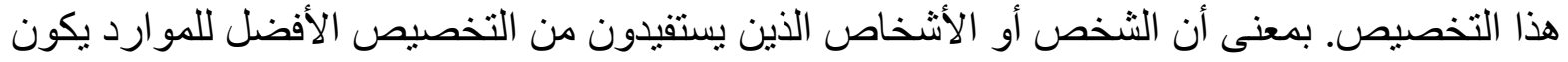

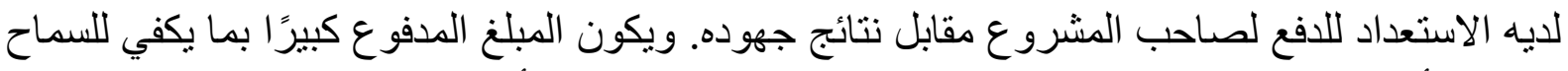

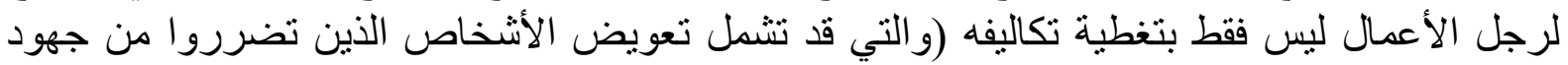

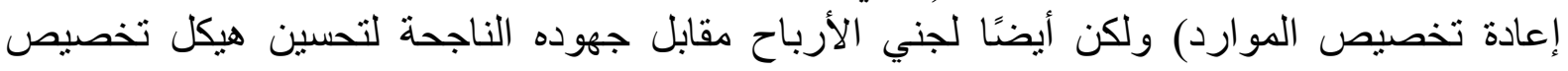

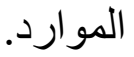

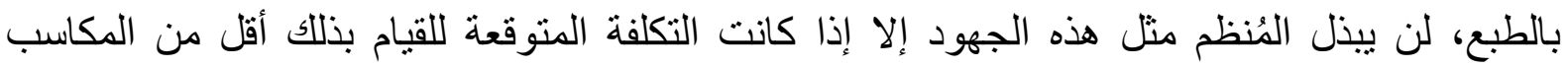

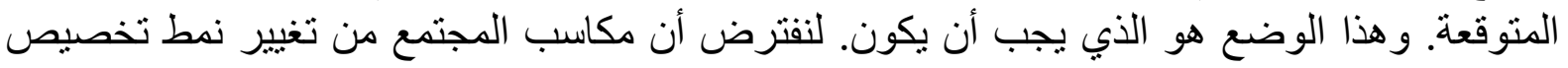

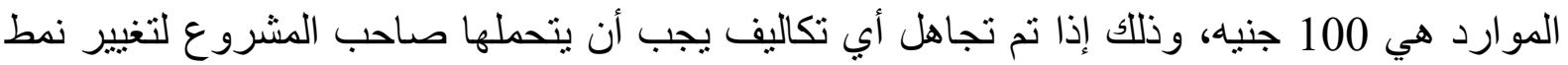

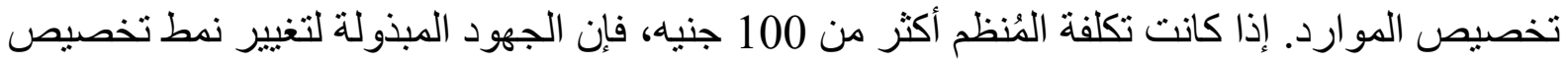

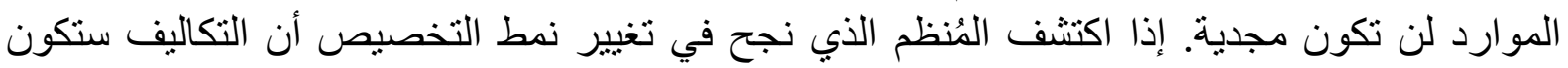

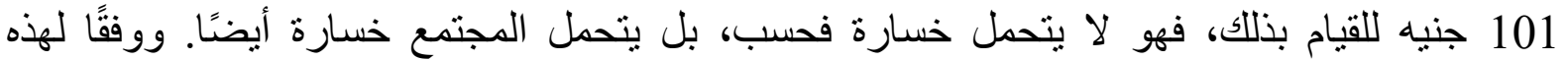

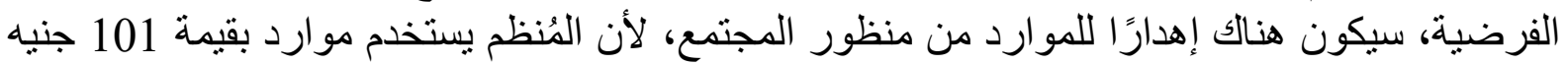

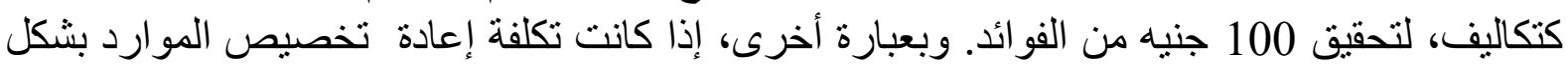

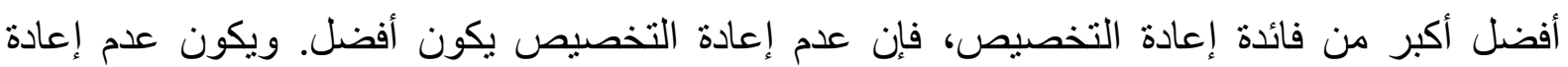

${ }^{170}$ Carl Dahlman, (1979). The Problem of Externality, 22 J. L. \& ECON., 141. P.152.

${ }^{171}$ Donald J. Boundreaux \& Roger Meiners, (2019). Externality: Origins and Classifications, 59 Nat. Resources J., 1, P.22.

${ }^{172}$ Carl Dahlman, (1979). The Problem of Externality, 22 J. L. \& ECON., 141, P.156. 
تخصيص الموارد هو التخصيص الأفضل للموارد من حيث الكفاءة الاقتصادية. وبالتالي، لا يتم النظر

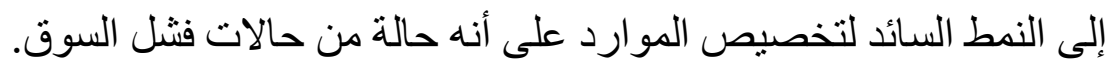

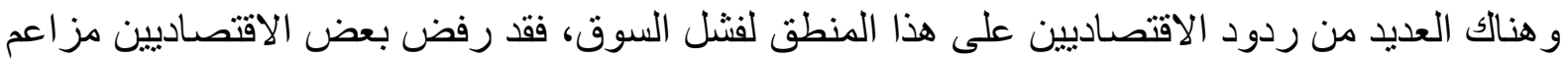

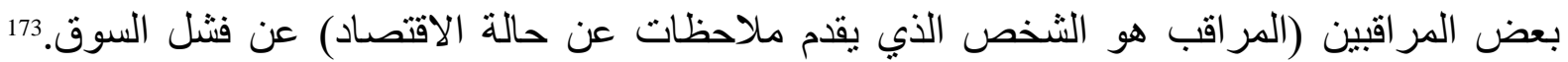

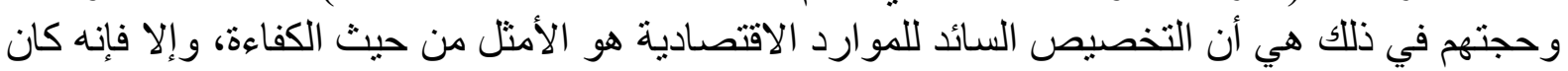

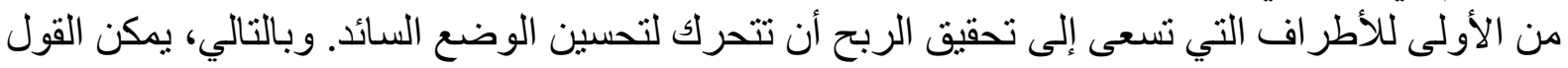

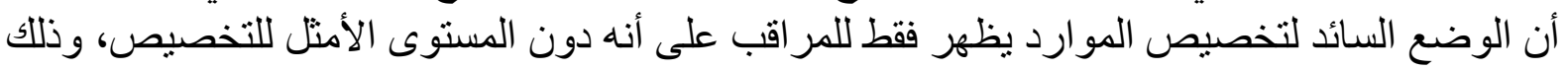

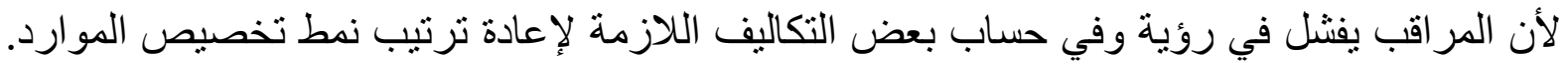

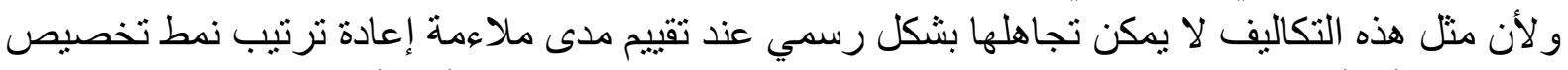

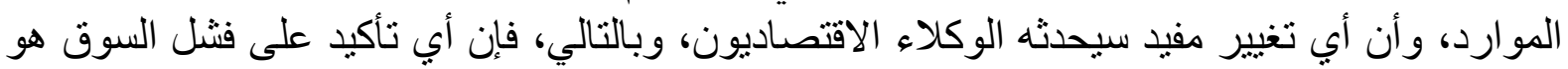
قول غير و اقعي.

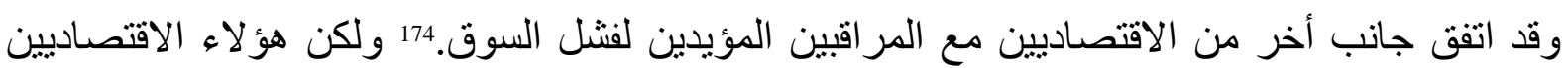

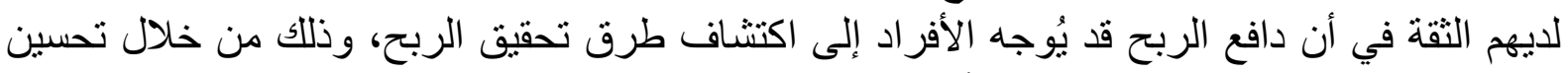

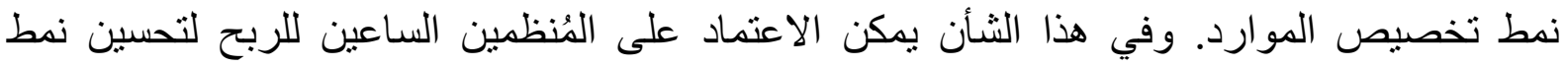

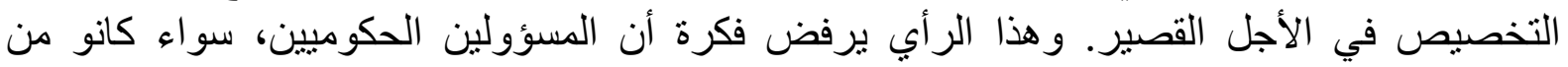

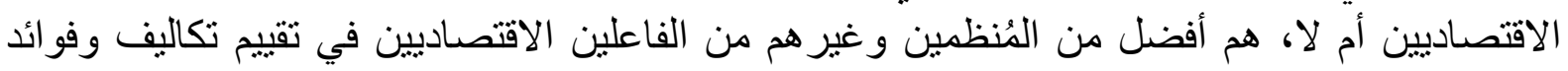

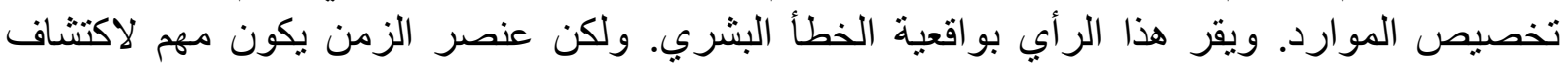

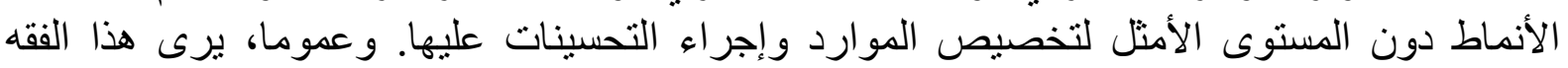

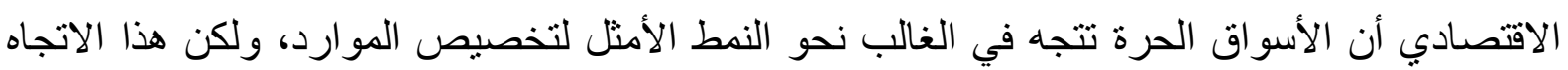

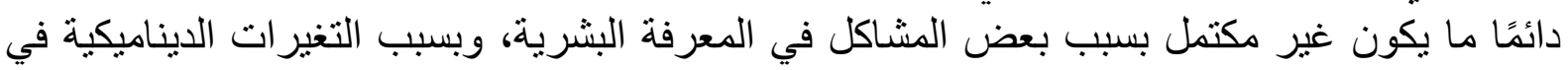

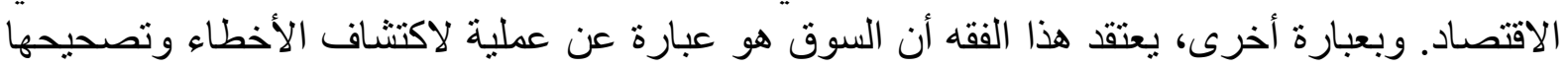
باستمر ار، ولكن هذه العملية لا تكتمل أبدًا.

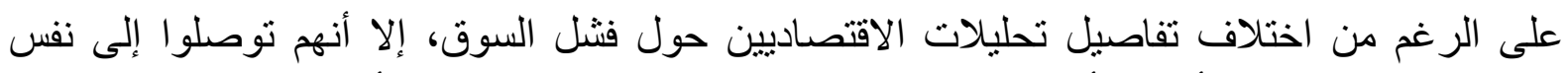

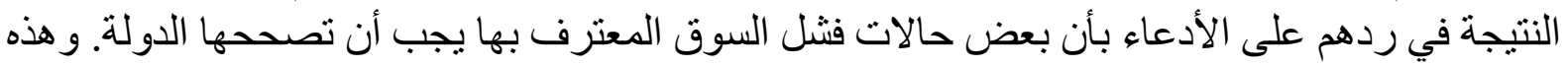

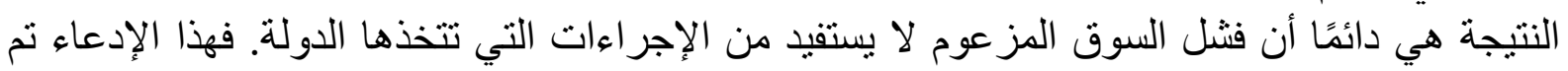

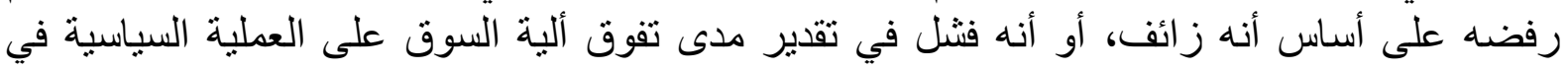

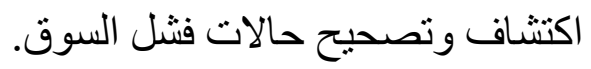

وقد كان رد اقتصاديون آخرون على ادعاءات المُر اقبين بوجود بعض حالات الات فنثل السوق، أنهم مؤيدين

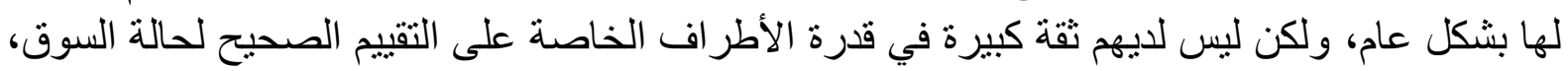

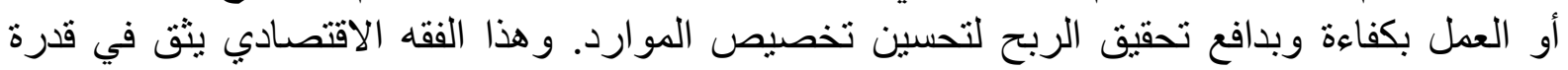

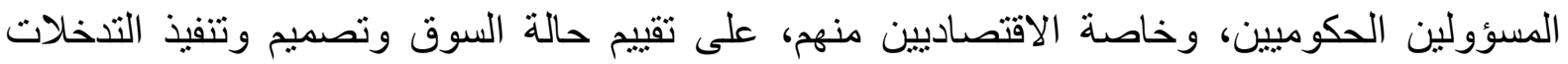

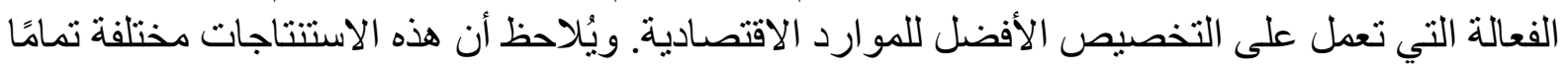

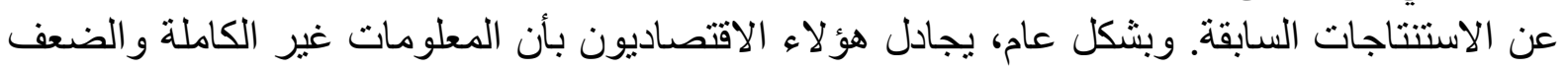

${ }^{173}$ George J. Stigler, (1976). The Xistence of X-Efficiency, 66 AM. ECON. REV., PP. 213- 216.

${ }^{174}$ F.A. Hayek, (2014). Competition as a Discovery Procedure, in: the market and other orders (Bruce Caldwell ed.), PP. 304-13. 
البشري و عدم الكفاءة المؤسسية تولد قدرًا كبيرًا من فثنل السوق ـ الفنثل الذي لا يمكن تصحيحه إلا من

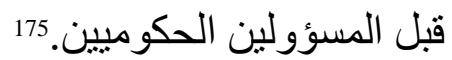

على الرغم من الخلاف بين هؤلاء الاقتصاديين حول نظرية فنثل السوق، إلا أن الجميع يتفق على حقيقة

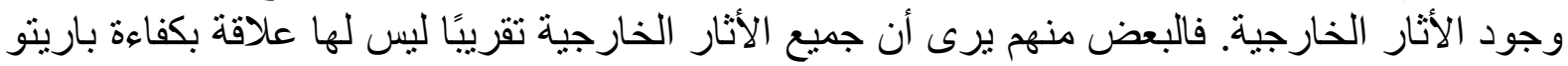

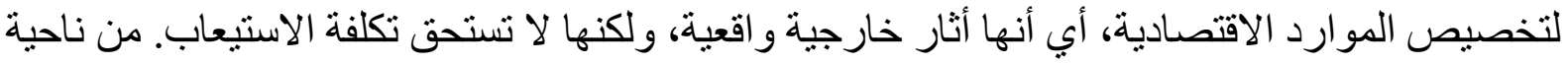

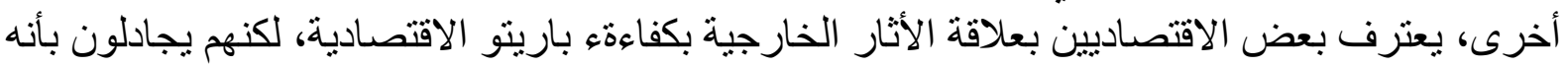

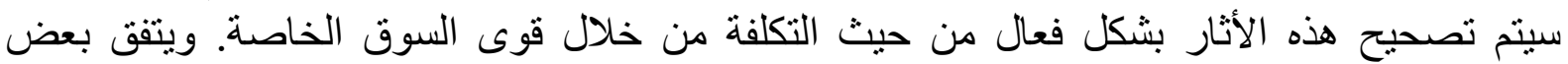

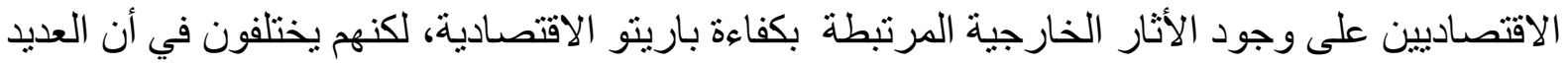

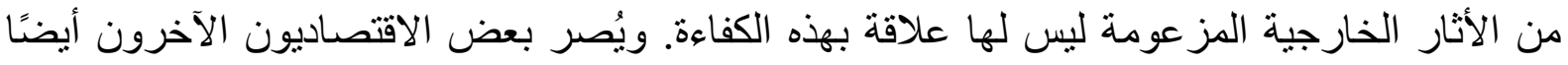

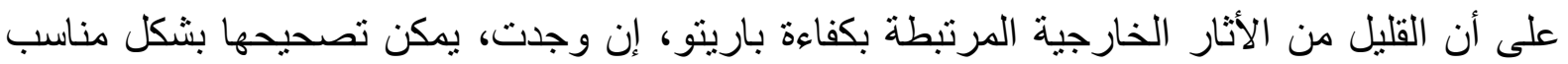

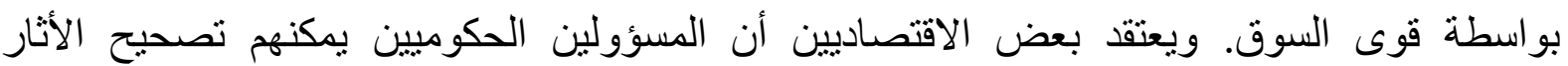
الخارجية المرتبطة بكفاءة باريتو بطرق فعالة من حيث التكلفة.

من خلال مر اجعة أصول مفهوم الأثار الخارجية، وُجد أنها بدأت مع الاقتصادي الثهير ألفريد مارشال

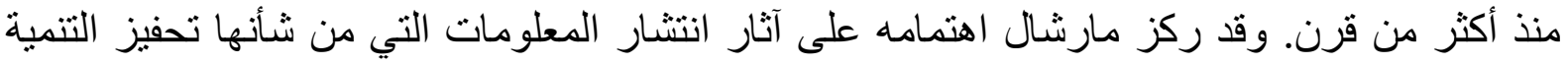

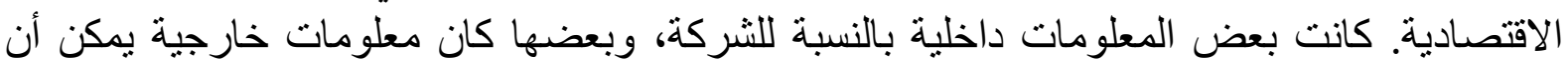

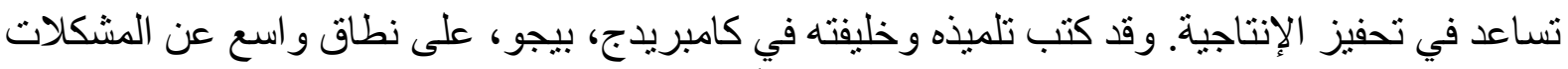

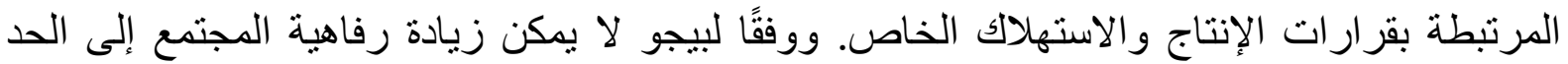

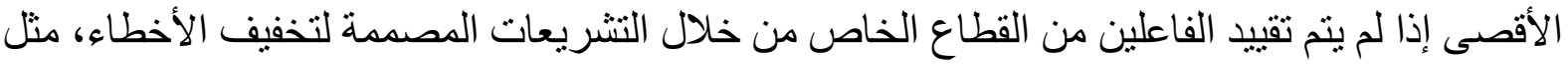

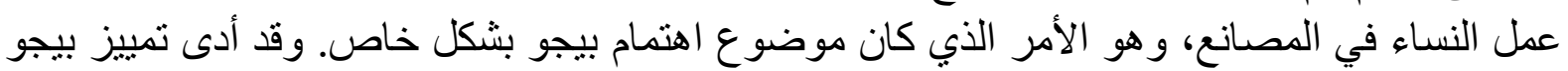

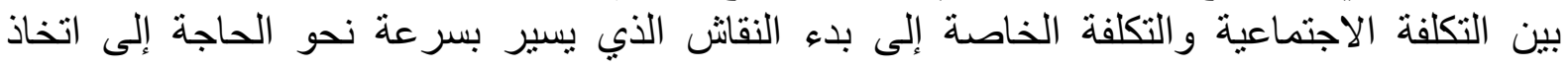
إجر اءات حكو مية لتصحيح الأخطاء الاقتصادية.

وقد أظهر بعض الاقتصاديين، وخاصة في الخمسينيات من القرن الماضي، الذين قاموا بتوسيع العمل التابل

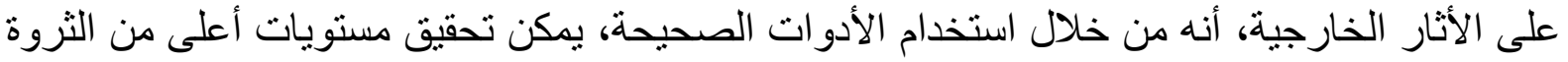

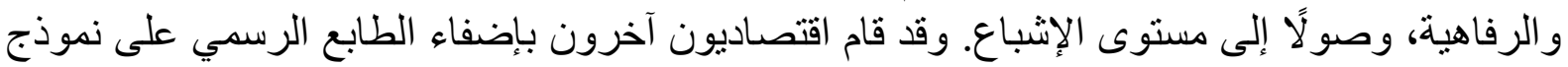

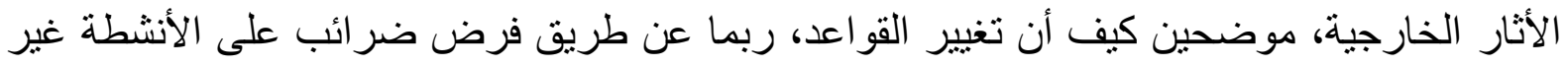

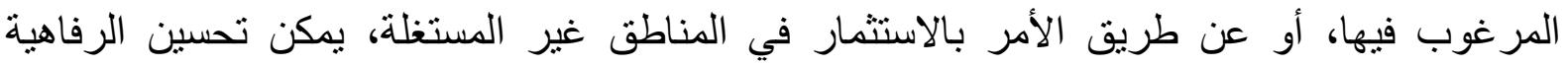

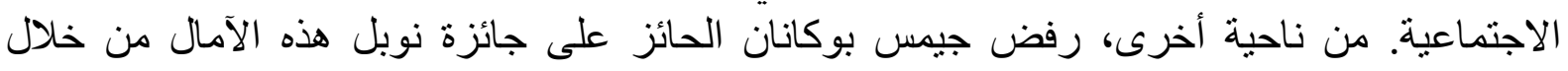

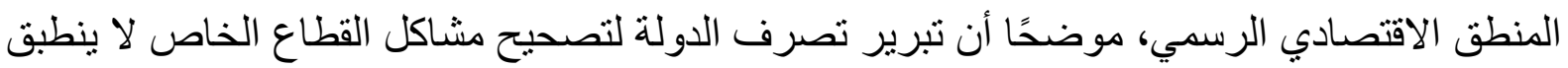

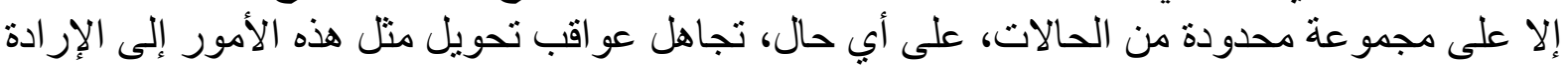

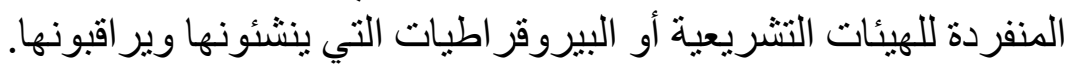

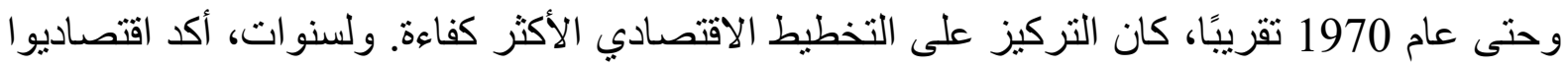

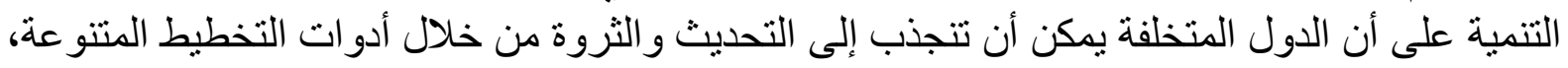

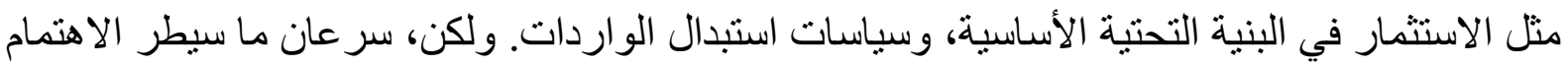
الخاص بالمسائل البيئية على تطبيق الأثار الخارجية. وعلى مدى نصف قرن حتى الآن، رسم الآنية

175 Joseph E. Stiglitz, (1989). Markets, Market Failures, and Development, 79 AM. ECON. REV., P. 197. 
الاقتصاديون العديد من المخططات لتقليل الأثار الخارجية، أي سد الفجوة بين الناتج الاجتماعي الأمثل

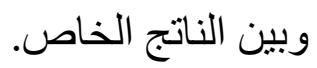

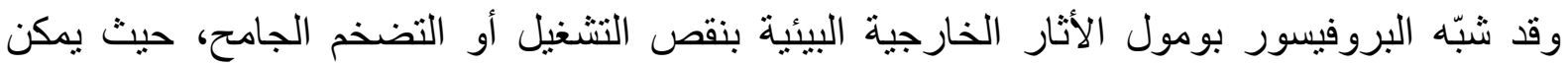

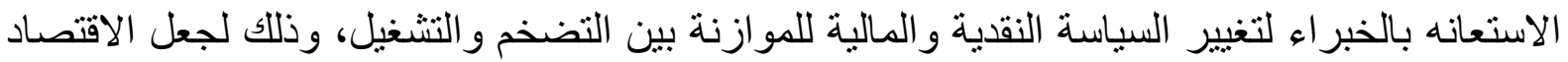

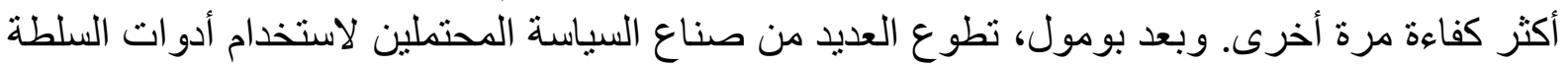

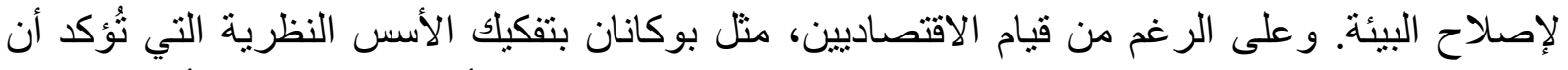

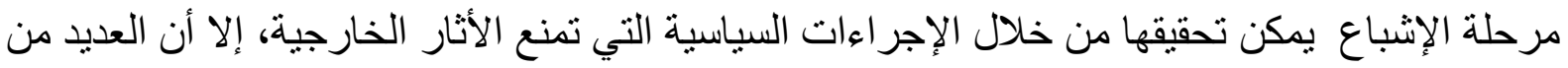

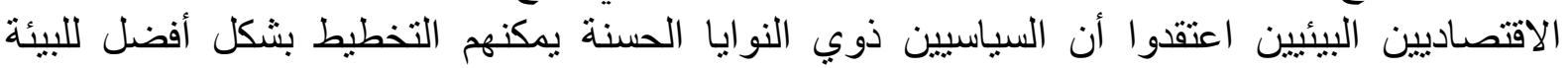

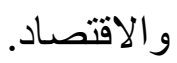

ويُلاحظ أن معظم الاقتصاديين يؤيدون رونالد كواس في الاعتقاد بأنه عندما يتم تحديد حقوق الملكية

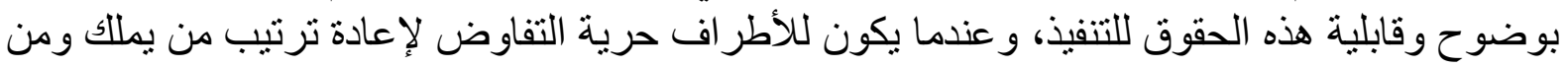

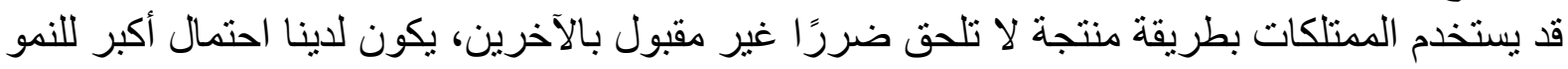

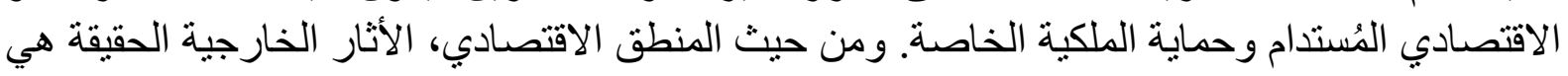

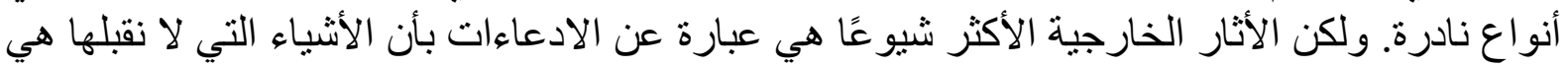

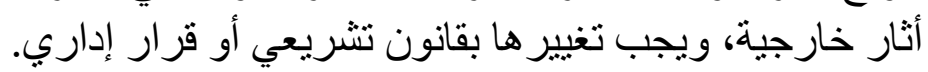




\section{3}

يزخر الفقه الاقتصادي بالعديد من تعريفات الأثار الخارجية الاقتصادية، إلا أن جانبًا كبيرًا من هذه

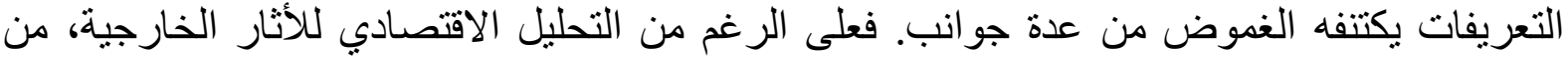

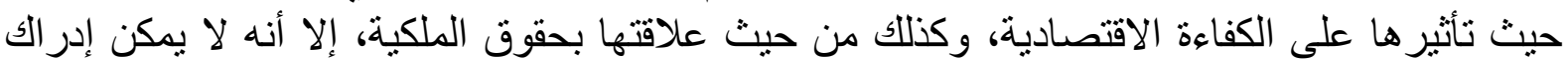

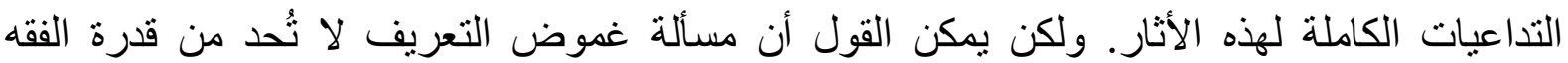
الاقتصادي على تحليل المشكلة، فمسألة التعريف لا تمثل الإشكالية الأساسية، طالما أن الفكرة نفسها

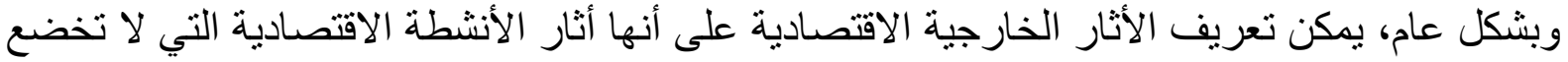

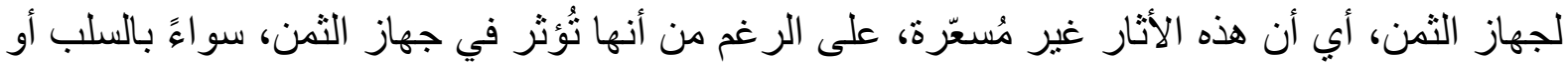

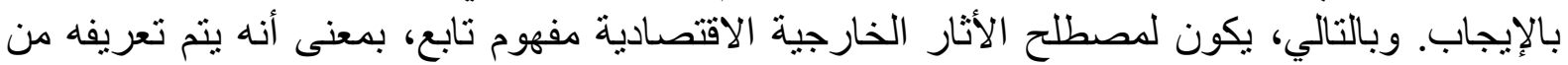

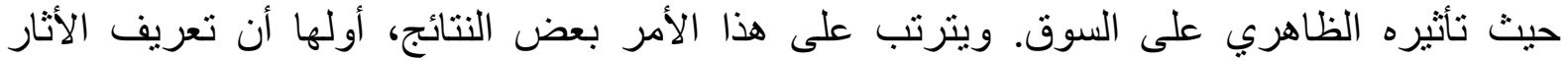

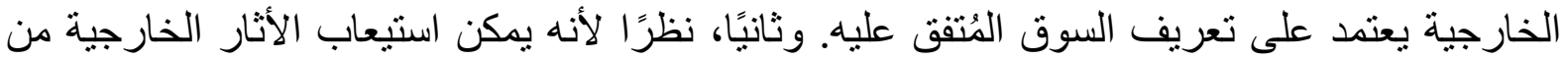
خلال ألية السوق، تعتمد الطبيعة المحددة لهذا الاستيعاب (الحل) على تعريف السوق أيضًا. 176 وقد ميز الفقه الاقتصادي بين العديد من الفئات أو الأنواع المختلفة للأثار الخارجية الاقتصادية. وقد ساعد

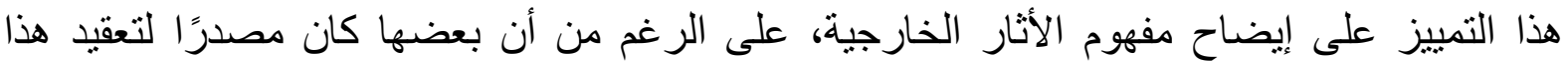

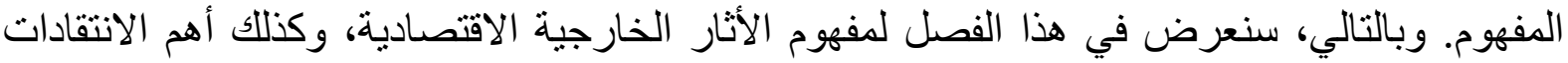
الفلسفية التي ؤجهت لهذا المفهوم، ومفهوم مبدأ الضرر الناتج عن الأثار الخارجية الاقتصـادية. ويهدف هذا الفصل أيضًا إلى عرض وتحليل أهم أنواع أو فئات الأثنار الخارجية الاقتصـادية. وهذه

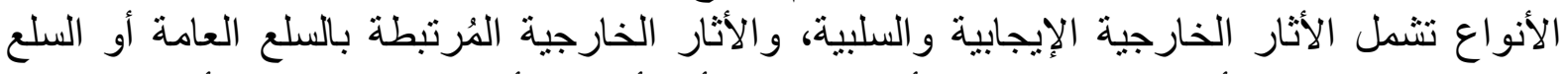

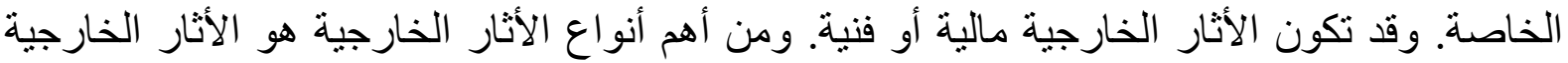
الأخلاقية، والأثنار الخارجية ونية للوضع الاستهلاكي.

ولذلك ينقسم هذا الفصل إلى المباحث التالية:

المبحث الأول: مفهوم الأثثار الخارجية الاقتصادية.

المبحث الثاني: أنواع الأثار الخارجية الاقتصادية.

المبحث الثالث: الأثار الخارجية للوضع الاستهلاكي.

\footnotetext{
176 Nathalie Berta and Elodie Bertrand, (2014). Market Internalisation of Extrnalities: What is the falling? Journal of the History of Economic Thought, 36, P. 331.
} 


\section{المبحث الأول: مفهوم الأثار الخارجية}

قد يكون من الصعب وضع تعريف دقيق لمفهوم الأثار الخارجية الاقتصادية. و عادةً ما يتم تضمين العديد من العناصر في تعريف الأثار الخارجية. ولكن، كل عنصر من هذه العناصر يخضع للشر ح و التفسير .

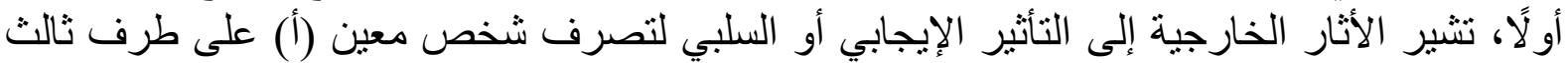

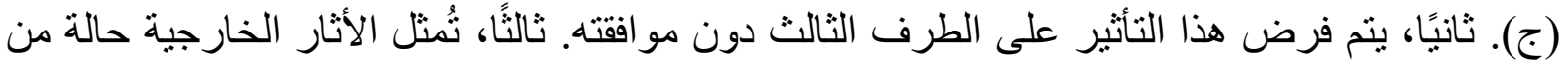
عدم الكفاءة الاقتصادية.

وثُبرز الخاصية الأولى للأثار الخارجية حقيقة أن هذه الأثار عبارة عن آثار غير مباثرة، وهي حدث

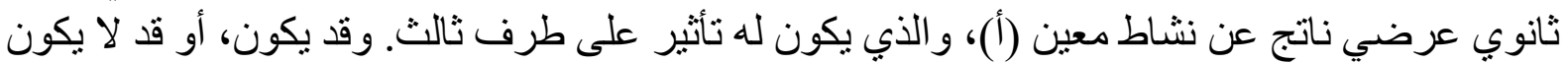

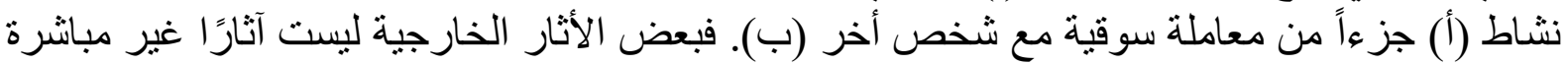

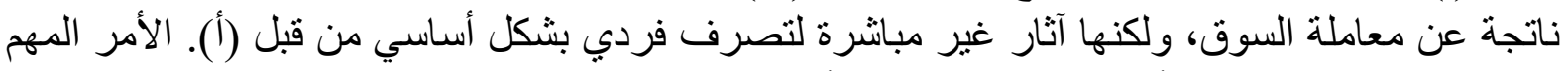

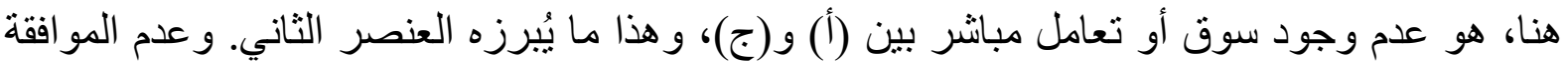

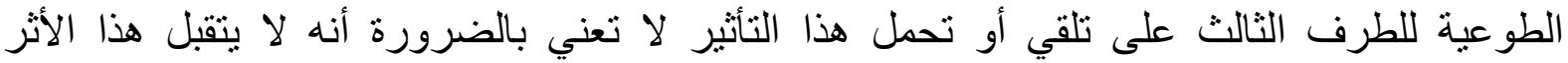

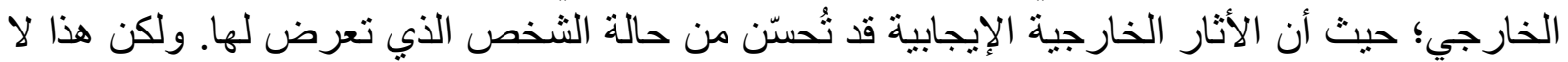

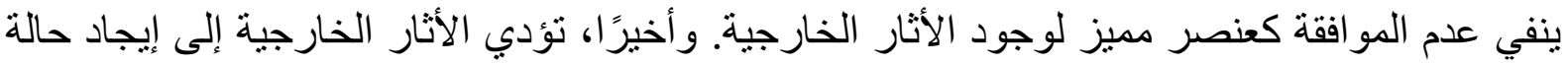

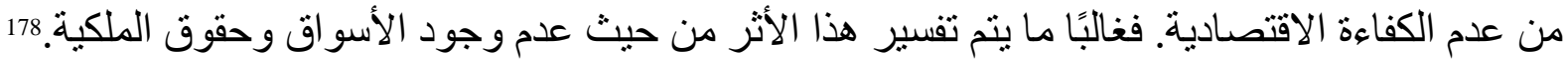

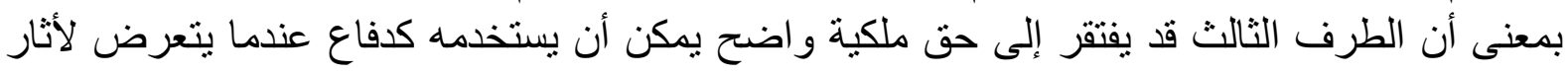
خارجية سلبية.

كما سبق القول أن ألية الأسواق تفشل أحيانًا في تحقيق كفاءة تخصيص الموارد الاقتصادية، ولكن كيف

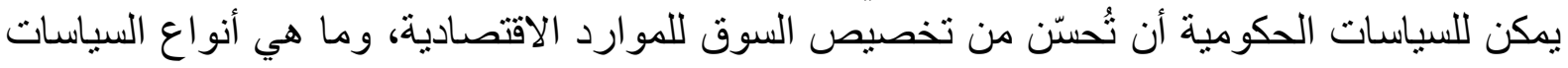

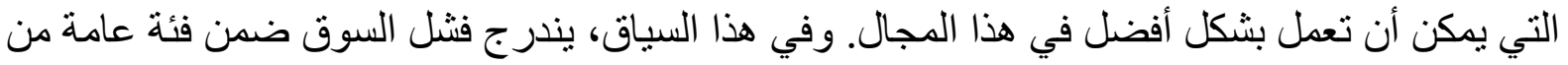

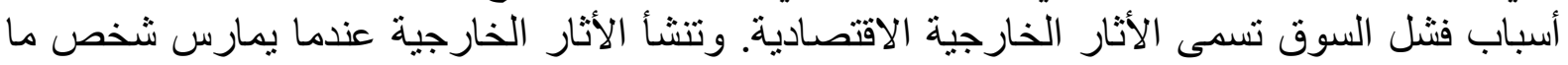

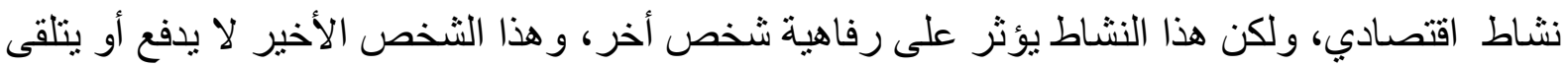

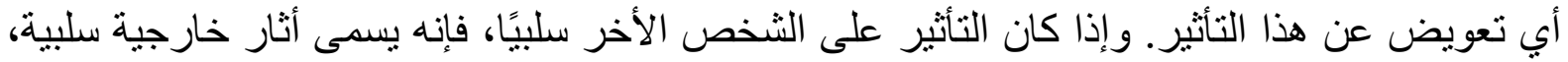
و إذا كانت الأثار الخارجية مفيدة له، فإنها تسمى أنثار خارجية التئ إيجابية. 179

في ظل وجود الأثنار الخارجية، لا يتعلق اهتمام المجتمع فقط بالنتائج التي تُحققها ألية السوق بالنسبة

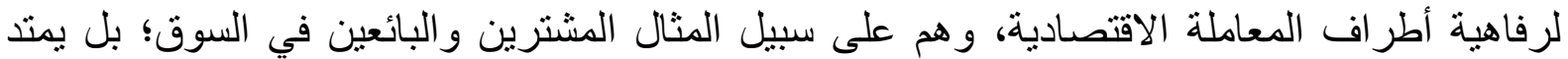

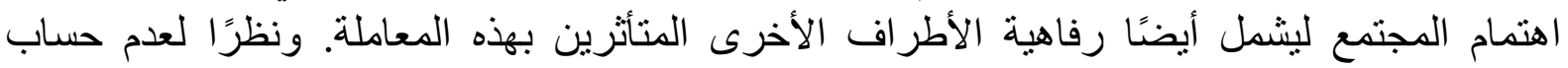

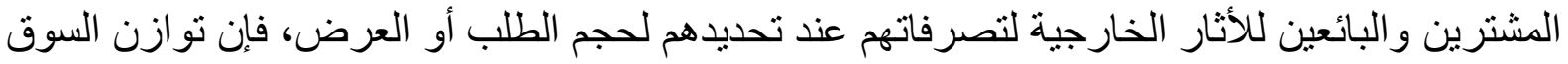

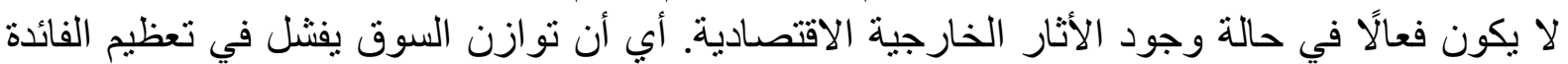

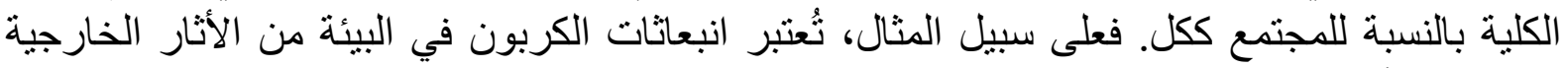
السلبية. فمثلًا، لن تأخذ شركات إنتاج الورق التي تسعى إلى تحقيق مصلحتها الذاتية في الاعتبار التكلفة

\footnotetext{
${ }^{177}$ Lagueux, Maurice. (2010). "The Residual Character of Externalities." The European Journal of the History of Economic Thought, 17 (4), P. 957.

${ }^{178}$ Berta, Nathalie. (2017). "On the Definition of Externality as a Missing Market." European Journal of the History of Economic Thought, 24 (2), P. 287.

179 Meade, J. E. (1973). The Theory of Economic Externalities: The Control of Environmental Pollution and Similar Social Costs, Leiden: Sijthoff, P.15.
} 


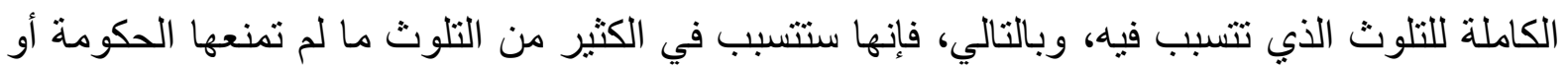

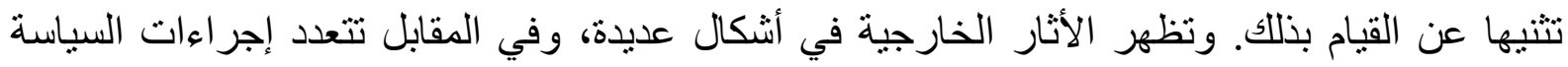

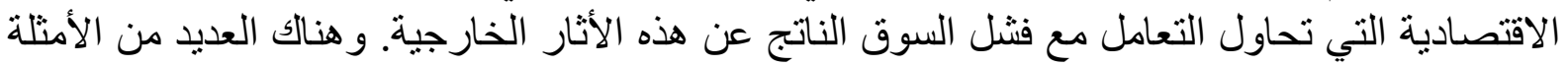

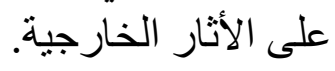

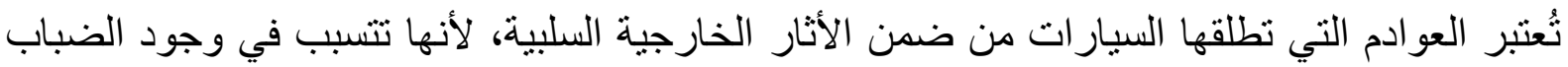

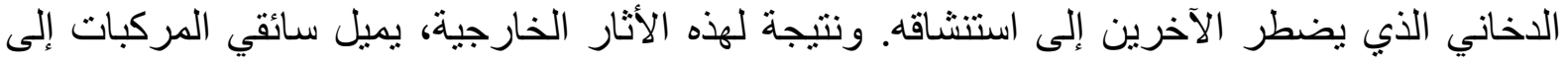

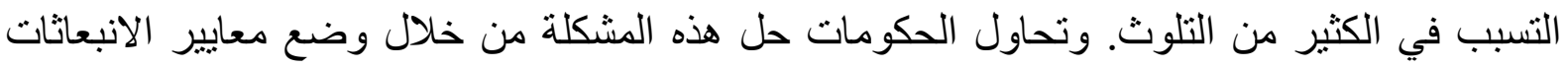

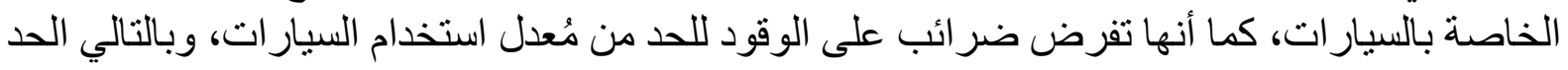

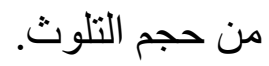

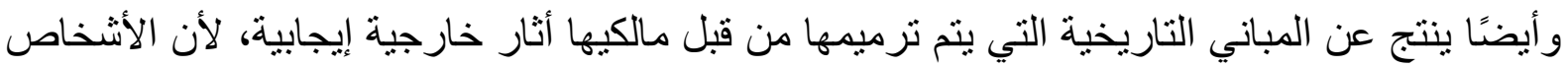

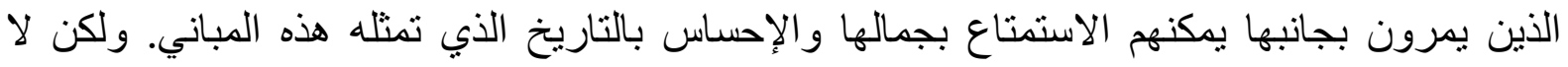

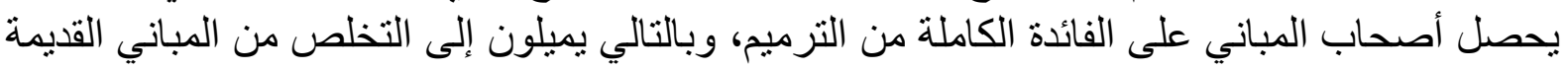

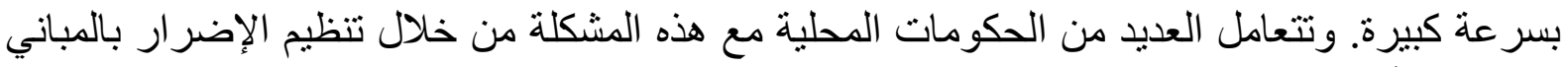

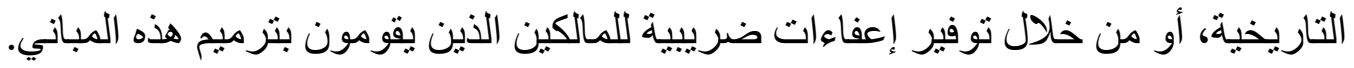

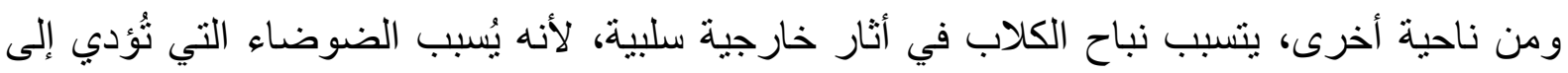

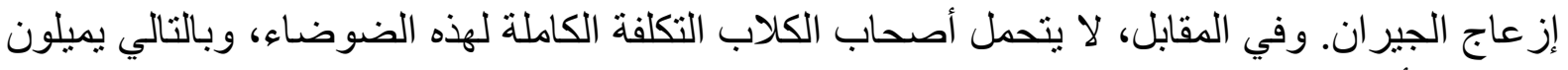

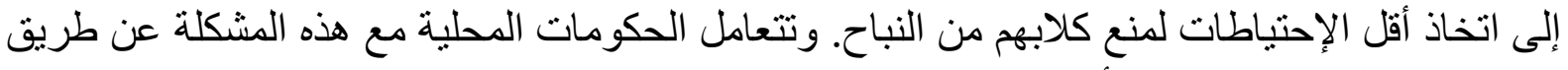

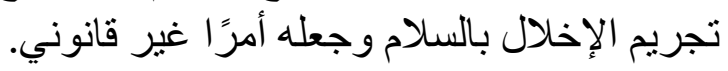

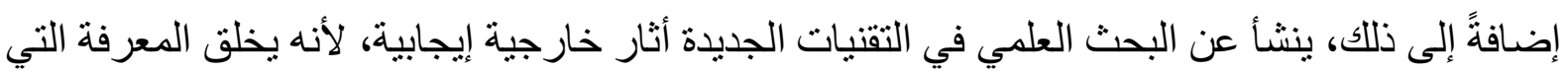

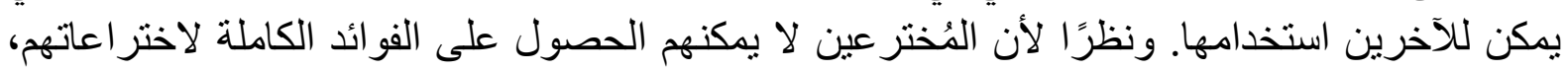

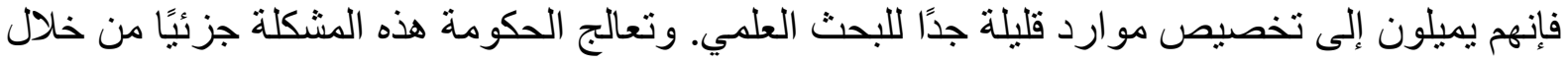

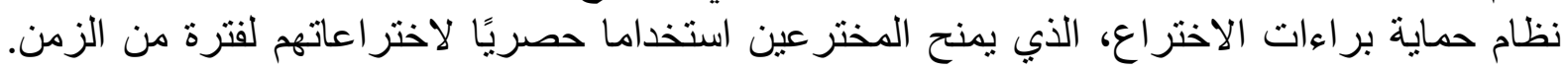

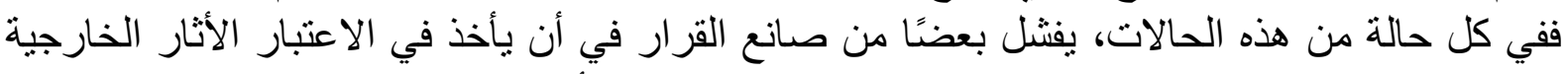

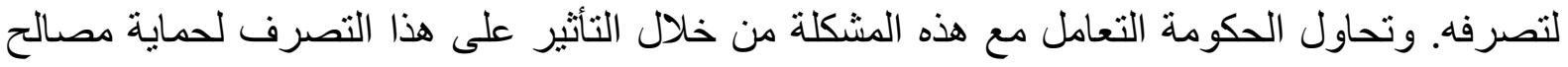

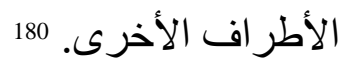

\section{أولًا: الانتقادات الفلسفية لمفهوم الأثار الخارجية الاقتصادية}

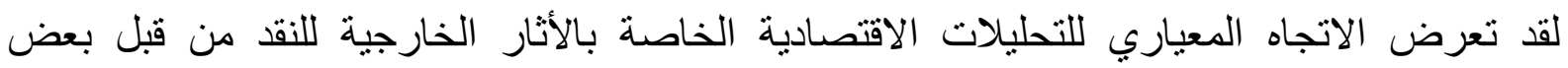

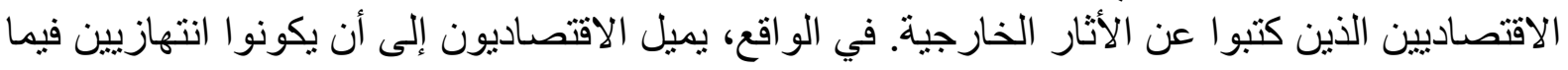

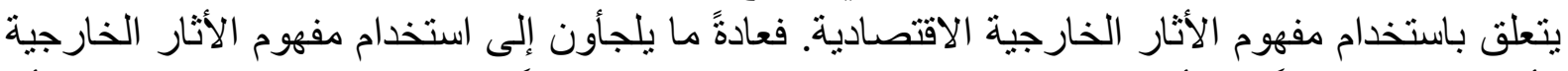

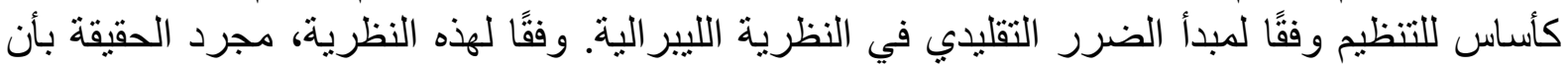

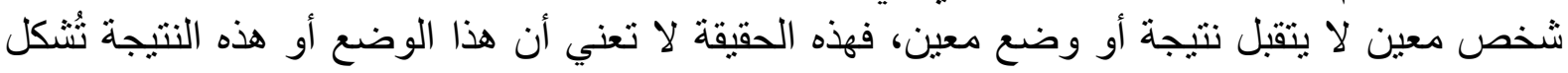

180 Mankiw, N. G., (2002). Principles of microeconomics. Toronto: Nelson Thomson Learning, P. 120. 
ضررًا، بمعنى أنها لبست تكلفة حقيقية بالنسبة لهذا الثخص، و لا تتطلب التعويض. التحليل الاقتصادي ما يدعم هذا التفسير المحدد للتكاليف أو الضرر .182

و هذا يعني أنه يتم استدعاء مفهوم الأثار الاقتصادية بشكل انتقائي. في الواقع، نظرًا لوجود الأثار

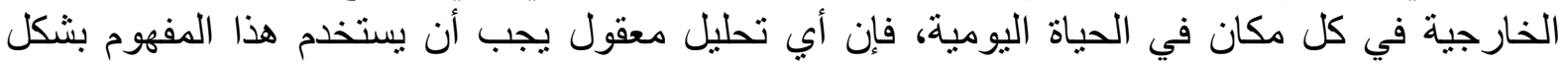

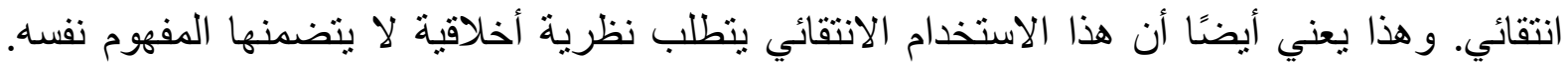

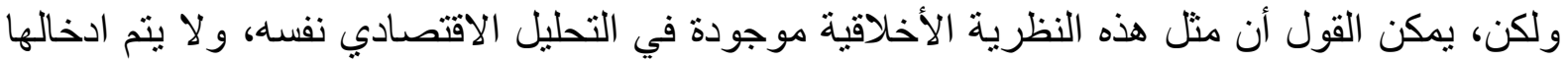

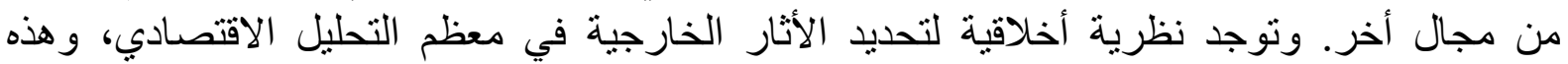
النظرية تتمثل في فكرة النفعية. وتُعرف المنفعة بدورها عادةً على أنها عملية إرضاء للتهية التفضيلات الثخصية. و هذا يعني أنه حتى لو استخدم الاقتصاديون مفهوم الأثنار الخارجية بشكل انتقائي، فإنه يمكن

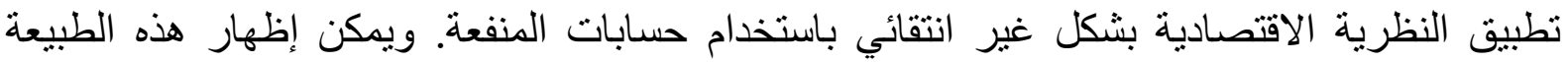

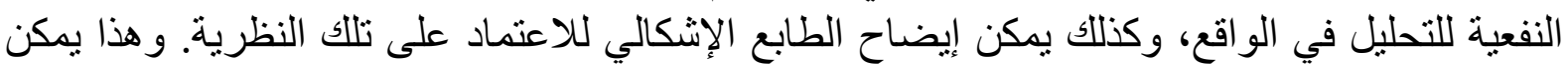

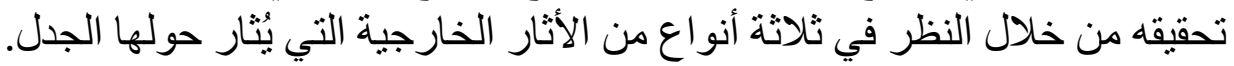

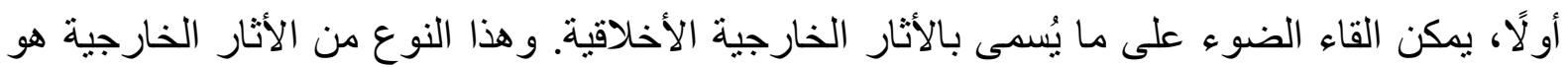

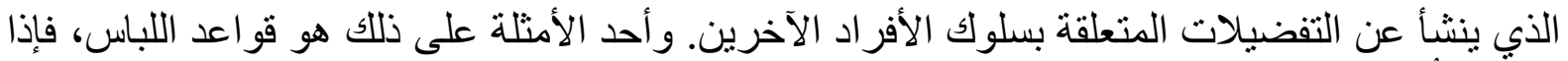

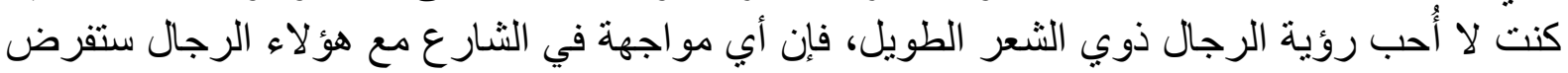

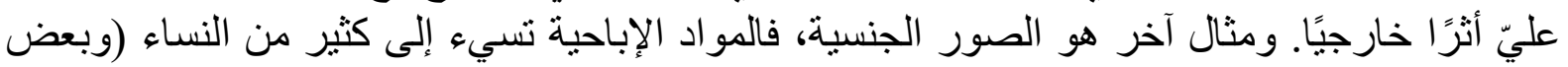

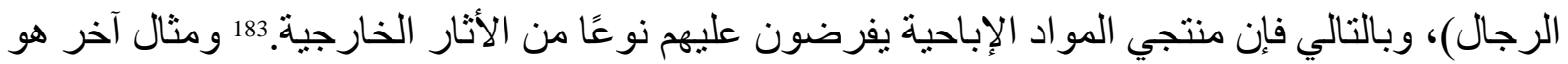

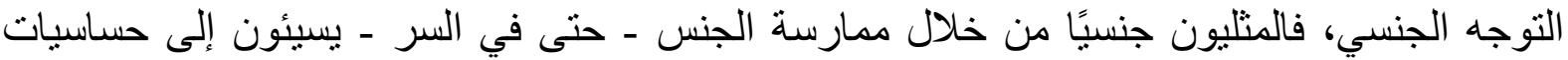

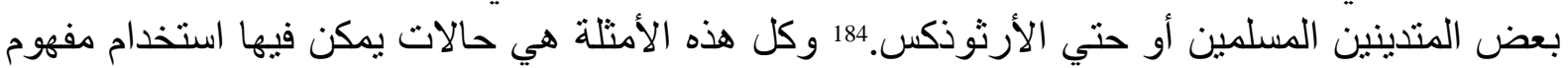

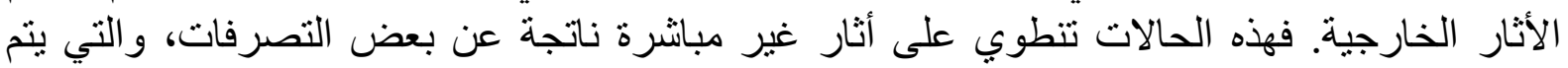

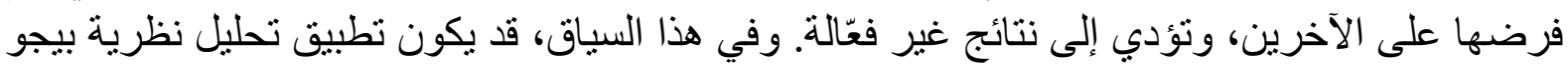

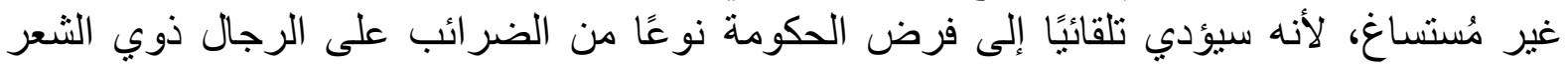

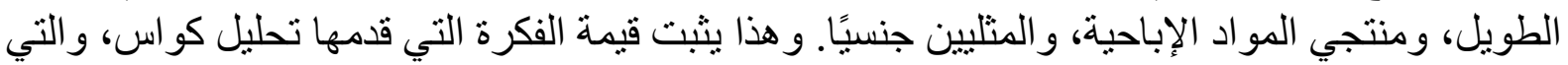

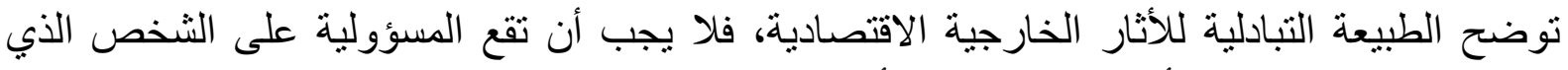
نحدده بشكل بديهي على أنه المُتسبب في الأثار الخارجية. وفي المقابل، يتعامل تحليل كواس مع مع هذا الحالات، من خلال تقديم قاعدة مفادها أنه لا يوجد أثر خارجي إلان عندما يكون هنالك أثنار تبادلية بين

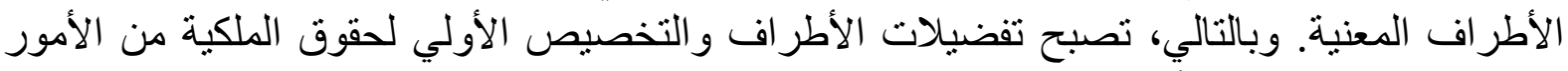
الحاسمة في حل مشكلة الأثثار الخارجية.

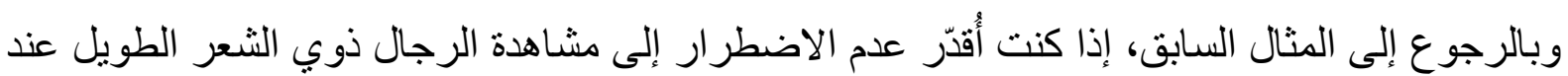

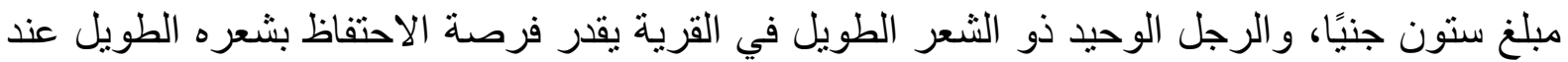

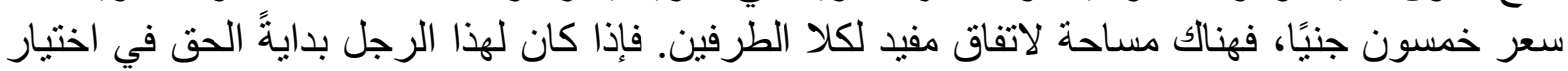

\footnotetext{
${ }^{181}$ Holtug, N., (2002). 'The Harm Principle', Ethical Theory and Moral Practice, 5(4), P. 357.

182 Satz, D., (2010). Why Some Things Should Not Be for Sale: The Moral Limits of Markets, New York: Oxford University Press, P.32.

${ }^{183}$ Trebilcock, M., (1993). The Limits of Freedom of Contract, London: Harvard University Press, P. 65.

${ }^{184}$ Herzog, D., (2000). 'Externalities and Other Parasites', TheUniversity of Chicago Law Review, 67(3), P. 912.
} 
شكل وطول شعره، فيمكنني إقناعه مقابل خمسة وخمسون جنيًا، على سبيل المثال، لقص شعره. و إذا كان

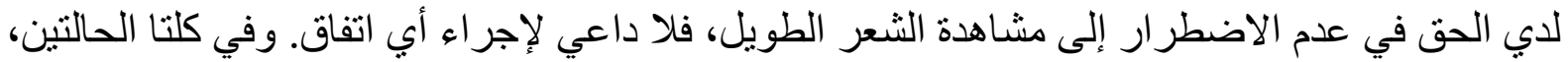

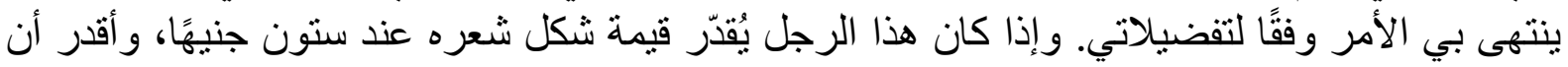

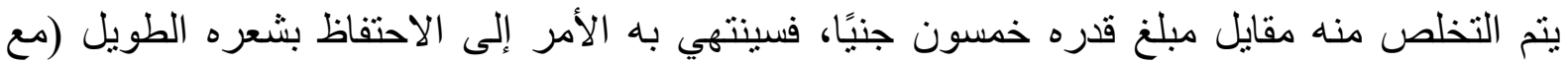

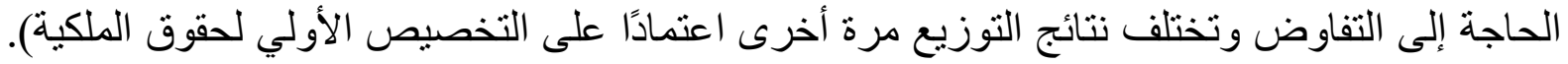

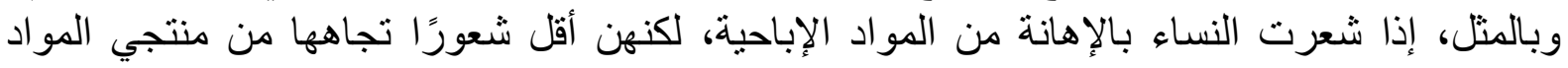

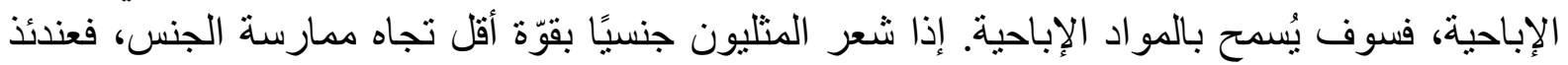

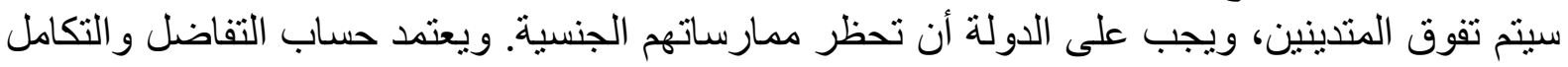

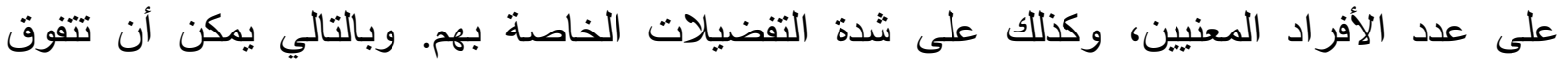

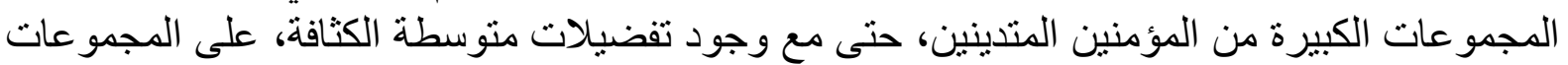

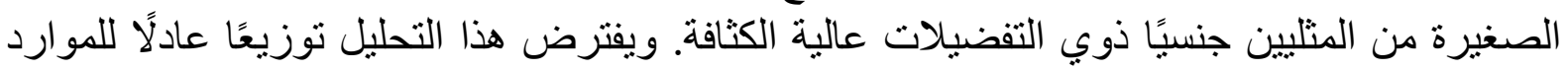

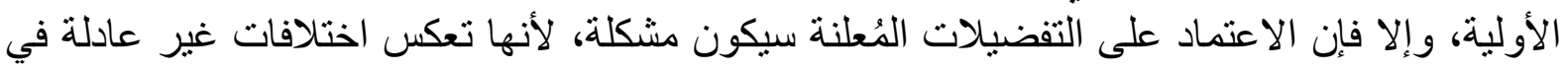
القوة الثر ائية.

وقد يتبادر إلى أذهان الكثيرين أن هذا التحليل قد يؤدي إلى نتائج خاطئة. فغالبًا ما يجادل الليبر اليون بأنه

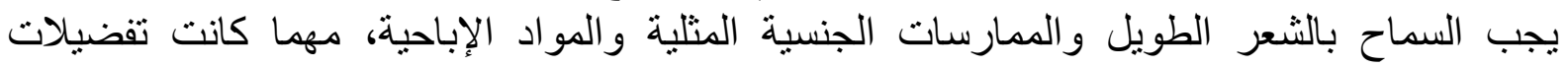

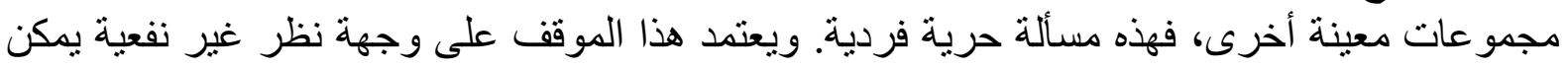

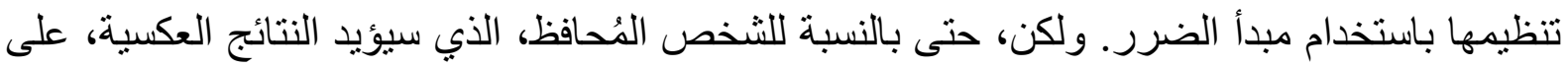

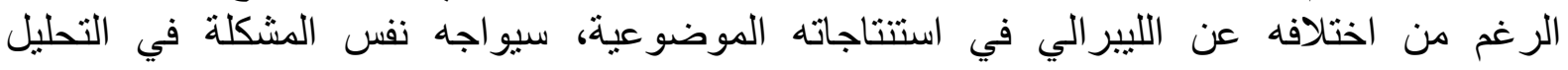

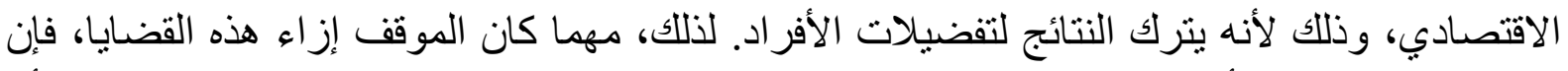

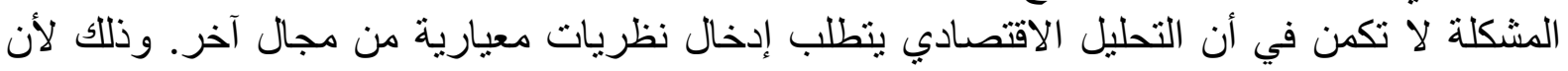

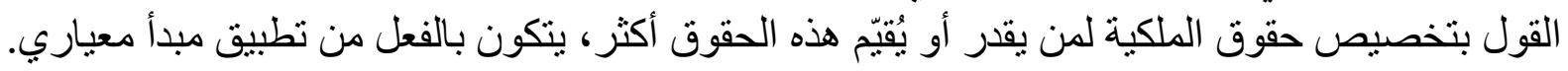

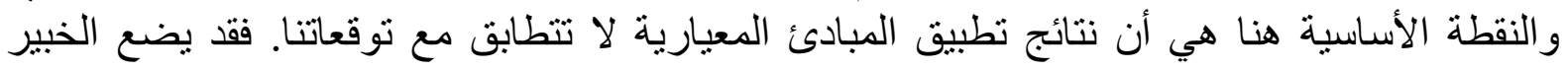

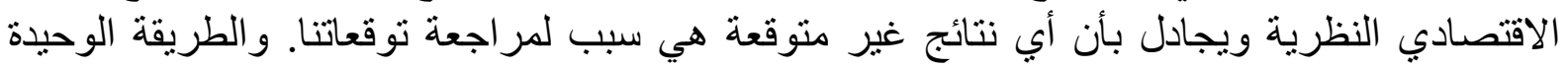

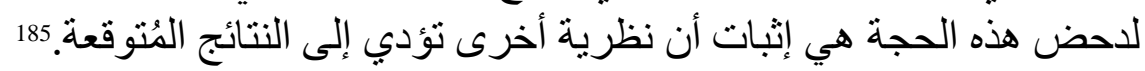

و هناك الكثير ممن ينظرون إلى أي سلوك يستاعون منه على أنه نوع من الضرر بالنسبة لهم، وأنه إهانة

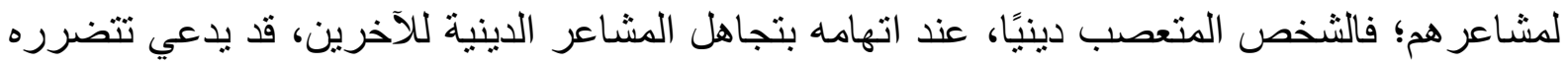

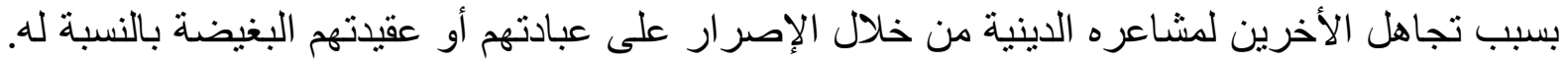

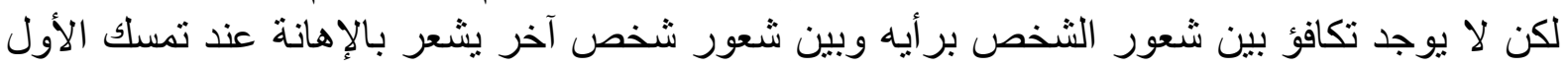

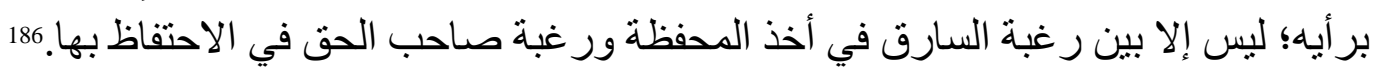

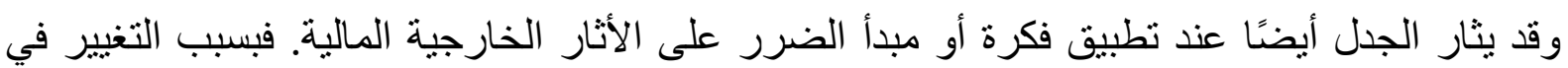

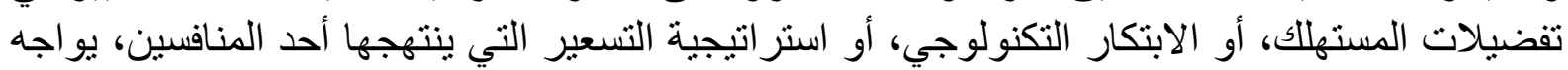
بعض المنتجين انخفاضًا في الطلب على منتجاتهم. وبالتالي، فإن السوق التنافسي الكامل يفرض التهن تكلفة على الخاسرين في المنافسة، و هذه التكلفة تُفرض عليهم بواسطة المستهلكون أو من خلال منافسو هم. هل

${ }^{185}$ Hatzis, A. (2015), 'Moral Externalities: An Economic Approach to the Legal Enforcement of Morality', in A. Hatzis and N. Mercuro (eds.), Law and Economics: Philosophical Issues and Fundamental Questions, Oxon/New York: Routledge, P. 226.

${ }^{186}$ Mill, J. S. (1991), 'On Liberty', in J. Gray (ed.), On Liberty and Other Essays, Oxford: Oxford University Press, P. 5. 


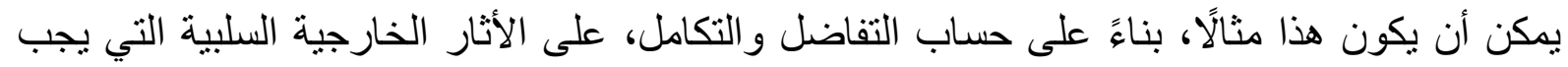

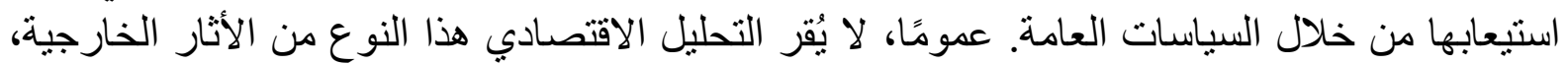

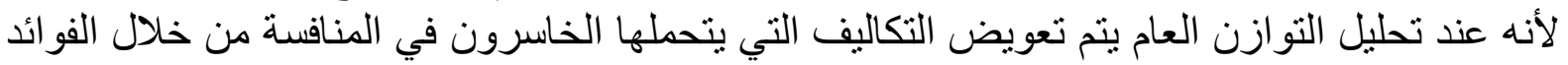

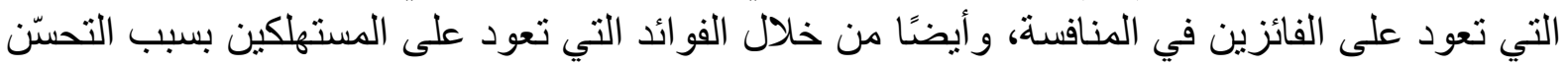

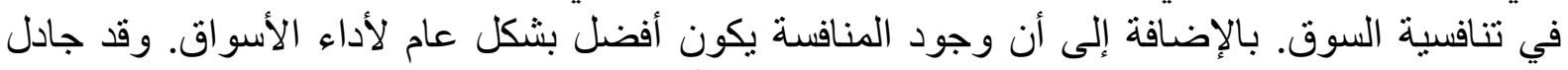

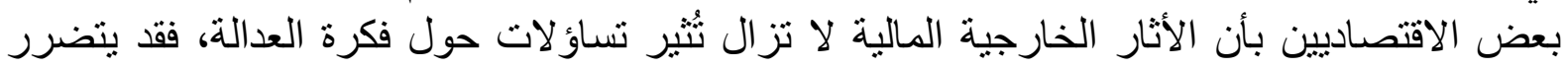

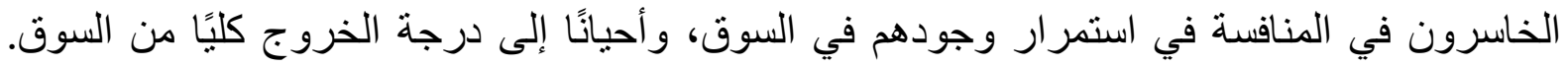

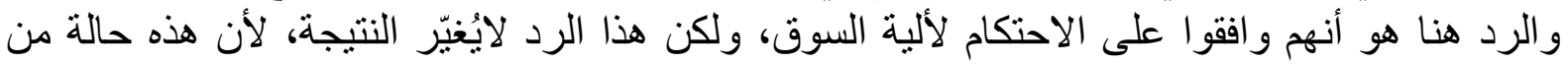

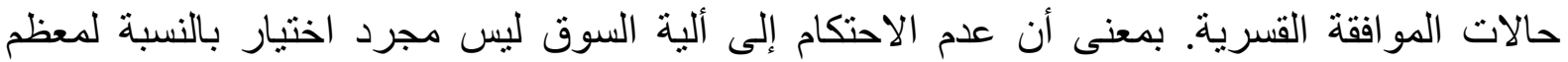

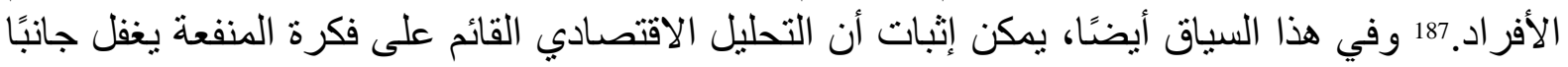
مهمًا من الجوانب الأخلاقية.

و النوع الثالث من الأثار الخارجية التي يُنثار حوله الجدل هو الأثار الخارجية للوضع الاستهلاكي

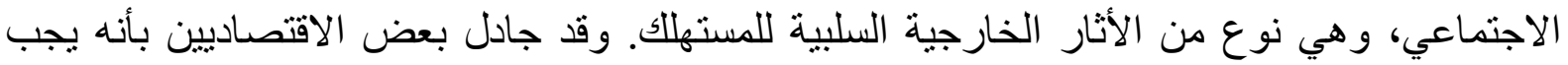

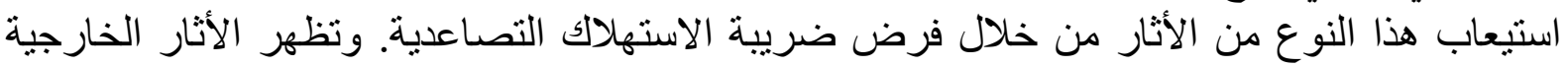

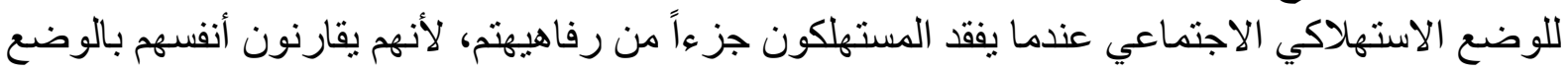

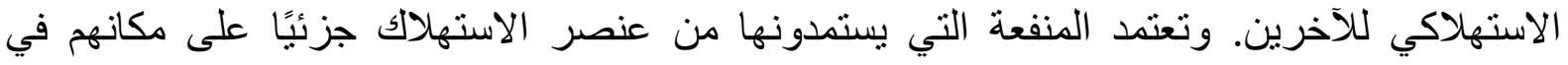

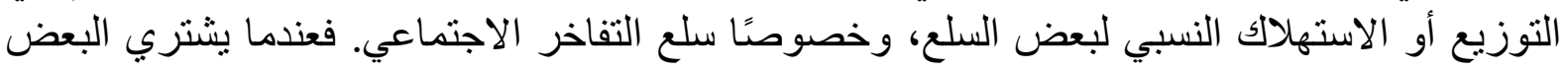

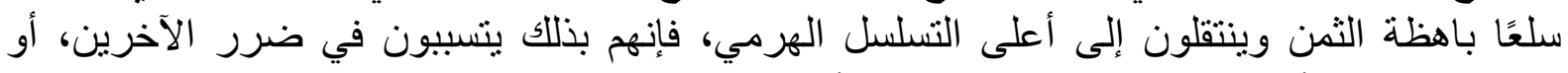

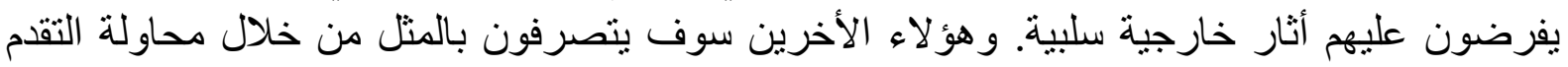

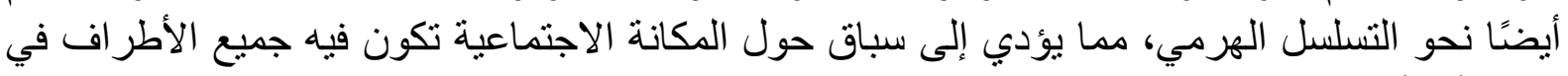

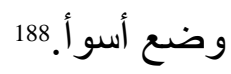

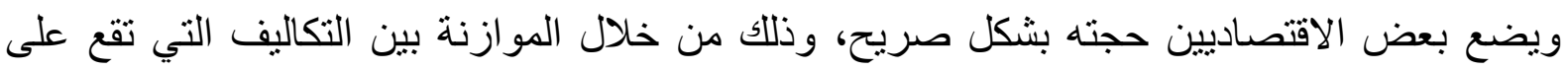

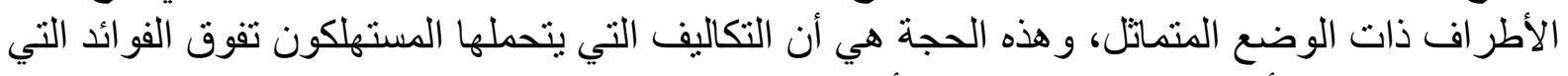

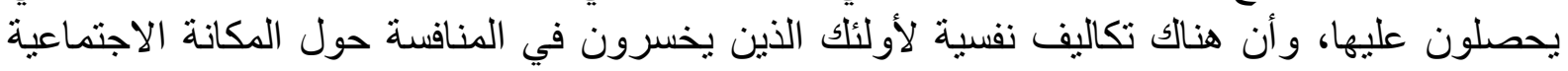

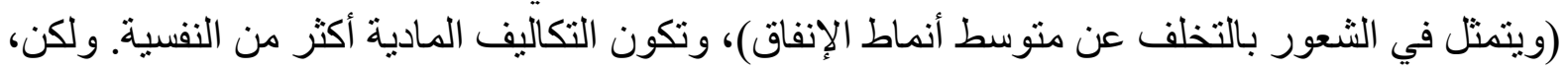

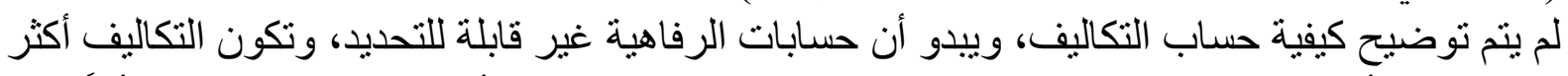

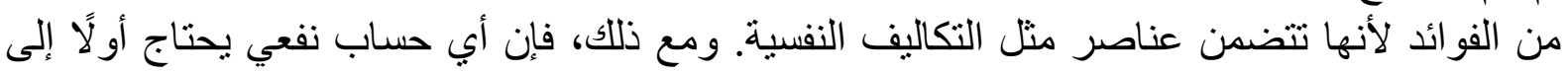

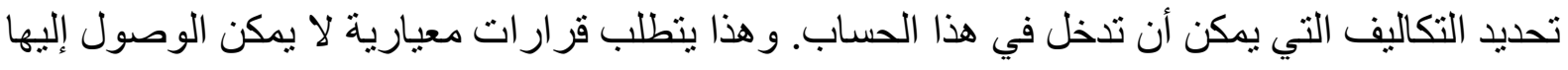

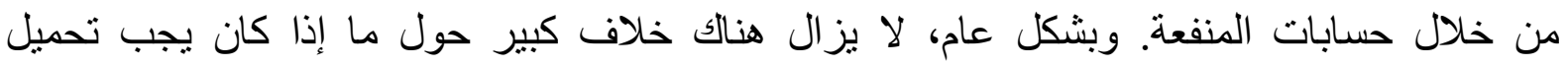

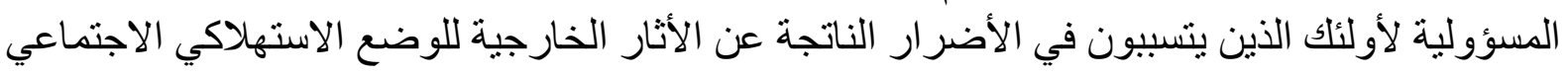

${ }^{187}$ Hausman, D. (1992). 'When Jack and Jill Make a Deal', Social Philosophy and Policy, 9(1), P. 103.

${ }^{188}$ Frank, R. (2008). 'Should Public Policy Respond to Positional Externalities?' Journal of Public Economics, 92(8-9), P. 1779. 
أم لا. ولقد دعم البعض استيعاب الأثار الخارجية للوضع الاستهلاكي الاجتماعي،189 بينما انتقدها البعض الآخر بشدة.

وتتثير كل هذه الحالات من الأثار الخارجية إلى المشاكل المختلفة المرتبطة بالحسابات النفعية المجردة،

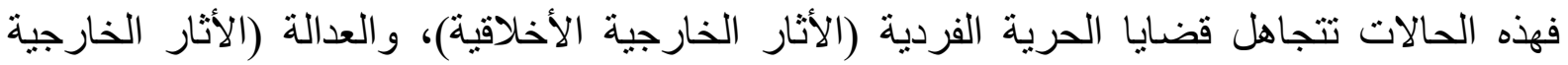

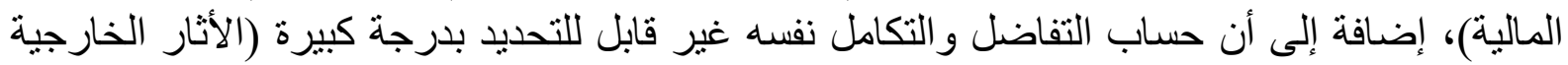
للوضع الاجتماعي). ولكن، كان الاقتصاديين وما زالوا حتى الآن ينتقدوا التحليلات الخاصة إنها بالأنثار الخارجية الاقتصادية بدون تقديم بديل. 191 فهل من الممكن إيجاد أرضية صلبة الإنة لتقديم تحليل معياري للأنار

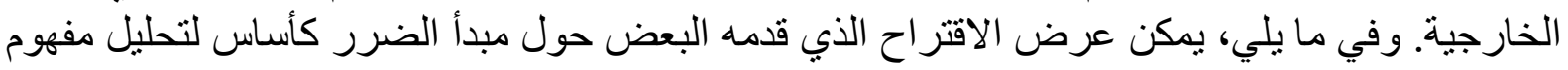

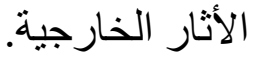

\section{ثانيًا: مبدأ الضرر ونظرية المصالح الأساسية}

بداية يمكن القول أن مبدأ الضرر قد تم تقديمه كمعيار للسماح للدولة بالتدخل في الحياة الخاصة للأفر اد.

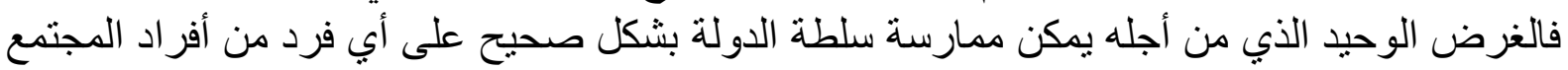

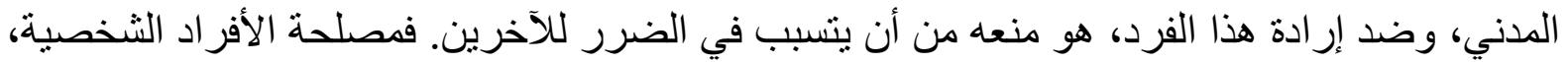

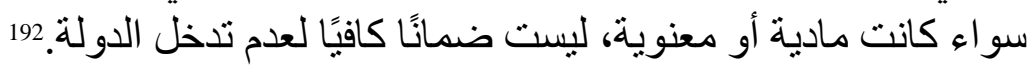

وفي هذا السياق، يمكن توضيح التشابه بين مبدأ الضرر ومفهوم الأثار الخارجية، ويمن تقديم بعض

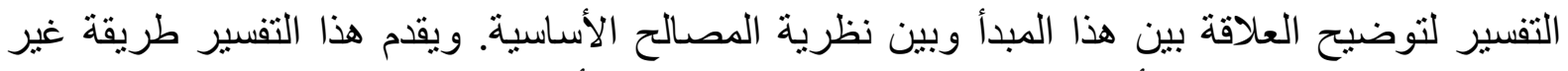

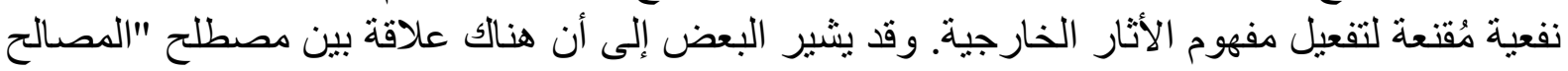

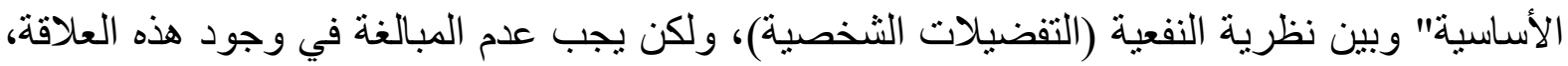

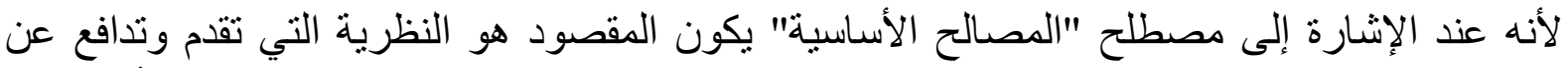

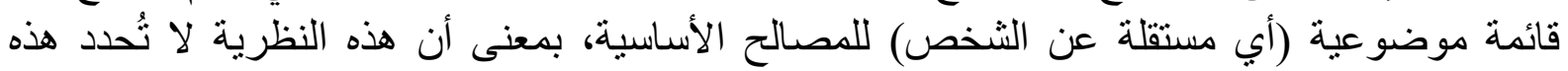
المصالح بناءً على التفضيلات عوبة الثخصية.

إن تسبب شخص معين في إلحاق الضرر بشخص آخر يشبه في العديد من النواحي فرض أثار خارجية

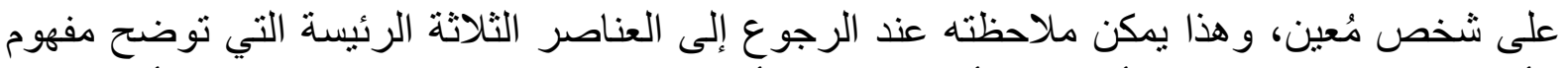

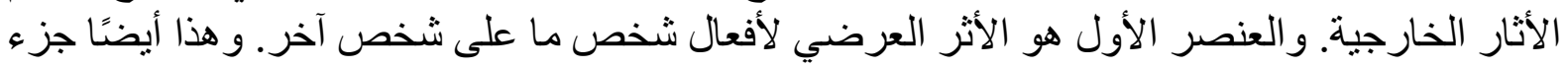

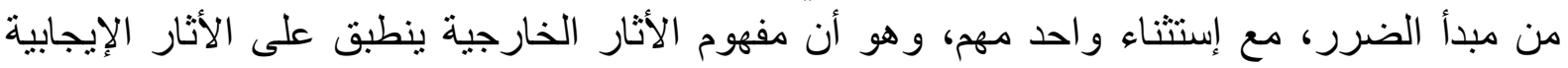

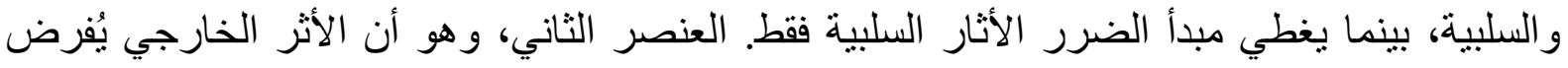

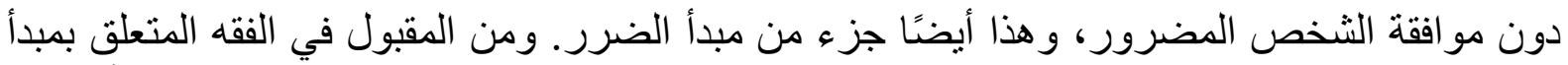

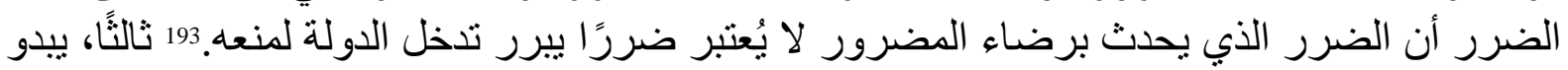

${ }^{189}$ Heath, J. (2005). 'Liberal Autonomy and Consumer Sovereignty', in J. Christman and J. Anderson (eds.), Autonomy and the Challenges to Liberalism. New Essays, Cambridge: Cambridge University Press, P. 204.

190 Kashdan, A. and D. Klein (2006). 'Assuming the Positional: Comment on Robert Frank', Economic Journal Watch, 3(3), P. 412.

${ }^{191}$ Herzog, D. (2000). 'Externalities and Other Parasites', TheUniversity of Chicago Law Review, 67(3), PP. 895-923, P. 912.

192 Mill, J. S. (1991). 'On Liberty', in J. Gray (ed.), On Liberty and Other Essays, Oxford: Oxford University Press, PP. 5-12, P. 14.

${ }^{193}$ Feinberg, J. (1984). Harm to Others, Oxford: Oxford University Press, P.115. 
أن مبدأ الضرر للوهلة الأولى لا يشتمل على أي مضمون مشابه للعنصر الثالث من تعريف الأثار

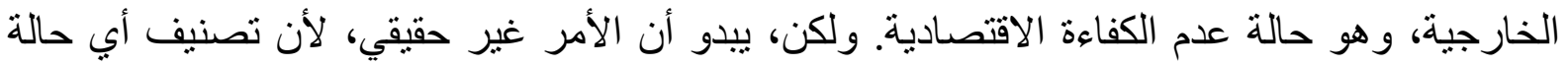

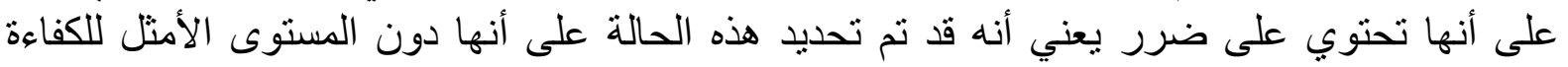

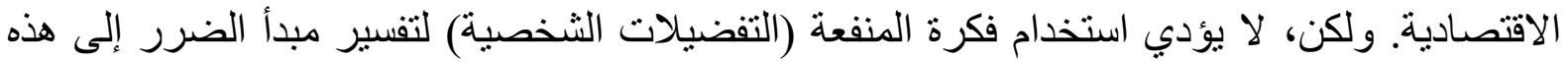

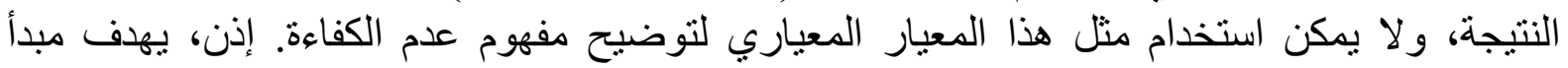

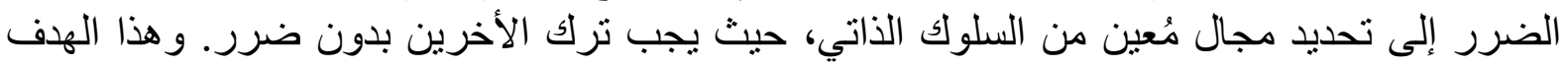

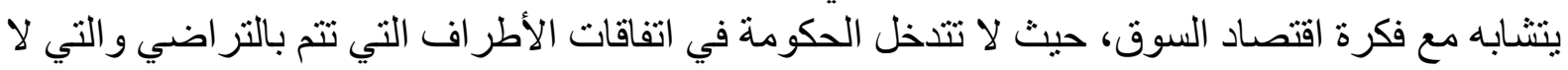

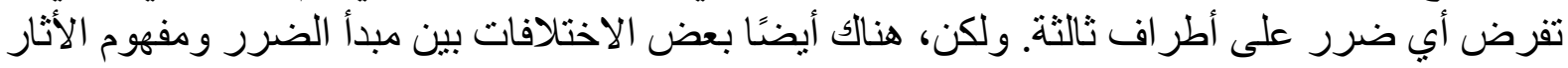

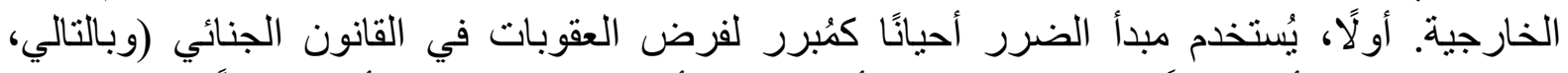

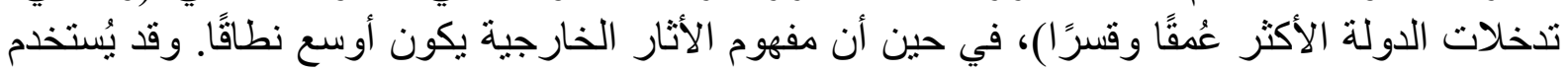

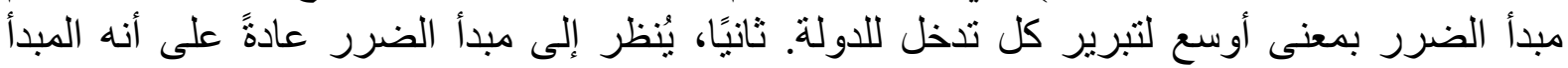

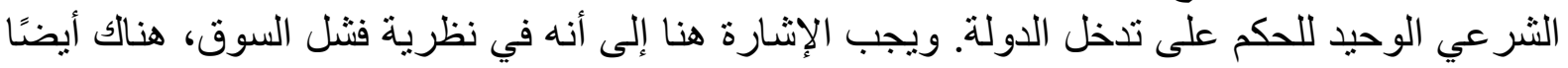

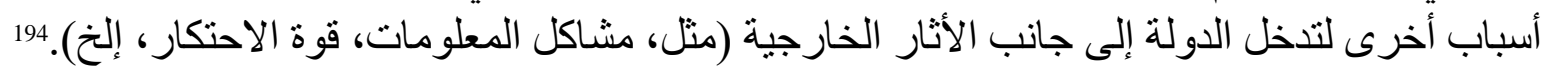

إن النقطة الأساسية حول التحليل الفلسفي لمبدأ الضرر هي أن هذا المبدأ يشتمل على نفس مشكلة التحليل

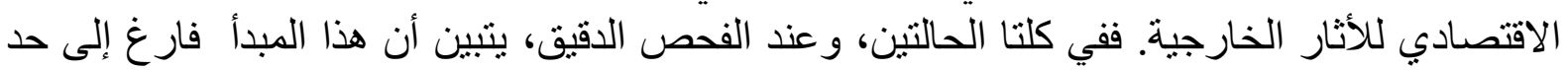

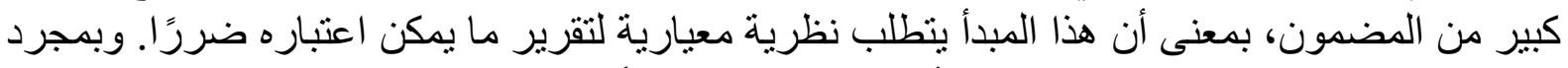

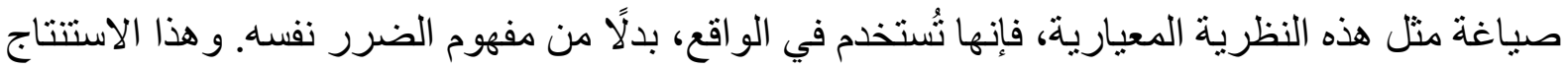

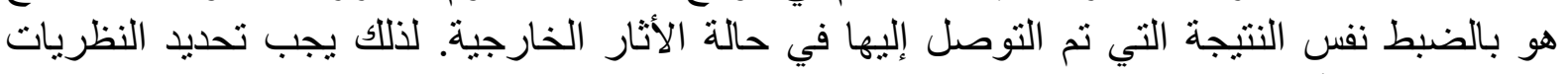

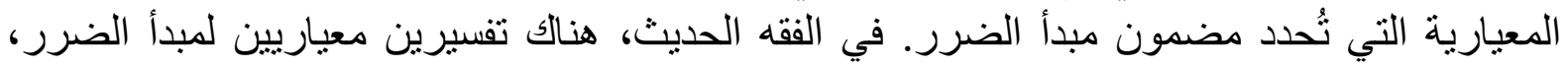
التفسير الأول من حيث مصالح الرفاهية، والثاني من حيث الاستقالية الثنخصية.

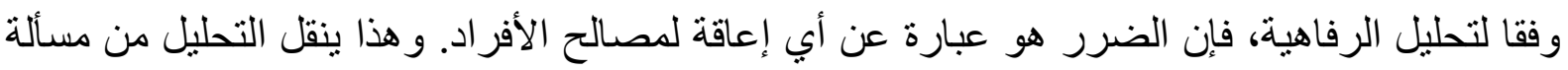

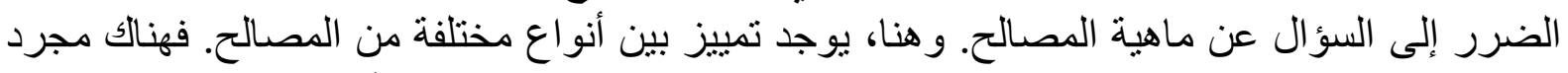

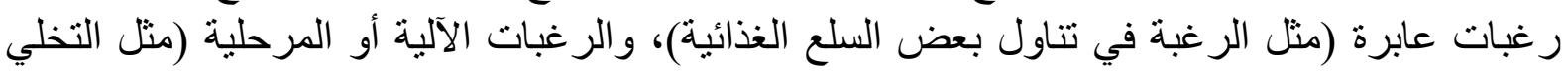

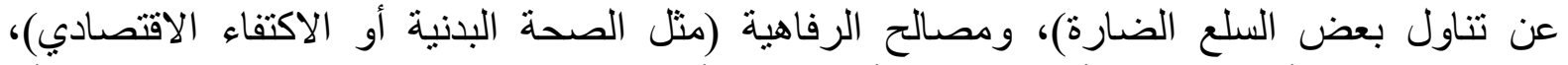

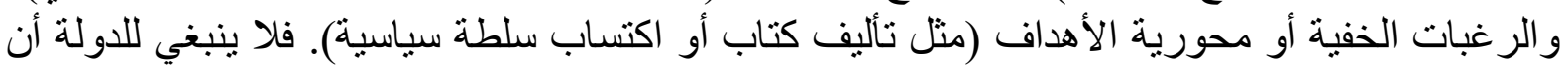

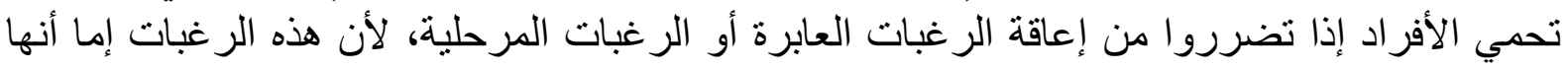

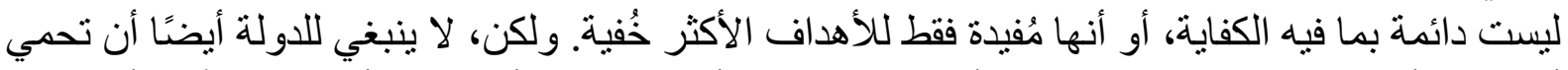

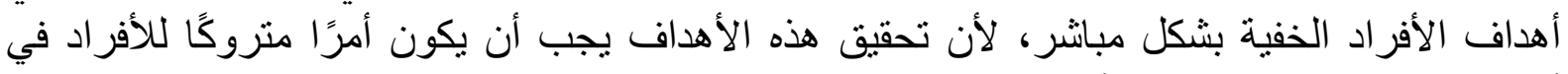

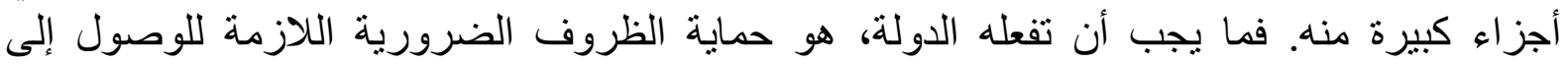

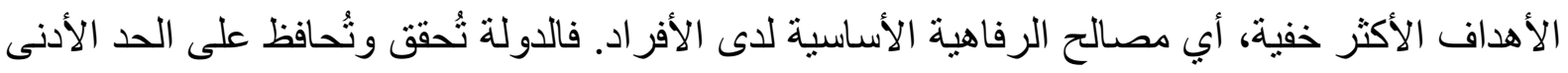

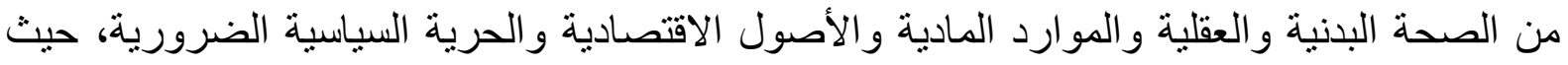

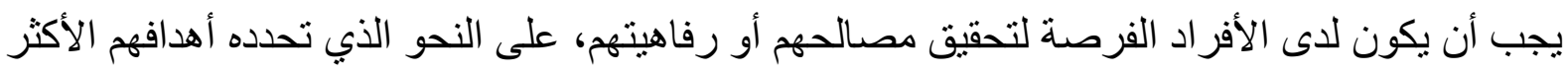

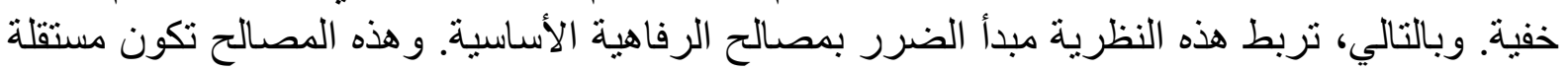

${ }^{194}$ Wertheimer, A. (2002). 'Liberty, Coercion, and the Limits of the State', in Robert Simon (ed.), The Blackwell Guide to Social and Political Philosophy, Malden, MA \& Oxford: Blackwell Publishers, P. 38.

${ }^{195}$ Holtug, N. (2002). 'The Harm Principle', Ethical Theory and Moral Practice, 5(4), P. 357. 
عن الرغبات أو الاهتمامات المحددة الخاصة بشخص معين، فهي ما يهتم به الجميع، بحكم وجود رغبات ومصالح أخرى أكثر تحديدًا و أكثر شخصية. الاته 196

و التفسير البديل لمبدأ الضرر هو أنه يجب فهم مبدأ الضرر على أنه حماية لشروط الاستقلالية الشخصية.

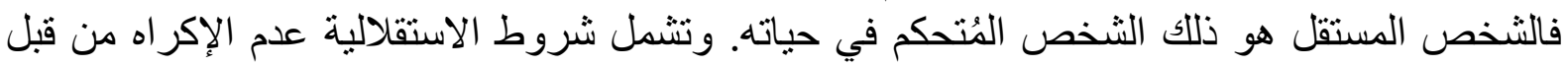

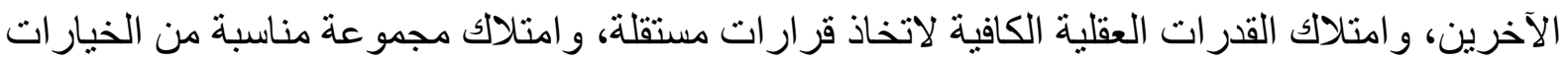

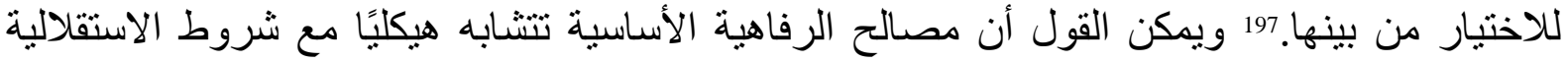

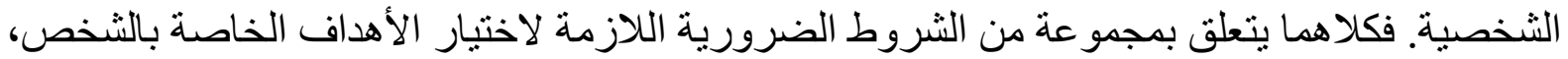
أو تحقيق أهداف أكثر خفية. وهذا التشابه بين كلا النظريتين - من حيث مجموعة الثروط الثرونة الموضو عية

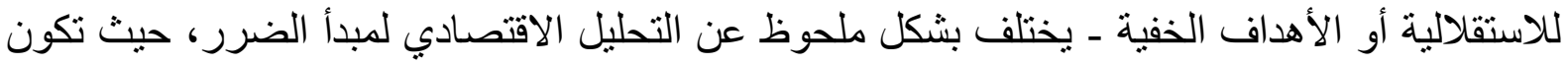

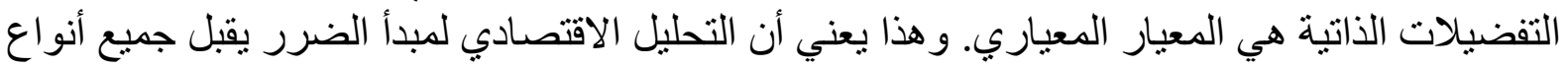

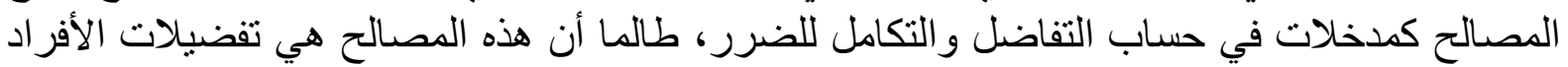
موضوع التحليل. وهذا التحليل يجعل مفهوم الضرر أو الأثار الخارجية متوقف على قنى فناعات عابرة و أهداف غير ملموسة. 198

إن التقارب الجو هري بين نظريتي المصالح الأساسية والاستقلالية الثخصية حول فكرة الضرر يدور

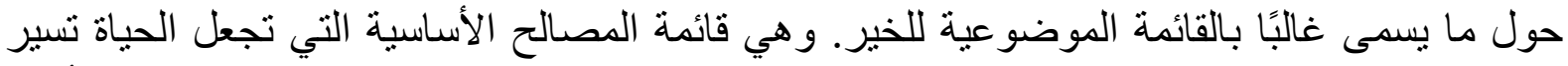

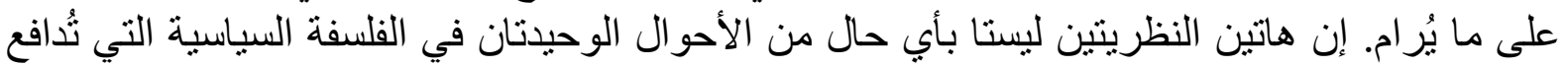

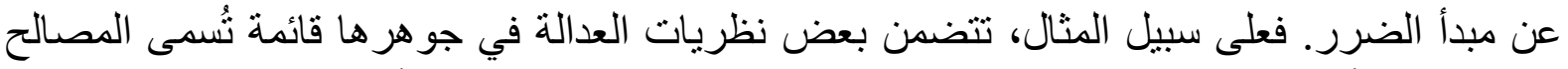

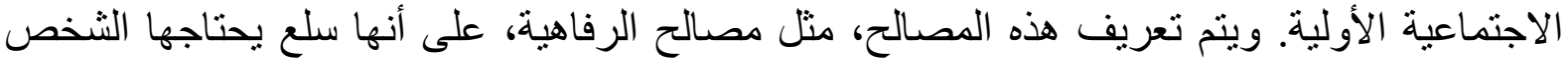

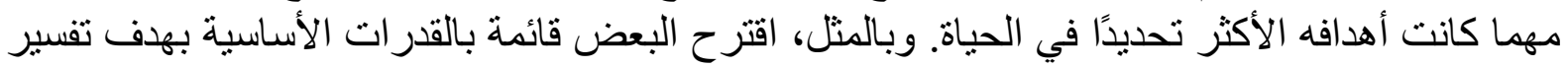
مبدأ الضرر. 199 وقد أنتج آخرون نظريات عن حقوق الإنسان الأساسية أو السلع الأساسية للإنسان.

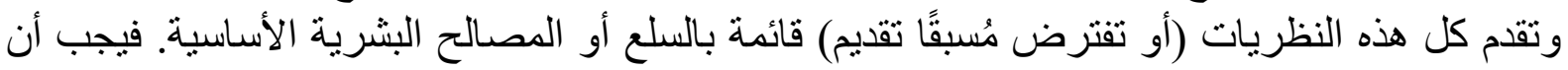

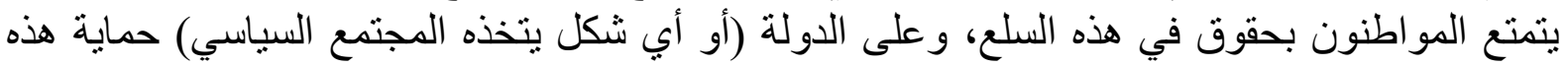

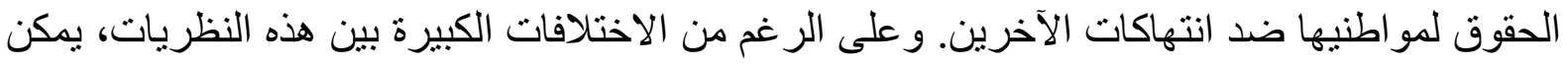

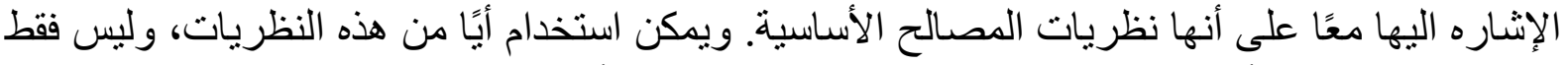

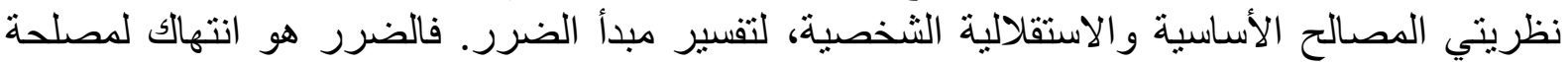
أساسية. وفي سياق هذا التحليل، ليس المطلوب اختيار نظرية معينة ضمن هذه الفئة، كل ما هو مطلوب

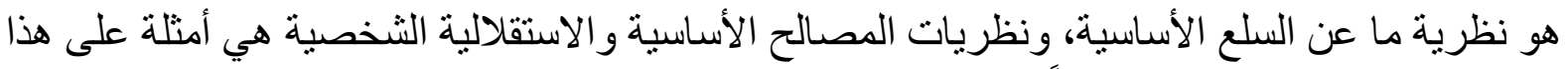
النوع من النظريات الأكثر ارتباطًا بمبدأ الضرر. ولكن يمكن للباحث بيساطة أن يأخذ نظريته المفضلة على سبيل المثال، و التفكير فيها عند تفسير مبدأ الضرد الضرد.

قد يكون من الممكن استخدام نظريات المصالح الأساسية في إيجاد حلول أكثر منطقية لبعض أنواع الأثار

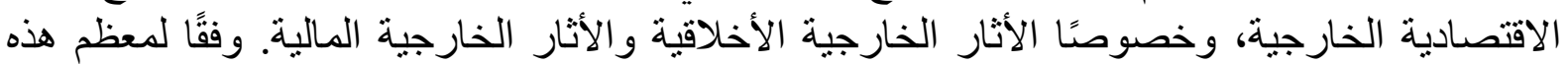

\footnotetext{
${ }^{196}$ Feinberg, J. (1984). Harm to Others, Oxford: Oxford University Press, P.56.

${ }^{197}$ Raz, J., (1986). The Morality of Freedom, Oxford: Clarendon Press, P.70.

${ }^{198}$ Raz, J., (1987). Autonomy, Toleration, and the Harm Principle', in R. Gavison (ed.), Issues in Contemporary Legal Philosophy. The Influence of H.L.A. Hart, Oxford: Clarendon Press, P. 313.

${ }^{199}$ Nussbaum, M., (2000). Women and Human Development. The Capabilities Approach, Cambridge: Cambridge University Press, P.12.

${ }^{200}$ Finnis, J., (2011). Natural Law and Natural Rights, Oxford: Oxford University Press, P.198.
} 


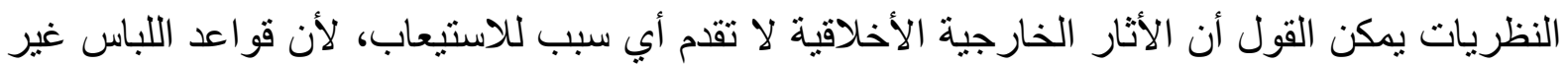

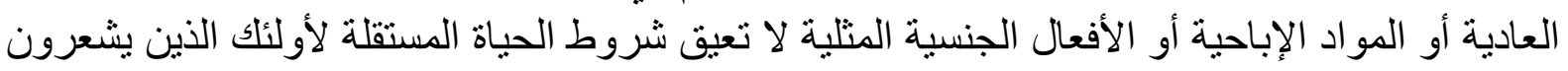

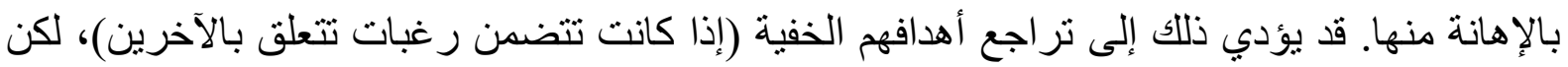

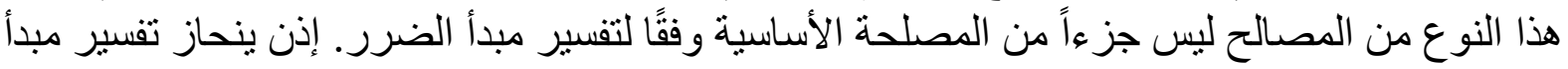

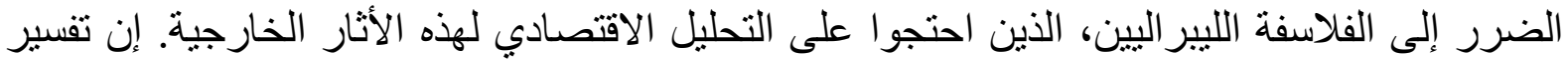

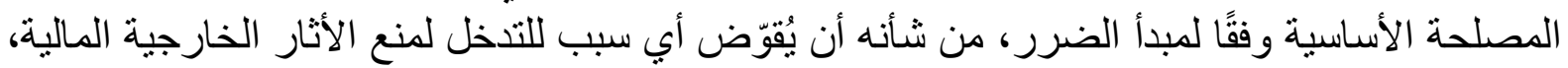

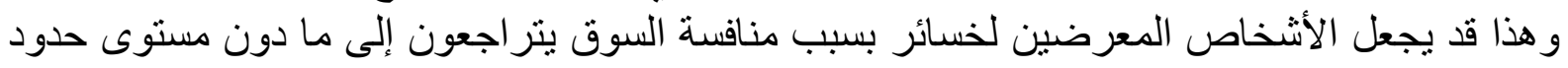

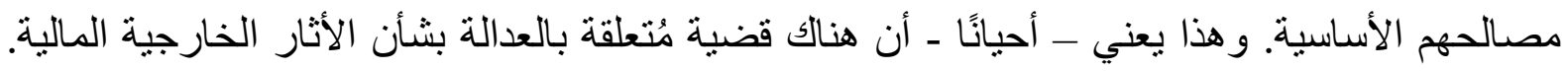

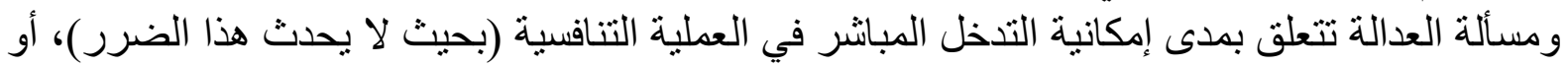

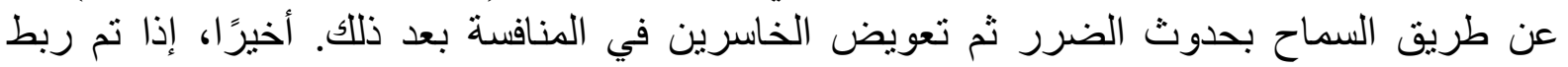

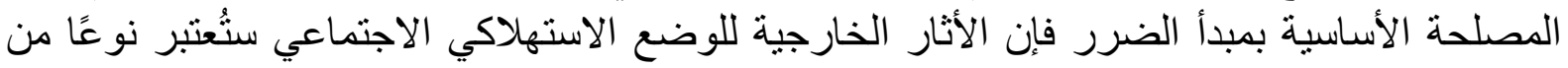

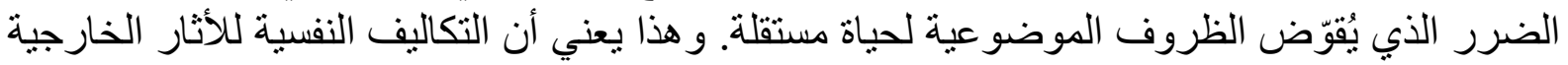

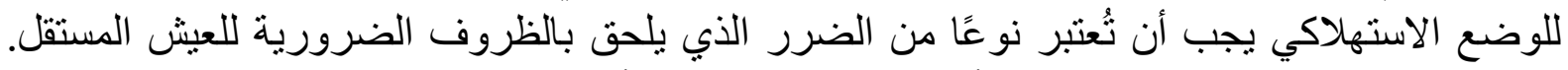

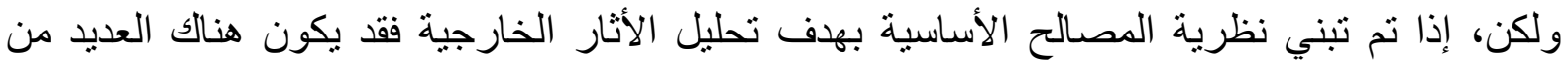

وقد يعترض البعض على أن مفهوم الضرر لا يمكن أن يُستخدم مع حالات الأثار الخارجية الإيجابية

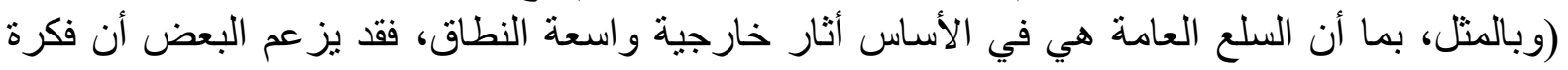

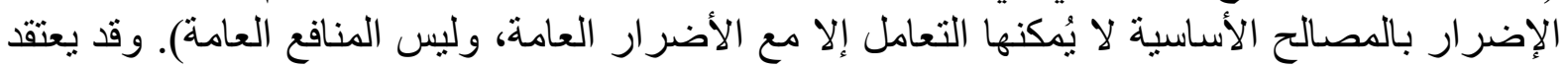

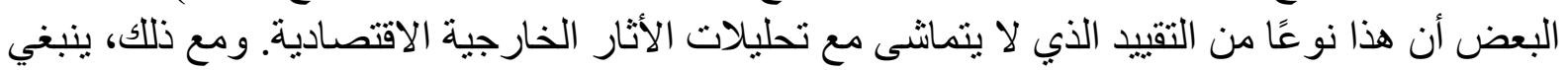

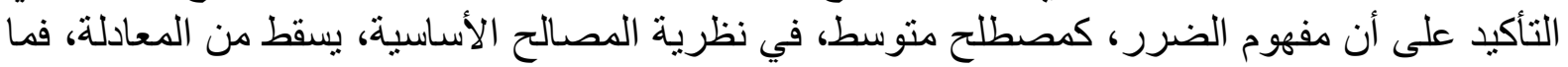

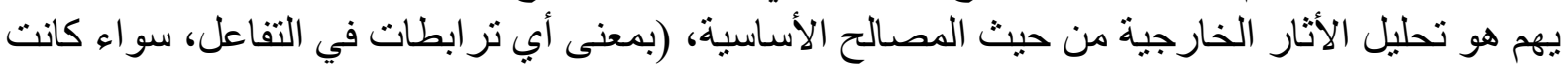

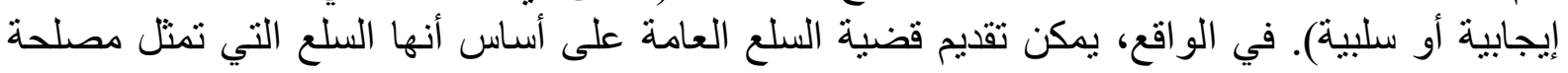

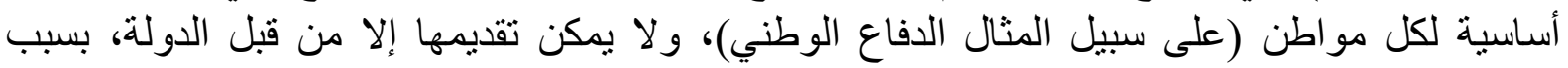

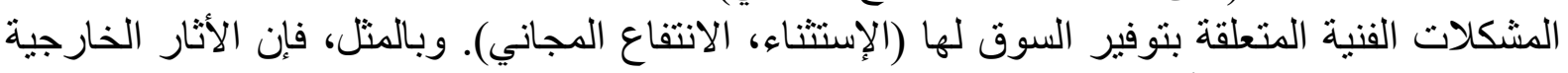

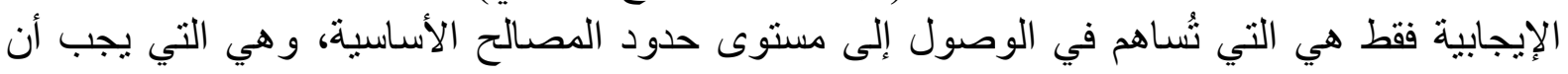

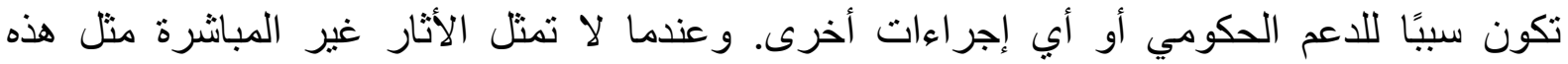

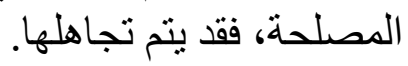

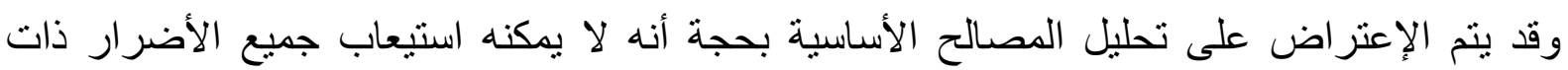

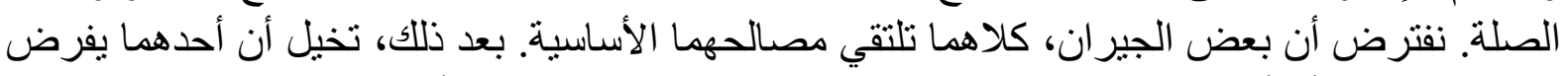

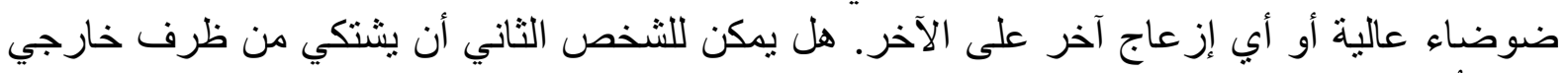

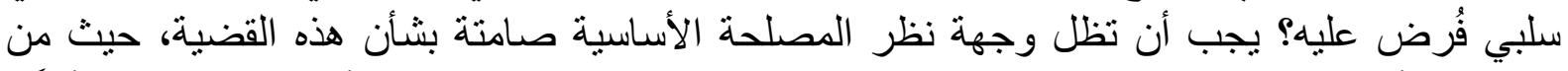

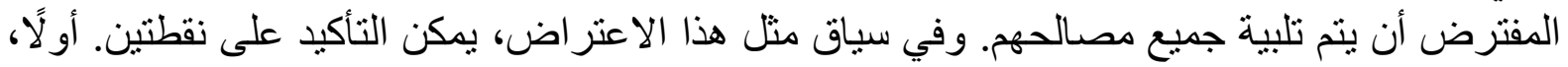

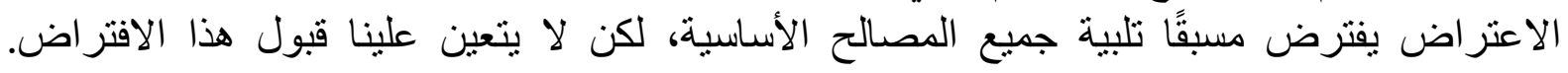

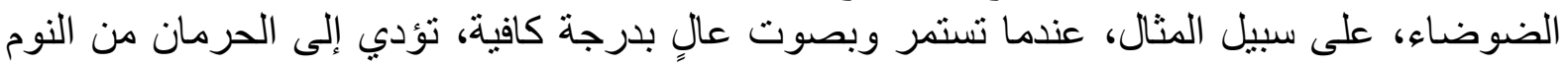

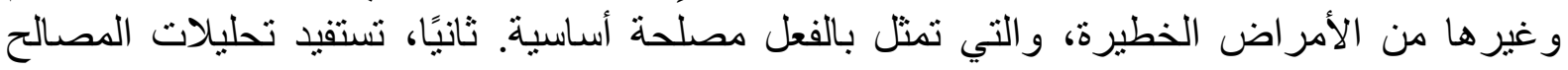

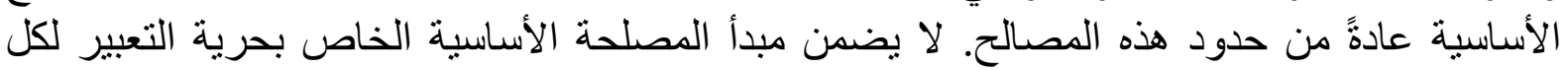

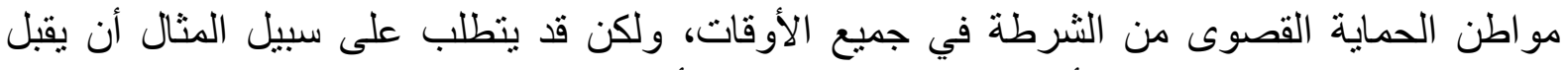
الثخص القيود في اللحظات و الأماكن التي يمكن للشخص في أن يسير فيها في الثوار فئ للتعبير عن قضيته. 
إذا نم الوصول في هذه الحالة إلى حدود الحماية من الضوضاء، فيجب بالفعل التغاضي عن المضايقات

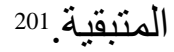

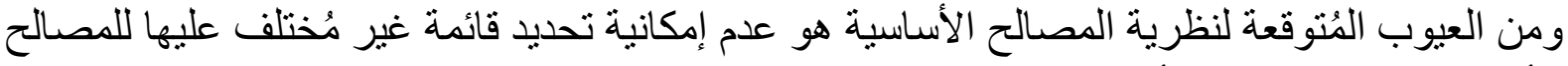

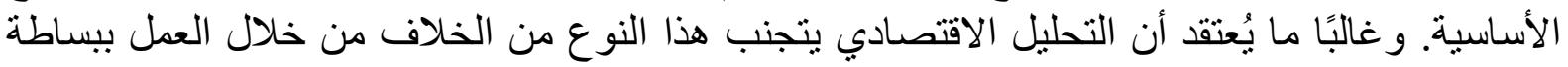

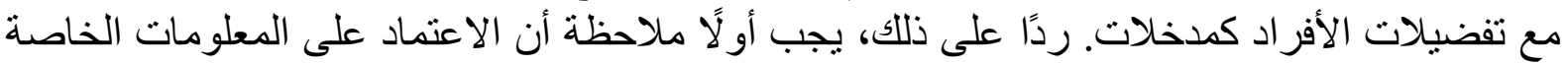

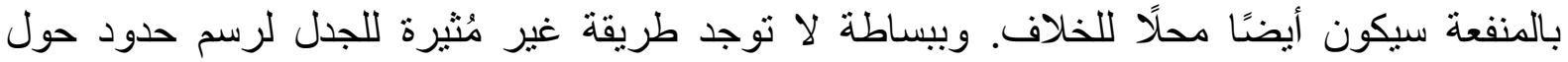

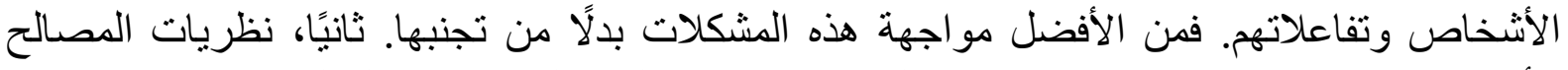

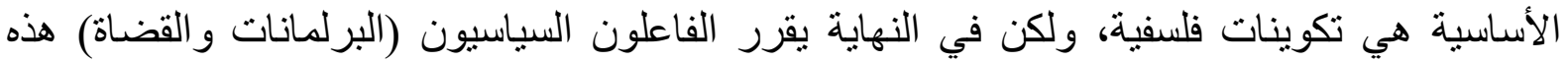

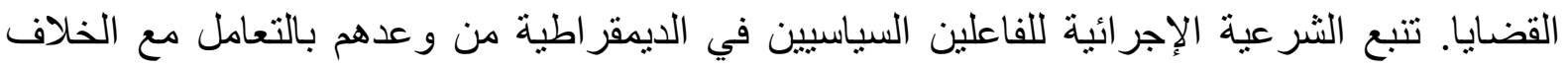

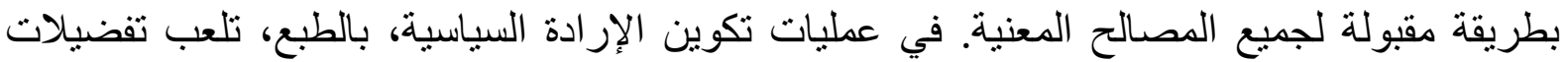

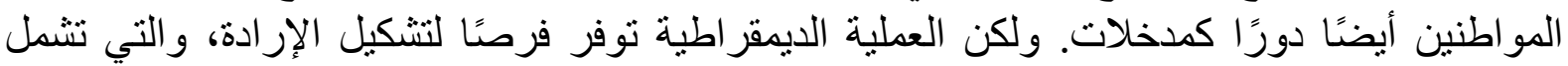

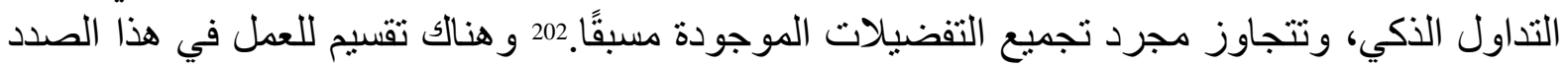

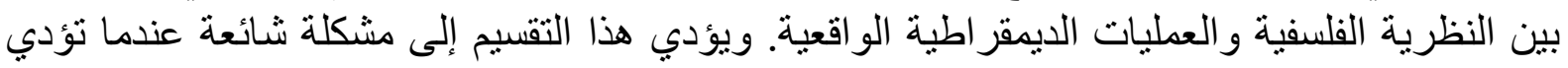

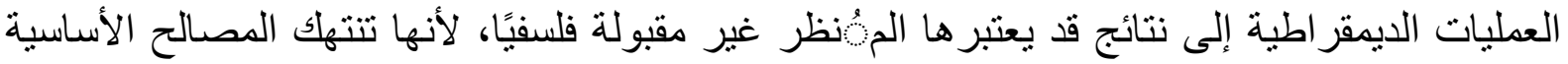

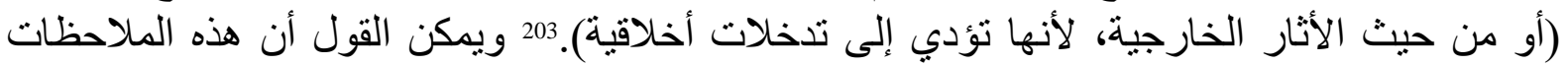
كافية لإظهار تماسك وجاذبية نظريات المصنالح الأساسية في مجال تحليلات الأنار الخار الخارجية.

\section{المبحث الثاني: أنواع الأثار الخارجية الاقتصادية}

يمكن تقسيم الأثار الخارجية إلى إيجابية وسلبية، ويمكن تقسيمها أيضًا إلى أنار خارجية مالية وفنية.

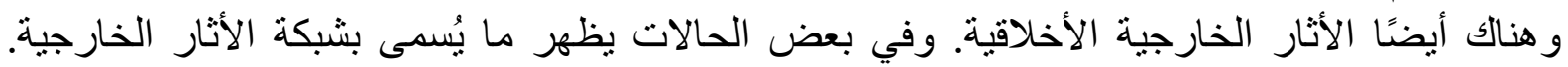

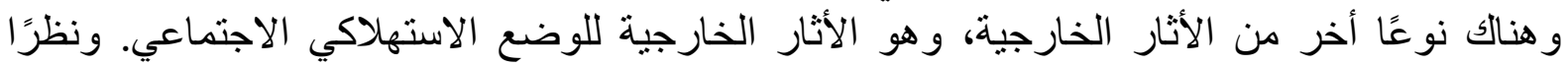

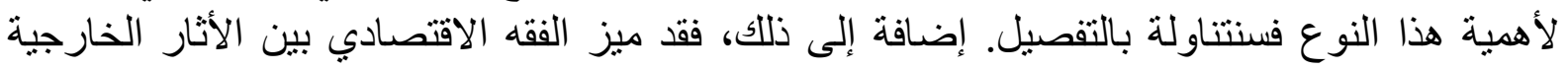
للسلع العامة و السلع الخاصة.

أولاً: الأثار الخارجية السلبية والإيجابية

بدايةً يجب معرفة أسباب فثل المشترين و البائعين في الأسواق في حساب الأثار الخارجية التي تنشأ عن

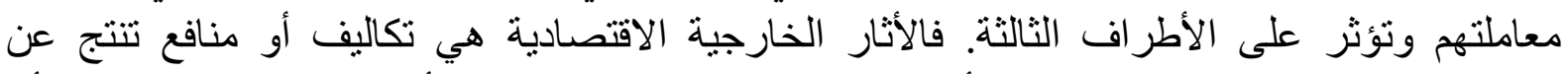

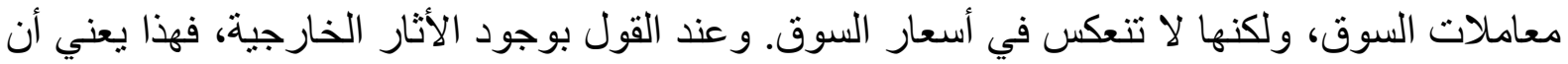

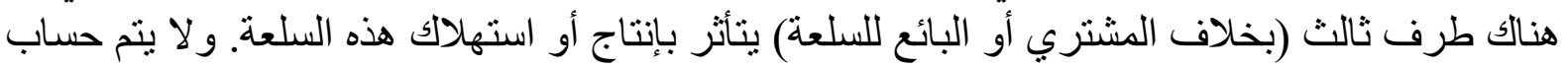

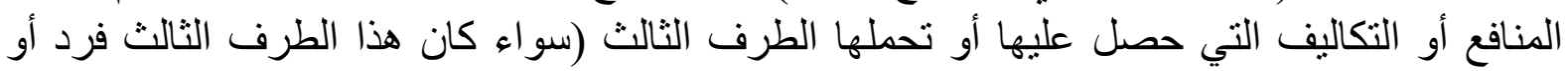
شركة) من قبل المشترين أو البائعين للعنصر الذي نشأ عن إنتاجه أو استهلاكه أثنارًا خارجية.

\footnotetext{
${ }^{201}$ Shiffrin, S. V. (2000). 'Paternalism, Unconscionability Doctrine, and Accomodation', Philosophy \& Public Affairs, 29(3), P. 205.

${ }^{202}$ Lewinsohn-Zamir, D. (1998). 'Consumer Preferences, Citizen Preferences, and the Provision of Public Goods', The Yale Law Journal, 108(2), P. 377.

${ }^{203}$ Claassen, R. (2011). 'Making Capability Lists. Philosophy versus Democracy', Political Studies, 59(3), P. 491.
} 
و الطرف الثالث هو الثخص الذي يتحمل، مثلًا، تكاليف تلوث الهو اء و الماء. و غالبًا ما يتم تنظيم هؤلاء

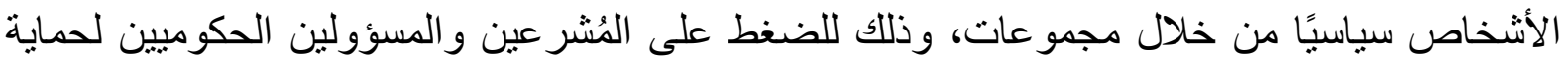

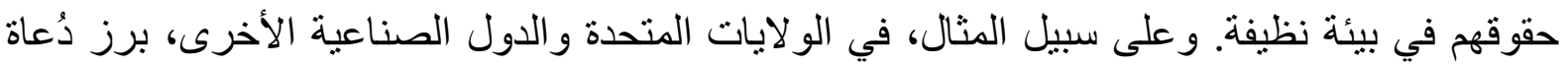

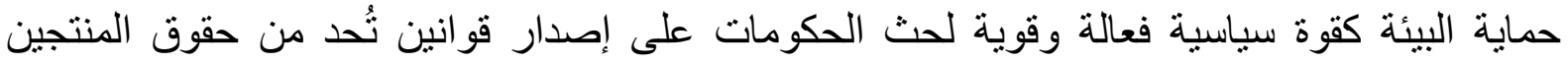

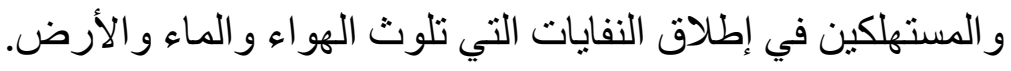

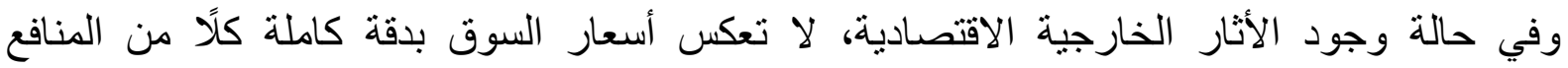

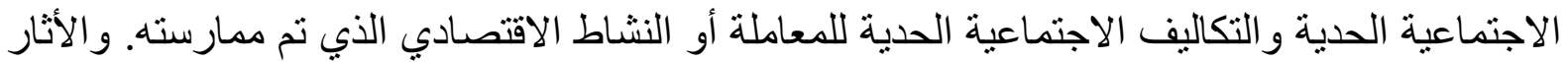

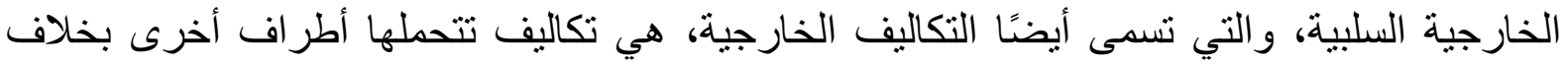

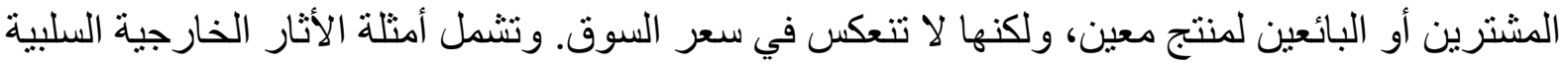

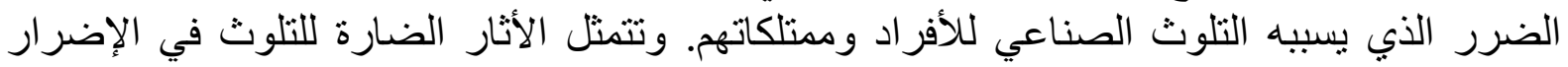

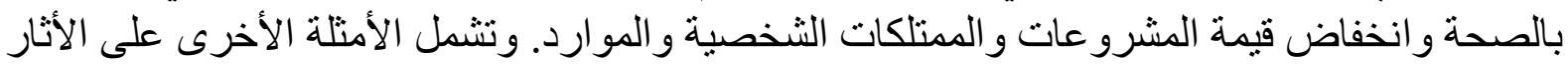

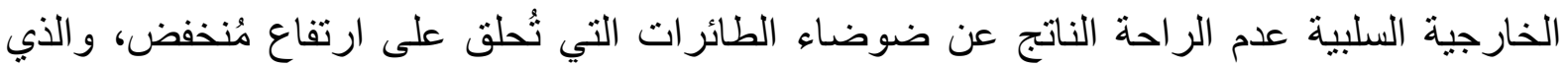

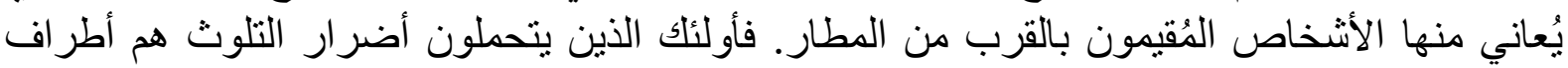

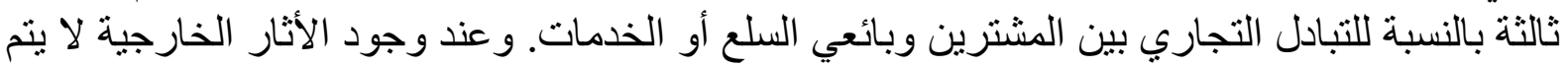
مر اعاة مصالح هذه الأطر اف من قبل المشترين والبائعين للسلع و الخدمات.

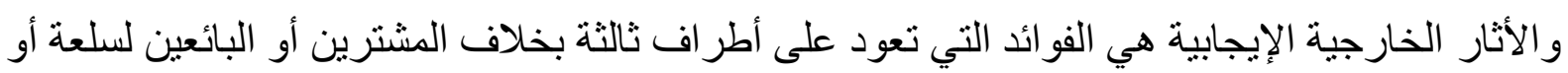

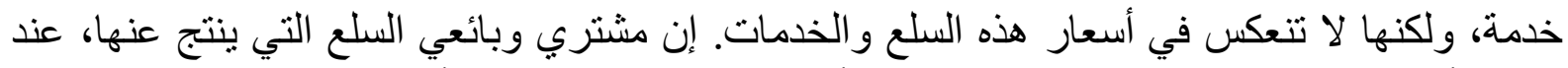

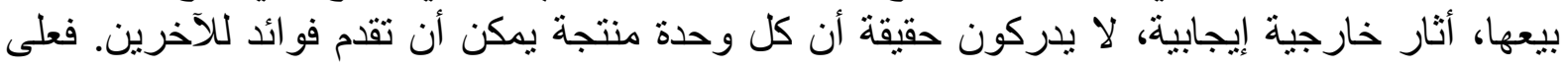

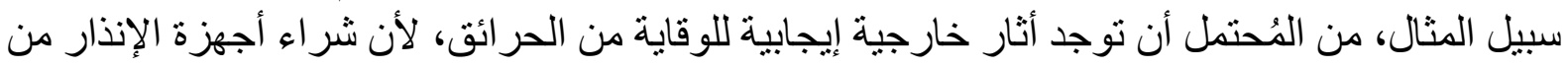

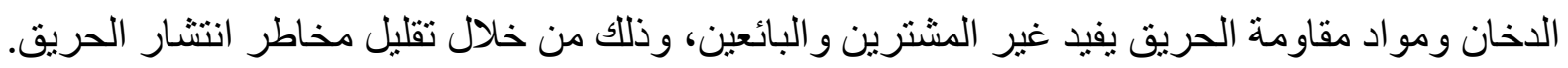

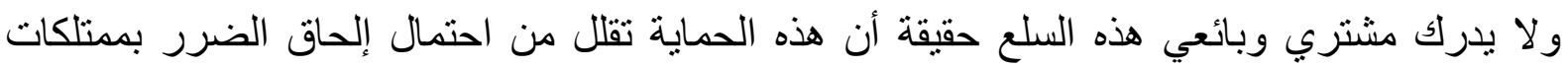

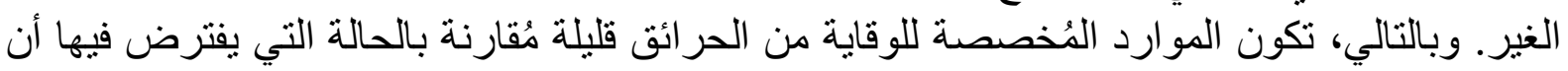
تتحمل الأطر اف الثالثة مقابل الفو ائد الخارجية التي يتلقونة لإنها.

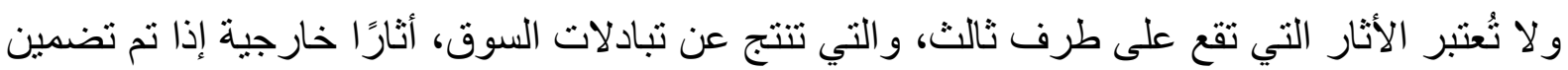

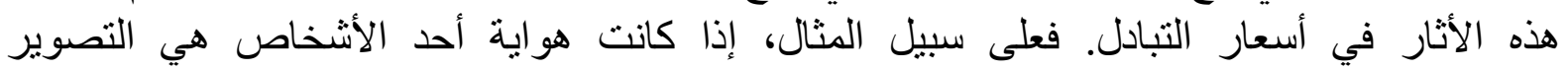

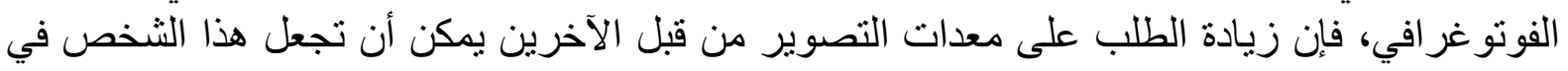

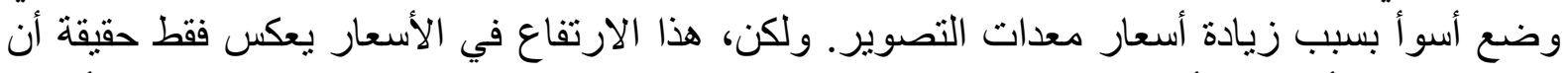

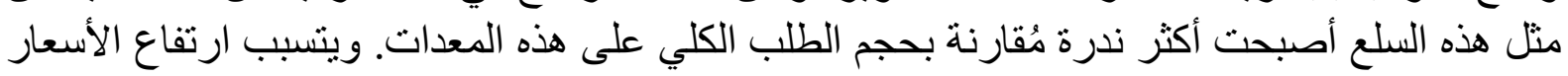

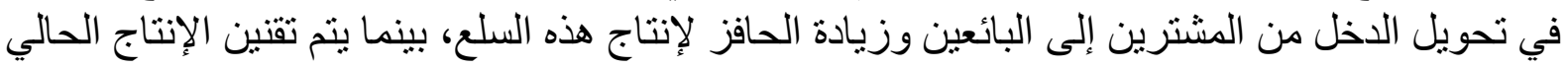

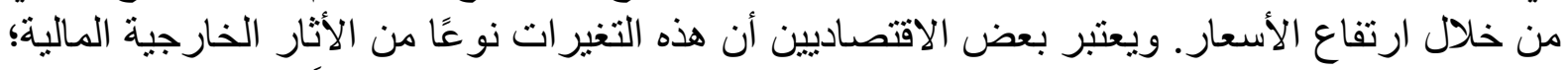

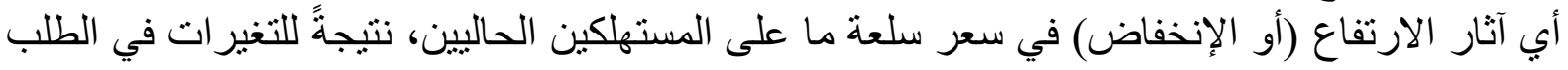

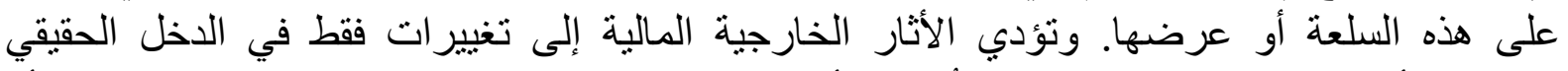

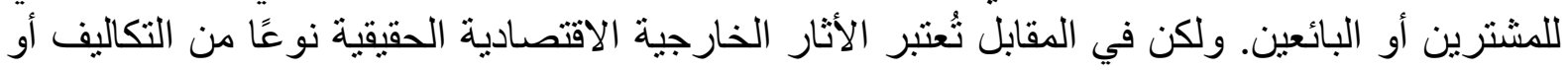

${ }^{204}$ Hyman, David N., (2011). Public Finance: A Contemporary Application of Theory to Policy, (10ed) South-Western, Cengage Learning, P. 98. 
الفوائد التي ليس لها سعر، أي أنها آثار خارجيه لتبادلات السوق، ولكنها تكون خارج نطاق جهاز

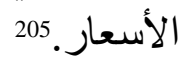

\section{ثانيًا: الأثار الخارجية العامة والأثار الخارجية الخاصة}

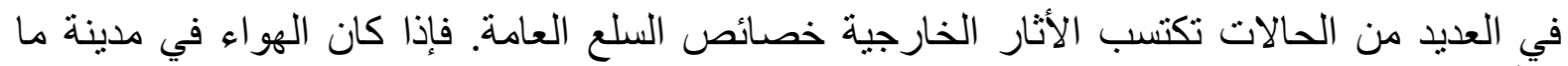

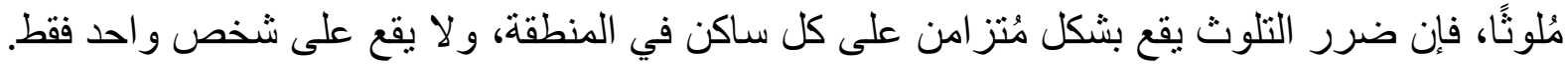

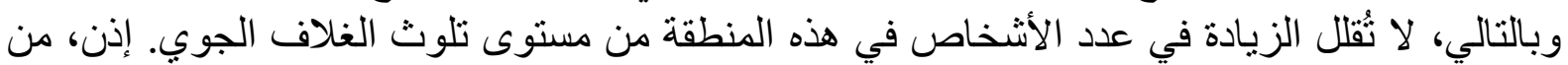

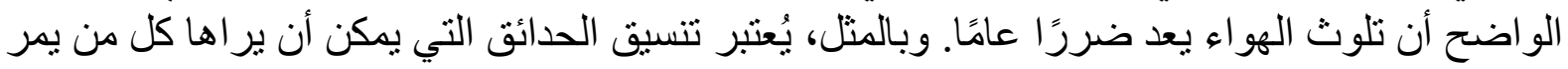

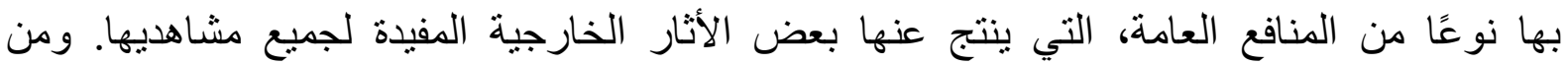

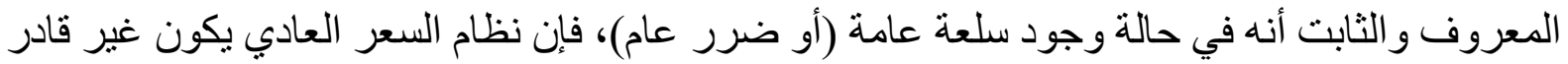

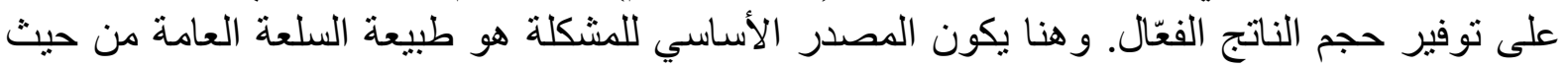

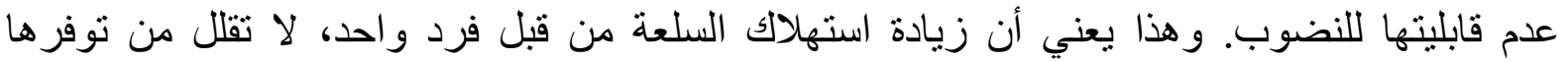

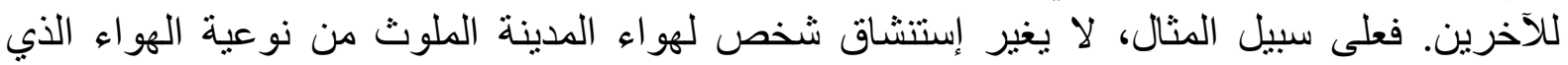

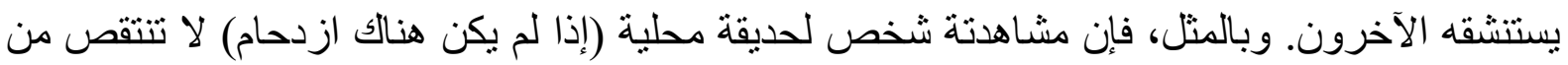
مُنتعة المشاهدين الآخرين.

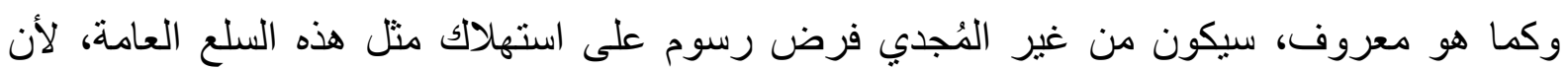

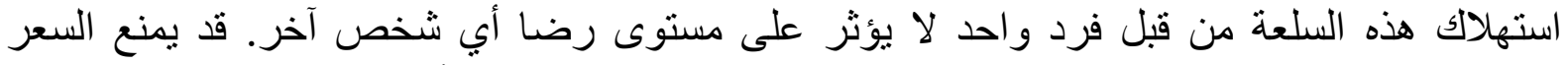

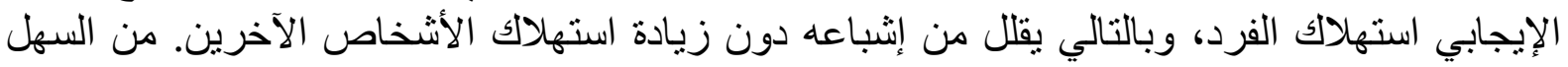

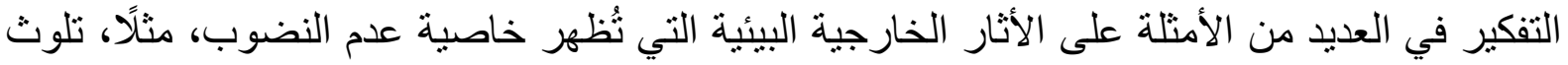

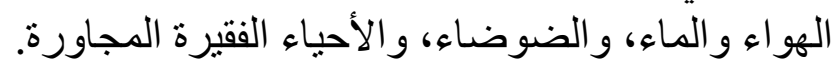

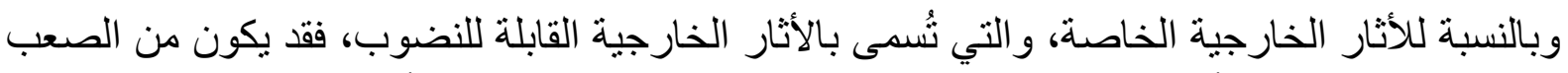

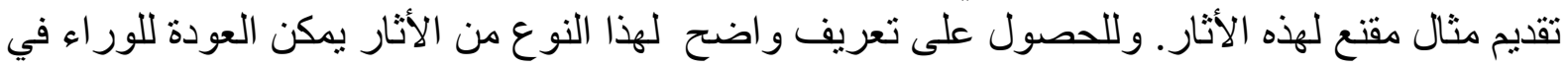

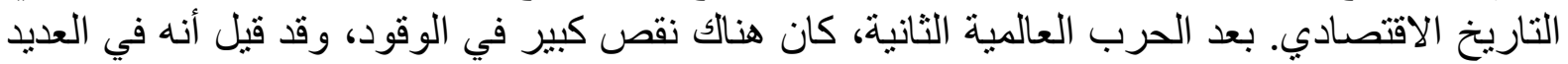

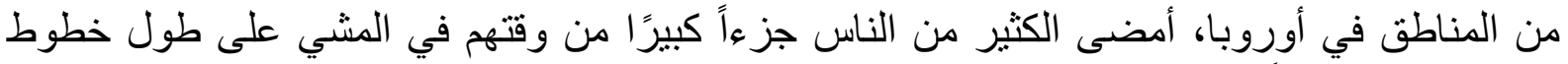

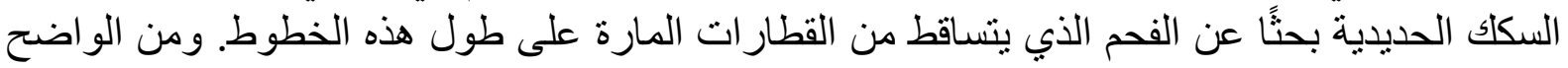

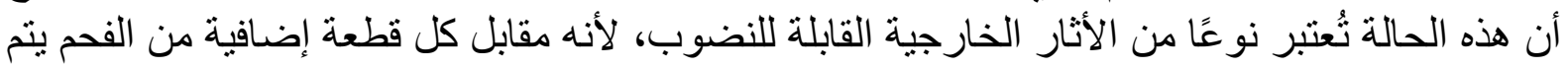
جمعها بو اسطة شخص معين، سيكون هنالك كمية أقل بكثبر متاحة للآخرين.

وكان سبب ترك الفحم على طول خطوط السكك الحديدية هو بلا شك أن شركات السكك الحديدية لم تجد المبد

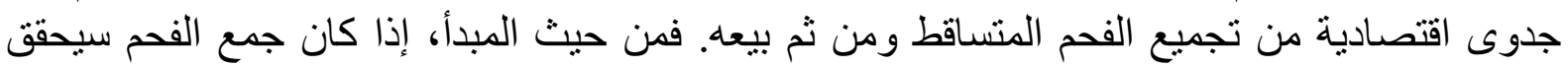

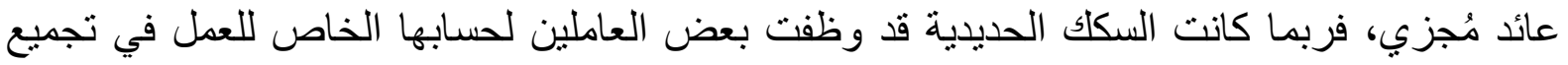

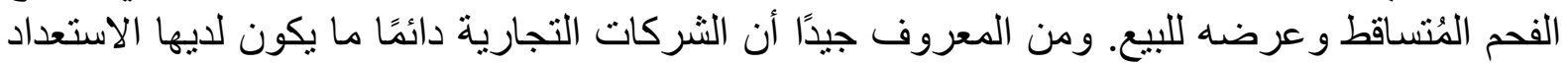

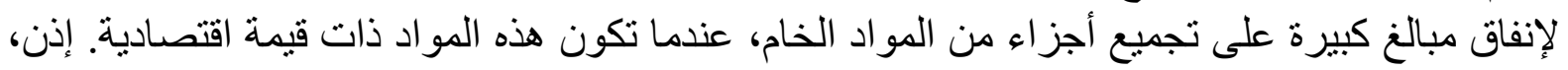

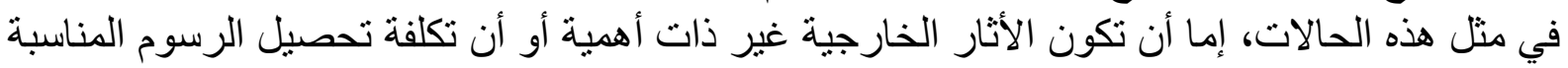

${ }^{205}$ M. Olson, Jr. and R. Zeckhauser, (June, 1970). "The Efficient Production of External Economies," American Economic Review LX, P. 512.

${ }^{206}$ Mishan, E J, (1969). "The Relationship between Joint Products, Collective Goods, and External Effects," Journal of Political Economy, University of Chicago Press, vol. 77(3), May/June, P. 342. 


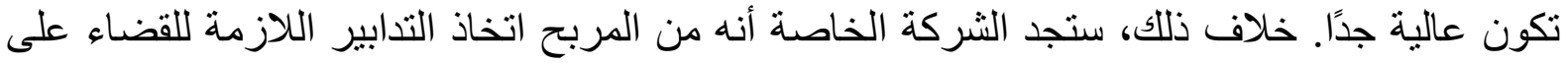

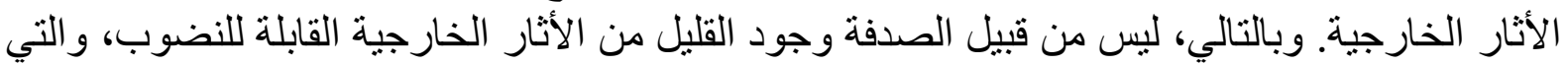

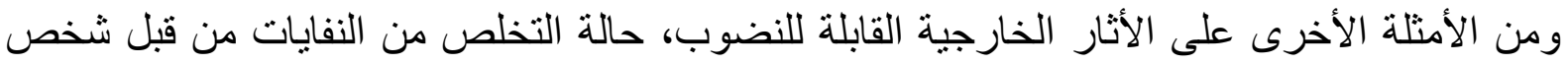

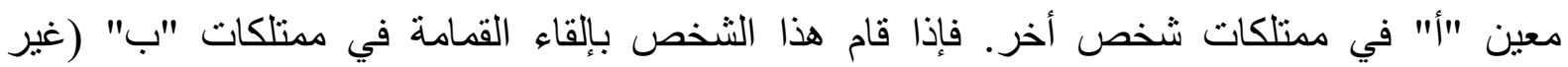

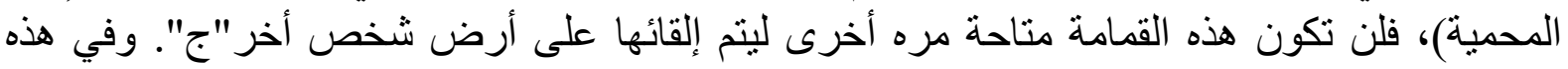

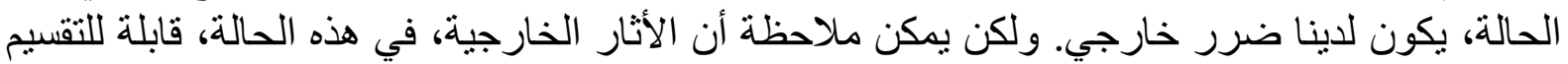

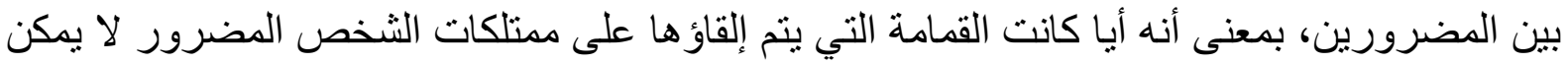

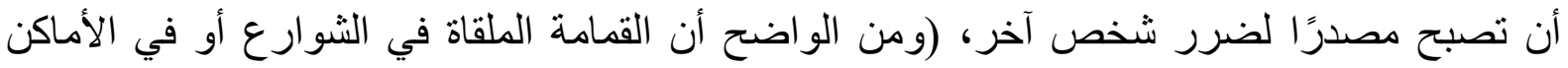

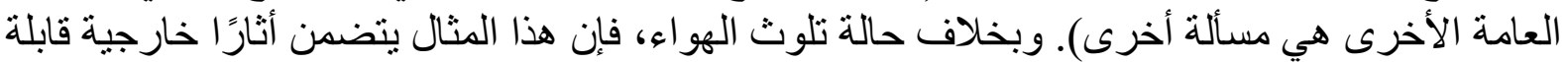

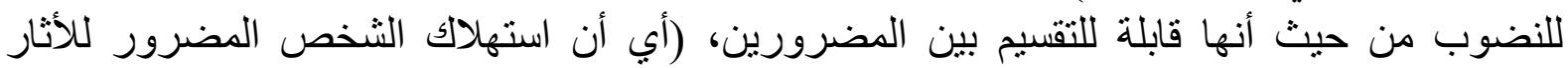

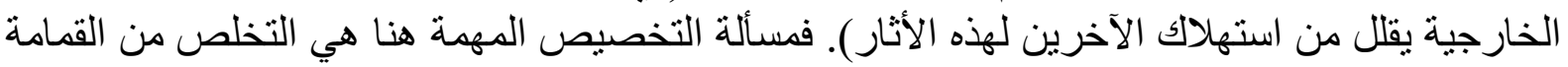

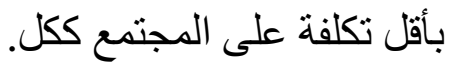

باختصار ، يمكن أن تتخذ الأثار الخارجية أحد شكلين مختلفين، شكل عام (غير قابل للنضوب)، أو شكل

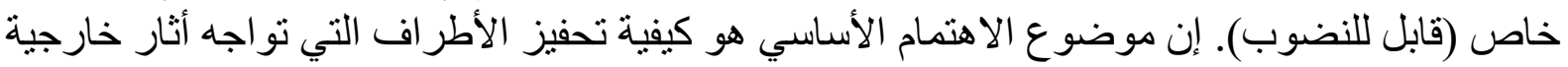

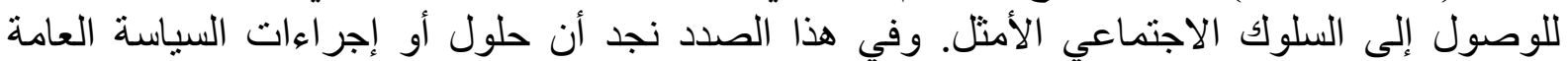

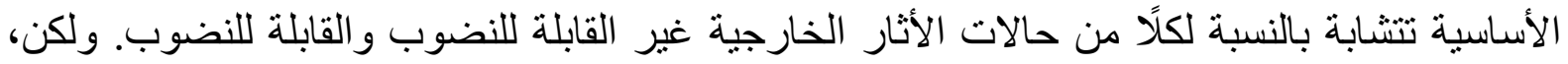
هنالك فئة فر عية من الأثار الخارجية القابلة للنضوب التي قد يتطلب مو اجهتها بعض التدابير التكميلية.

ثالثًا: الأثار الخارجية الأخلاقية

تكمُن حجة وجود الأثنار الخارجية الناتجة عن التصرفات غير الأخلاقية، التي تُسبب ضررًا غير مباشر

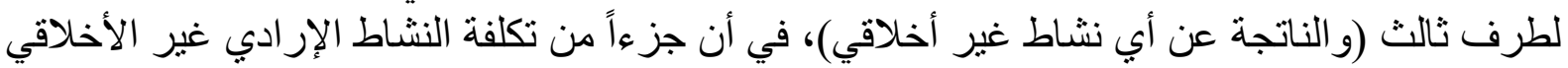

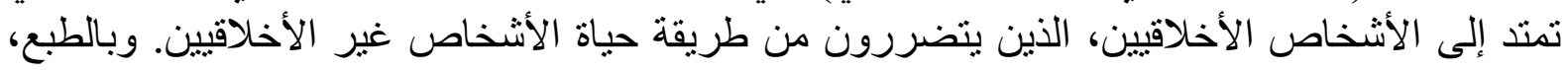

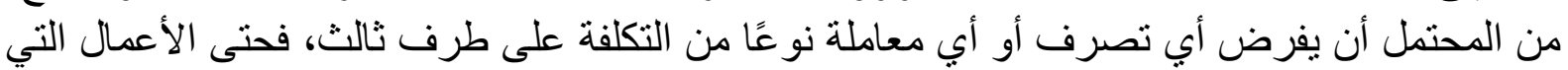

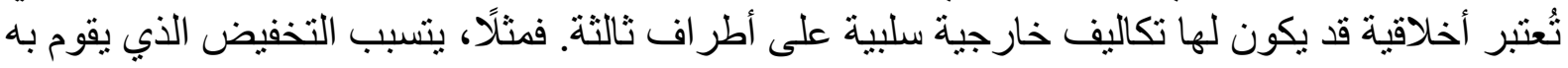
أحد المتاجر في فرض أثنار خارجية سلبية على المشرو عات الصغيرة الهية المجاورة. ولكن، التكلفة الخارجية

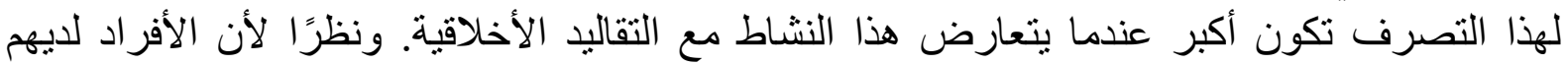

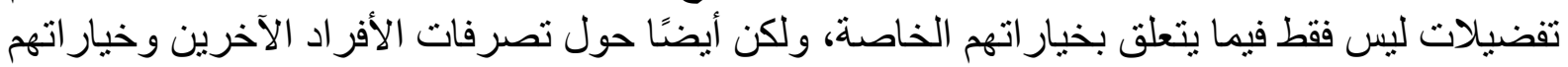

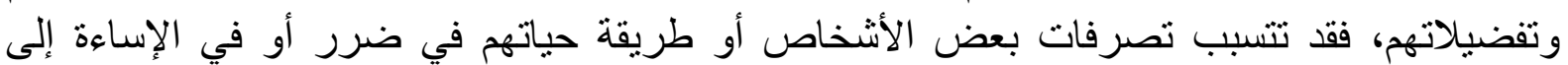

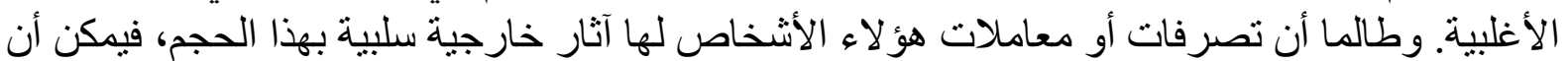

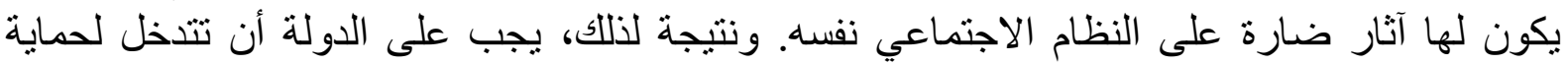
الأغلبية المُنضررة من خلال إجبار الأشخاص غير الأنير الأخلاقيين على استيعاب تكلفة لا أخلاقياتهم، وهذا

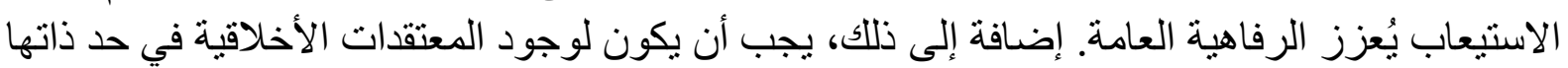
تأثير على تصميم القانون، وذلك لأن المعتقدات الأخلاقية تشكل الأذواق التي يؤدي إثبانياعها إلى إلى زيادة رفاهية الأفر اد.

${ }^{207}$ Shavell, S., (2002). 'Law versus morality as regulators of conduct', American Law \& Economics Review 4, P. 227. 
ويمكن ربط هذه الحجة بسيادة مبدأ الديمقر اطية، فالحقوق الدستورية هي في النهاية حقوق ضد الأغلبية

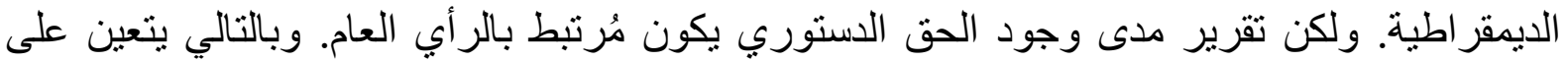

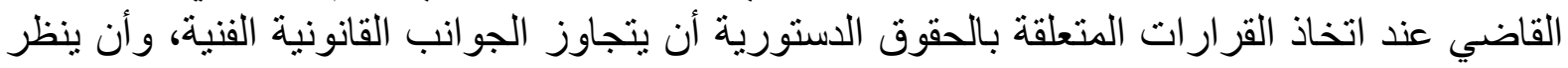

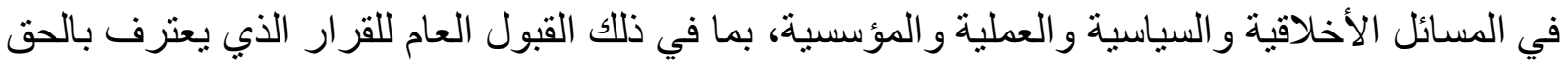
الجديد. أي أن الطريقة الديمقر اطية لا تتجاهل عقيدة الأفراد تجاه القضايا التي تُؤثر عليهم.

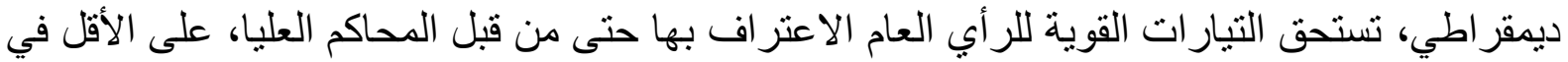

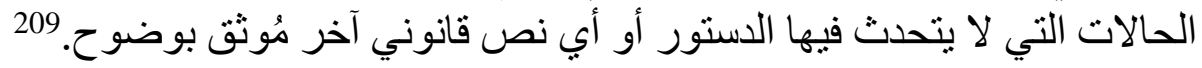

و هنا يمكن القول أن مبدأ الضرر بنطبق على هذا النوع من الأثار الخارجية السلبية. 210 وفقًا لهذا المبدأ،

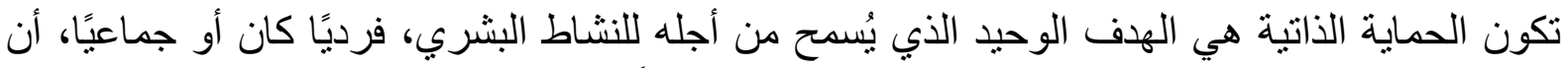

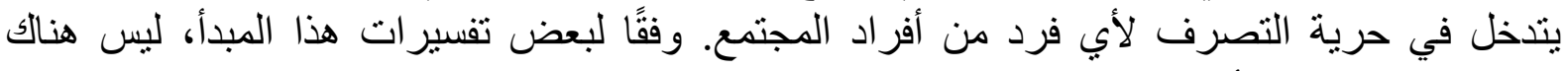

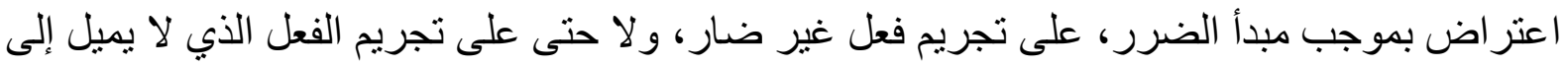

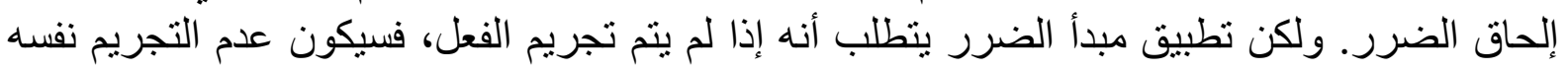
نوعًا من الضرر.

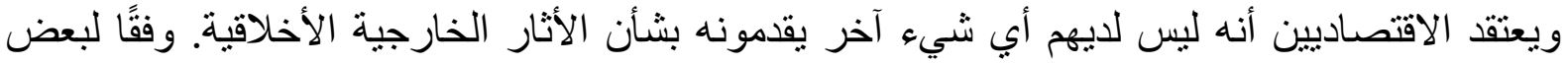

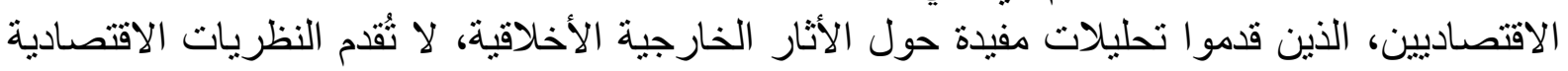

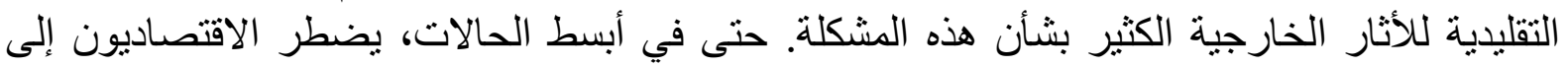

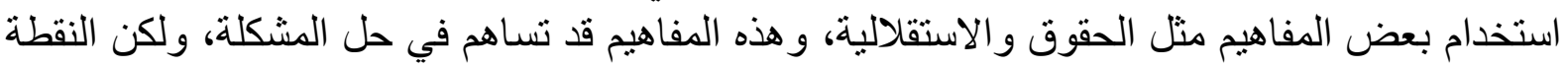

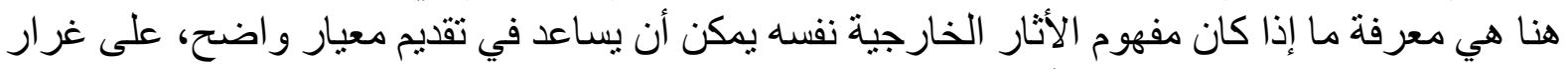

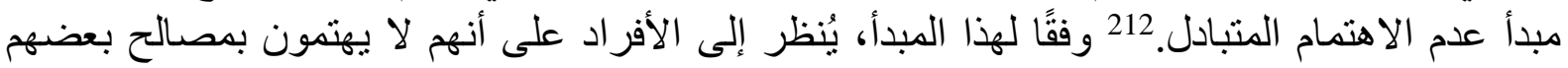

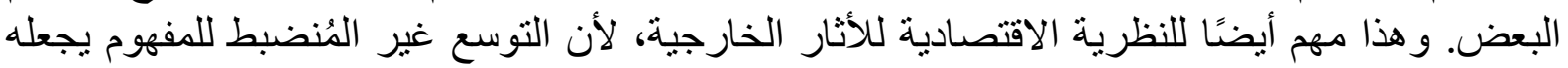
عديم الأهمية.

وفي هذا السياق يمكن القول أن المعيار الليبر الي قد يكون مهم أيضًا، وهو منو افق مع المعيار الاقتصادي.

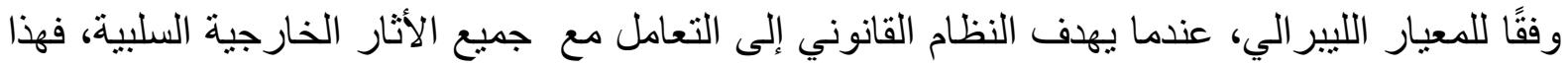

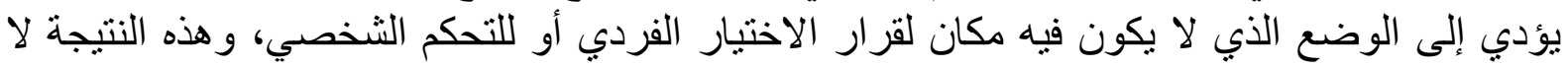

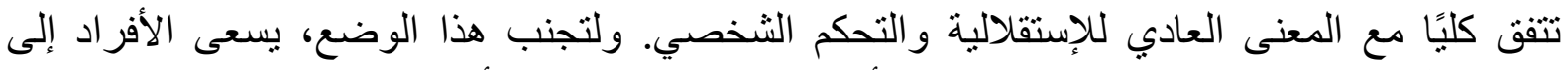
الوضع الذي تسمح لهم فيه الاستقالية بفرض الفي لأثار خارجية سلبية على الأخرين. 213

أما بالنسبة لنظرية تكاليف المعاملات فلم تحاول وضع حدود للأثار الخارجية، لأن اهتمامها الرئيس كان

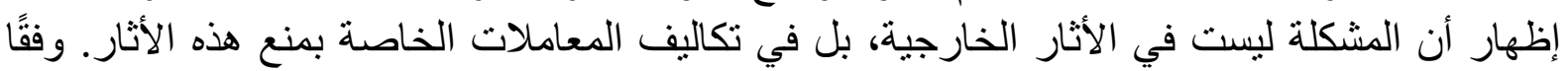

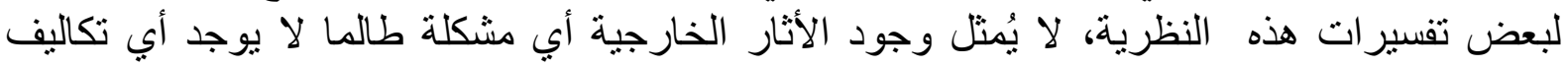

${ }^{208}$ Posner, R.A. (1997). 'Should there be homosexual marriage? And if so, who should decide?' Michigan Law Review 95, P. 1578.

${ }^{209}$ Posner, R.A., (2003). 'Wedding bell blues', New Republic, December 22.

${ }^{210}$ Mill, J.S., (1859). On Liberty, London: J.W. Parker and Son.

${ }^{211}$ Gardner, J. and Shute, S., (2000). 'The wrongness of rape', in J. Horder, Oxford Essays in Jurisprudence: Fourth Series, Oxford: Oxford University Press, P. 216.

${ }^{212}$ Trebilcock, M.J., (1993). The Limits of Freedom of Contract, Cambridge, MA: Harvard University Press, P.75.

${ }^{213}$ Epstein, R.A., (1995). 'Are values incommensurable, or is utility the ruler of the world?' Utah Law Review, P.700. 


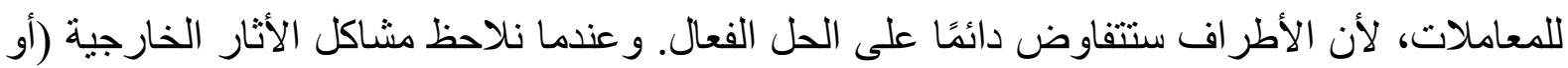

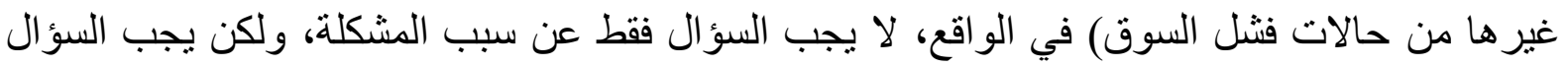
عن تكاليف المعاملات التي تمنع التفاوض في على التى حل هذه المشكلة. 214

فإذا كان الأمر يتعلق بالتفاوض في بيئة منخفضة التكلفة للمعاملات، فيمكن تحديد الأطر اف المتفاوضة،

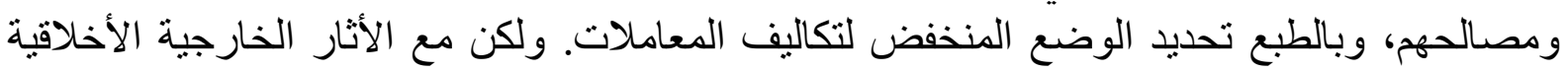

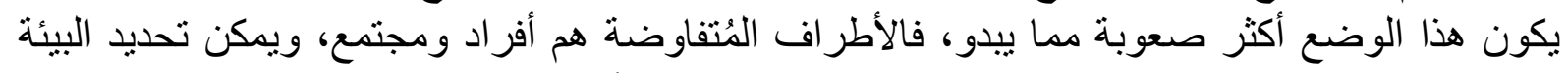

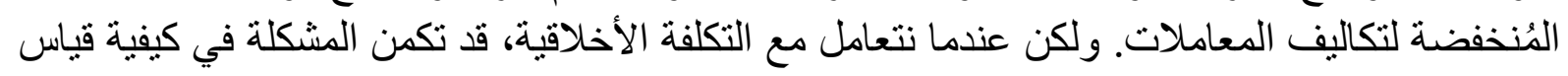
مدي الاستعداد لافع هذه التكاليف.

\section{1. الحقوق النادرة وغير النادرة والحق في الملكية الذاتية}

يُمكن تصنيف الأثار الخارجية إلى أثار مادية أو فنية وأثنار مالية. و المثال على النوع الأول هو التلوث

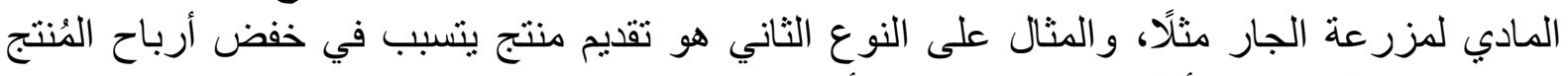

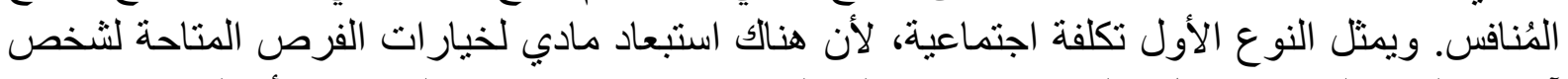

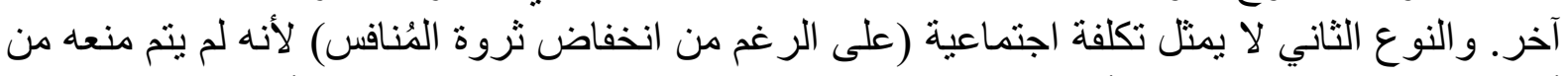

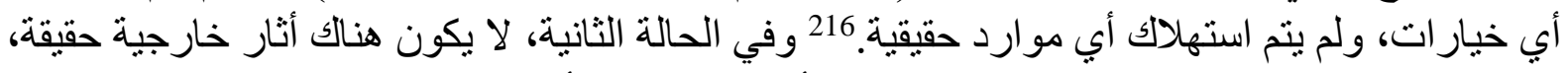

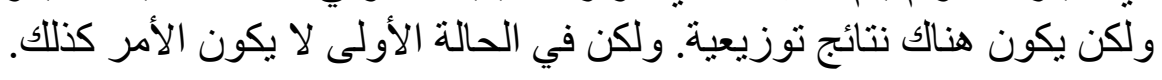

ولتعظيم الحرية، يجب التمبيز بين الحقوق النادرة و غير النادرة. و لا يمكن منح الحقوق النادرة للجميع،

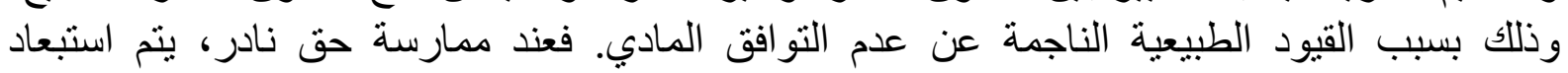

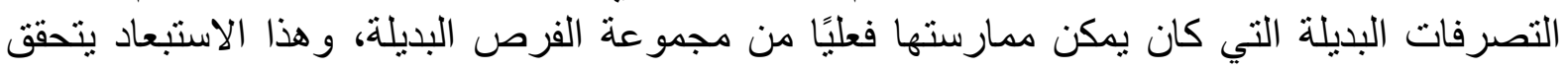

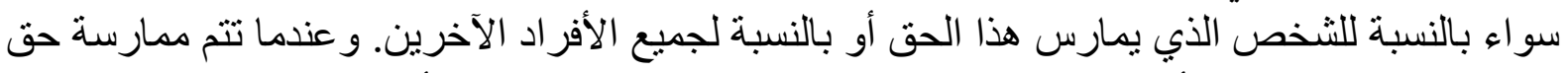

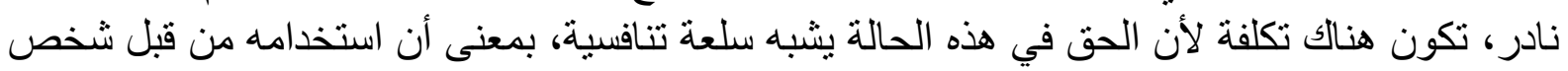

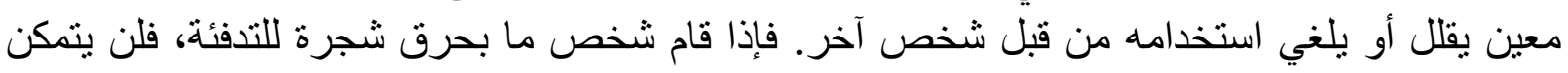

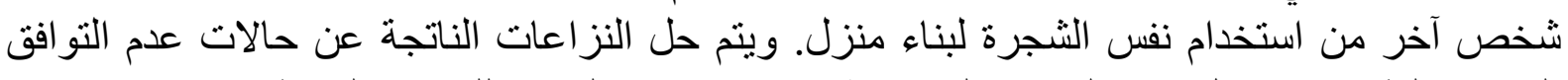

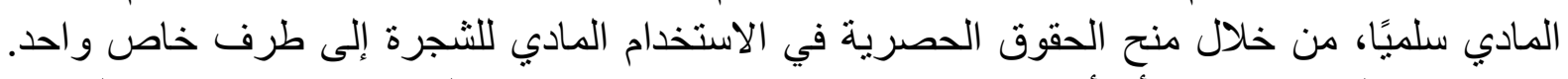

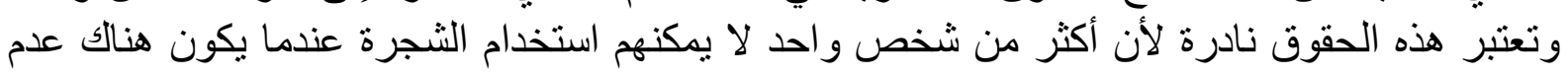

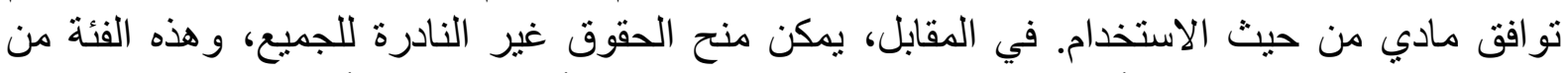

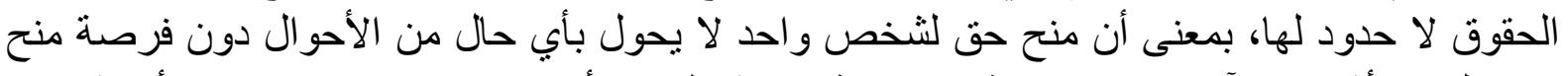
نفس الحق لأشخاص آخرين. إن حرية الانخر اط في نشاط لهن غير أخلاقي وغير ضار لان لا تمنع أي شخص آخر من فعل الثيء نفسه.

ولتعظيم الحرية، يجب تخصيص كل حق نادر لأفراد معينين، ويجب تخصيص جميع الحقوق غير النادرة للجميع. وبالتالي، ينبغي منح حق الملكية الذاتية لكل فرد على حدة، وليس فقط لطبقة الأشخاص

\footnotetext{
${ }^{214}$ Friedman, D.D. (2000). Law's Order: What Economics Has to Do with Law and Why It Matters, Princeton, NJ: Princeton University Press, P.40.

${ }^{215}$ Hatzis, Aristides N., (January 1, 2015). Moral Externalities: An Economic Approach to the Legal Enforcement of Morality, Law and Economics: Philosophical Issues and Fundamental Questions. Edited by Aristides N. Hatzis \& Nicholas Mercuro. London/New York: Routledge, P. 226.

${ }^{216}$ Holderness, C.G., (1989). 'The assignment of rights, entry effects, and the allocation of resources', Journal of Legal Studies 18, P.184.
} 


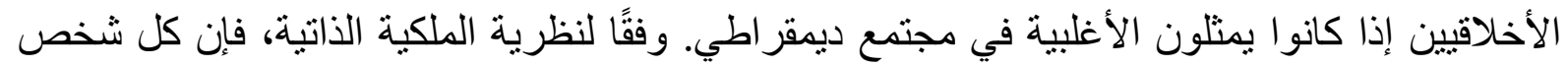

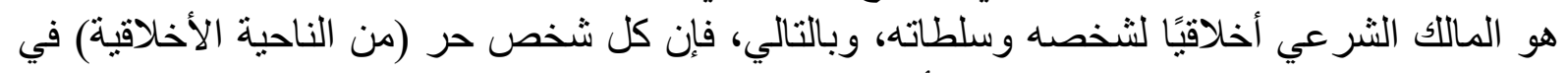
استخدام تللك الصلاحيات كما يشاء، بشرط ألا بستخدمها بقوة ضئ وبد الآخرين.

تتكون الملكية الكاملة للكيان الذاتي من مجموعة كاملة من حقوق الملكية. وتشمل هذه الحقوق، حقوق

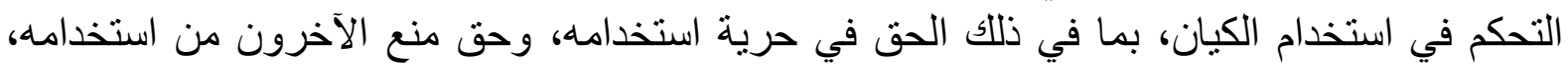

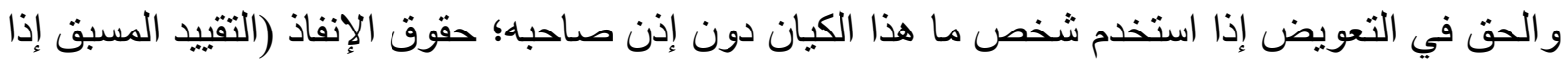

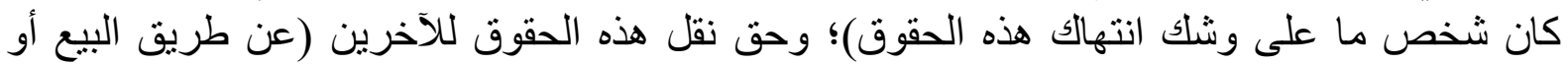

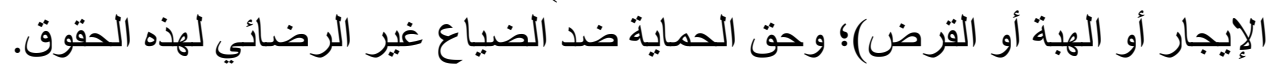

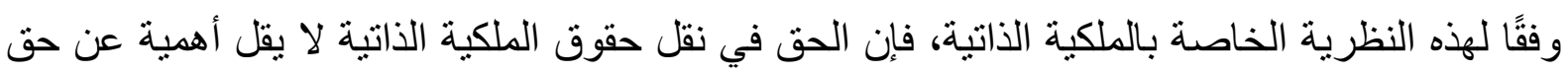

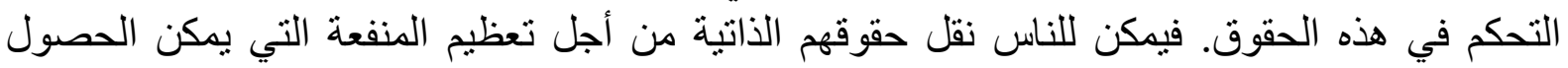

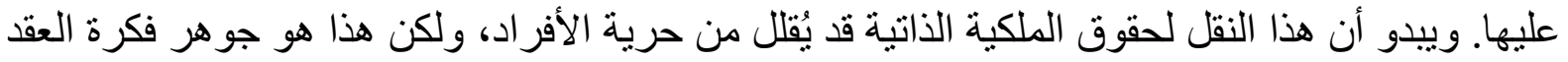

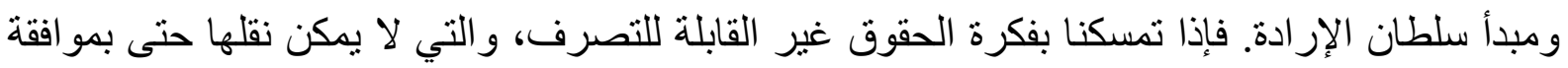

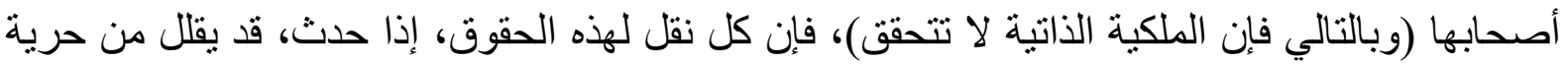

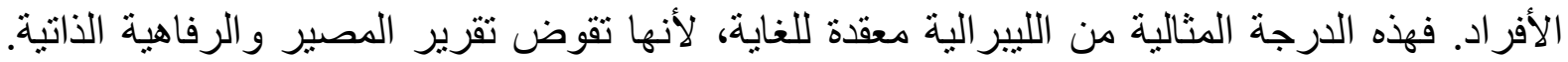

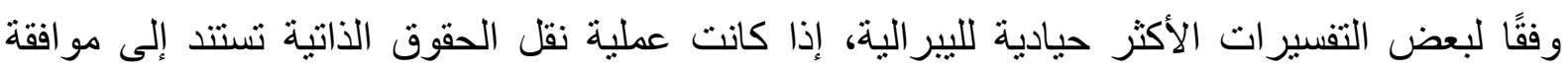

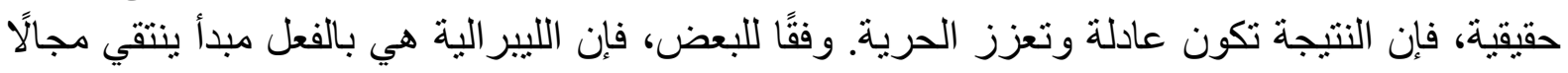

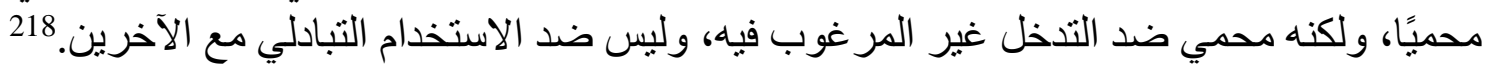

\section{2. قيمة الأثار الخارجية الأخلاقية في إطار نظرية تكاليف المعاملات}

في هذا السياق، يمكن التساؤل عن عدم أخذ الأثار الخارجية المالية في الاعتبار. وبما أن المجتمع لها لهاعله

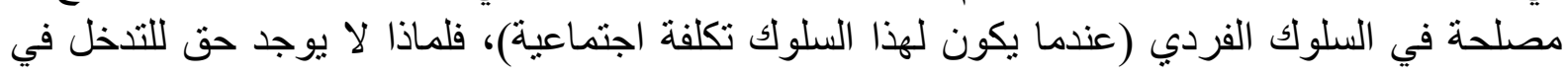

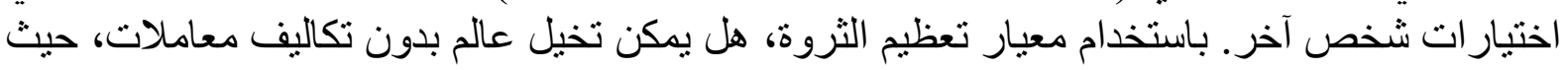

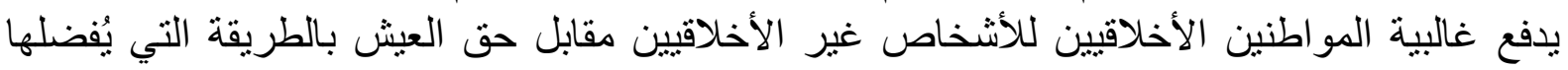

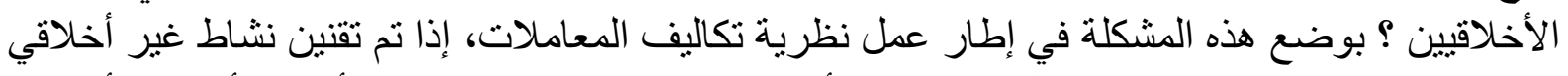

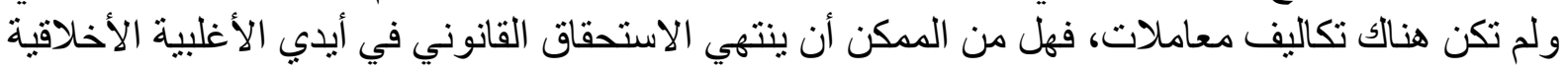

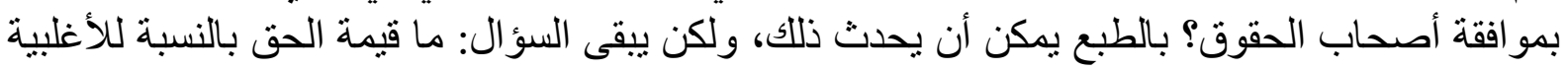

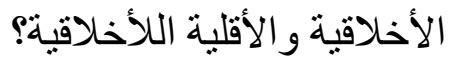

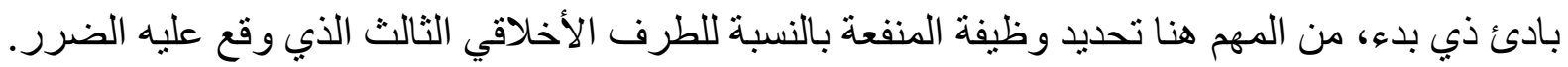

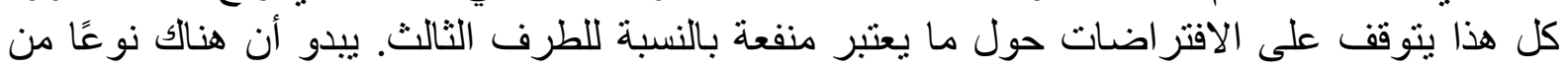

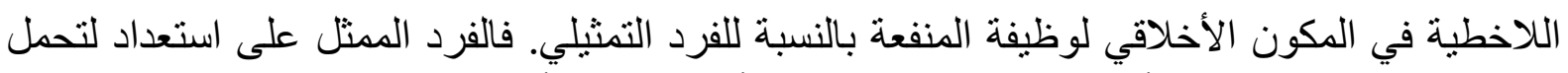

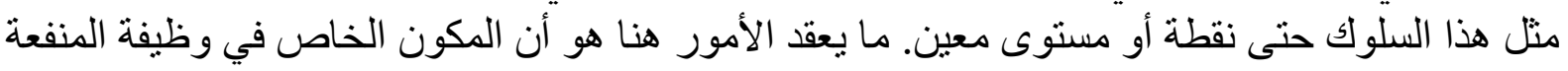
من فرد إلى آخر مرتفع للغاية. لذا فإن الحديث عن دالة منفعة متوسطة (أو دالة الفرد التمثيلي) ليس مفيدًا للغاية.

${ }^{217}$ Cohen, G.A. (1995). Self-Ownership, Freedom, and Equality, Cambridge: Cambridge University Press, P.67.

${ }^{218}$ Barry, B., (1986). 'Lady Chatterley's lover and doctor Fischer's bomb party: liberalism, Pareto optimality, and the problem of objectionable preferences', in J. Elster and A. Hylland (eds.) Foundations of Social Choice Theory, New York: Cambridge University Press, P.19. 
لهذه الأسباب وغير ها، تكون قيمة الحق غير محددة في معظم الحالات. ونظرًا لأن الفوائد والتكاليف

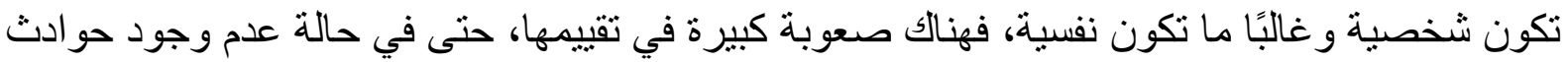

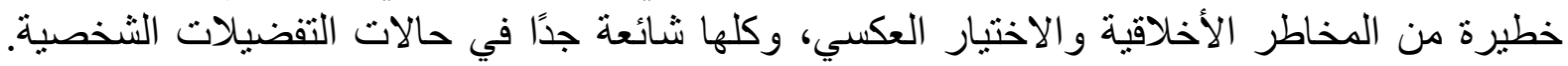
وتتطابق بعض الحلول، و التي تسمى (محاكاة السوق)، مع النسخة المعيارية لنظرية كو اس. عندما تكون

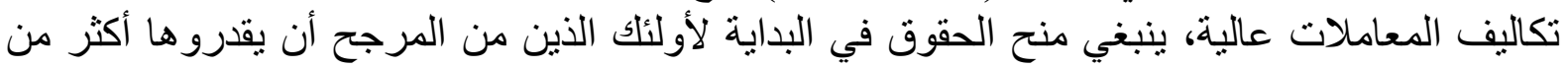

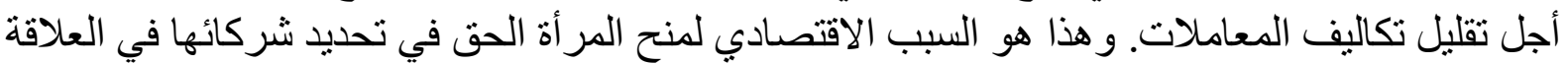

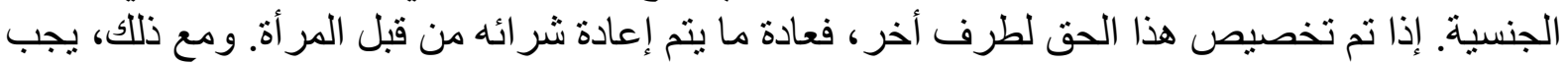

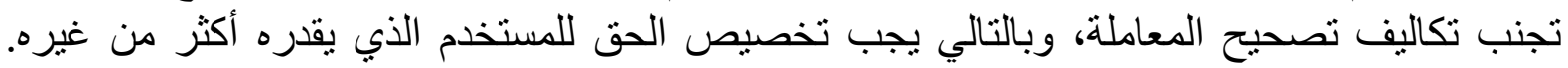

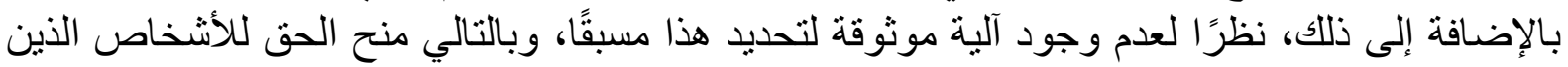
يقدرونهم أكثر من غير هم، يجب منح الحقوق في البداية للمالك الطبيعي. 219

وون المعايير التي قد تكون مفيدة في هذا الثأن هو معيار أفضل شخص لديه القدرة على نقل الحق، ووفقًا لهذا المعيار يجب أن يتم تخصيص الحقوق بطريقة تزيد من احتمالية تصحيح أخطاء التخصيص التصن الذي يتم عن طريق ألية السوق. وفي هذه الحالة يأتي هذا إلى الاستراتيجية التي بموجبها يتم منح الحق للطية الطرف الذي يمكن نقله منه بسهولة أكبر. ففي جميع حالات التملك الذاتي (بيع الأعضاء، الأمومة البديلة، القتل

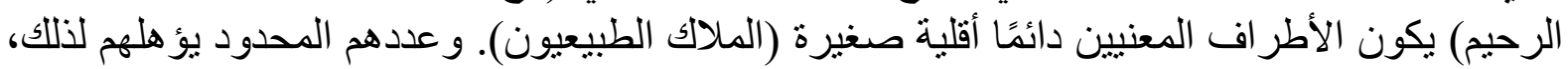

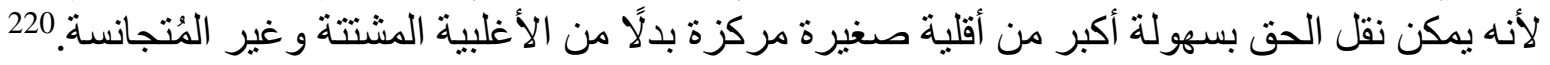

\section{3. تقليل تكاليف المعاملات من خلال الاعتراف بالحقوق الفردية}

في هذا السياق، تظهر مشكلة مهمة، وهي تحديد مقدار تكاليف المعاملات التي يمكن تحملها إذا تم تخصيص حق الملكية الذاتية ليس للأشخاص أنفسهم، ولكن للمجتمع ككل. وتتضح هذه هذه المشكلة بوضوح

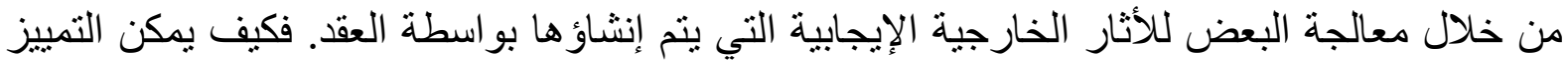
بين الأثار الخارجية الإيجابية وحقوق الطرف الثالث المستفيد الناتجة عن العقد؟ ويمكن الإجابة على هذا لإنا

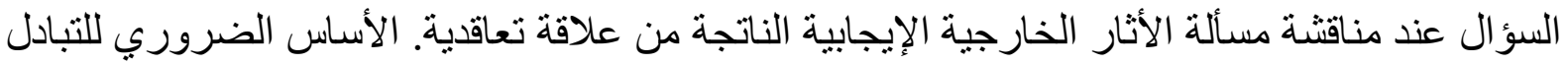

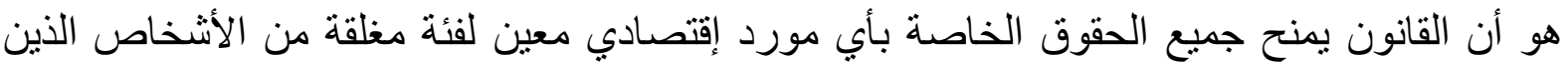
يمكن التعرف عليهم بوضوح، وكل شخص منهم يكون قادر على التعاقد في أي لحظة. ويتم إغلاق هذه إنه

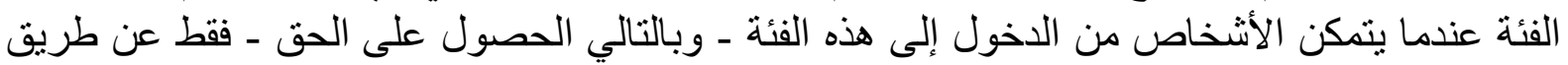

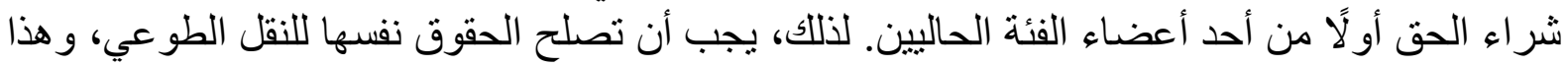

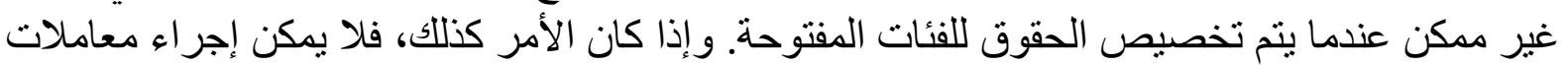

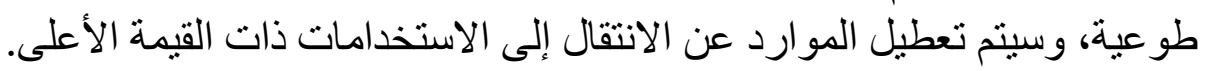

يمكن القول أن الفئة المفتوحة في الأثنار الخارجية السلبية (الأثار الخارجية المالية) يتم إنشاؤها عندما

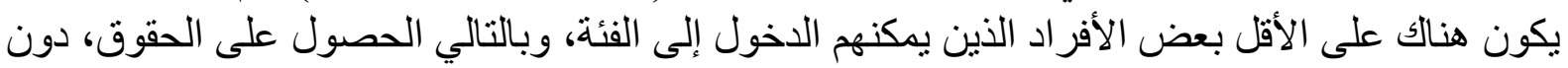
شر ائها أولًا من الملاك الطبيعيين. بمعنى أن الفئة تكون مفتوحة عندما يكون الدخول إليها غير مُقيد. 221

${ }^{219}$ Posner, R.A., (1983). The Economics of Justice, 2nd edition, Cambridge, MA: Harvard University Press, P.72.

${ }^{220}$ Calabresi, G., (1970). The Costs of Accidents: A Legal and Economic Analysis, New Haven, CT: Yale University Press, P.151.

${ }^{221}$ Holderness, C.G., (1989). 'The assignment of rights, entry effects, and the allocation of resources', Journal of Legal Studies 18, P.182. 
فإذا مُنحت حقوق الحماية المعنوية لعدد كبير جدًا من الأفراد (المجتمع بأسره) من خلال الاعتراف

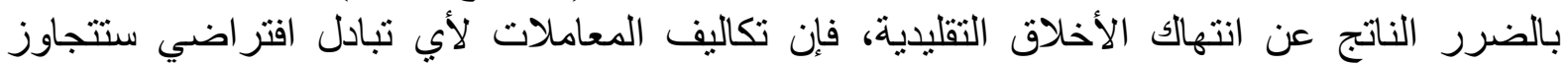

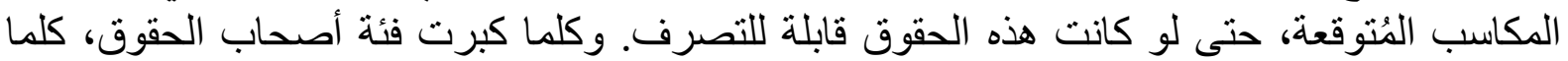

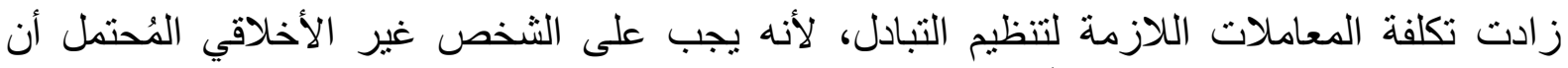

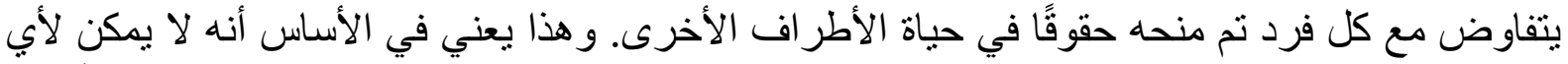

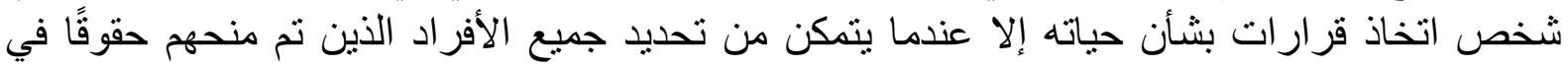

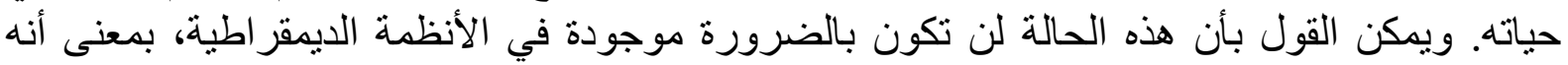
يكفي إقناع الأغلبية فقط. ولكن في كل الأحوال، ستكون تكلفة المعاملة هائلة من حيث الونة الوقت الضائع. 222

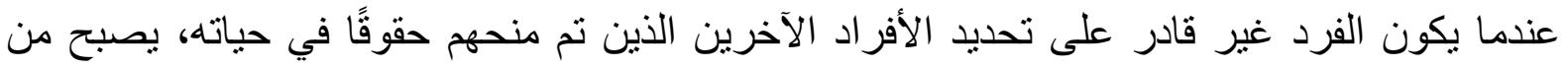

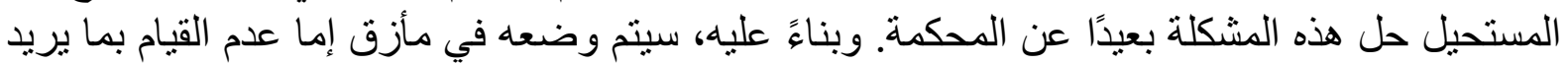

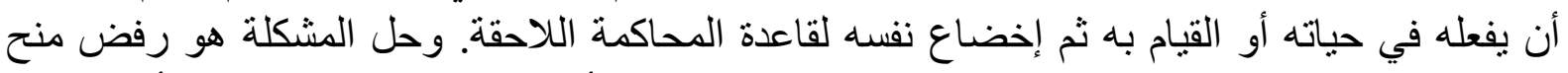

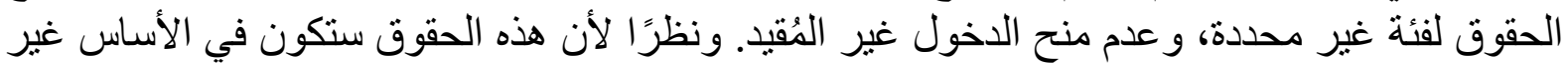

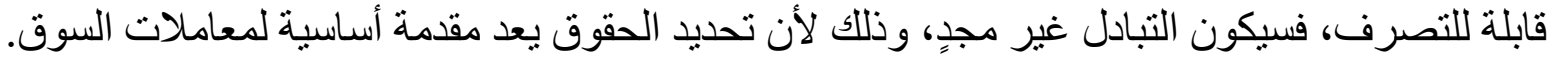

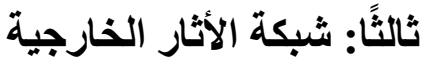

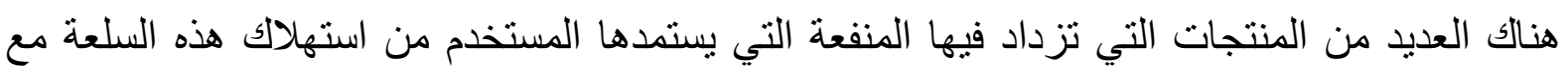

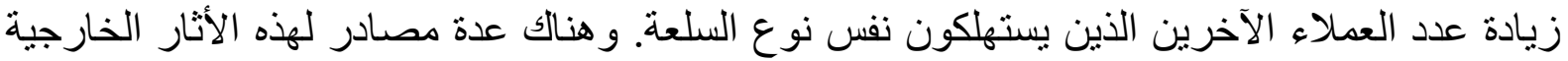

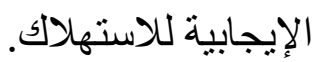

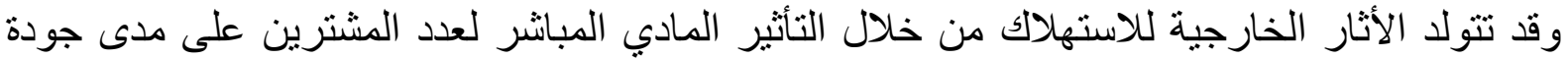

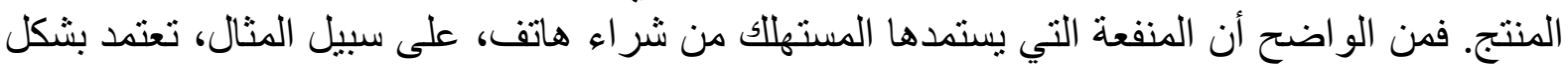

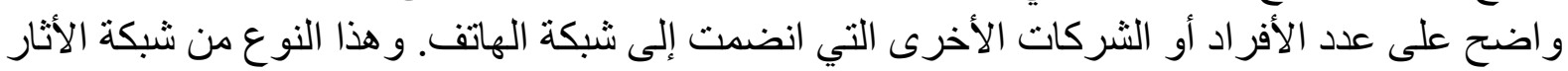

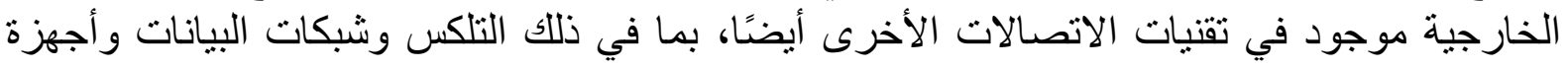

$$
\text { الفاكس عبر الهاتف.223 - 2 2 }
$$

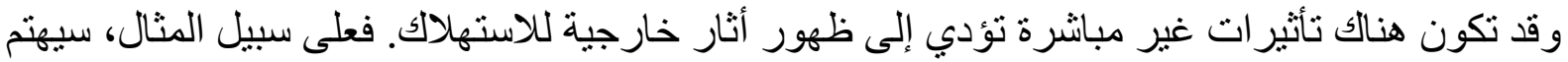

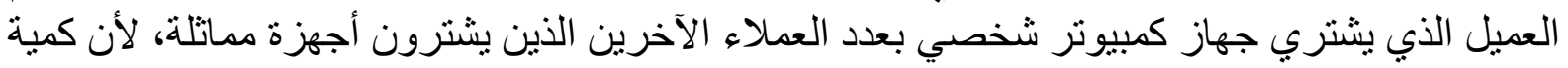

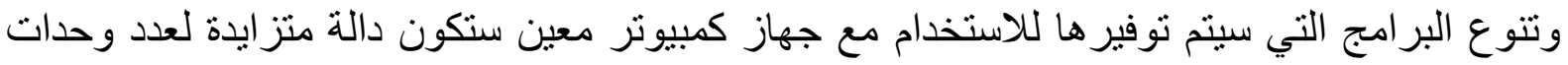

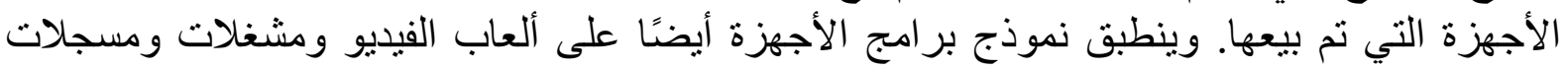

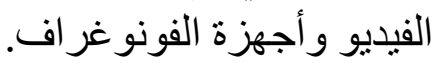

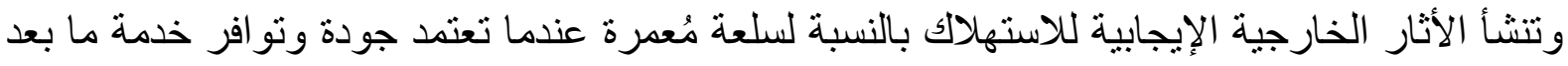

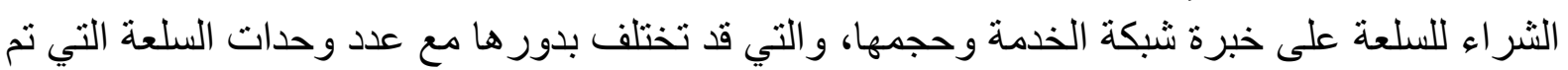

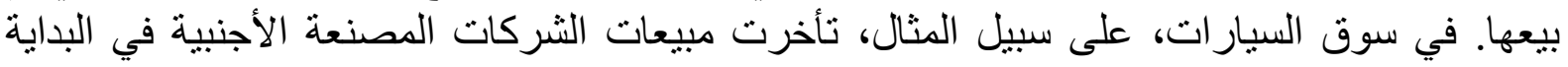

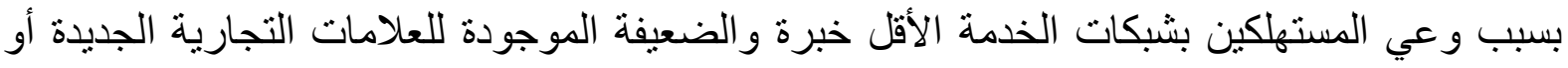

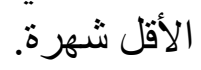

${ }^{222}$ Holderness, C.G., (1985). 'A legal foundation of exchange', Journal of Legal Studies 14, P. 326.
${ }^{223}$ Armstrong, Mark, (1998). Network interconnection in telecommunications. Econ. J.108, P. 545. 
في كل هذه الحالات، تعتمد المنفعة التي يستمدها مستخدم معين من السلعة على عدد المستخدمين الآخرين

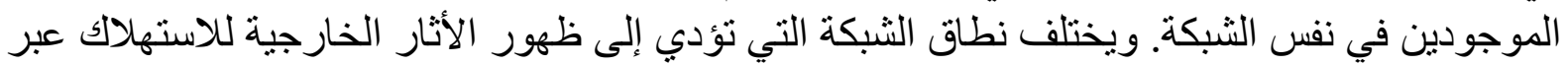

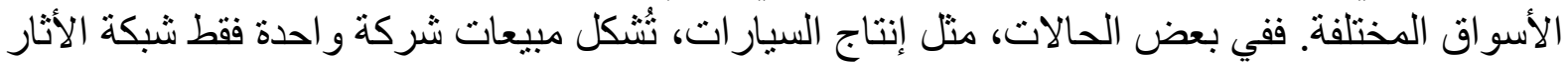

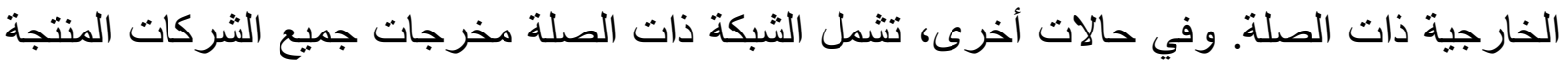

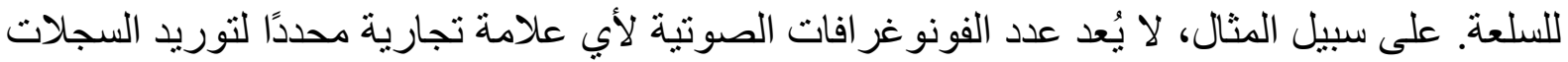

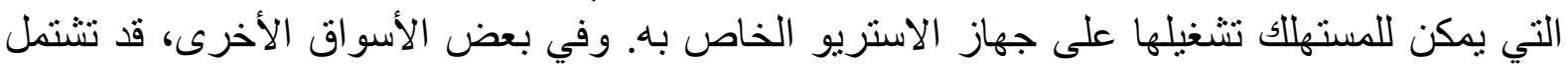

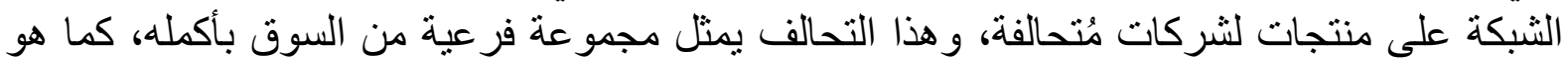

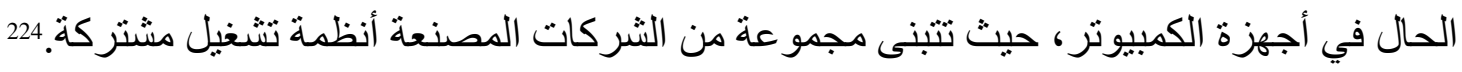

و السمة المركزية للسوق، التي تحدد نطاق الثبكة ذات الصلة، هي مدى إمكانية استخدام منتجات

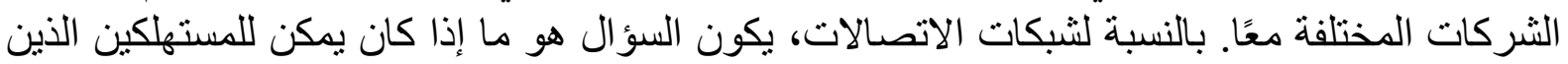
يستخدموا خدمات إحدى الشركات الإتصال بالمستهلكين الذين اشتركوا في في خدمات الثرات الثركات الثات الأخرى.

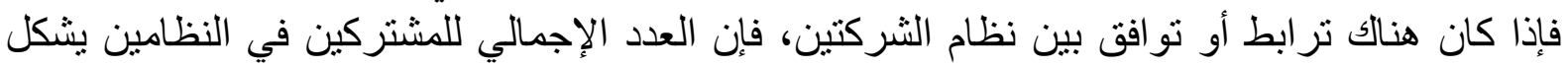

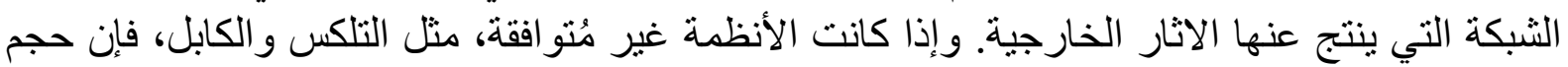
النظام الفردي لكل شركة يكون هو المقياس لشبكة الأثار الخارجية المناسبة لمستخدمي هذانة النظة النظام.

وبالمثل، بالنسبة لأسواق الأجهزة والبرامج الالكترونية، تكمن المشكلة في مدى إمكانية تشغيل البرامج

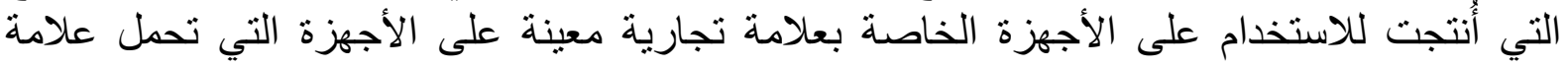

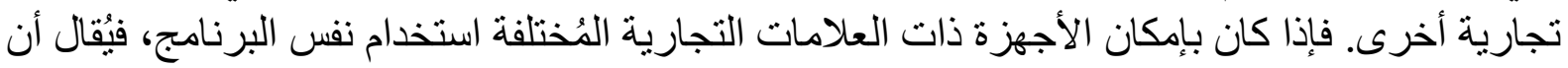

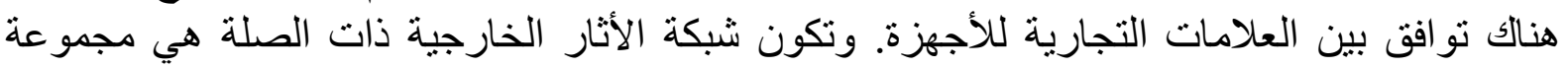

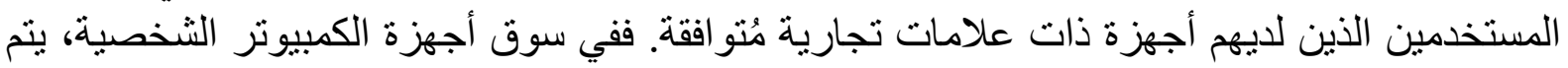

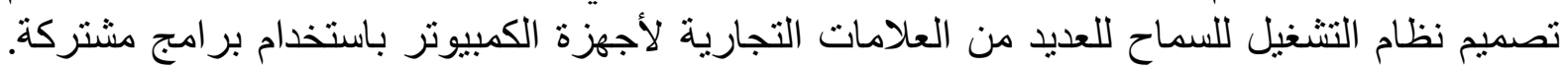

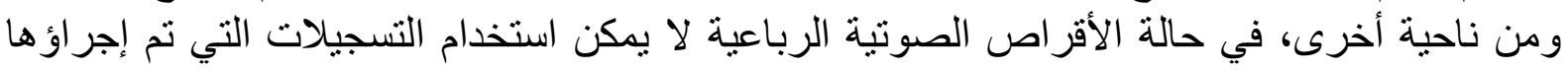

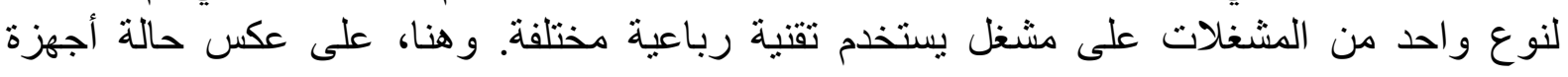
الاستريو، تشتمل الثبكة ذات الصلة لعلامة تجارية معينة من المعدات على مجمو عة العلامات التجارية التي تستخدم نفس التقنية، وليس السوق بأكمله. 225

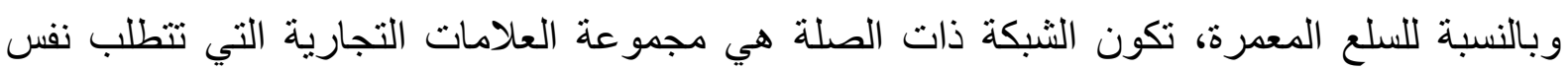

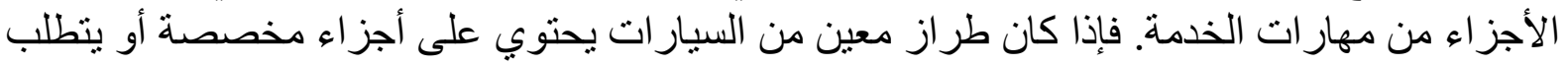

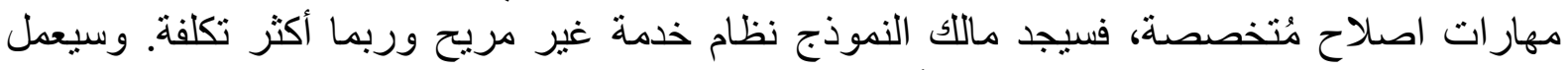

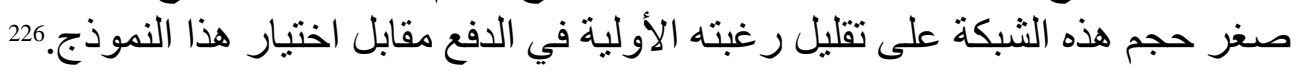

\footnotetext{
${ }^{224}$ Banerji, A., Dutta, Bhaskar, (2009). Local network externalities and market segmentation. Int. J. Ind. Organ.27, P. 605.

${ }^{225}$ Baake, Pio, Boom, Anette, (2001). Vertical product differentiation, network externalities, and compatibility decisions. Int. J. Ind. Organ.19, P. 267.

226 Michael L. Katz and Carl Shapiro, (Jun., 1985). Network Externalities, Competition, and Compatibility, The American Economic Review, Vol., 75, No. 3, P. 424.
} 


\section{المبحث الثالث: الأثار الخارجية للوضع الاستهلاكي}

من الناحية التقليدية، ركزت نظريات النمو الاقتصادي على كفاءة و إنتاجية المنظمات الاقتصادية اللازمة الإدة التادية

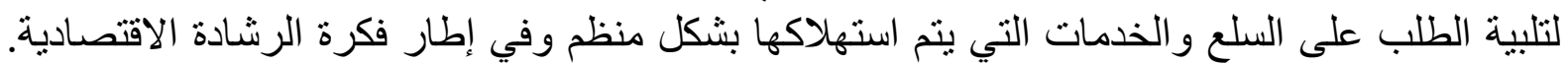

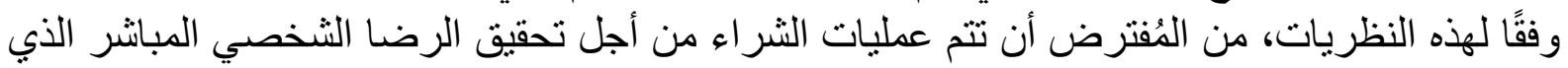

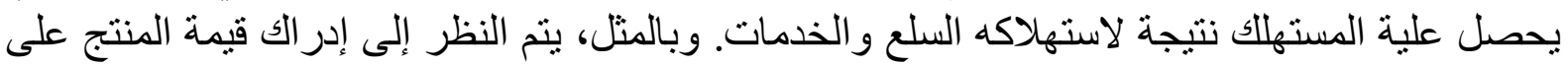

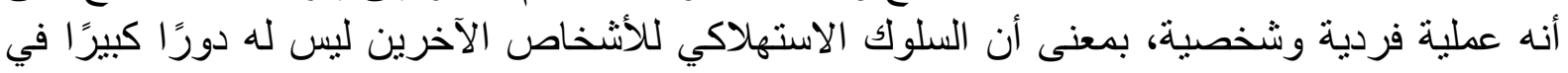
تحديد هذه القيمة.

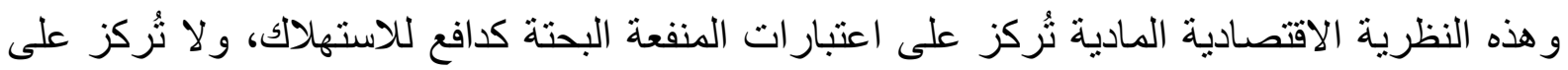

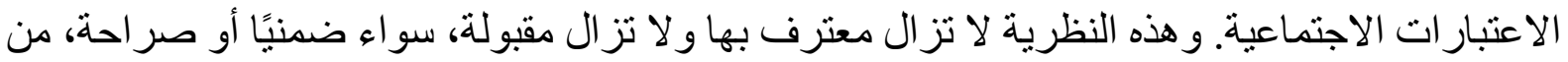

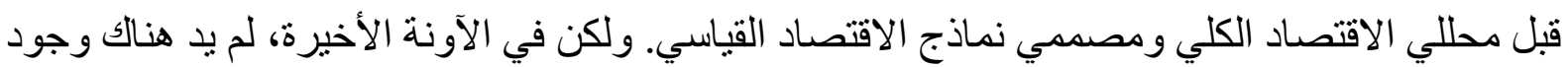

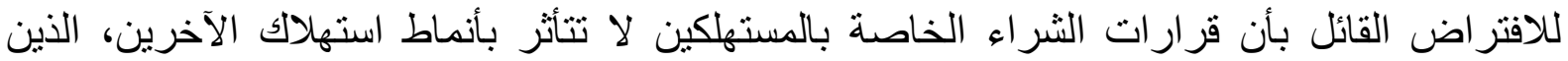

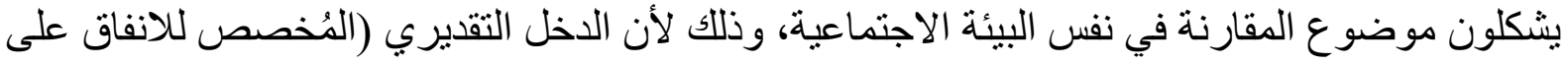

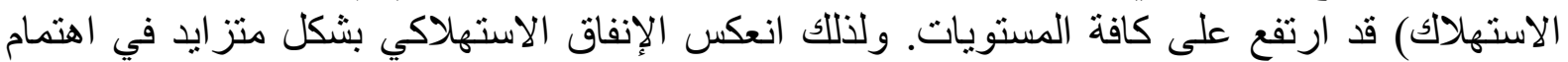

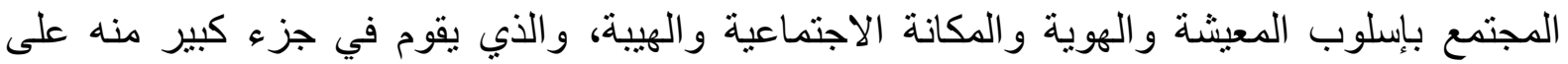
الاستهلاك التفاخري للسلع و الخدمات التي تُعزز من الككانة الاجتماعية.

وبحلول سبعينيات القرن الماضي، أصبح واضحًا، من الناحية الواقعية، خصوصيًا في المجتمعات الأكثر

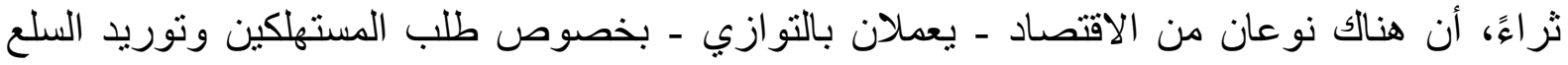

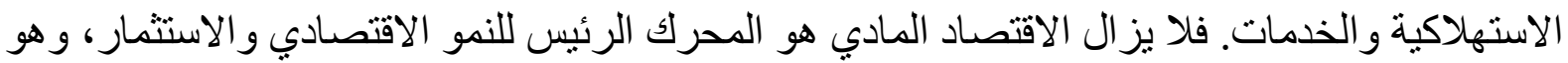

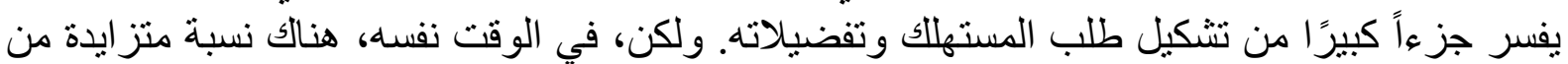

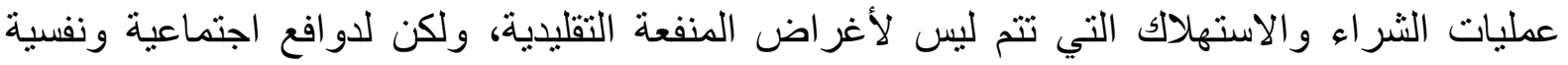

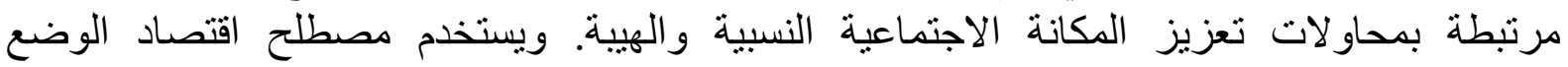

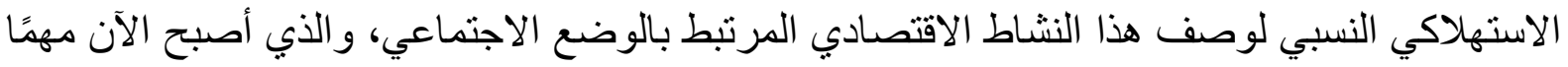

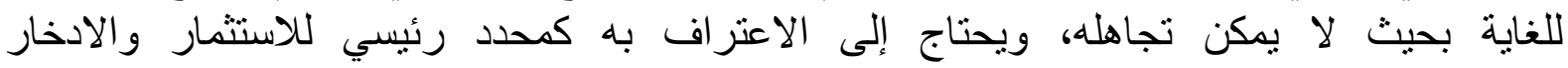

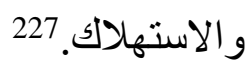

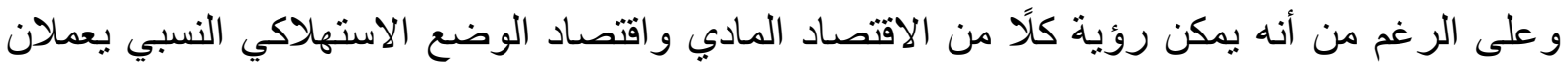

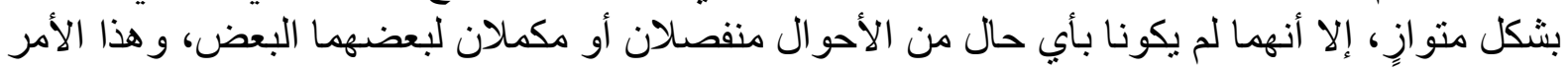

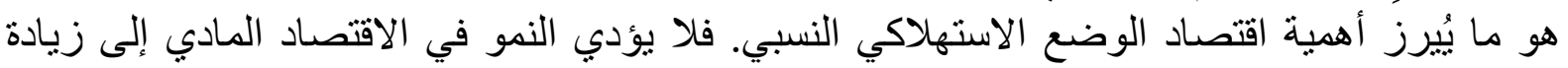

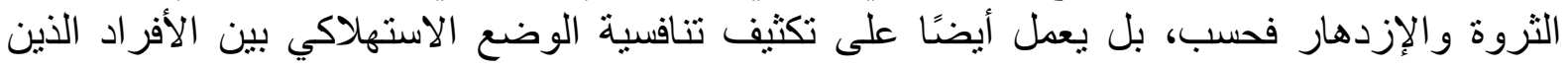

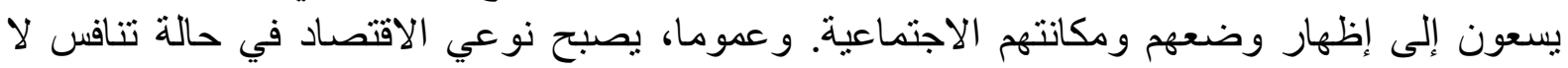

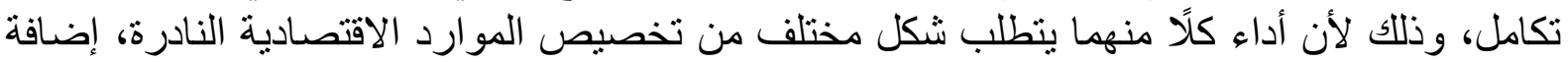

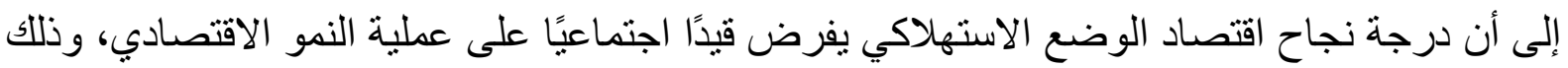

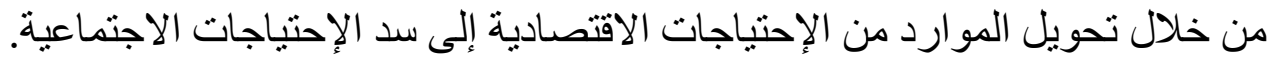

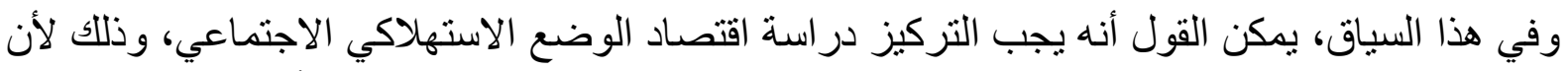

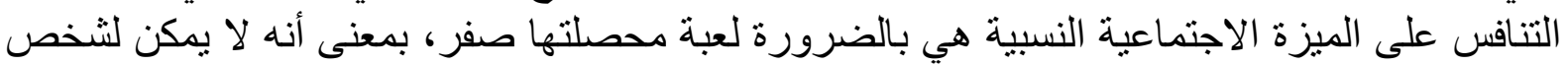

${ }^{227}$ Hirsch F., (1976). Social Limits to Growth, Harvard University Press: Cambridge, MA, PP. 52-54. 
ما أن يحقق بعض المكاسب الاجتماعية إلا على حساب شخص آخر. وبالتالي، فإن الطلب على المكانة

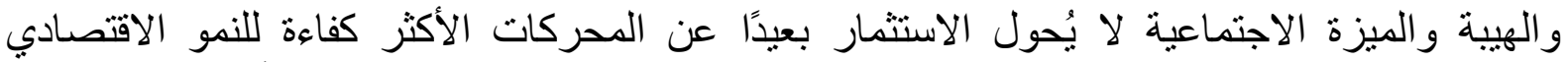

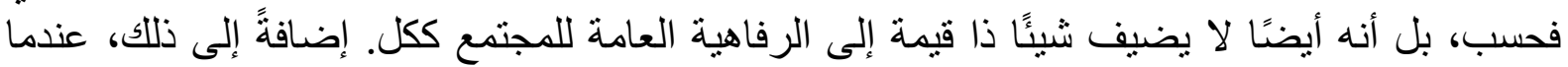

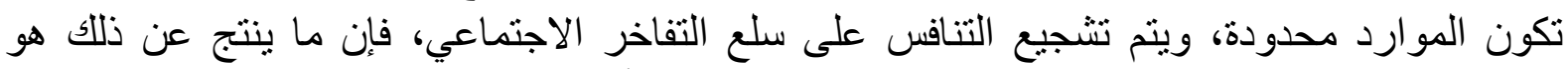

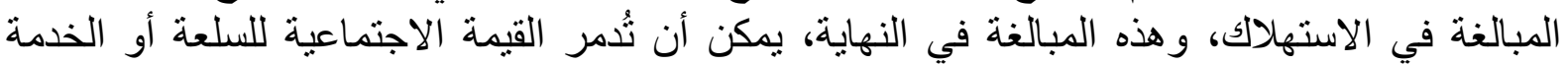

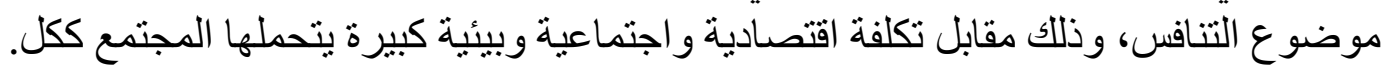

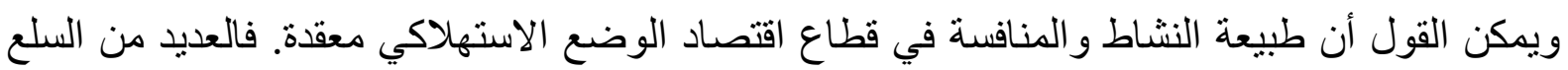

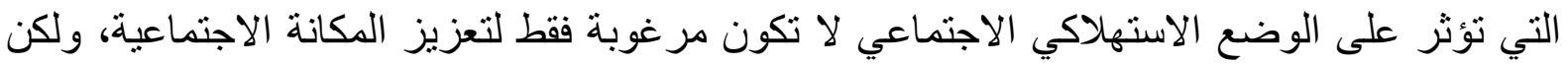

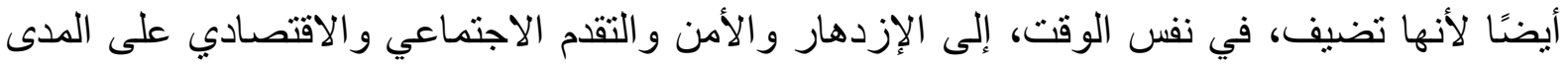

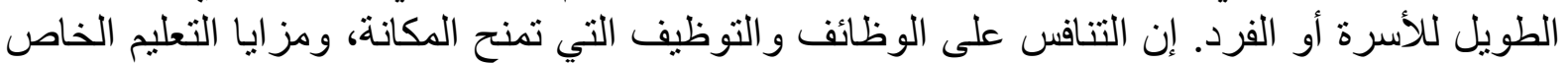

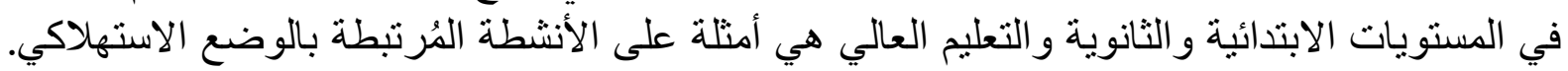

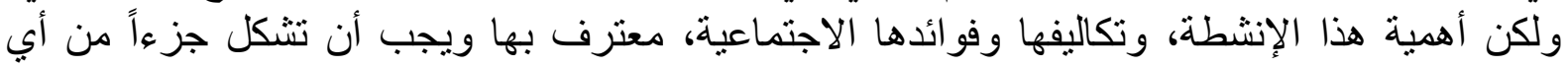

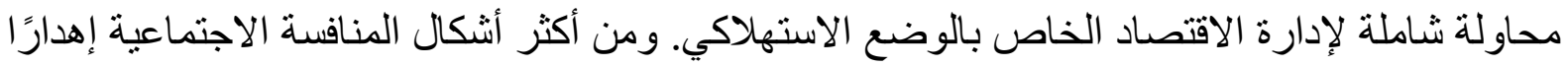

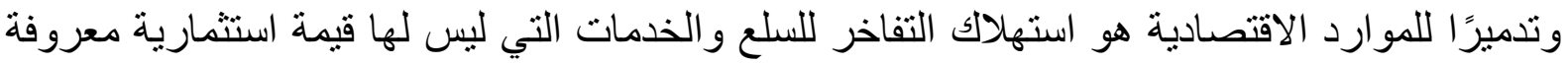
على المدى البعيد، ويتم القيام به فقط لتأمين مكاسب فورية في الوضع ولئ والهيبة ولئية والمكانة الاجتماعية

و هناك العديد من الحالات التي يؤدي فيها زيادة الاستهالك لنوع معين من المنتجات إلى تقليل قيمة المنتج

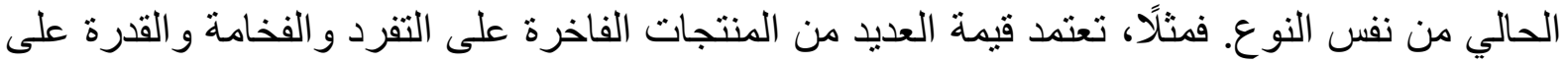

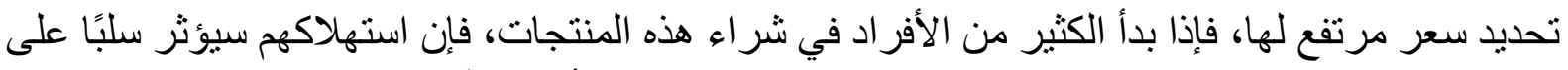

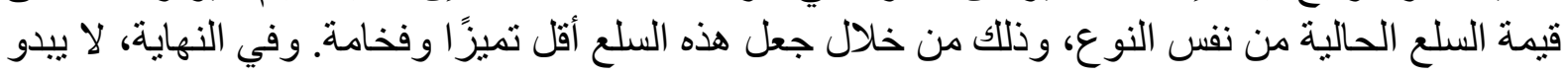

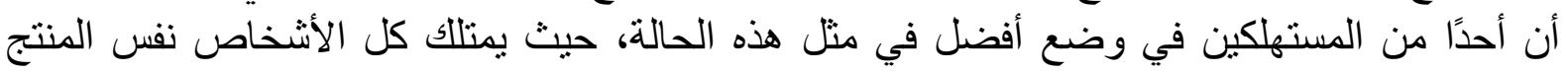

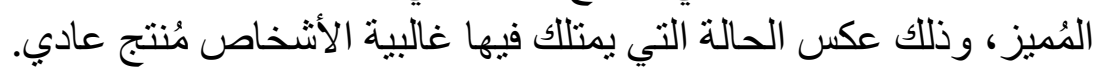

و هذا المثال يوضح الحالة التي بستهلك فيها كل شخص أكثر، ولكن لا يوجد شخص في وضع أفضل.

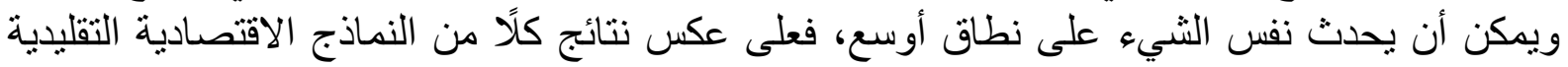

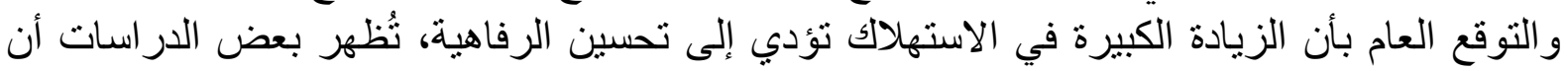

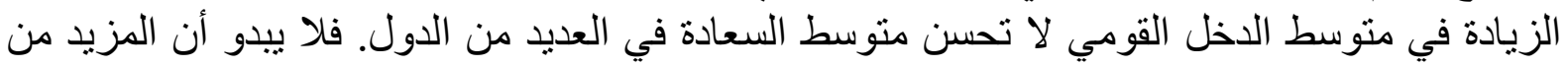
المال والاستهلاك يجعل المجتمع أكثر سعادة. 228 ويتم استخدام هذه النظرية بالفعل لانتقاد النقاد طريقة الحياة

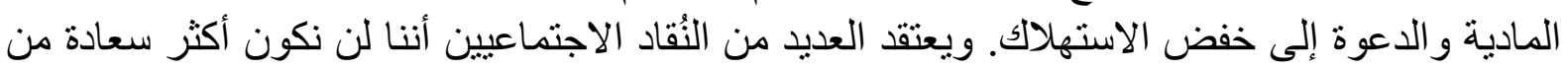
خلال امتلاك المزيد من الأصول، ولكن هذا النقد قد يفتقر إلى الأساس النظري. 229

وتقدم العديد من الأبحاث التي تدور حول اقتصاديات السعادة بعض التفسيرات لهذه النظرية. وفي هذا السياق، تقدم بعض الدر اسات مفارقة مثيرة للاهتمام، و هذه المفارقة تتمثل في أن متوسط مستوى السعادة

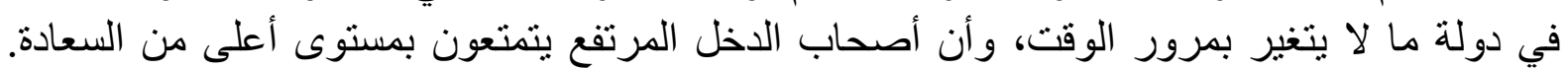

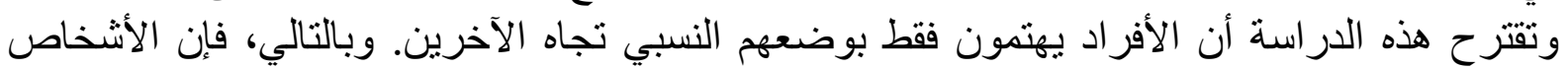

${ }^{228}$ Easterlin, R. A., (1974). Does Economic Growth Improve the Human Lot? Some Empirical Evidence.' In :Nations and Households in Economic Growth, Academic Press (London), P. 89.

${ }^{229}$ Frank, R. H., (2010). Luxury fever: Weighing the cost of excess. New Jersey: Princeton University Press. 


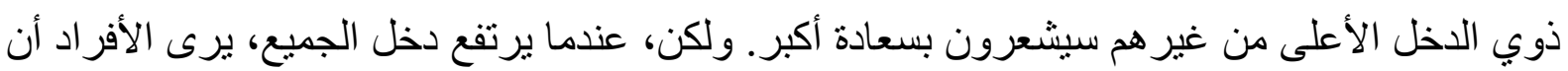

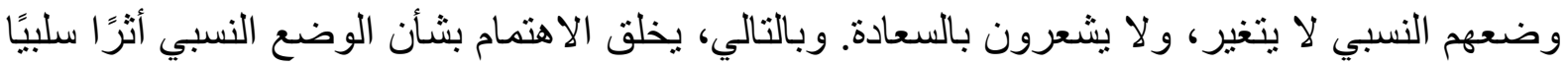

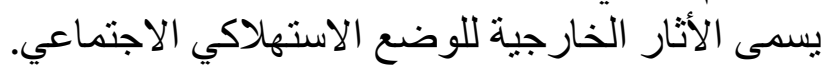

فإذا تم الاعتر اف بحقيقة وجود الأثار الخارجية للوضع الاستهلاكي الاجتماعي، فإن ذلك يلكئ يمكن أن يُغير

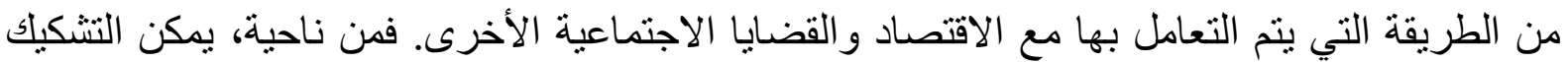

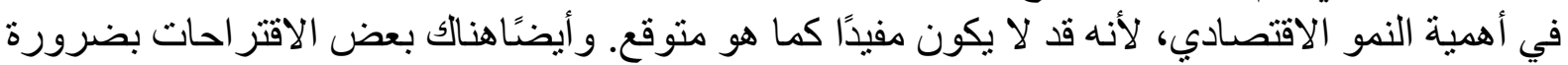

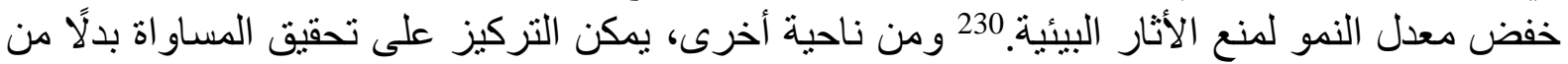

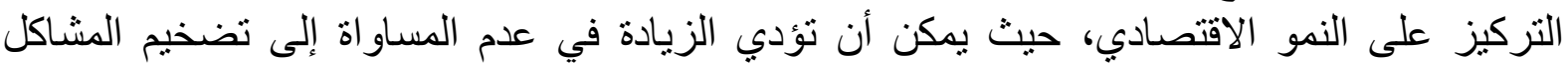

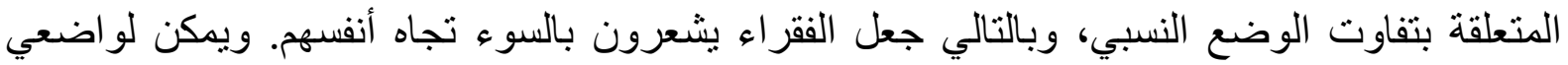

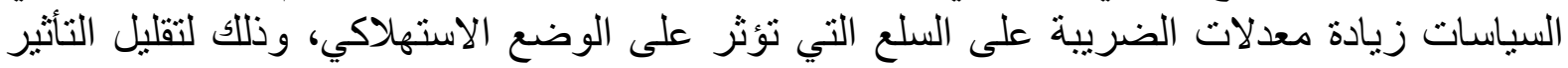

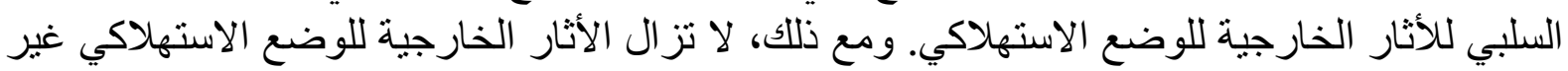

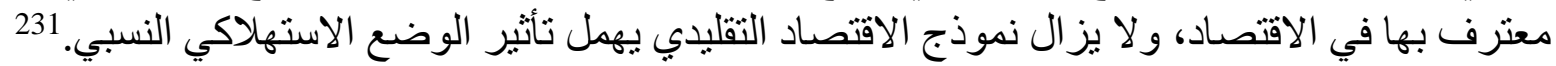

\section{أولًا: تعريف الأثار الخارجية للوضع الاستهلاكي الاجتماعي}

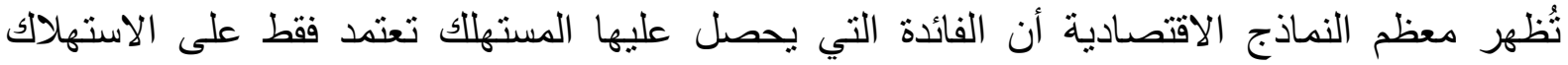

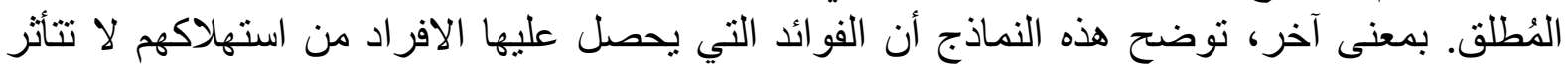

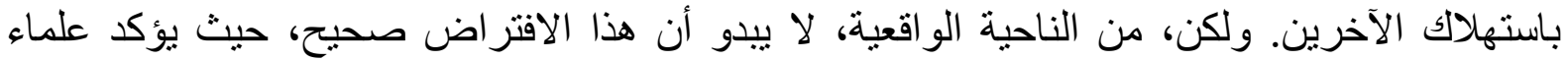

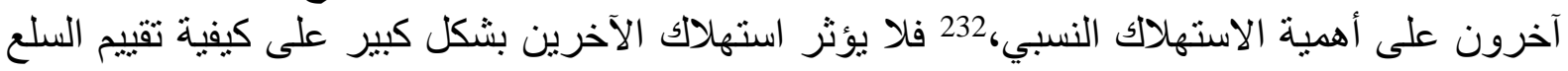

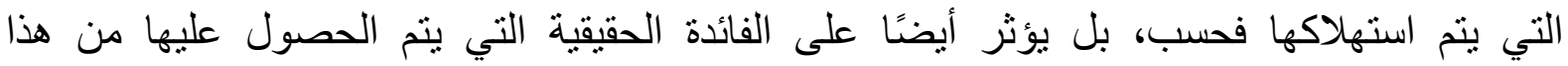

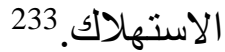

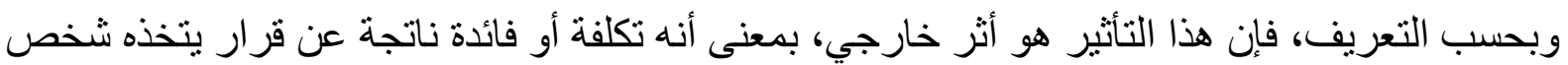

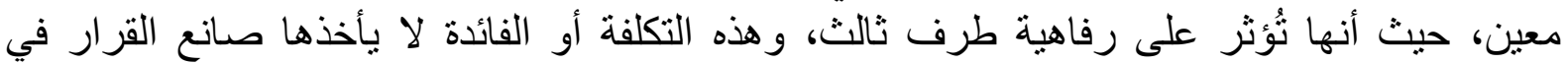

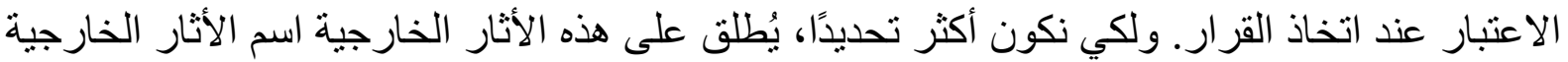

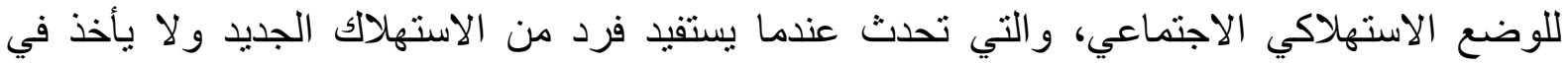

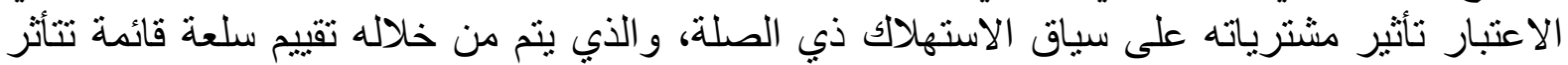
بالوضع الاستهلاكي له.

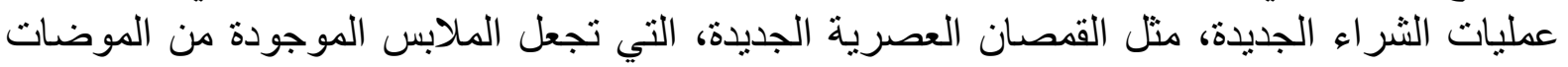

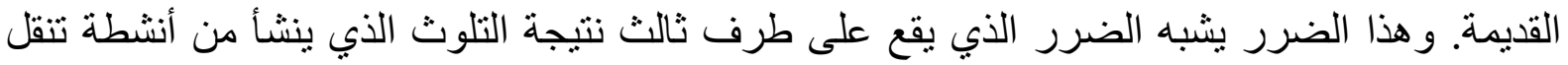

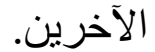

ويجب عدم الخلط بين الأثار الخارجية للوضع الاستهلاكي وبين شبكة الأثار الخارجية، والتي تؤثر أيضًا

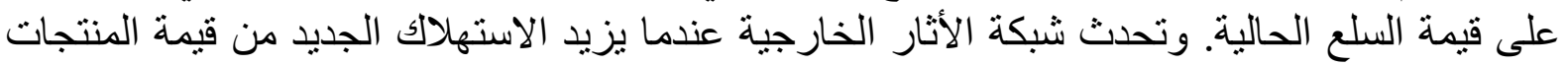

${ }^{230}$ Jackson, T., (2009). Prosperity without growth. London: Earthscan, P.43.

${ }^{231}$ Hopkins, E., \& Kornienko, T. (2004). Running to Keep in the Same Place: Consumer Choice as a Game of Status. The American Economic Review. 94 (4), P. 1085.

${ }^{232}$ Veblen, T. (2007). The theory of the leisure class, Oxford Universiyy Press., P.49.

${ }^{233}$ Carlsson, F., Johansson-Stenman, O., \& Martinsson, P., (2007). 'Do You Enjoy having More than others? Survey Evidence of Positional Goods.' Economica. 74 (296), P. 586.

${ }^{234}$ Frank, R. H., (2008). Should Public Policy Respond to Positional Externalities? Journal of Public Economics. 92 (8), P.1780. 
الحالية، والتي تحدث غالبًا في خدمات الثبكات الاجتماعية، وبعض التقنيات مثل الألعاب عبر الإنترنت

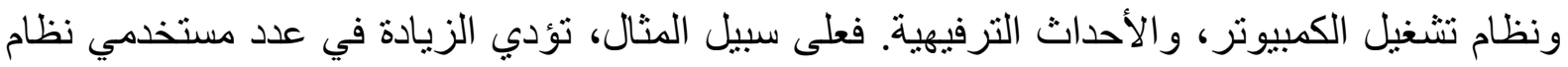

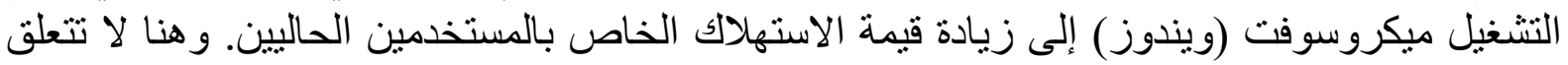

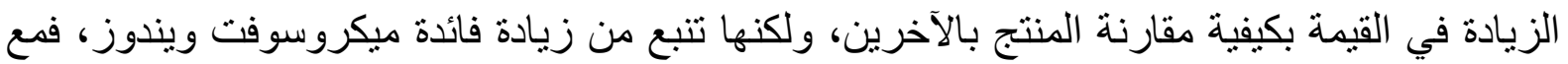

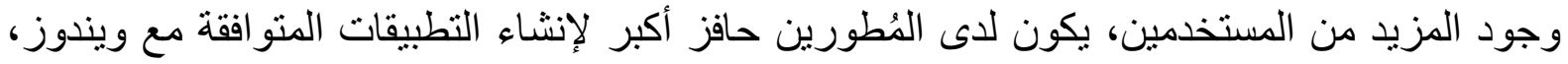

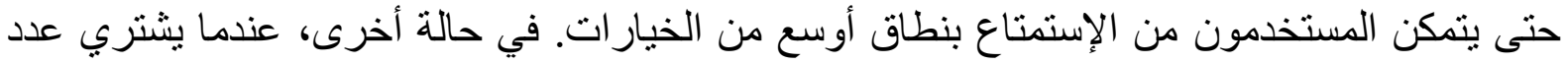

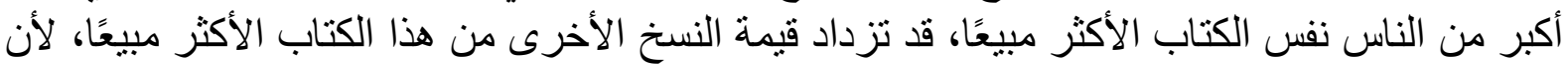

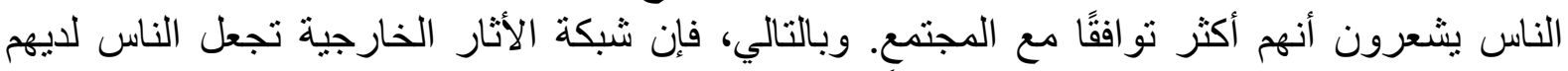

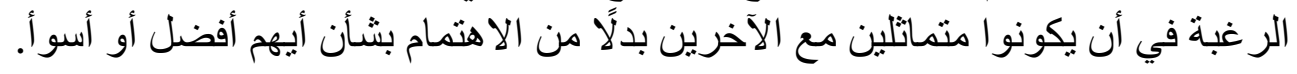

ويختلف تعريف الأثار الخارجية للوضع الاستهلاكي عن شبكة الأثار الخارجية، لأنه يتوقف على أهمية

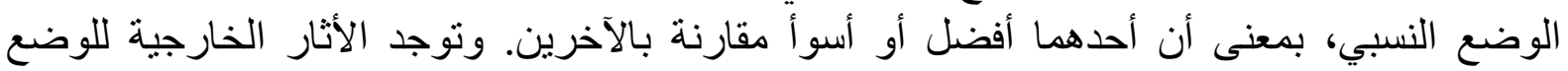
الاستهلاكي عندما تعتمد الفائدة التي يحصل عليها فرد واحدي واحد على الوضع النسبي للآخرين. 235 وبهذا

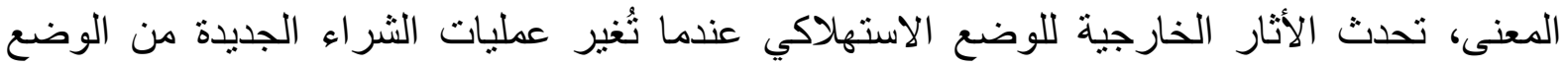

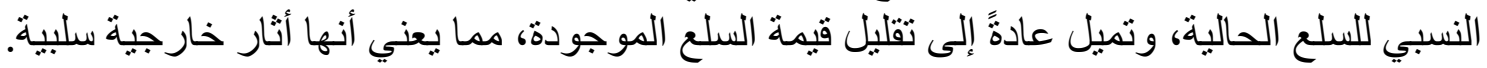

\section{1 استهلاك التفاخر في النظرية الاقتصادية}

إن استهلاك التفاخر الاجتماعي ليس ظاهرة حديثة، فقد سيطر الاستهلاك الخاص بالوجاهة الاجتماعية

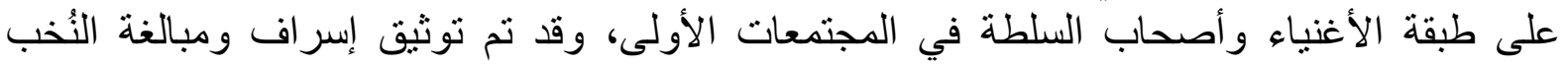

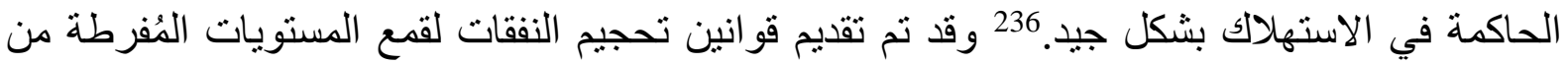

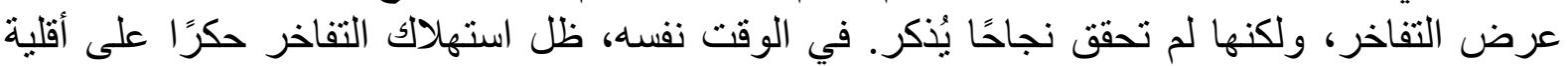
مميزة عززت ثروتها وتفوقها الاجتماعي من خلال مستويات فاحشة من التبذير التفاخري.

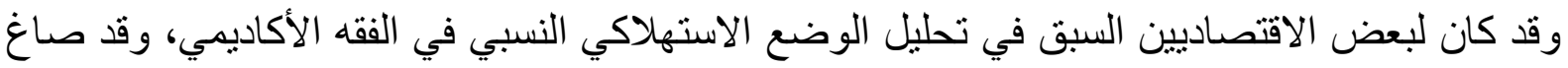

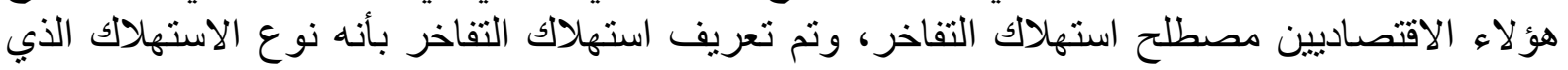

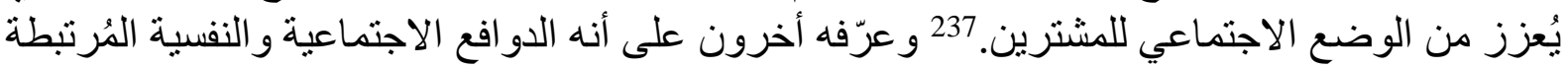

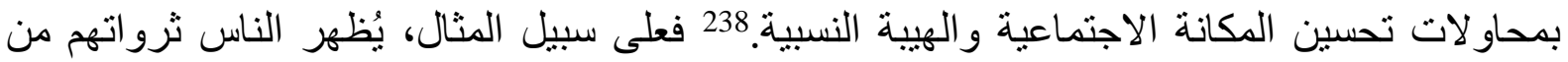

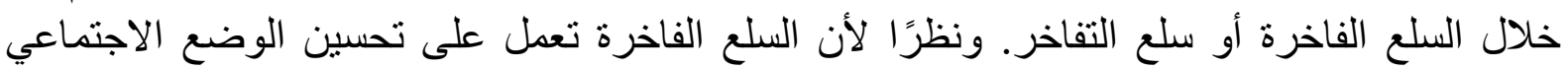

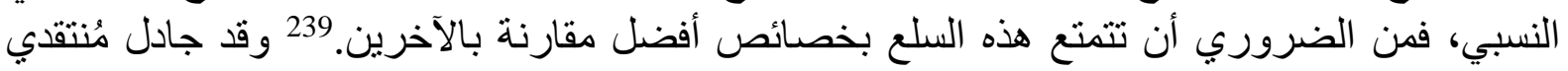

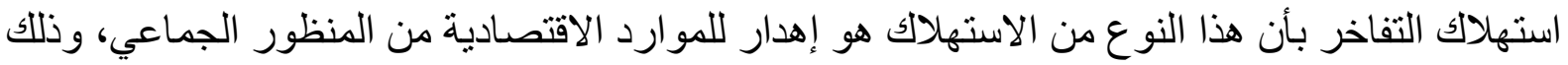

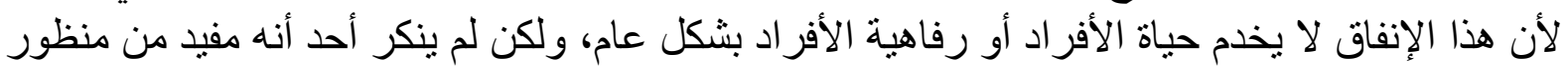
المستهلك الفردي.

\footnotetext{
${ }^{235}$ Mankiw, N. G., \& Taylor, M. P., (2014). Economics. (3rd ed.).

${ }^{236}$ Hunt A., (1996). Governance of the Consuming Passions. Macmillan Press: London, P.77.

${ }^{237}$ Veblen, T. (1899). The theory of the leisure class: An economic study of institutions. New York: Macmillan Co.

238 Mason, R., (2000). Conspicuous Consumption and the Positional Economy: Policy and Prescription since 1970. Managerial and Decision Economics. 21 (3), P. 123.

${ }^{239}$ Carlsson, F., Johansson-Stenman, O., \& Martinsson, P. (2007). Do You Enjoy having More than Others? Survey Evidence of Positional Goods. Economica. 74 (296), P. 586.
} 


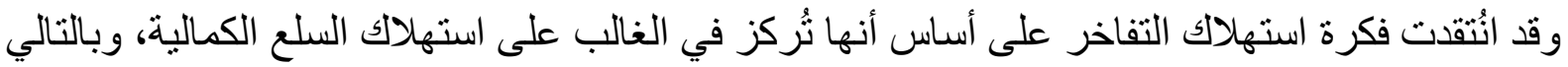

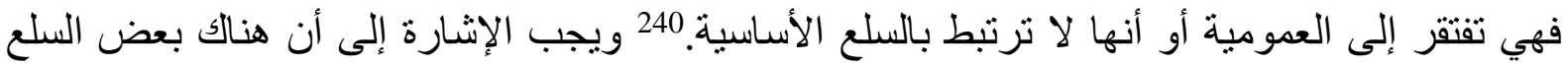

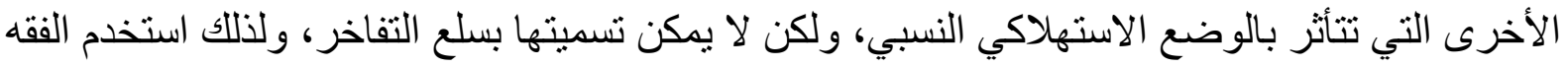

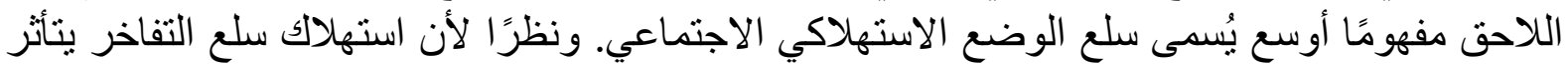

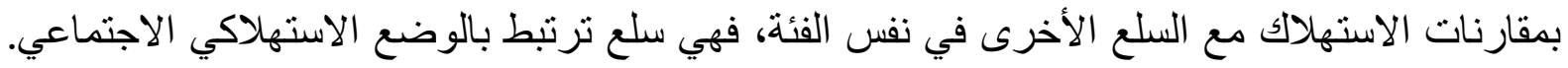

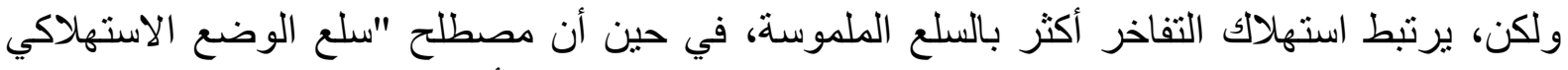

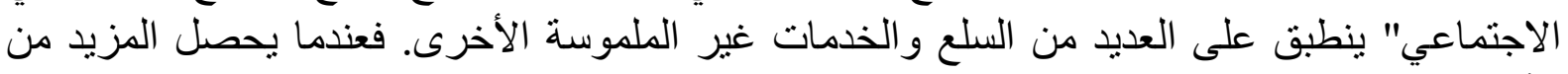

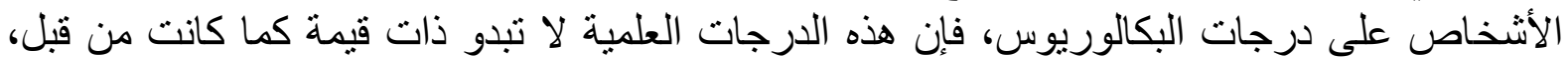

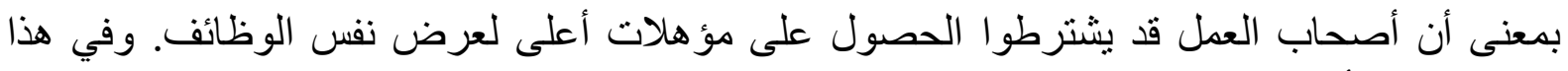

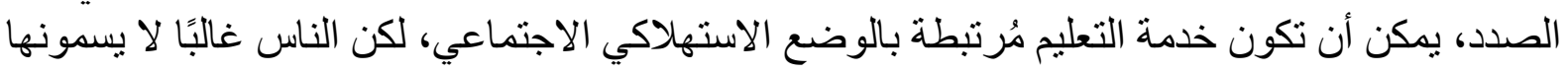

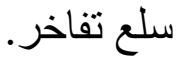

ويعرّف البعض سلع الوضع الاستهلاكي الاجتماعي على أنها تلك السلع التي تكون فيها العلاقة قوية بين

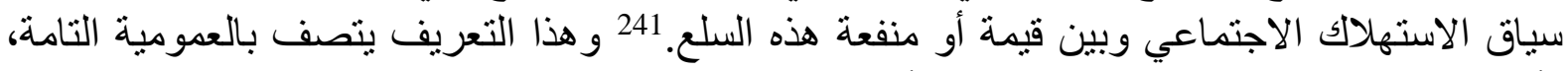

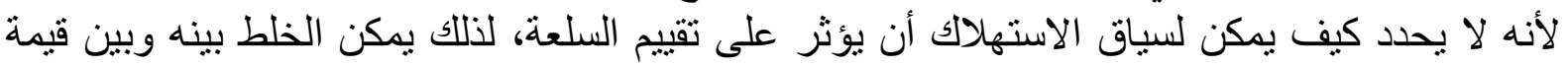

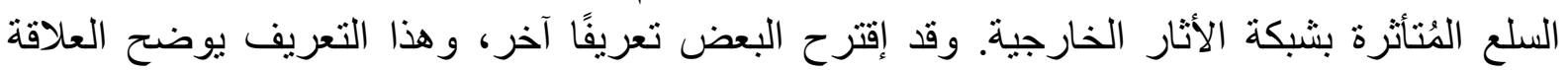

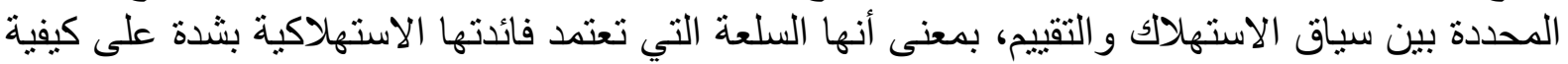

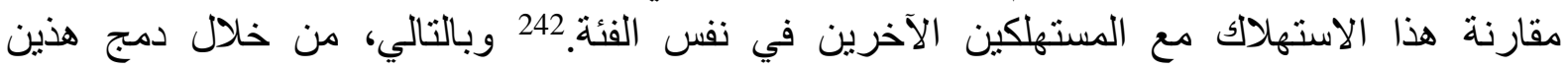

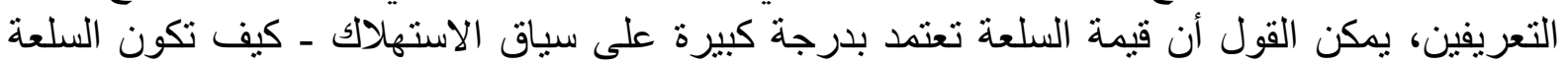
أفضل أو أسوأ من غير ها: العنا

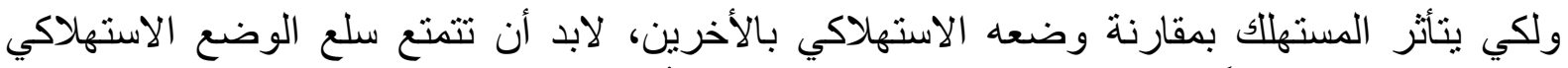

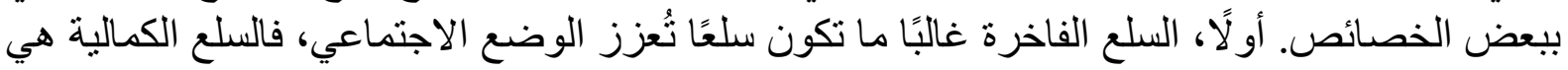

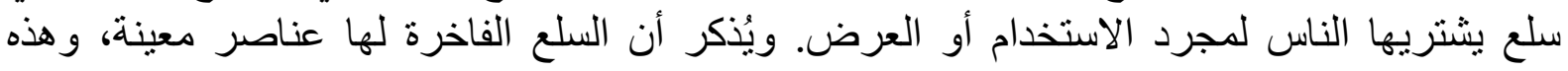

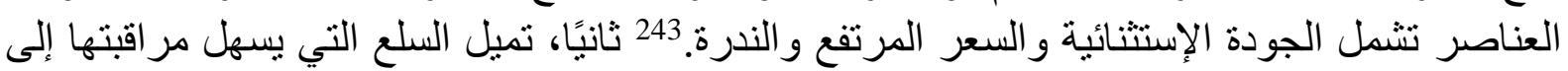

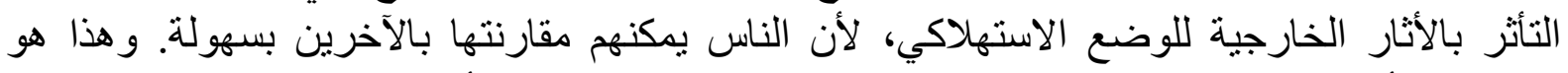

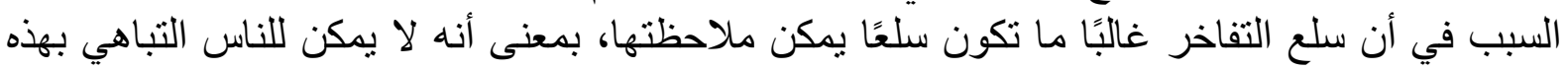

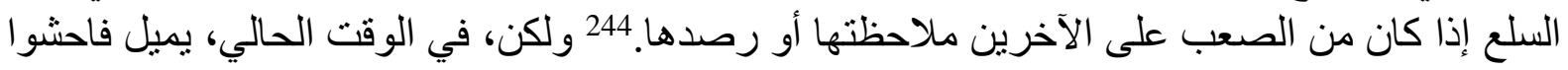

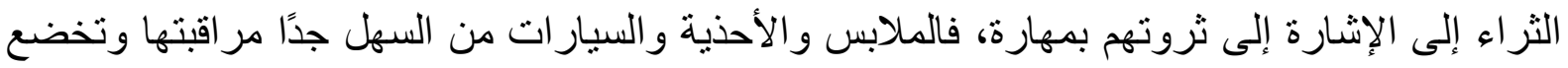

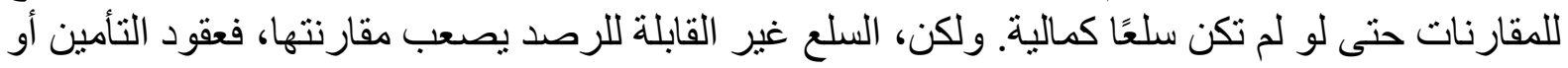

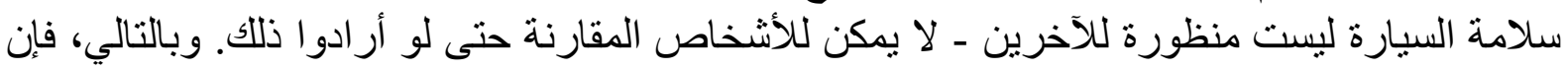
هذه السلع لا تخضع للمقارنات، ويتمتع الناس بفو لائد هذه السلع دون الحاجة الحنّة إلى مقارنتها بسلع الآخرين.

240 Trigg, A. B., (2001). Veblen, Bourdieu, and Conspicuous Consumption. Journal of Economic Issues. 35 (1), P. 99.

${ }^{241}$ Frank, R. H., (2008). 'Should Public Policy Respond to Positional Externalities?' Journal of Public Economics. 92 (8), P.1778.

${ }^{242}$ Frank, R. H., (2005). Positional Externalities Cause Large and Preventable Welfare Losses. The American Economic Review. 95 (2), P. 137.

${ }^{243}$ Kapferer, J., \& Michaut, A., (2015). 'Luxury and Sustainability: A Common Future? The Match Depends on how Consumers Define Luxury.' Luxury Research Journal. 1 (1), P. 3.

${ }^{244}$ Frank, R. H., (1985). 'The Demand for Unobservable and Other Non-positional Goods.' The American Economic Review. 75 (1), P. 101. 


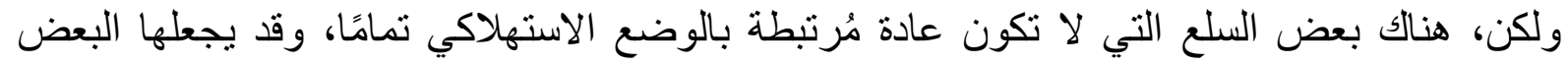

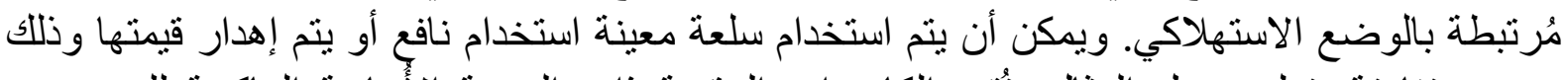

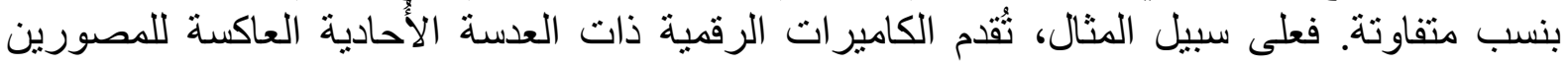
المُحترفين قيمة وظيفية كبيرة، ومع ذلك، يشتريها كثير من الناس في الوقت الحاضر فقط فلثة للتباهي

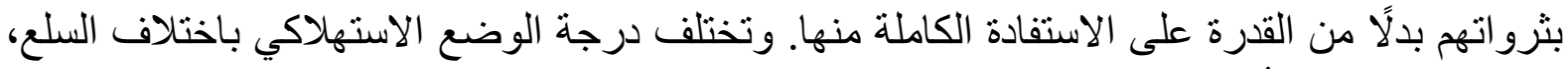
على سبيل المثال، ثُظهر بعض الأبحاث أن السيار ات و المنازل تثأثر بالوضع الأنه الاستهلاكي النسبي أكثر

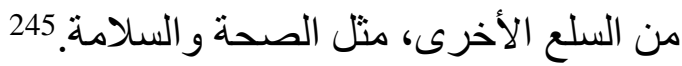

ويُذكر أنه في الخمسين عامًا الماضية، ومع ظهور المجتمعات الأكثر ثراءً ومساواة، إنتهى احتكار

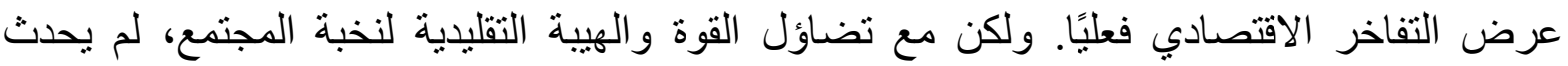
انخفاض ممانل في جاذبية استهلاك التفاخر، حيث كان هنالك تغير في طبيعه و اتجاه هذا الاستهلاك.

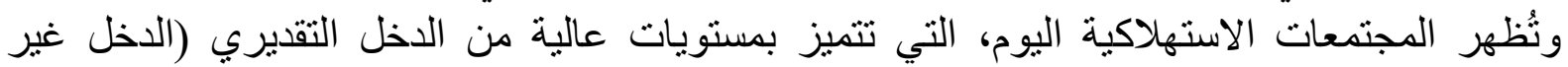

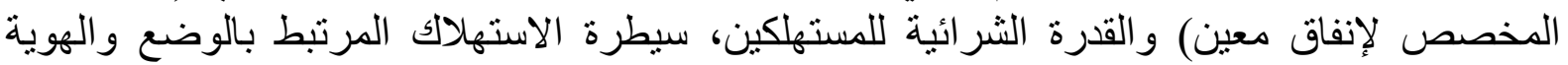

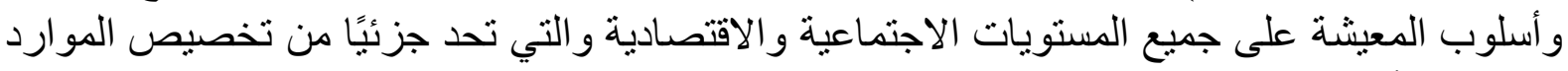
النادرة في أي اقتصاد معين.

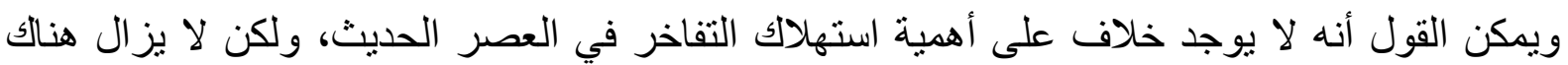

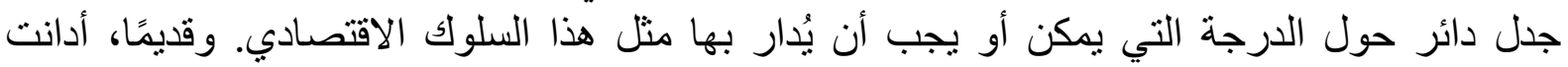

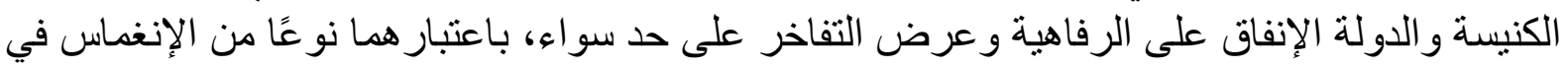

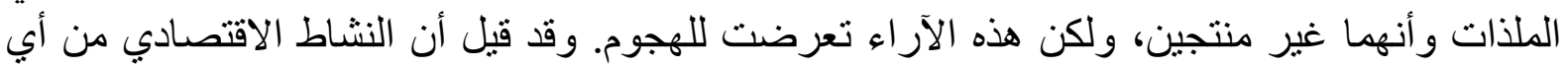

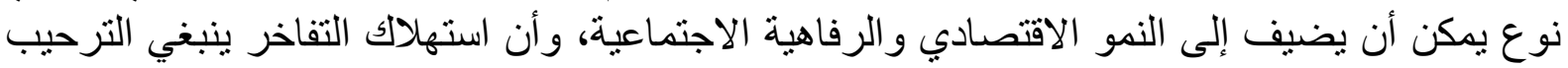
به كقوة للخير. ولكن هذا الر أي أثنار بعض الغضب في ذلك الوقت في 246 كما نأى الاقتصاديون الكلاسيكيون

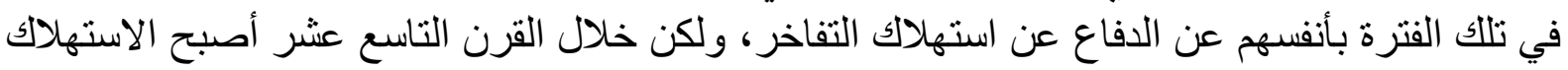

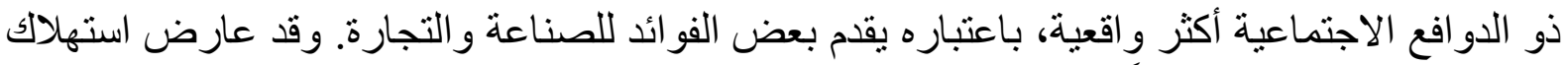

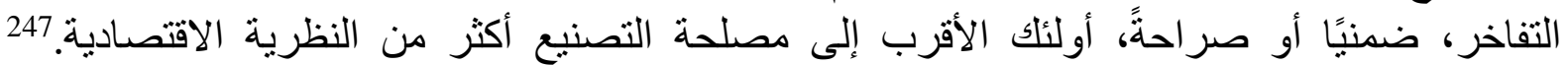

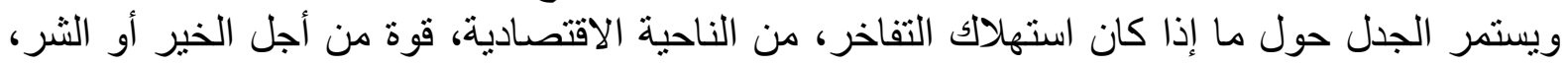

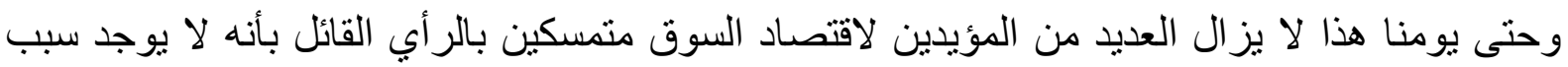

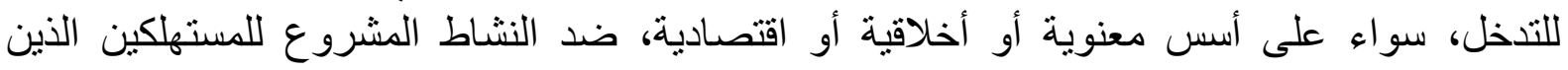

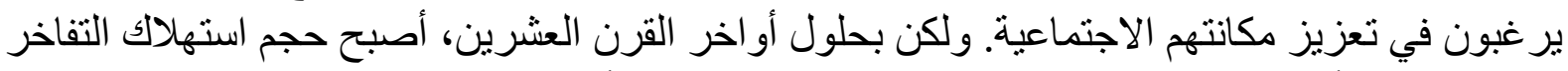

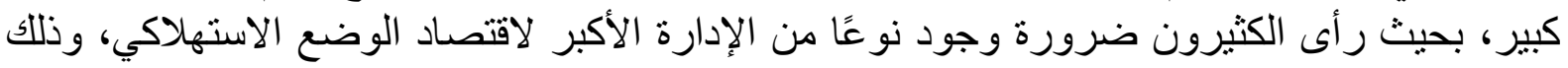
لتحقيق زيادات مُستدامة في النمو الإنتاجي طوريل فيل الأجل.

إن الحجج القائلة بأن الاستهالك المُّفرط، و المدفوع بتحسين الوضع الاجتماعي في المجتمعات الثرية اليوم

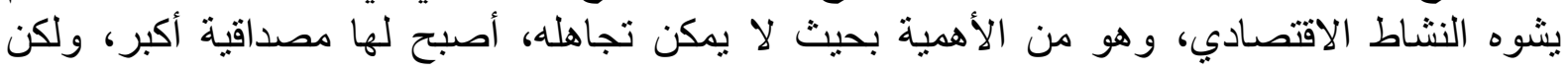

${ }^{245}$ Solnick, S. J., \& Hemenway, D., (2009). 'Do Spending Comparisons Affect Spending and Satisfaction?' The Journal of Socio-Economics. 38 (4), P. 568.

${ }^{246}$ Mandeville B., (1988). The Fable of the Bees: or, Private Vices, Public Benefits. Clarendon Press: Oxford, P.43.

${ }^{247}$ List F., (1841). The National System of Political Economy. Reprinted 1965 (5th edn). Augustus M. Kelley: New York, P.68. 
السياسات و الحلول كانت بطيئة من حيث التطور ـ و على وجه الخصوص، كانت هناك خلافات حول كيفية خفض الطلب على سلع التفاخر، أو توجيهه إلى مجالات الاستههلاك الأكثر إنتاجية.

ويُعتقد أن الحل الوحيد على المدى البعيد لسوء تخصيص الموارد الناتج عن سلوك المستهلك المدفوع

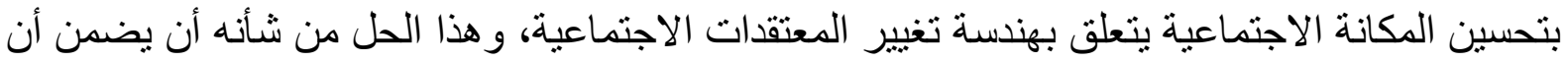
المصلحة الاجتماعية أصبحت شرطًا لتحقيق المصلحة الذاعة التية. وبهذه الطريقة، يمكن تأمين الفوائد

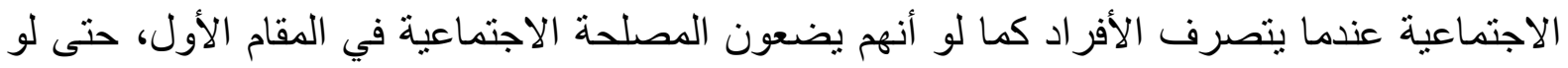

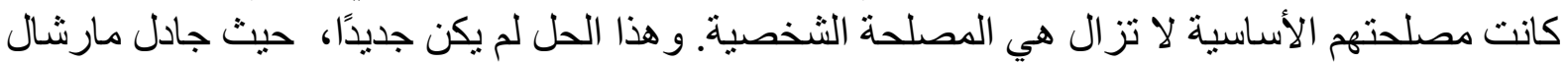
بأن التعامل مع استهلاك التفاخر، الذي يُهدر الموارد الاقتصادية لتعزيز المكانة الاجتماعية، يكمن تغيير

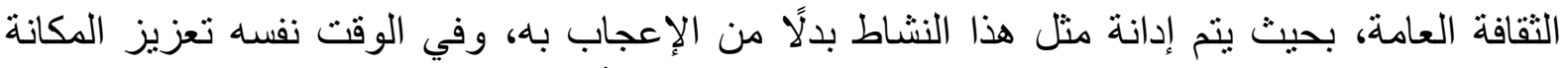

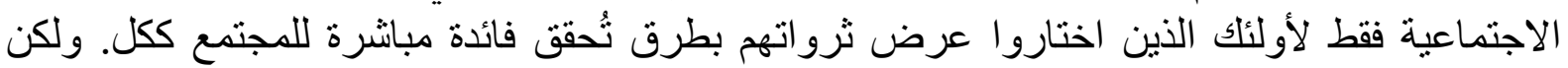

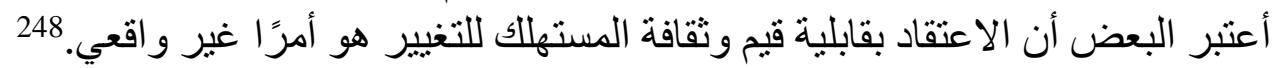

و على عكس هذا الحل، أكد البعض على أن أي محاولات هندسية لتغيير نمط الطلب على سلع التفاخر

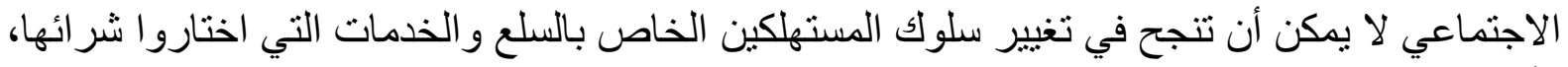

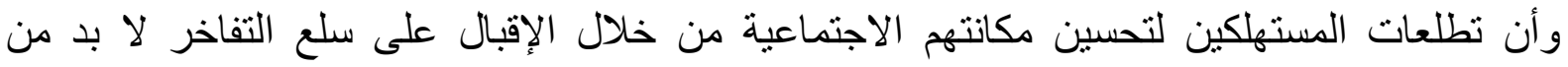

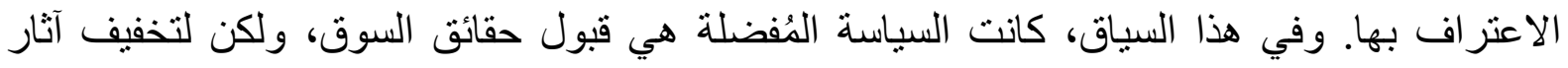
سلوك المستهلك يتم فرض ضريبة استهلاك على فئات الاستهلاك التي تفرض فئل آثنارًا خارجية (سلبية)

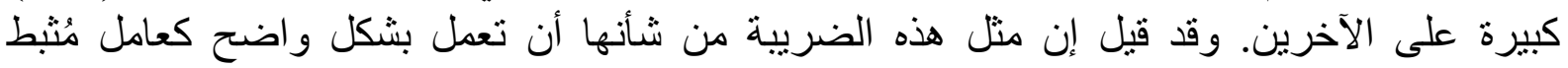

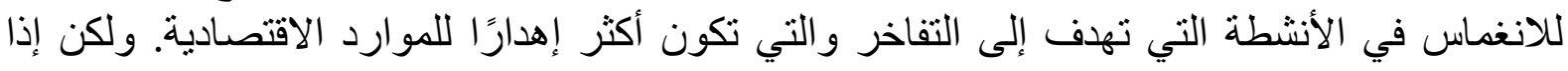

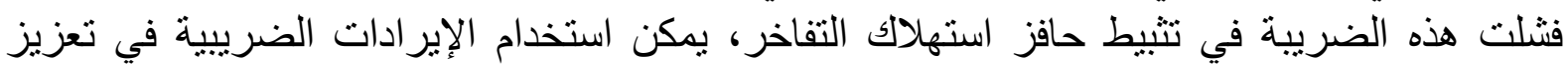
المصلحة الاجتماعية الأوسع، وذلك لتعويض بعض التض النتائج السلبية لمنل هذا الاستهلاك. 249

وقد أثنار الإقتر اح الخاص بفرض ضريبة الاستهلاك العديد من الأسئلة المتعلقة بتنفيذها وآثار ها. أولًا، لم

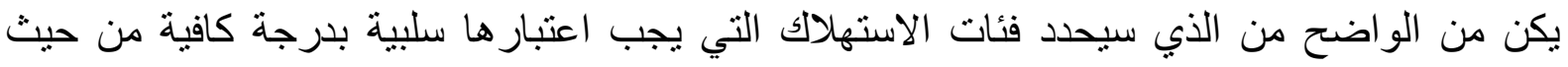

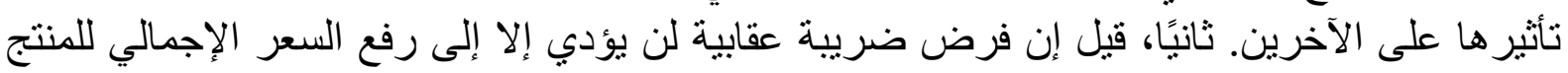

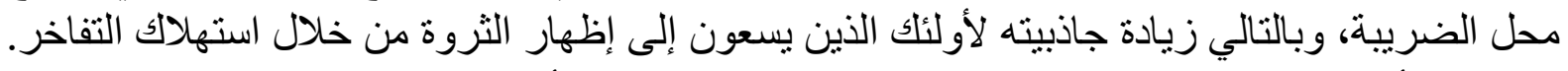

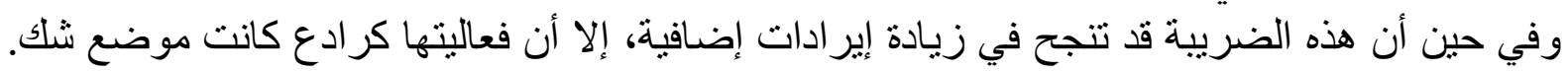
و أخيرًا، هناك بعض المخاوف بثأن مخاطر الركود و البطالة بين موردي السلع تنافسية الاستهلاك (سلع التفاخر) إذا تم تقليل الطلب عليها بنجاح الهذ وبشكل كبير.

وقد تم الرد على هذا النقد الأخير بالقول إن الأموال التي لم تُنفق على استهلاك التفاخر سيتم ادخار ها

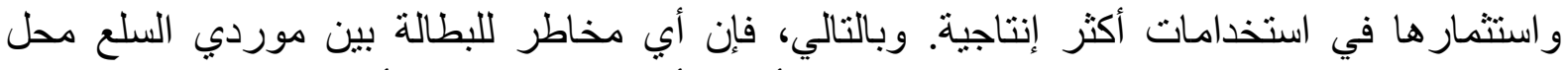

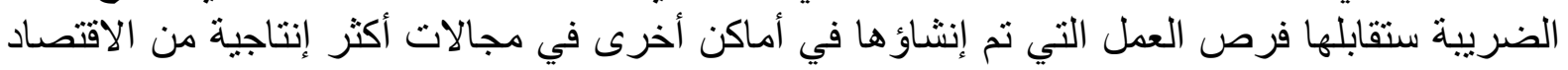

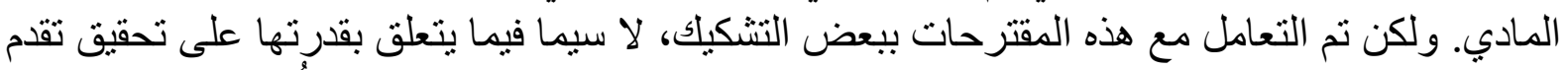

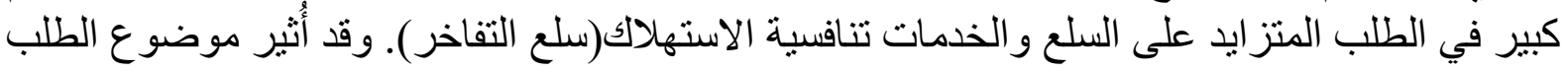

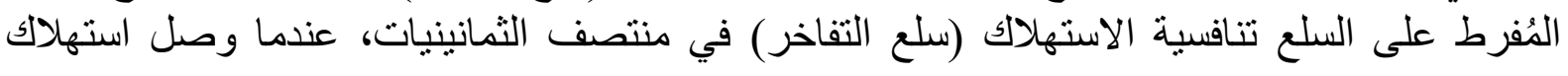

${ }^{248}$ Hirsch F. (1976). Social Limits to Growth. Harvard University Press: Cambridge, MA, PP. 179180.

${ }^{249}$ Frank RH., (1985). Choosing the Right Pond: Human Behavior and the Quest for Status. Oxford University Press: New York. PP. 249-250. 
التفاخر في الو لايات المتحدة وأماكن أخرى إلى المستويات التي بدأت معهاز زيادة الاهتمام السياسي بالأثار

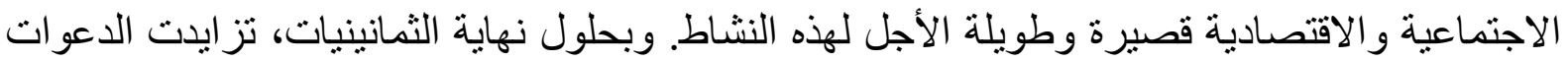
إلى قدر أكبر من التنخل السياسي.

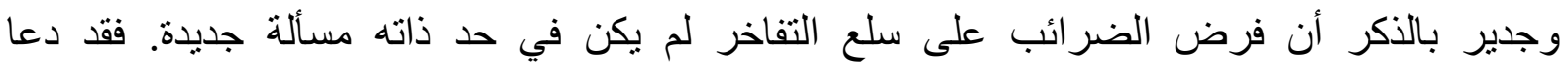

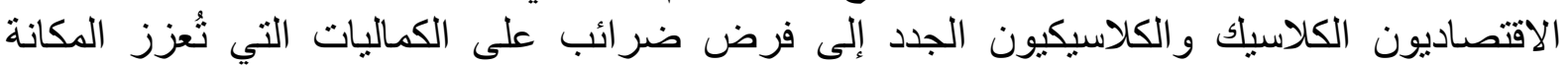

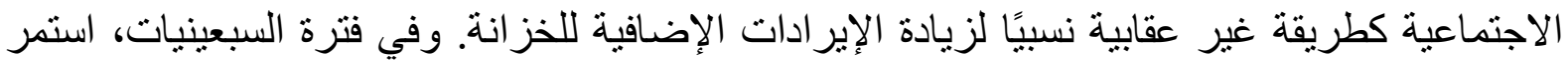

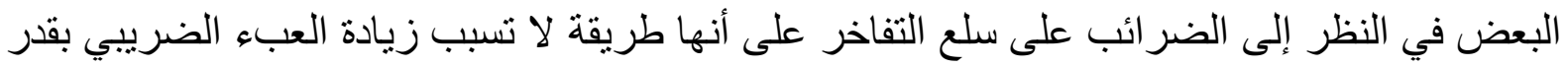

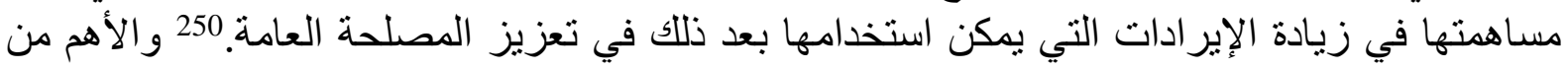

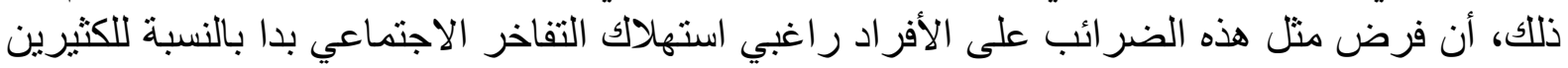

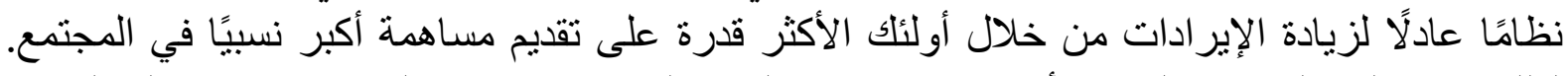

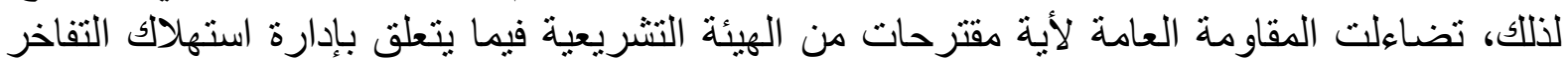
الاجتماعي، ليس أقلها في الولايات المتحدة لإية

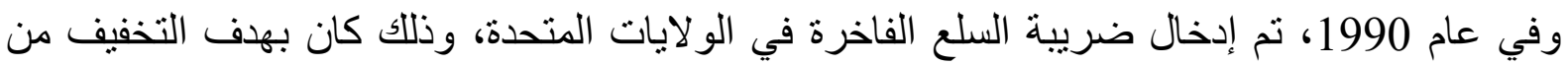

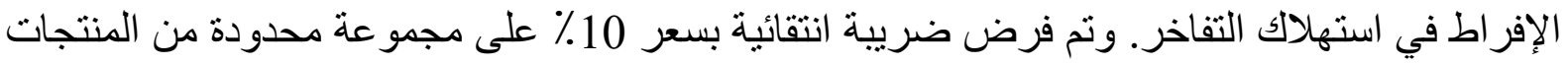

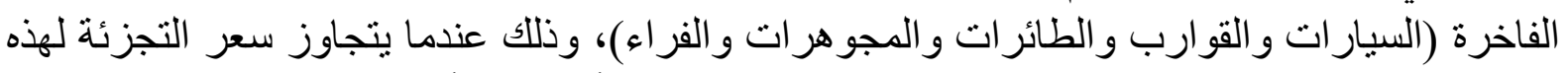

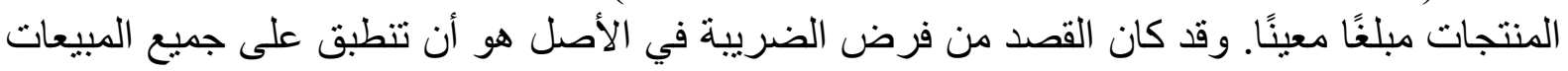

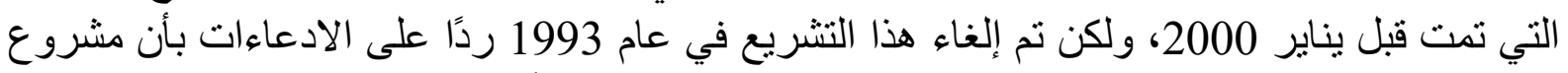

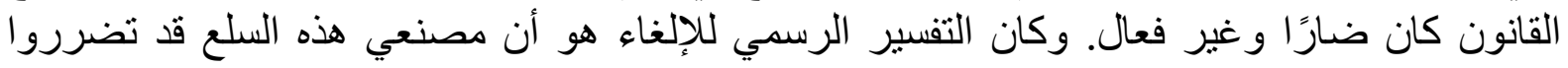

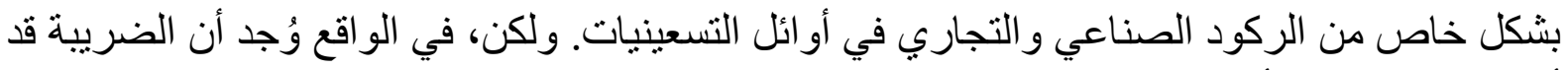

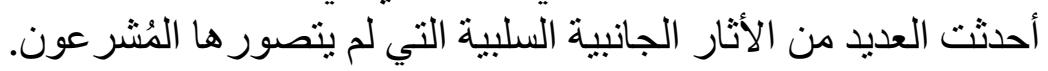

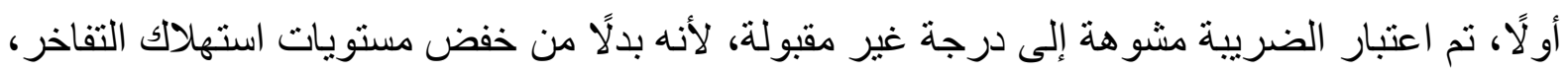

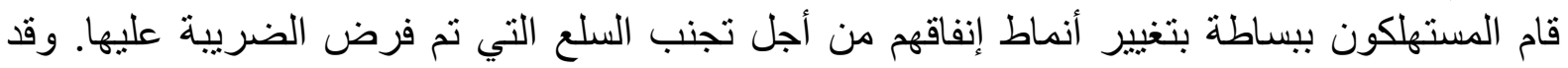

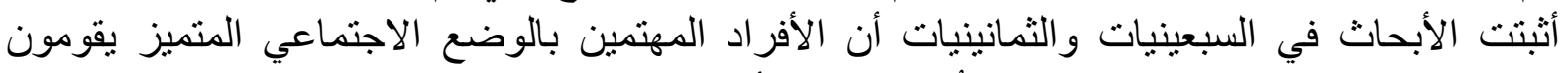

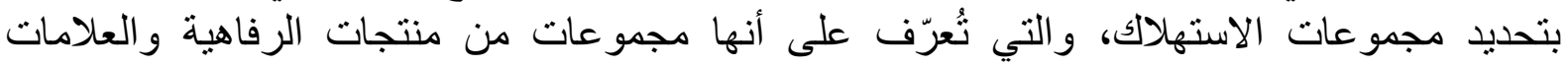

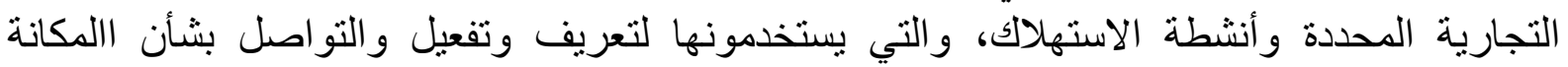

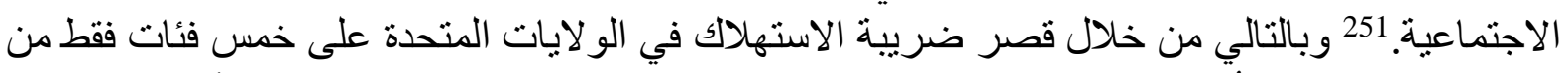

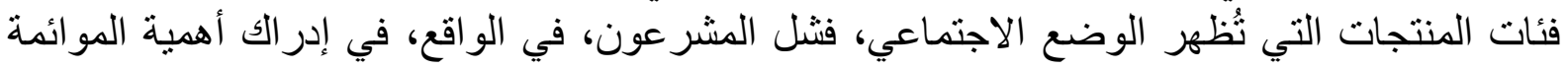

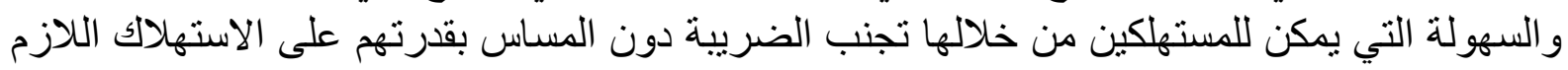
لإظظهار المكانة الاجتماعية.

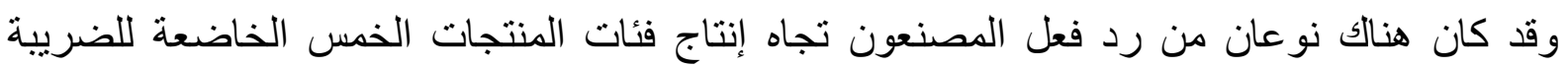

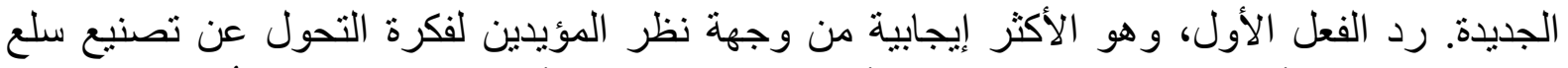

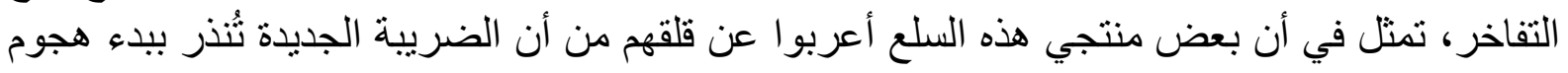

${ }^{250}$ Miller E., (1975). Status goods and luxury taxes. American Journal of Economics and Sociology 34, PP. 141-154.

${ }^{251}$ Douglas M, Isherwood B., (1978). The World of Goods. Penguin Books: London.

${ }^{252}$ Solomon MR, Assael H., (1987). The forest or the trees: a gestalt approach to symbolic consumption. In Marketing and Semiotics: New Directions in the Study of Signs for Sale, UmikerSebeok J (ed.). Mouton de Gruyter: Berlin, P. 189. 


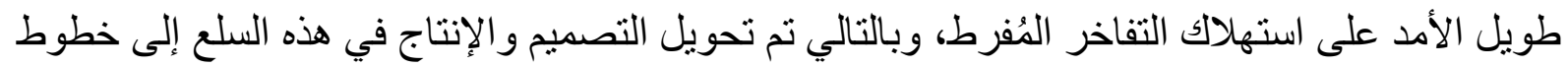

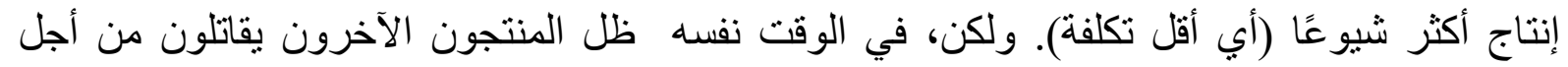

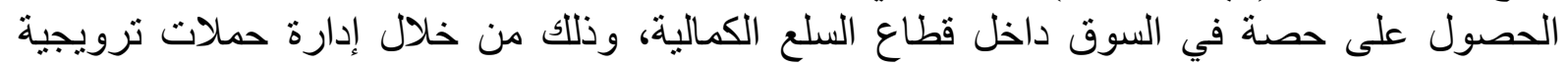

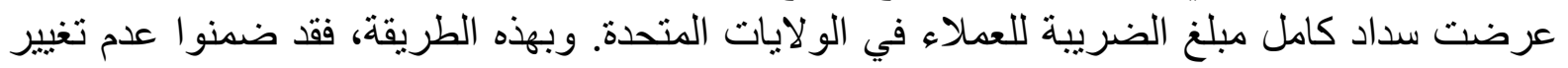

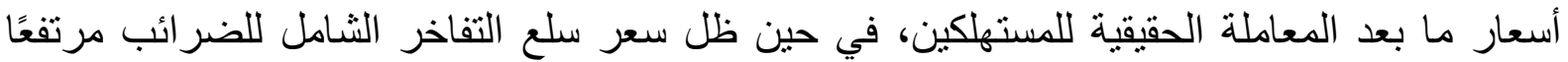
بشكل يُحفز استهلاك التفاخر.

وبشكل عام، يرى البعض أن ضريبة السلع الفاخرة كانت فانشلة من حيث استهاف التهاف التحول المُنظم لأنشطة

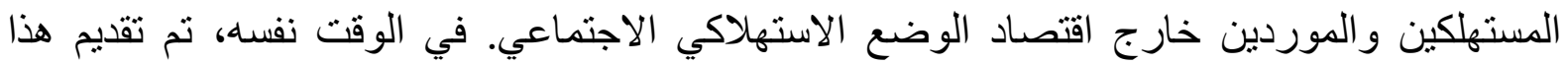

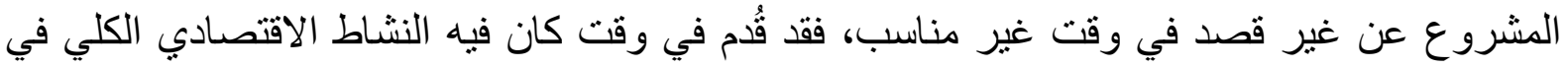

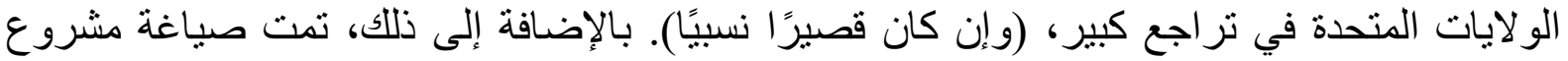

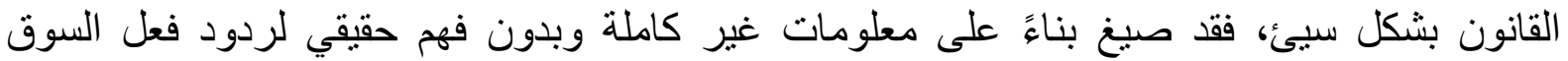

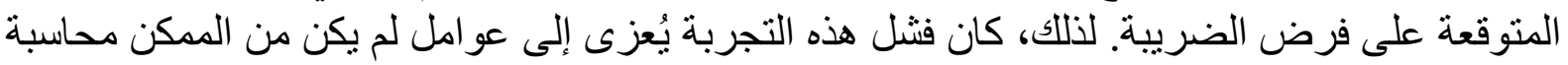

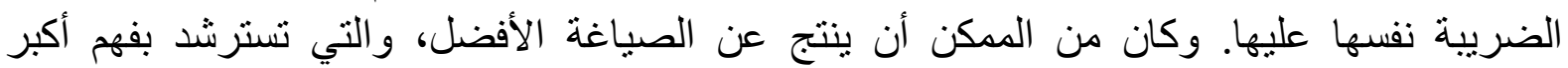
للاستهلاك اللازم لإظهار الوضع الاجتماعي، نتائج أكثر إنتاجية.

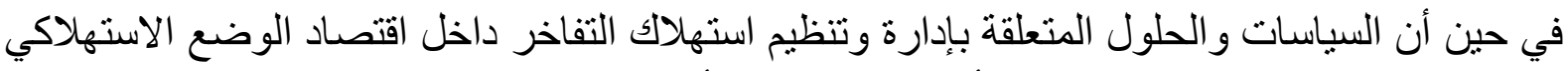

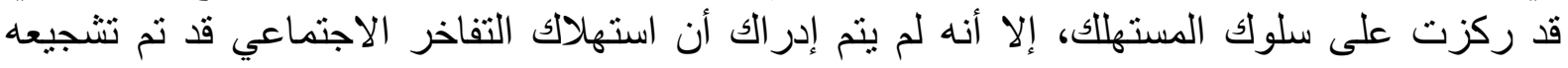

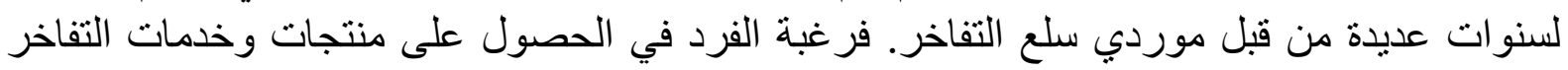

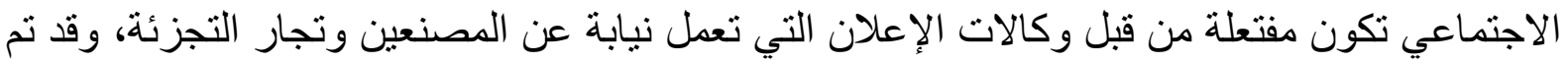

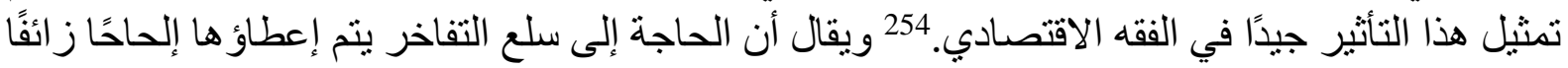

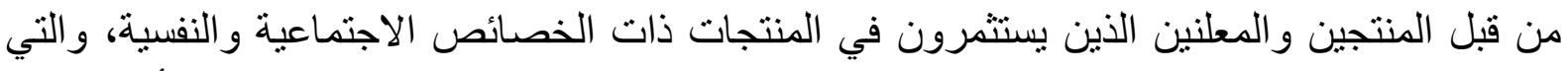

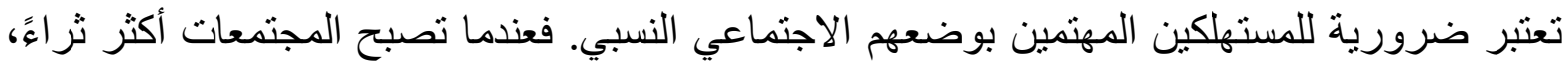

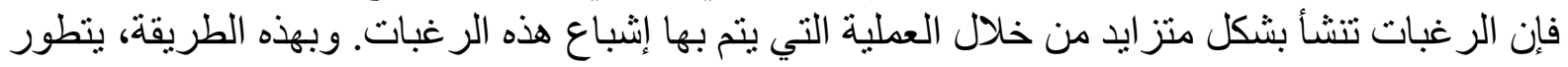

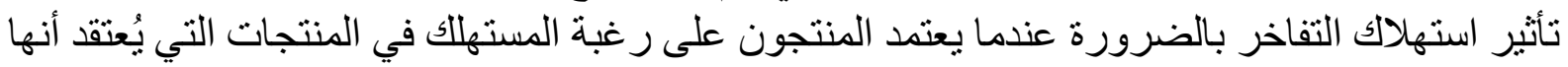
تضيف إلى المكانة الاجتماعية والفيبية.

وقد تم التأكيد على أن الترويج للسلع المرتبطة بالوضع الاستهلاكي الاجتماعي وتوريدها يتم من خلال

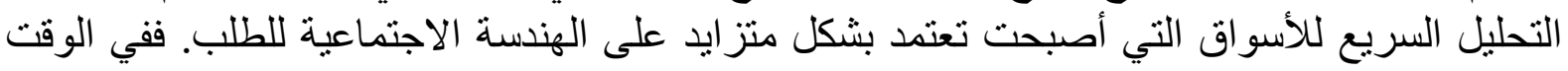

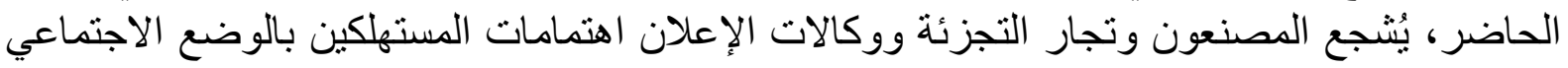

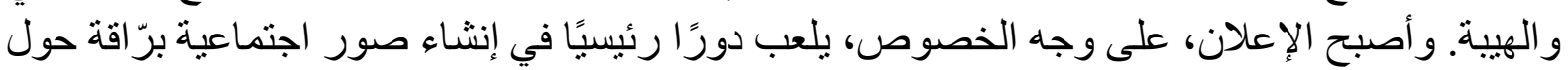

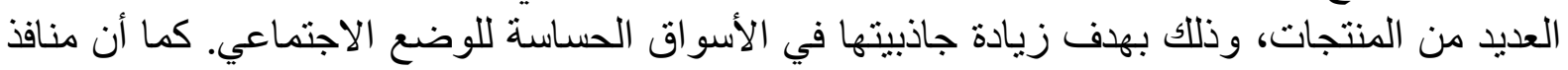

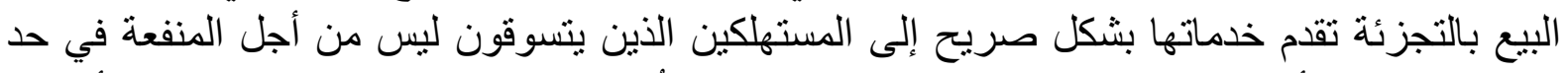

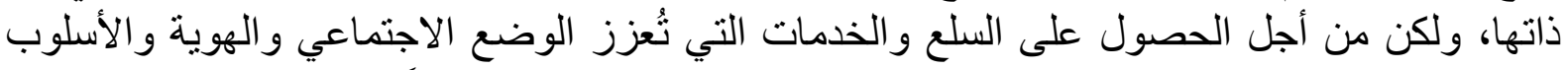

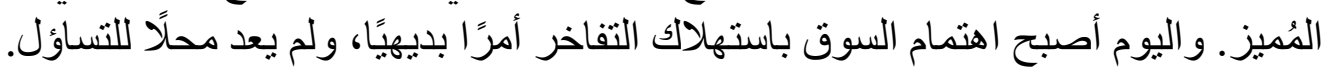

و غالبًا ما يكون النقد الموجه إلى ما يسمى "خلق الحاجة أو الطلب" قائم المائم على الجوانب الأخلاقية

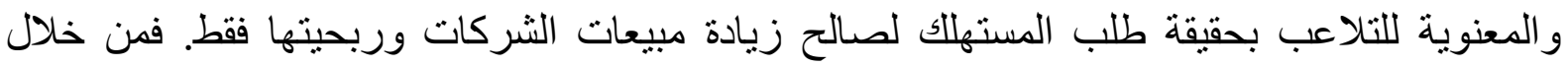

${ }^{253}$ Mason R., (1998). The Economics of Conspicuous Consumption. Edward Elgar: Cheltenham. PP. $157-159$.

${ }^{254}$ Galbraith J.K., (1963). The Affluent Society. Houghton Mifflin: Boston,P.111. 


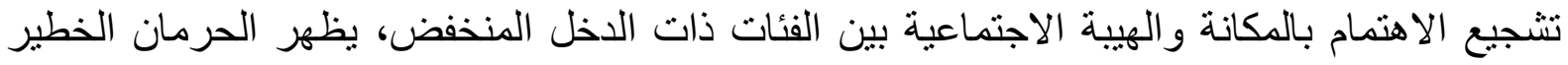

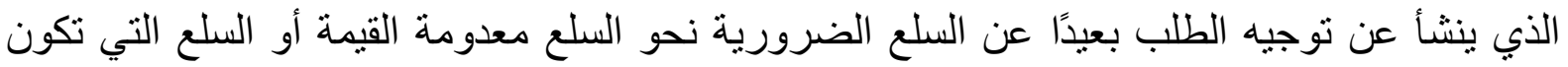

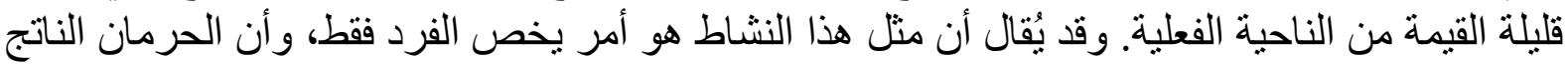

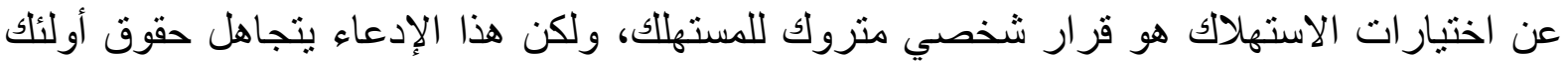

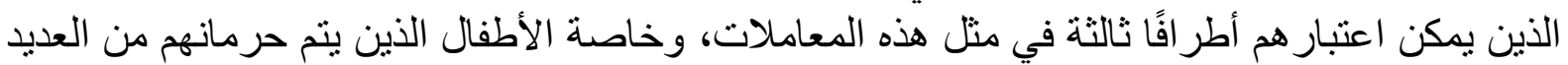

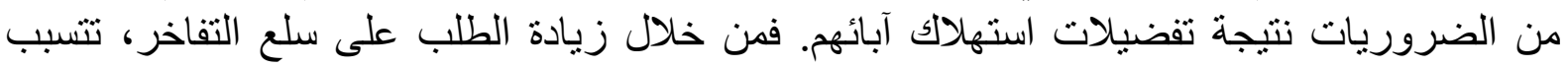

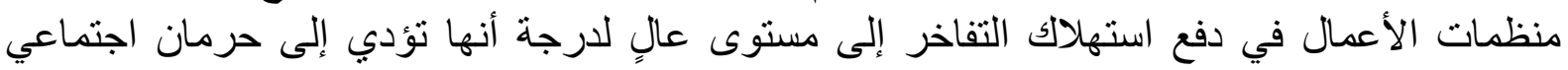
حقيقي. 255

وفي الواقع، لم تنجح هذه الانتقادات القائمة على الأسس الأخلاقية والمعنوية في التغيير من السلوك التهوك

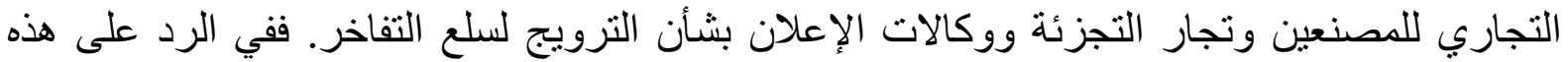

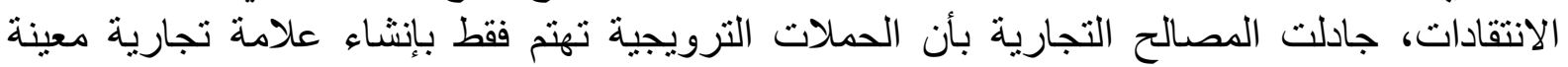

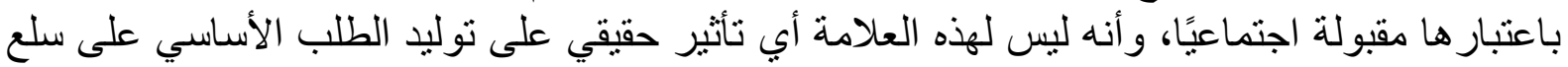

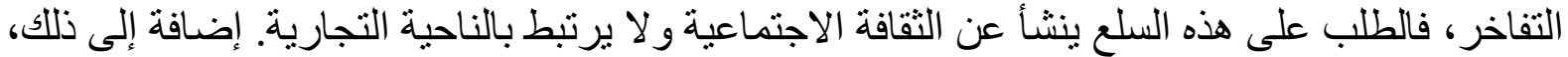

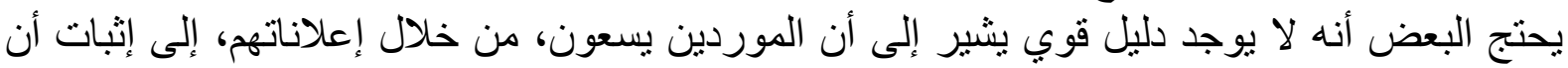

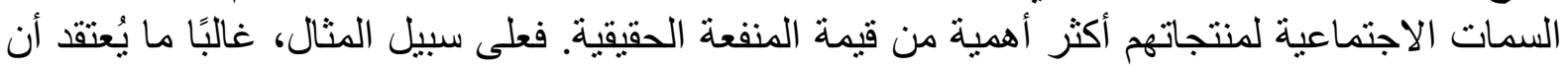

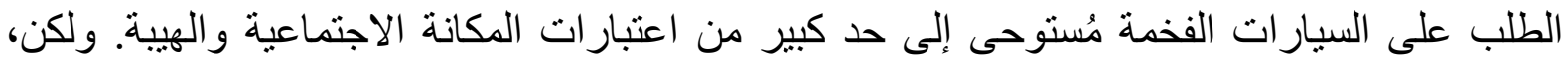

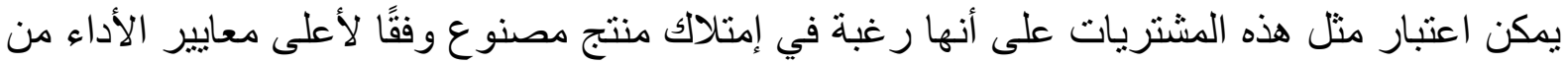

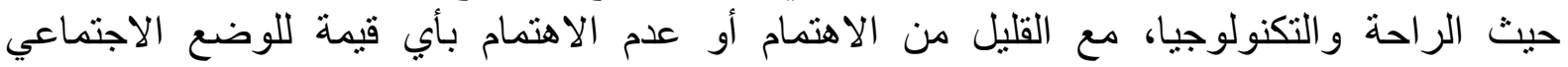
المُنصور.

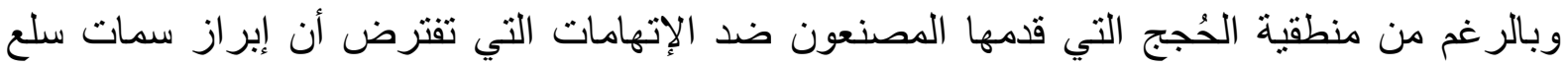

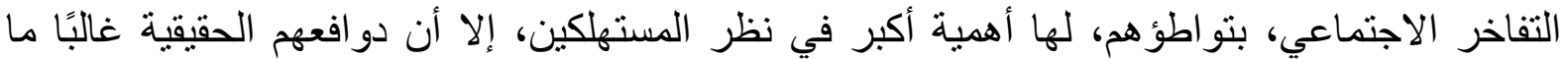

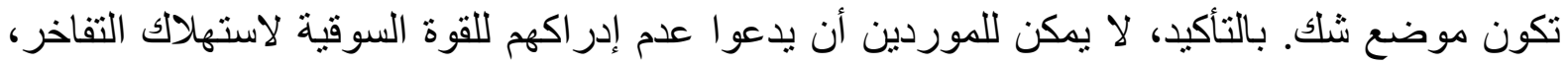

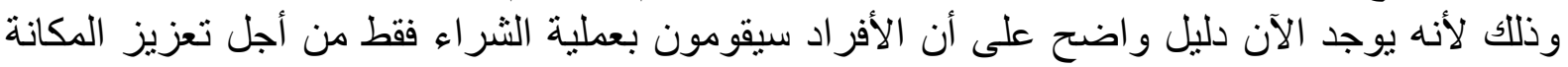

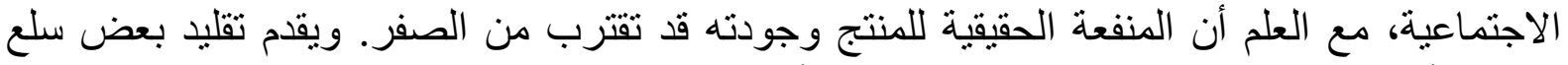

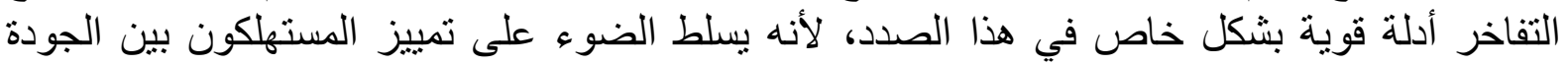

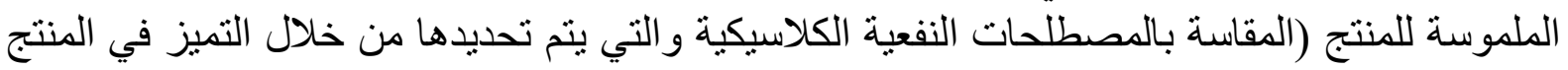
من حيث الاستخدام) وبين قيمته الاجتماعية.

في الو اقع، لا يُقدر المستهلكون الذين يشترون عن عمد منتجات مُقلدة سوى المكانة الاجتماعية المرتبطة

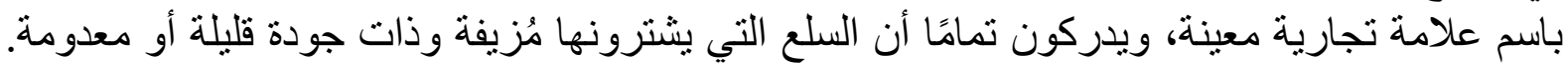

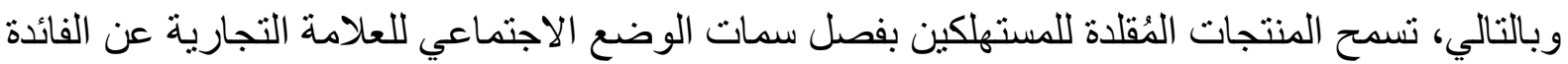

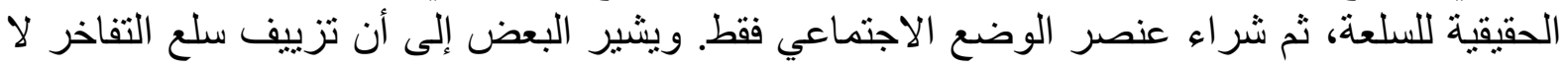

${ }^{255}$ Mason R., (1985). Ethics and the supply of status goods. Journal of Business Ethics 4, PP. 457464.

${ }^{256}$ Lancaster K., (1971). Consumer Demand. Columbia University Press: New York, P. 174. 
يخدع الفرد الذي يشتري المنتج، بل يخدع الئر اقب الذي يرى السلعة وينم استهلاكها و الإعجاب بها على الذى

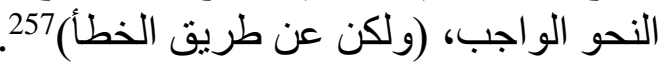

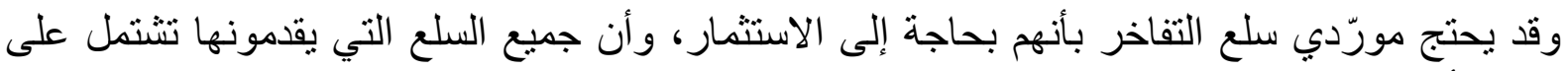

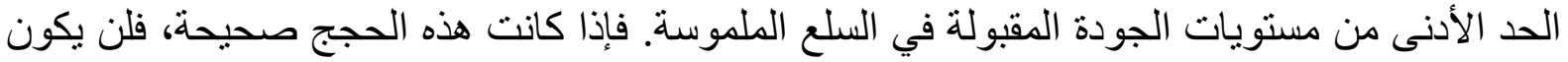

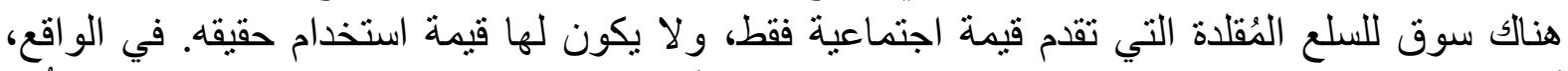

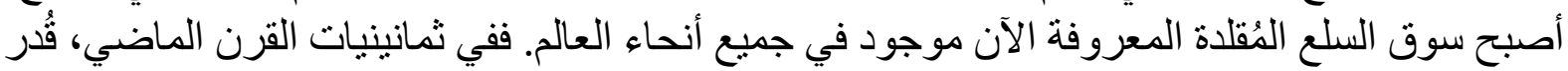

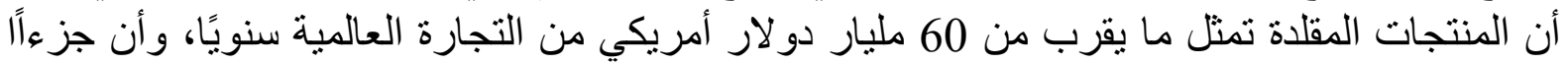
كبيرًا من هذه الأعمال يتعلق بالطلب على عنى السلع المزيفة.

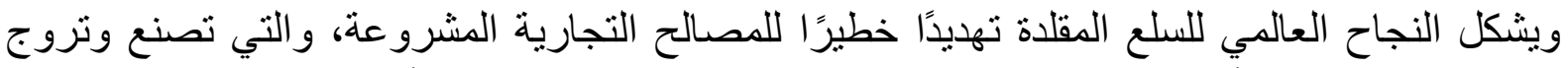

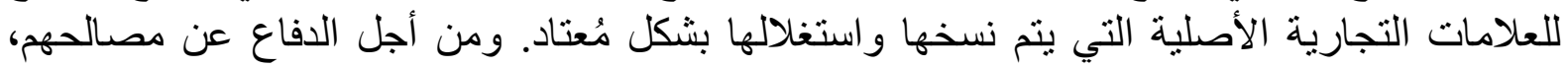

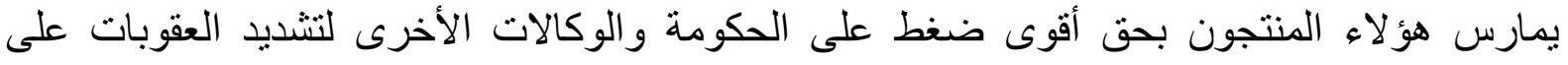

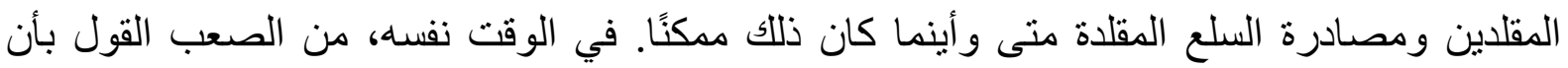

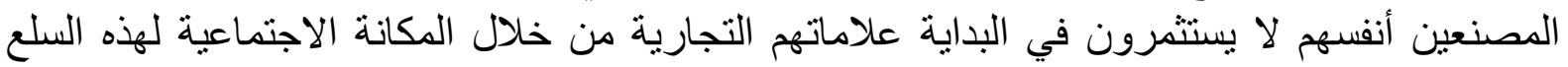

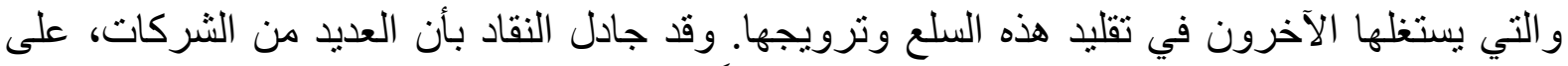

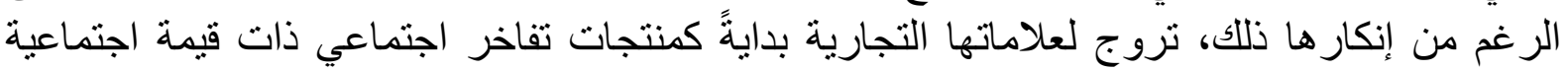

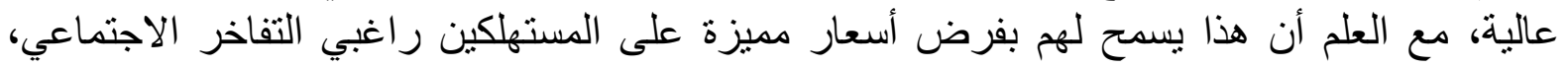
و الذين يعتبروا الأسعار المرتفعة من السمات الإيجابية للمنتج.

\section{2. سياسة التعامل مع استهلاك التفاخر الاجتماعي}

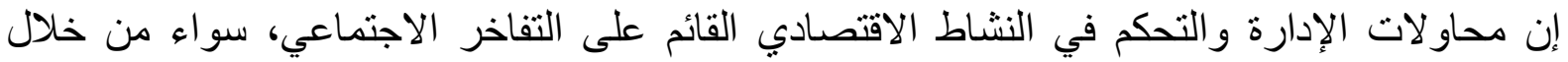

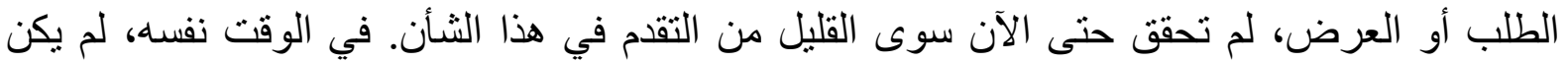

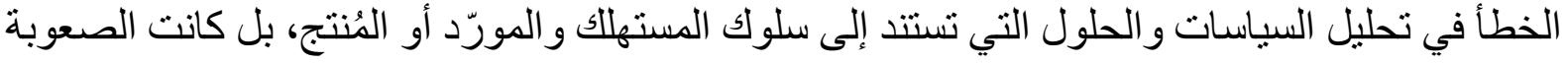

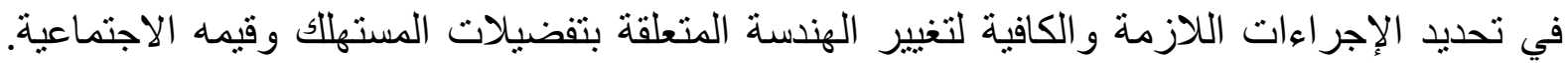

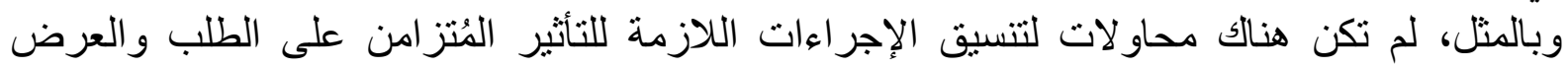
الخاص بسلع التفاخر.

فمن ناحية الطلب، من الواضح أن أبي نجاح في تحقيق التحول من الإنفاق على استهلاكك التفاخر

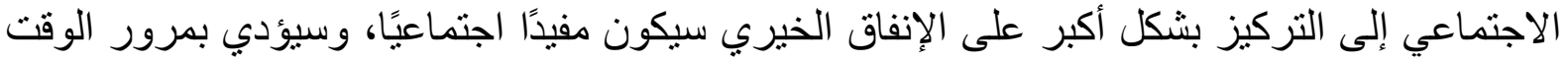

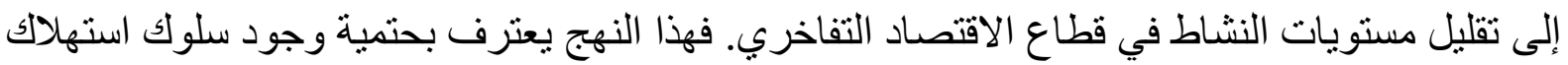

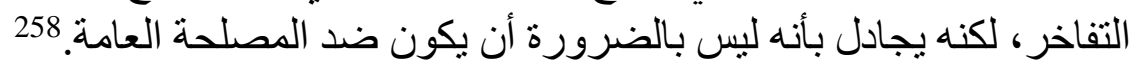

إن نظرية تتجيع استهلاك التفاخر الاجتماعي الذي يُعزز الأثار الخارجية الإيجابية تكون مُقنعة عندما ينتم

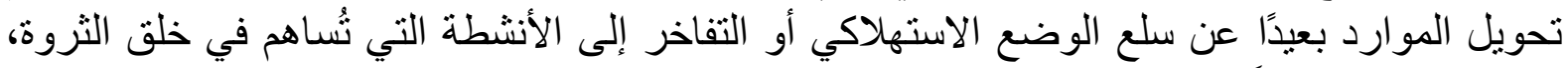

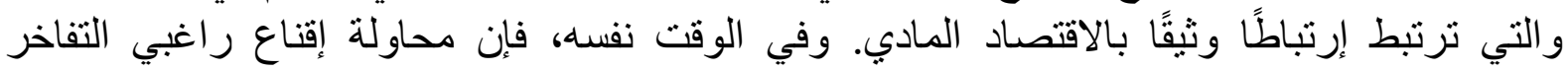

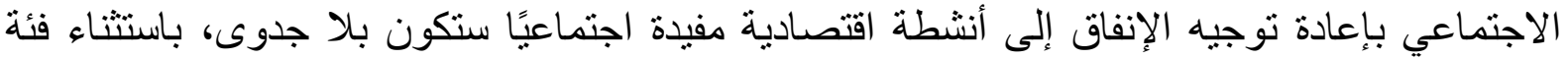

${ }^{257}$ Grossman GM, Shapiro C., (1988). Foreign counterfeiting of status goods, Quarterly Journal of Economics 102, PP. 79-100.

${ }^{258}$ Congleton RD. (1989). Efficient status seeking: externalities and the evolution of status games, Journal of Economic Beha6ior and Organization 11, PP. 175-190. 


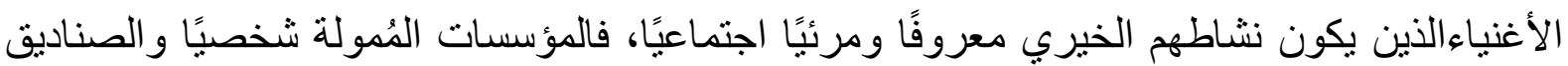

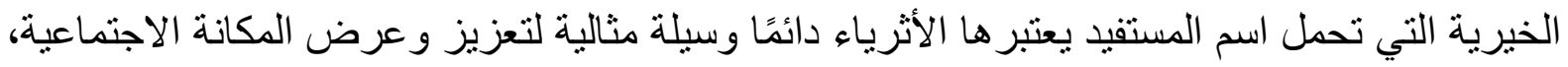

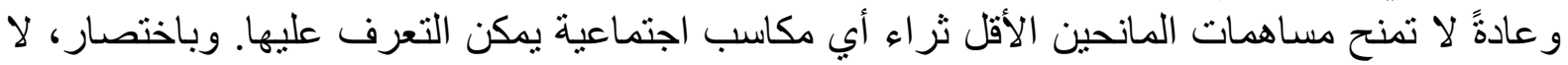
يوجد حافز حقيقي للغالبية العظمى من راغبي التفاخر الاجتماعي للنظر في الاستثمار الخيري كوسيلة

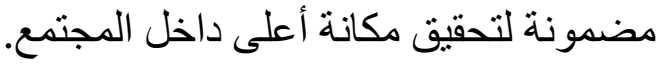

وبالنظر إلى هذه القيود، لا يمكن تتجيع النشاط الخيري إلا من خلال الحوافز الاقتصادية. و وعلى وجها

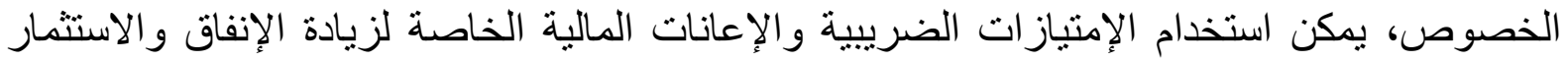

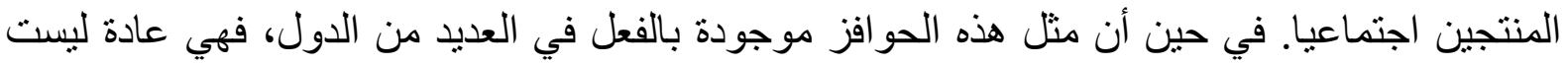

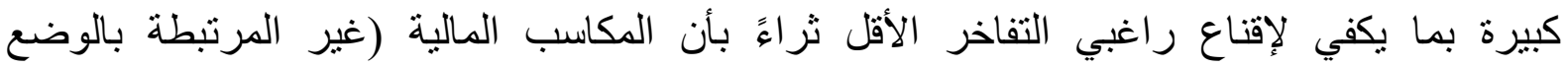

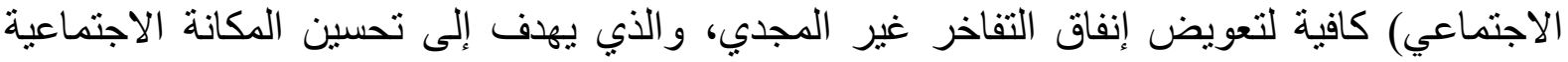

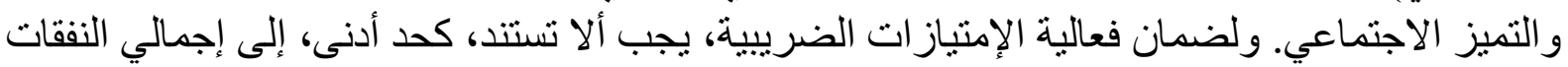

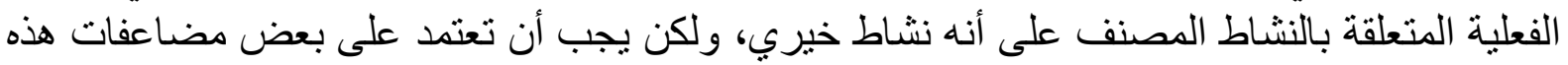

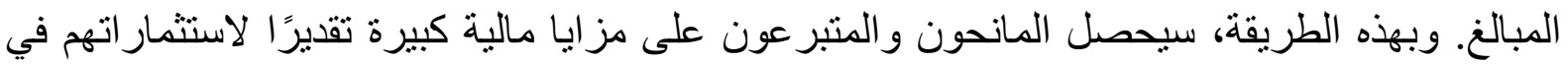

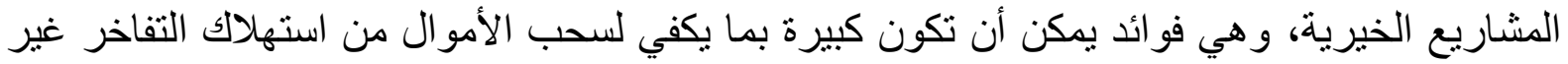
المجدي في اقتصاد الوضع الاستهلاكي.

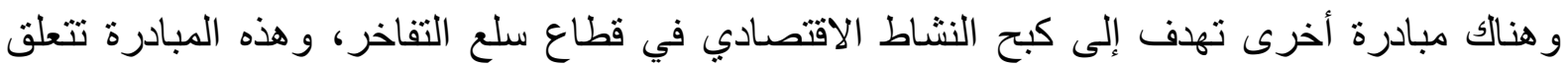

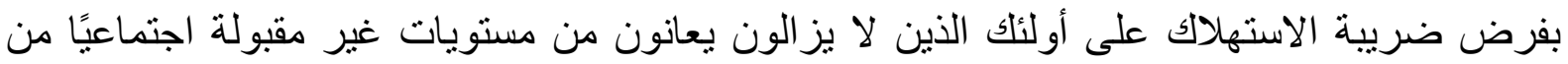

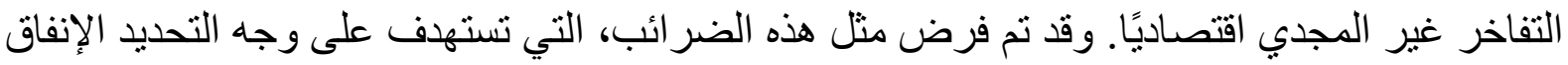

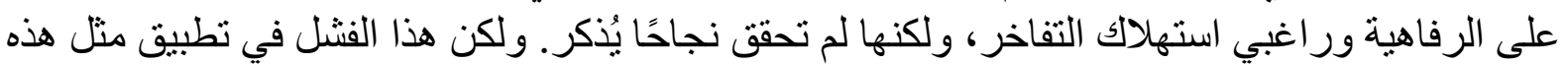

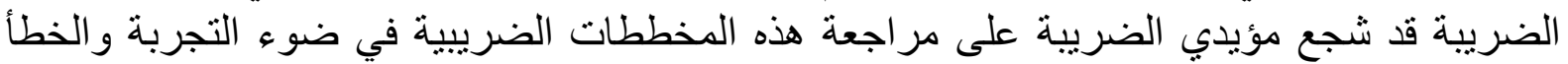

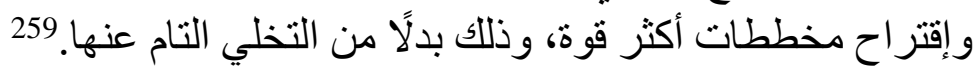

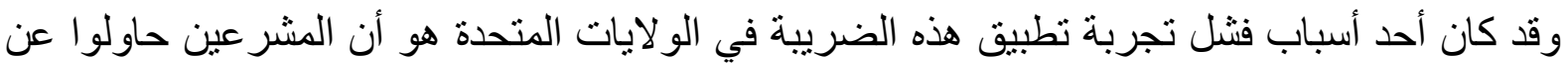

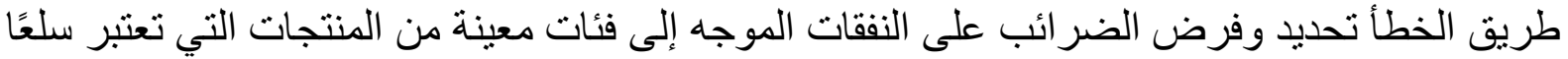

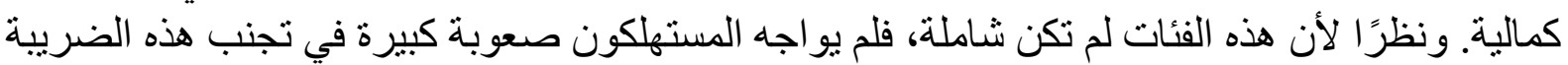

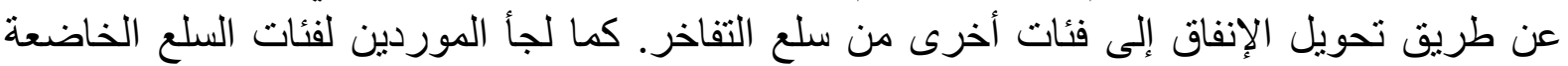

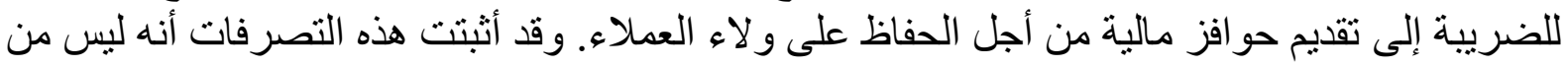

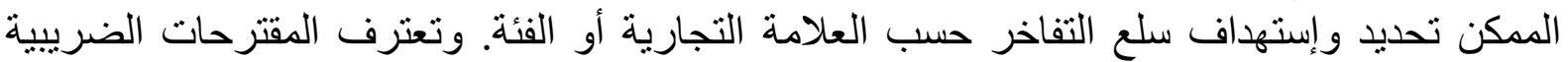

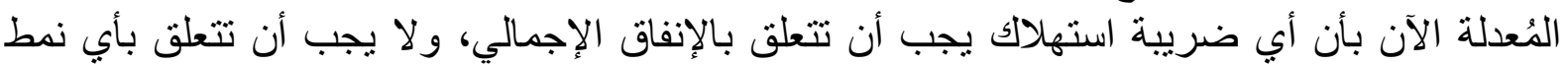

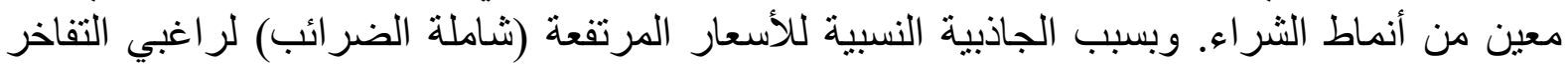

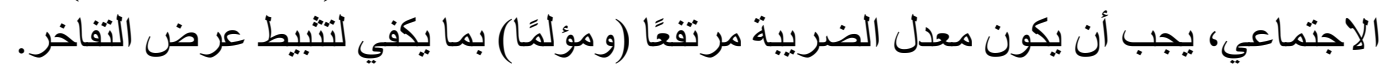

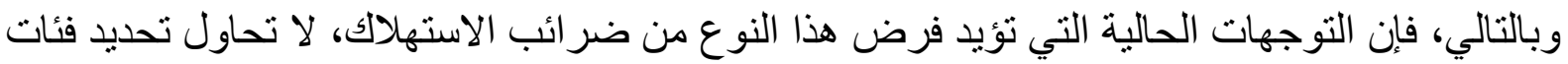

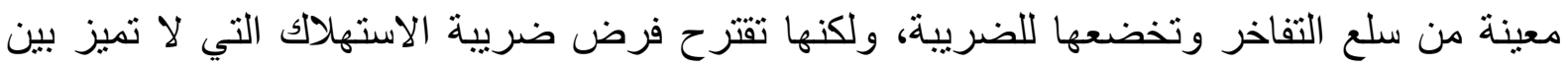

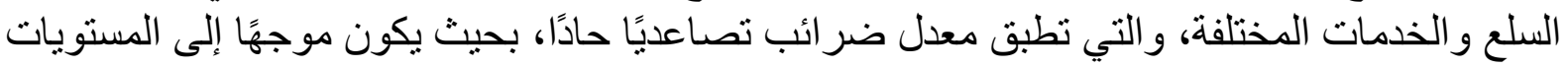
المختلفة من الذخل، ويفرض على الاستهلاك الإيجابي الذي يزيد عن حد معين. وبهذه الطريقة، يتم توعية النية

${ }^{259}$ Frank RH., (1997). The frame of reference as a public good, Economic Journal 107, PP. 18321847. 
الأفر اد بضرورة دفع غرامات مالية كبيرة على الانغماس في مستويات عالية من استهلاك التفاخر ، وهذا

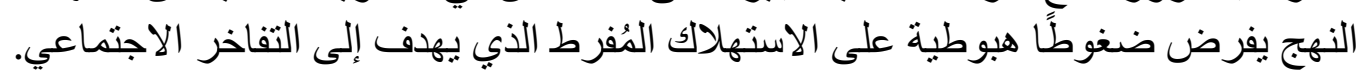

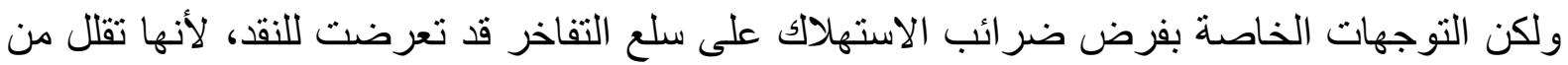

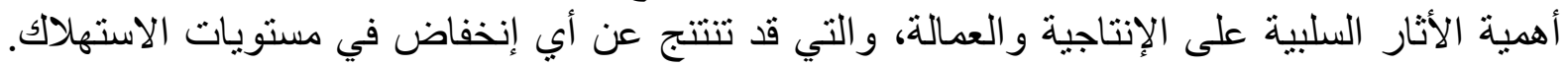

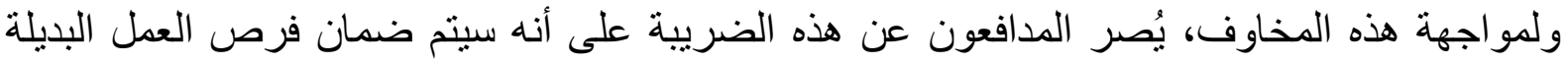

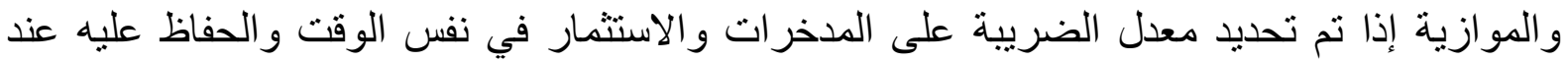

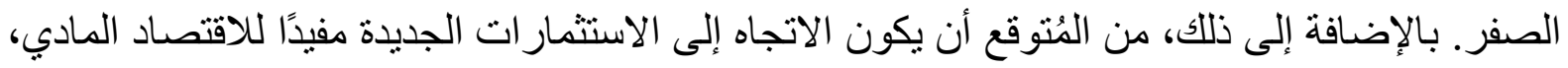

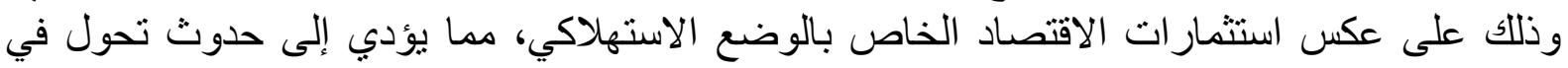
نشاط الاقتصاد الكلي الذي تهدف ضريبة الإن الاستهلاد إلى تأمينه.

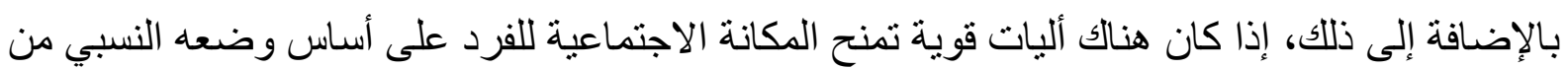

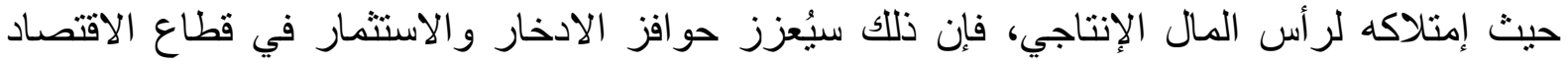

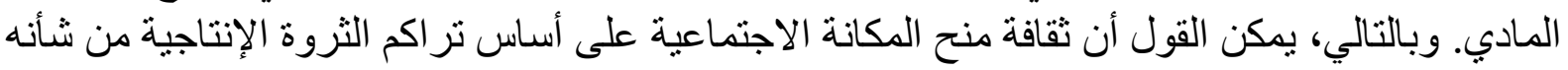

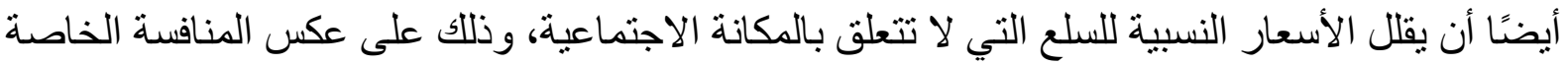

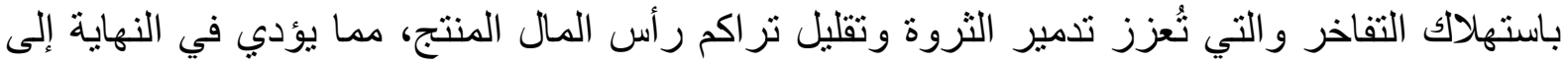

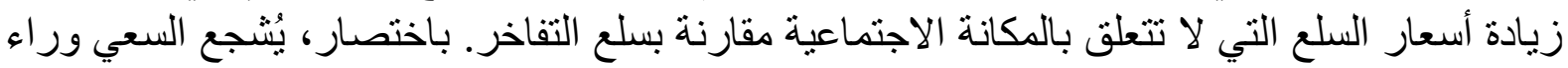

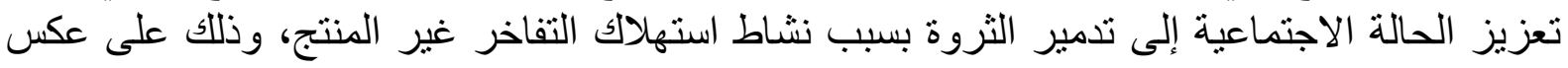

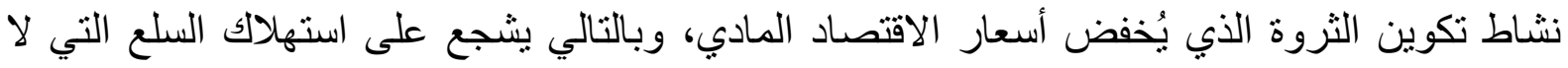
تتعلق بالمكانة الاجتماعية.

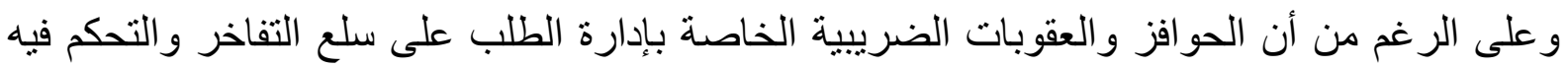

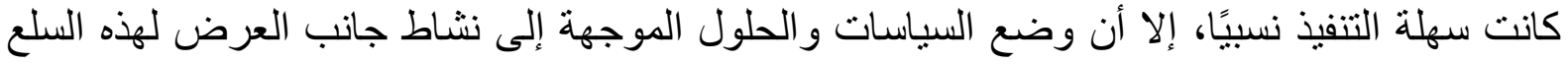

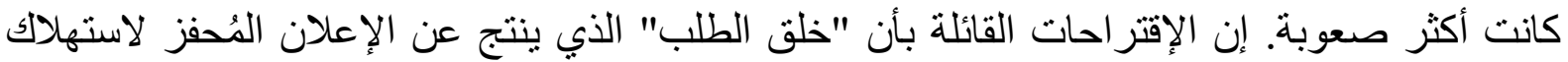

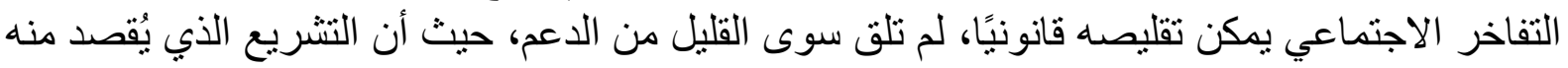

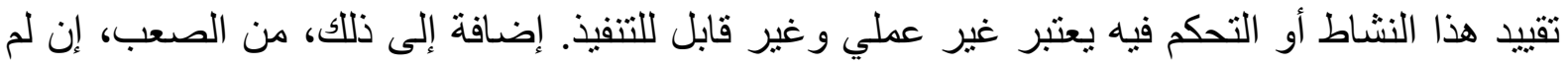

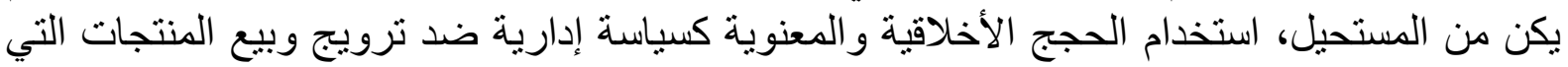

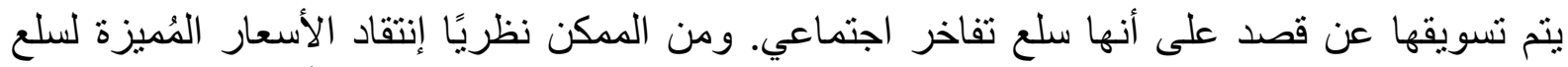

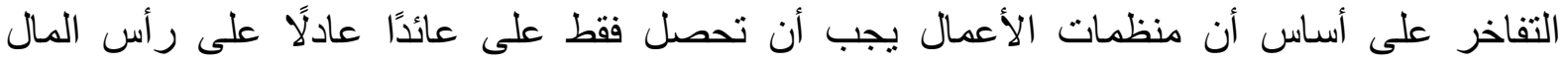

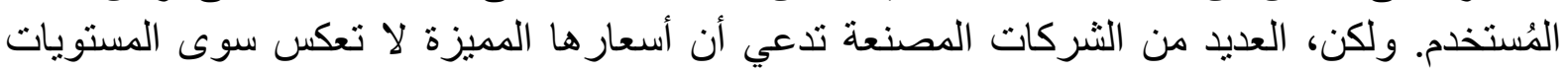

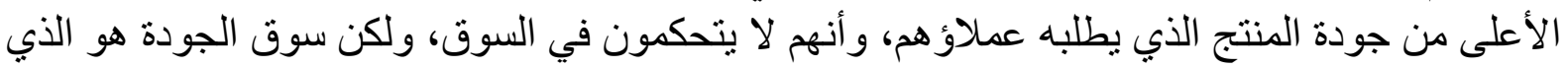

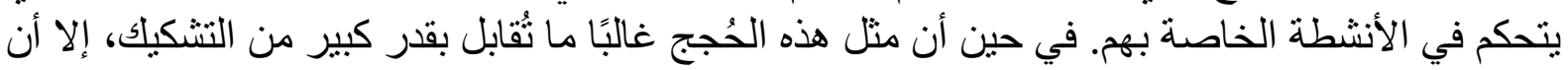

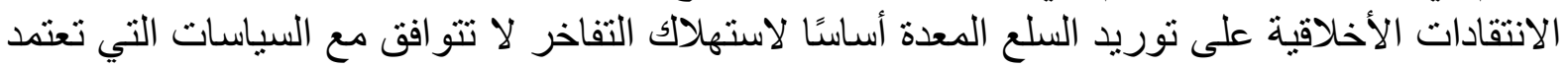
على التقيد أو التشريع.

إن السعي إلى تحجيم النشاط الاقتصادي المتعلق بالوضع الاستهلاكي الاجتماعي من خلال الإدارة

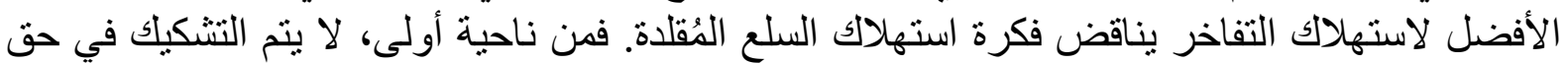

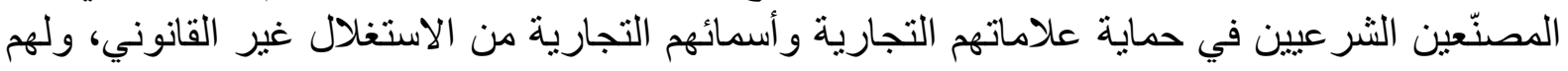

${ }^{260}$ Congleton RD., (1989). Efficient status seeking: externalities and the evolution of status games. Journal of Economic Beha6ior and Organization 11, PP. 175-190. 
كل الحق في هذه الحماية بموجب القانون، سواء من خلال مصادرة السلع المُقلدة أومحاكمة المُزورين.

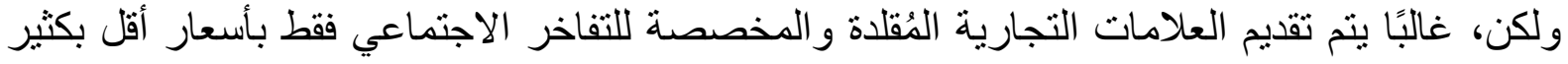

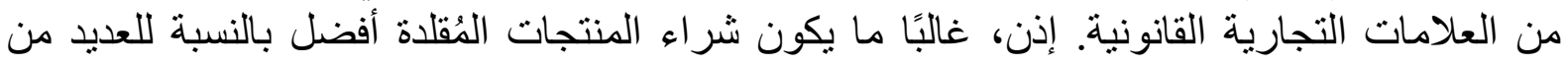
المستهلكين راغبي التفاخر والمهتمين فقط بالوضع الاجتماعي وقيمة المكانة الاجتماعية المرتبطة

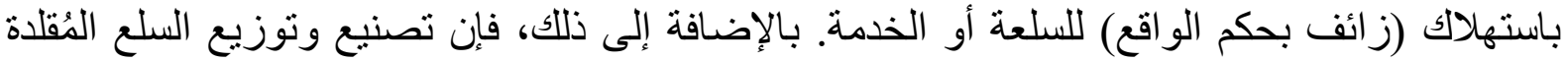

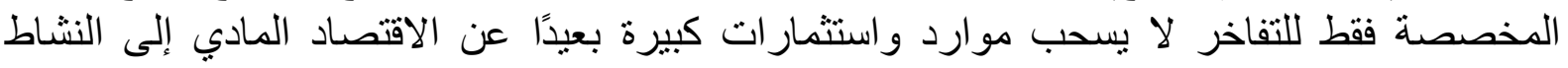

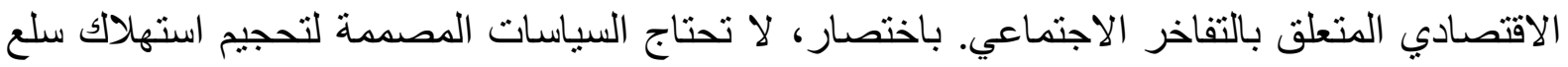

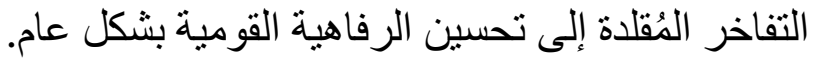

وبالنظر إلى هذه الصعوبات والقيود الخاصة بإدارة جانب العرض لسلع التفاخر، فقد وجها صنّاع

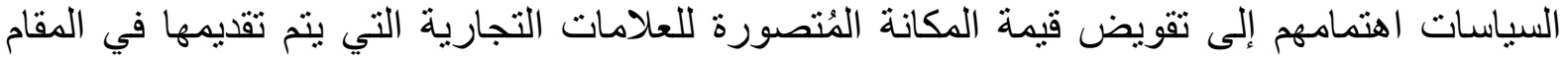

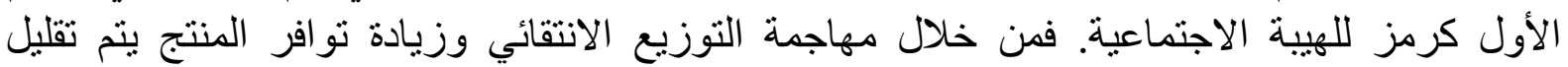

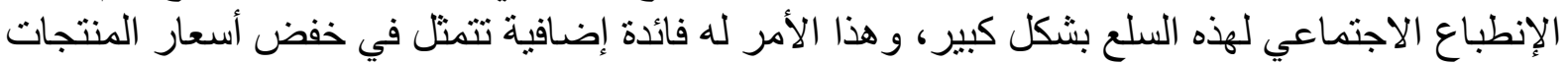

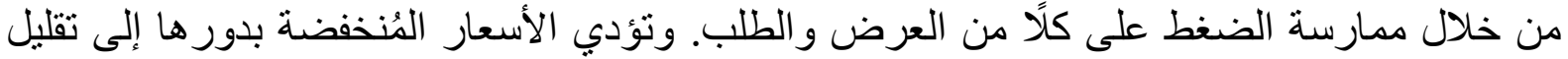

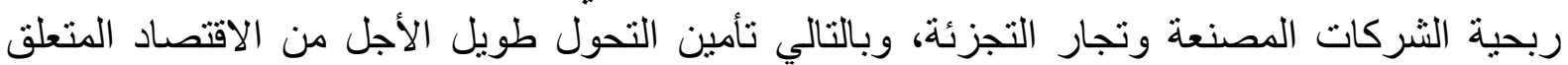
باستهالك التفاخر إلى النشاط التجاري للاقتهاد التهار المادي.

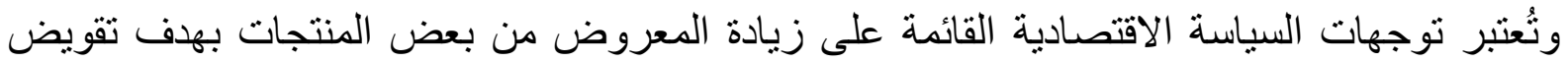

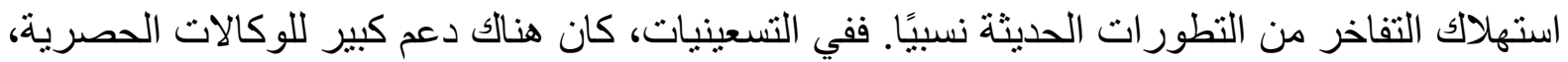

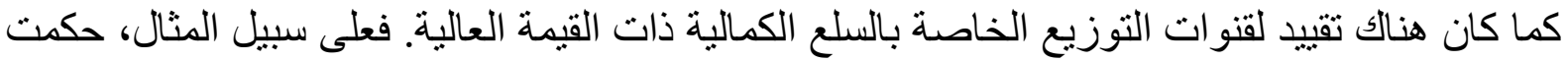

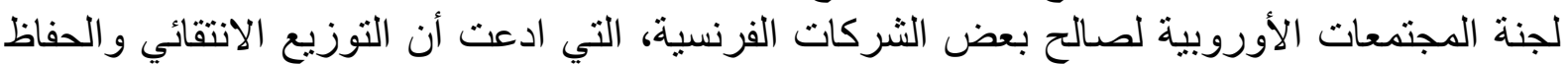

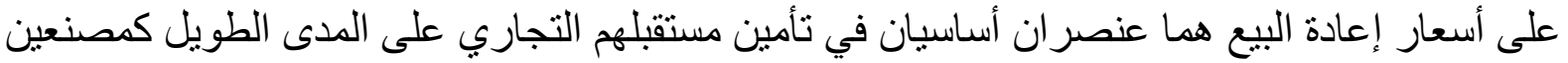

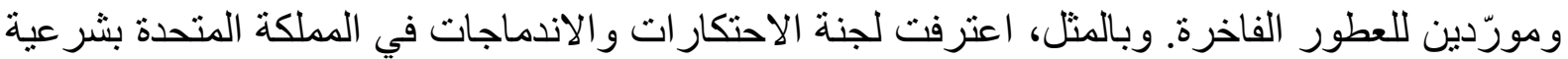

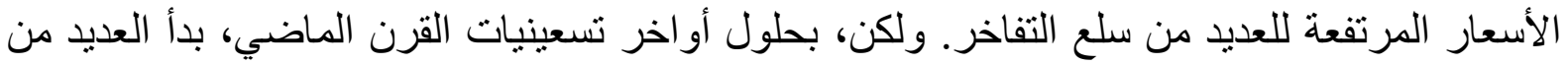

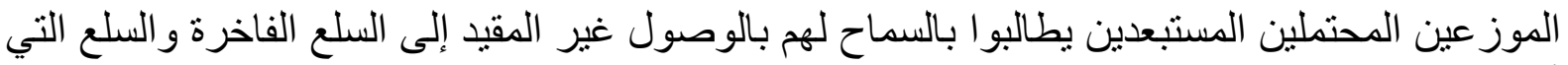

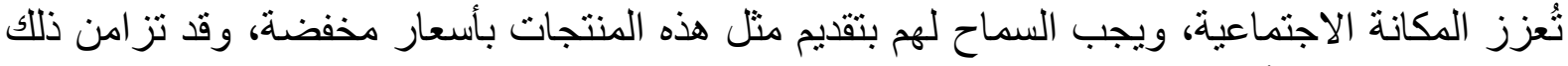

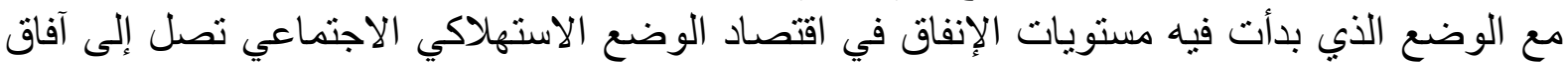

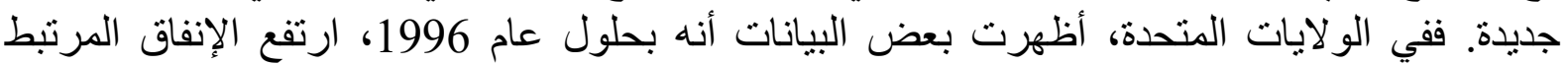

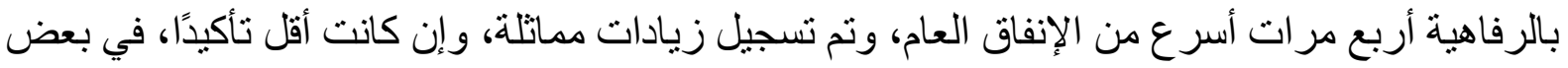

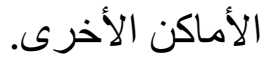

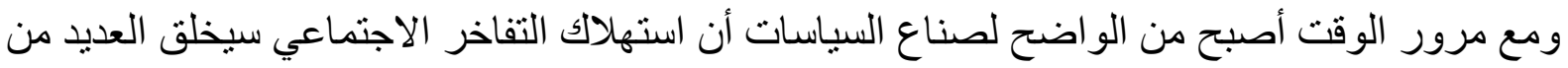
المشاكل الاقتصادية الخطيرة على المستوى الكلي، حيث يستمر الطلب على منتجات التفاخر الاجتماعي

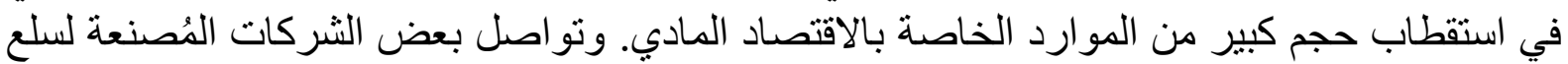

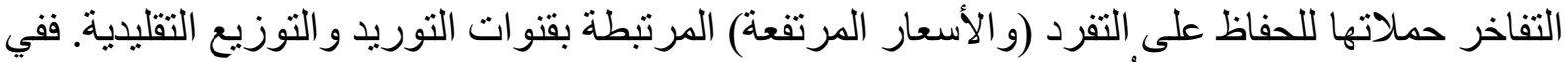

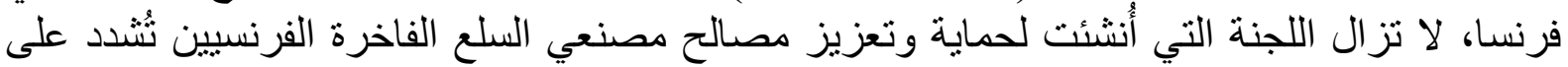

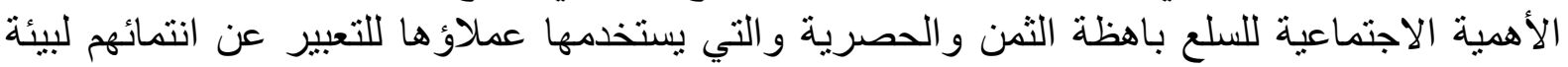

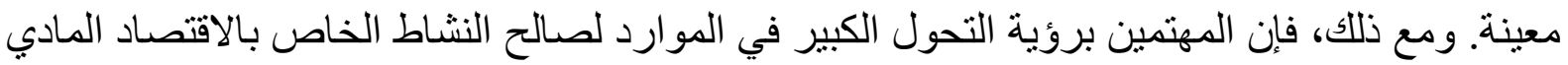

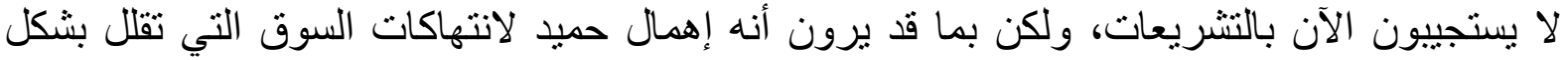

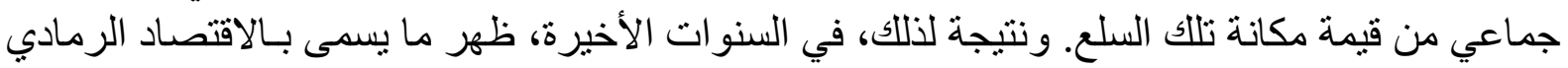




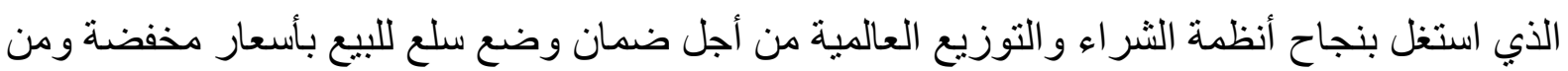

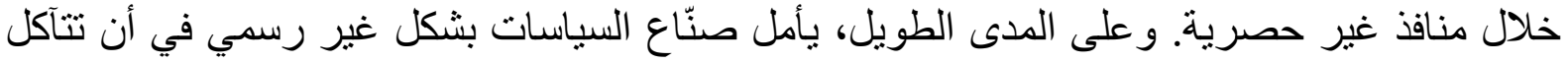

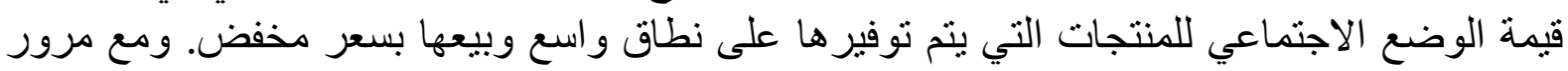
الوقت، سبقل الطلب على السلع ذات الوضع الاستهلاكي الاجتماعي المهرة بشكل واضح ويقل الترويج لها بالتناسب.

\section{ثانتًا: الجوانب الاقتصادية للوضع الاستهلاكي الاجتماعي}

عموما، تعتمد مدى جاذبية المظهر الخاص بشخص معين على نتيجة المقارنة الإيجابية لهذا المظهر مع الإن

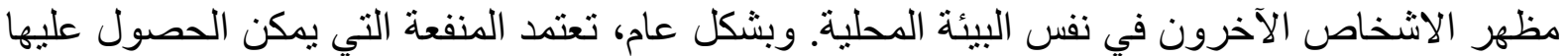

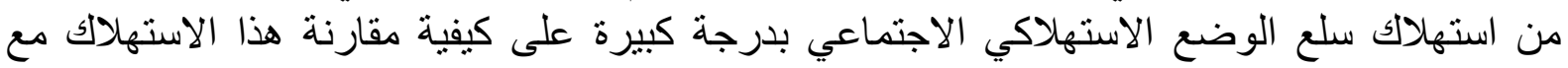
استهلاك الاشخاص الآخرين في نفس الفئة. 262

و عموما يهتم الأفراد بالوضع الاستهلاكي النسبي إما بسبب عامل خارجي (الوضع الاجتماعي، وكيف

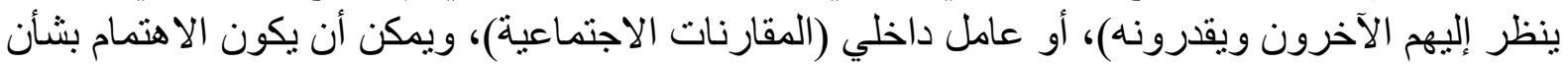

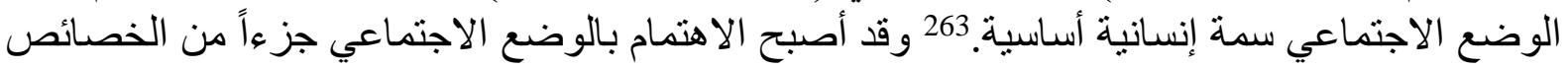

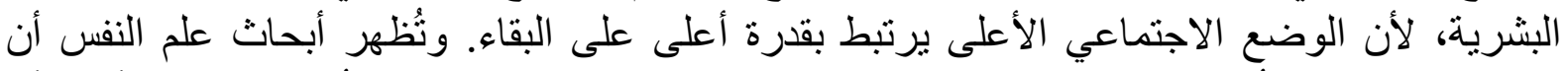

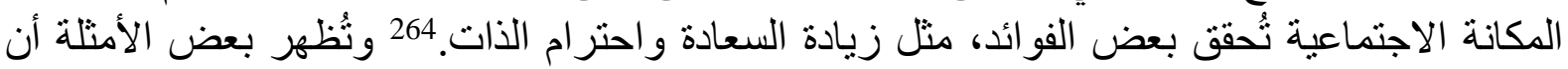

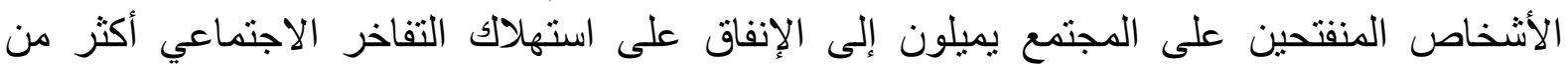

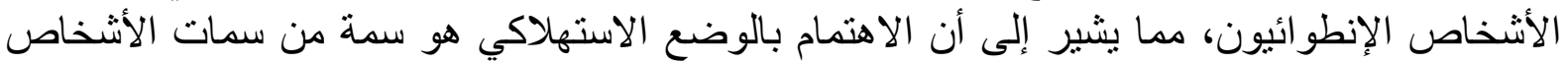
المنفتحين.

وتكون الرغبة في إجراء مقارنات اجتماعية متأصلة في أذهان الأفراد ويصعب تغييرها، وتحدث

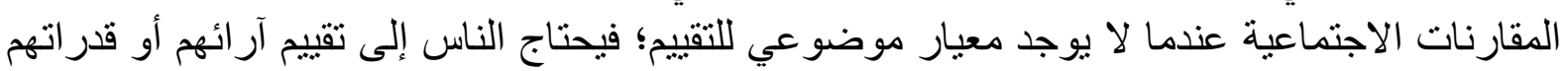

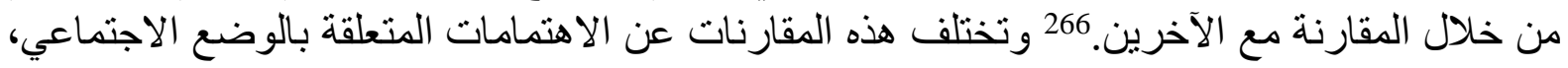

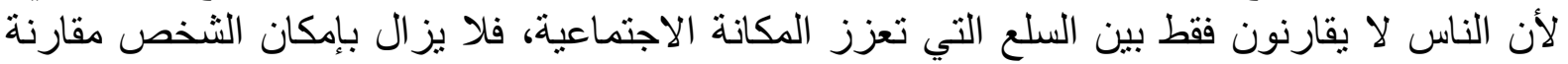

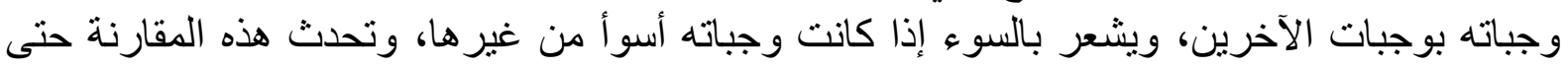

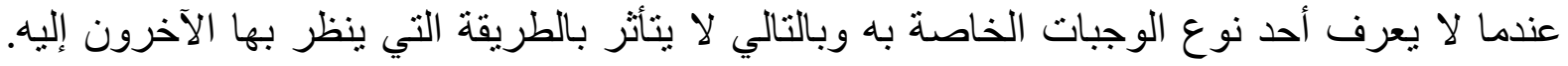

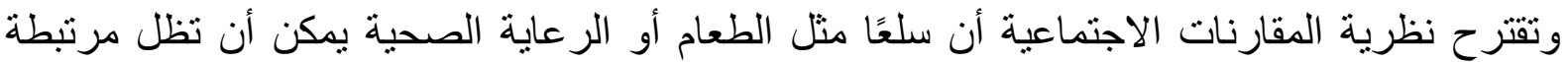
بالوضع الاجتماعي، ولكن تأثنير المقارنة يكون أقل بكثير من المقارنة الخاصة بـلة بلع التفاخر الاجتماعي.

\section{1. الأثار الخارجية الاستهلاكية لسباقات التشلح}

${ }^{261}$ Frank RH., (1985). Choosing the Right Pond: Human Behavior and the Quest for Status. Oxford University Press: New York.

${ }^{262}$ Hirsch, Fred, (1976). Social Limits to Growth. Harvard University Press, Cambridge, Mass.

${ }^{263}$ Hopkins, E., \& Kornienko, T., (2004). 'Running to Keep in the Same Place: Consumer Choice as a Game of Status.' The American Economic Review. 94 (4), P. 1085.

${ }^{264}$ Ferrer-i-Carbonell, A., \& Frijters, P., (2004). 'How Important is Methodology for the Estimates of the Determinants of Happiness?' The Economic Journal. 114 (497), P. 641.

${ }^{265}$ Landis, B., \& Gladstone, J. J., (2017). 'Personality, Income, and Compensatory Consumption: Low-Income Extraverts Spend More on Status.' Psychol Sci. 28 (10), P. 1518.

${ }^{266}$ Festinger, L., (1954). 'A Theory of Social Comparison Processes.' Human Relations. 7 (2), P. 117. 


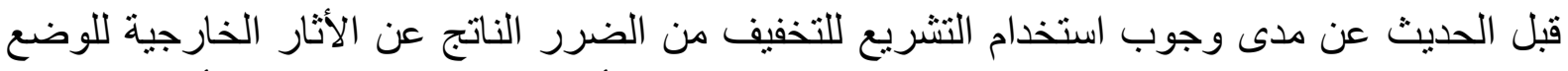

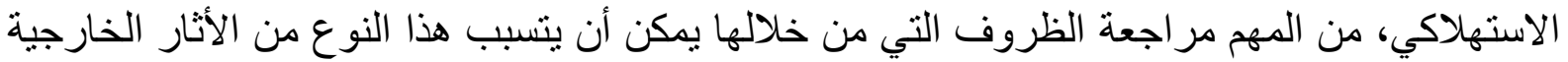

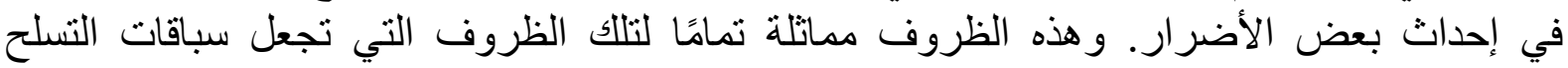
العسكري بين الدول المتنافسة نوعًا من إهدار الموارد الطارد الاقتصادية، وبالتالي التسبب في عدم الكفاءة

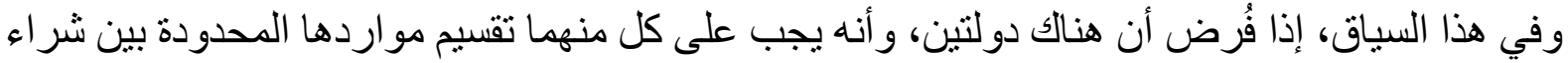

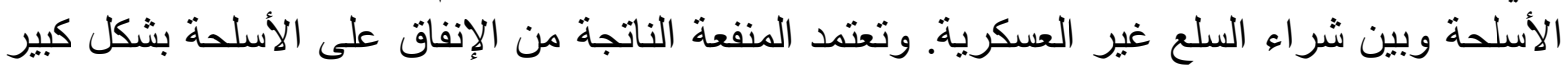

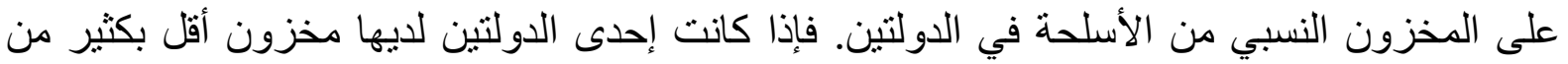

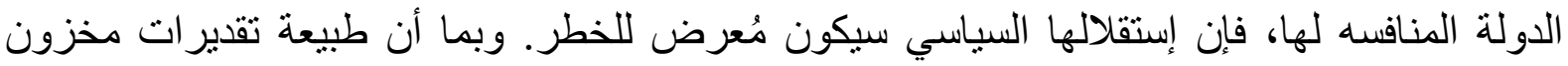

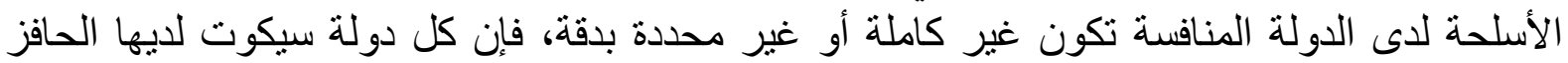

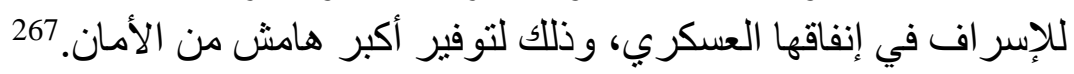

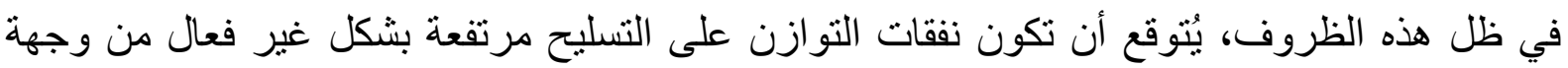

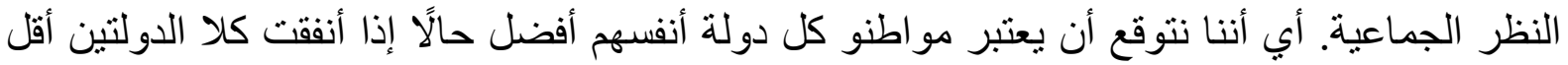

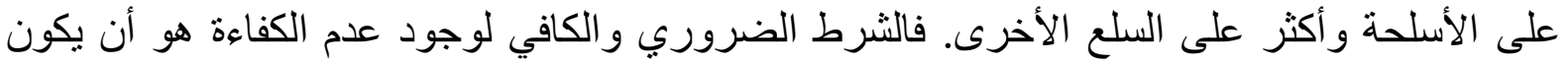

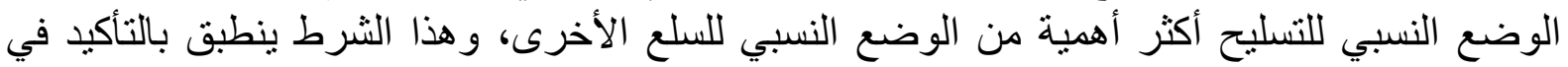

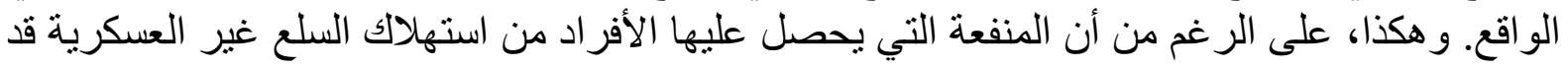

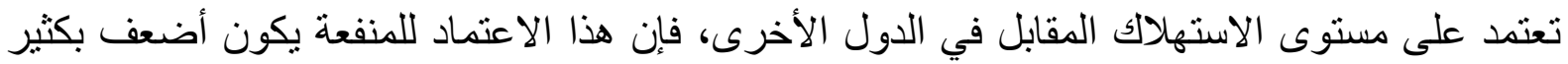

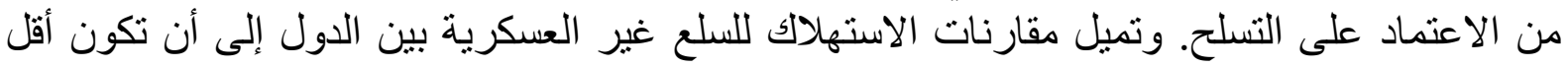

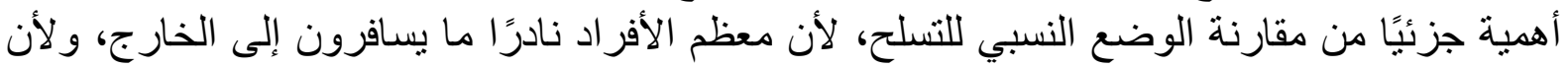

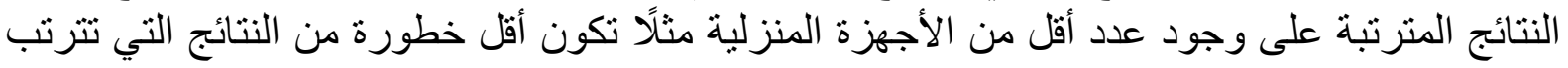

$$
\text { على عدم وجود قدر كافي من التسليح. }
$$

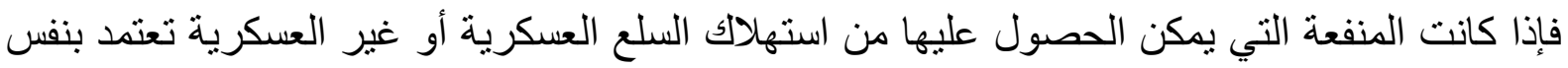

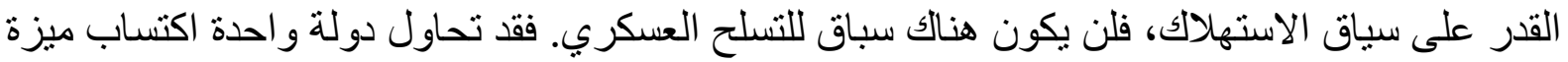

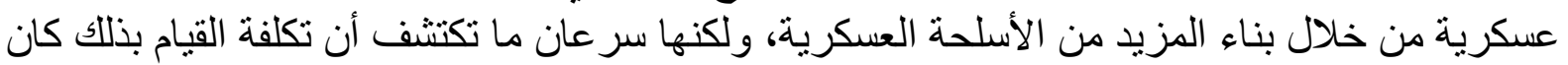

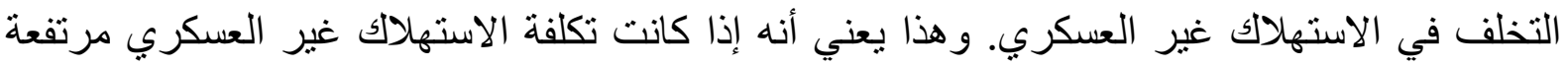
بقدر الفائدة التي يمكن الحصول عليها من الاستهلاك العسكري، فلن يكون هناك حافز لبناء لبناء الكثير من الأسلحة العسكرية.

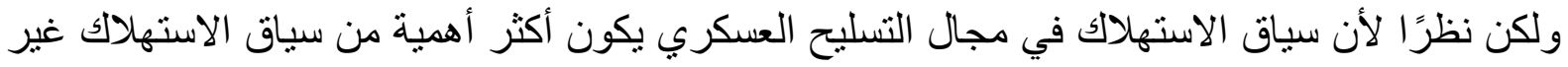

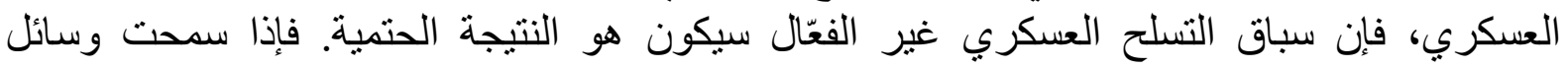

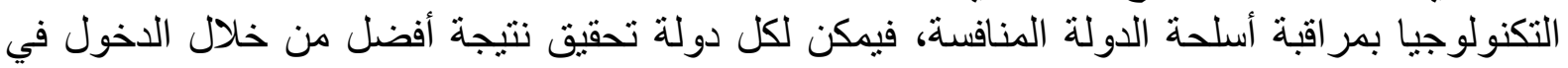

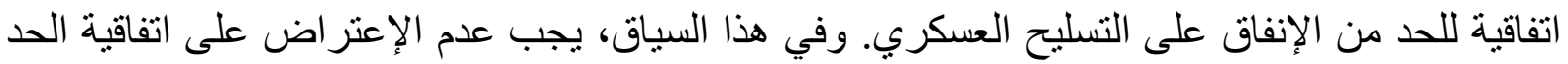

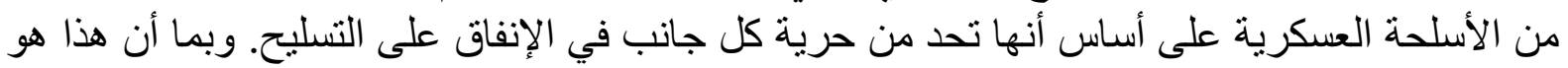

\footnotetext{
${ }^{267}$ Tran Xuan Thang, (2019). Negative positional externality of conspicuous and positional goods on society: An empirical analysis on income and clothing consumption for 9 EU countries, Aalto University, P.4.

${ }^{268}$ Frank, Robert H., (2008). Should public policy respond to positional externalities? Journal of Public Economics, Elsevier, vol. 92(8-9), August, PP. 1777-1786.
} 
بالضبط الهدف الذي يسعى كل طرف لتحقيقه من خلال الدخول في هذا الاتفاق، وبالتالي فإن مثل هذا

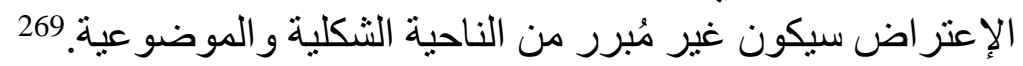

بالطبع، هنالك العديد من الأسباب الأخرى التي قد ثُبرر رفض الاخول في اتفاقية للحد من التسلح، فقد يكون هنالك بعض التخوف، على سبيل المثال، من أن تقنية التحقق من مدى إلتزام الأطر اف بالف بالاتفاقية

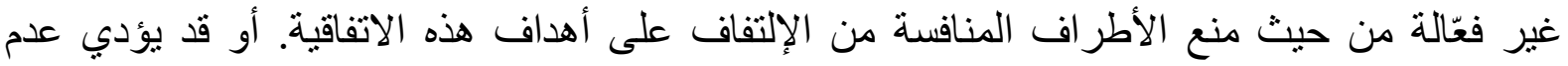

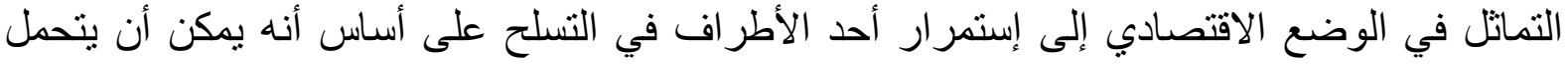

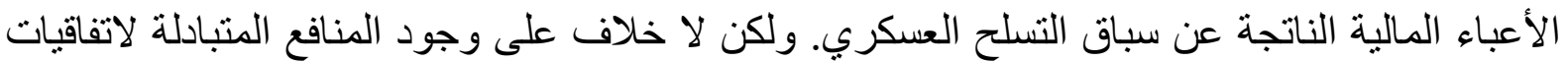

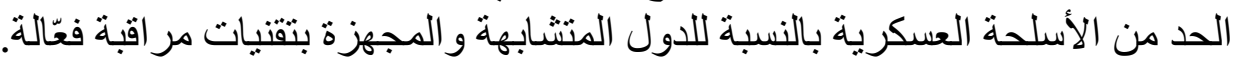

و هنا يمكن القول أن المسائل الخاصة بالأثار الخارجية للوضع الاستهلاكي الاجتماعي تتشابه في الأساس

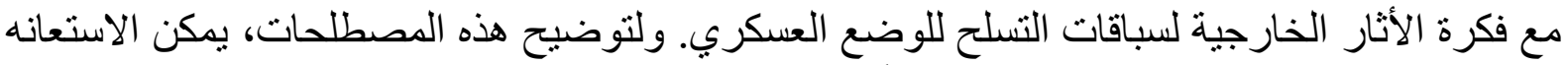

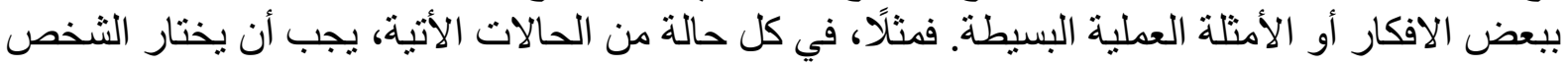

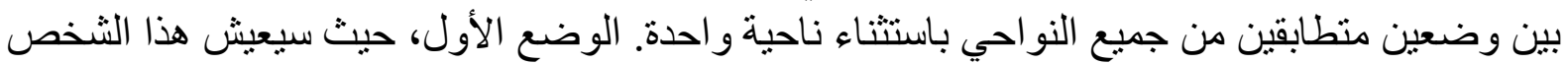

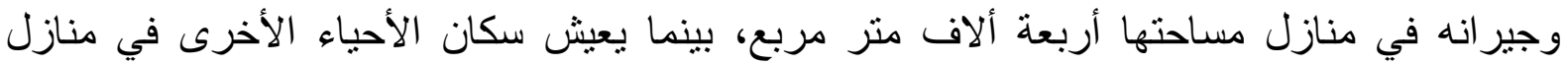

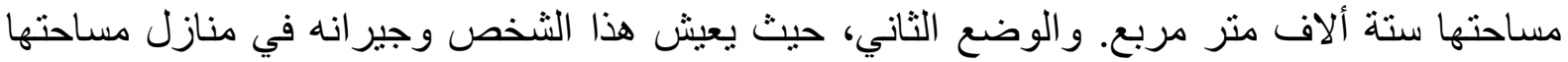

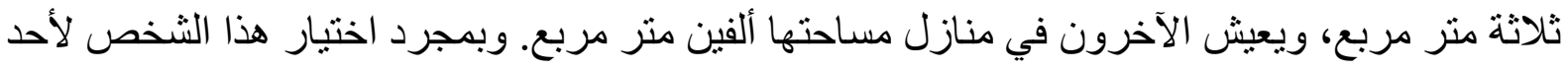
الوضعين، سيستمر وضعه الاستهلاكي على مقياس الإسكان المحلي. فئل فئري.

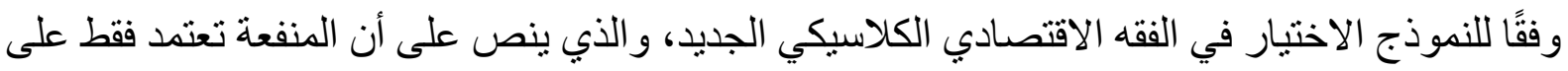

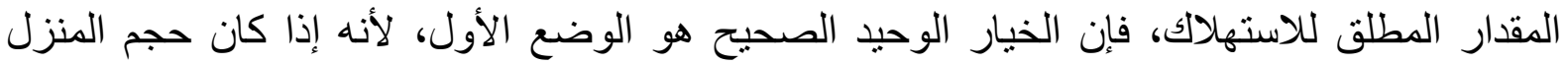

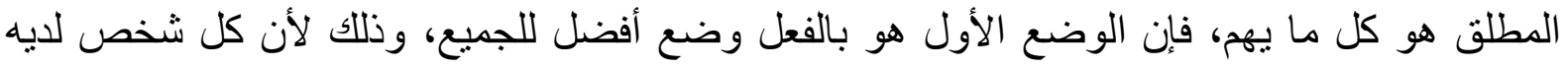

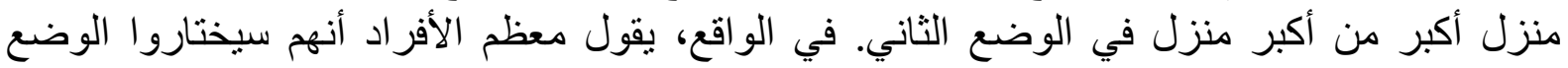

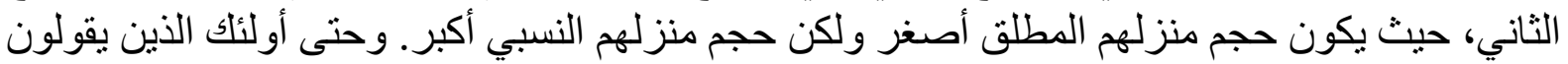

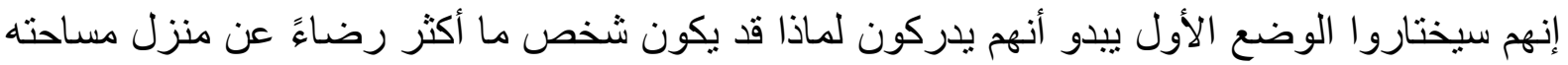
ثلاثة ألاف منر مربع في الوضع الثاني مقارنة بمنزل أكبر بكثير في الوضع الوض الأول.

في المثال العملي الثاني، يكون اختيار الثخص بين وضعين. الوضع الأول هو الذي يكون فيه احتمال

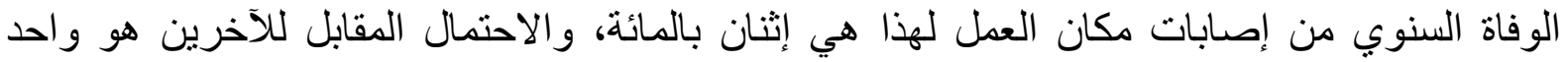

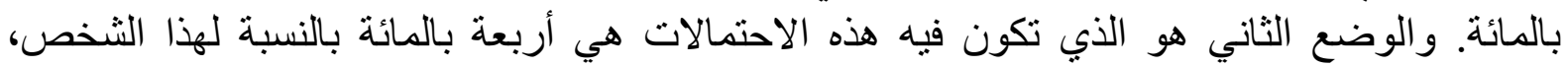

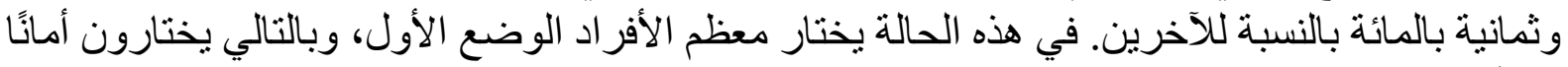

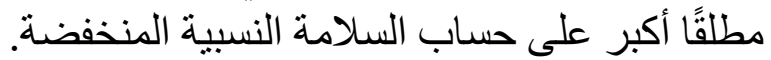

وبالتالي، تُشير سلع الوضع الاستهلاكي الاجتماعي إلى السلع التي يكون الإرتباط بين سياق الاستهلاك

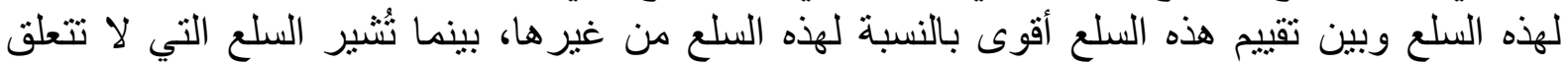

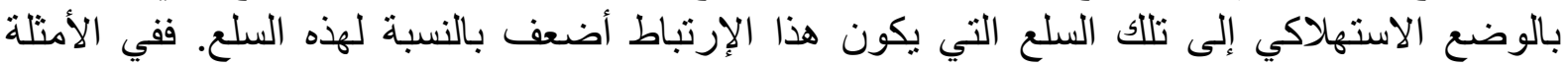

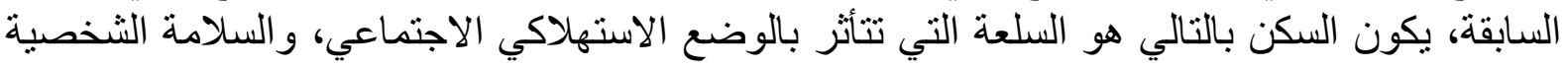

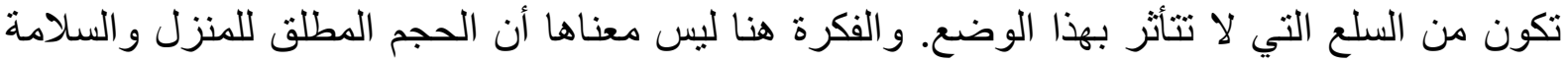

${ }^{269}$ Tran Xuan Thang, (2019). Negative positional externality of conspicuous and positional goods on society: An empirical analysis on income and clothing consumption for 9 EU countries, Aalto University, P.4. 
النسبية لبستا موضع اهتمام. ولكن، يمكن القول أن الوضع الاستهلاكي يكون له وزن أكبر من حيث التأثير على الاستهلاك في المجال الأول عنه في المجال الثاني.

في الوقت الحالي، يمكن أخذ ردود الفعل النموذجية في الأمثلة السابقة بالقيمة الاسمية. وهذا بعني الإني

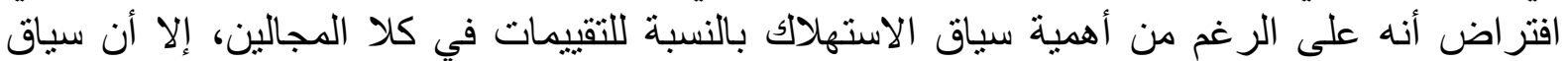

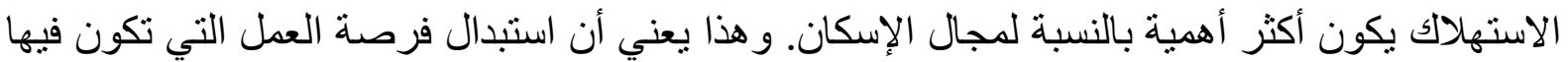

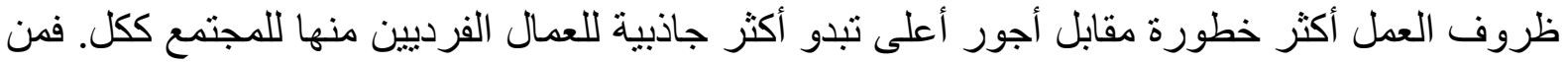

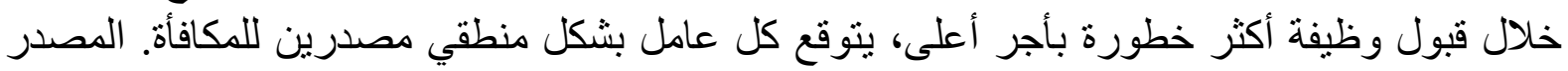

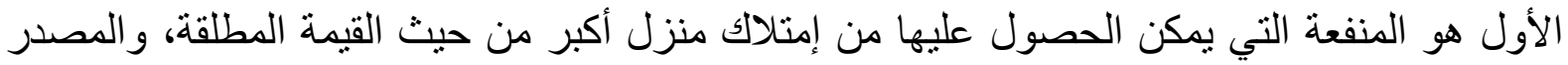

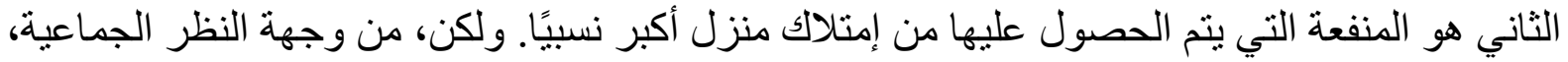

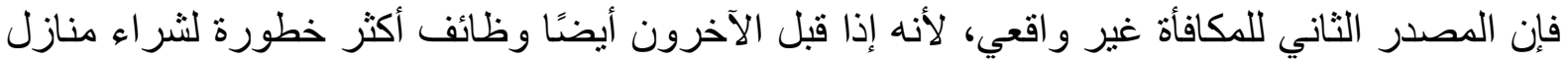

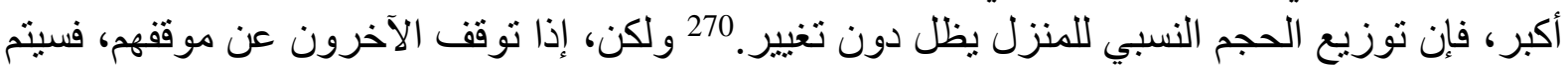

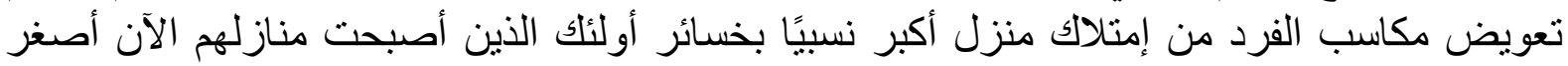

نسبيًا.

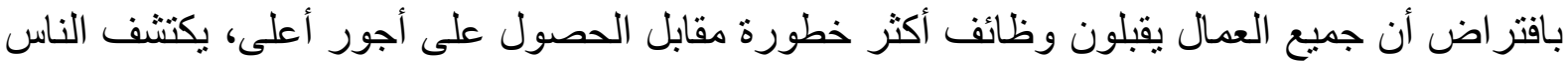

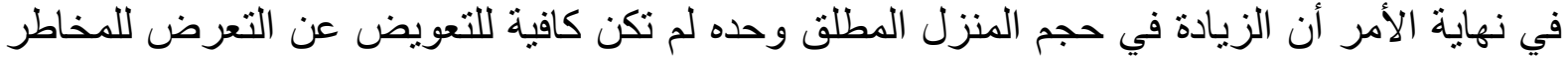

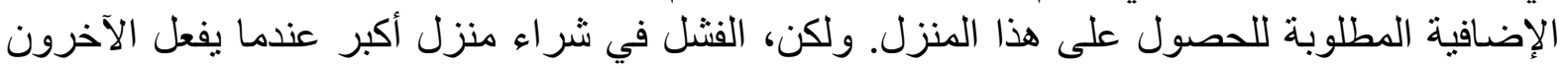

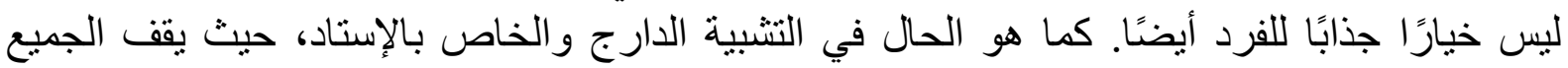
للحصول على رؤية أفضل، ولكن عندما يقق الجميع لا يرى أحد أفضل مما لو كان الجميع جالسين. من هذه الأمثلة البسيطة، يجب أن يكون و اضحًا أن سباقات التسلح يمكن أن تؤدي إلى خسائر في الرفاهية

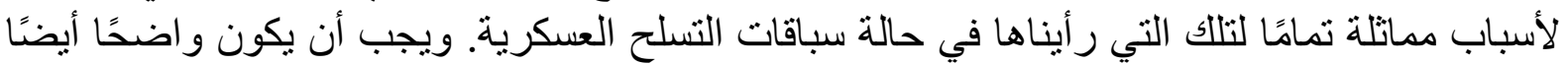

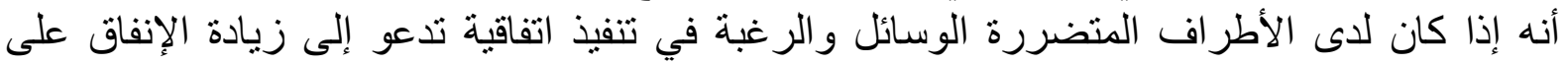

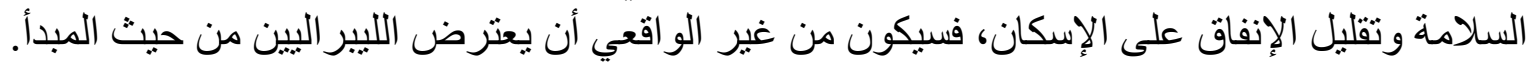

\section{2. العلاقة بين الأثار الخارجية للوضع الاستهلاكي والسلع غير السوقية}

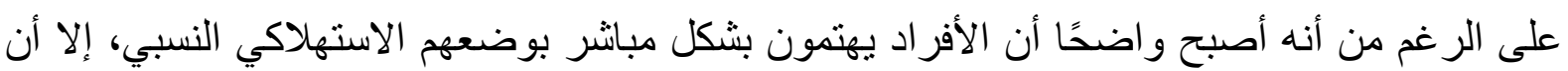

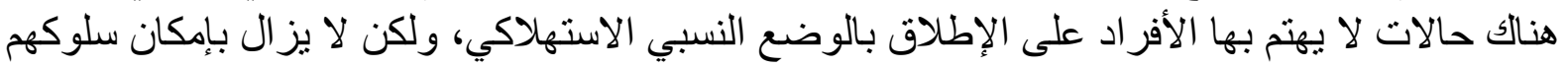

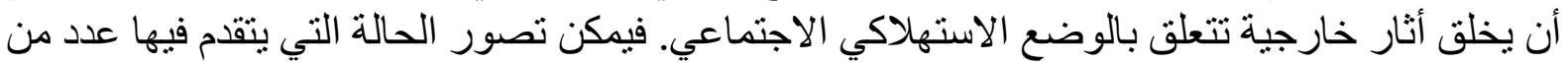

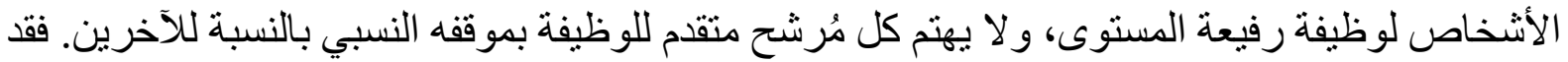

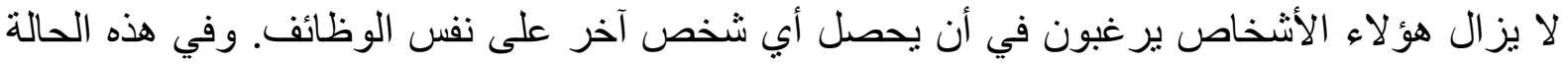

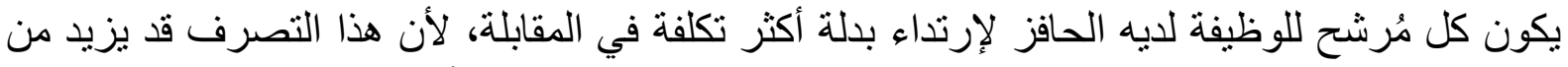

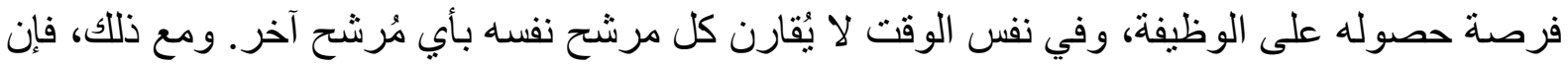

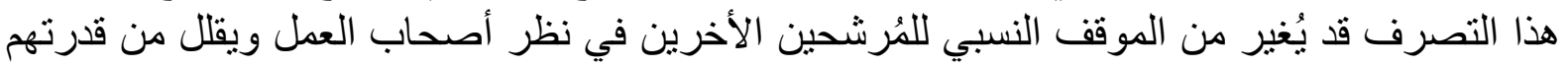

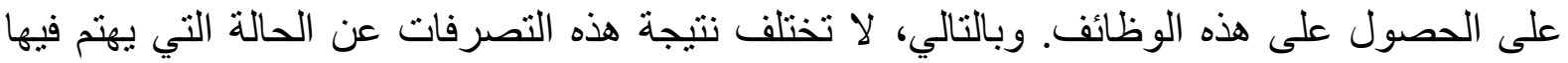

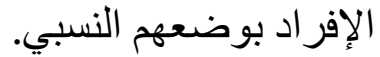

${ }^{270}$ Frank, Robert H., (1985). The demand for unobservable and other non-positional goods. American Economic Review 75, March, P. 101. 


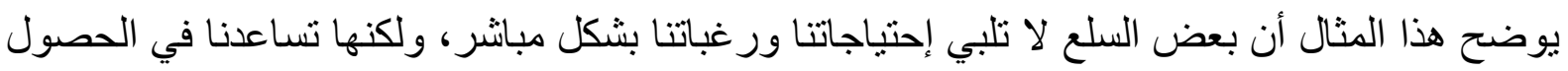

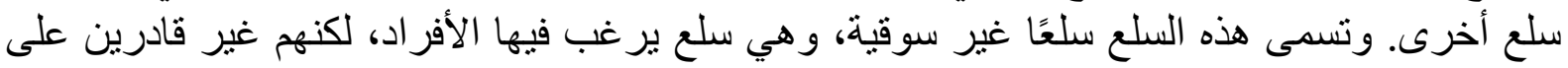

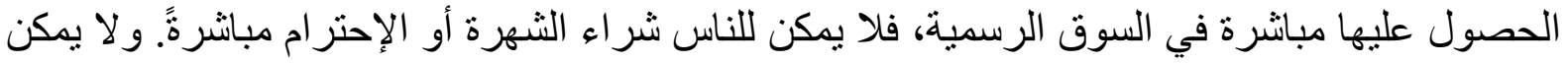

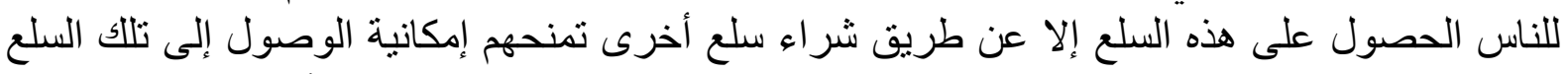

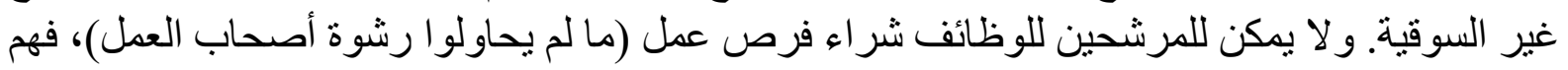

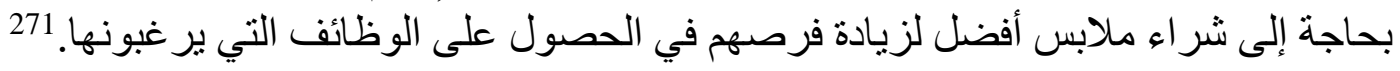

ويمكن أن يكون هناك علاقة قوية بين السلع غير السوقية والقيم التي تُحققها سلع التفاخر الاجتماعي

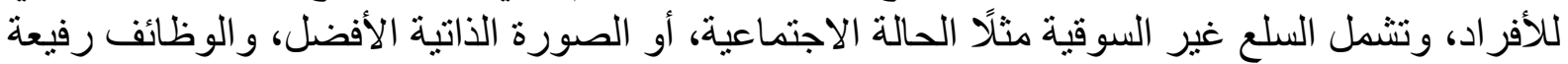

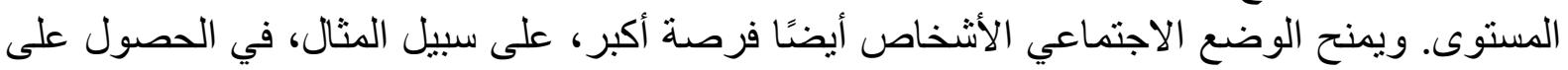

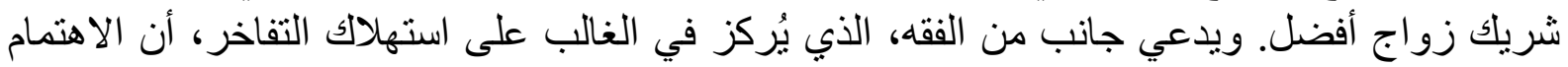

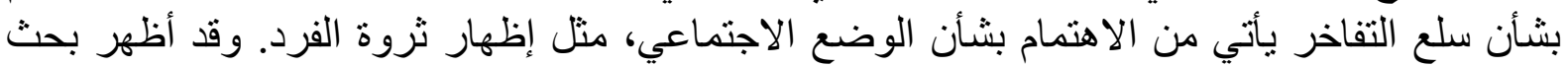

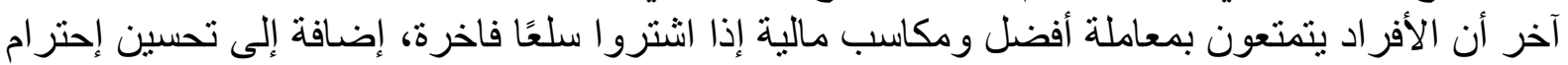

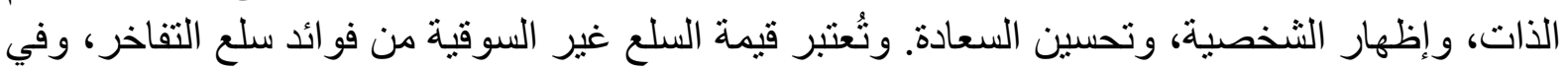

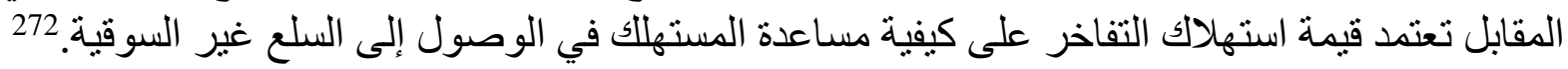

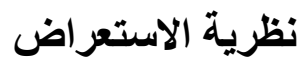

يمكن تفسير إهدار الموارد الناتج عن المنافسة على الوضع الاستهلاكي النسبي من خلال نظرية

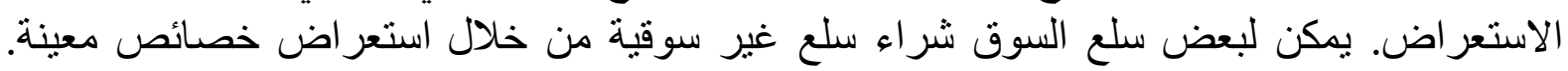

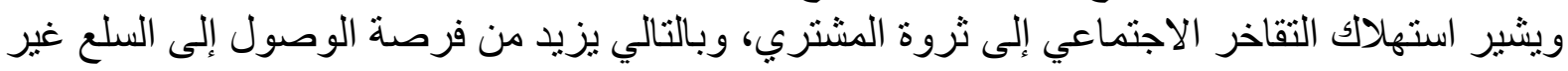

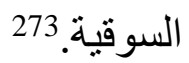

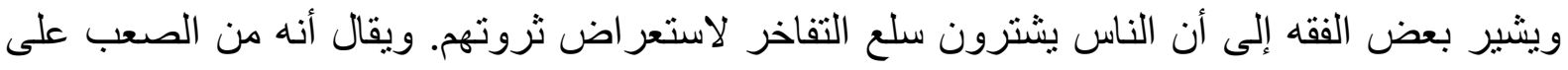

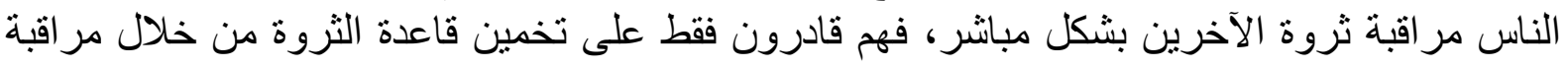

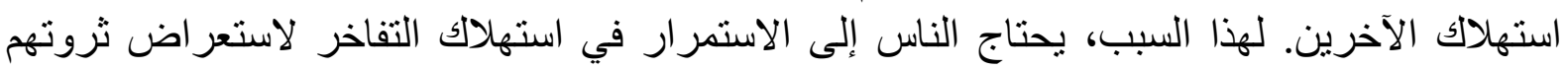

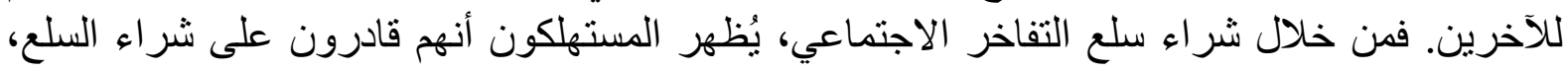

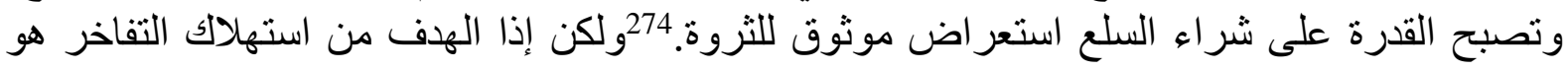

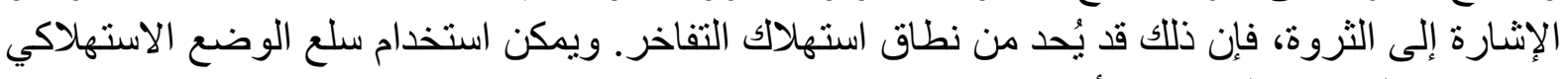

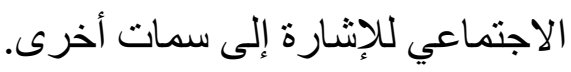

${ }^{271}$ Perez-Truglia, R., (2013). 'A Test of the Conspicuous-consumption Model using Subjective Wellbeing Data.' The Journal of Socio-Economics. 45, P. 146.

272 Nelissen, R. M. A., \& Meijers, M. H. C., (2011). 'Social Benefits of Luxury Brands as Costly Signals of Wealth and Status.' Evolution and Human Behavior. 32 (5), PP.343-355.

${ }^{273}$ Perez-Truglia, R., (2013). 'A Test of the Conspicuous-consumption Model using Subjective Wellbeing Data.' The Journal of Socio-Economics. 45, PP.146-154.

${ }^{274}$ Veblen, T., (2007). The theory of the leisure class: An economic study of institutions. New York: Macmillan Co. 


\section{الندرة الاجتماعية للسلع غير السوقية}

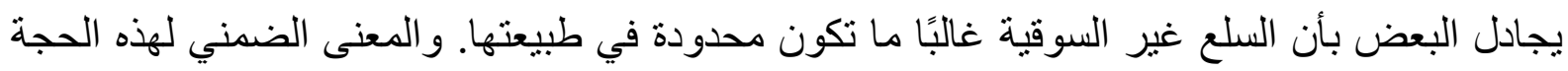

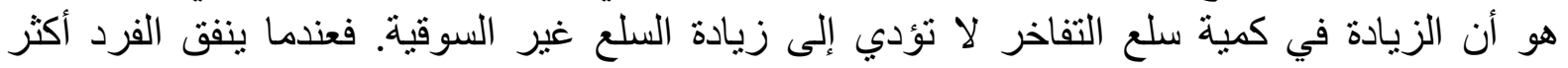

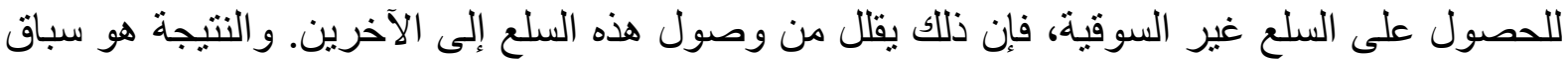

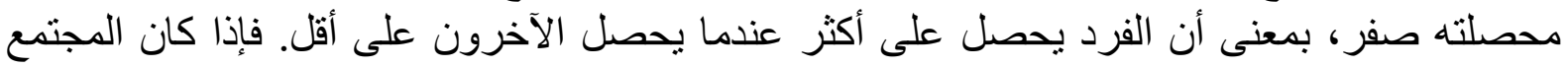

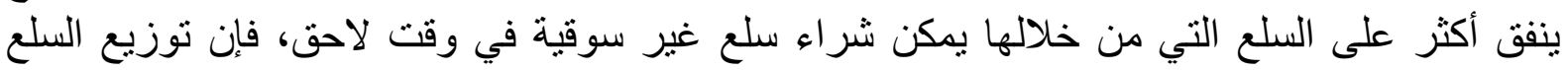

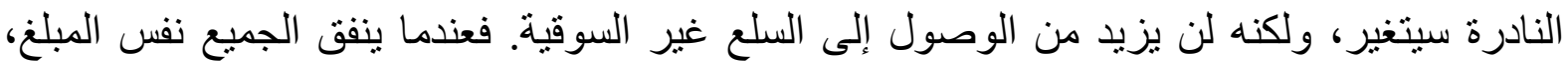

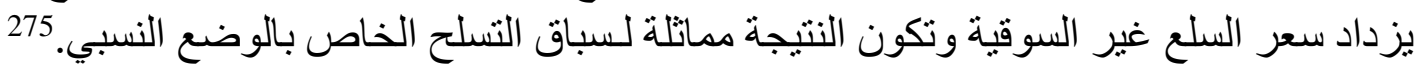

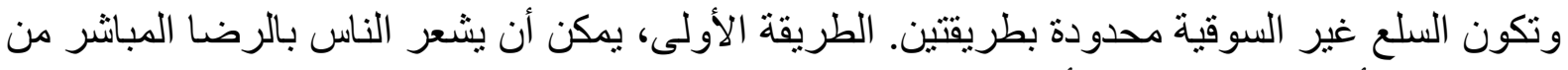

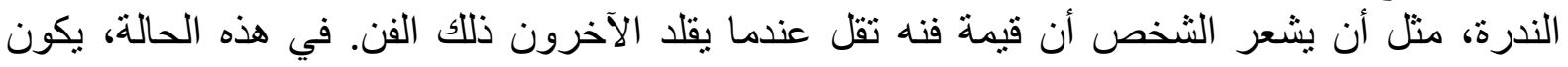

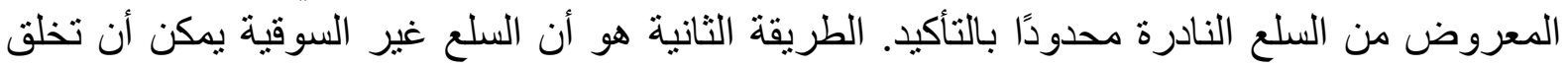

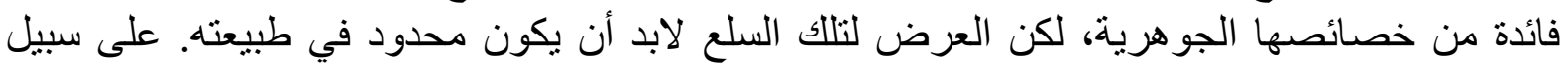

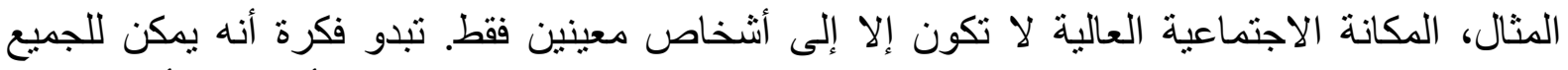

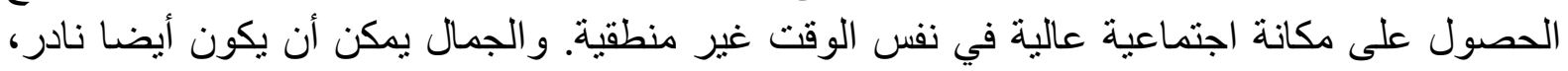

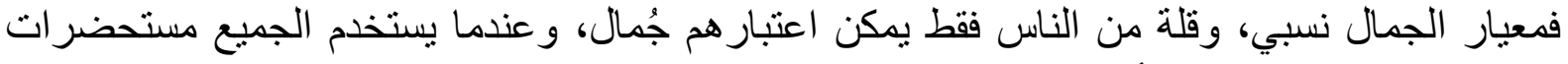

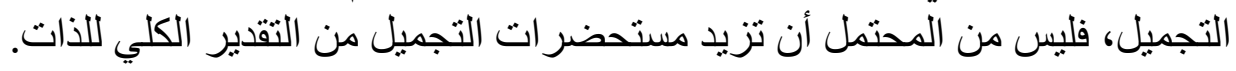

\section{3. العلاقة بين الأثار الخارجية للوضع الاستهلاكي والأعراف الاجتماعية}

لا يعتمد استهلاك سلع التفاخر الاجتماعي فقط على التنافس على الوضع الأنع الاستهلاكي كما هو مقترح في

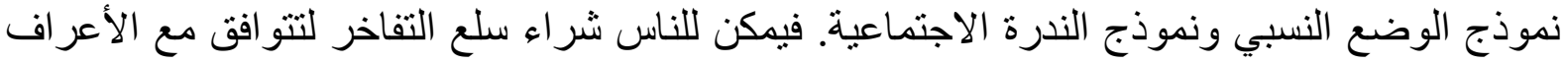

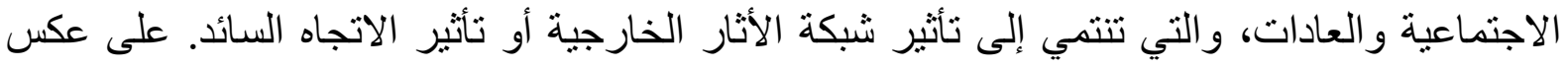

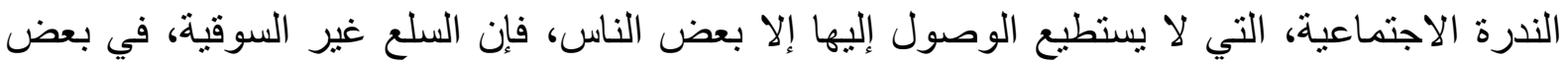

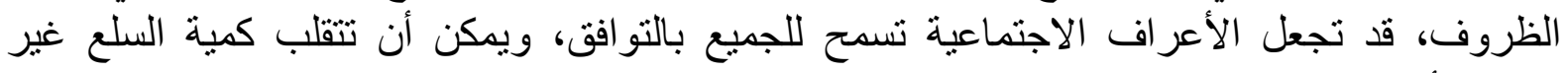
السوقية أو تتغير.

تتطلب الأعر اف الاجتماعية مستوى من الاستهلاك المقبول، ويقارن الناس أنفسهم بـالمعيار السائد للاقية،

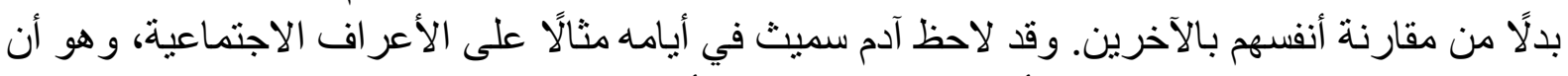

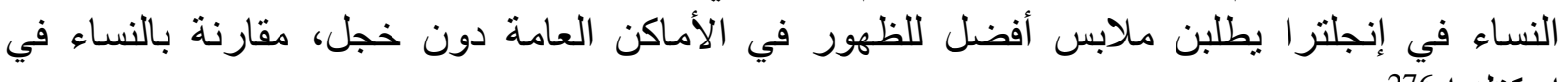
اسكتلندا.

ويختلف تأثير الاتجاه السائد عن الأثار الخارجية للوضع الاستهلاكي. فقد وجد البعض أنهان الأشخاص النهاص

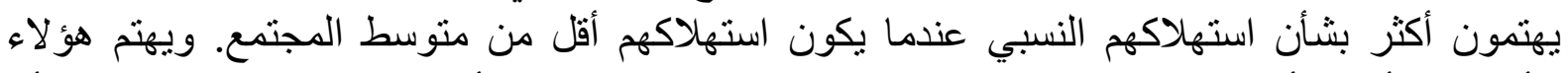

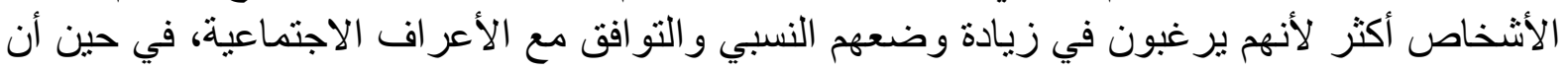

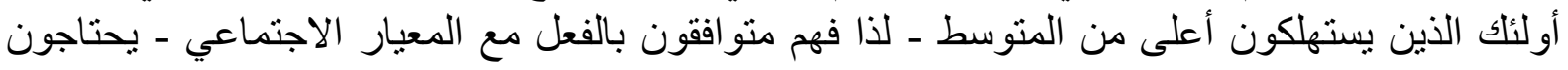

${ }^{275}$ Hirsch, F., (1976). Social limits to growth. Cambridge: Harvard University Press.

${ }^{276}$ Alpizar, F., Carlsson, F., \& Johansson-Stenman, O. (2005). 'How Much do we Care about Absolute Versus Relative Income and Consumption?' Journal of Economic Behavior \& Organization. 56 (3), P.405. 
فقط إلى الاهتمام بموقفه النسبي. وفي بعض المجتمعات التي لا تشجع على التباهي، قد يتجنب الناس حتى استهلاك كميات أعلى من المعتاد.

و وع ذللك، تتأثر الأعراف الاجتماعية بالأثار الخارجية للوضع الاستهلاكي. فالمعايير الاجتماعية تكون

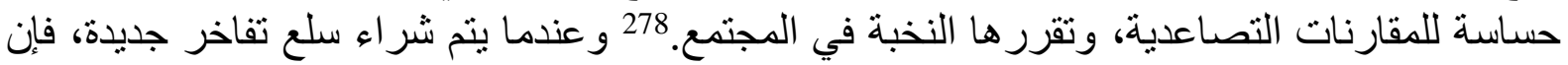

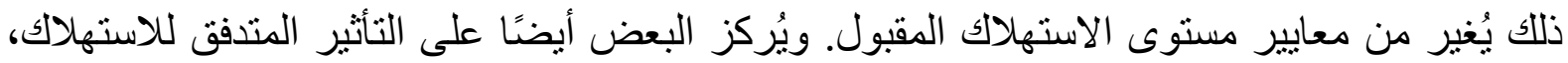

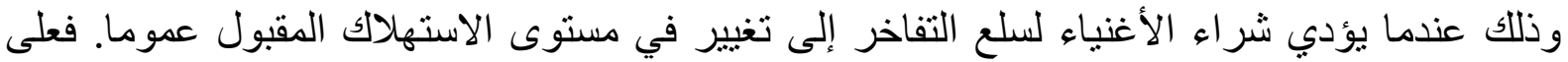

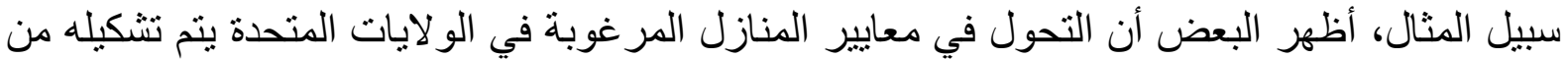

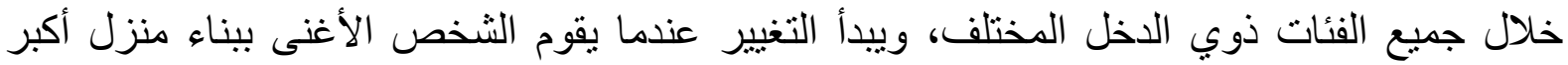

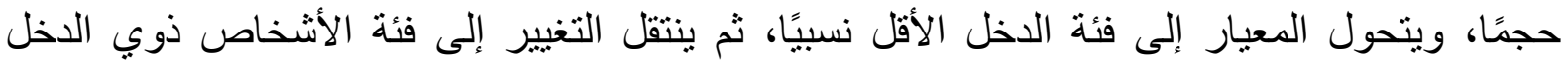

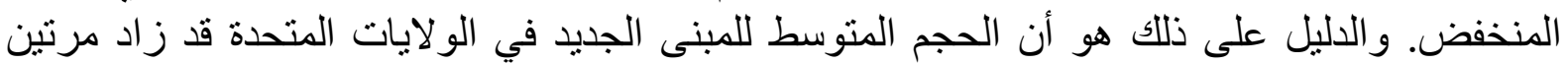

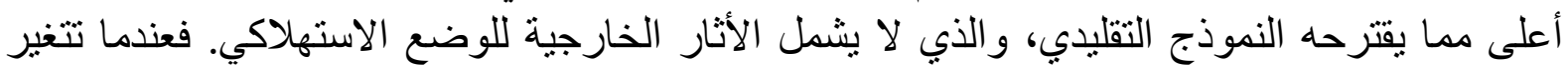

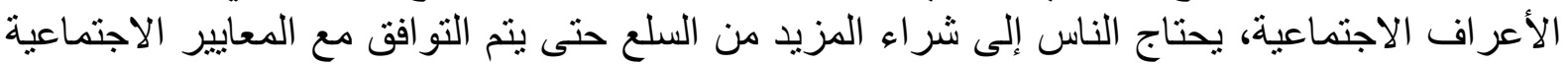

وتتثكل المعايير الاجتماعية من خلال العديد من العوامل، وبالتالي يمكن أن تنحرف عن متوسط مستوى

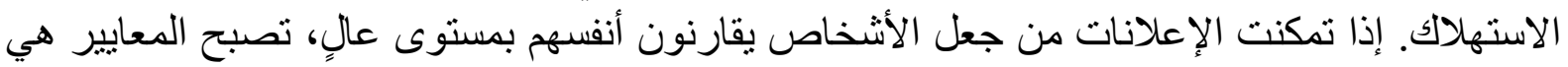
المعيار الذي يضعه المعلنون.

\section{4. التأثير السلبي للأثار الخارجية للوضع الاستهلاكي على السعادة}

لقد تعلم معظمنا منذ الصغر ألا نهتم بشأن كيفية مقارنة ممتلكاتنا بممتلكات الآخرين. وثُنبع هذه النصيحة

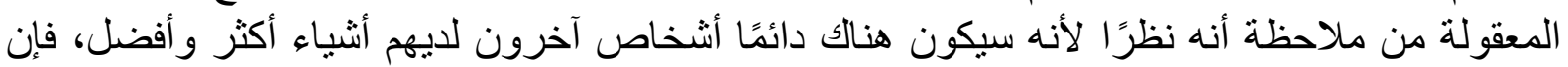

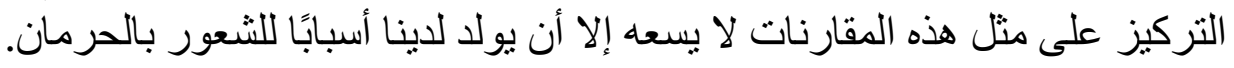

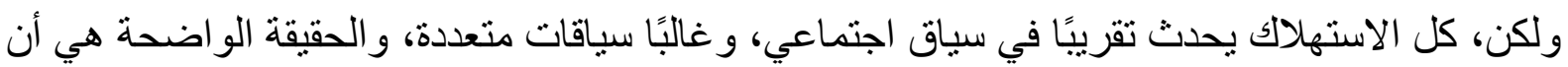

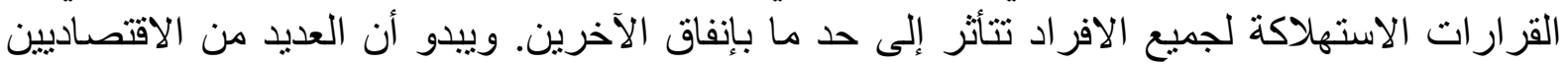

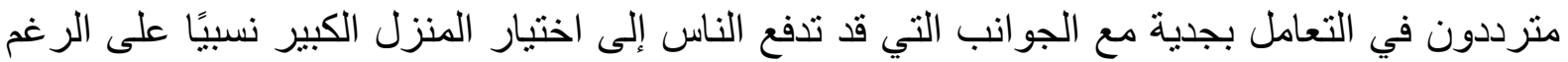

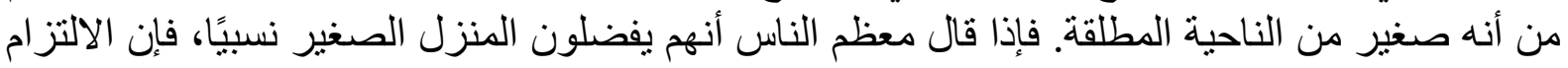

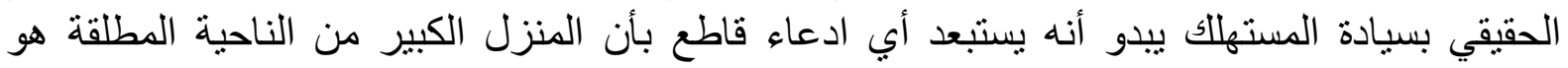

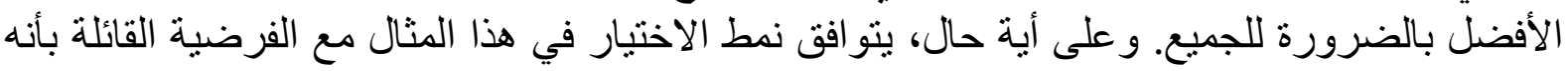

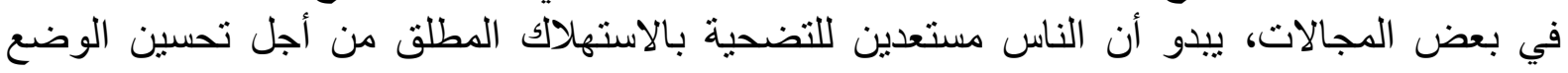

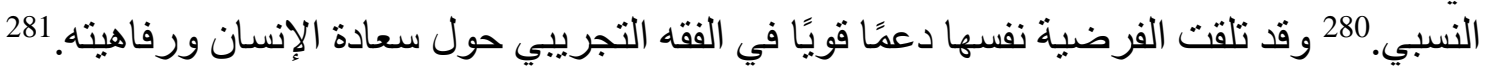

277 Andersson, F. W., (2008). Is concern for relative consumption a function of relative consumption? The Journal of Socio-Economics 37, PP. 353-364.

${ }^{278}$ Bourdieu, P., (1984). Distinction: A social critique of the judgment of taste. Cambridge, Mass.: Harvard University Press, P.405.

${ }^{279}$ Frank, R. H., (2005). 'Positional Externalities Cause Large and Preventable Welfare Losses.' The American Economic Review. 95 (2), PP.137-141.

${ }^{280}$ Kahneman, Daniel, Diener, Ed, Schwartz, Norbert (Eds.), (1999). Understanding Well-Being: Scientific Perspectives on Enjoyment and Suffering. Russell Sage, New York.

${ }^{281}$ Layard, Richard, (2005). Happiness: Lessons from a New Science. Penguin, London, P.41. 
لعدة عقود، كان علماء الاجتماع، وخاصة علماء النفس، يحاولون بجدية قياس الرفاهية الذاتية للإنسان.

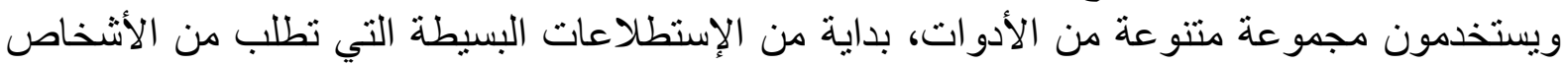

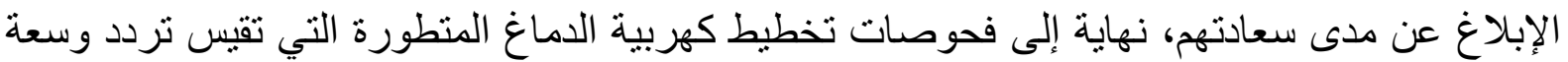

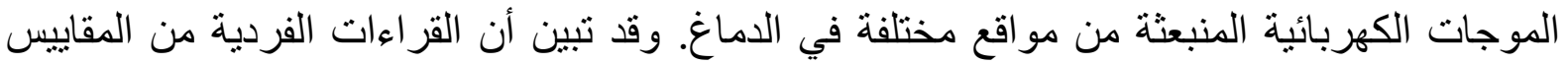

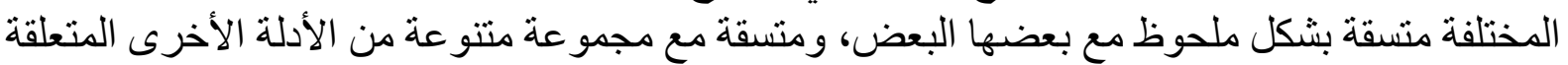

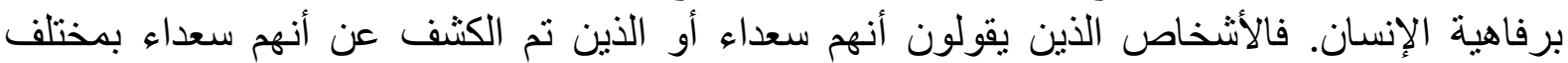

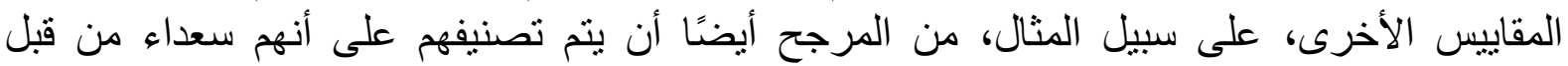

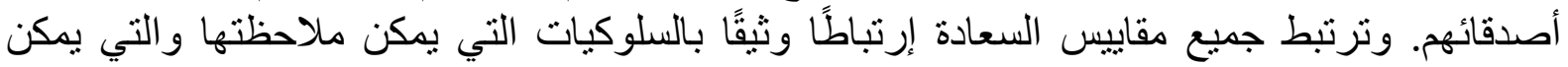

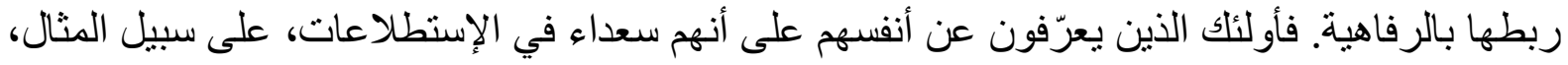

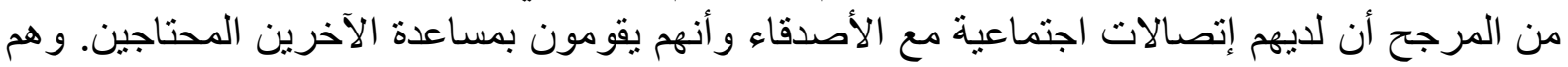

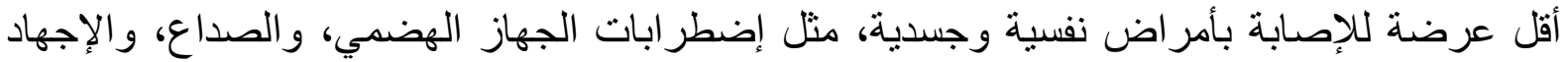

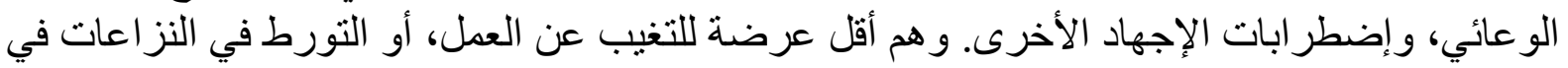

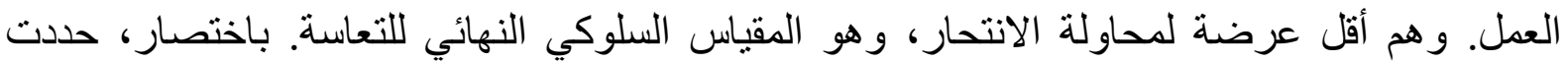

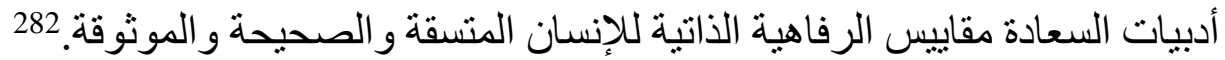

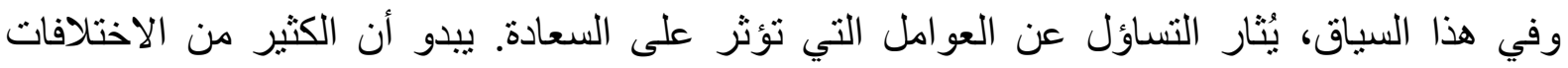

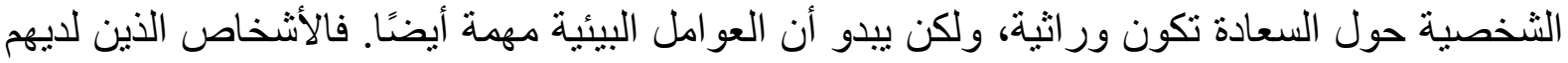

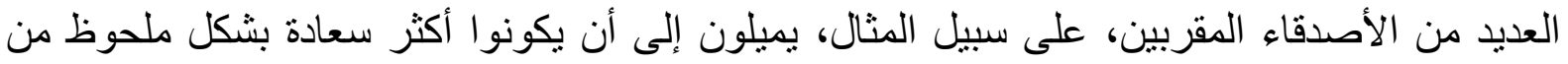

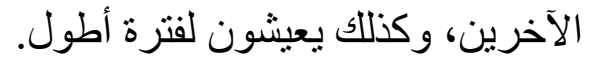

ولكن، ماذا عن علاقة الدخل بالسعادة. تشير الدراسات إلى أنه عندما يرتفع دخل الجميع، فإن مقاييس

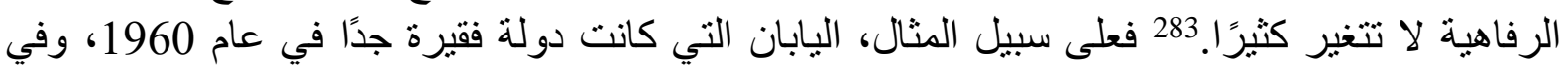

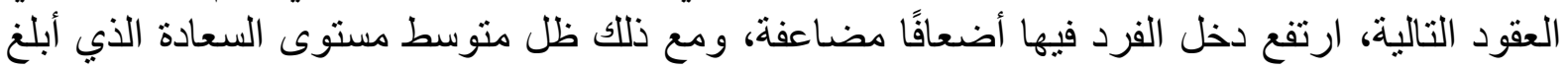

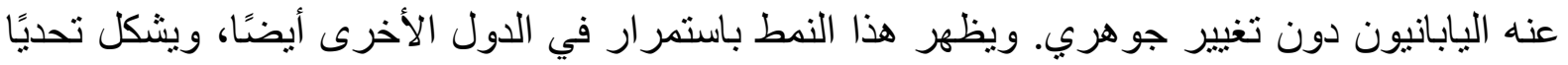

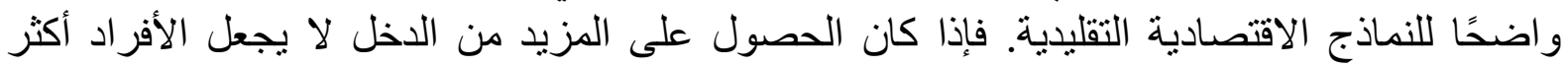

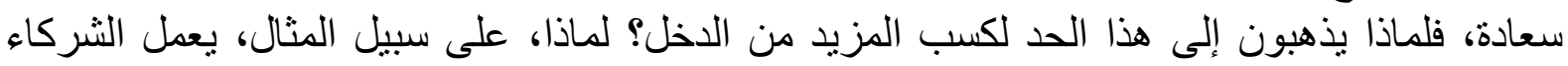

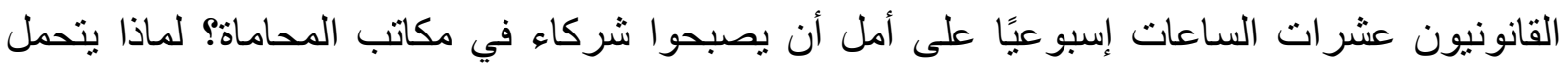

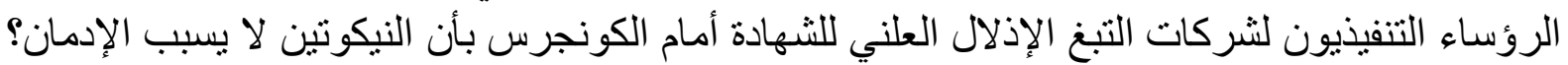

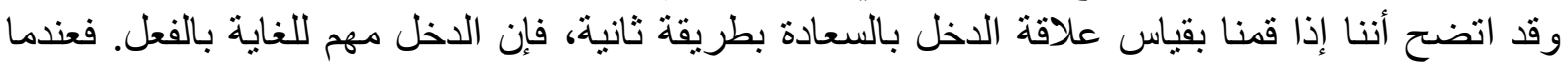

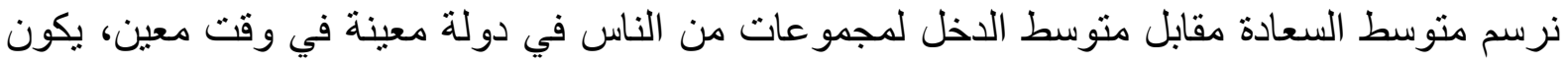
الأغنياء في الو اقع أكثر سعادة من الفقر اء. 284

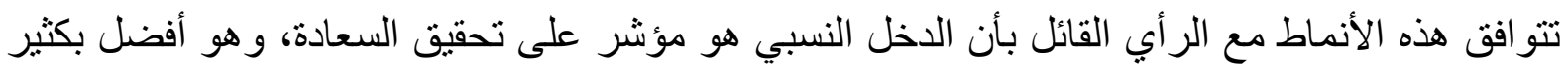

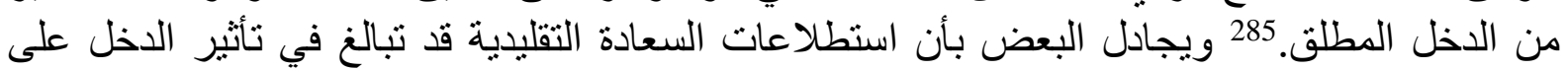

\footnotetext{
${ }^{282}$ Frank, Robert H., (1999). Luxury Fever. The Free Press, New York.

${ }^{283}$ Diener, Ed, Ed Sandvik, Larry Seidlitz, and Marissa Diener, (1993). The Relationship between Income and Subjective Well-Being: Relative or Absolute? Social Indicators Research, 28, P. 195.

${ }^{284}$ Clark, Andrew, Oswald, Andrew, (1996). Satisfaction and comparison income. Journal of Public Economics 61, P. 359.

${ }^{285}$ Easterlin, Richard, (1995). Will raising the incomes of all increase the happiness of all? Journal of Economic Behavior and Organization 27, PP. 35-47.
} 


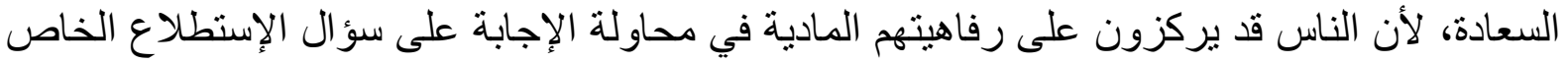

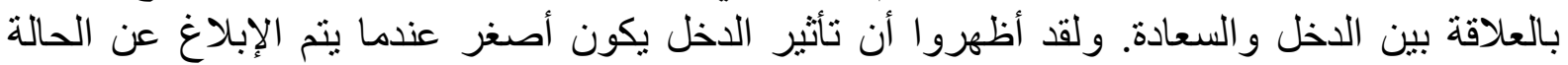

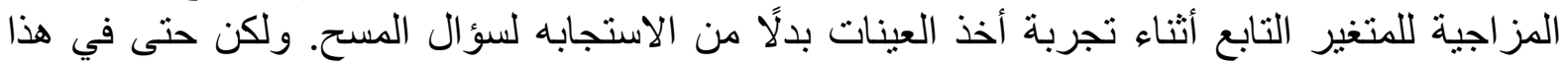

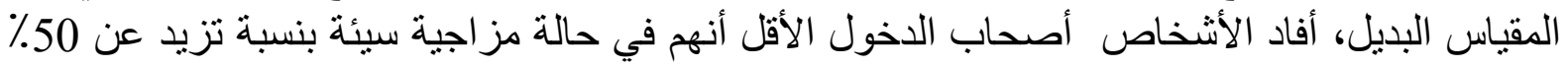

$$
\text { أكثر من الأشخاص أصحاب الأنغاص الأنول الأعلى. }
$$

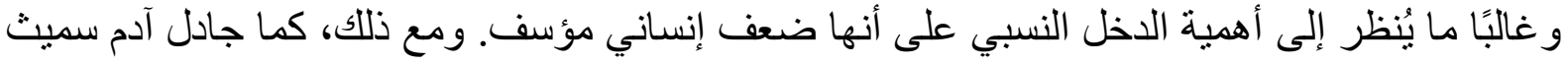

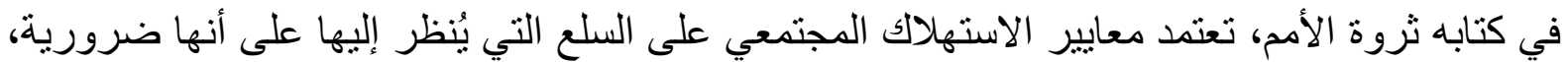

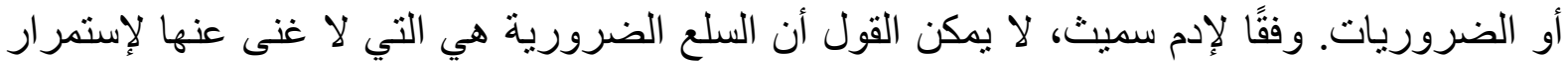

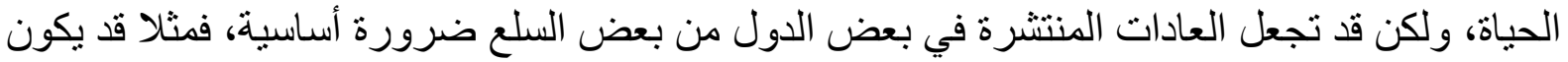

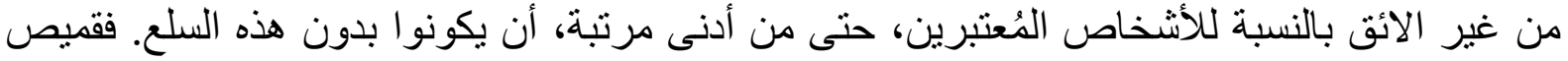

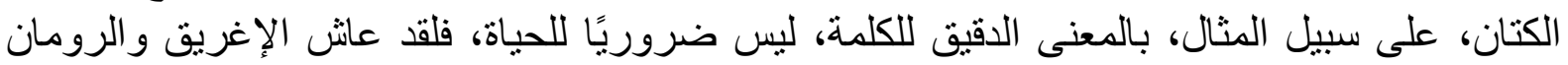

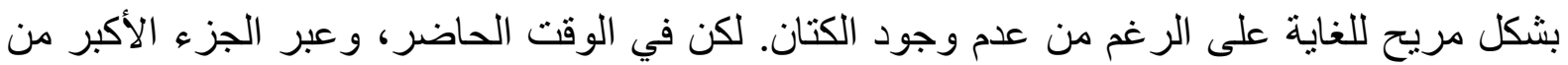

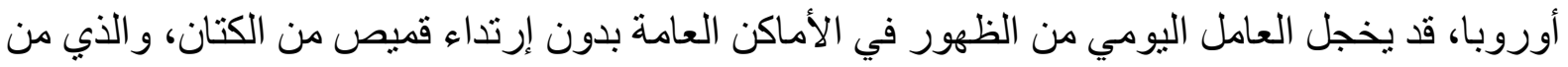

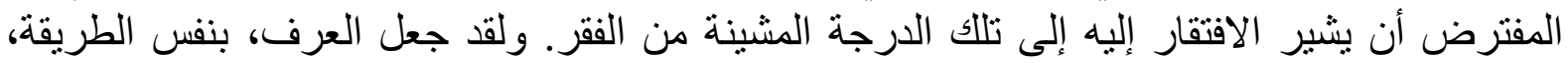

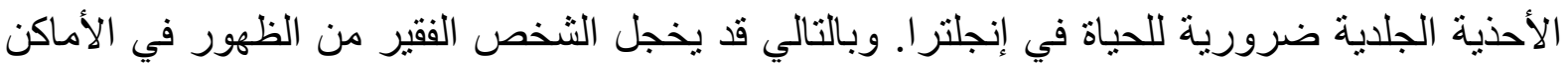

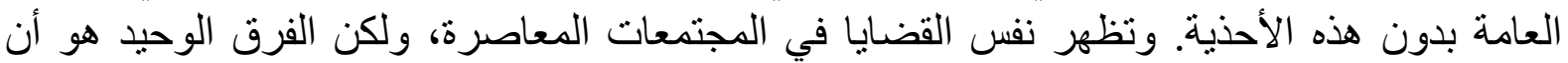
المعايير التي تحدد الضروريات الآن قد تصاعدت بشكل كبير منذ أيام آدم سميث.

\section{5. الأثار الخارجية للوضع الاستهلاكي تفرض تكاليف اقتصادية مادية}

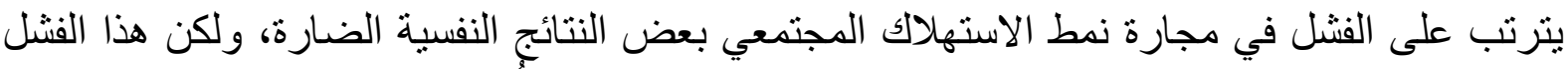

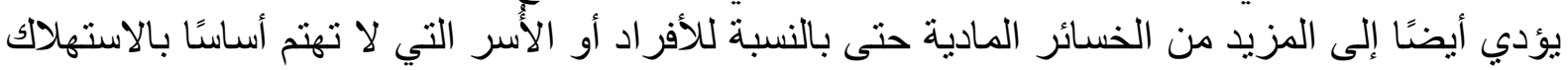

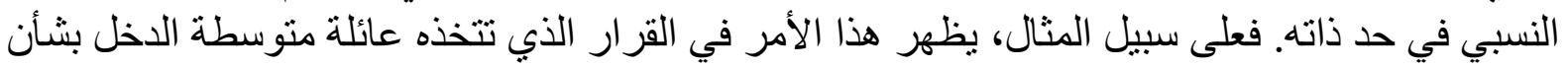

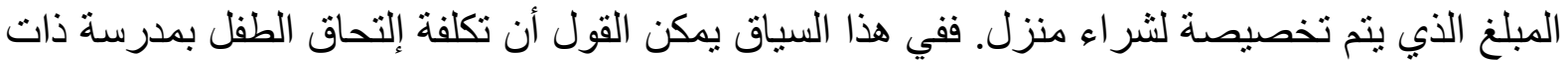

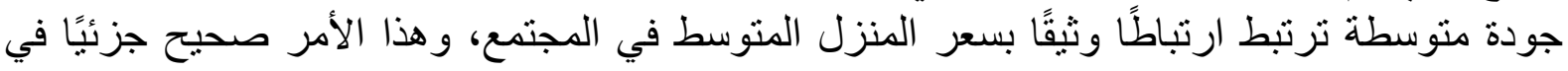

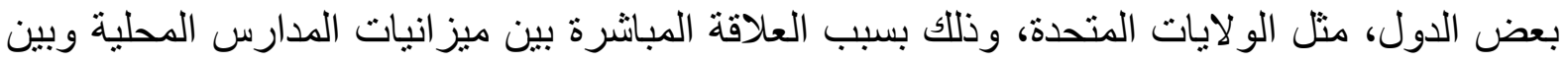

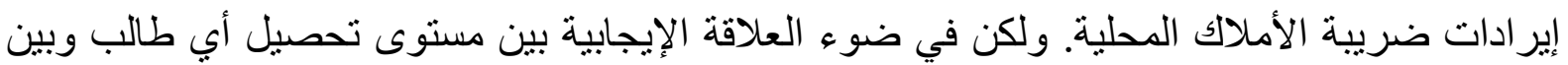

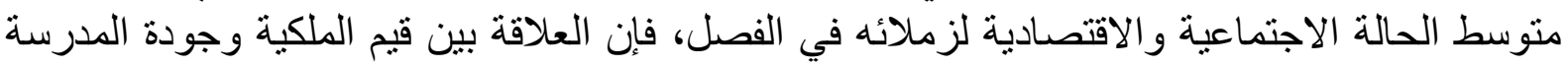

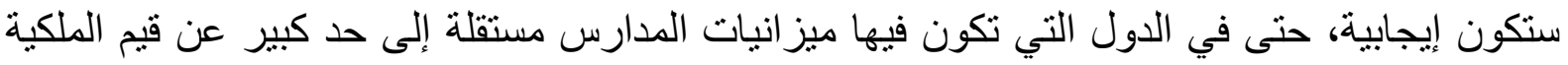

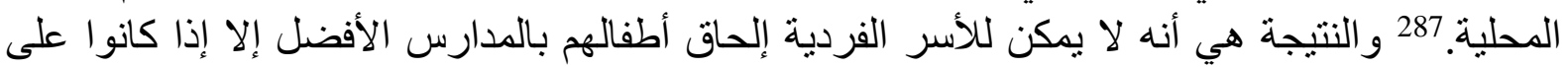

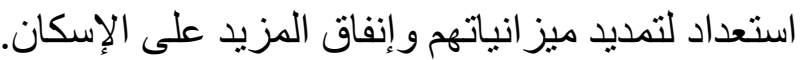

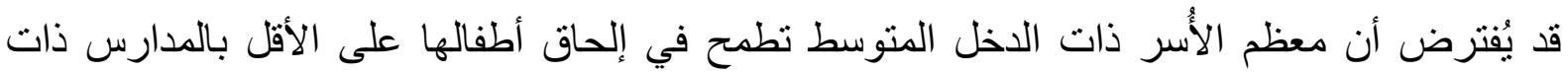

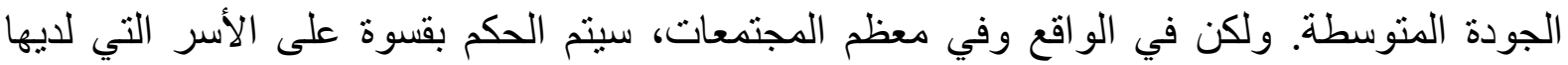

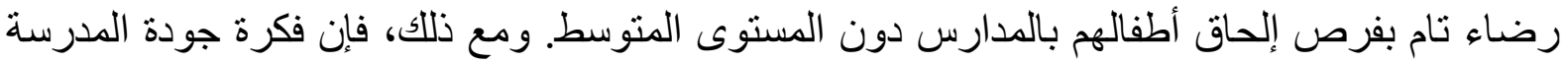

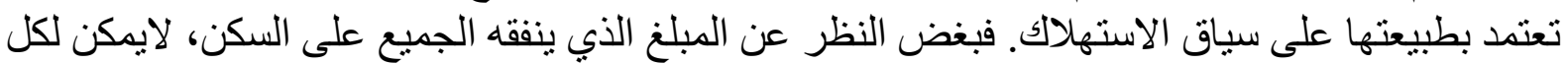

${ }^{286}$ Kahneman, Daniel, Krueger, Alan B., Schkade, David, Schwartz, Norbert, Stone, Arthur B., 2006. Would you be happier if you were richer? A focusing illusion. Science 312, June 30, PP. 1908-1910. ${ }^{287}$ Hoxby, Caroline, (2000). Peer effects in the classroom: learning from gender and race variation. NBER Working Paper No. W7867 August, P.4. 


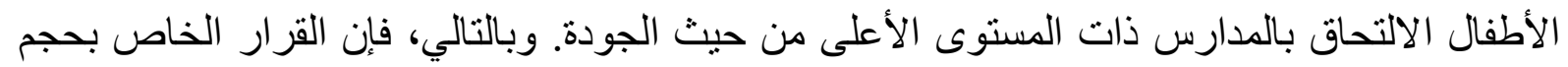

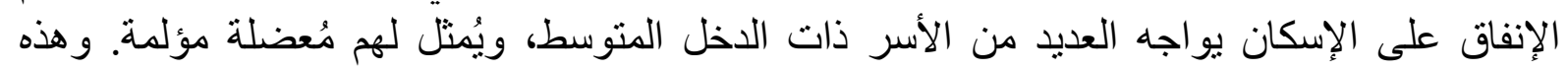

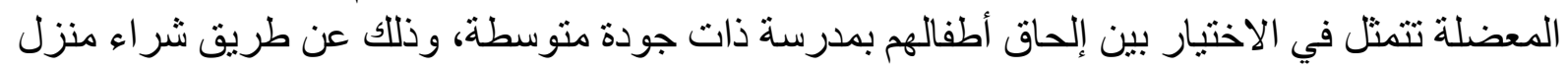

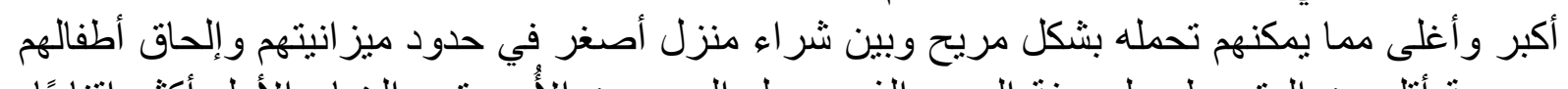

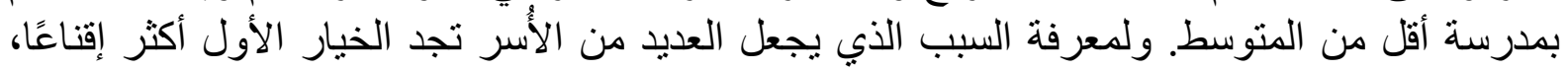
فيحب عدم افتر اض أنهم اتخذو هذا القرار بدافع الحسد أو الغيرة.

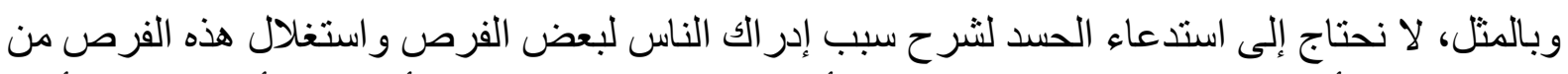

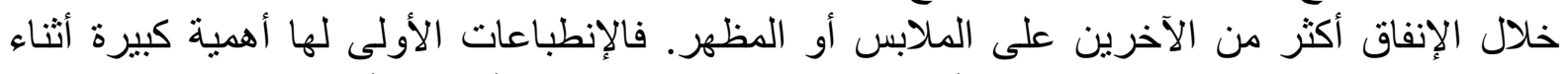

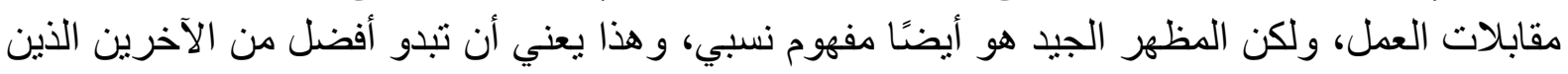

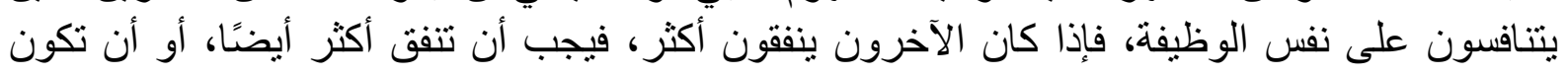
مستعدًا للعيش مع احتمالات منخفضة للحصول على الحف الوظيفة التي تريدها. 


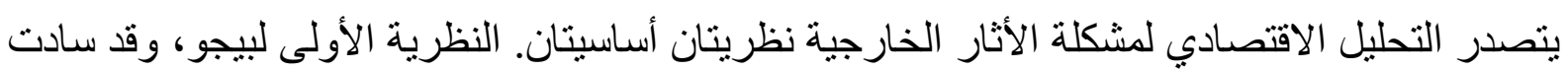

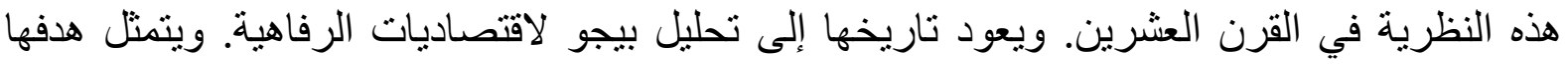

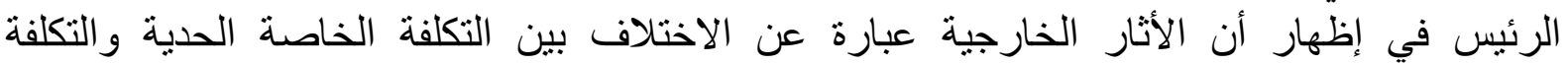

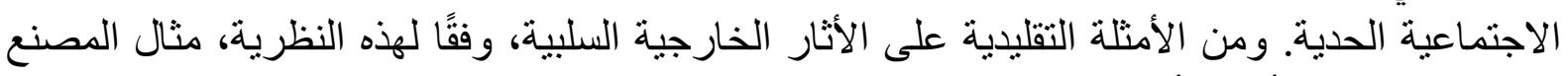

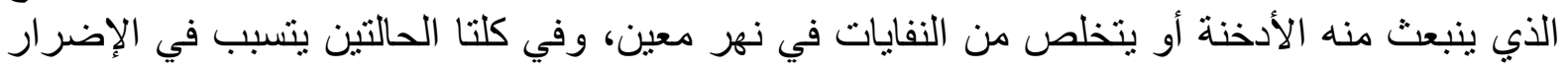

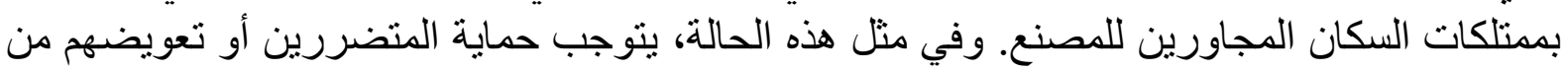

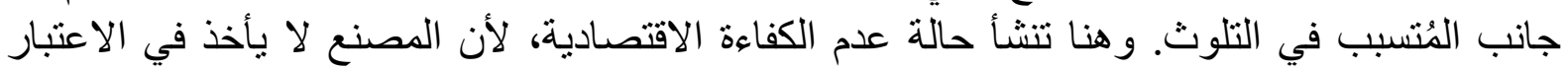

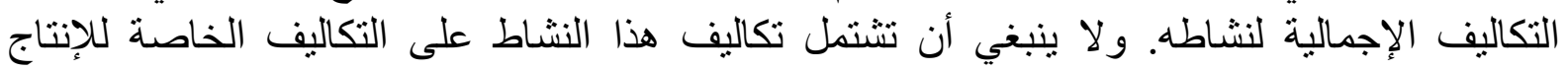

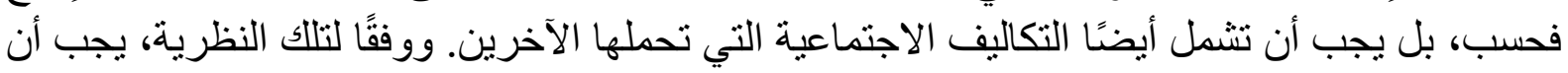

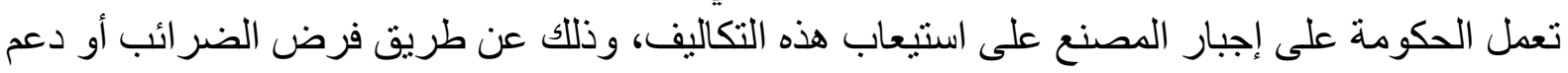

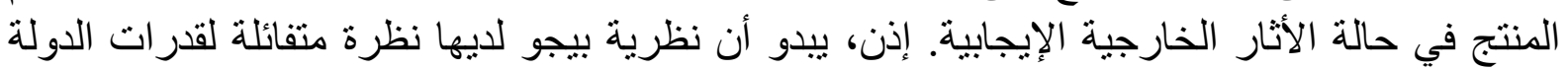
على حل مشاكل الأثار الخارجية.288

وكرد فعل على هذا التحليل، ظهرت نظرية كواس. فقد جادل كواس بأن تحليل بيجو يتجاهل وجود

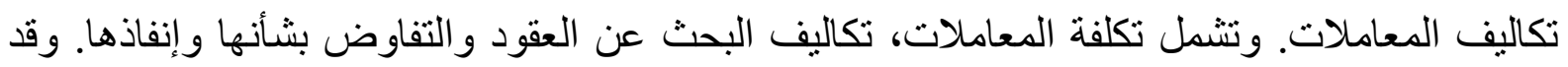

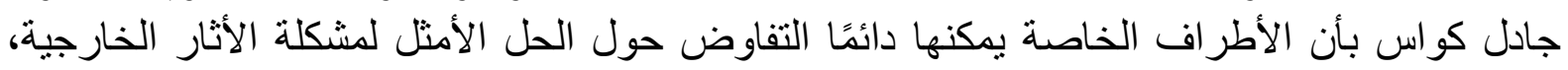

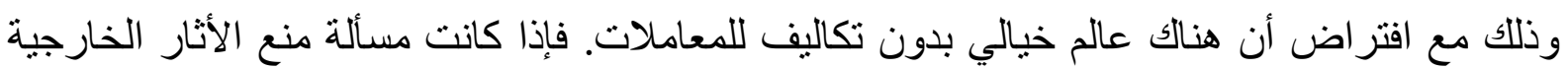

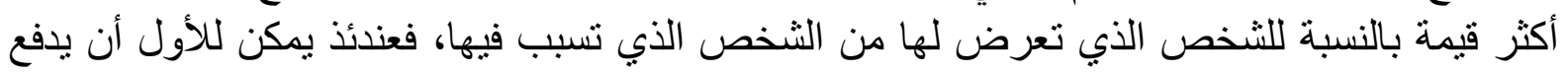

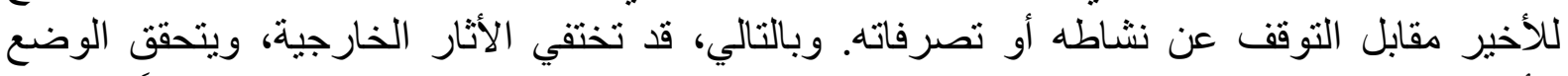

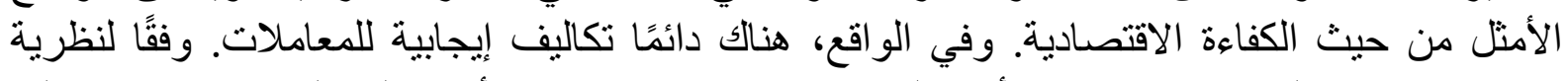

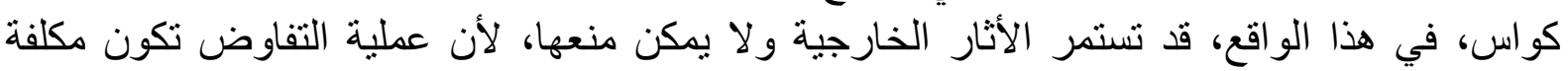

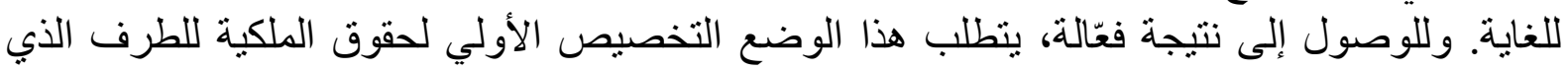

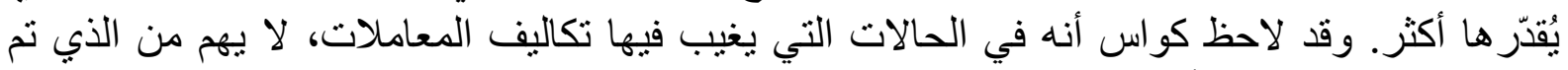

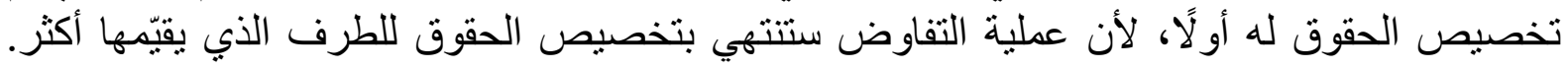

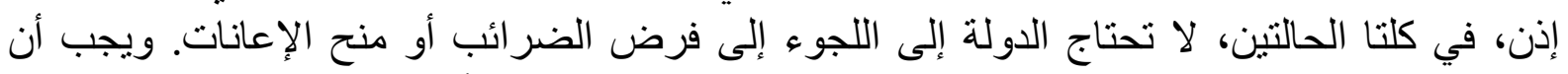

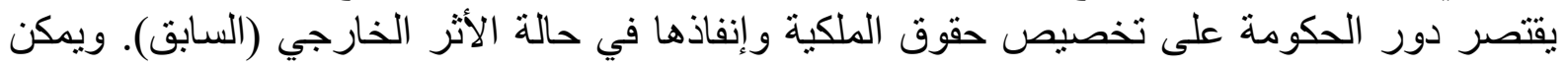
لالية السوق القيام بالباقي.

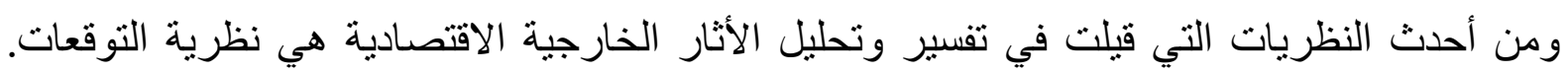

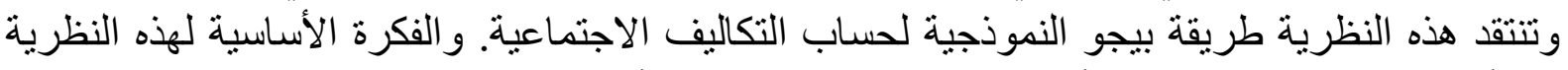

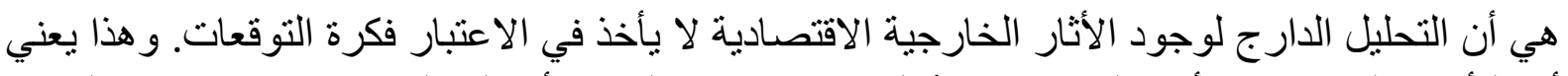

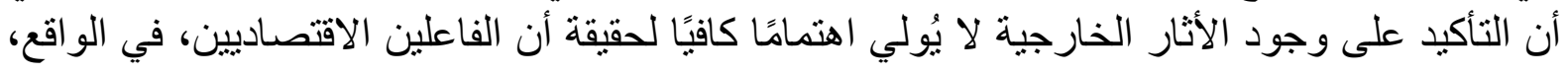

${ }^{288}$ Claassen, Rutger, (2016). Externalities as a basis for regulation: a philosophical view. Journal of Institutional Economics. -1, PP. 1-23.

${ }^{289}$ Coase, R. H., (1960). 'The Problem of Social Cost', The Journal of Law and Economics, 3, PP. 144. 
يكون لايهم توقعات معقولة حول احتمالية تعرضهم لأثار غير مباشرة كنتيجة لتصرفات الآخرين. و عندما

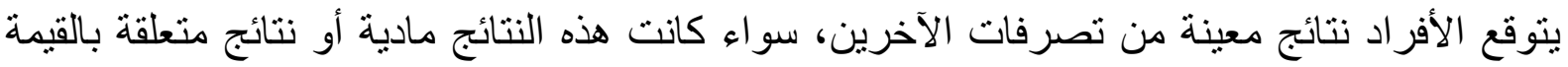

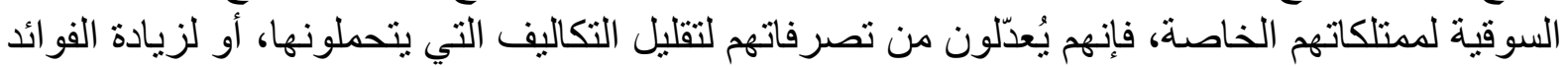

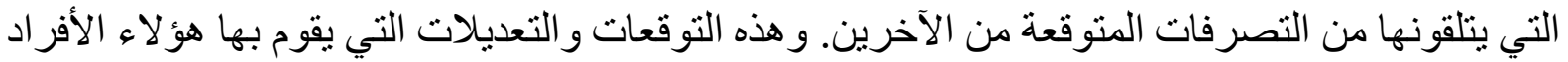

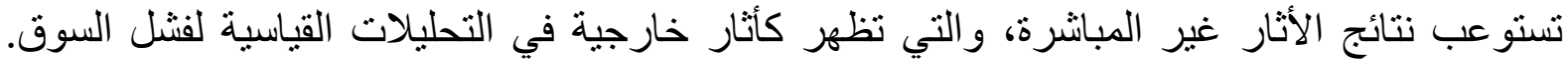

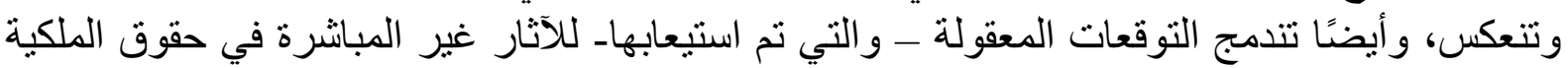
وفي القيمة المُقدّرة لهذه الحقوق.

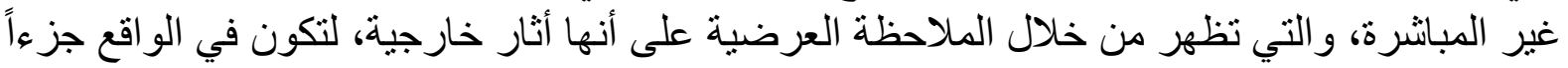
من هيكل حقوق الملكية.

إضافةً إلى ذلك، تشمل النظرية الاقتصادية للأثار الخارجية علاقة هذه الأثار بالكفاءة الاقتصادية. وهذا

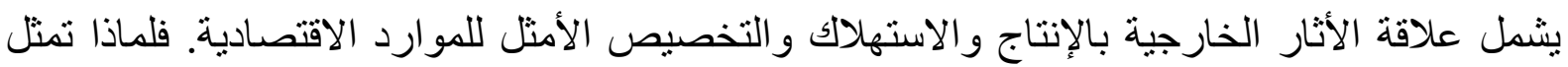

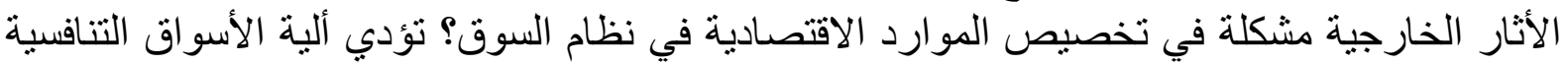
الحرة إلى تحديد الأسعار التي يتساوي عندها التكاليف الحدية مع الفوائد الحدية التي تحملها البائعون

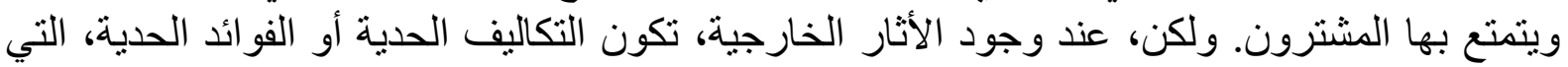

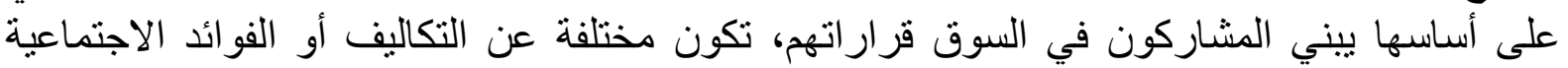
الحدية الفحلية. 291 وبالتالي يجب توضيح كيفية تأثنير الأثار الخارجية على الرفاهية التهارية الاقتصادية. ويوضح

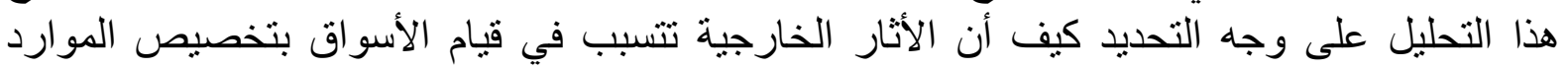
الاقتصادية بشكل غير فعّال.

ولتوضيح التحليل الاقتصادي لهذه النظريات رأينا تقسيم هذا الفصل إلى المباحث التالية: المبحث الأول: نظرية كواس لتكاليف المعاملات. المبحث الثاني: نظرية التوقعات للأثار الخارجية. المبحث الثالث: الأثثار الخارجية والكفاءة الاقتصادية للسوق.

290 M. Rahmatian \& L. Cockerill, (2004). Airport Noise and Residential Housing Valuation in Southern California: A Hedonic Pricing Approach, Vol. 1, No. 1, International Journal of Environmental Science \& Technology, PP. 17, 18.

${ }^{291}$ Heller, Walter P., and David A. Starrett, (1976). "On the Nature of Externalities." In Steven A. Y. Lin, ed., Theory and Measurement of Economic Externalities. New York: Academic Press, PP. 9 21. 


\section{المبحث الأول: نظرية كواس لتكاليف المعاملات}

ترجع الأصول التاريخية لنشأة نظرية كو اس إلى الوقت الذي أقدم فيه كواس على تحليل مدى فعّالية ألية

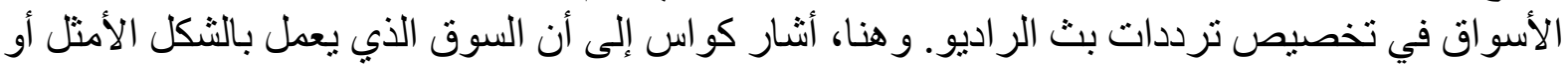

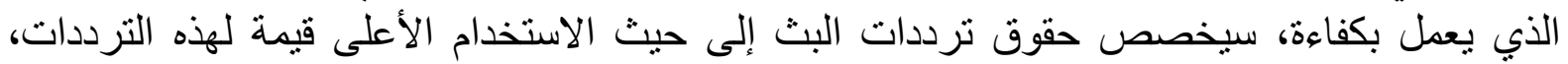

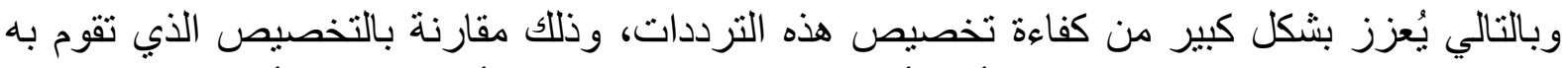

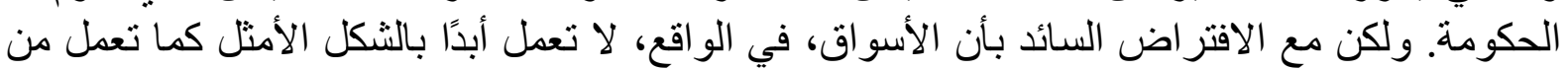

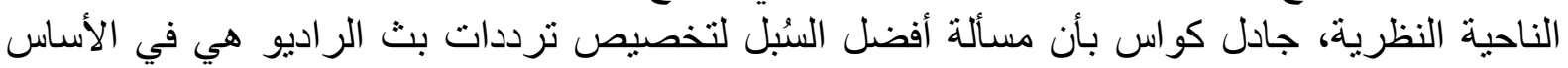

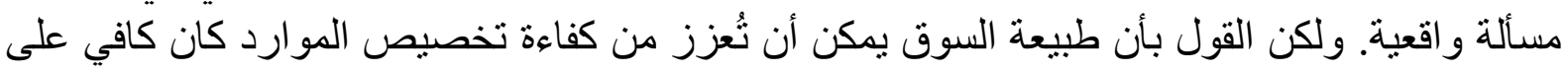

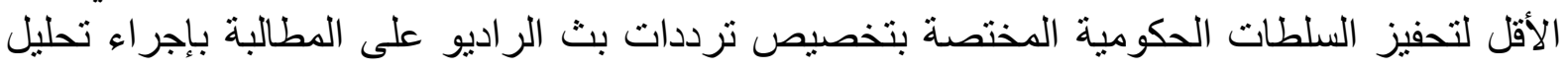
جاد في هذا الثنأن.

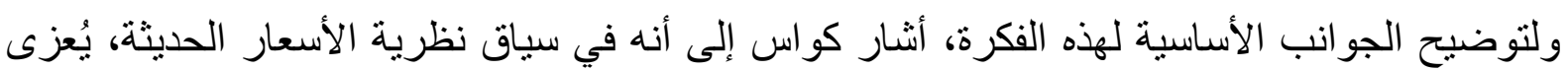

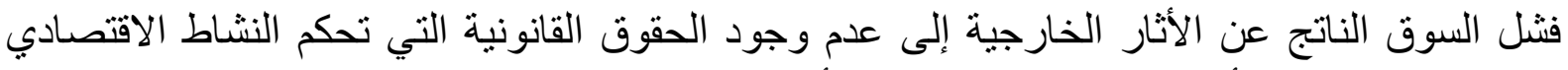

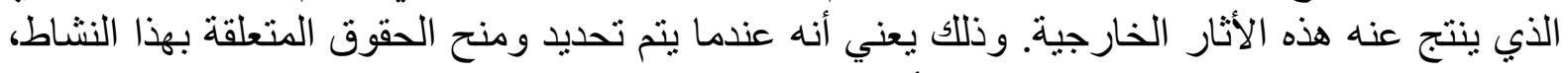

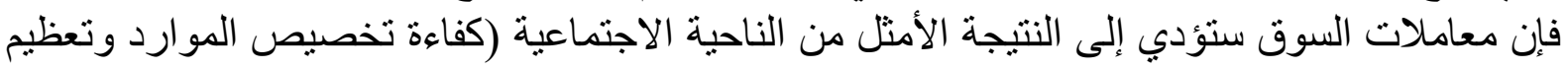

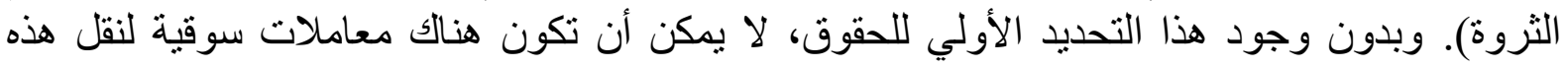

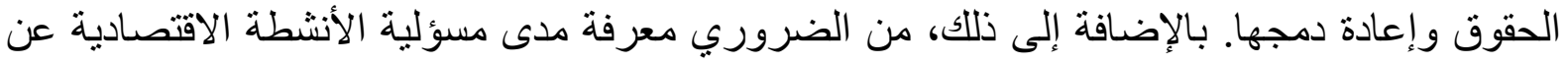

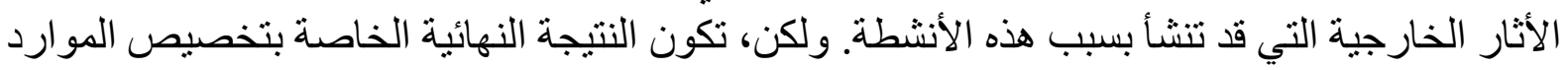

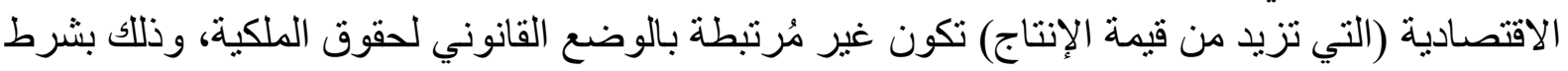

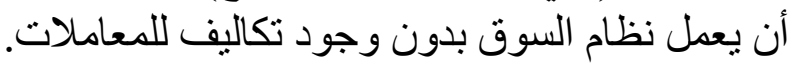

وفي سياق إثبات صحة هذه النظرية، يمكن القول أنها لم تستهدف تحليل القواعد القانونية، ولكنها

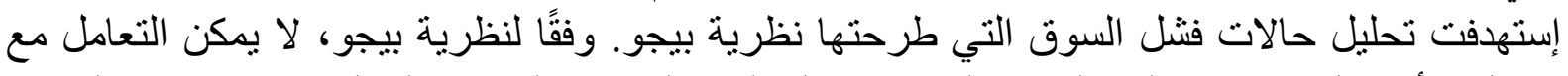

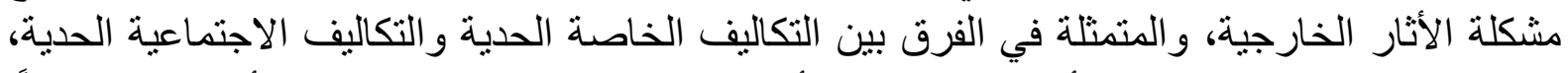

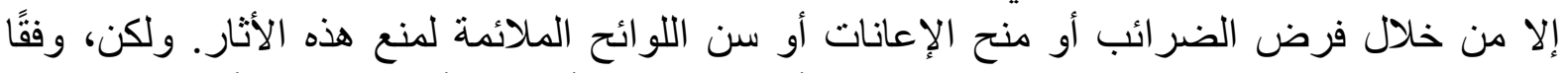

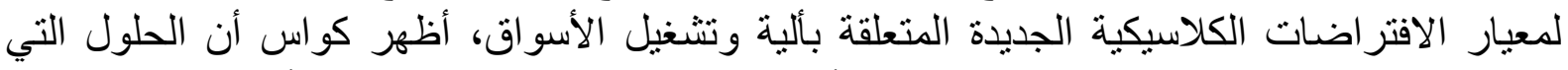

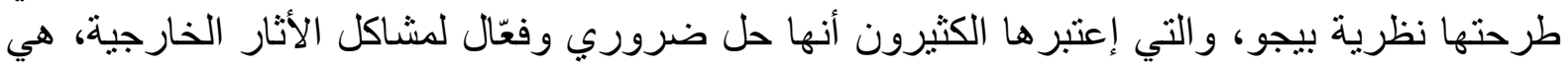

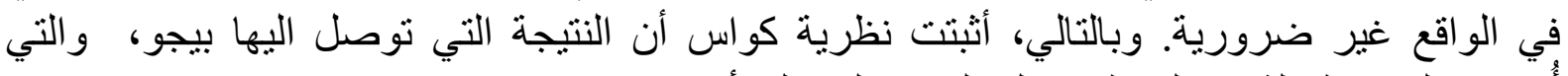
أُعتبرت لفترة طو فيلة من المعطيات المُسلم بها، ليس لها أي مبرر.

وفقًا لنظرية كواس، يمكن للأسو اق التي لا يوجد بها أي نز اعات حول حقوق الملكية أن تتعامل مع مشكلة

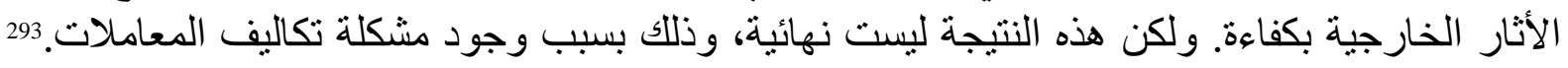

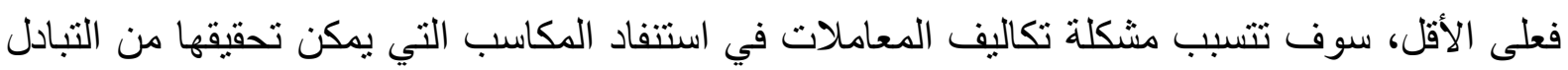

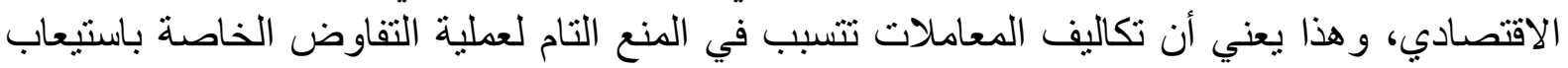

${ }^{292}$ Coase, Ronald H., (1960). "The problem of social cost'. Journal of Law and Economics, 3, PP.144.

${ }^{293}$ Dahlman, Carl J., (1979). 'The problem of externality. Journal of Law and Economics, 22, PP.14162. 


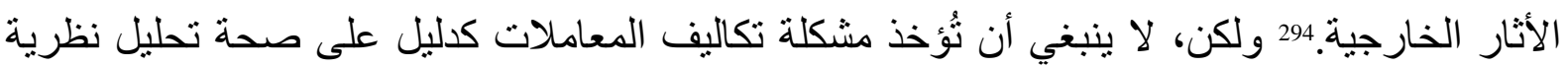

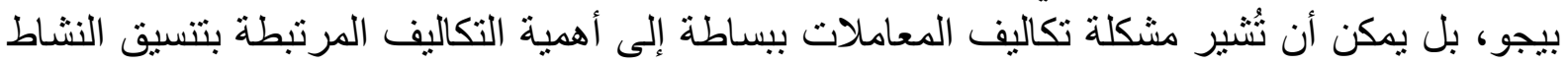

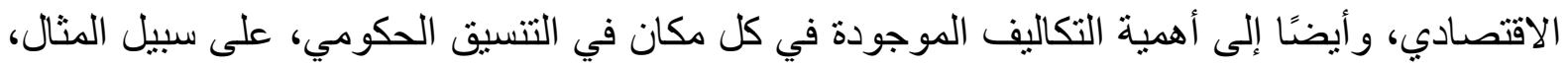

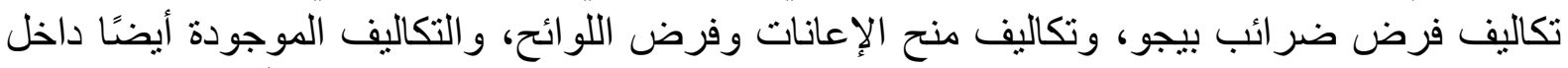

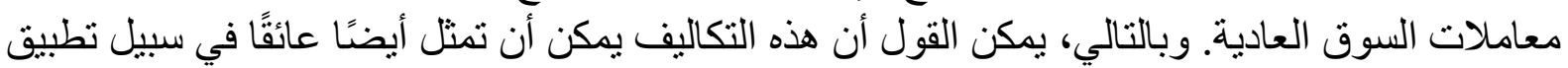
نظرية بيجو.

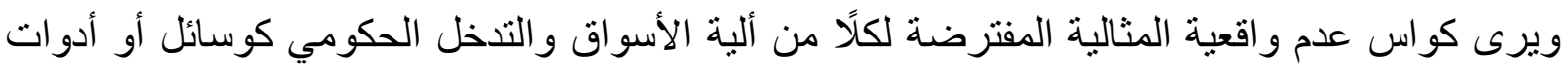

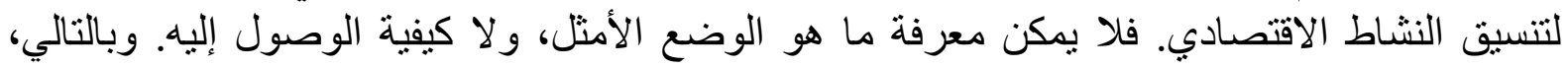

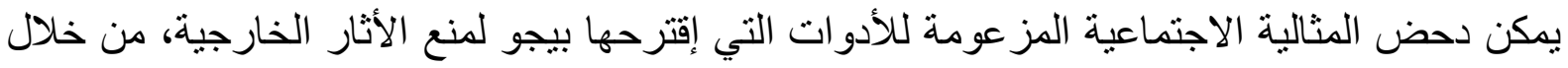

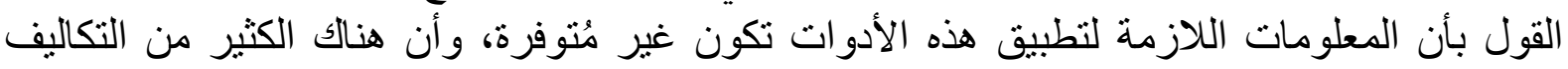

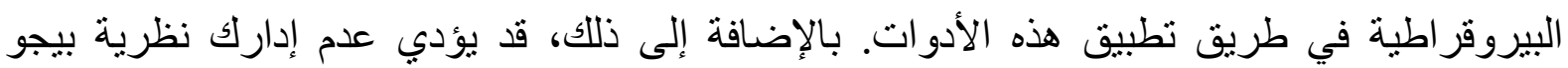

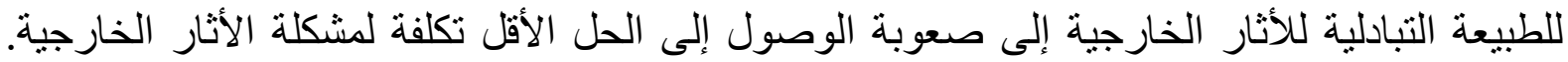

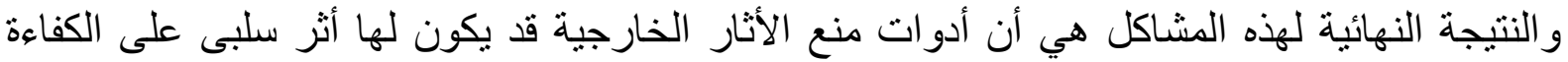

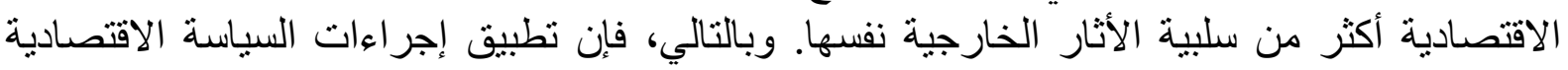

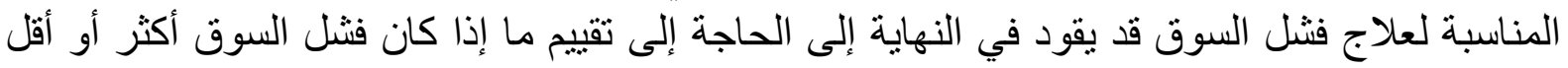

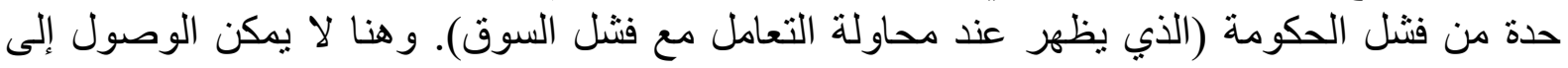
نتيجة هذا التقييم إلا من خلال التحليل المؤسسي المقارن لكل حالة على حدة.

باختصار، أظهرت مشكلة تكاليف المعاملات أن النهج الكلاسيكي الجديد لتحليل الأثار الخارجية كان التهان

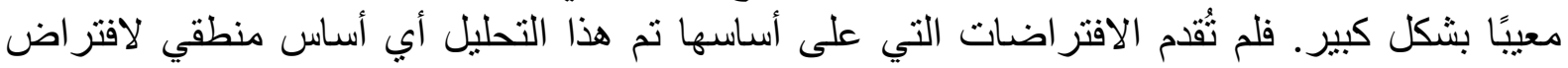

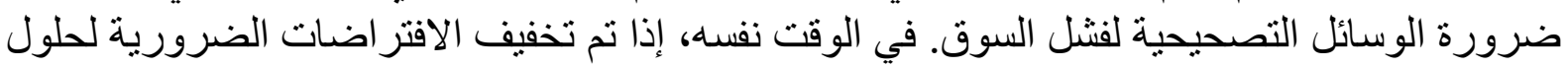

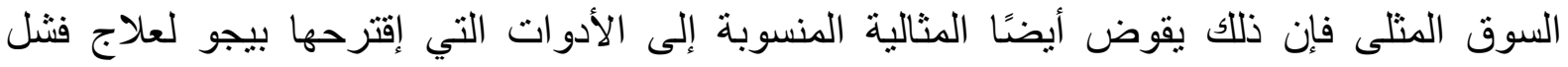

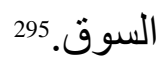

\section{أولًا: فرضيات ونتائج نظرية تكاليف المعاملات (نظرية كواس).}

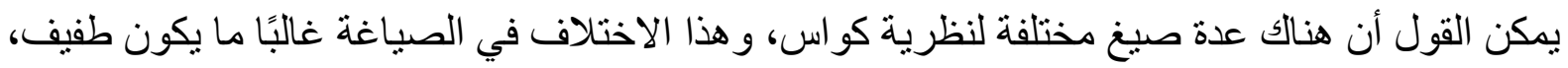

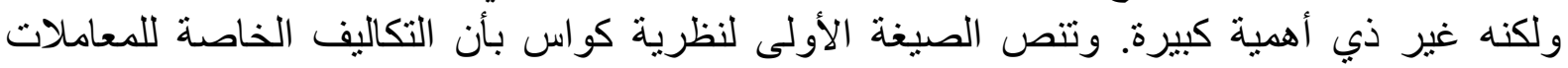

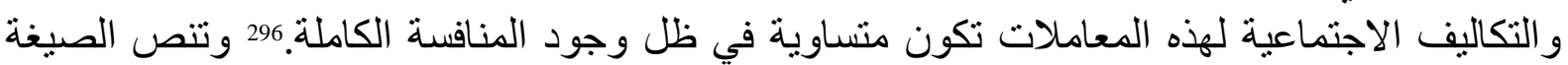

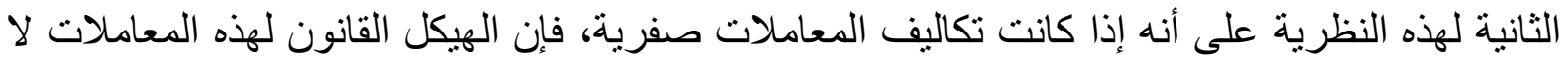

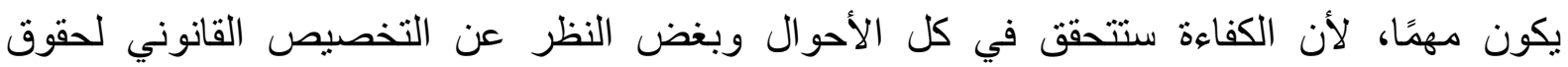

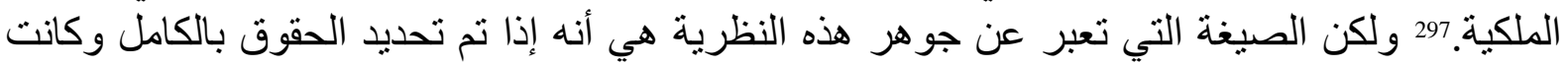

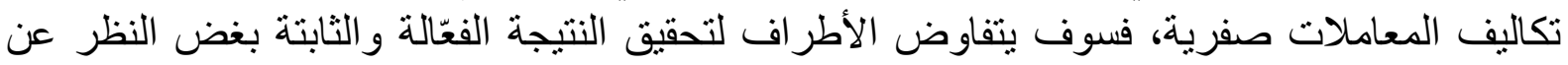

${ }^{294}$ Barzel, Yoram. (1985). 'Transaction costs: are they just costs?' Journal of Institutional and Theoretical Economics, 141, PP.4-16; Allen, Douglas W., (1991). 'What are transaction costs?' Research in Law and Economics, 14, PP.1-18.

${ }^{295}$ Coase, Ronald H., (1960). "The problem of social cost'. Journal of Law and Economics, 3, PP.144.

${ }^{296}$ Stigler, George J., (1966). The Theory of Price. 3rd edn. Macmillan, P.113.

${ }^{297}$ Polinsky, A. Mitchell., (1974). 'Economic analysis as a potentially defective product: a buyer's guide to Posner's Economic Analysis of Law'. Harvard Law Review, 87, P.1655. 
التحديد الأولي للحقوق القانونية.298 وتحتوي صيغة هذه النظرية على بعض الافتر اضات، وتحتوي أيضًا على بعض النتائج.

ولنبدأ بالنتائج، وتحتوي هذه النظرية على نتيجتين، ويمكن فهما بطريقة أفضل على أنهما فرضيتان

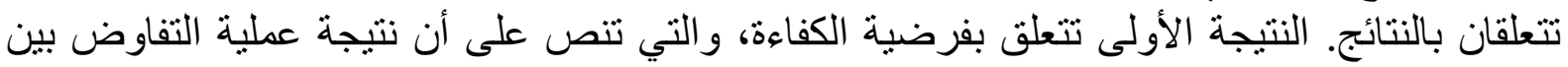

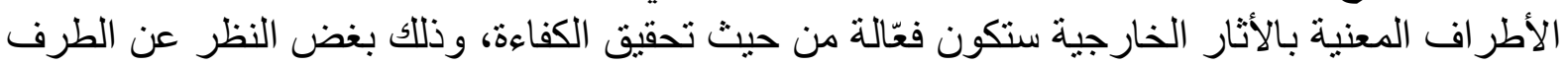

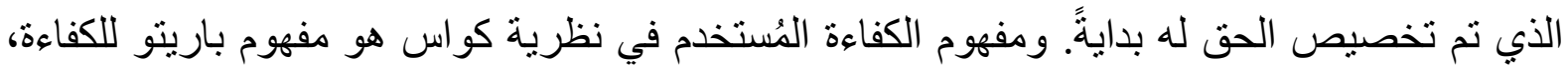

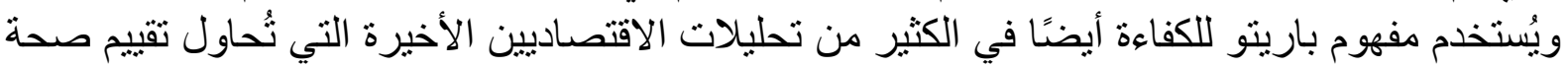

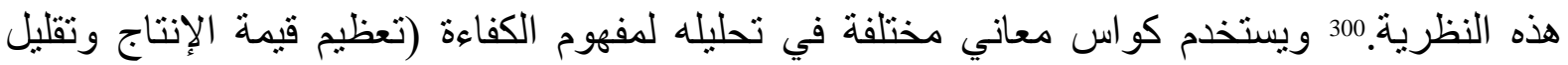
التكاليف)، بينما يُعد تعظيم الثروة وتقليل التكلفة من المتغير ات الأكثر استخداما لمفهوم الكفاءة في القانون

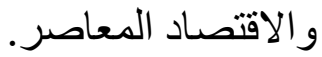

وتعتبر النتيجة الثانية لهذه النظرية من النتائج الضمنية، وهي تتمثل في فرضية الثبات. ومضمون هذه وإه

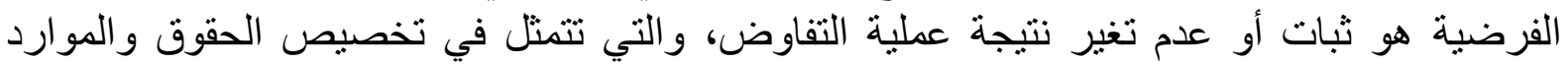

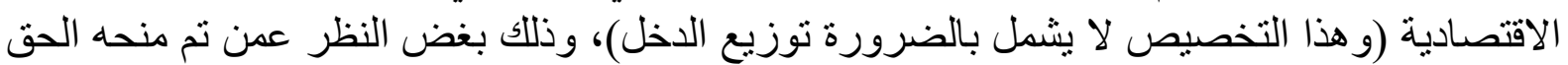

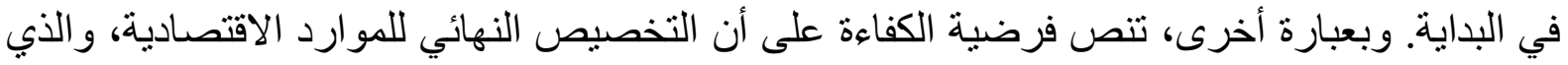

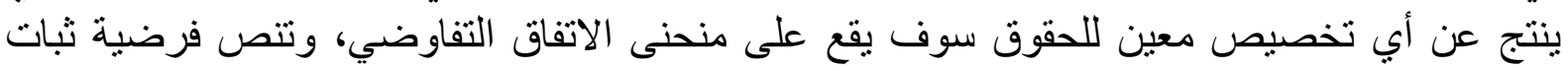

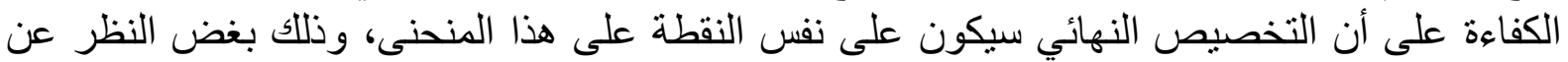

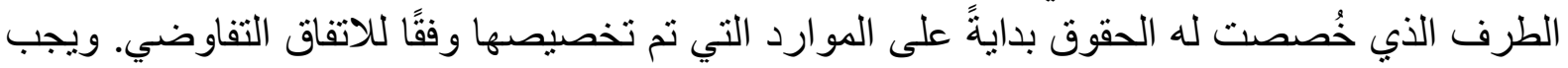

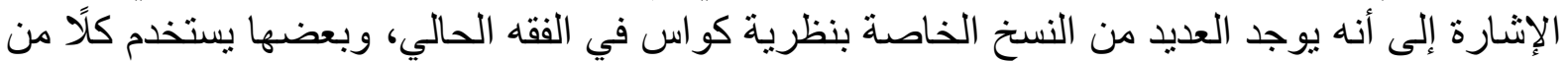

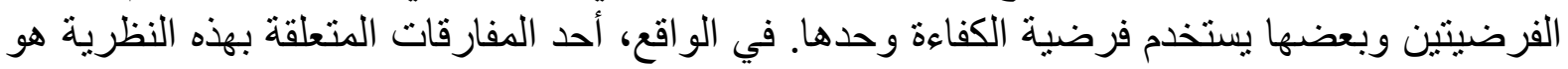

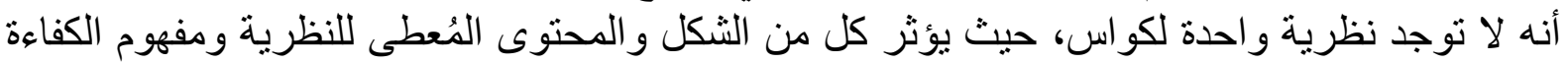
المُستخدم على الاستنتاجات المتعلقة بصحة النظرية.

ويمكن توضيح نتائج النظرية باستخدام بعض الأمثلة البسيطة، وأحد هذه الأمثلة يرتبط بمجال قانون

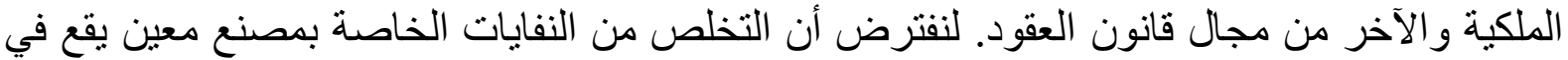

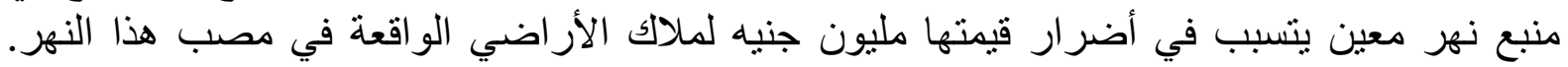

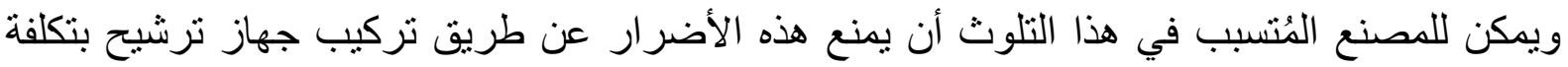

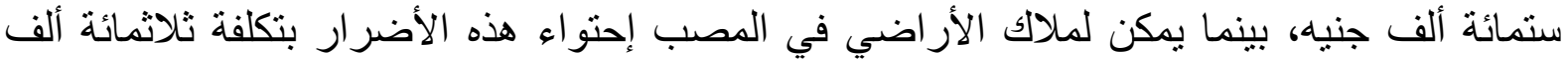

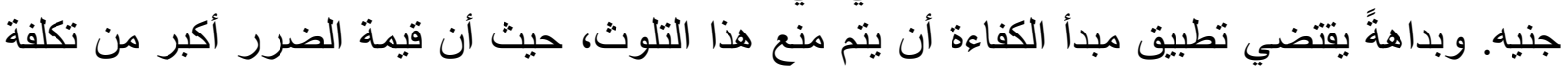

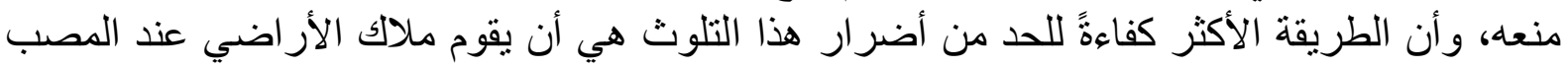
باستيعاب هذا الضرر الناتج عن التلوث.

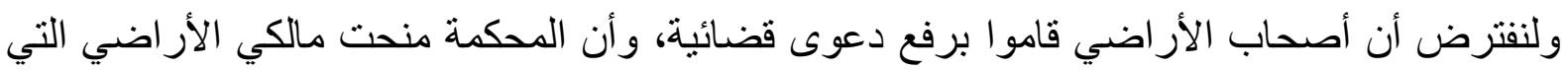

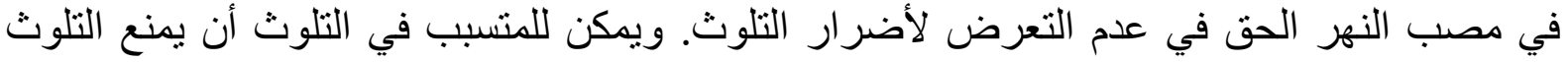

\footnotetext{
${ }^{298}$ Medema, Steven G. and Richard O. Zerbe, Jr., (1999). "The Coase Theorem'. In The Encyclopedia of Law and Economics. Boudewijn Bouckaert and Gerrit De Geest (eds.). Edward Elgar Publishing. ${ }^{299}$ Steven G. Medema (1999). Symposium on the Coase Theorem: Legal Fiction: The Place of the Coase Theorem in Law and Economics. Economics and Philosophy, 15, P. 209.

${ }^{300}$ Buchanan, James M., (1986). 'Rights, Efficiency, and Exchange: The Irrelevance of Transactions Cost'. In J. M. Buchanan, Liberty, Market and the State: Political Economy in the 1980s, New York University Press.
} 
بتكلفة ستمائة ألف جنيه. ولكن، نظرًا لأن ملاك الأراضي في المصب يمكن أن يستو عبوا الأثار السلبية

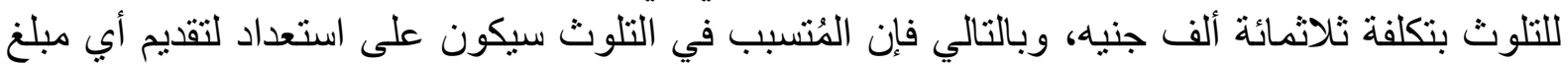

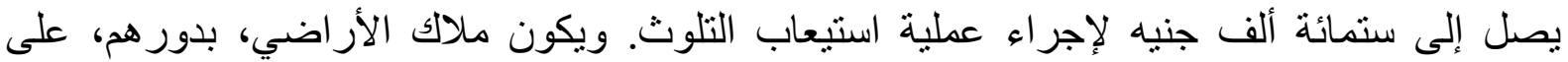

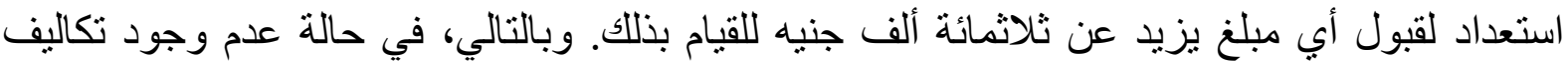

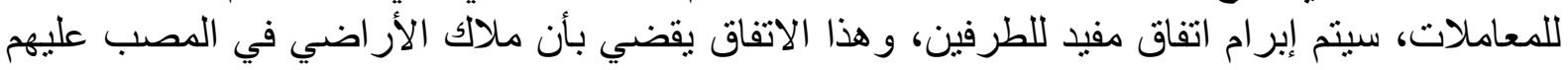

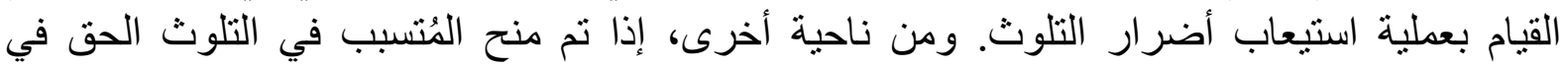

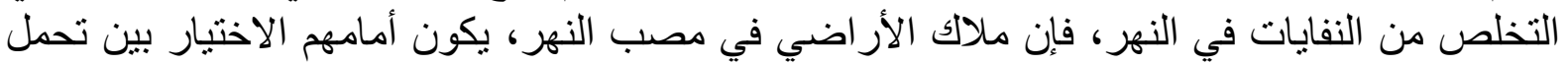

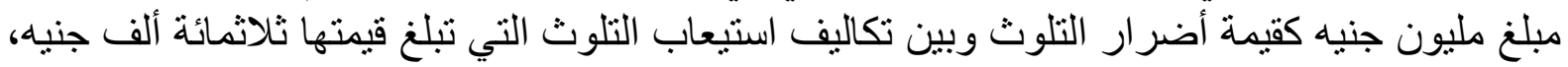

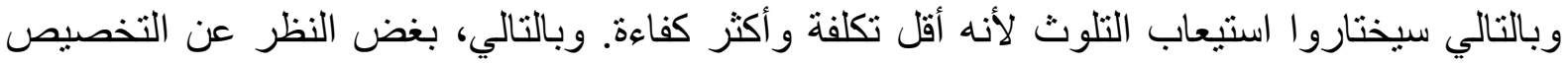

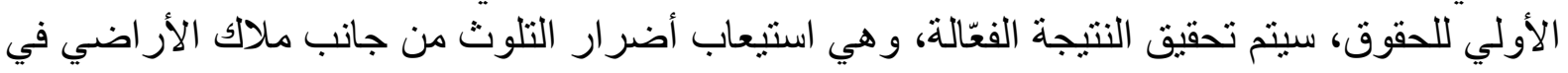
مصب النهر.

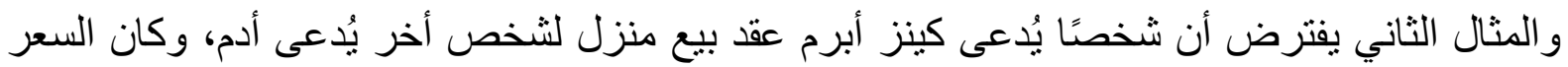

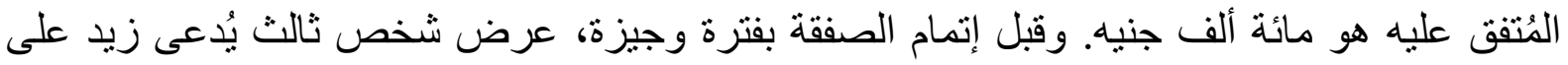

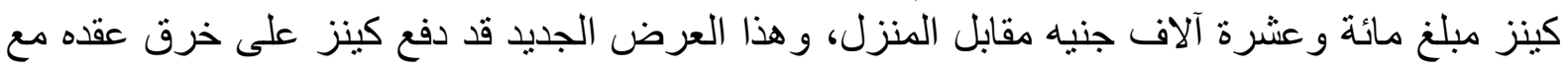

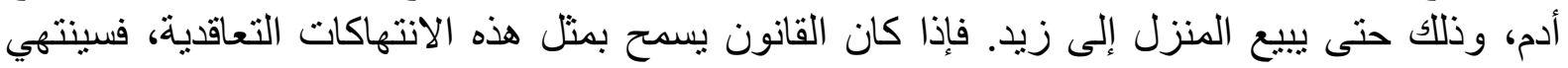

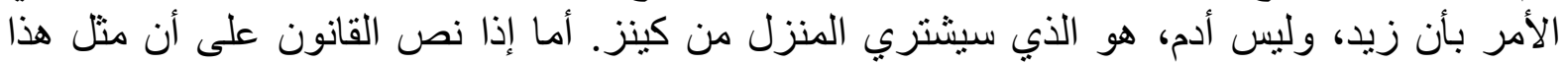

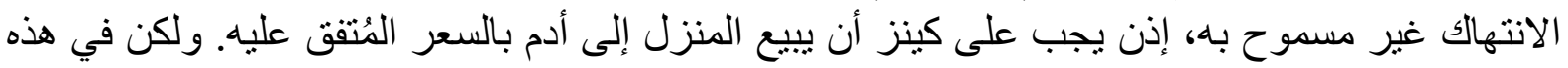

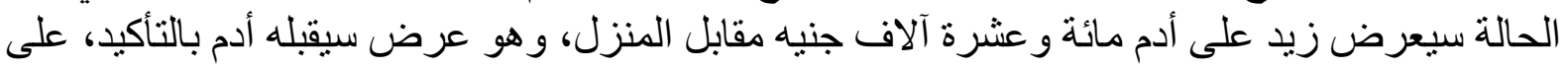

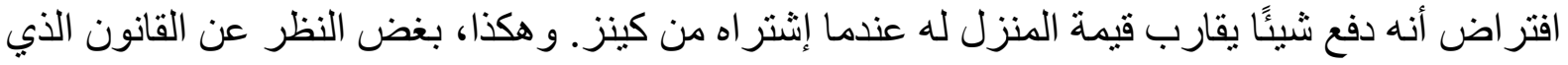

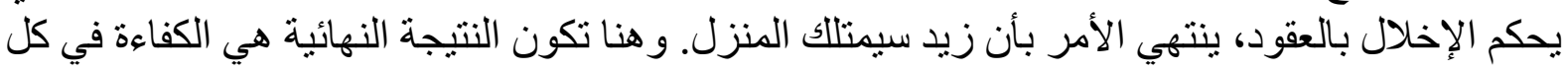

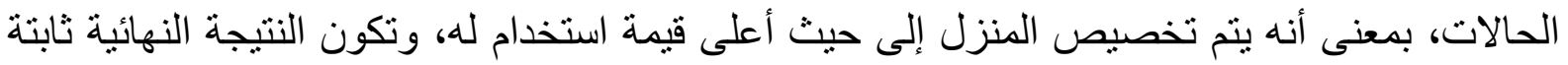
أيضًا في ظل الاحتمالات المختلفة لتخصيص الحتئ الحقوق.

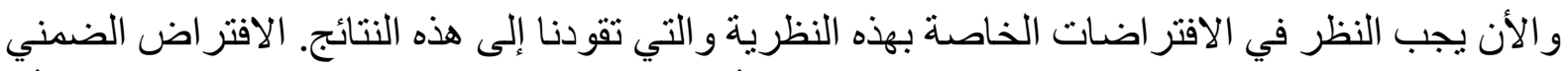

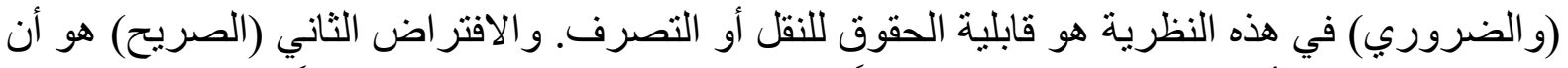

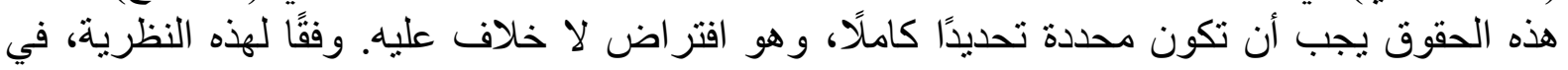

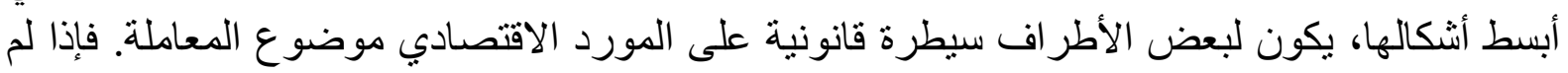

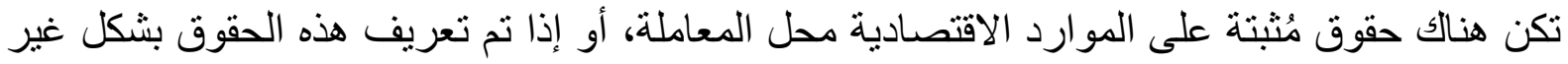

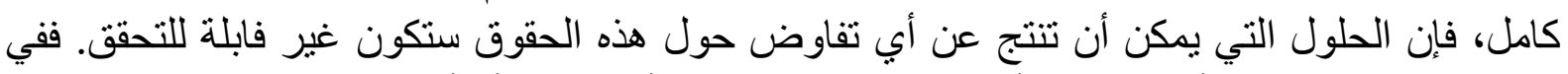

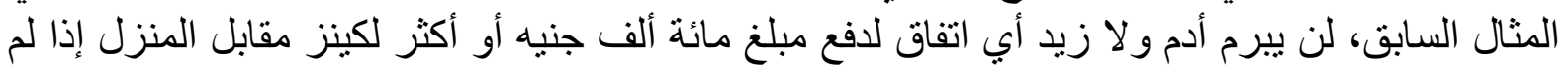
تكن هناك حقوق ملكية مسبقة.

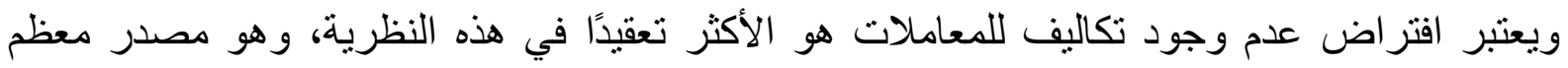

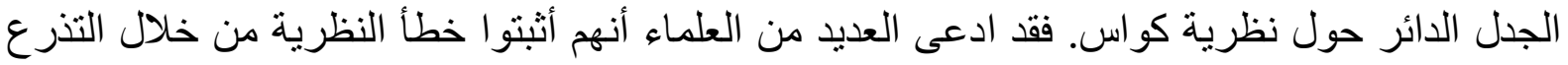

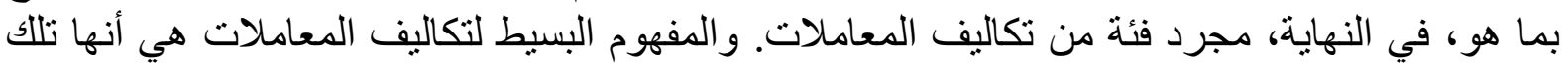

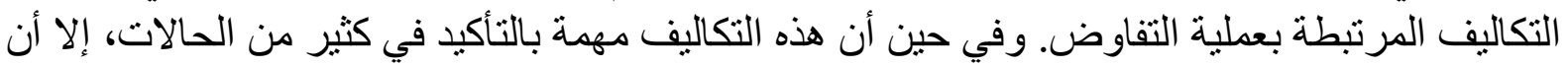
التعريف الأكثر شمولًا هو أن تكاليف المعاملات هي تكاليف إنشاء حقوق الملكية و الحفاظ عليها، ولعل اللاكل 
أهمها (من منظور التطبيق) هي تكاليف المعلومات.301 وبداهةً تتضح ضرورة وأهمية هذا الافتر اض

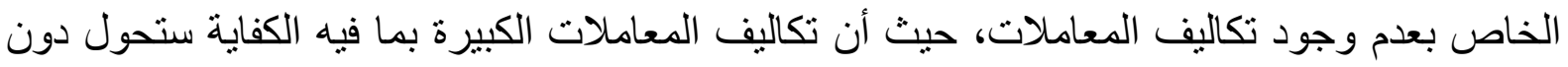

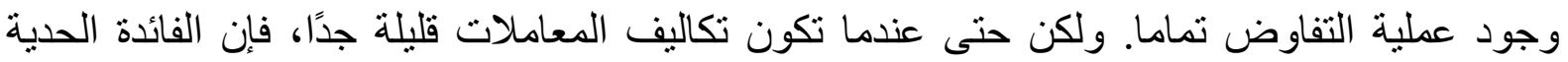
للتفاوض الإضافي ستتجاوز التكلفة الحدية في مرحلة ما، مما يؤدي إلى أن التخصيص التصني النهائي للموارد سيعتمد بالفعل على من يتم تخصيص الإون الحقوق لله بدايةً.

و الافتر اض الضمني الآخر لنظرية كواس هو أن أطر اف المعاملة الاقتصادية يسعون دائمًا لتحقيق أقصى

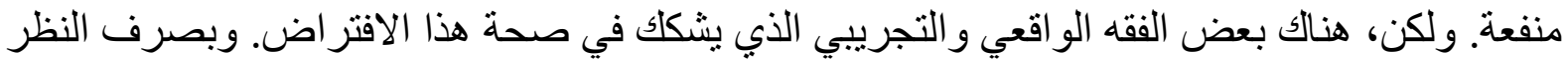
عن هذا التشكيك، يؤدي تبني مفهوم باريتو للكفاءة إلى تفعيل شكل ووظائف المنفعة، و التي يمكن أن تؤثر في حد ذاتها على نتيجة التفاوض.

\section{ثانيًا: دلالات النظرية}

تتبع قوة نظرية كواس من الأثار أو التداعيات التي يمكن أن تظهر كنتيجة لتطبيق هذه النظرية. الأثر

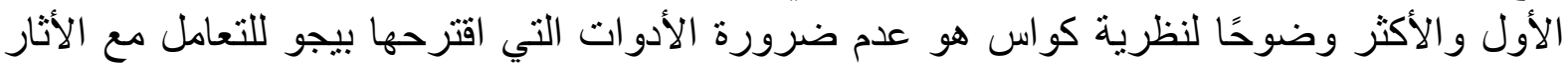
الخارجية. فيُعتبر التخصيص أو التحويل البسيط للحقوق إلى طرف آخر كافئ كافيًا لضمان تحقيق الكفاءة من

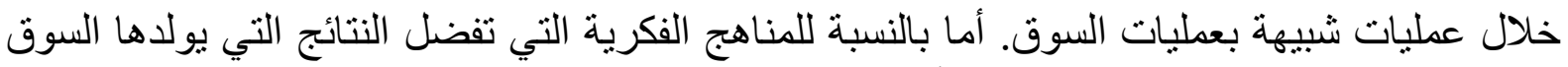

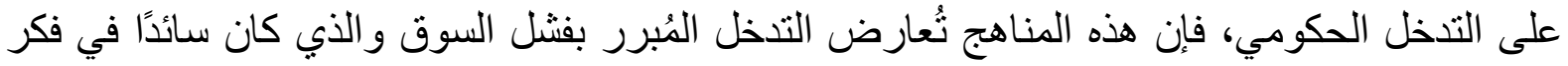

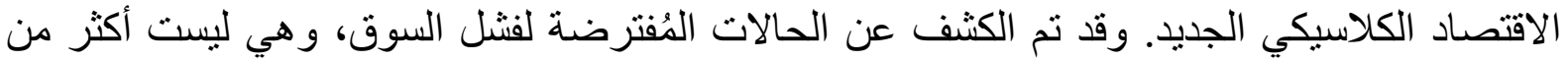

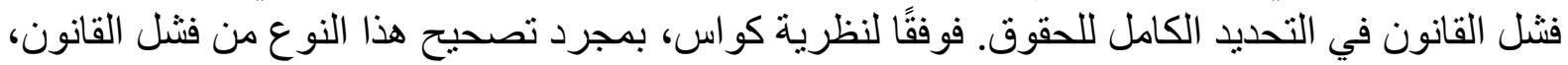

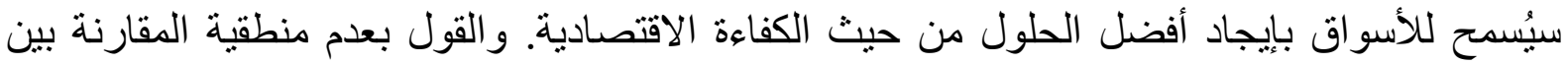

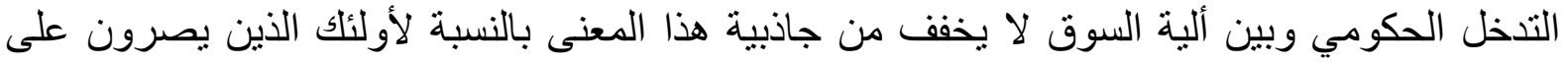

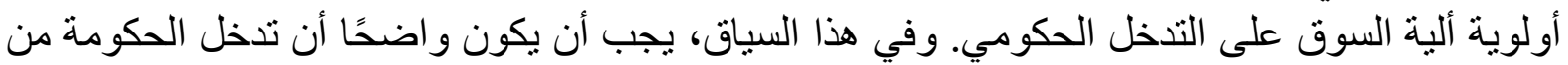

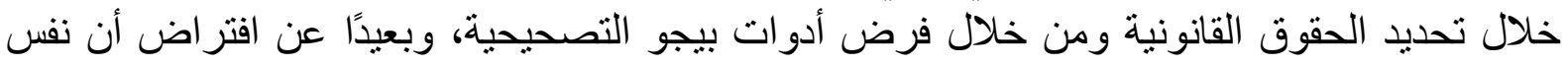

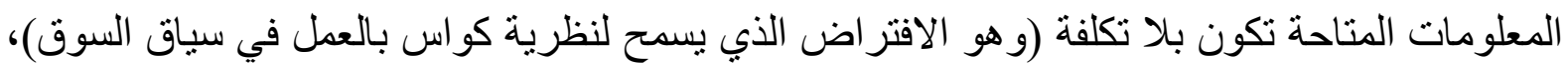
يُمكن أيضًا للحكومة أن تقوم باستيعاب الأثنار الخارجية بكفاءة وباستخدام أدوات بيجو التصحية بـية

والأثر الثاني لنظرية كواس يتمثل في أنه سيتم استيعاب الأثنار الخارجية بكفاءة، ليس فقط من خلال

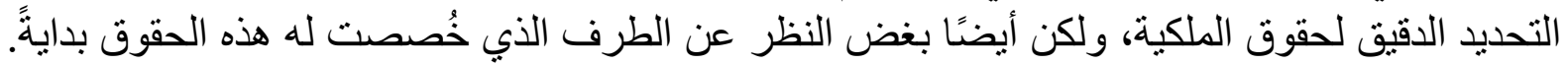

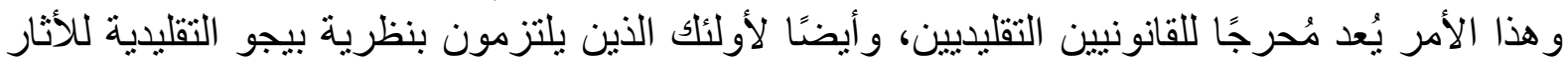

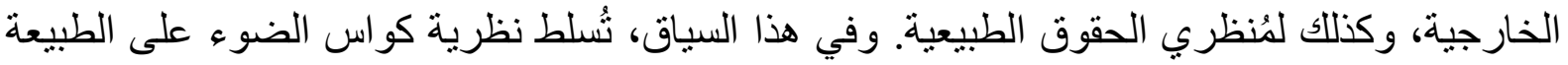
التبادلية للأثار الخارجية، فقد تفرض الأثنار الخارجية التي تنتج عن النشاط الاقتصادي لشخص هـئ معين

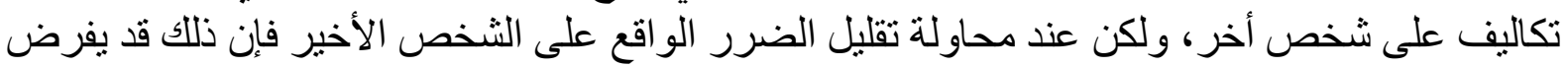

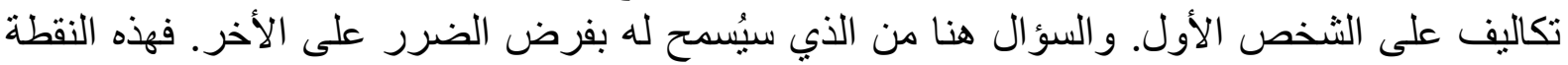

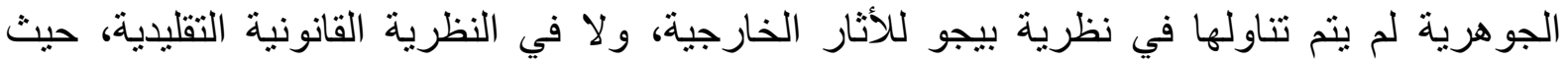
افترضت هذه النظريات أن أحد الأطراف (مثل المُتسبب في التلوث) هو سبب الأنار الخار الخارجية وأن

${ }^{301}$ Allen, Douglas W., (1998). 'Property Rights, Transaction Costs, and Coase: One More Time'. In Coasean Economics: Law and Economics and the New Institutional Economics, pp. 105-18. Steven G. Medema (ed.). Kluwer, P.108.

${ }^{302}$ Hovenkamp, Herbert J., (1990). 'Marginal utility and the Coase Theorem'. Cornell Law Review, 75, P.783. 
الطرف الآخر هو المضرور، وبالتالي يجب فرض قيود على نشاط الثخص الذي يتسبب في وجود هذا

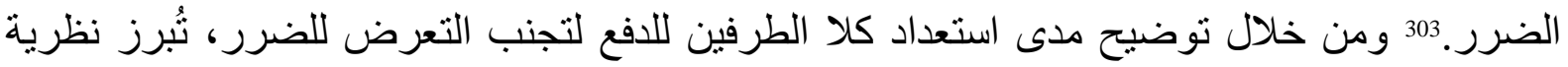
كواس هذه العلاقة التبادلية بشكل واضح للغاية. ولكن الأثر المُعقد لوجهة نظر كو اس هو أنها طمست

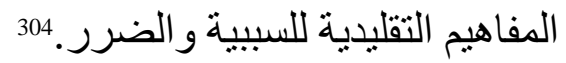

ويترتب على القول بأن تحقق الكفاءة الاقتصادية لا يعتمد على الطرف الذي خُصصت له حقوق الملكية

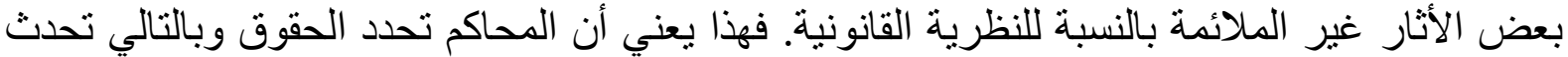

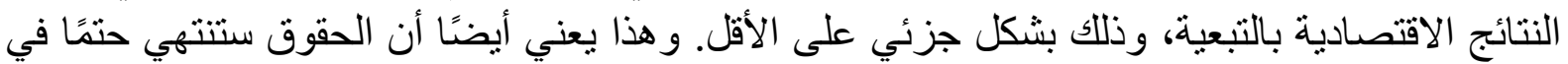

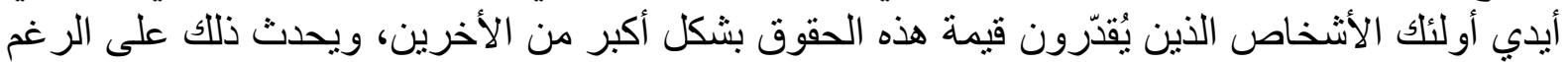

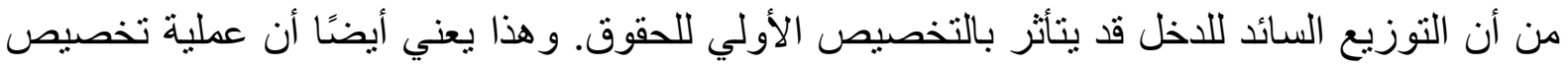

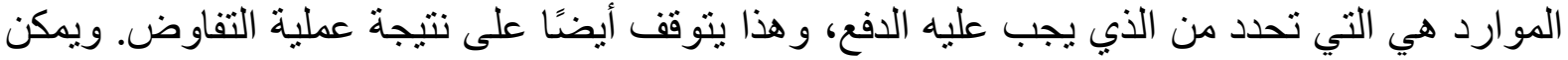

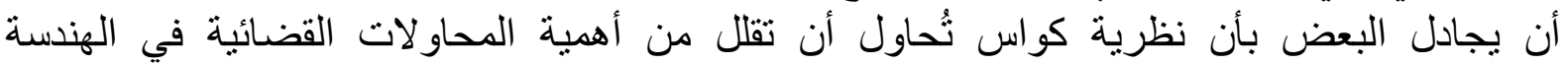
الاجتماعية، لأن الأطراف سوف تتفاوض حول نتيجة الجهود القضائية عندما يكون من مصلحتهر

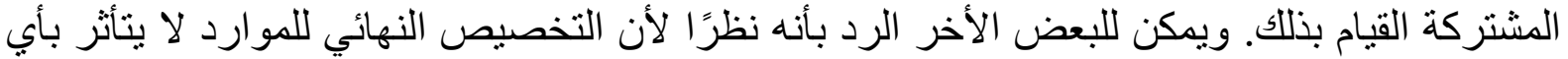

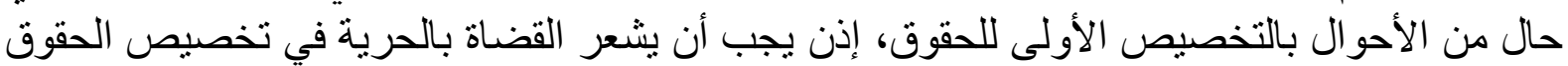

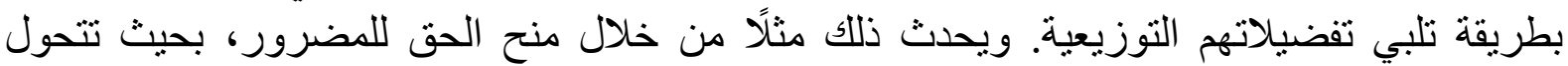
الترضيات من العامل المُتسبب في الضرر إلى المضرور وليس وليس العكس. 305

ثالثًا: أهمية نظرية كواس

من الاستتناجات الملحوظة لنظرية كواس هو أن هناك مستويات معينة من الإنتاج الفعّال التي تتحقق ببساطة عندما تتم عملية تخصيص حقوق الملكية القابلة للتبادل. ويتحقق ذلك بغض التضات النظر عن الطرف

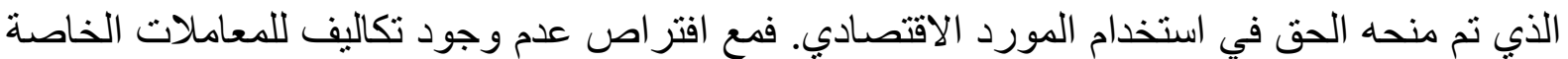

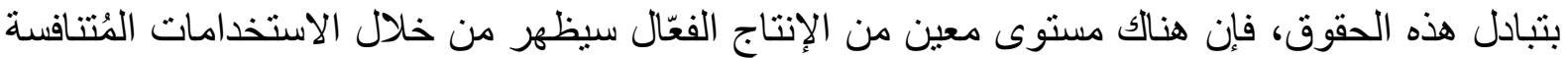

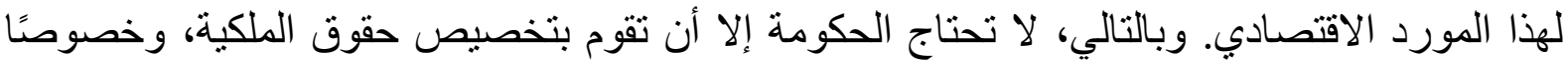

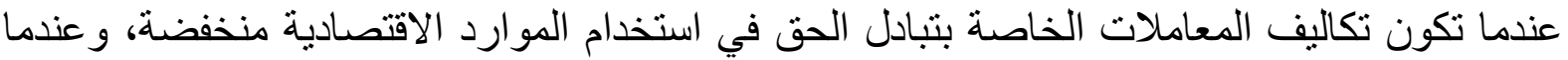
يكون عدد الأطراف المشاركة في استخدام هذه الحقوق قليل. وفي هذه الحالة، يكون التفاوض بين

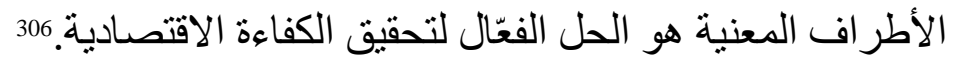

ولكن، عندما تقوم الحكومة بتخصص حقوق الملكية، فإنها بذلك تُقلم موردًا له قيمة اقتصادية للطرف

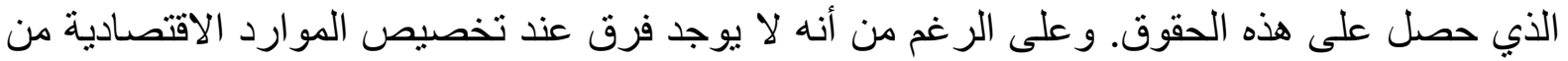

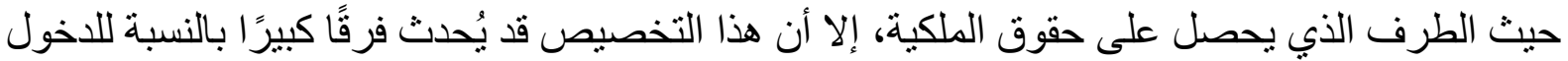

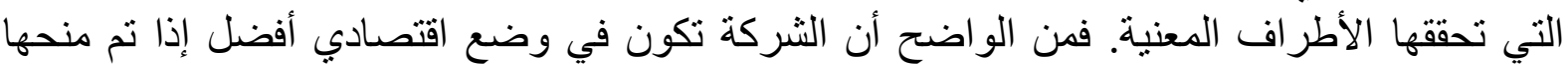
الحق في إطلاق التلوث أو انبعاثات الكربون. ولكن في هذه الحالة، يتأثر دخل الأطر اف الأخرى التي

\footnotetext{
${ }^{303}$ Coase, Ronald H., (1993). 'Law and Economics at Chicago'. Journal of Law and Economics, 36, P. 239.

${ }^{304}$ Landes, William M. and Richard A. Posner, (1983). 'Causation in tort law: an economic approach'. Journal of Legal Studies, 12, P.109.

305 Steven G. Medema, (1999). Symposium on the Coase Theorem: Legal Fiction: The Place of the Coase Theorem in Law and Economics. Economics and Philosophy, 15, P. 209.

${ }^{306}$ North, Gary, (1992.). The Coase Theorem: A Study in Economic Epistemology, Tyler, TX: Institute for Christian Economics, P.23.
} 


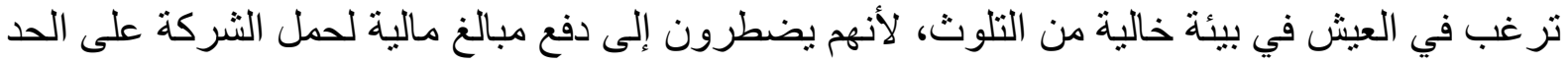

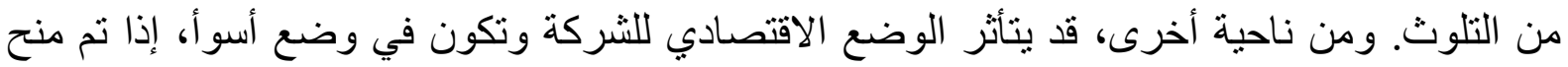

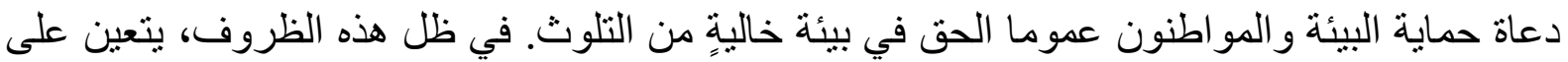

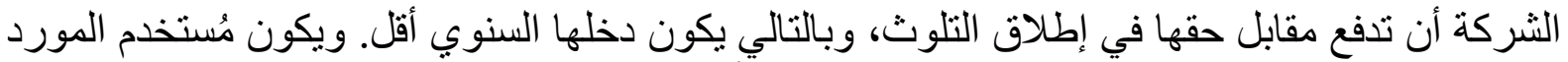

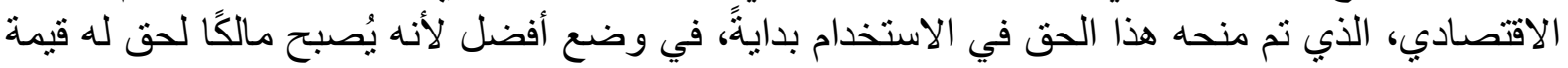

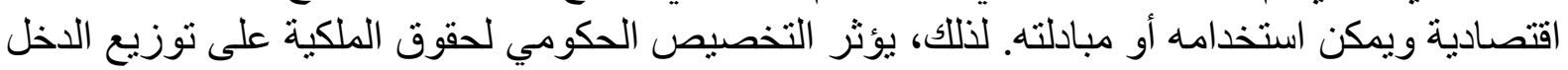
بين الأطر اف المستخدمة للموارد الاقتصادية التي تكون محلًا لهذه الحقوق.

وتثنير نظرية كواس أيضًا إلى أن الأثار الخارجية السلبية هي في الحقيقة نزاعات تتعلق بحقوق استخدام

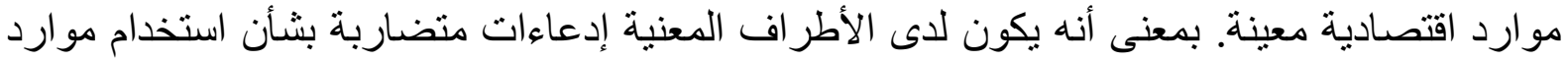

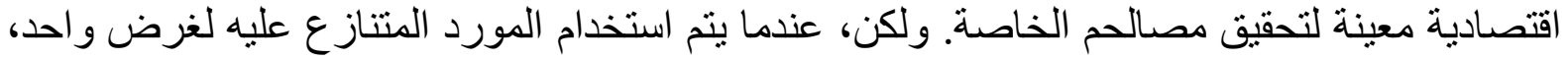

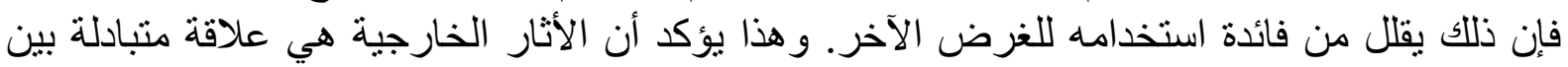

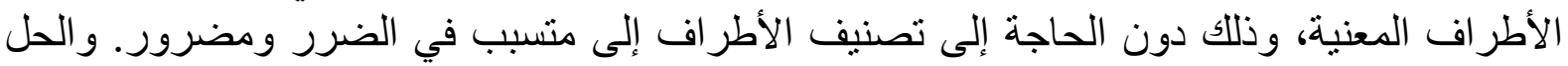

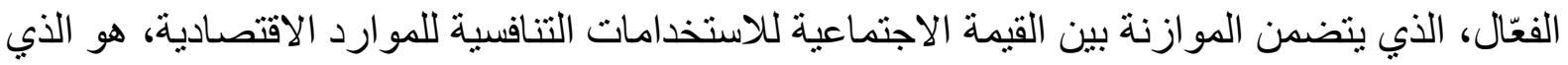
يحقق التوازن بين صافي القيمة الاجتماعية لكلا الاستخدامين.

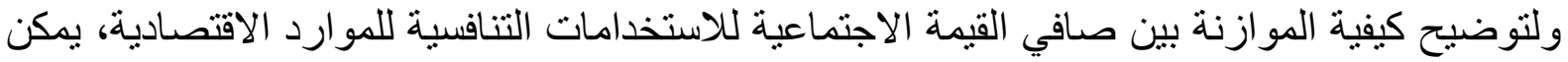

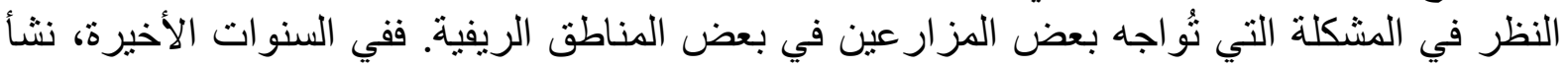

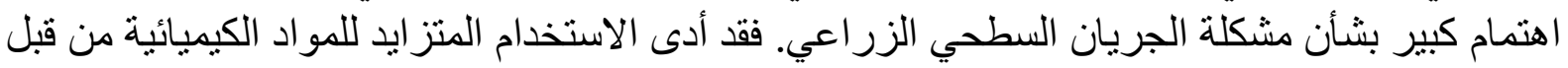

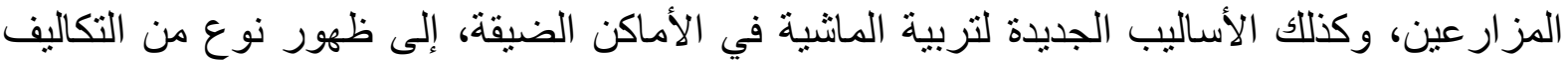

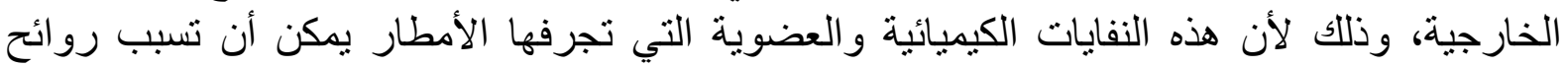

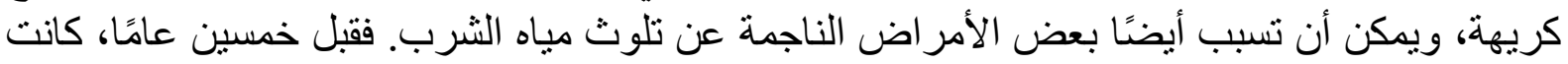

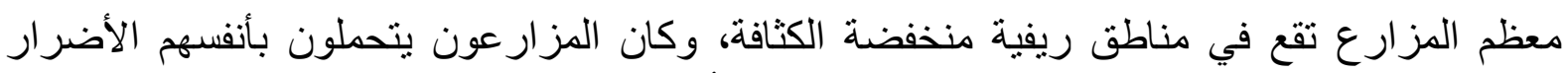

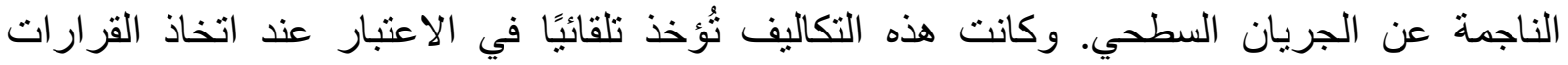

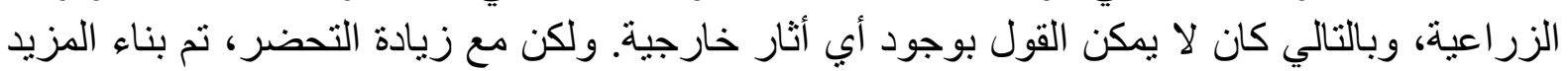

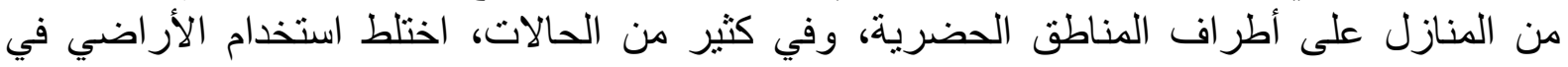

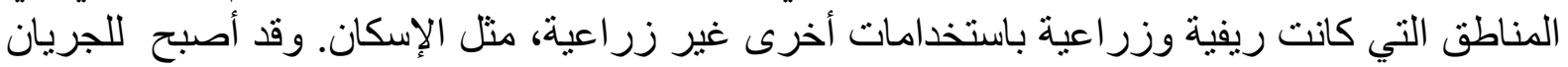

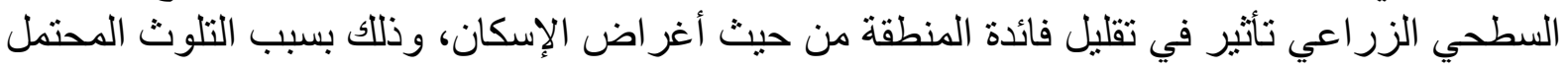
للآبار وبسبب عدم الراحة الناجمة عن انتشار الروائح الكنائحة الكريهة. 307

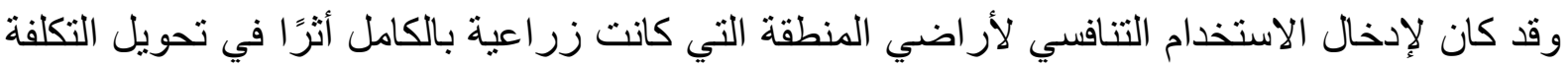

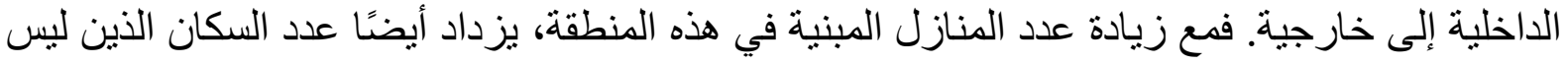

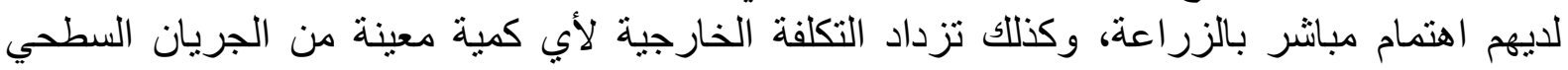

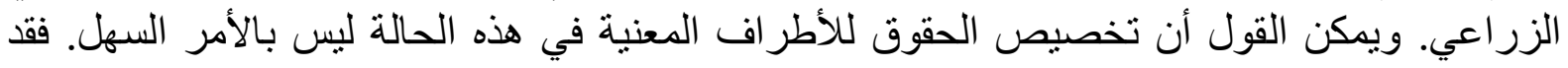

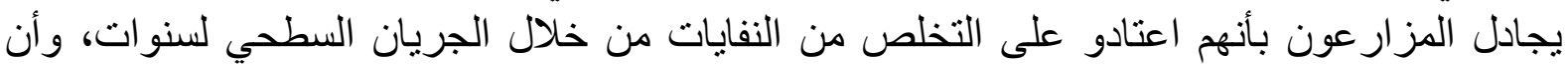

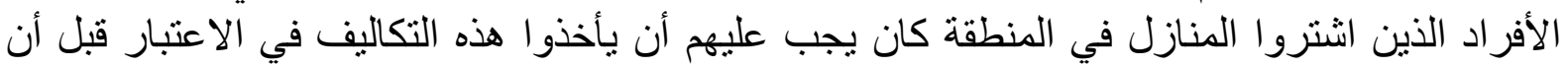

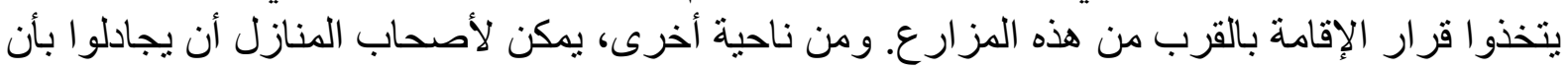

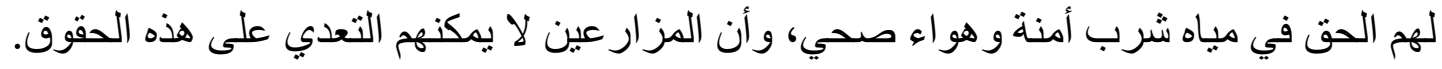

${ }^{307}$ Schweizer, Urs., (1988). “Externalities and the Coase Theorem: Hypothesis or Result?” Journal of Institutional and Theoretical Economics 144 (2), P. 245. 


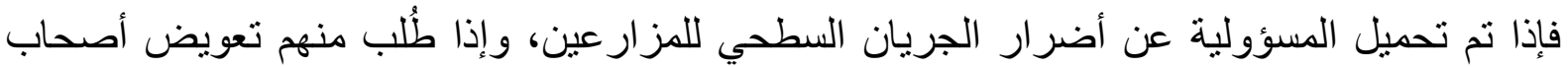

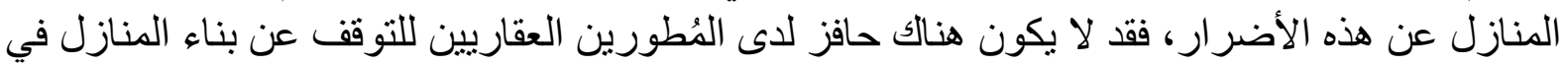

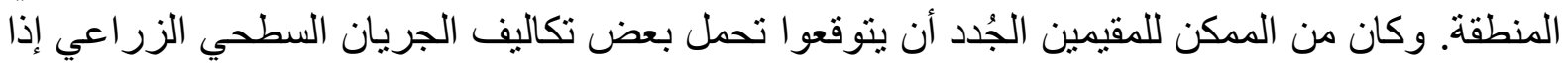

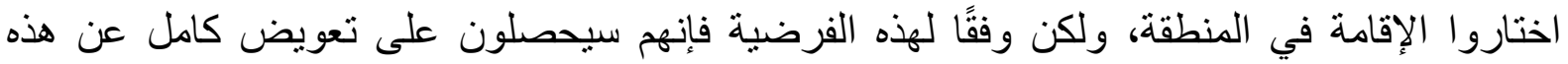

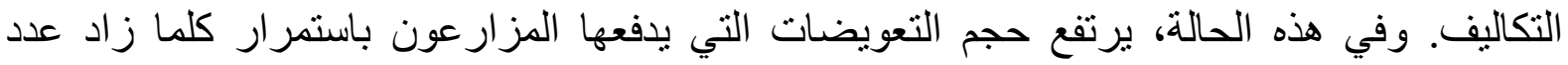

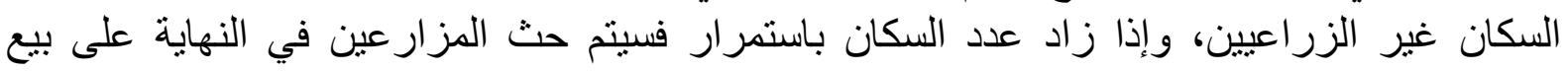

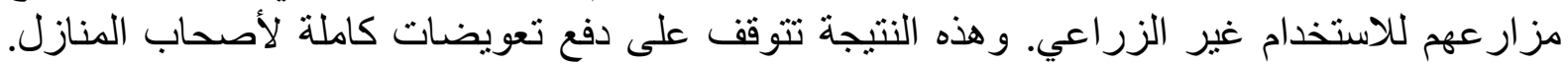

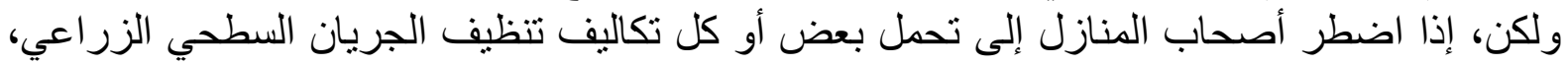

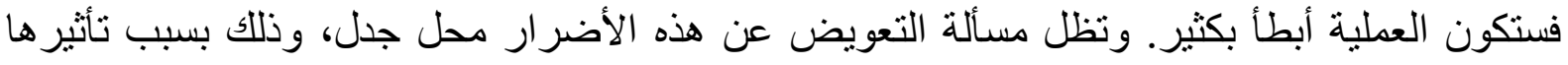

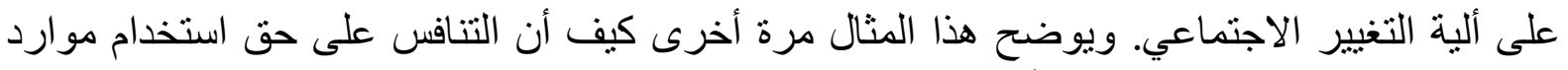

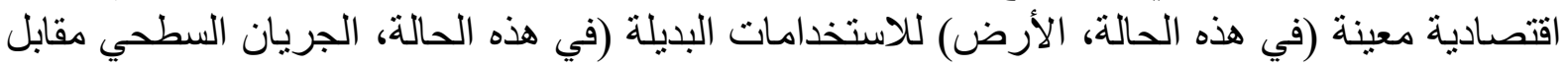

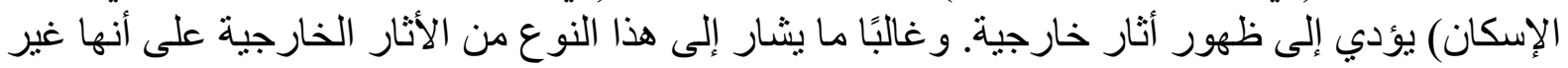

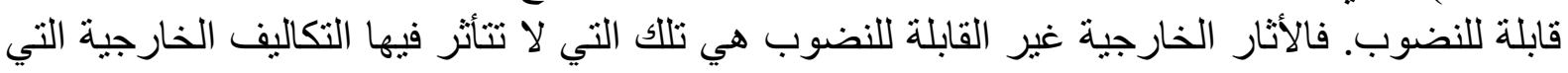

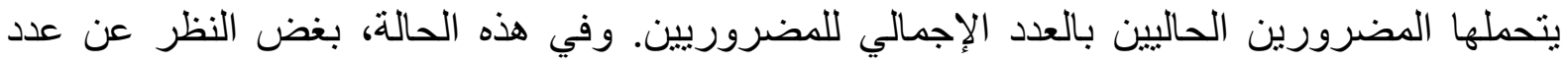

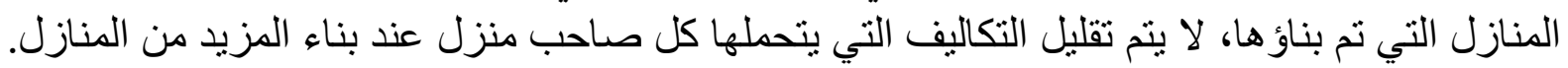

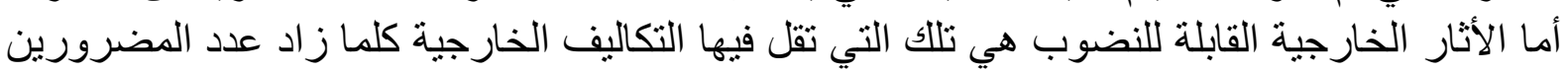

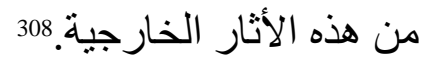

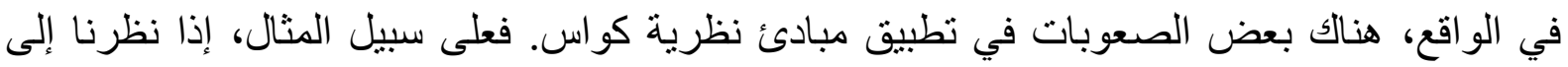

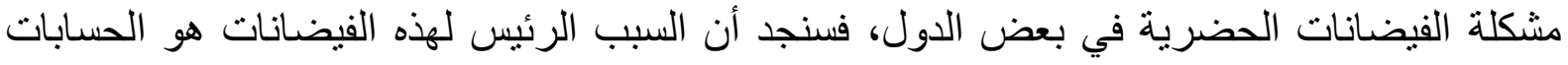

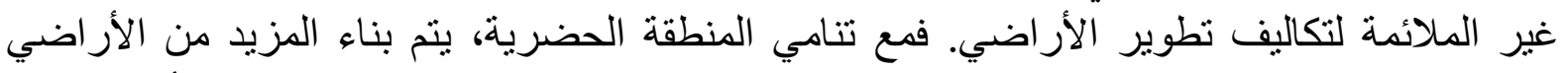

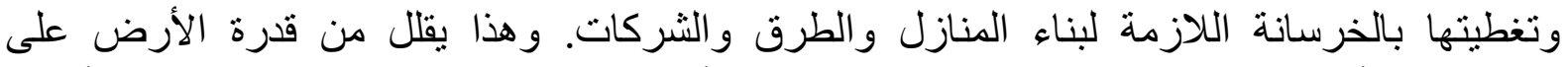

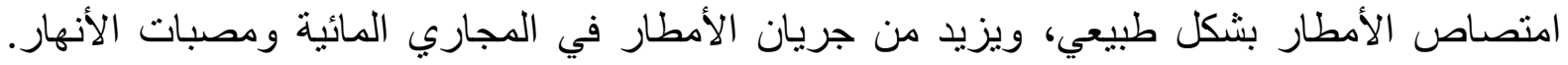

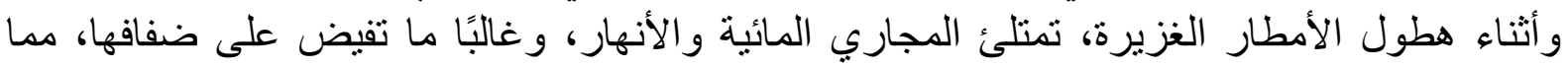

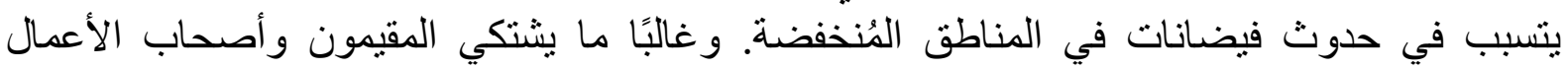

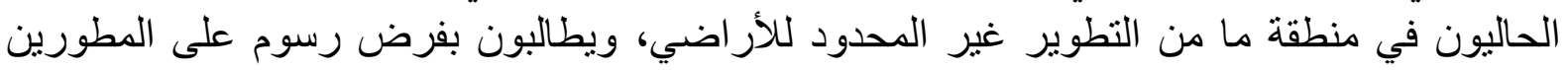

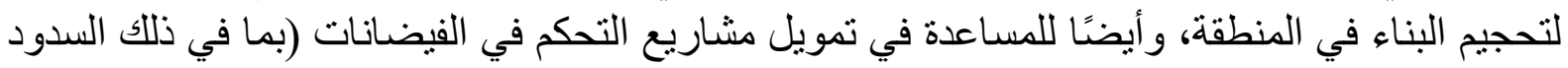

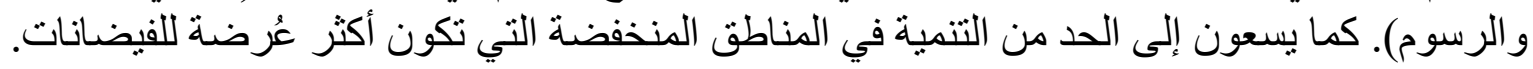

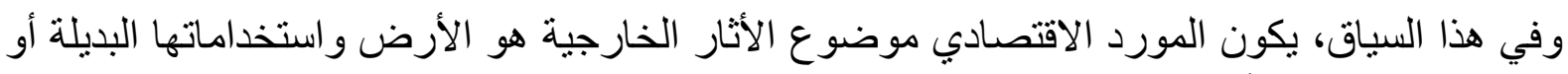

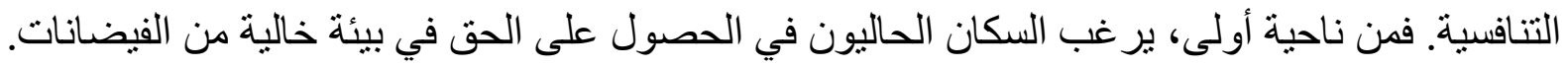

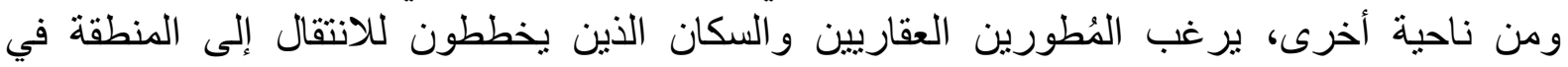

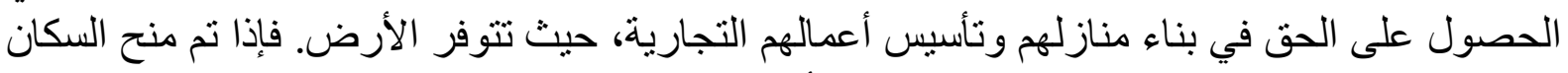

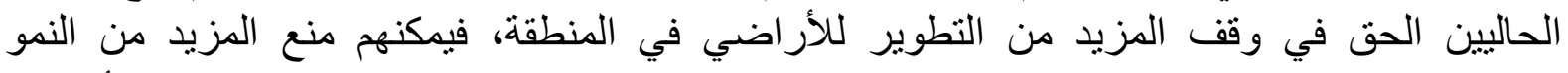

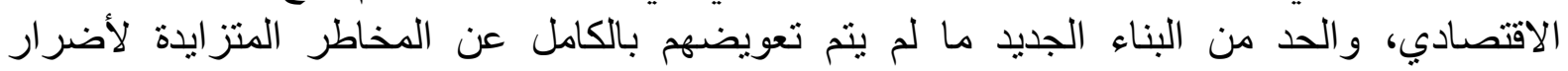

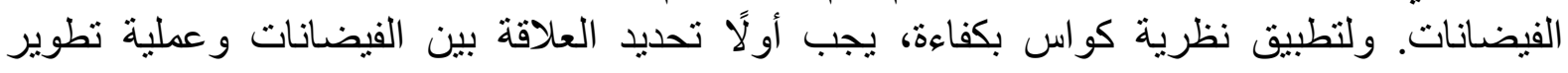

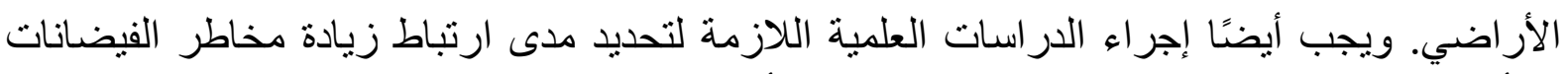
والأضرار الناجمة عنها بتطوير كل فدان إضافي للأراضي في هذه المنطقة، ويجب النيب كذللك تحديد مقدار

${ }^{308}$ Veljanovski, Cento G., (1982). "The Coase Theorems and the Economic Theory of Markets and Law." Kyklos 35 (1), P. 53. 
المخاطر المتعلقة بالعمليات الطبيعية الأخرى بخلاف تطوير الأراضي. بالإضافة إلى ذللك، إذا كان العديد

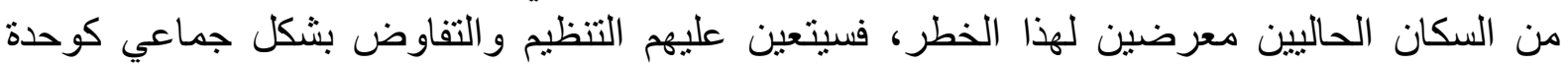

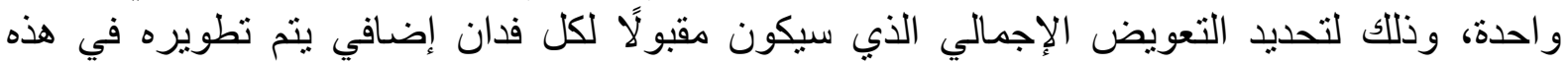

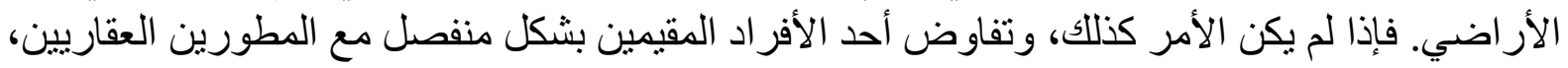

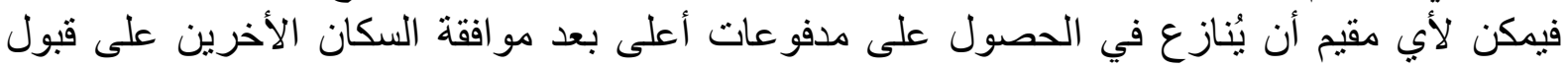

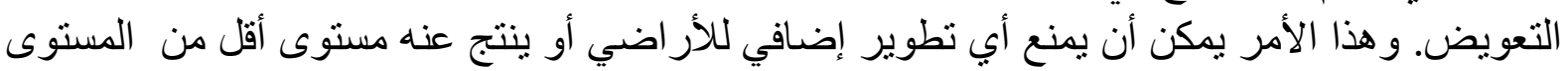
الفعّال لتطوير الأر اضي.

وبالمثل، إذا شارك العديد من المُطورين في عملية التطوير، وكان لهم حقوق غير محدودة لتطوير

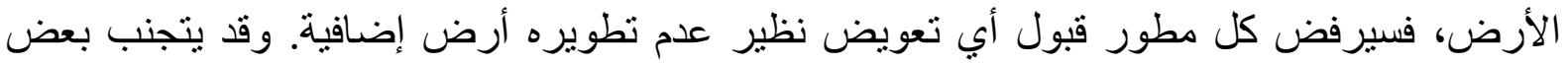

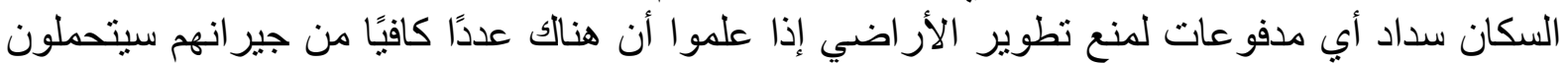

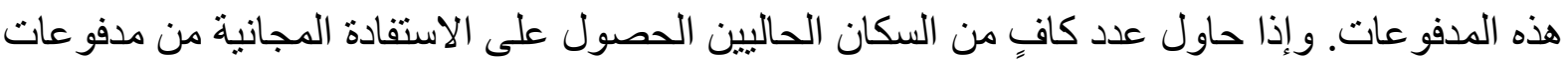

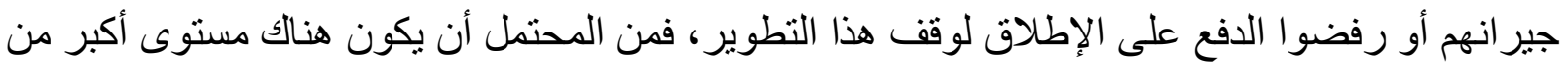

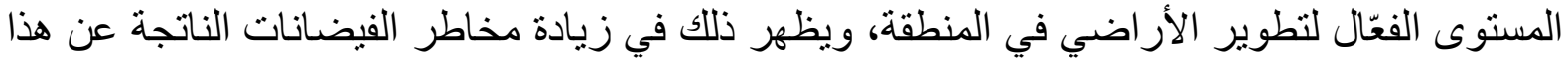
التطوير.

أخيرًا، قد تكون تكاليف المعاملات اللازمة للتفاوض على اتفاق معين مرتفعة جدًا، وذللك عندما يشتمل هذا الاتفاق على العديد من المقيمين والمطورين الحاليين. وقد تُحاول الأطر اف المعنية أيضيًا التخطيط لتقليل التكاليف اللازمة لتحقيق النتائج التي ير غبون فيها. بالنظر إلى أوجه عدم اليقين المتعلقة بالتكاليف

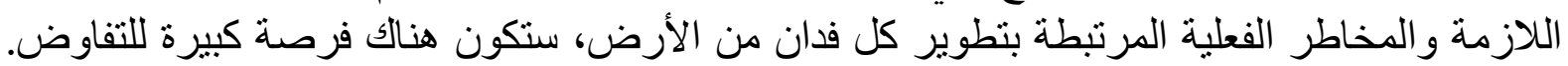

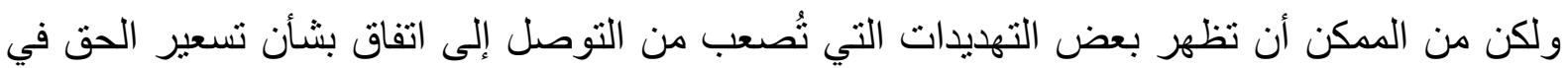

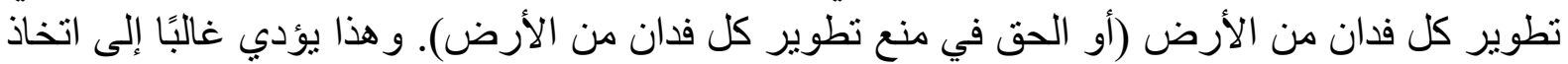
إجر اءات سياسية لفرض الرسوم أو اللوائح الحكومية و التي تحد من من التنمية.

\section{ثالثًا: أهم الاختلافات والتشابه بين نظرية كواس وبيجو}

في هذا السياق يمكن تسليط الضوء على ثلاثة ملامح أساسية لتحليل الأثار الخارجية الاقتصادية. نوضح من خلالها أهم الاختلافات المهمة بين نظرية بيجو ونظرية كواس، وكذلك الملامح المشتركة بين كلا

النظريتين.

أولًا، يُظهر تحليل كواس الطبيعة التبادلية للعلاقة بين كلًا من الطرف الذي تسبب في الأثار الخارجية وبين الطرف الذي تعرض لها. وفي هذا الصدد، يختلف هذا التحليل بشكل جذري عن تحليل نظرية

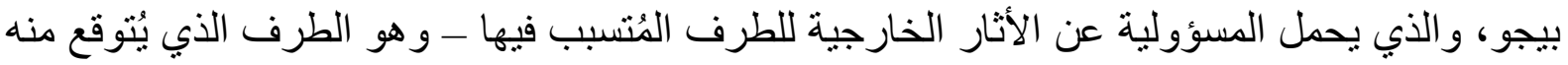

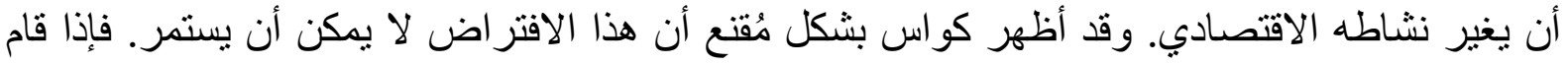

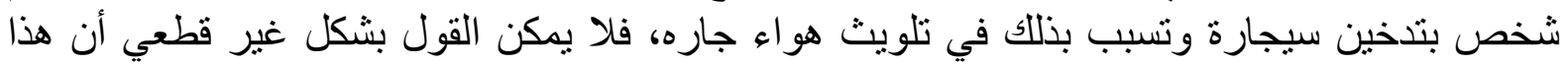

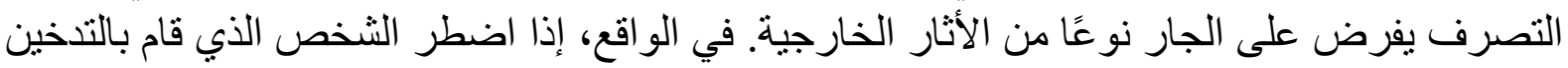

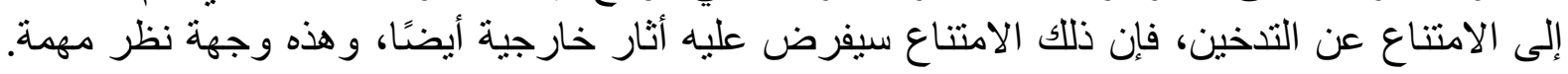

${ }^{309}$ Farrell, Joseph., (1987). "Information and the Coase Theorem." Journal of Economic Perspectives $1(2)$, P. 113.

${ }^{310}$ Dahlman, Carl J., (April 1979). "The Problem of Externality." Journal of Law and Economics 22, P. 145. 


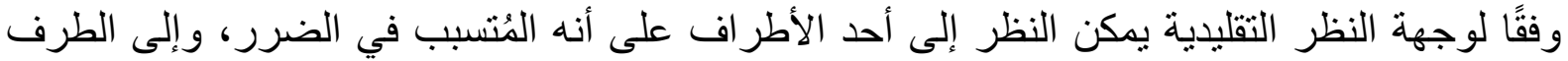

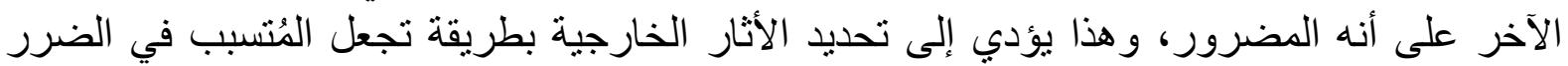

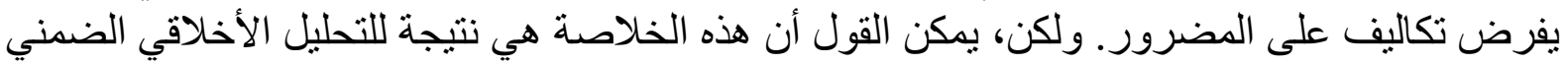

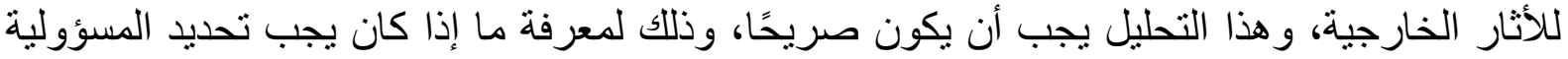

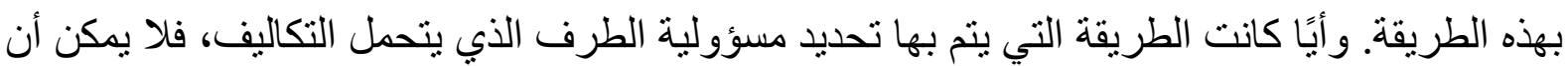

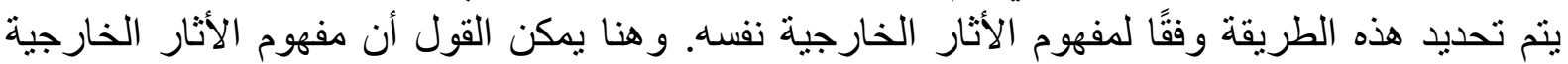

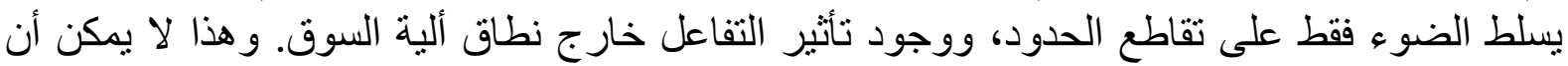

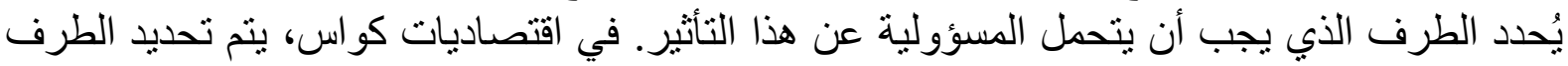
المسؤول من خلال تخصيص حقوق الملكية للطرف الذي يُقِّرّ ها أكثر ، و هذا في حد ذاته معيار معياري.

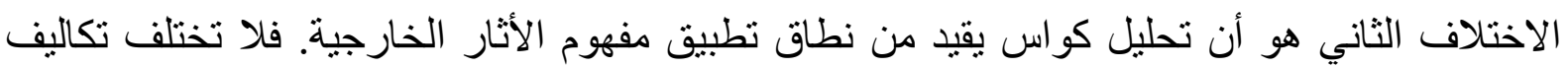

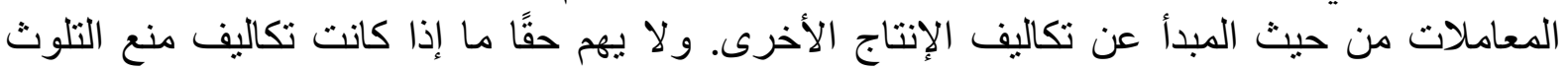

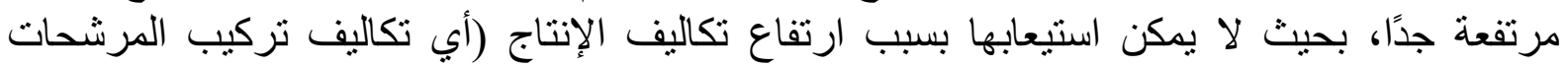

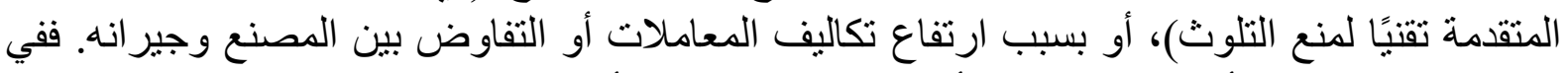

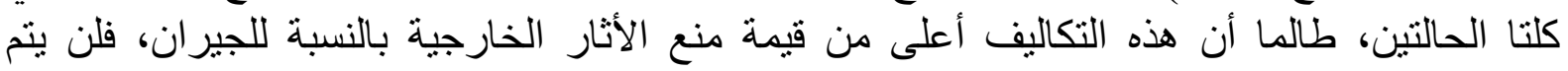

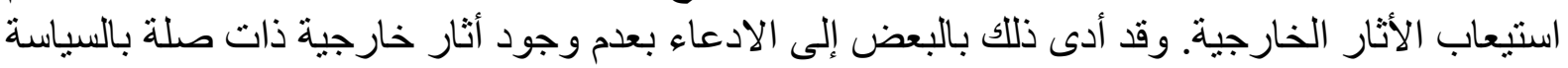

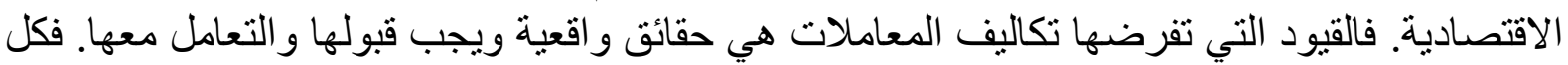

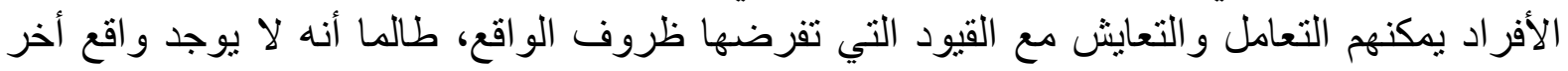

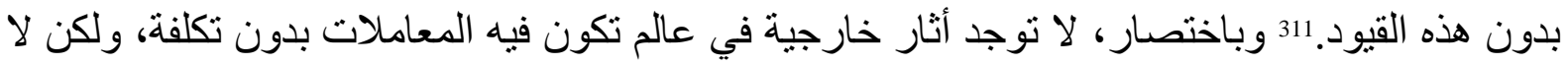

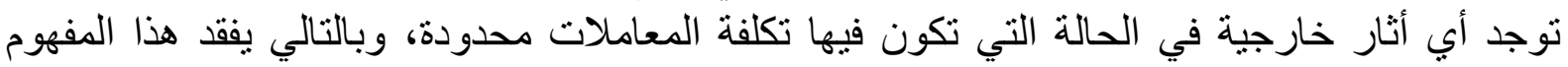
و اقعيته.

ولكن، قد يكون هذا الاستنتاج غير نهائي، لأنه ينظر إلى تكاليف المعاملات الحالية على أنها ثابتة ولا لالا

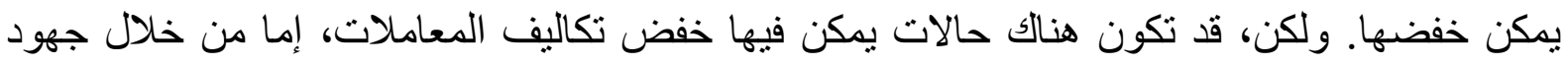

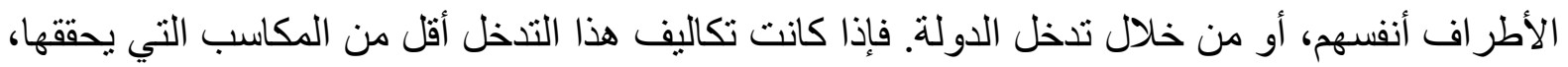

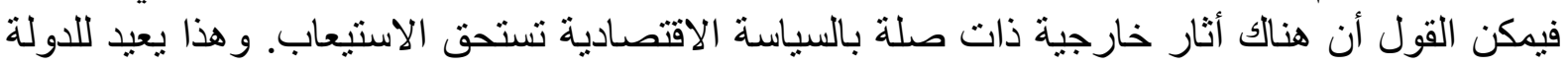

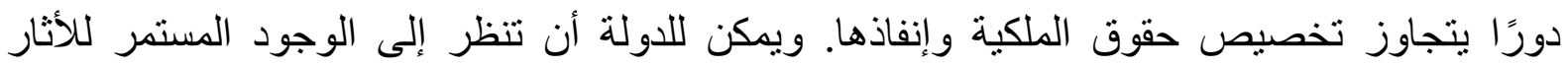

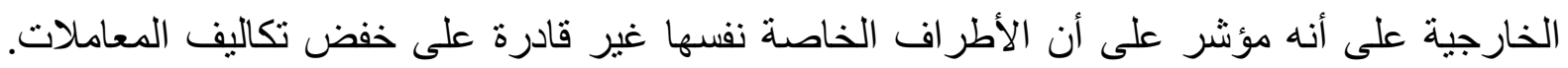

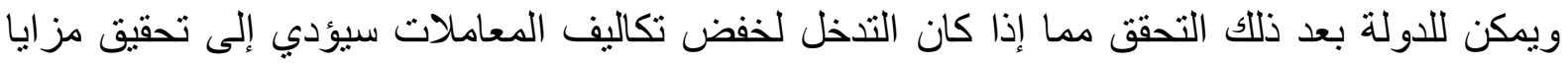

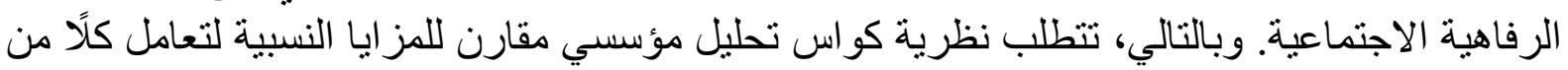

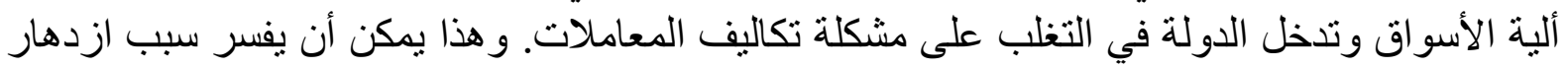

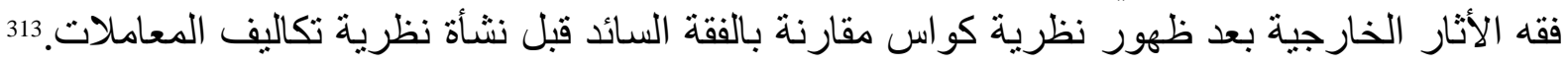

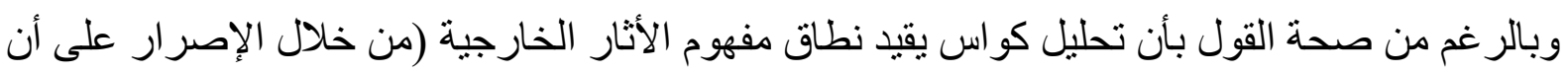

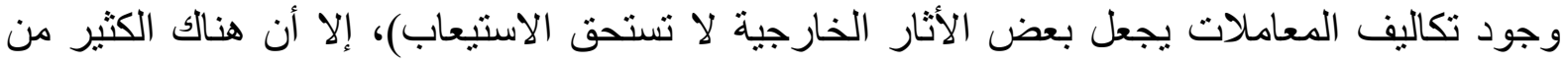

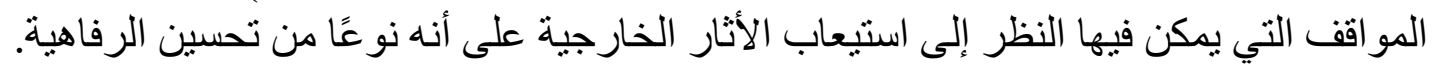

${ }^{311}$ Dahlman, C., (1979). 'The Problem of Externality', The Journal of Law and Economics, 22(1), P. 146.

${ }^{312}$ Lagueux, M., (2010). 'The Residual Character of Externalities', European Journal of the History of Economic Thought, 17(4), P. 957.

313 Demsetz, H., (1996). 'The Core Disagreement between Pigou, the Profession, and Coase in the Analysis of Externalities', European Journal of Political Economy, 12(4), PP. 565-579. 


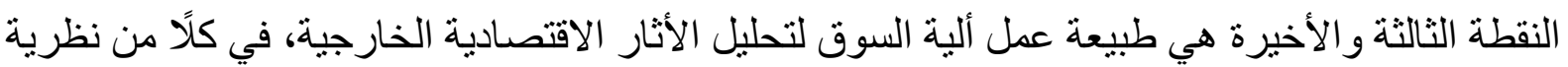

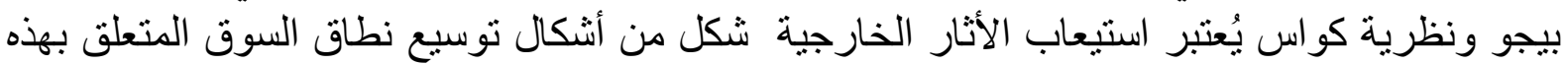

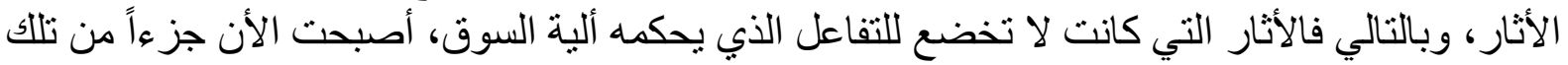

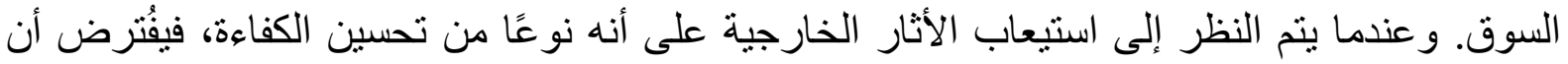

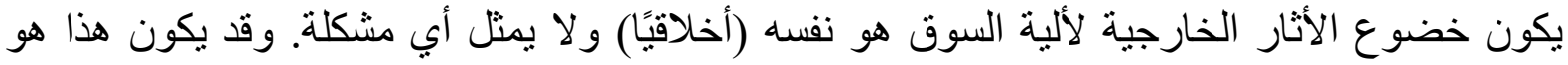

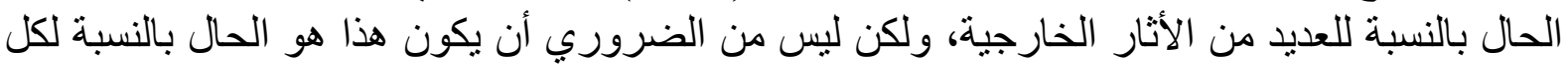

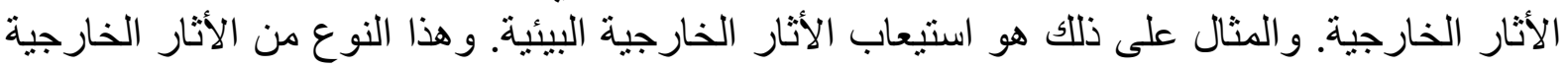

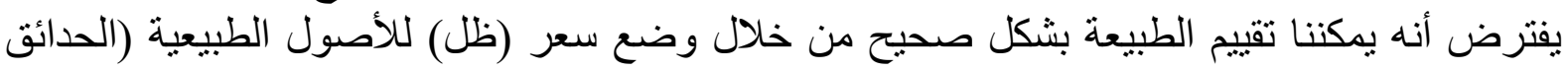

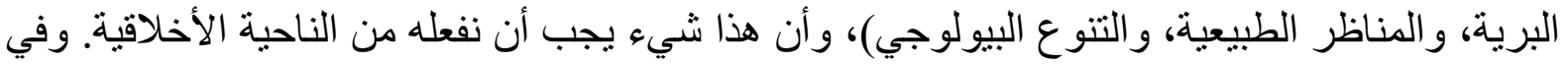

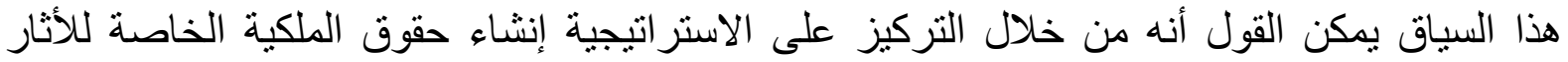

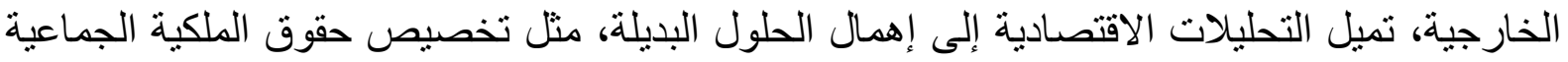

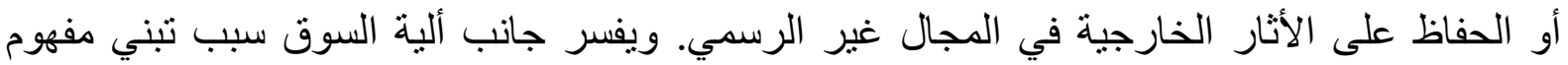

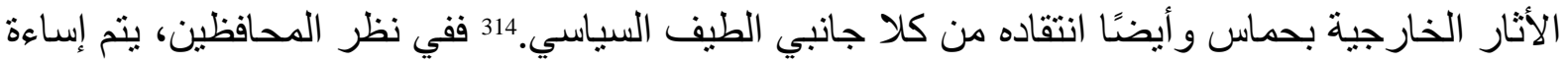

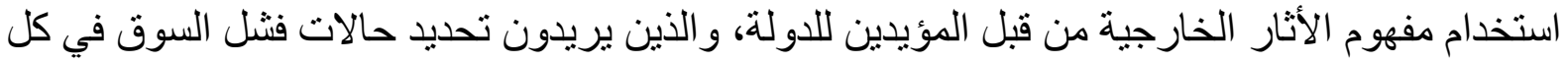

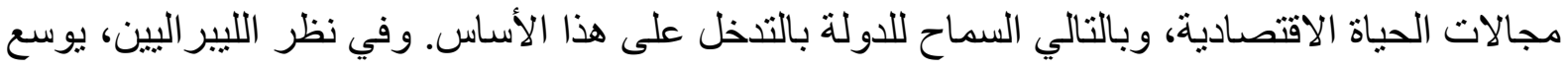

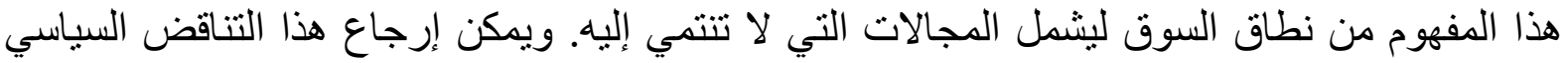

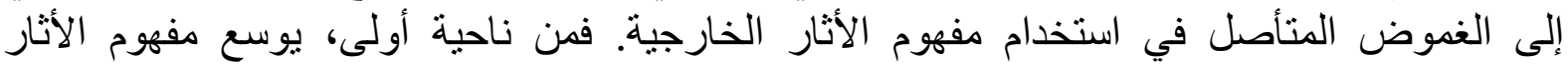

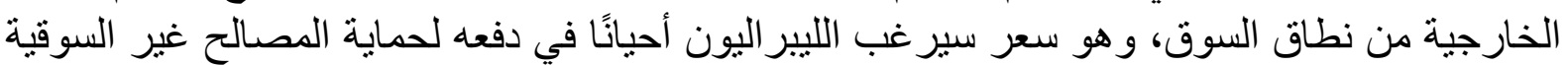

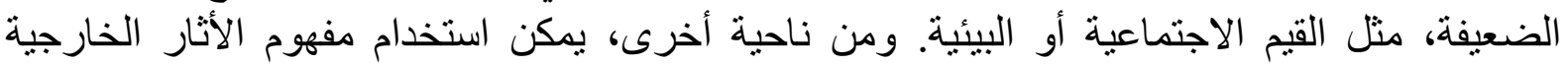

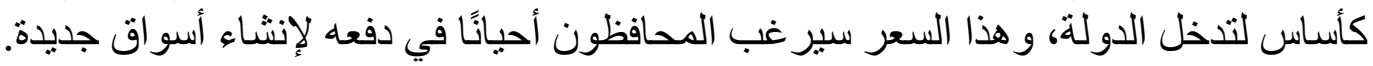

\section{المبحث الثاني: نظرية التوقعات للأثار الخارجية}

فيما يتعلق بطبيعة الأثار الخارجية، يقدم بعض الاقتصاديين نظرية توضح مفهومًا مختلفًا للأثنار

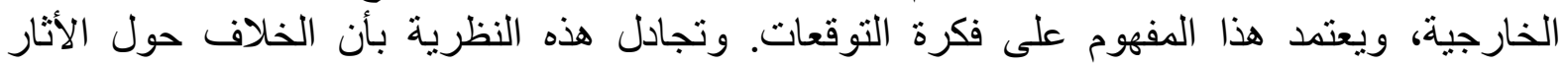

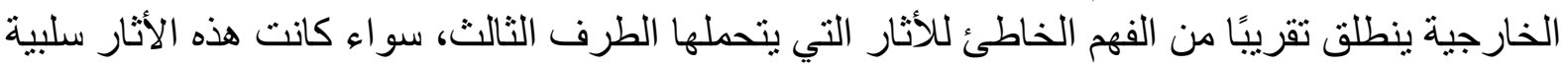

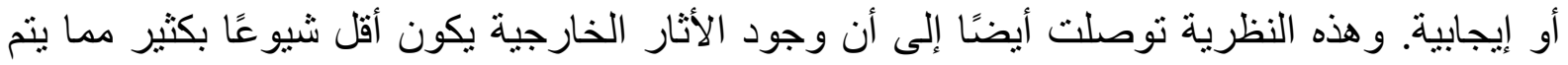

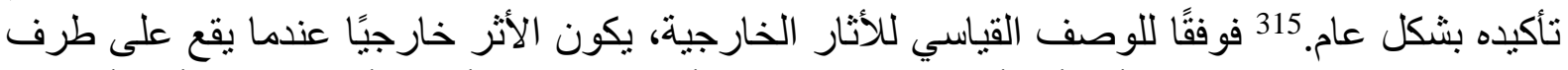

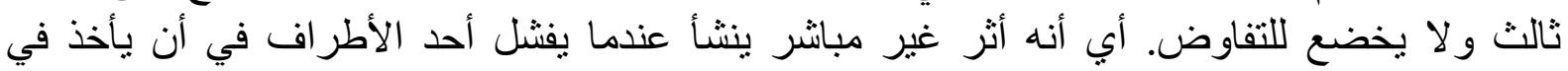
الاعتبار التكلفة التي يتحملها أو الفائدة يحصل علئر أليها طرف ثنالث نتيجة هذا الفعل.

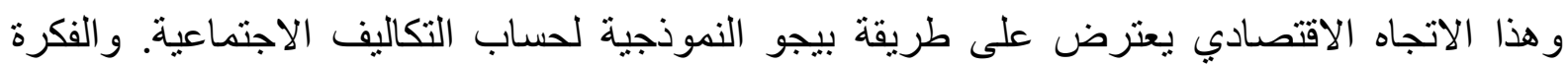

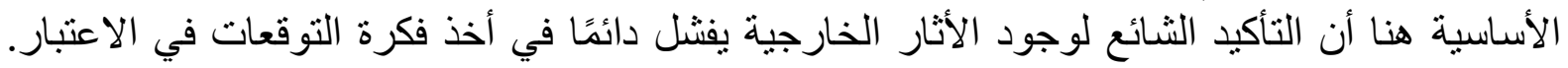

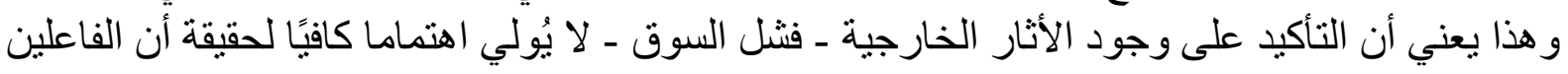

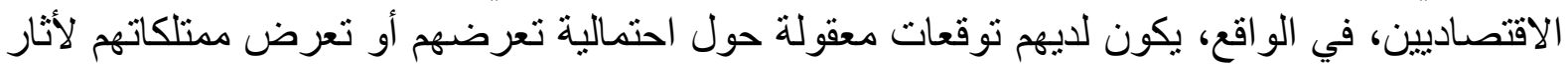

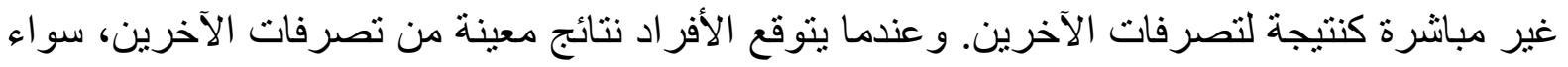

314 Arnold, N. S., (2009). Imposing Values. An Essay on Liberalism and Regulation, Oxford: Oxford University Press, PP. 28-36.

315 Donald J. Boundreaux \& Roger Meiners, (2019). Externality: Origins and Classifications, 59 Nat. Resources J. 1, P.22. 


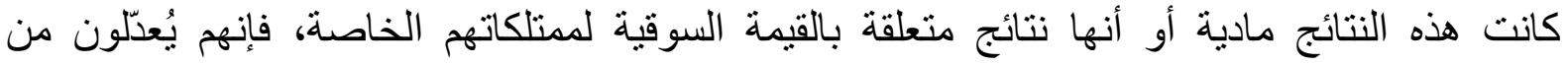

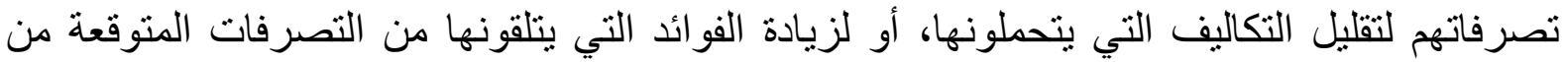

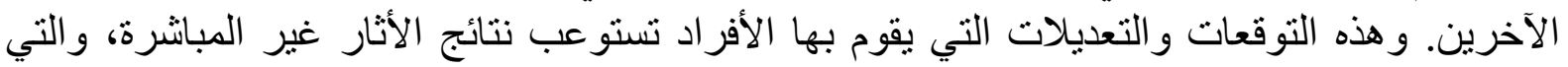

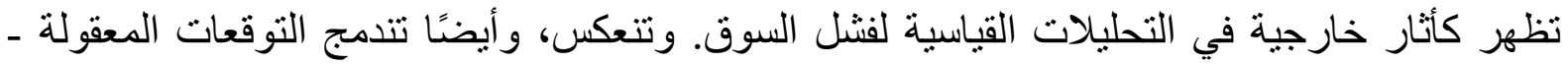

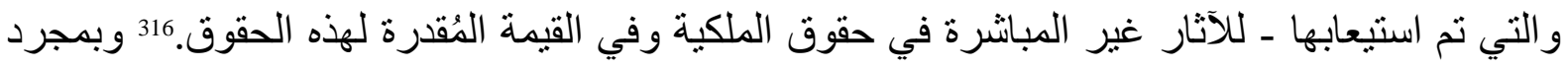

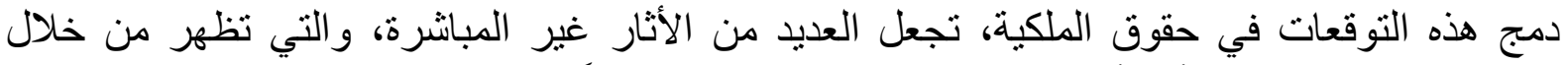

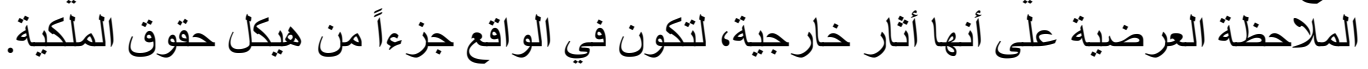

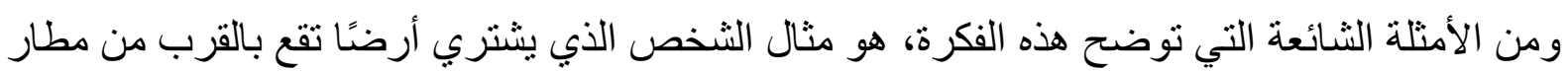

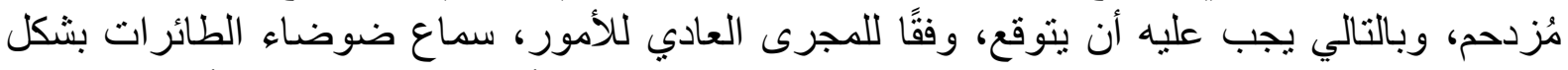

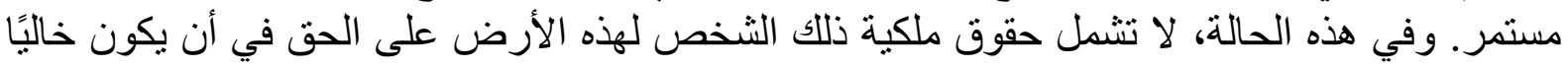

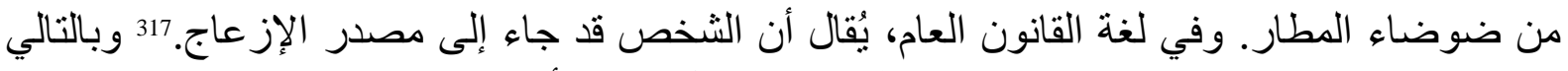

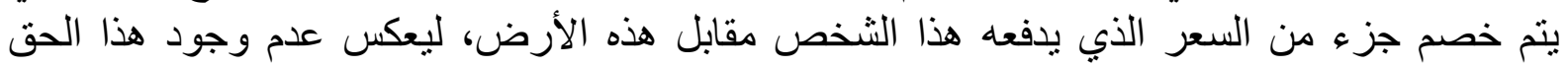

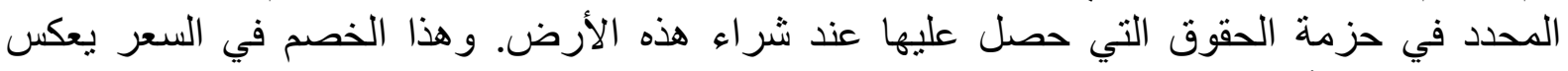

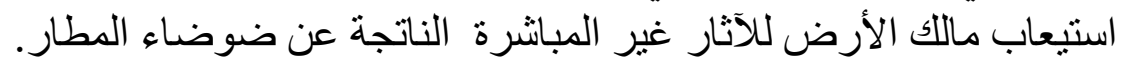

أولًا: تصنيف الأثار الخارجية وفقًا لنظرية التوقعات

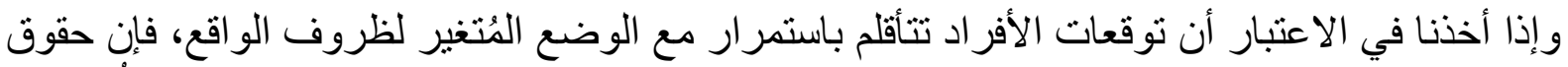

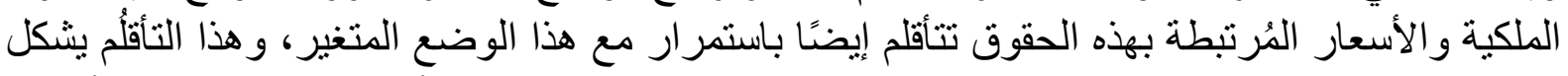

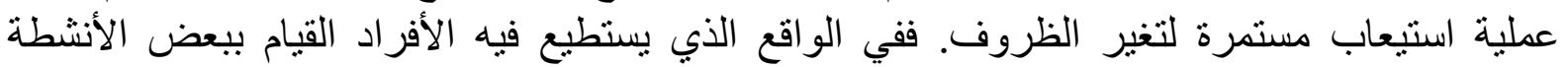

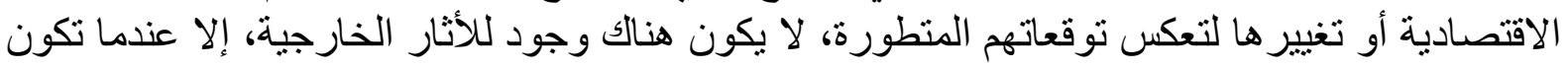

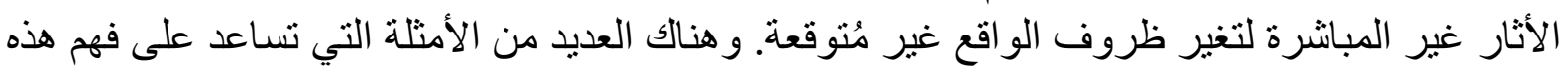
الفكرة.318

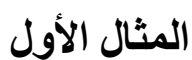

نفترض أن شخص يُدعى (زيد) يمتلك قطعة أرض معينة، و عرض عليه شخص أخر يدعى (جون) مبلغ

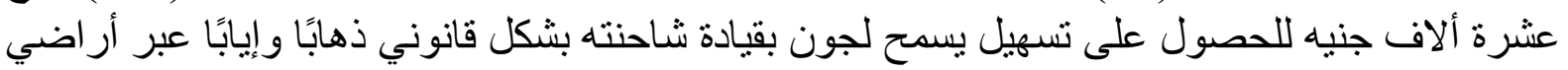

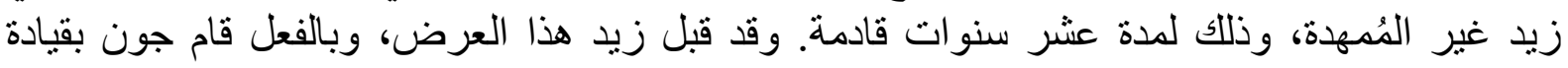

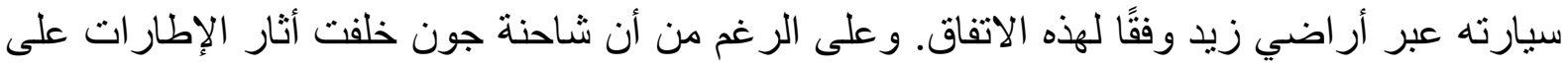
أرض زيد، وهو أمر غير مقبول بالنسبة لزيد، إلا أنه بمكن القول أرفا أنه لا توجد أنثار خارجية وفقًا لهذا الاتفاق.

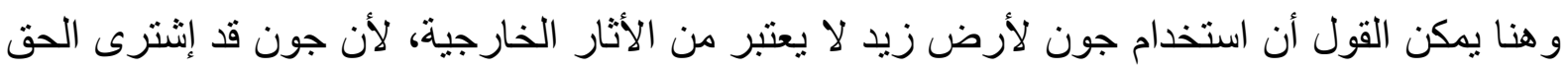
في المرور بشاحنته عبر أر اضي زيد. وبالر غم من أن هذا التبرير هو الصني الصحيح و المنطقي، إلا أنه لا يعبر

316 M. Rahmatian \& L. Cockerill, (2004). Airport Noise and Residential Housing Valuation in Southern California: A Hedonic Pricing Approach, International Journal of Environmental Science \& Technology, Vol. 1, No. 1, pp. 17- 25.

317 Roy E. Cordato, (1998). Time Passage and the Economics of Coming to the Nuisance: Reassessing the Coasean Perspective, 20 Campbell L. REV., P. 273.

318 Carl Dahlman, (1979).The Problem of Externality, Journal of Law and Economics, Vol. 22, No. 1, pp. 141-162 


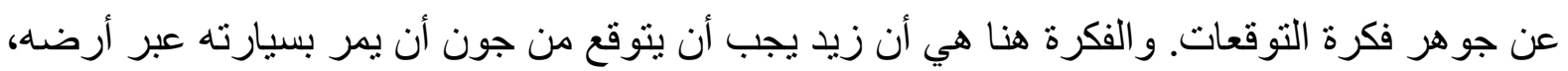

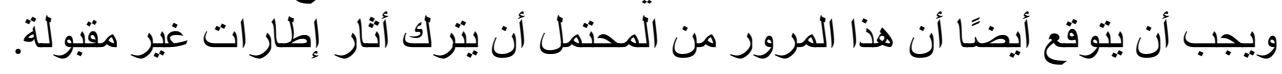

فقي اللحظة التي باع فيها زيد حق الارتفاق لجون، توقع زيد أن جون سيمر بسيارته من خلال أرضها،

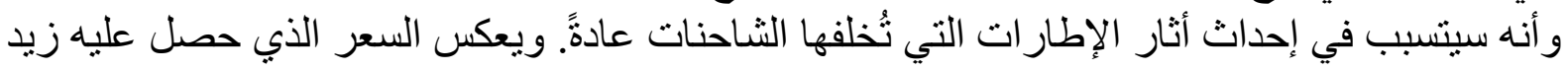

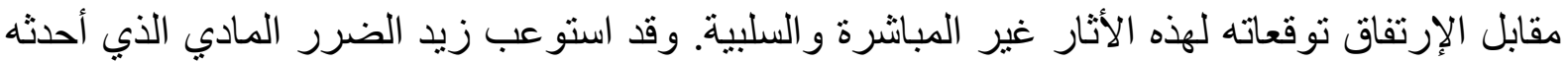

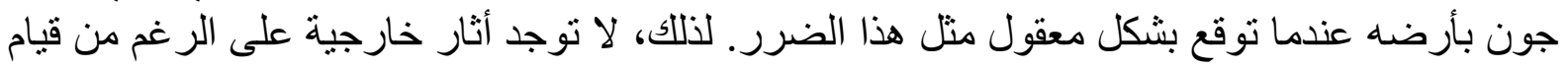
شخص واحد (جون) بإلحاق أضر ار مادية بممتلكات شخص من آخر آخر (زيد).

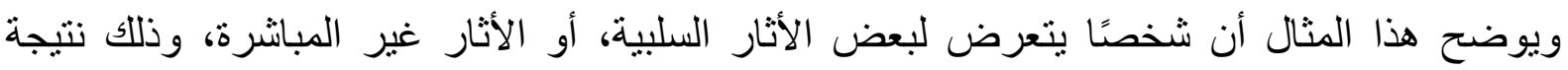

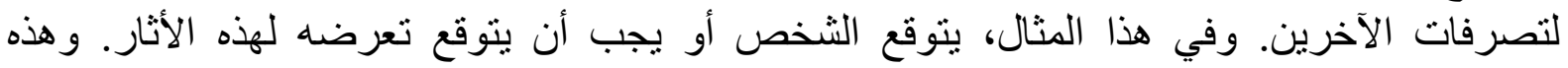

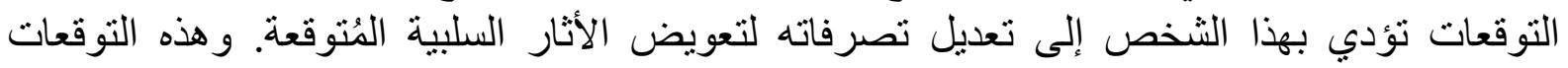

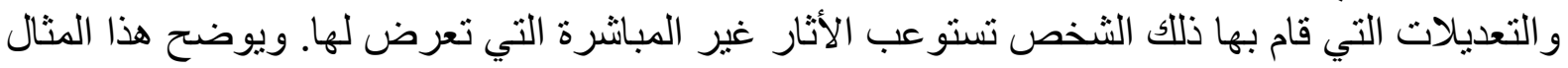

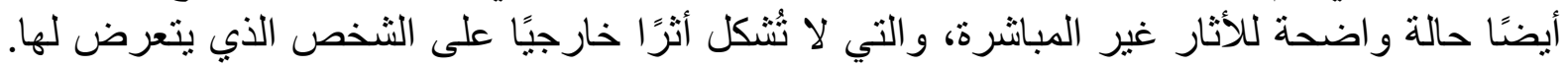

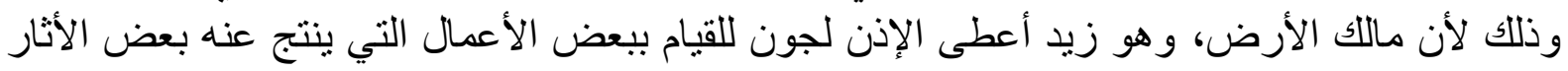

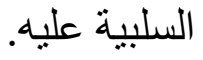

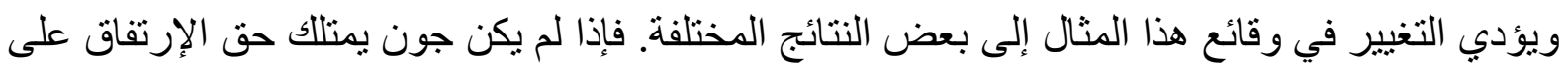

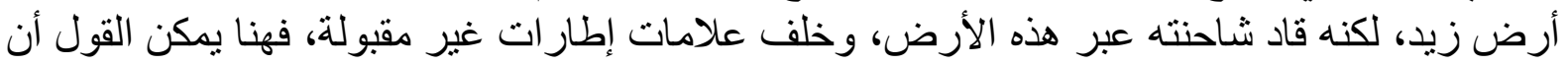

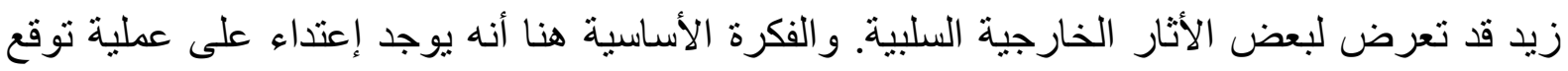

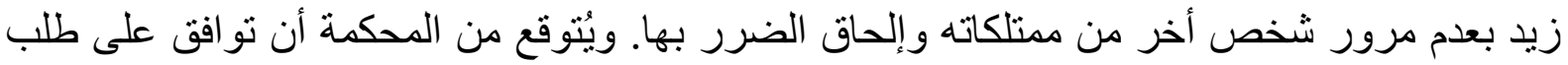

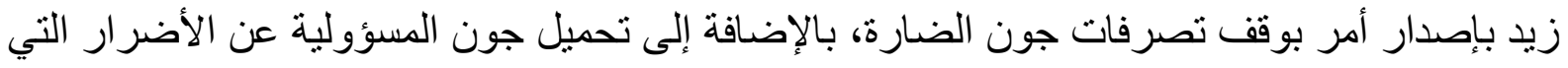

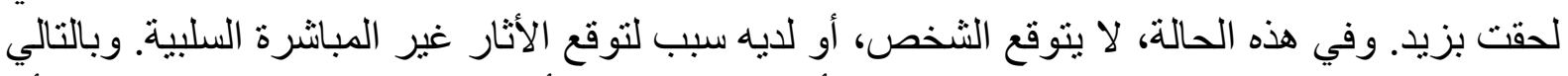

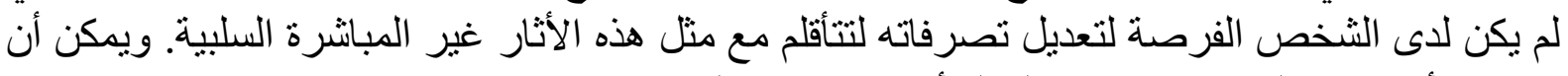
تسمى الأثار غير المباثرة في هذه الحالة أثنار خارجية سلبية.

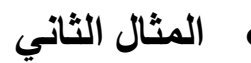

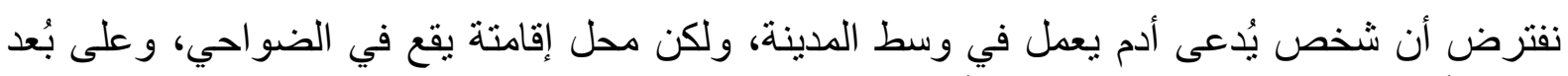

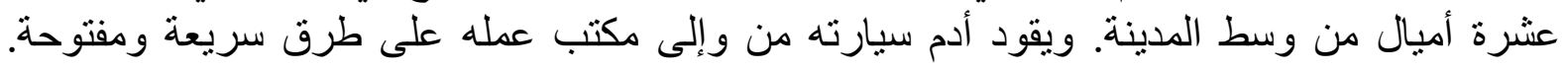

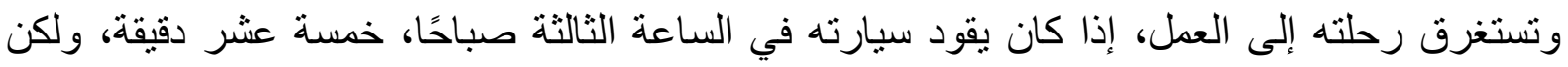

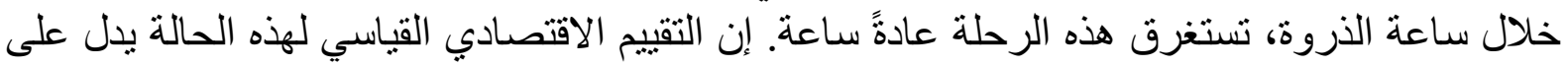

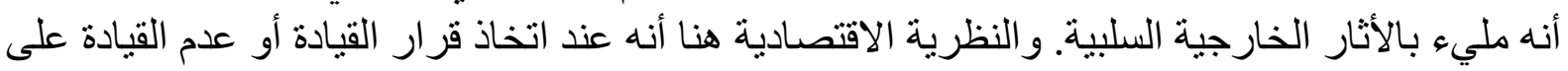

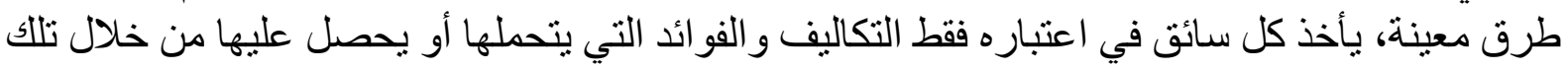

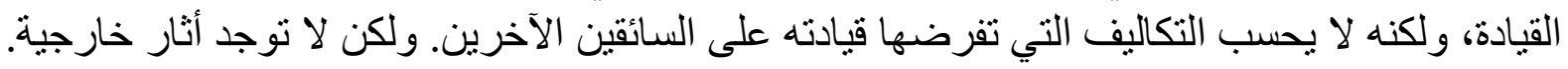

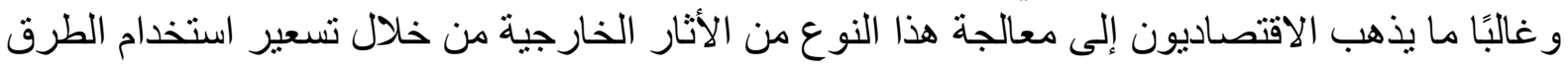

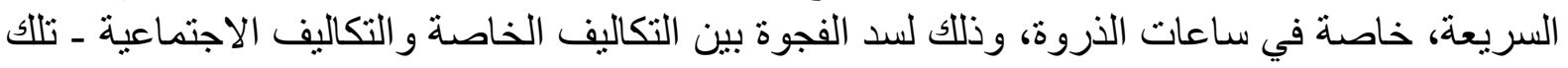


التي يفرضها السائق على السائقين الآخرين. ومن الواضح هنا صحة التأكيد على أن رفع تكاليف القيادة سيؤدي إلى تقليل القيادة.

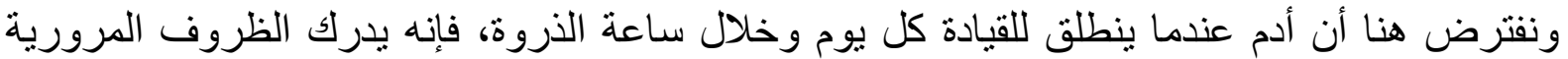

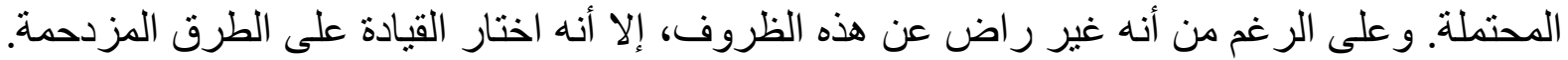

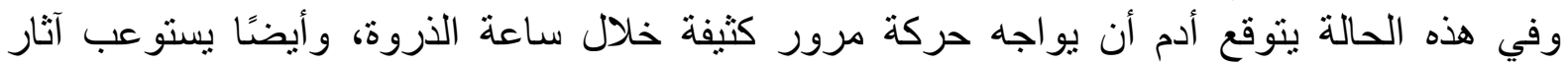

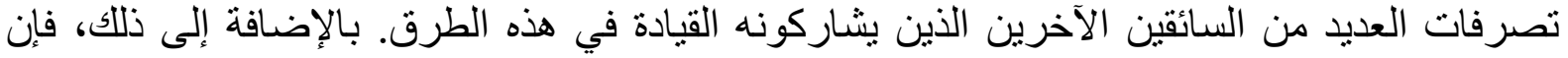

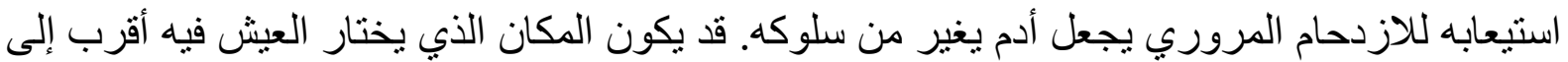

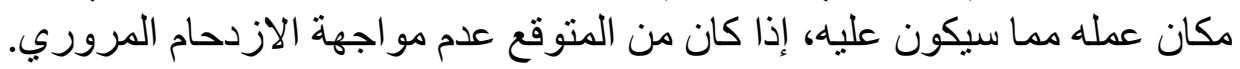

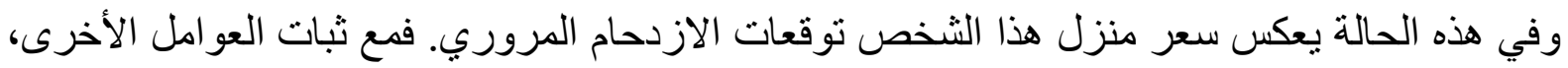

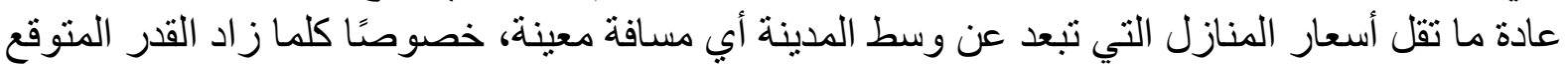

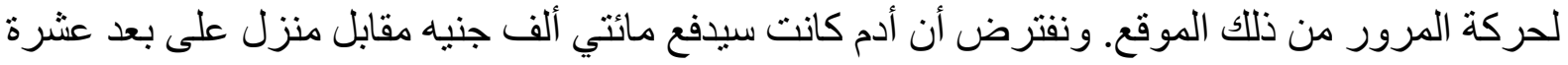

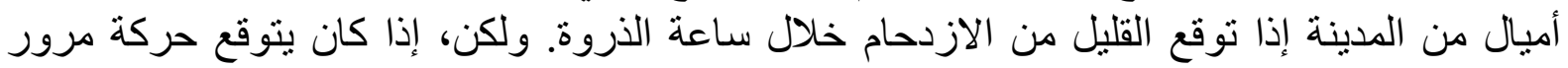

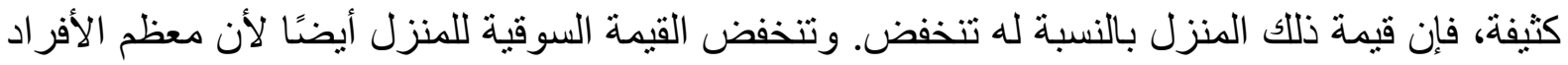

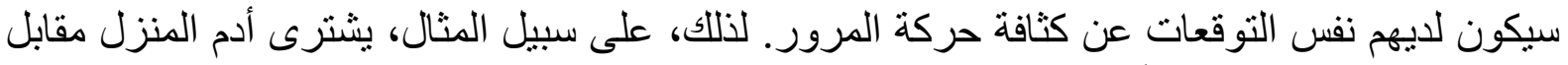

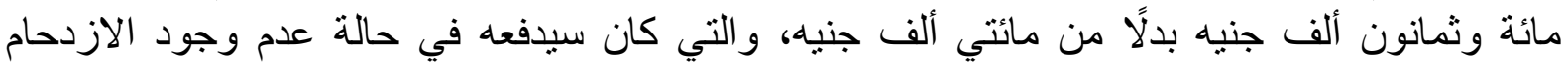

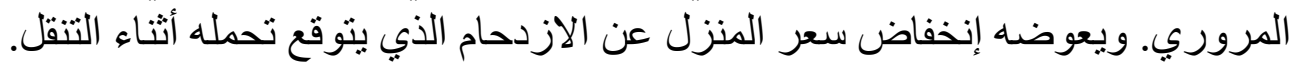

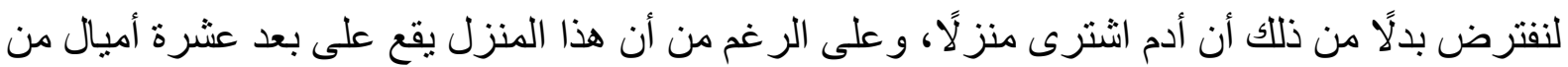

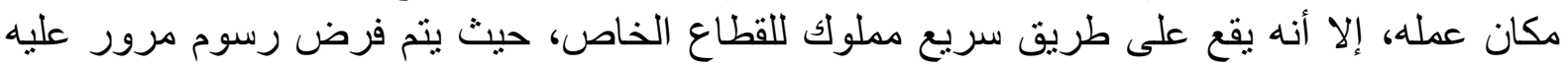

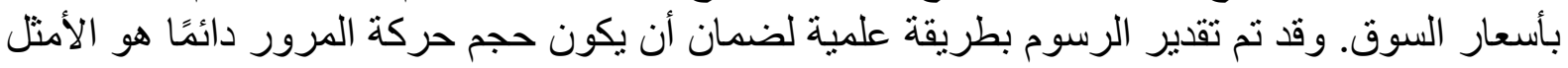

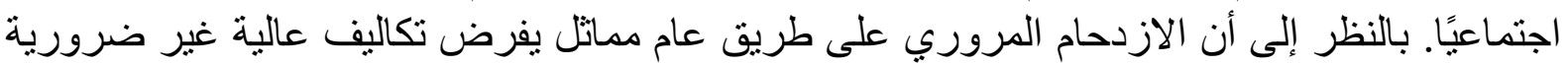

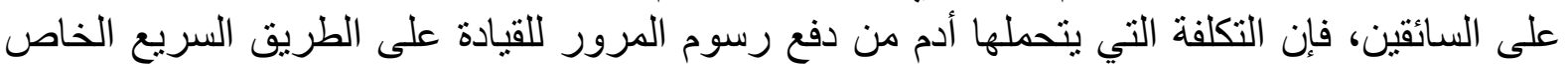

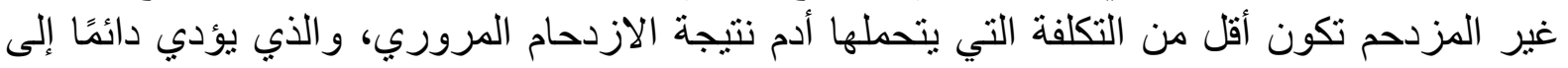

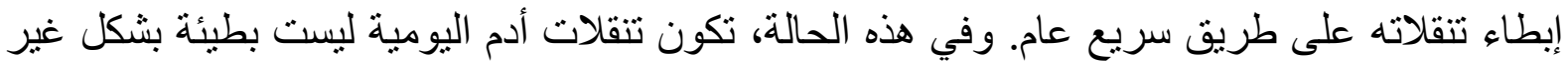

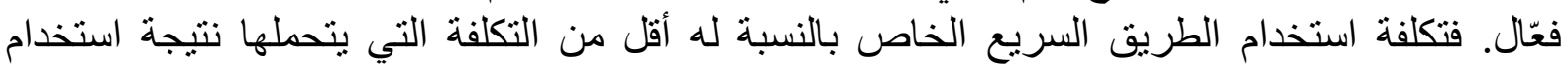

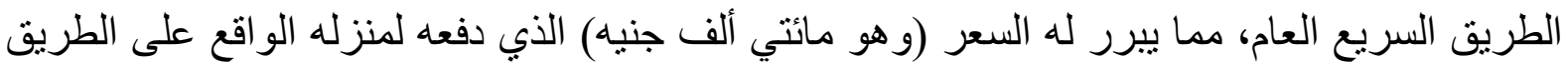

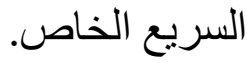

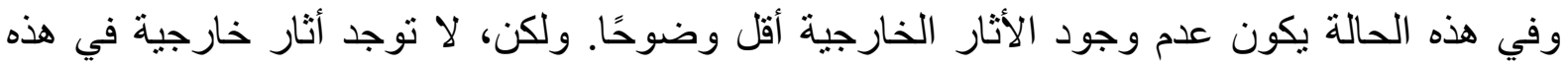

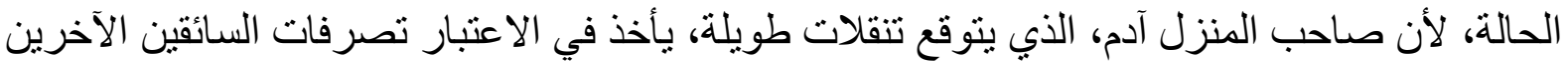

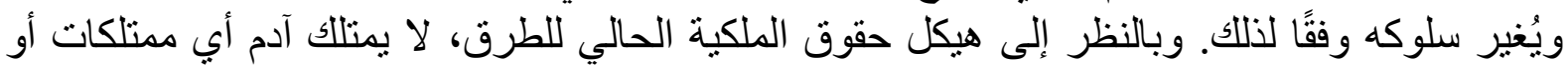

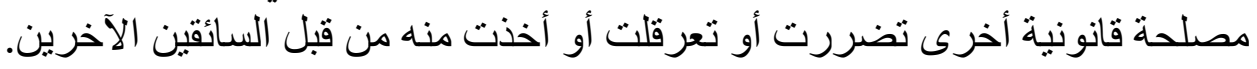

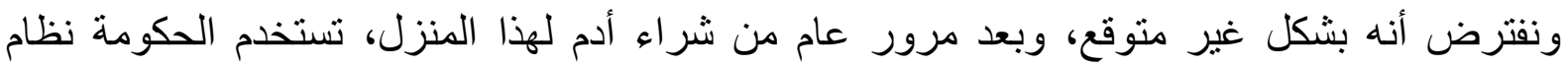

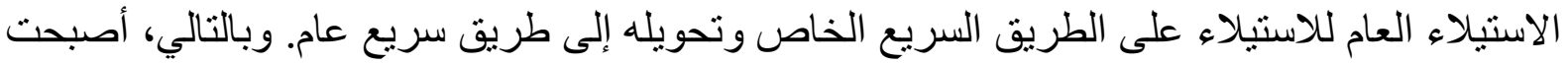

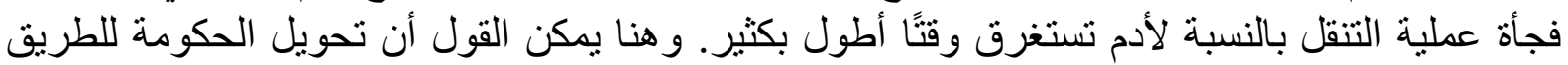

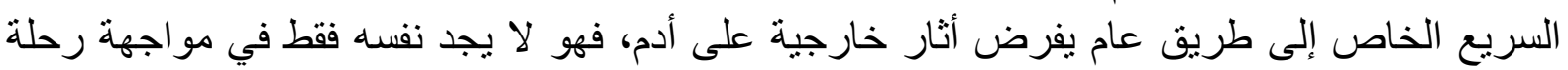

${ }^{319}$ Harold Demsetz, (2011). The Problem of Social Cost: What Problem? A Critique of the Reasoning of A.C. Pigou and R.H. Coase, 7 REV. L. \& ECON. 1, P. 3. 
تنقل أطول مما كان يتوقعه بشكل معقول عندما اشترى المنزل، ولكن القيمة السوقية لمنزله أيضًا

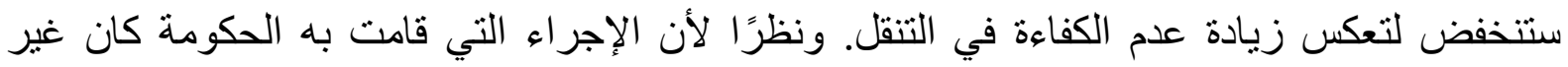

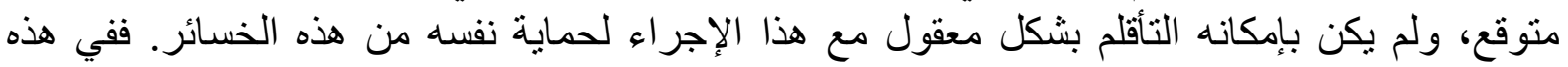

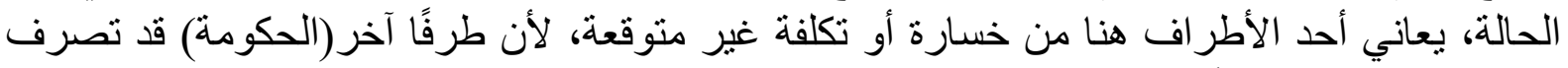
بطريقة غير متوقعة وفقًا للمجرى العادي للأمور .

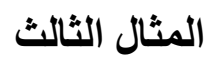

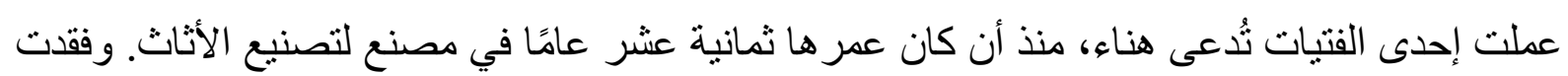

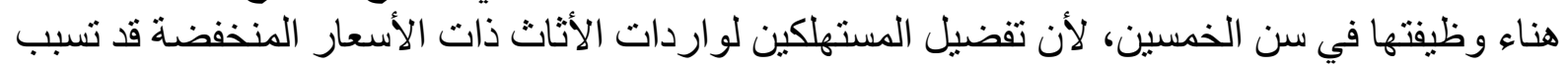

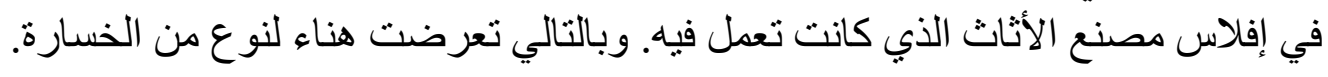

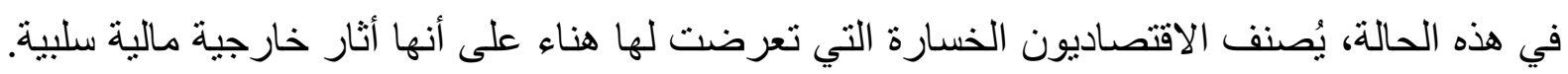

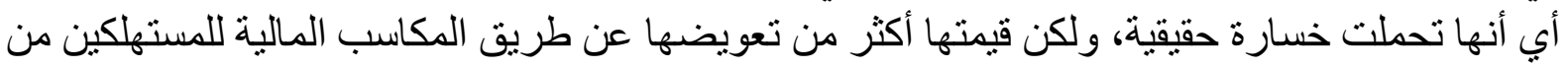

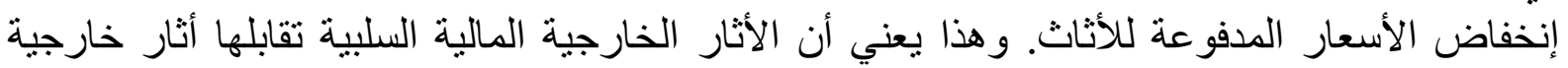

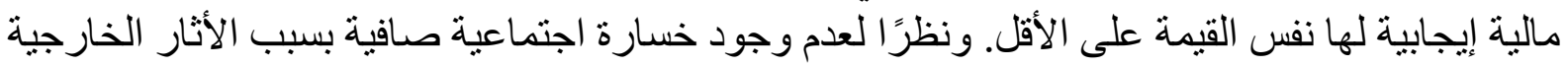

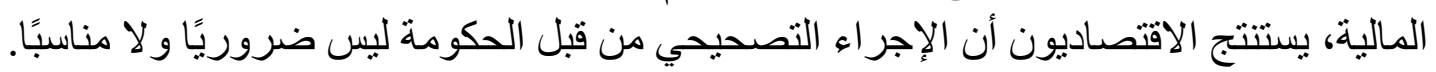

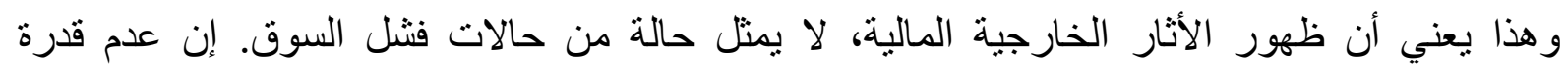

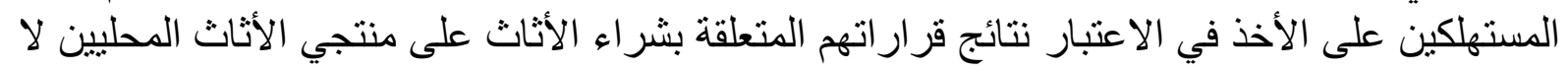

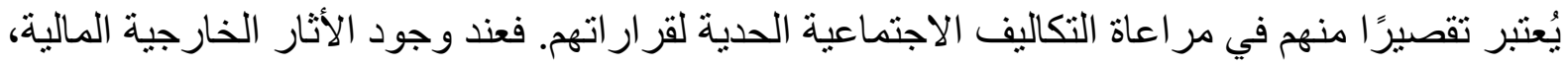

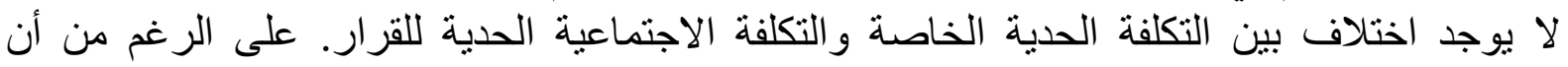

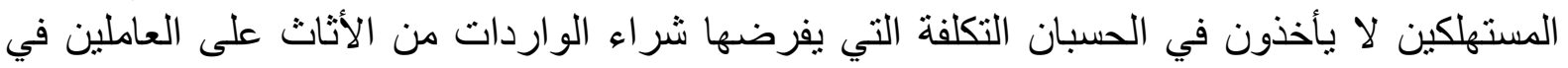

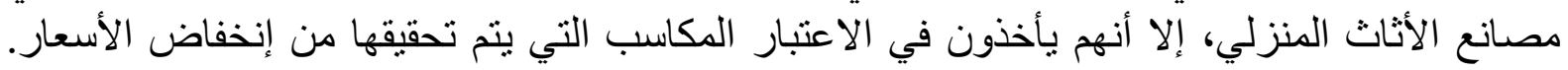

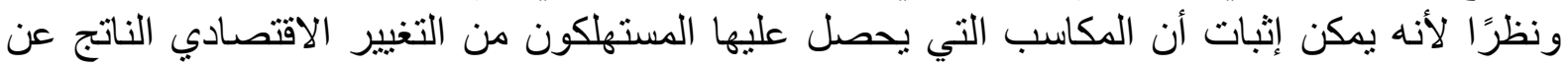

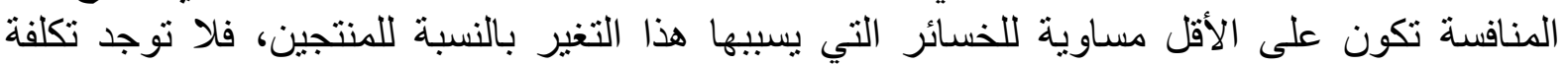
اجتماعية صافية للتغير الاقتصادي الناتج عن النافية المنافية.

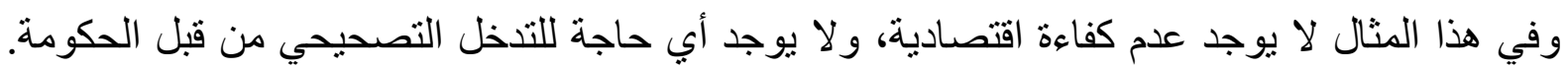

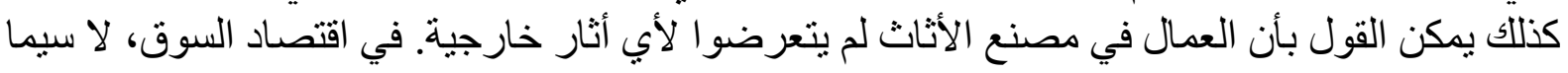

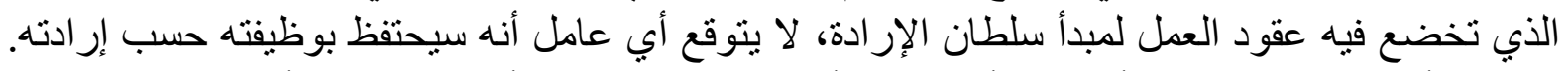

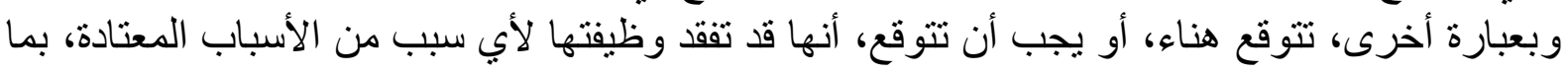
في ذللك التغير ات في ظروف نغ السوق.

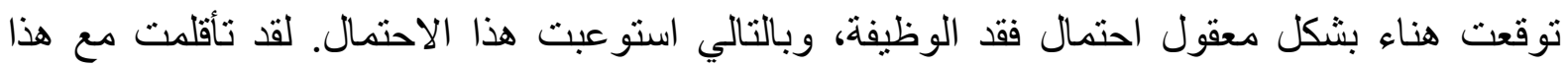

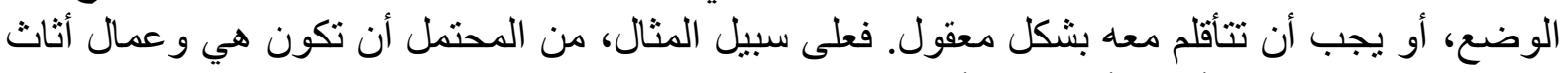

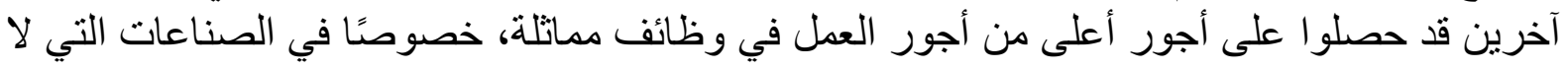

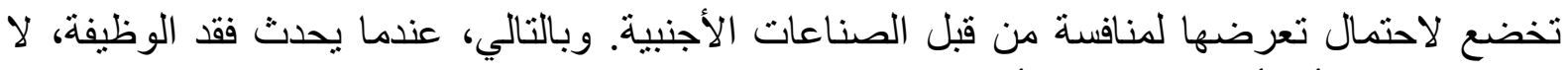

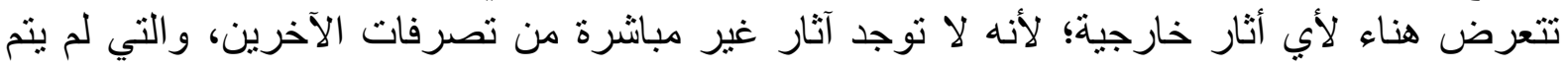

${ }^{320}$ Donald J. Boundreaux \& Roger Meiners, (2019). Externality: Origins and Classifications, 59 Nat. Resources J. 1, P. 27. 


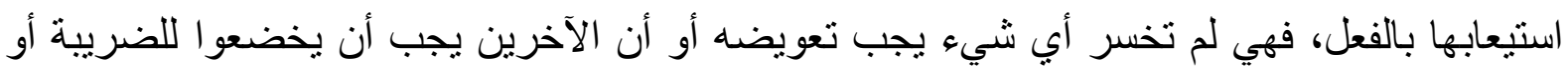

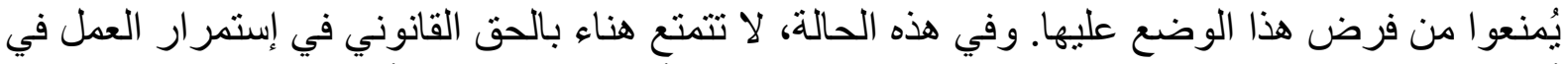

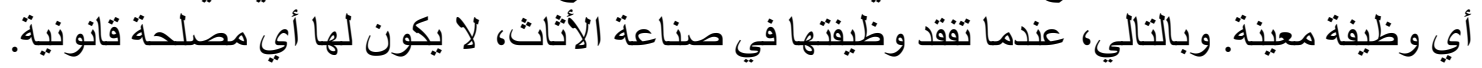

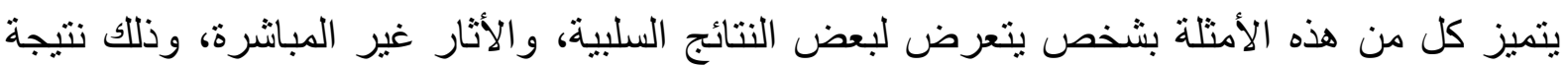

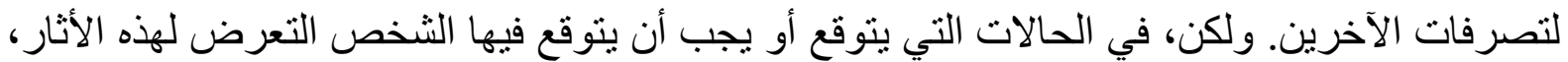

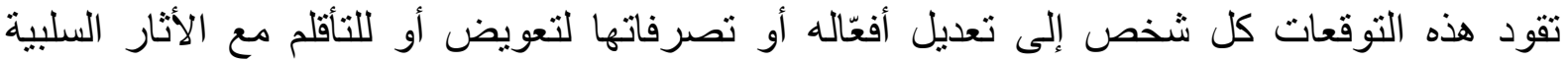

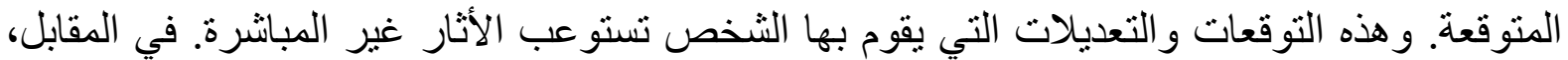

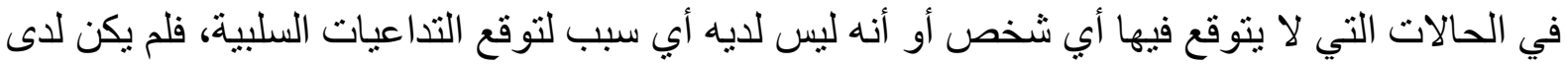

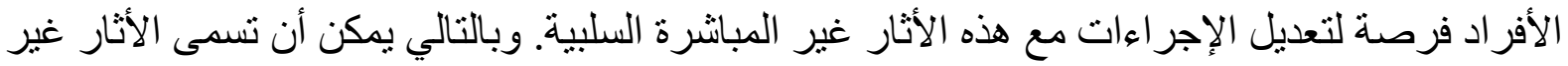
المباشرة في هذه الحالات بالأثار الخارجية.

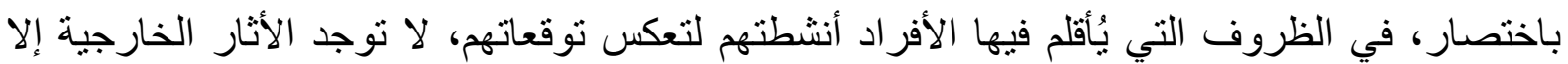

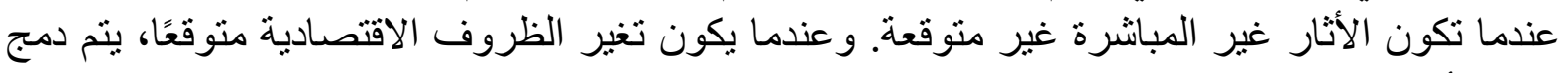

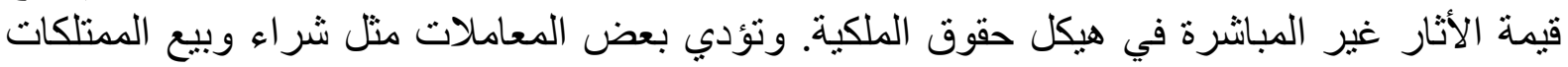

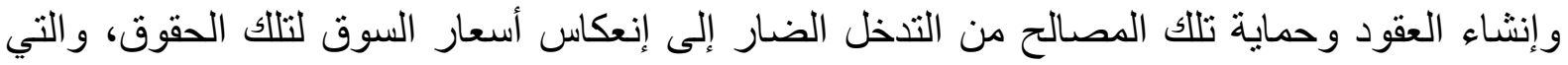

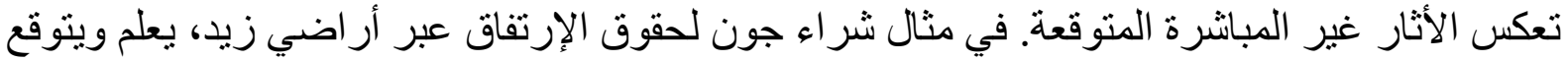

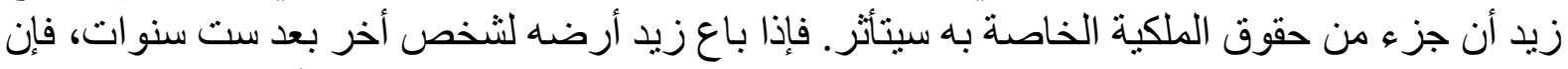

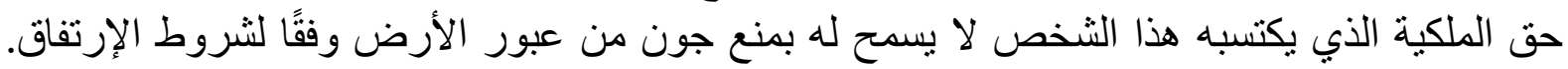

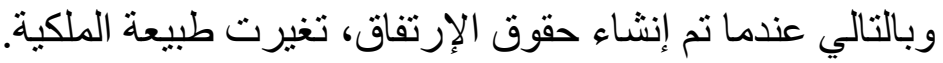

وفي مثال آدم الذي كان يقود سيارته على الطريق السريع العام، والذي لم يكن لديه توقع معقول

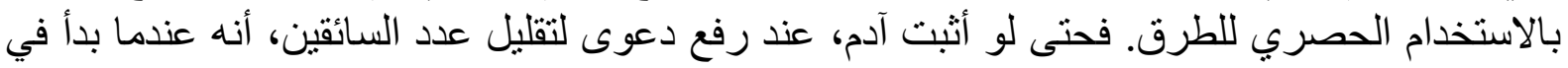

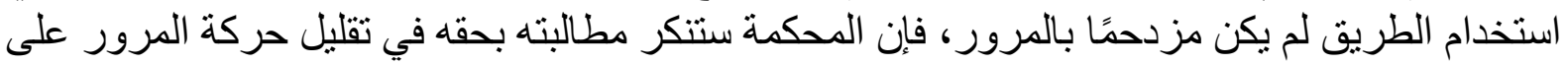

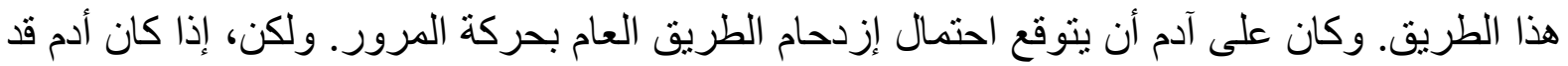

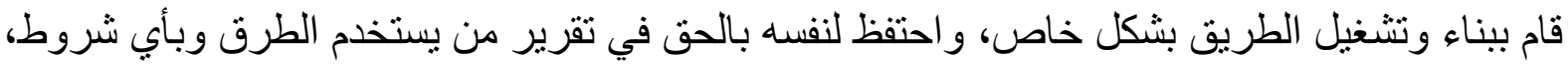

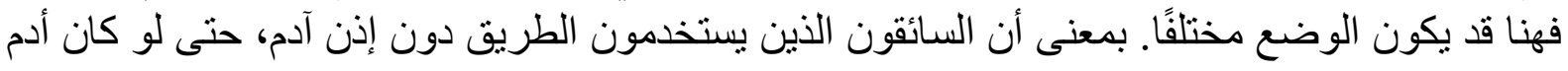
لم يكن يستخدم هذا الطريق، فإنهم بذللك ينتهكون حقه في المنالكية.

وفي حالة هناء التي تعمل في مصنع الأثاث، فإن مو افقتها على العمل وفقًا لمبدأ سلطان الإرادة تعني أنها

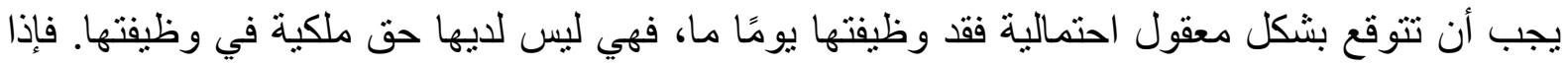

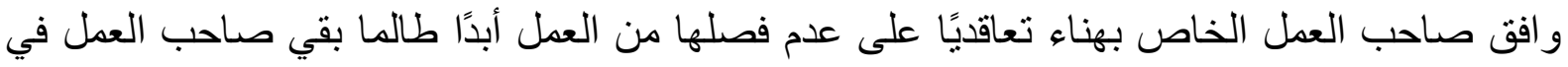
العمل، فعندئذ سيكون لديها، بموجب عقد العمل، حقوق ملكية معينة في وظيفتها.

ثانيًا: الأثار الخارجية هي الأثار غير المُتّوقعة

يمكن القول أن الأسعار والأجور وقيم السوق الأخرى تتغير باستمرار لتعكس توقعات الأفراد بوجود الأبرد

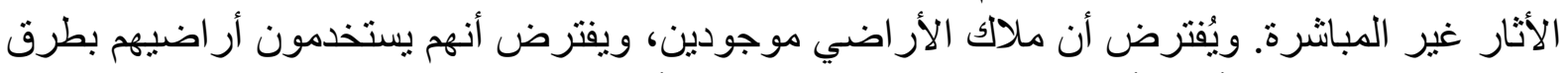

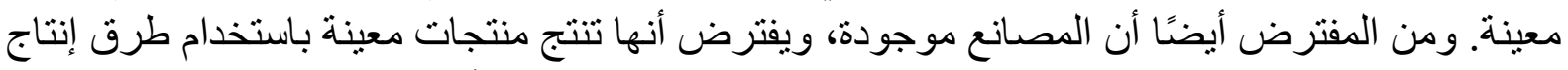

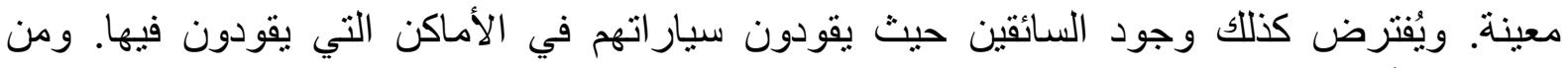

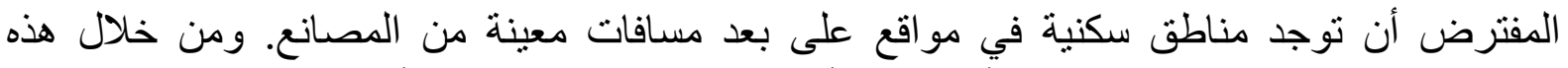

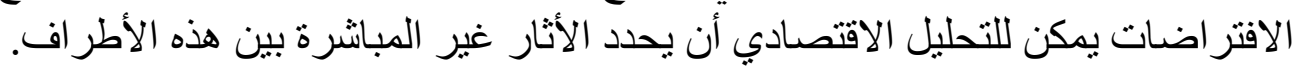


وفي أحد الأمثلة الثائعة، يتسبب أحد المصانع في تلويث الهواء الذي تستخدمه مغسلة قريبة لتنظيف ملابس عملائها، وبالتالي يتسبب هذا المصنع في وجود بعض الأثار غير المباثرة التي تلتحملها التهائلة المغلة.

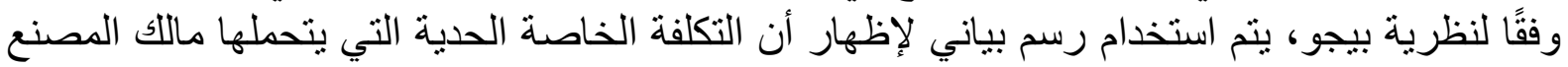

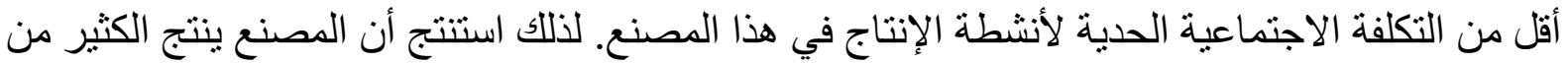

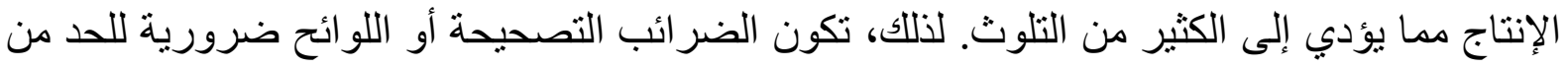
الأثنار غير المباشرة. ويتفق كواس وبيجو على وجود أثنار غير مباشرة، لكنهما يختلفان حول الحل.

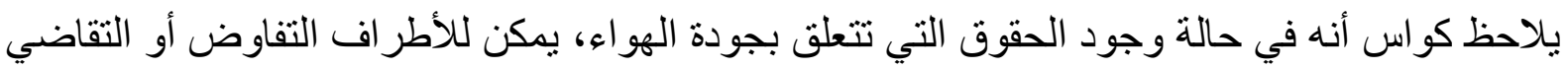

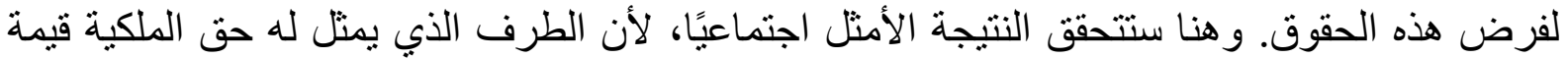
أعلى سيشتريه أو لا يبيعه للطرف وفن الآخر.

وفي هذه الحالة يمكن القول أن المصانع والمغاسل لا يتم إنشائها بشكل مفاجئ، بل يتم إنشاء كل منها في وقت ومكان معينين، و هذا التو اجد يكون مصحوب بمجموعة من التوقعات حول الأنشطة الاقتصادية التي

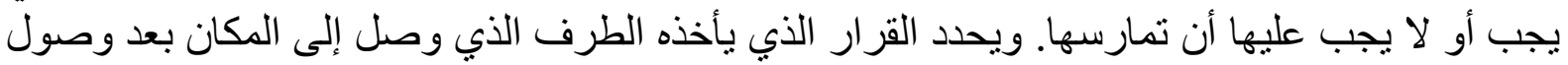

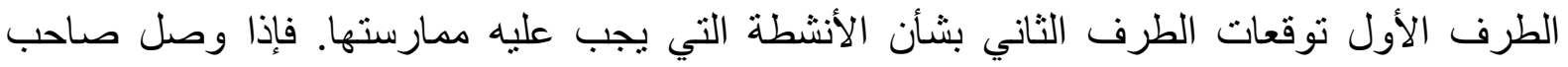

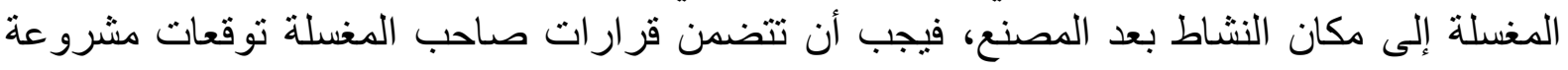
لتشغيل المصنع، بما في ذلك أي آثار غير مباثرة من المحتمل أن تؤثر عليه. ويعكس السعر الذي دفعه

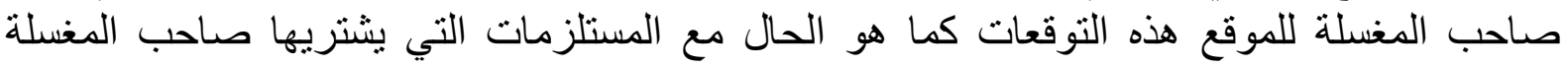
لتشغيل نشاطه. وبالنظر إلى أن صاحب المغسلة اختار إنشاء هذا النشاط في المكان و الوقت الته الذي التي حدده

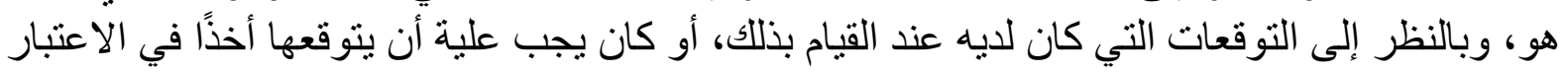

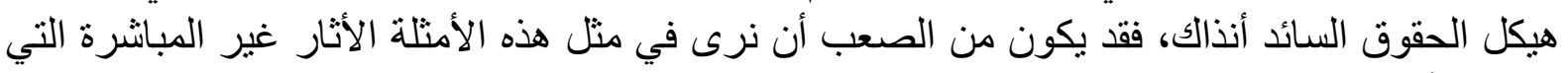

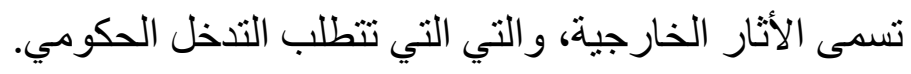

و ولا جدال في أن هنالك بعض الأثار المادية غير المباشرة التي يسببها المصنع للمغسلة، ولكنها ليست أثار

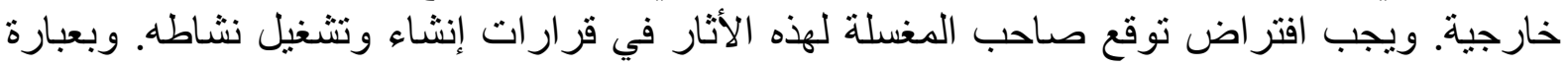

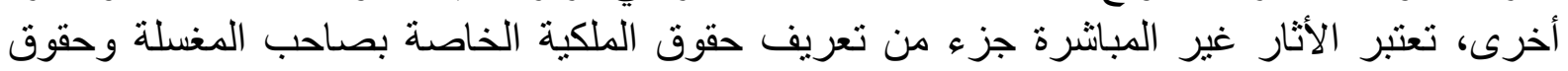

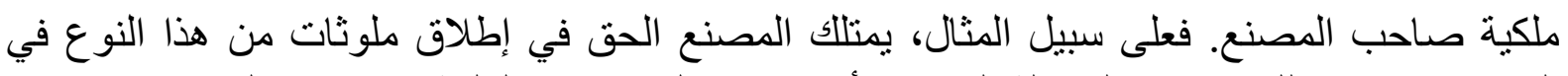

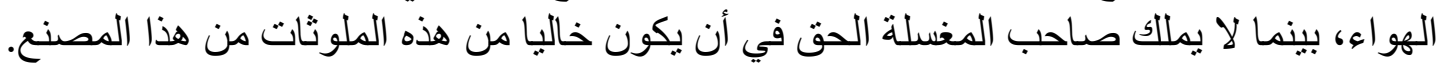

و لا توجد الأثار الخارجية إلا عندما تتسب تصرفات طرف آخر في إحداث أثنار غير مباشرة وغير

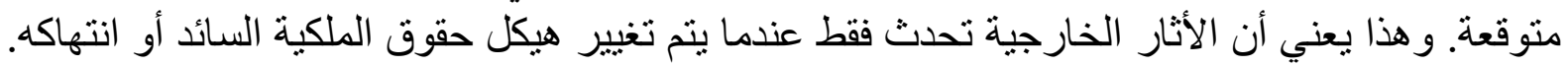

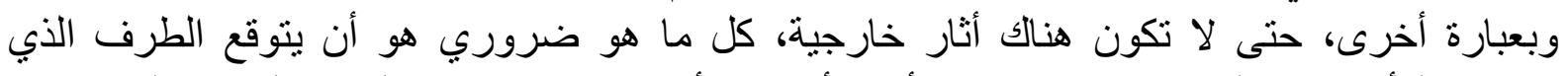

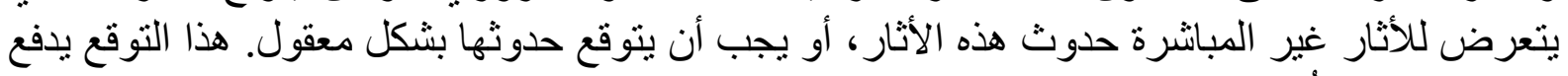

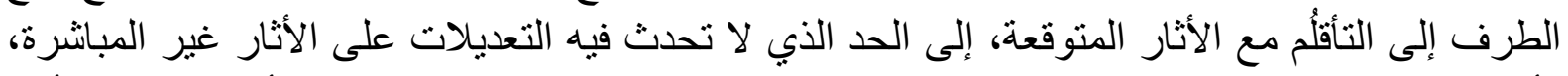

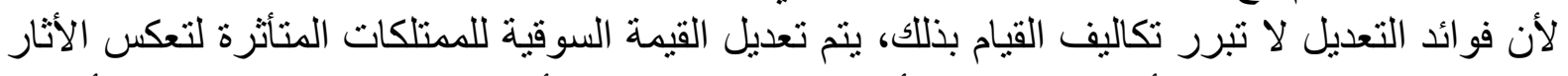
غير المباشرة. و هذا يعني أنه من المحتمل ألا يؤدي توقع بعض الأثار غير لأنير المباثرة إلى تعديل أنشطة

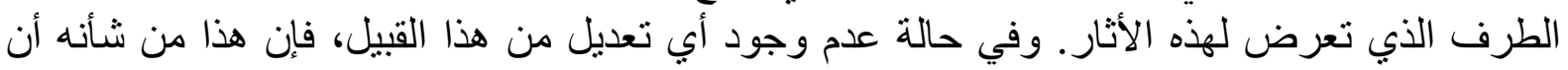

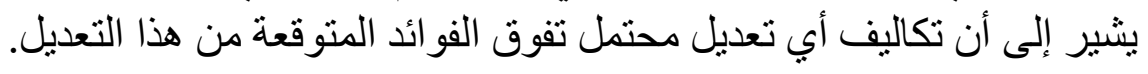
عندما يتوقع أحد الأشخاص حدوث أثار غير مباشرة، فإنه يتم استيعابها من الثخص الذي تعرض لهذه

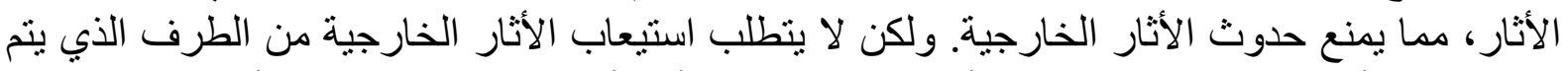

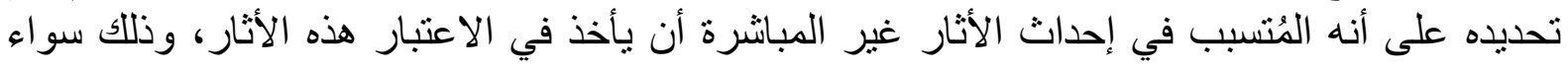


اختياريًا أو من خلال الضر ائب أو الإعانات التي تشمل قيمة هذه الأثار على الطرف الذي تعرض لهان الها.

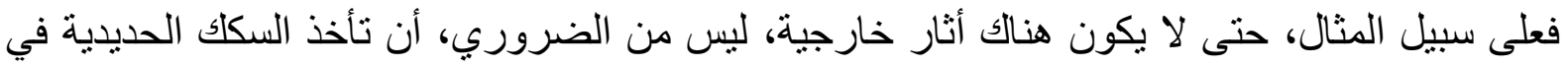

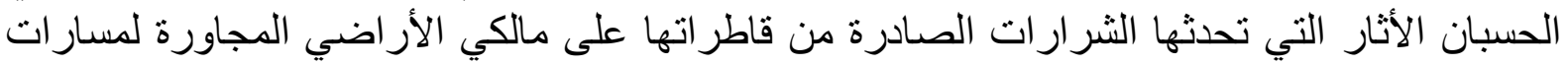

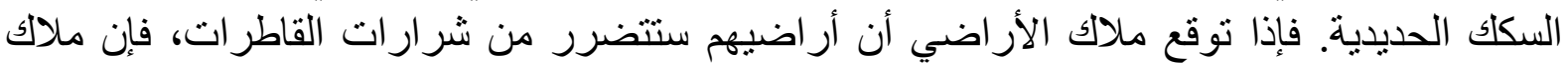

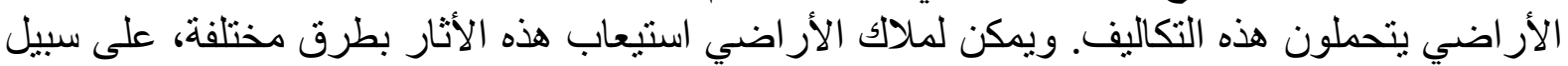

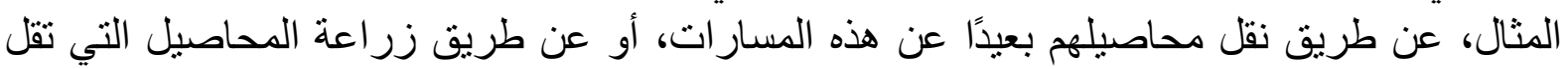

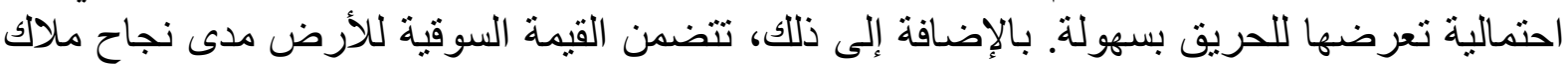

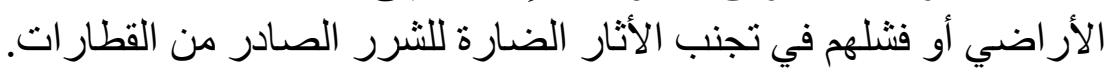

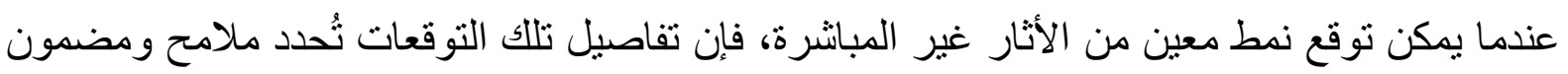

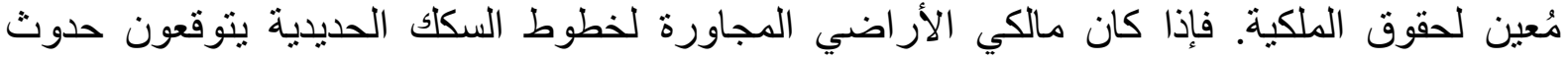

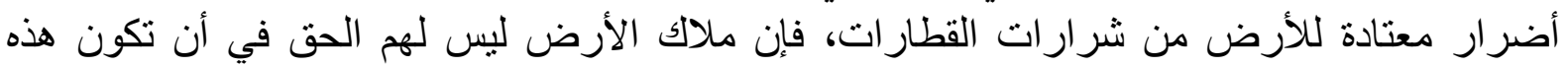

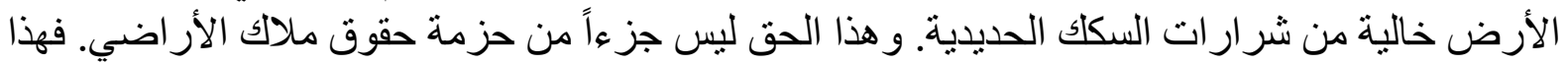

الجز ع مملوك للسكك الحديدية.

\section{ثالثًا: علاقة الأثار الخارجية بهيكل حقوق الملكية و الهندسة الاجتماعية}

بخلاف ما ورد في الفقه المتعلق بالأثار الخارجية، لا شيء قيل هنا يشير إلى أن عدم وجود الأثار غير

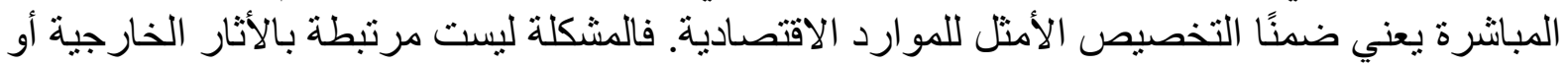

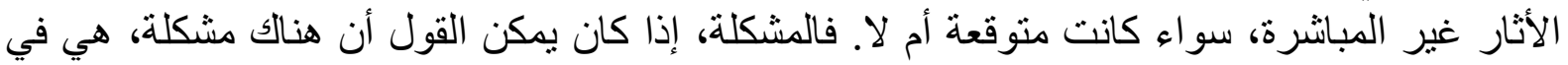

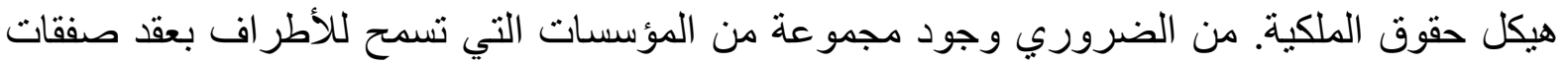
وفقًا لمجمو عة من الحقوق القابلة للتنفيذ و المحمية.

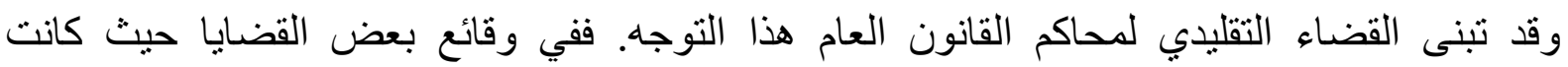

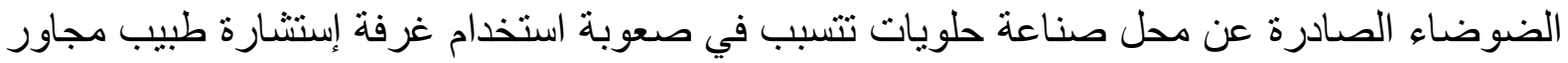

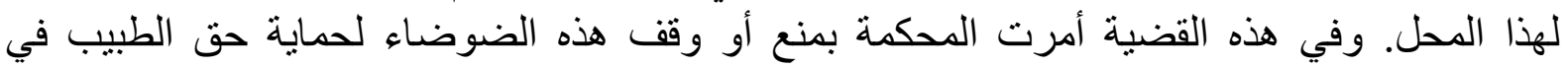

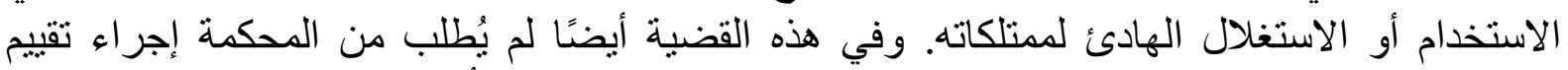

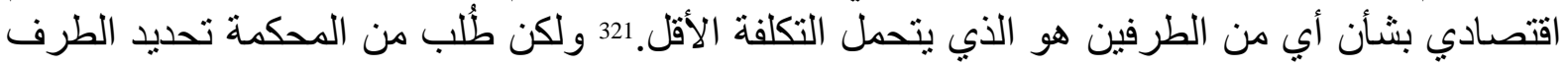

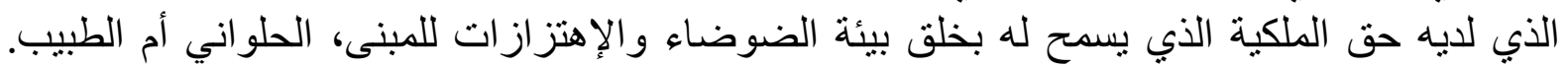

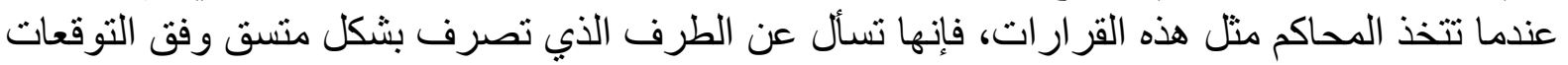

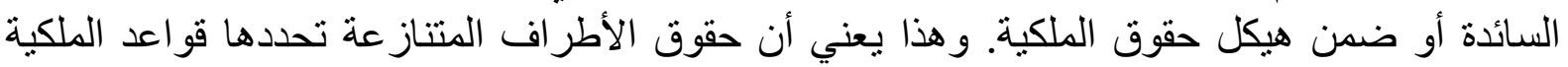

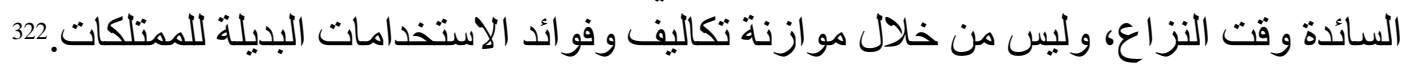

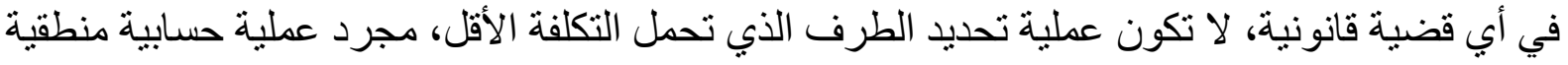

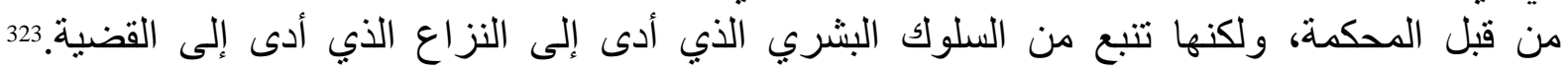

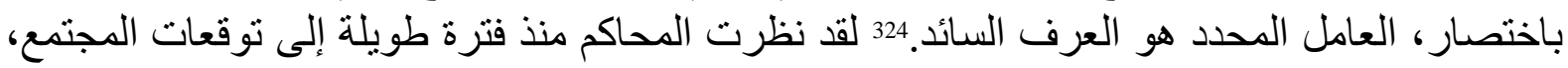

\footnotetext{
${ }^{321}$ Sturgis v. Bridgeman, L.R. 11 Ch. 857 (1879)

322 Ronald H. Coase, (1959). The Federal Communications Commission, Journal of Law and Economics, Vol. 2, pp. 1-40

${ }^{323}$ Anthony A. Peacock, (2010). Freedom and the Rule of Law, Lexington Books, P.179.

${ }^{324}$ Roscoe Pound, (1909). Law: Its Origin, Growth and Function, Political Science Quarterly, Vol. 24, No. 2 (Jun., 1909), pp. 317-320.
} 
لاكتثاف الطرف الذي يتصرف بطريقة أكثر انسجامًا مع التوقعات.325 وهذا الطرف هو الذي يتم الإقرار

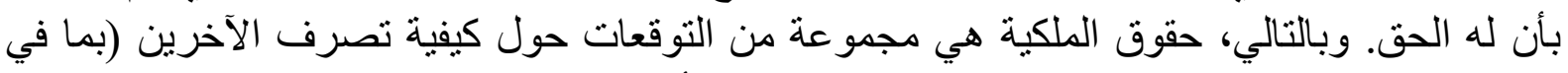

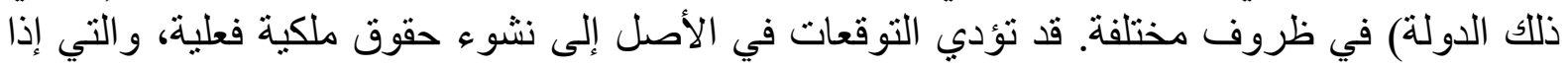

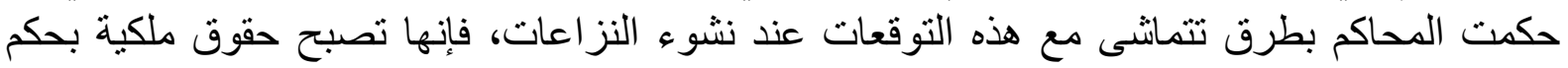

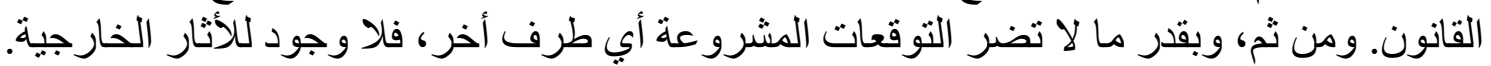
إن النمط السائد للتوقعات ـ وبالتالي الترتيب المحدد لحقوق الملكية الذي يعكس هذه التوقعات ـ ليس

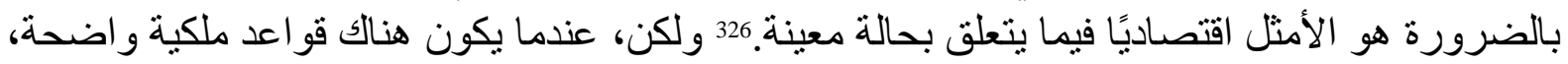

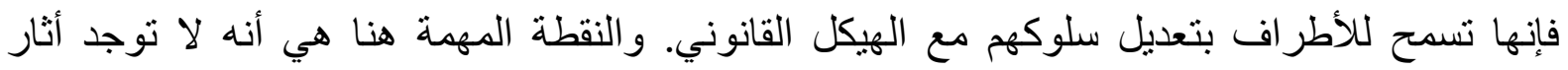

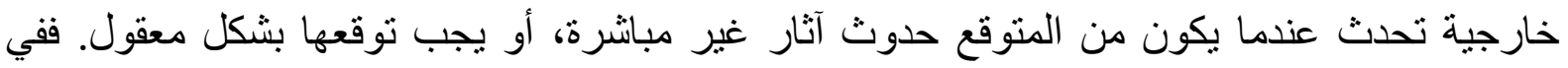

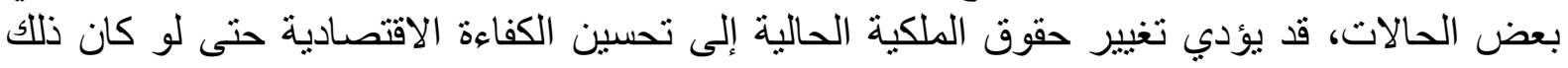

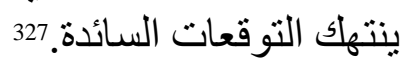

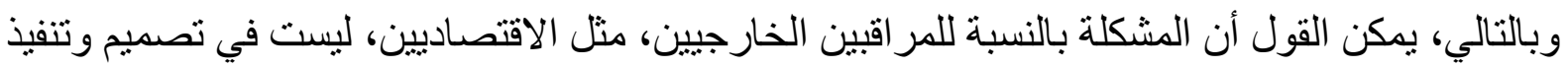

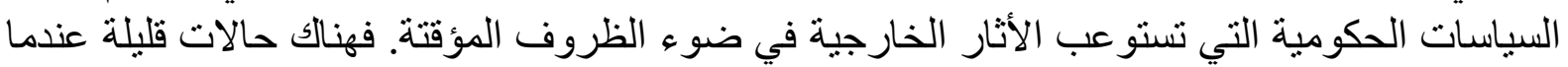

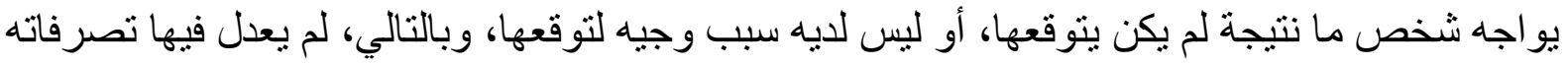

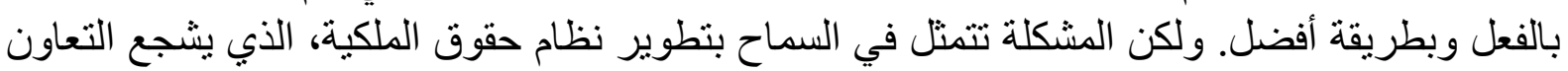

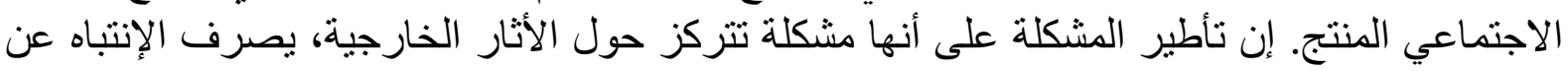

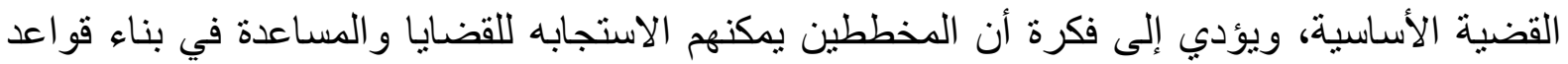

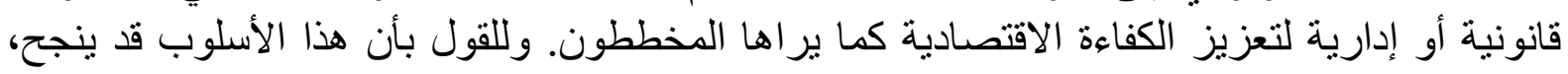

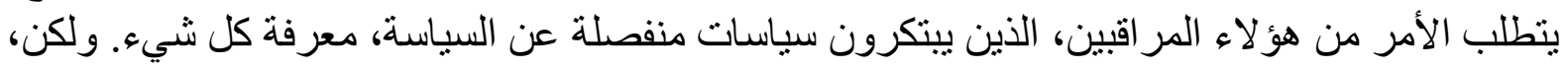
يمكن القول أيضًا أن كلا الافتر اضين غير معقول.

${ }^{325}$ F.A. Hayek, (1973). Law, Legislation, and Liberity: Rules and Order. Vol. 1, University of Chicago Press, P. 94.

${ }^{326}$ Henry E. Smith, (2004). Exclusion and Property Rules in the Law of Nuisance, Virginia Law Review, Vol. 90, No. 4, p. 965.

327 Alvin Roth, (2007). Repugnance as a Constraint on Markets, The Journal of Economic Perspectives, Vol. 21, No. 3, pp. 37-58. 37, P. 42.

328 James Buchanan, (1959). Positive Economics, Welfare Economics, and Political Economy, 2 J. L. \& ECON. 124, PP. 126-37. 


\section{المبحث الثالث: الأثار الخارجية والكفاعة الاقتصادية للسوق}

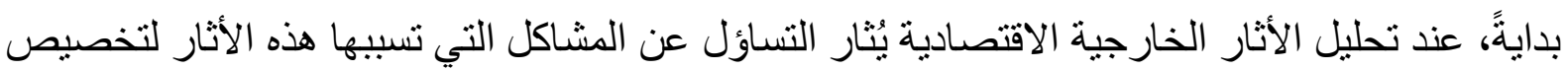

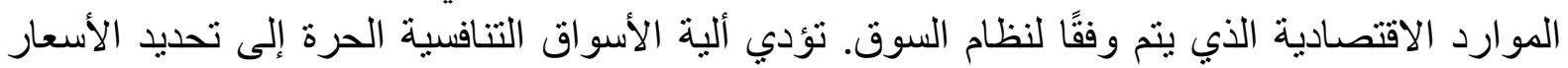

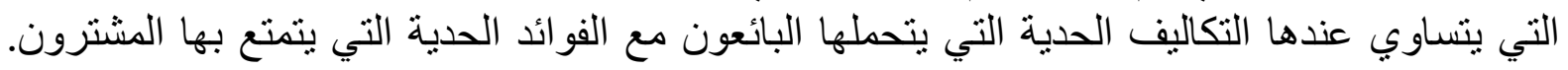

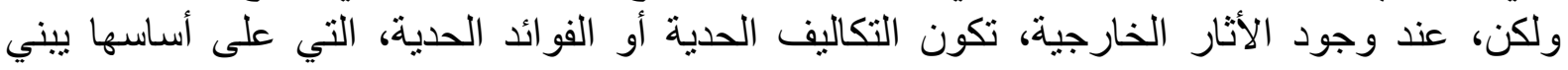

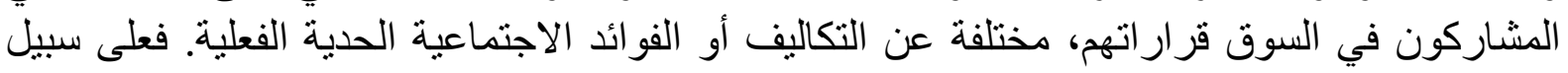

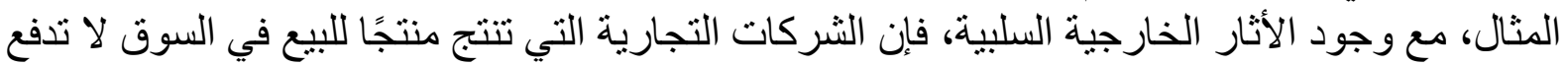

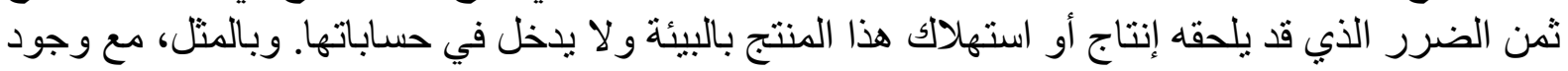

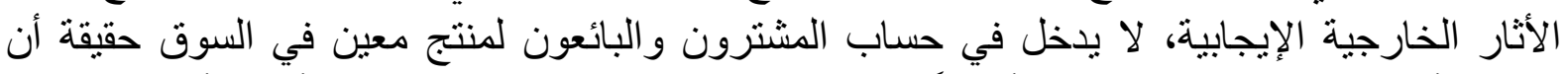

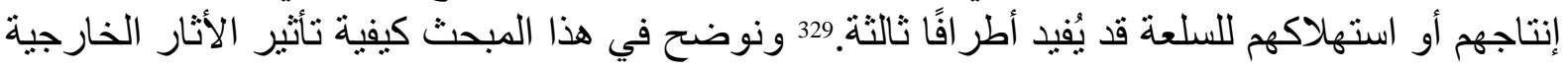

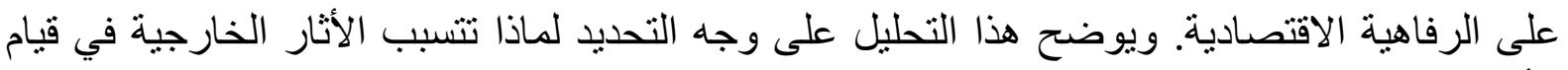

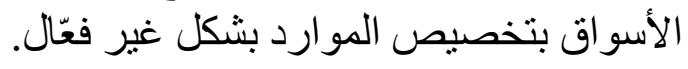

\section{أولاً: الأثثار الخارجية السلبية في الإنتاج}

لتوضيح كيفية نأثير الأثار الخارجية السلبية على الإتتاج، نفترض أن أحد مصانع الألمنيوم ينبعث منه

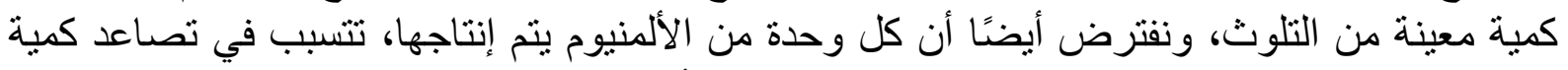

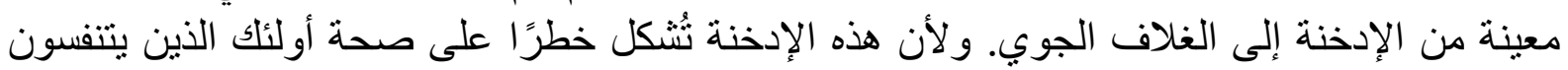

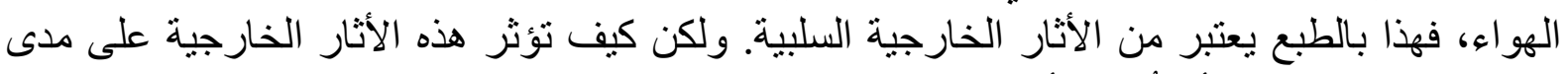
كفاءة النتائج التي يمكن أن تُحققها ألية السوق؟ النئ

يمكن القول أن بسبب وجود الأثار الخارجية، تكون التكلفة التي يتحملها المجتمع (التكلفة الاجتماعية)

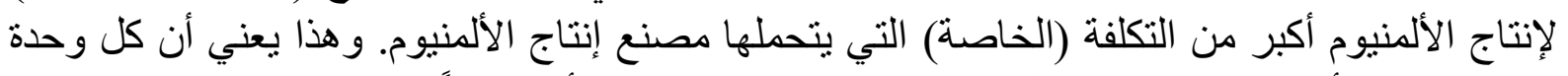

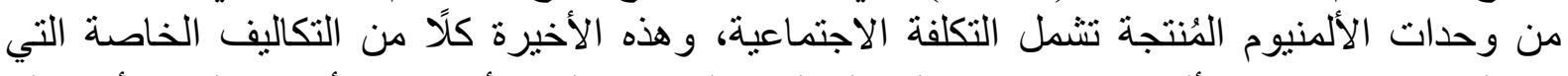

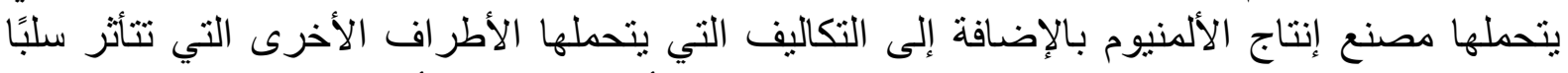

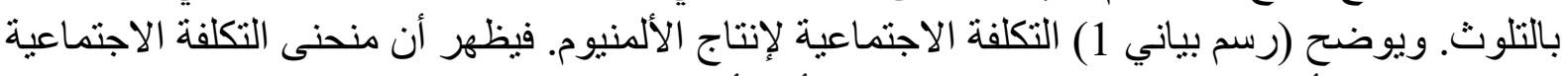

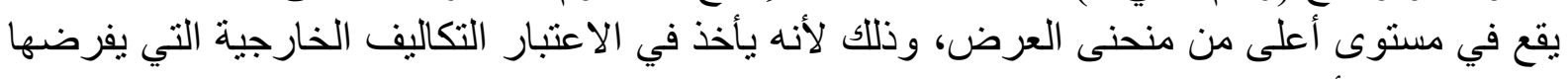

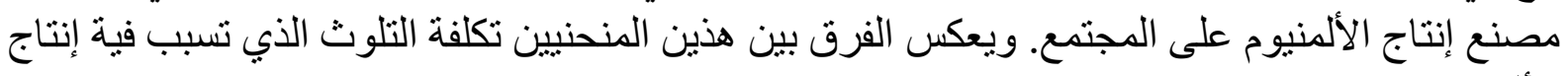

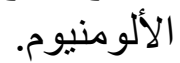

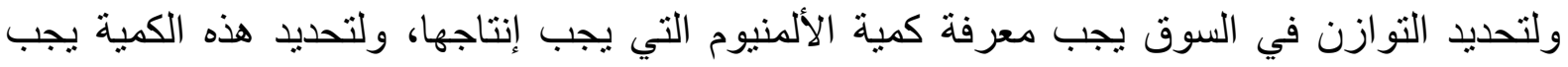

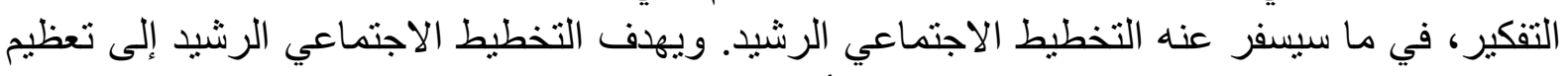

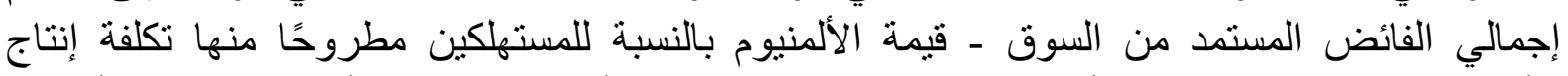

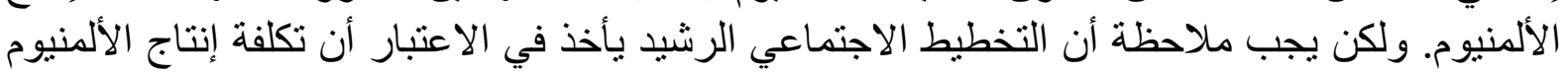
تشمل التكاليف الخارجية للتلوث.

${ }^{329}$ Heller, Walter P., and David A. Starrett. (1976). "On the Nature of Externalities.” In Steven A. Y. Lin, ed., Theory and Measurement of Economic Externalities. New York: Academic Press, PP. 9 21.

${ }^{330}$ Ayres, Robert U., and Allen V. Kneese., (1969). "Production, Consumption, and Externalities." American Economic Review 59 (3), P. 282. 


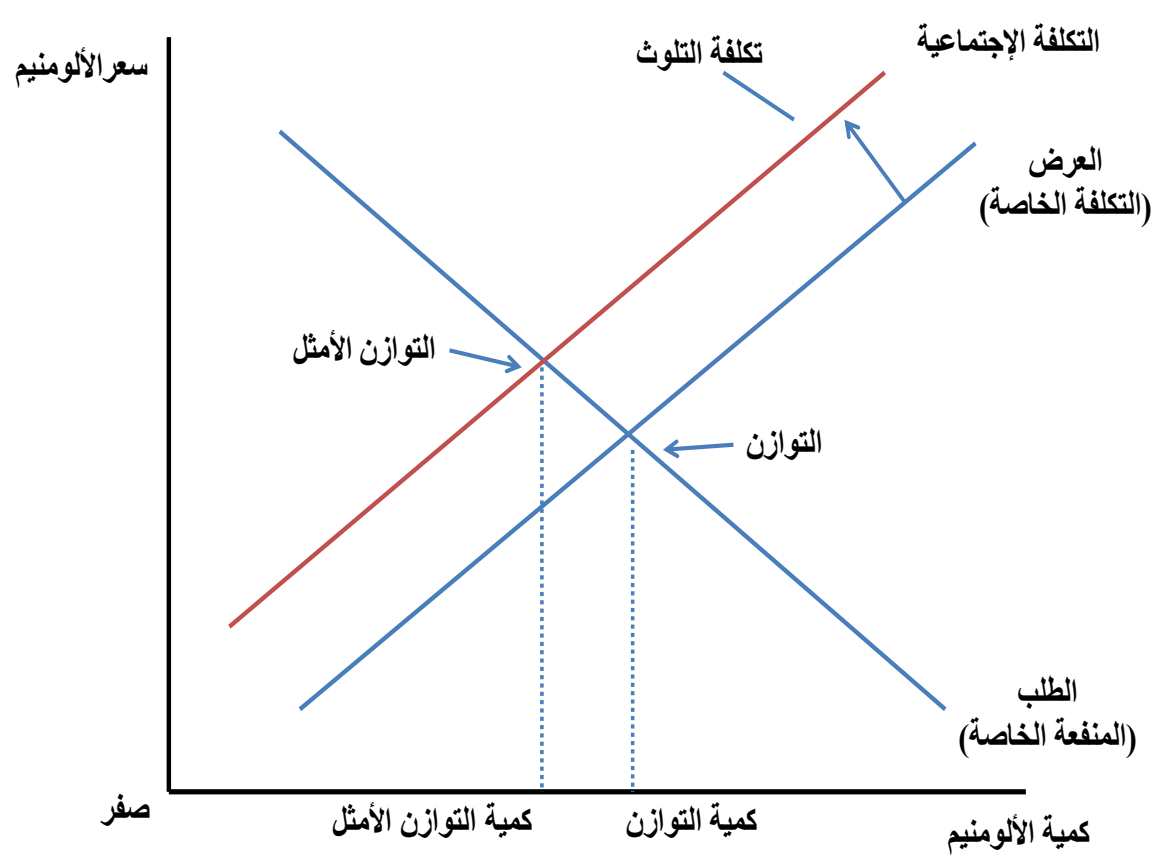

(رسم بياني 1) التلوث ومستوى الإنتاج الأمثل.

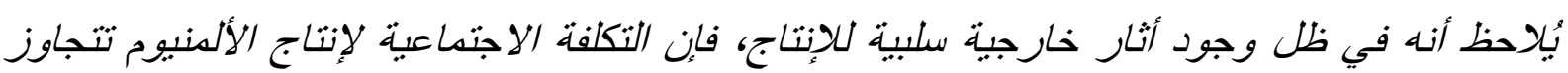

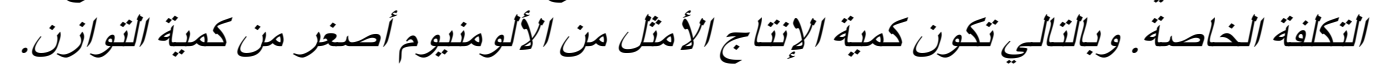

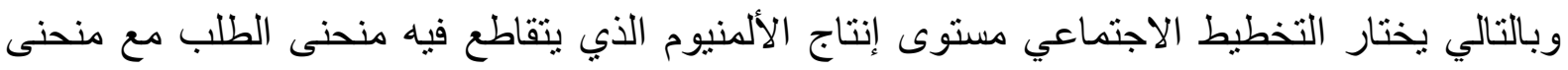

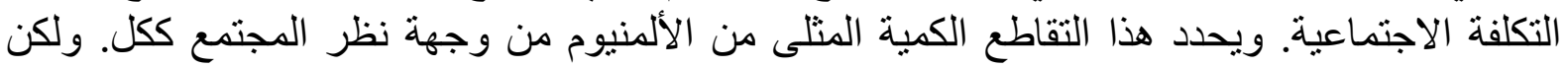

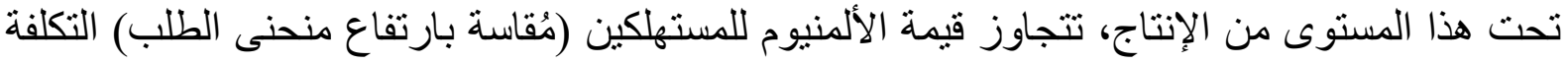

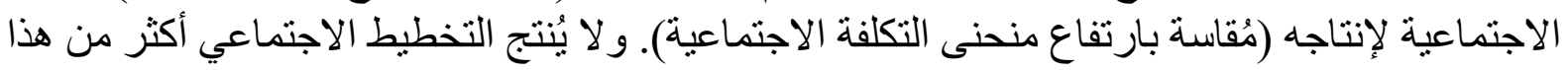

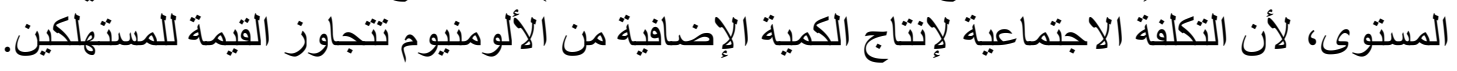

ويُّلاحظ أن كمية التوازن لإنتاج الألمنيوم، و التي يثار إليها في الرسم البياني على أنها توازن السوق،

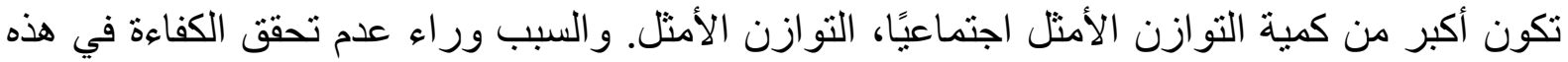

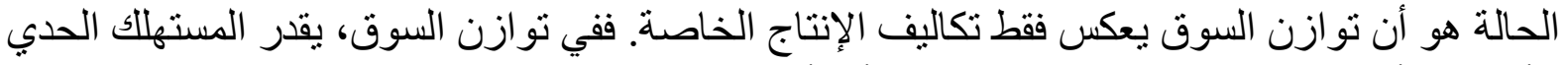

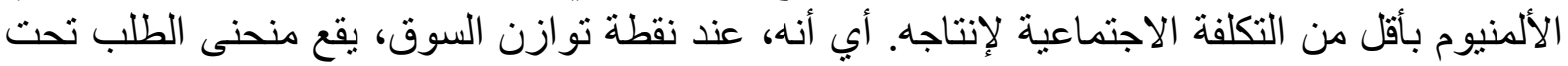

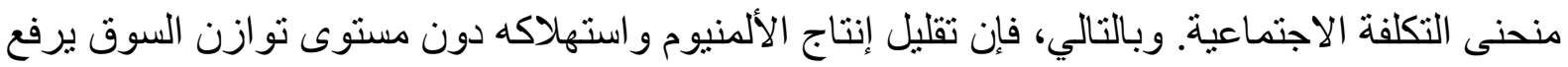

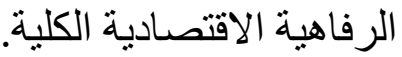

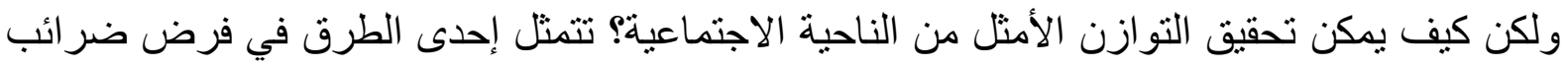

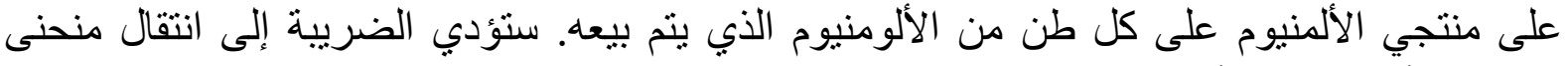

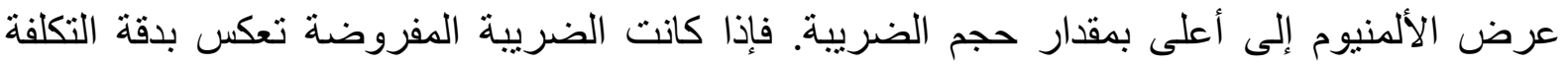


الاجتماعية للاخان المنبعث في الغلاف الجوي، فإن منحنى العرض الجديد سيتطابق مع منحنى التكلفة

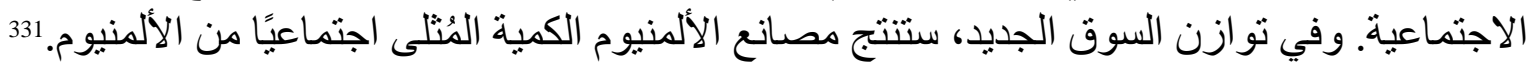

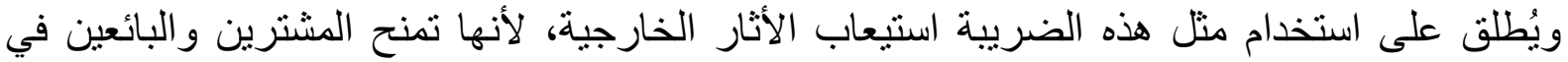

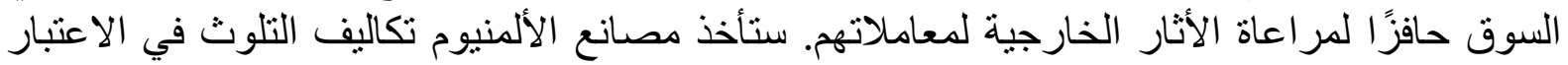

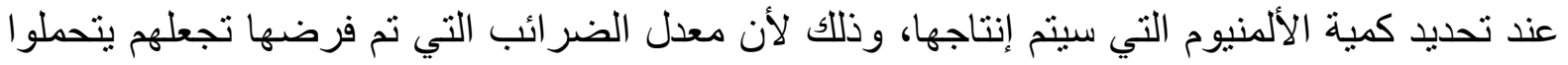
قيمة هذه التكاليف الخارجية.

\section{ثنانيًا: الأثار الخارجية الإيجابية في الإنتاج}

على الرغم من أن التكلفة الاجتماعبة للإنتاج في بعض الأسواق تتجاوز التكلفة الخاصة لهذا الإنتاج، إلا

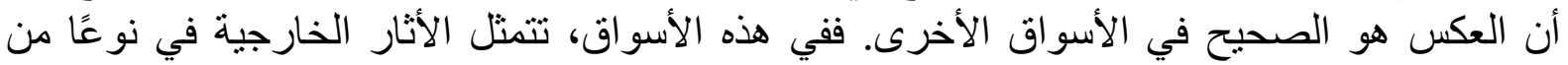

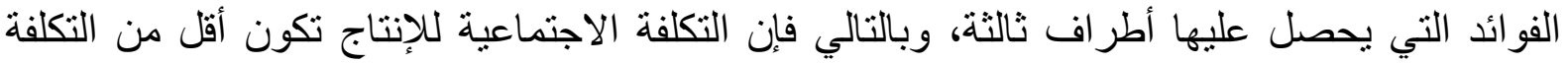

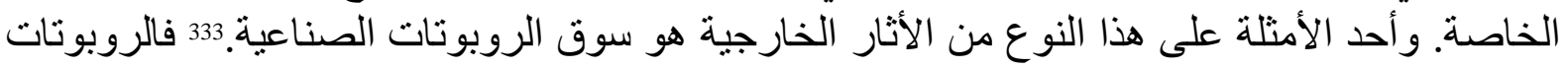

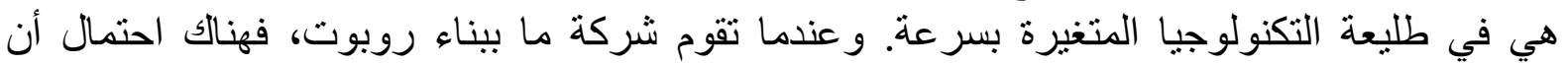

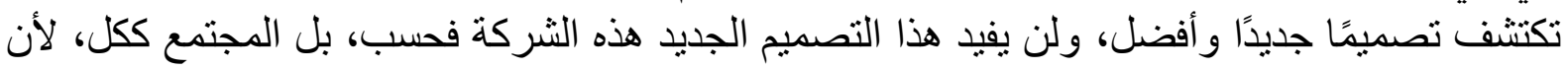

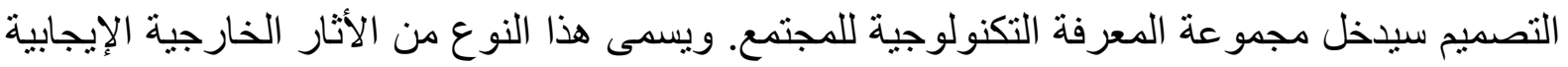
بالانتشار التكنولوجي.

إن تحليل الأثار الخارجية الإيجابية يشبه تحليل الأثار الخارجية السلبية. ويوضح (رسم بياني 2) الأثار

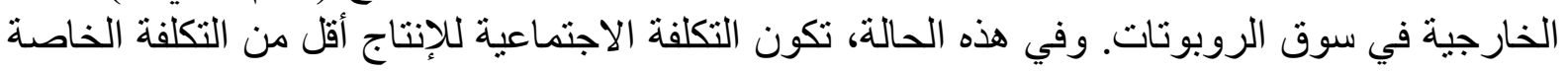

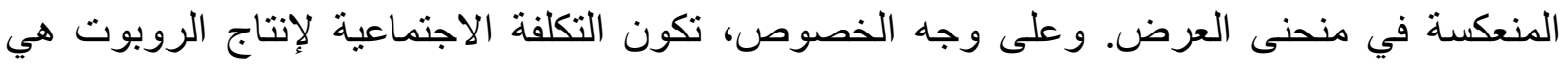

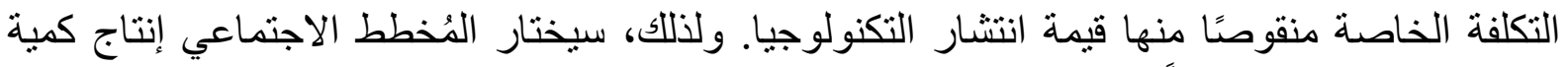
أكبر من الروبوتات مقارنةً بالسوق الخاص.

\footnotetext{
${ }^{331}$ Cornes, R., \& Sandler, T. (1996). The theory of externalities, public goods, and club goods (2nd ed.). Cambridge: Cambridge University Press.

332 Berta, Nathalie., (2017). "On the Definition of Externality as a Missing Market." European Journal of the History of Economic Thought 24 (2), P. 287.

${ }^{333}$ Robert U. Ayres and Allen V. Kneese, (Jun., 1969), Production, Consumption, and Externalities, The American Economic Review, Vol. 59, No. 3, P. 282.
} 


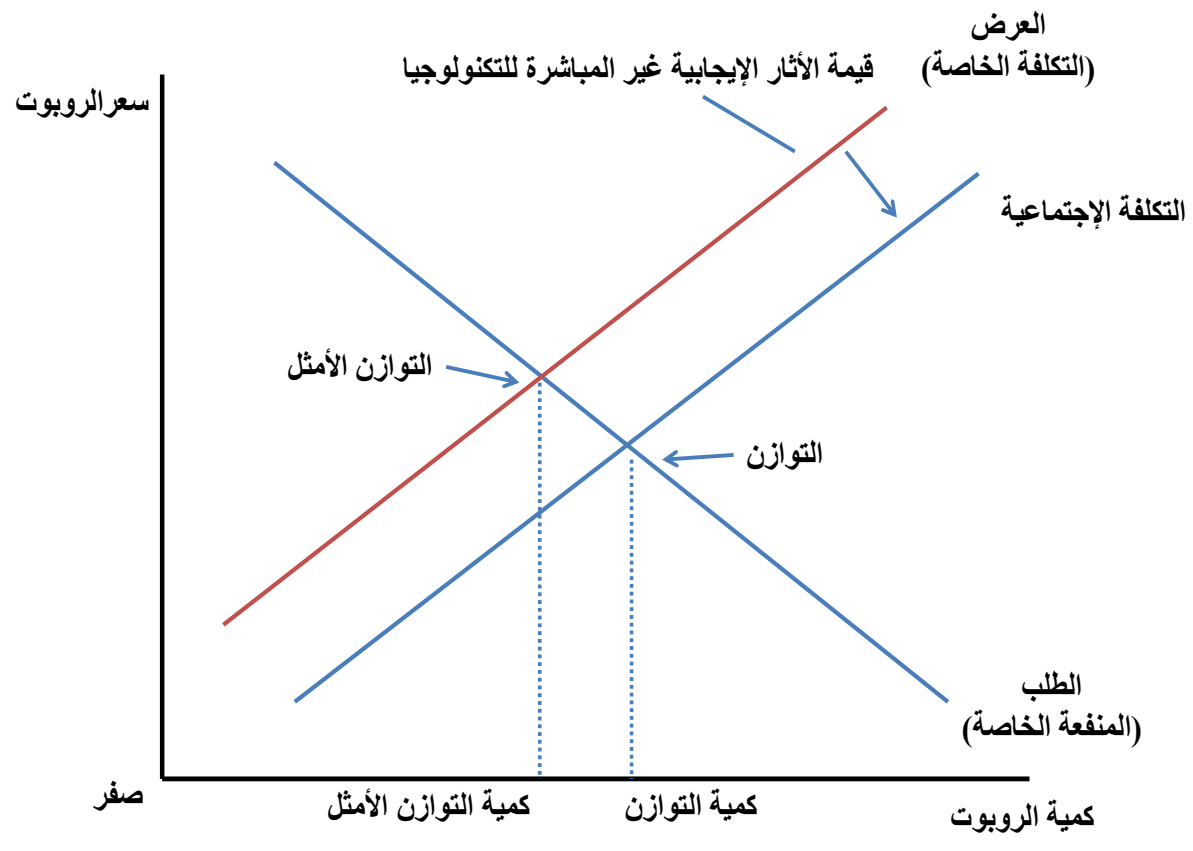

(رسم بياني 2) الأثار غير المباشرة للتكنولوجيا والتوازن الأمثل.

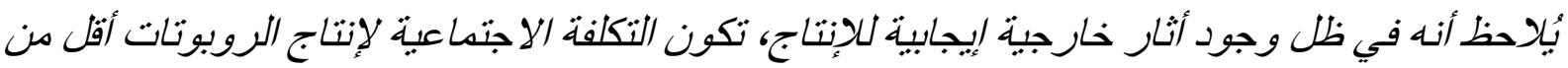

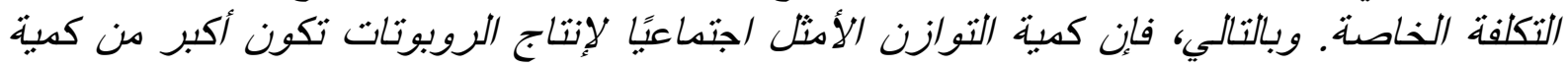
التوازن.

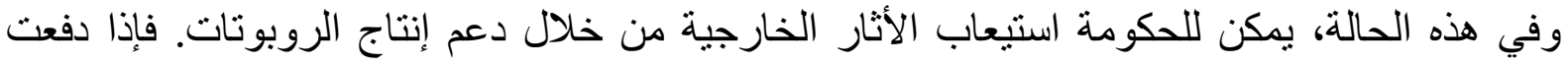

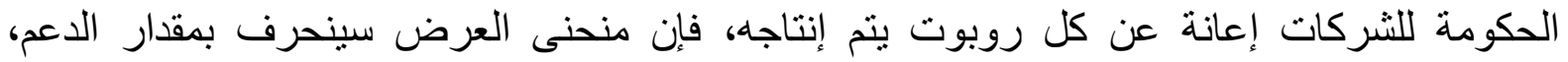

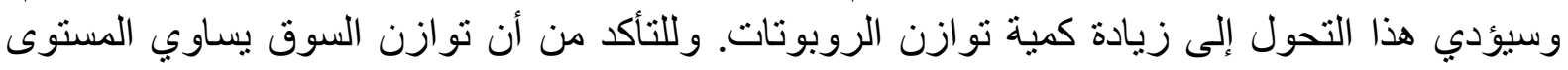

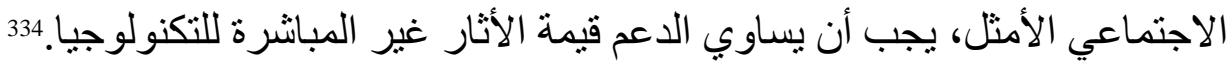

ثالثًا: الأثار الخارجية في الاستهلاك

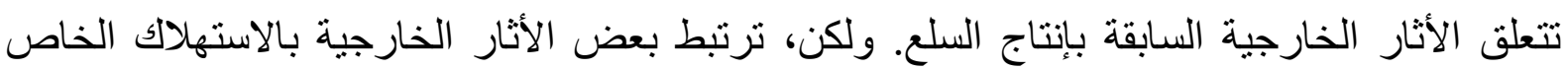

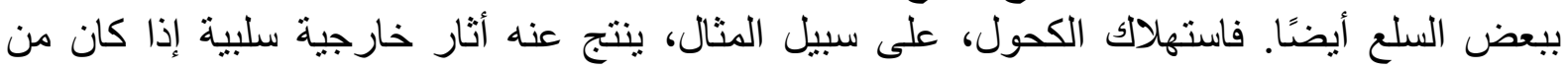

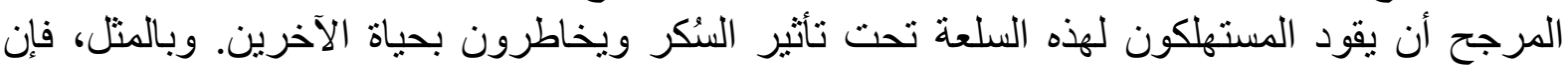

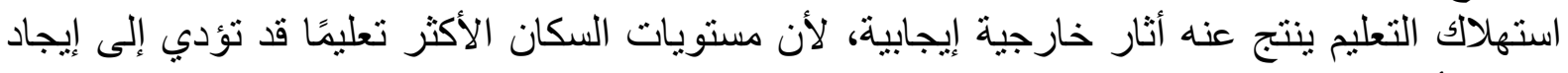
حكومة أفضل، مما يعود بالفائدة على الجميع.

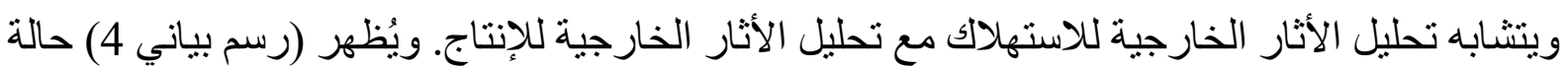

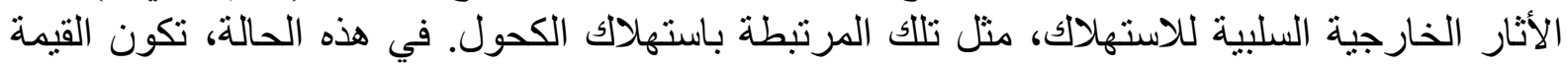

\footnotetext{
${ }^{334}$ Mestelman, S., (1982). 'Production externalities and corrective subsidies: a general equilibrium analysis.' Journal of Environmental Economics and Management 9, P. 186.
} 
الاجتماعية أقل من القيمة الخاصة، وتكون الكمية الأمثل اجتماعيًا أصغر من الكمية التي يحددها السوق

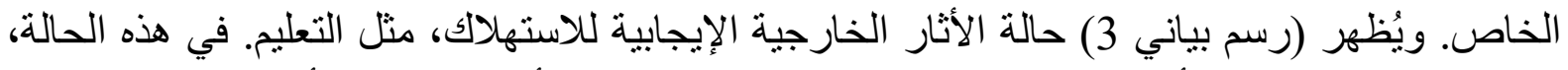

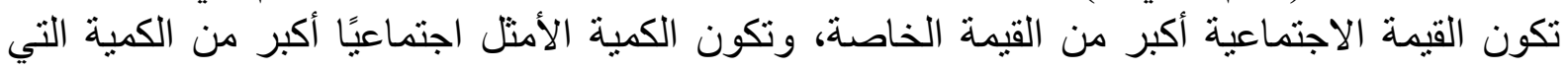
يحددها السوق الخاص.

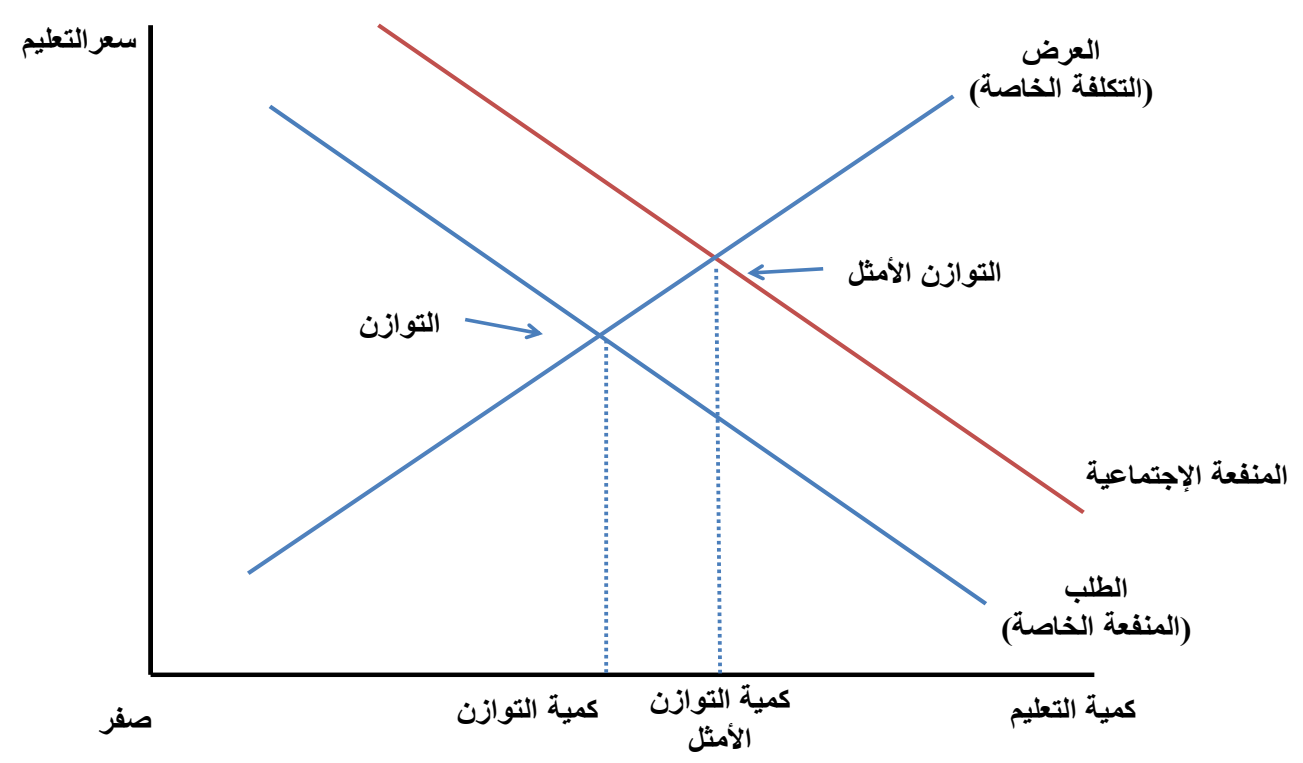

(رسم بياني 3) الأثار الخارجية الإيجابية في الاستهلاك.

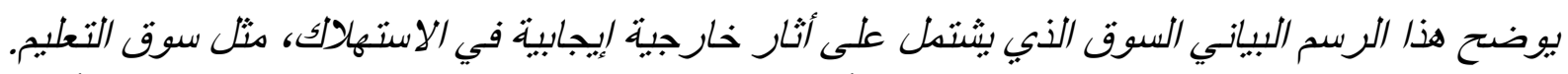

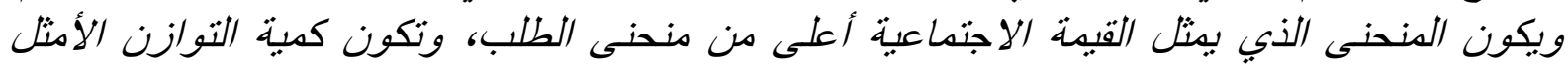
اجتماعيًا أكبر من كمية التوازن.

335 Meade, J. E., (1973). The Theory of Economic Externalities: The Control of Environmental Pollution and Similar Social Costs. Leiden: Sijthoff, P.90. 


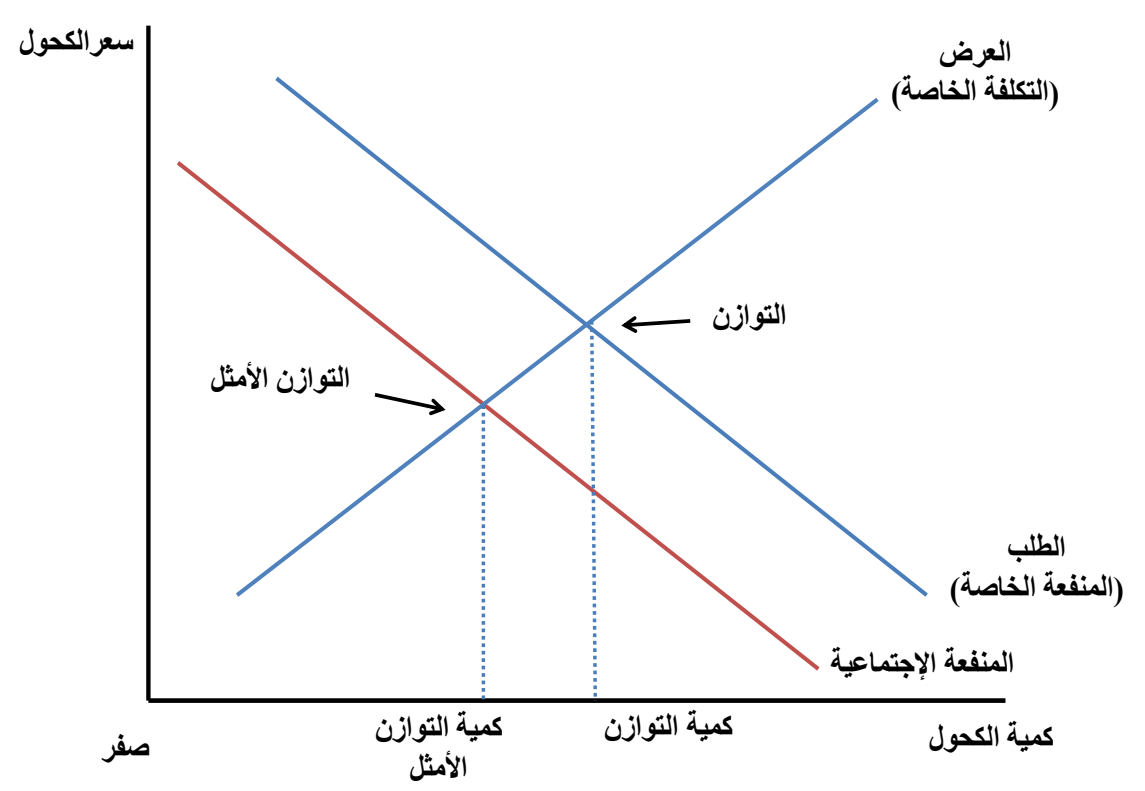

(رسم بياني 4) الأثار الخارجية السلبية في الاستهلاك.

يوضح هذا الرسم البياني السوق الذي يشتمل على أثار خارجية سلبية للاستهلاك، مثل سوق الهشروبات

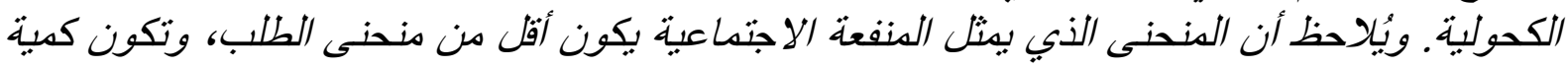

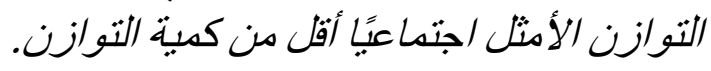

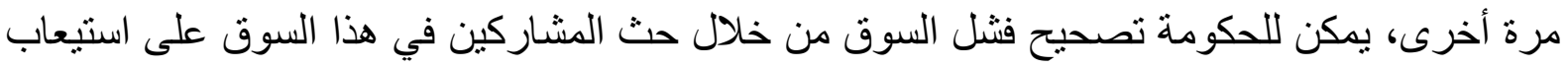

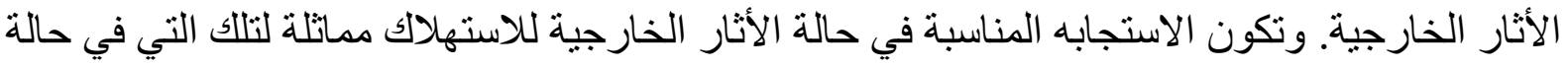

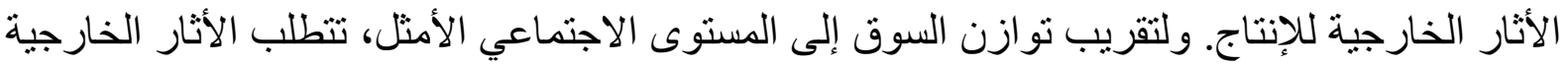

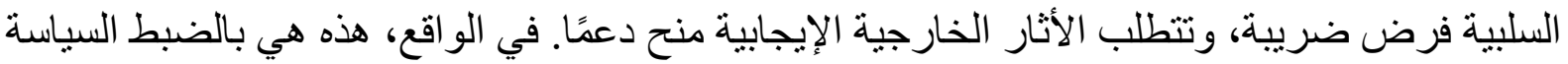

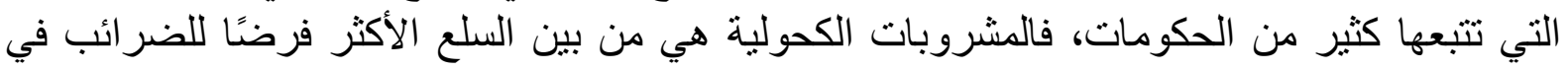

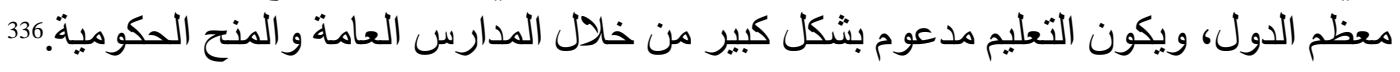

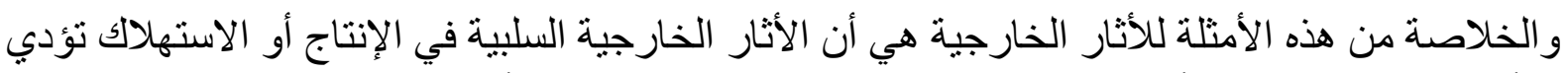

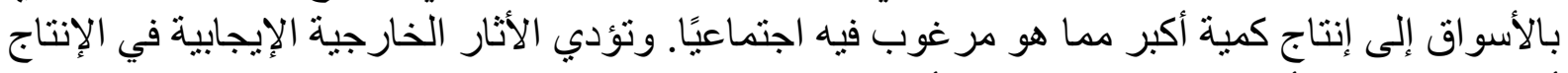

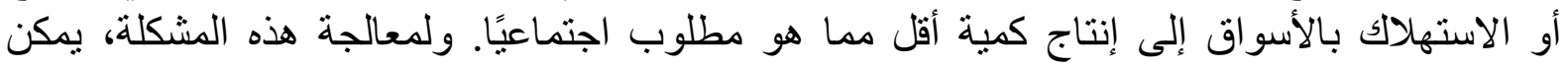

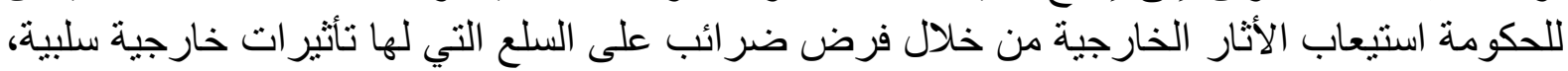
ودعم السلع التي لها أثار خارجية إيجايية.

\footnotetext{
${ }^{336}$ Wen-Fang Liu, Stephen J. Turnovsky, (2005). Consumption externalities, production externalities, and long-run macroeconomic efficiency, Journal of Public Economics 89, P. 1097.

${ }^{337}$ Bailey, Martin J. (1954). "The Interpretation and Application of the Compensation Principle." Economic Journal 64 (253), PP. 39-52.
} 


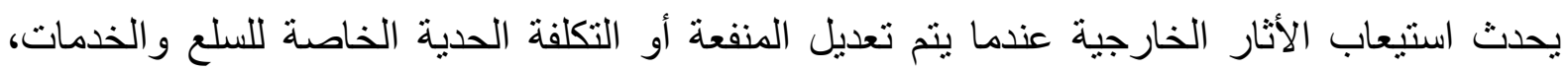
بحيث يأخذ المستخدمون في الاعتبار الفائدة أو التكلفة الاجتماعية الحدية الفعلية لقرار التهاتية التهم الاقتصادية.

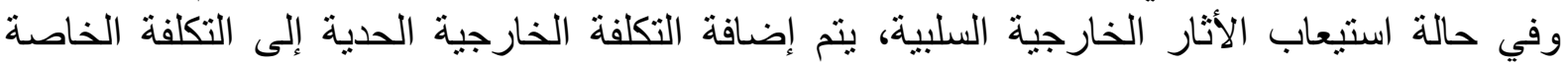

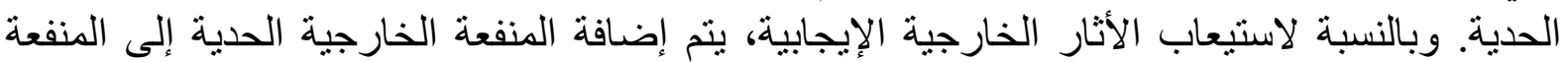

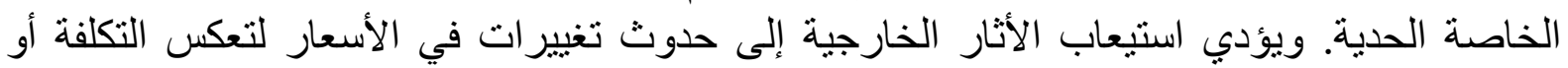
الفائدة الاجتماعية الحدية الكاملة للسلعة. 338

ويتطلب استيعاب الأثار الخارجية تحديد الأفراد المعنيين بهذه الأثار، وينطلب أيضًا قياس القيمة النقدية

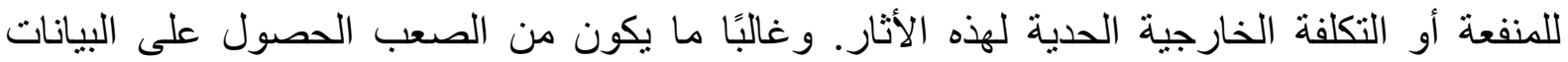

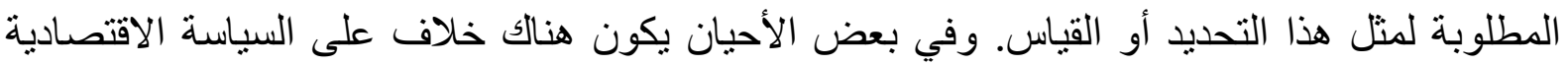

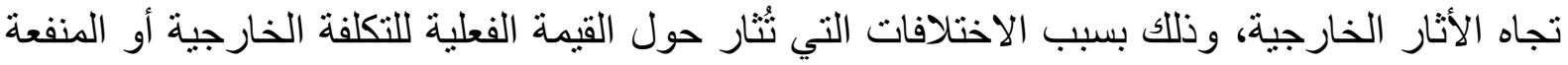

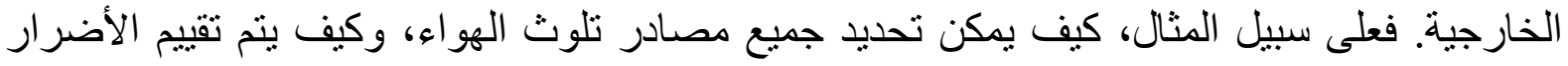

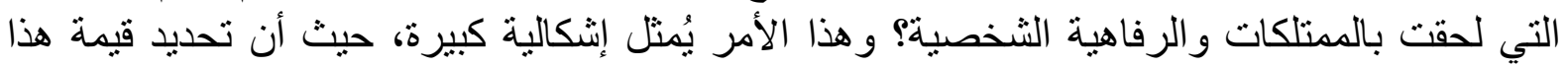

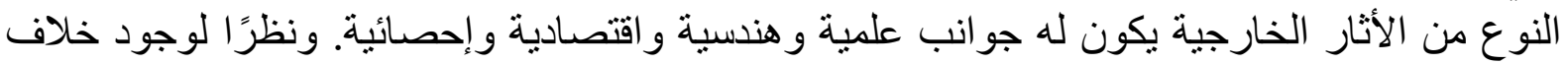

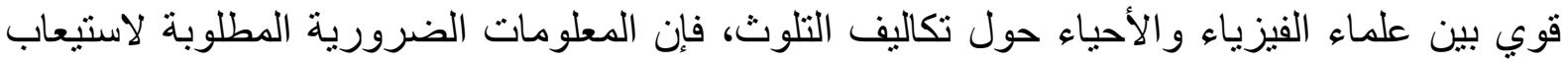
الأثار الخارجية يمكن أن يكون من الصعب الصعاه الحصول عليها.

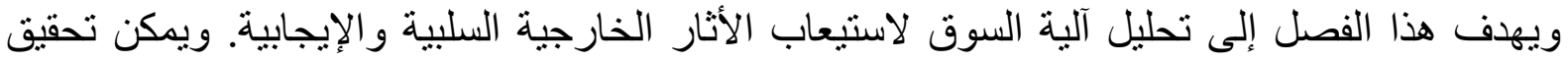

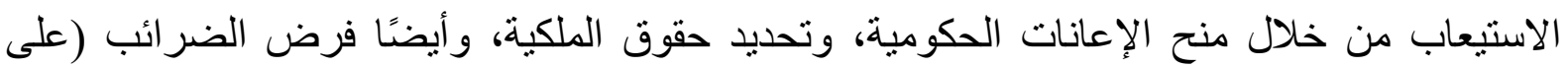

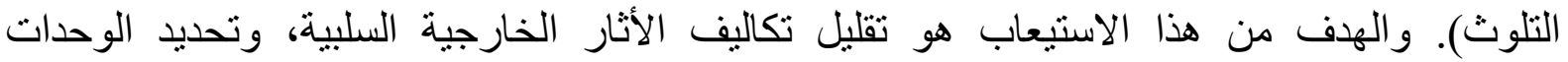
الاقتصادية التي تولد أثنار خارجية سلبية، و إلز امها بدفع مقابل هذه الأثار.

الأثار الخارجية السلبية هي تأثثرات ثانوية نؤدي إلى عدم الكفاءة في تخصيص الموائ التوارد الاقتصادية،

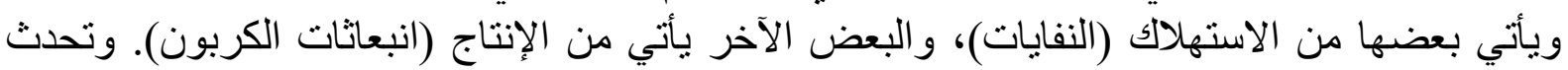

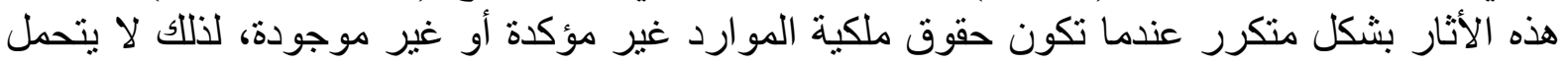

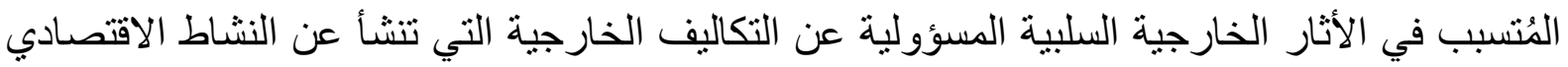

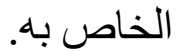

ولتوضيح كيفية تعامل السياسة العامة مع الأثار الخارجية السلبية أو الإيجابية، نُقسم هذا الفصل إلى

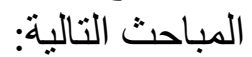

المبحث الأول: الضرائب التصحيحية واستيعاب الأثار الخارجية السلبية.

المبحث الثاني: الاعم التصحيحي واستيعاب الأثار الخارجية الإيجابية.

المبحث الثالث: حقوق ملكية استخدام الموارد الاقتصادية واستيعاب الأثار الخارجية: نظرية كواس.

${ }^{338}$ Berta, Nathalie, and Elodie Bertrand., (2014). "Market Internalization of Externalities: What Is Failing?" Journal of the History of Economic Thought 36 (3), P. 331. 


\section{المبحث الأول: الضرائب التصحيحية واستيعاب الأثار الخارجية السلبية}

عادة ما يتم فرض الضريية التصحيحية لتعديل التكلفة الخاصة الحدية لسلعة أو خدمة ما، وذلك من أجل

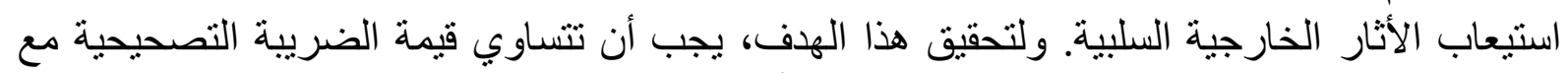

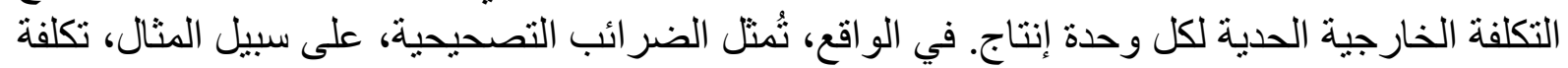

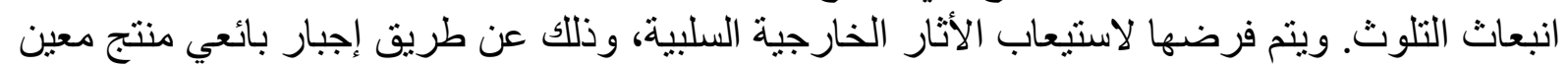
على دفع مبالغ مساوية للتكاليف الخارجية الحدية لكل وحدة من الإنتاج التي يتم بيعها. 339

ولتبسيط فكرة الضرائب التصحيحية، نفترض أنه نم فرض ضريبة التبانة تصحيحية على منتجي الورق

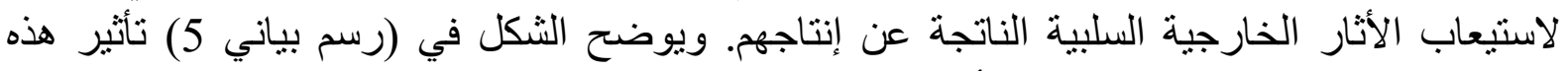

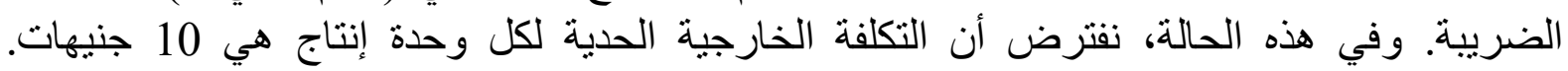

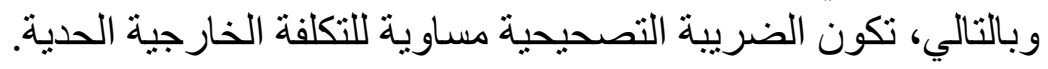

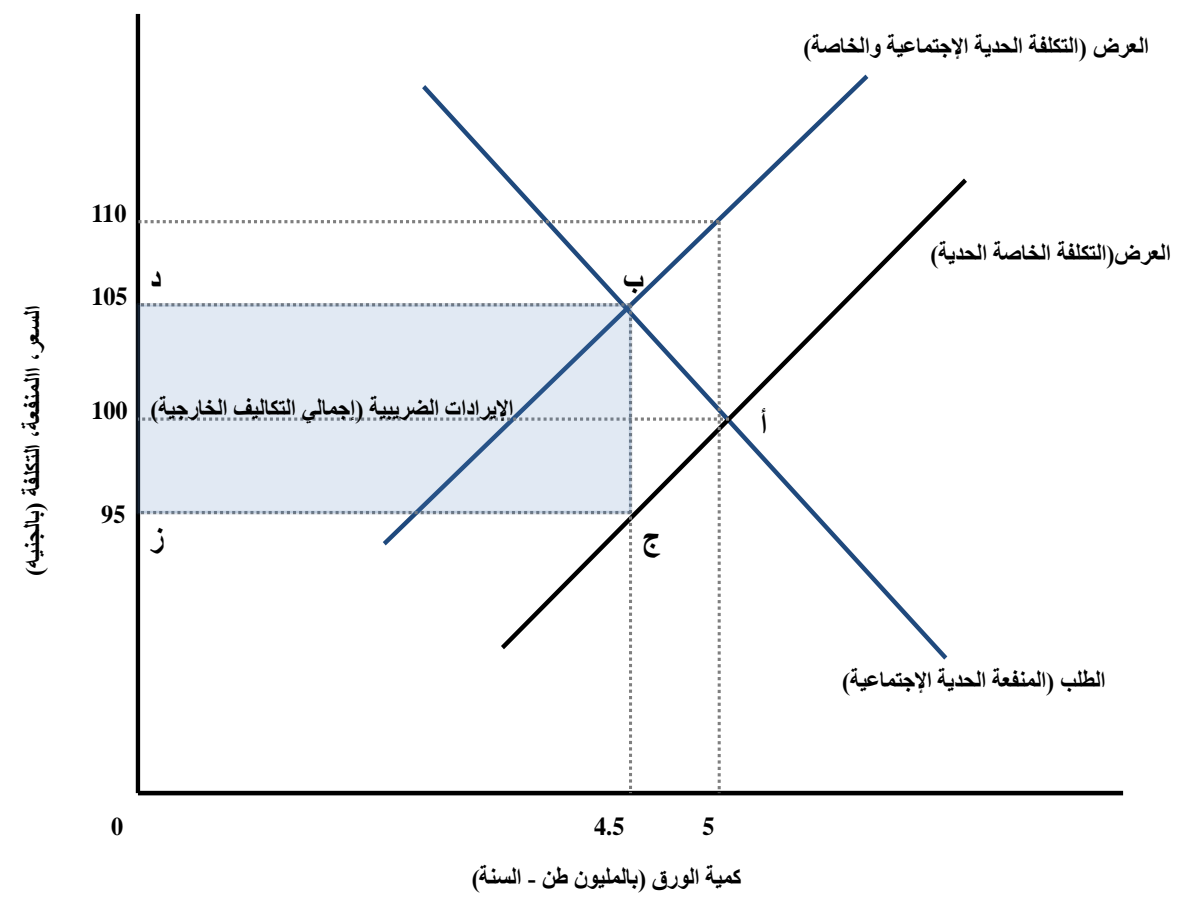

(رسم بياني 5) تأثير الضرائب التصحيحية.

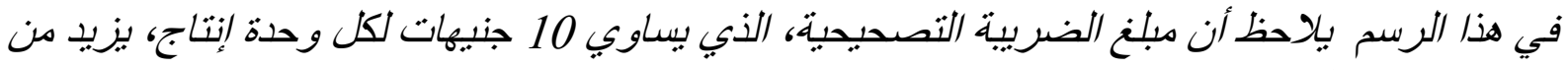

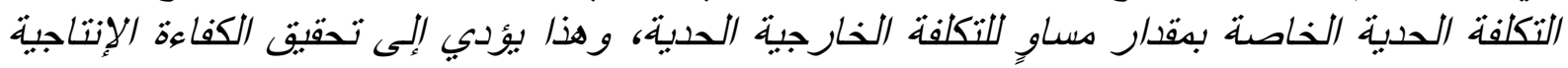

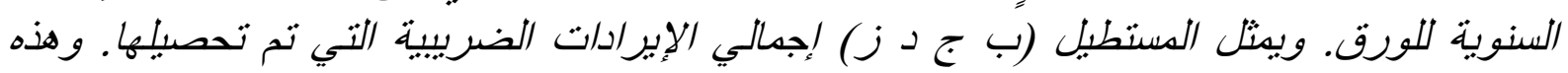

${ }^{339}$ Baumol, William J., (1972). "On Taxation and the Control of Externalities." American Economic Review 62 (3), P. 307. 
الإيرادات تساوي إجمالي التكاليف الخارجية عند مستوى الإتتاج الفعّال، ولكن بشرط ألا تختلف التكلفة الذارجية الحلية باختلاف الإنتاج.

في هذه الحالة، سيتم تحديد الضريبة بمبلغ 10 جنيهات لكل طن من الورق، ورئ وهي التكلفة الخارجية الحدية

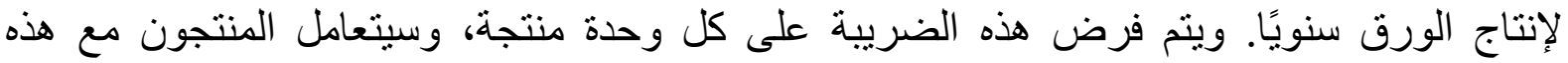

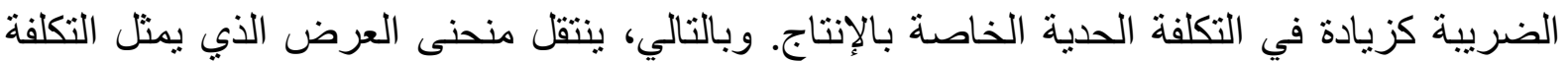

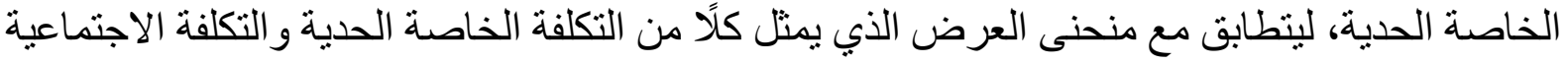

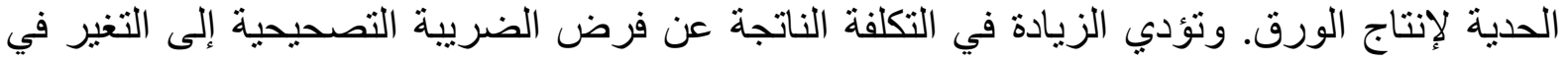

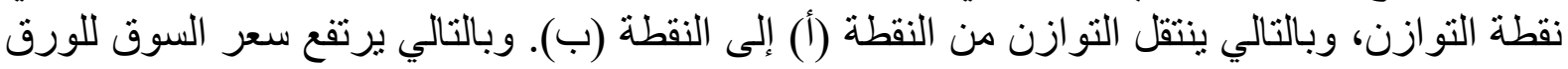

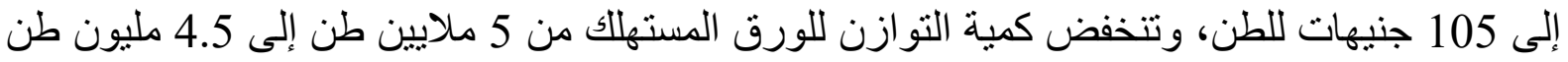
سنويًا. و هذا يساوي بالضبط كمية الإنتاج السنوي الفعّال.

وبالتالي إذا تم فرض ضريبة قدرها 10 جنيهات للطن، يكون إجمالي مبلغ الإير ادات الضريبية التباتية السنوية

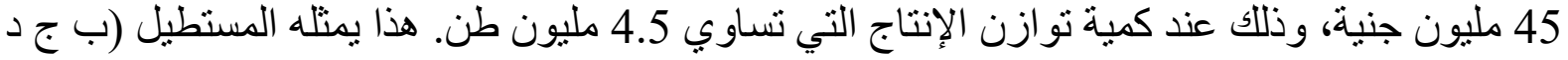

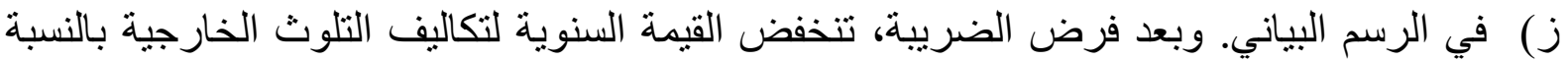

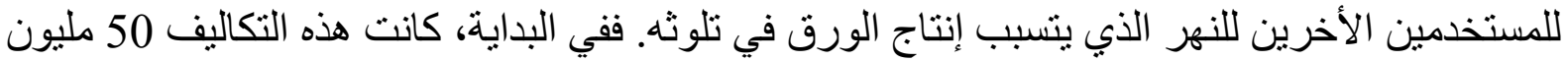

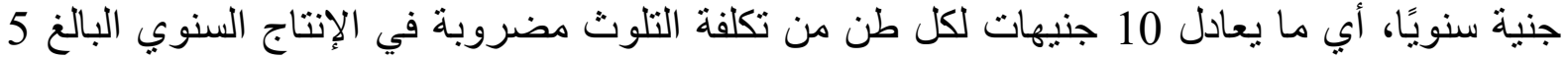

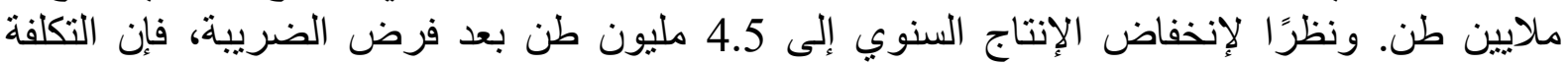
السنوية للتلوث من الورق المنتج تنخفض الإنتاج اللى 45 مليون جنيه.

وفي هذا السياق، يمكن القول أن فرض الضريبة التصحيحية لا يمنع مثلًا مصادر تلوث الأنهار نهائًًا،

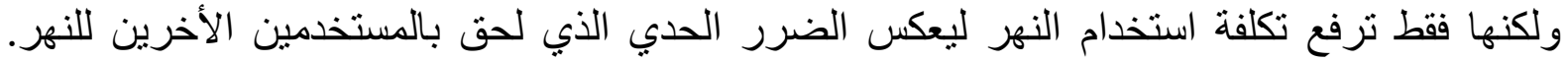

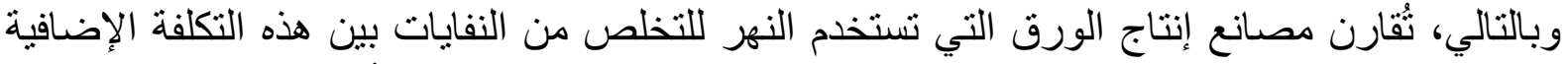

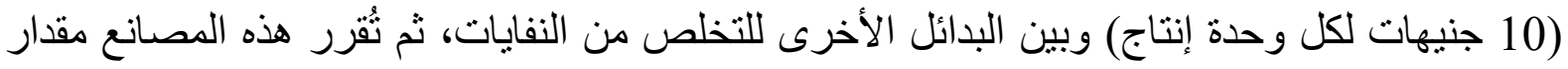

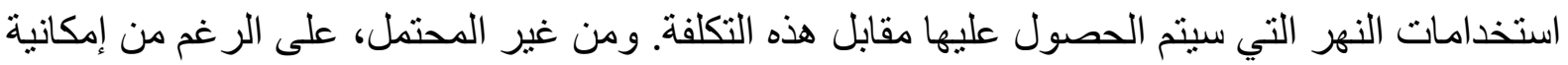

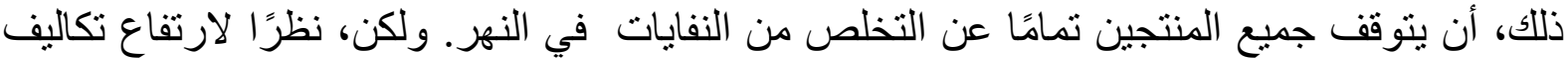

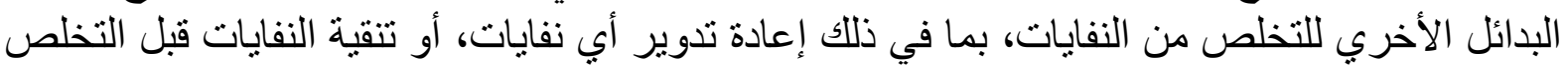

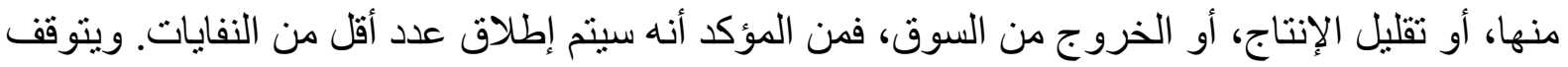

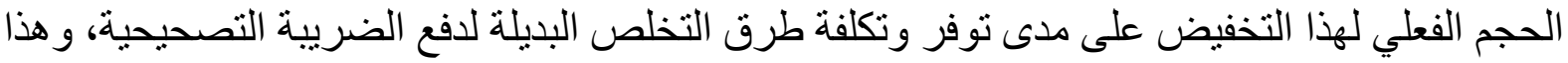

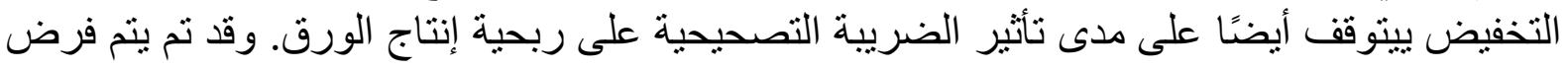

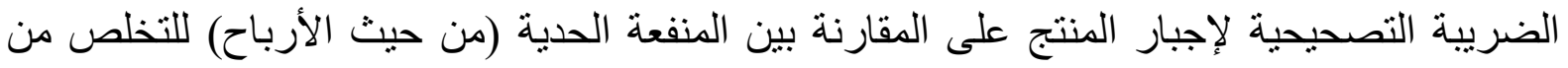

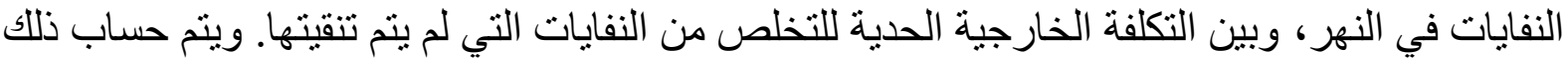
عن طريق إضافة التكلفة الخارجية الحدية إلى التكلفة الخاصة الحدية للنية للإنتاج.

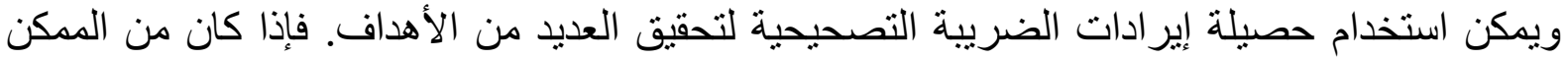

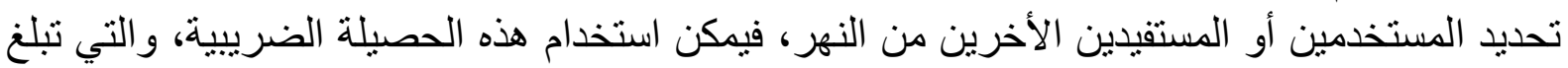

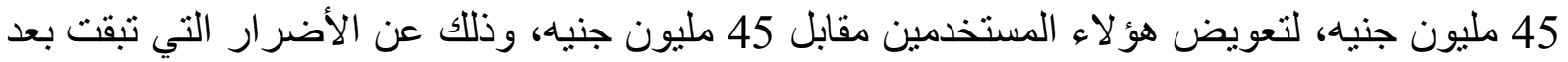

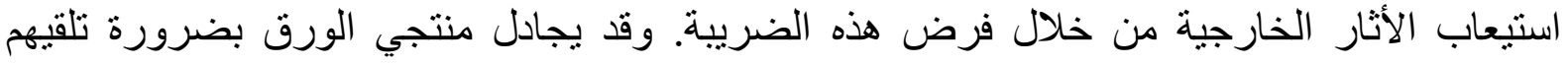

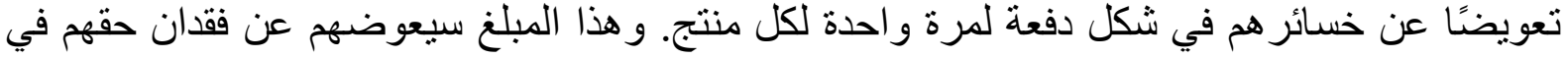

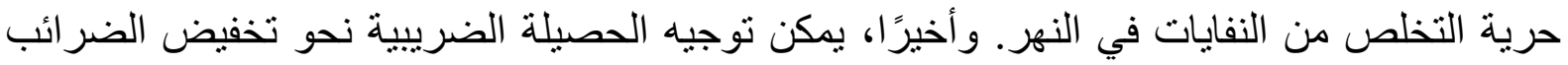
الأخرى، أو نحو زيادة الخدمات الحكومية. 


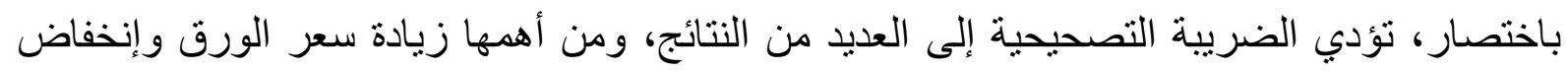

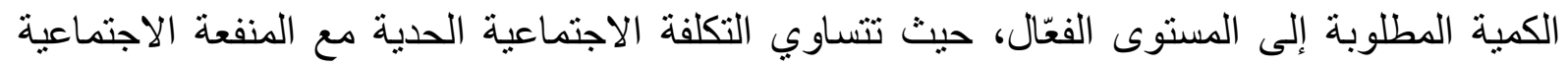

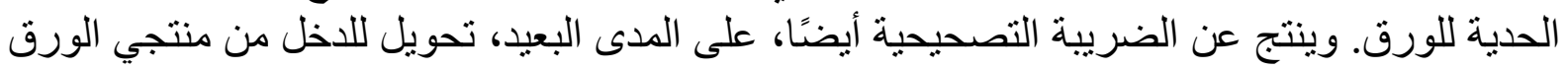

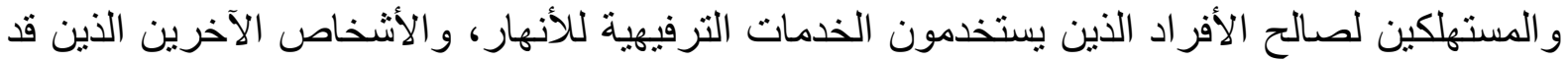

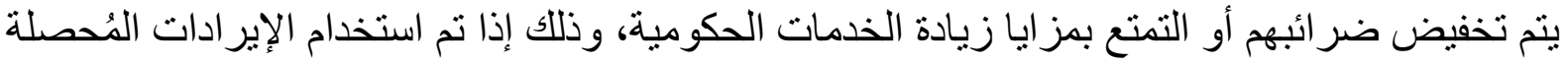

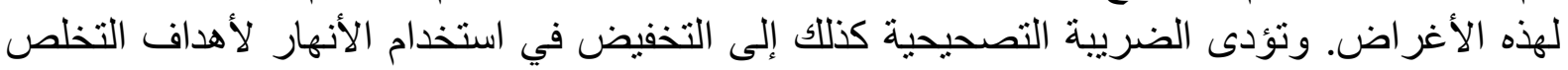

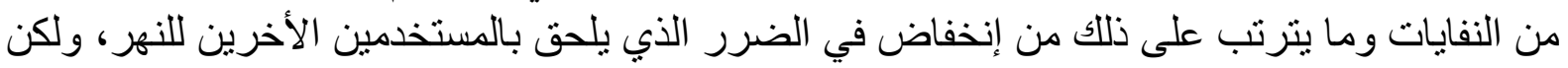

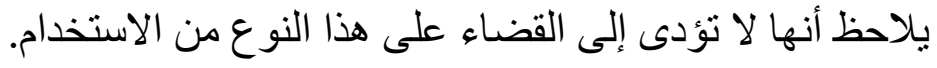

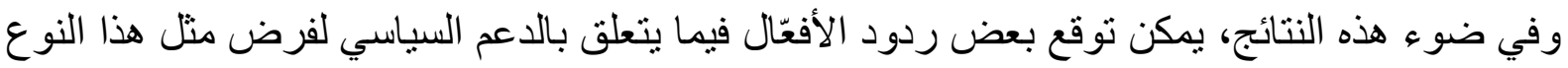

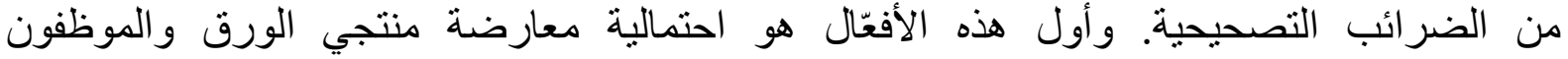

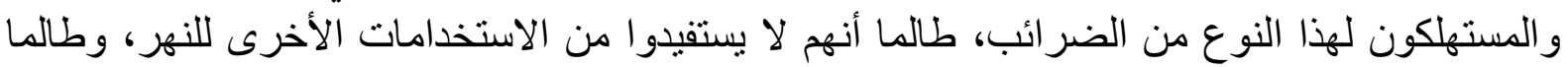

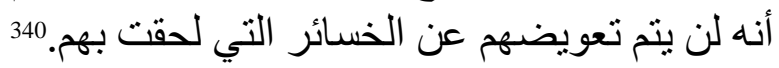

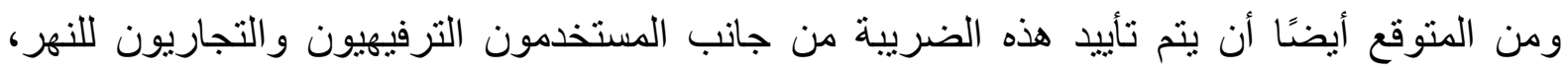

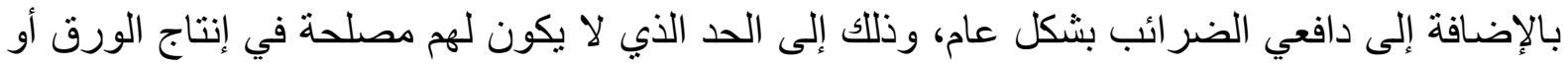

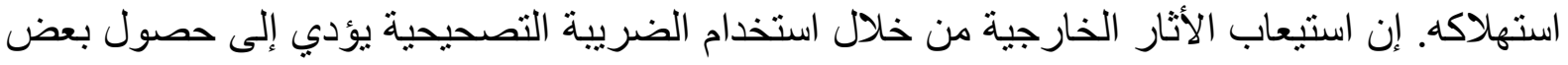

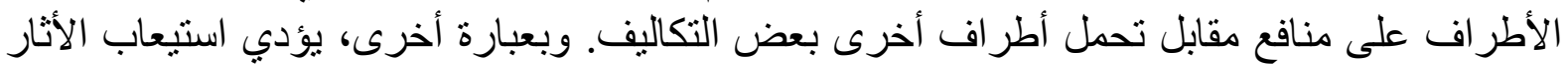

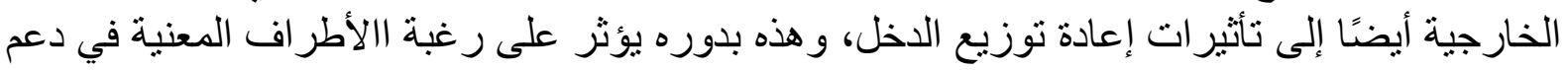
نظام الضر ائب التصحيحة.

\section{أولًا: استيعاب الأثار الخارجية السلبية للسلع المباعة في أسواق غير تنافسية}

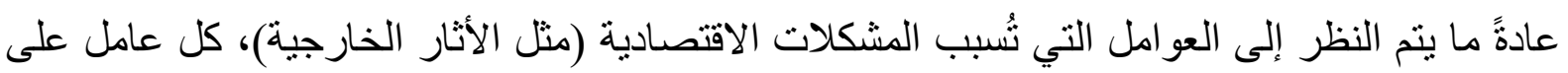

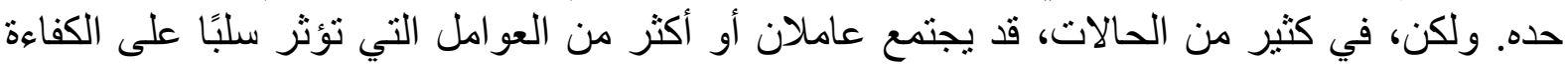

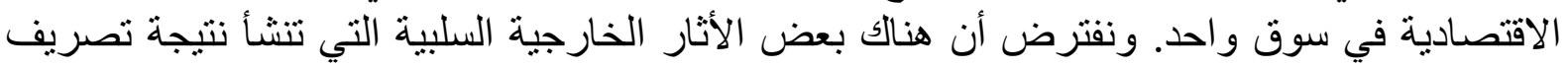

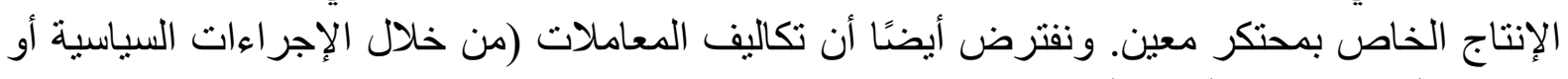
غيرها) الخاصة بمحاولة تفكيك هذا الاحتكار تكون مرتفعة، بحيث يكون تنفيذ هذا الاختيار غير هُجدي الإني

اقتصاديًا.

في هذه الحالة، يوجد نوعين من العوائق التي تمنع تحقيق مستوى الإنتاج الفعّال من حيث الكفاءة

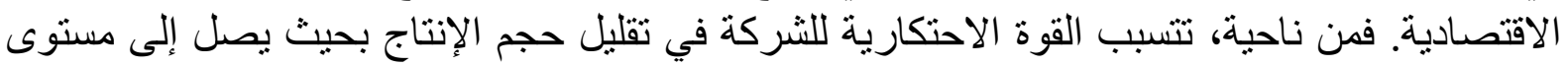

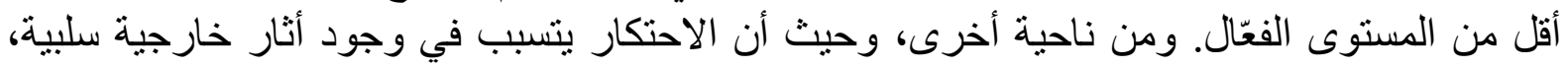
ومع افتر اض ثبات المتغير ات الأخرى، فإنه يتسبب في زيادة الإن حجم الإنتاج إلى مستوي أكبر من المستوى

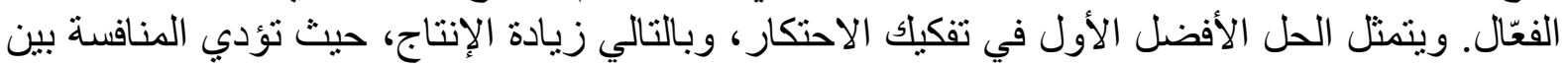

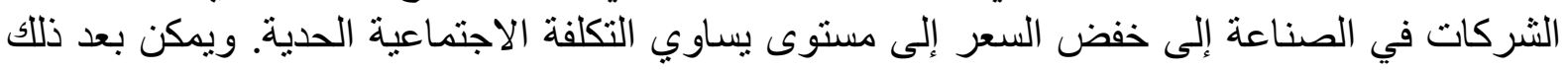

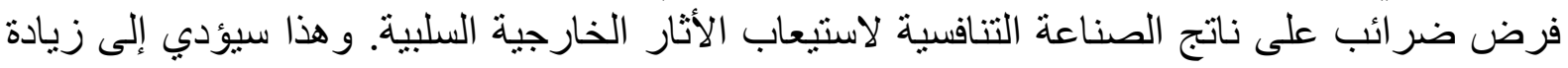

السعر في الصناعة، وتقليل الإنتاج.

${ }^{340}$ Cornes, Richard, and Todd Sandler., (1996). The Theory of Externalities, Public Goods and Club Goods. Second edition. New York: Cambridge University Press, P.405. 
ولكن، توجد طريقة بديلة لتحقيق نفس النتيجة الفعّالة. ينتج الاحتكار في البداية مستوى إنتاج سنويًا أقل

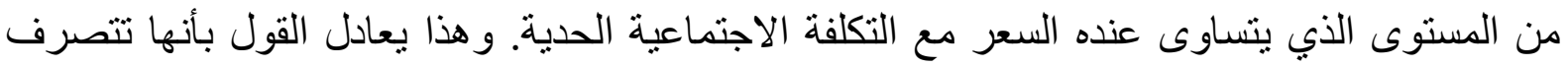

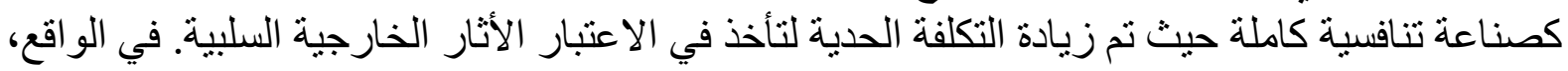

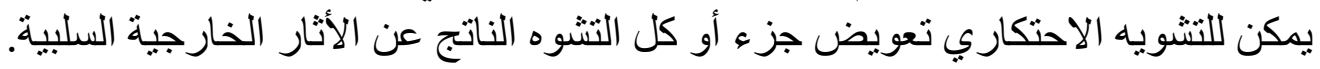

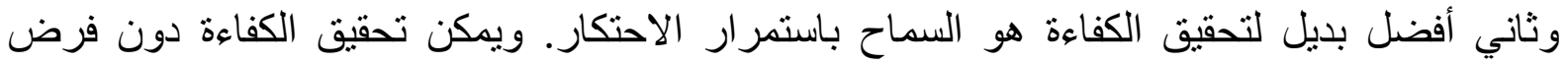

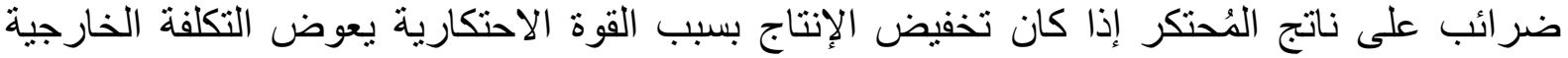

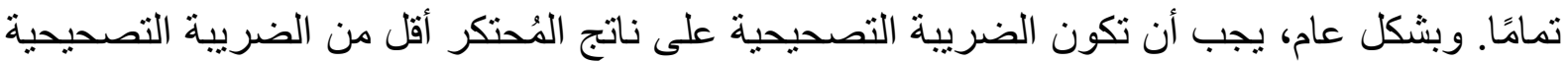

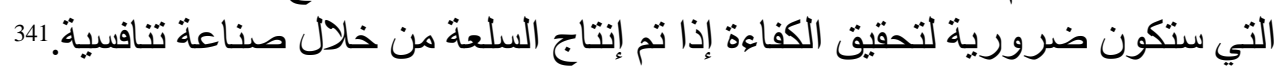

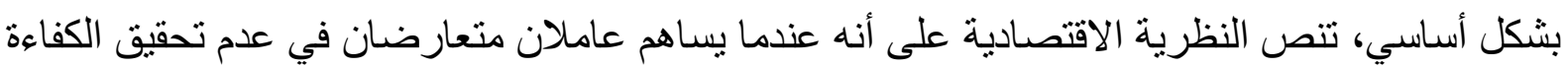

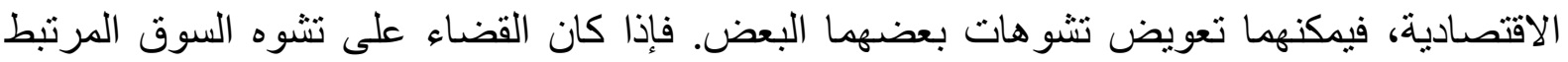

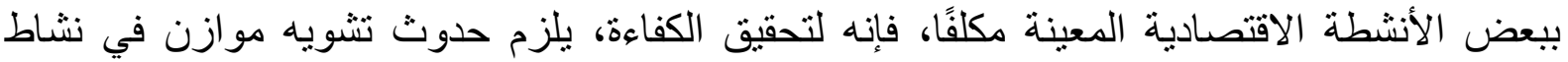

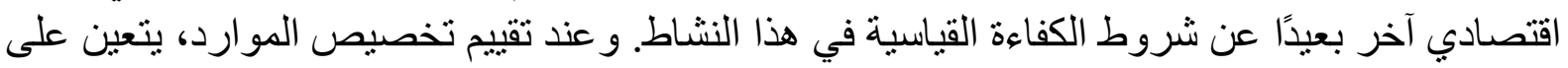
الخبير الاقتصادي معالجة كل مشكلة على أساس مخصص لتص لتحديد ما إذا كانت هناك أي مشكلة ثانية

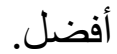

${ }^{341}$ Richard G. Lipsey and Kelvin Lancaster, (1956). "The General Theory of Second Best," Review of Economic Studies 24, PP.11-32. 


\section{المبحث الثاني: الاعم التصحيحي واستيعاب الأثار الخارجية الإيجابية}

يتشابه مفهوم الدعم التصحيحي مع مفهوم الضريبة التصحيحية. ويوضح (رسم البياني 6) كيف يمكن

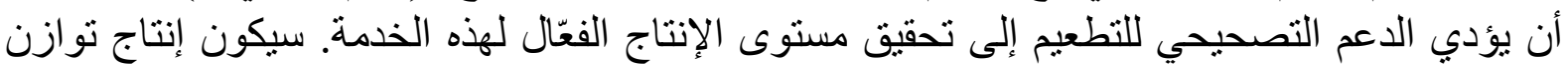
السوق التنافسي هو 10 ملايين تطعيم سنويًا بسعر السوق التنافسي البالغ 25 جنيه لكل تطعيم. ويعتبر هذا لإنا

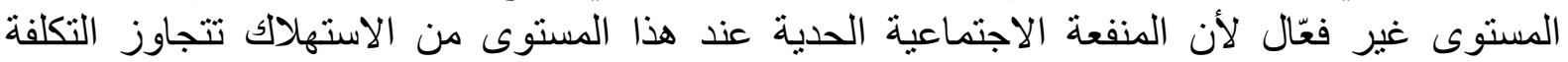

الاجتماعية الحدية.

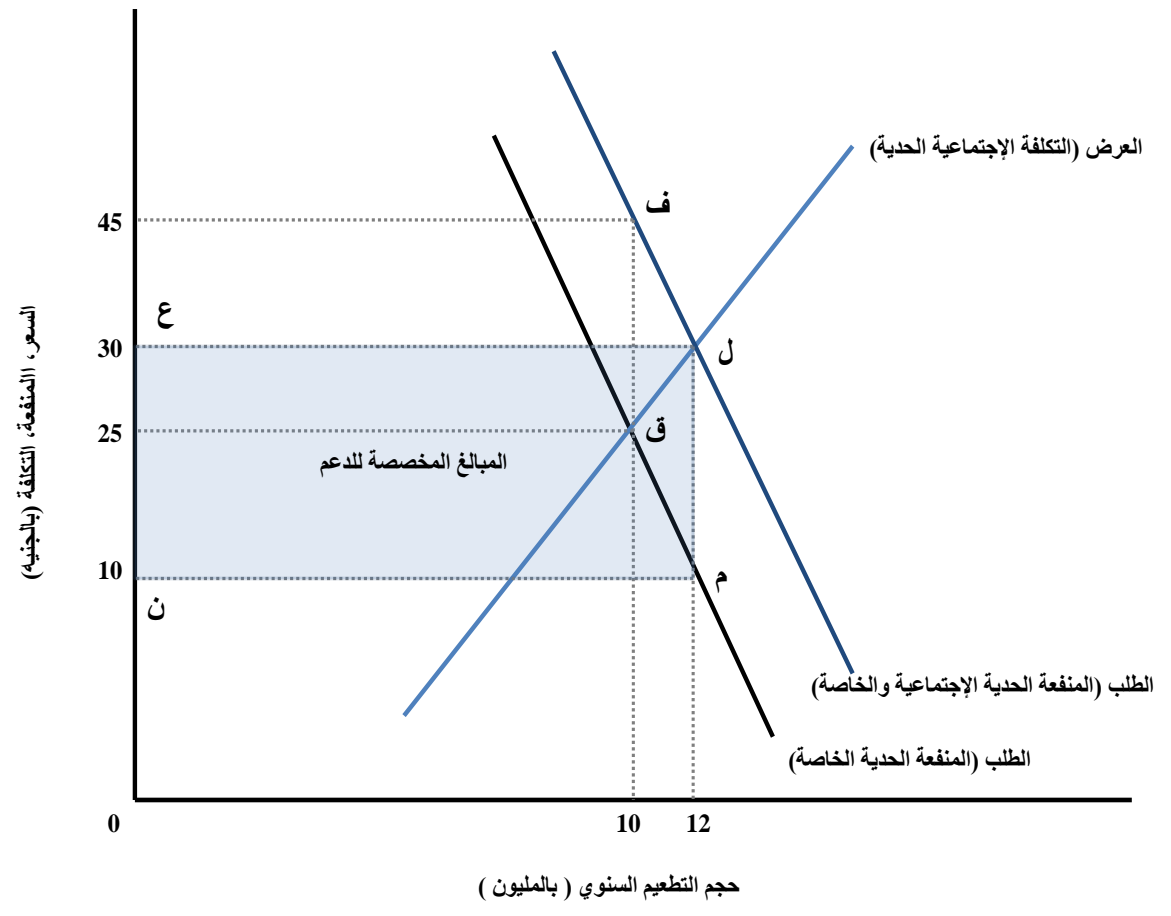

(رسم بياني 6 ) الاعم التصحيحي.

يوضح هذا الرسم البياني أن الدعم التصحيحي يتسبب في زيادة طلب المستهكين على التطعيمات،

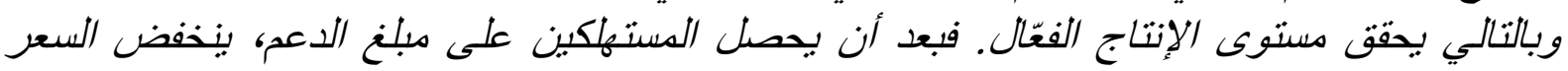

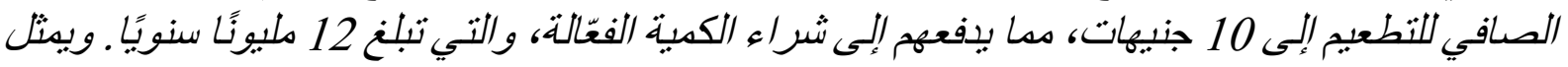
المستطبل (ل م ن ع) إجمالي مدفوعات الدعم عند مستوى الإنتاج الفعّال.

ويمكن تعريف الدعم التصحيحي على أنه المبالغ التي تدفعها الحكومة إما لمشترين أو لبائعين سلعة معينة، بحيث يتم تخفيض السعر الذي يدفعه المستهلكون. ويجب أن تتساوي قيمة هذا الداعم مع المنفعة الخارجية الحدية للسلعة أو الخدمة التي يتم استهلاكها. وفي هذه الحالة، تكون قيمة المنفعة الخارجية

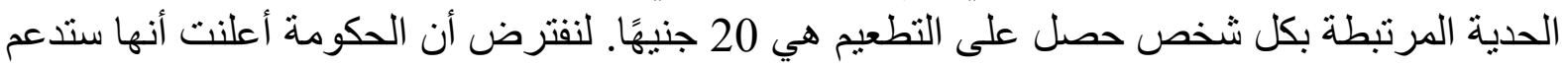
كل شخص تم تطعيمه بمبلغ قدره 20 جنيه، فهذا المبلغ يكون بمثابة إضافة إلى المنفعة الخاصة الحئ الحدية

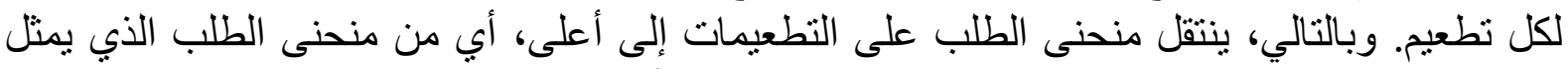

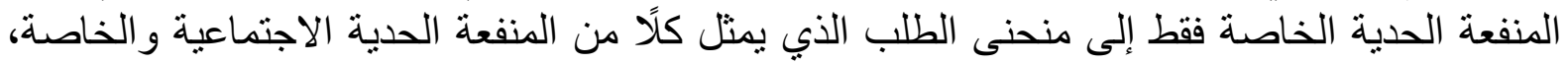
وذللك بمقدار 20 جنيه. ومع زيادة الطلب على التطعيمات، يتحرك توازن السوق من النقطة (ق) إلى كلى النقطة (ل) في الرسم البياني رقم 6. و عند هذه النقةة، يرتفع سعر السوق للتطعيم إلى 30 جنيه لتغطية 
الزيادة في التكاليف الحدية للإنتاج. ولكن، صافي سعر التطعيم ينخفض بعد تلقي المستهلكين للاعم.

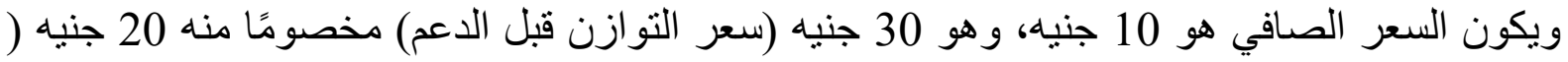

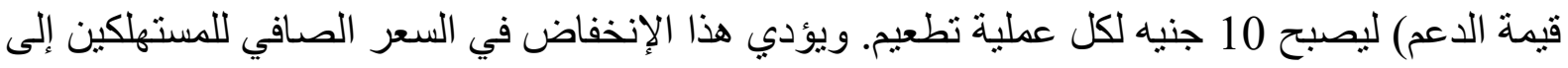
زيادة الكمية المطلوبة لتصل إلى 12 مليون سنويًا، وهو الناتج الفعّال.

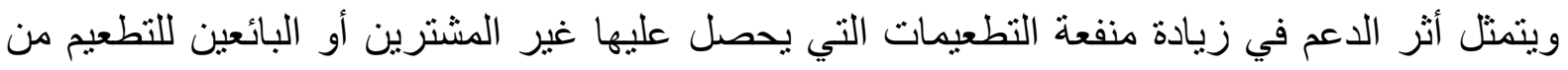

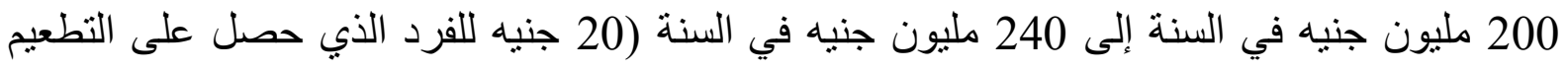

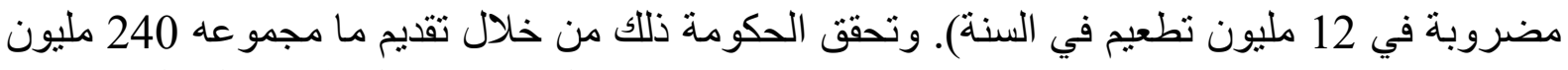

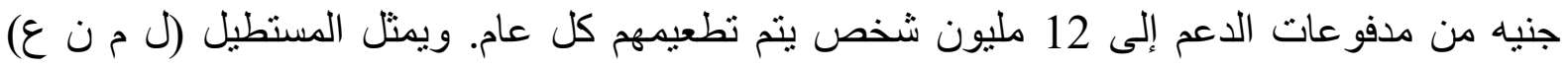

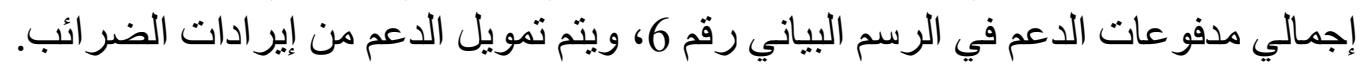

ومن ضمن الأمثلة على الدعم التصحيحي تقديم خدمات حكومية معينة بمستويات أقل من التكلفة الحدية

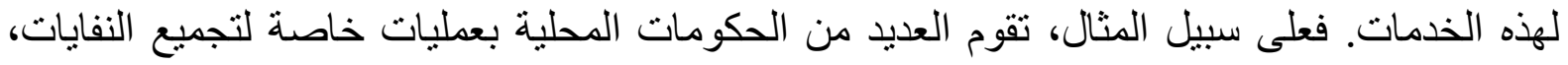

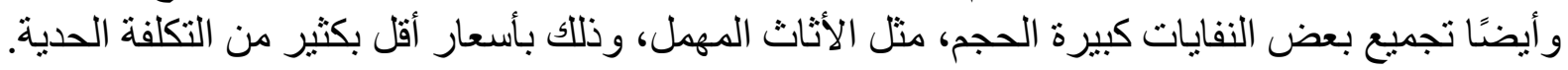

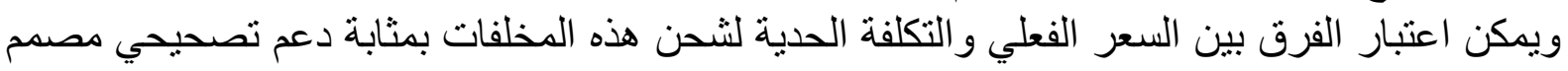

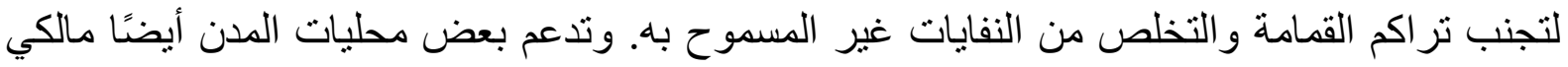

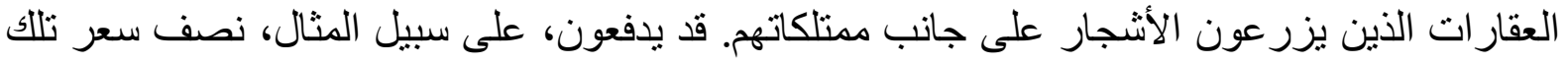

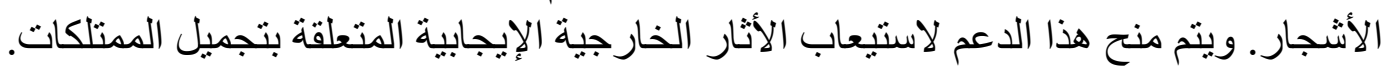

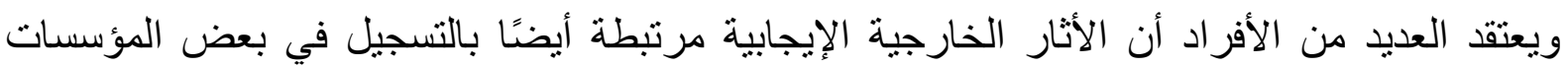

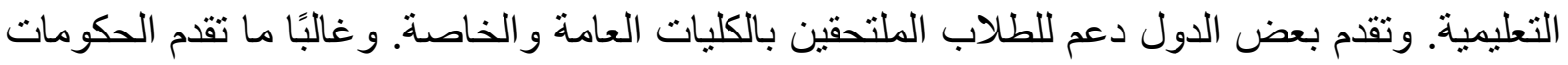

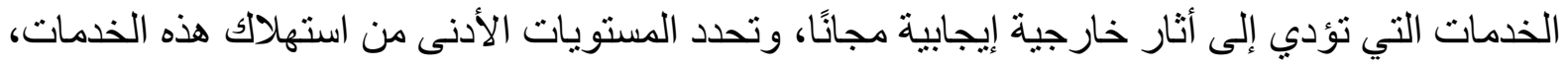

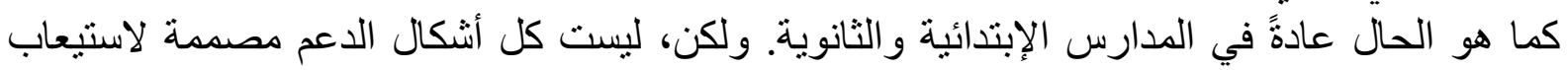

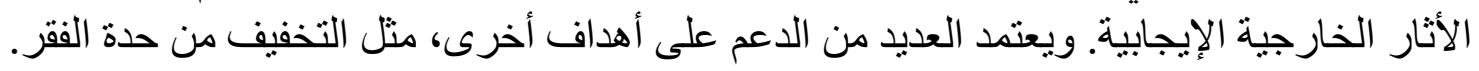




\section{المبحث الثالث: حقوق ملكية استخدام الموارد الاقتصادية واستيعاب الأثار الخارجية: نظرية كواس}

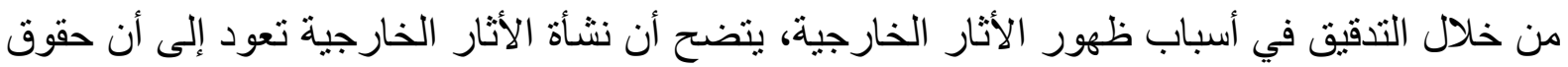

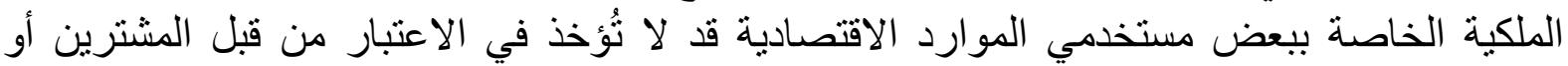

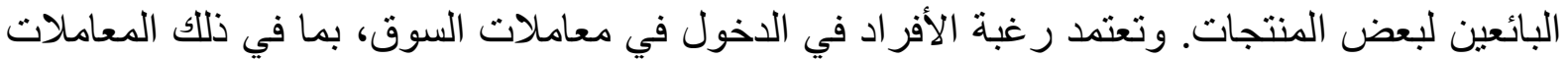

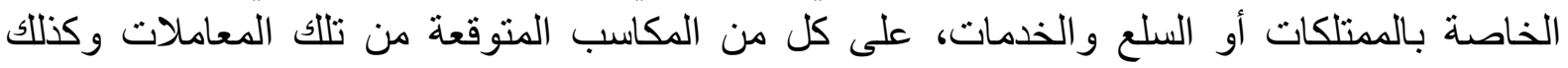

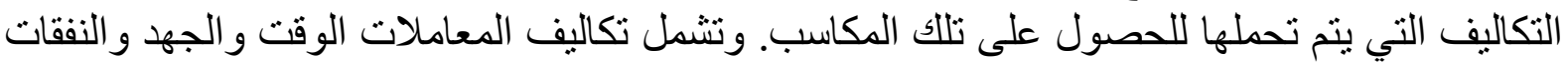

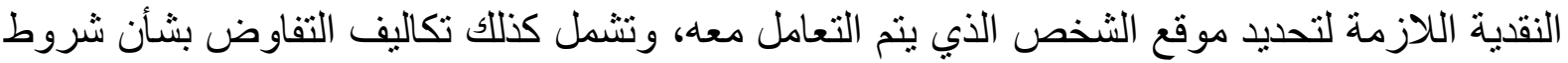

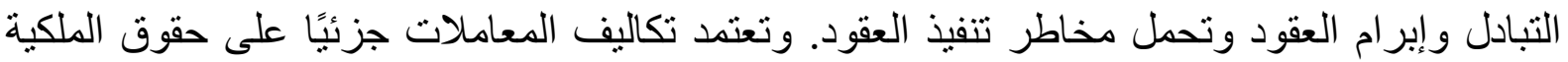

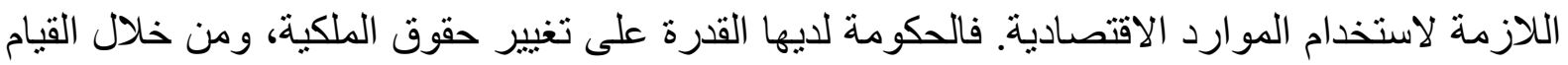

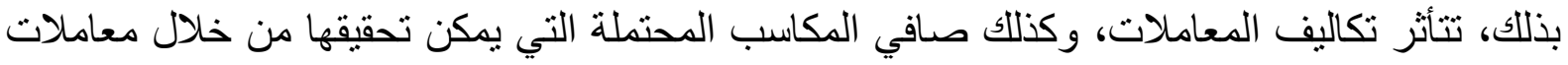

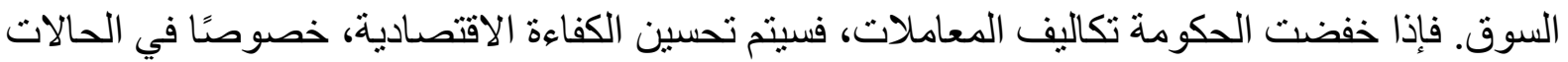

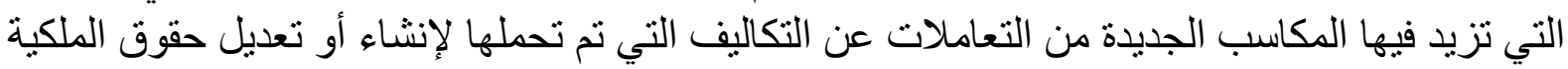
الموجودة مسبقًا.

ويمكن للحكومات أن تُعدل هيكل بعض الحقوق، وقد عدلت بالفعل حق الثركات التبات التجارية في انبعاث

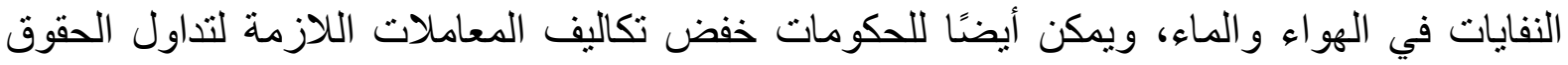

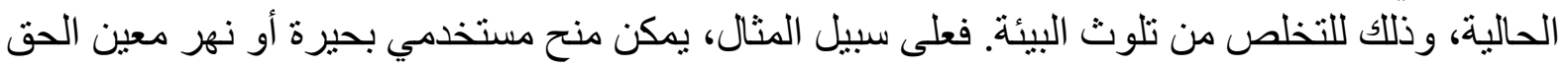

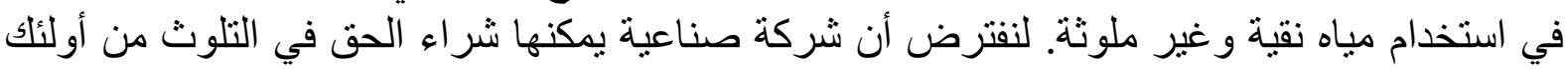

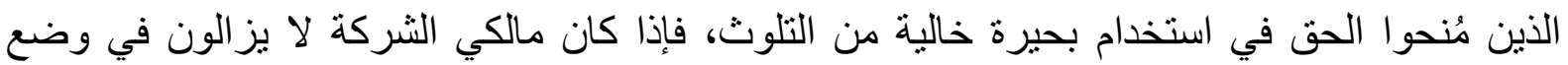

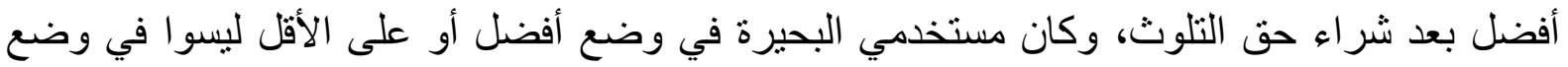

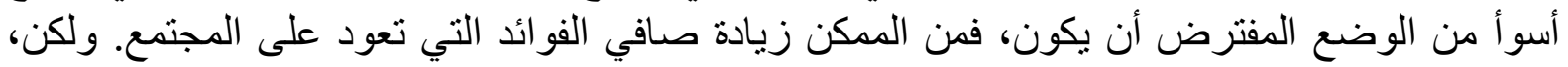

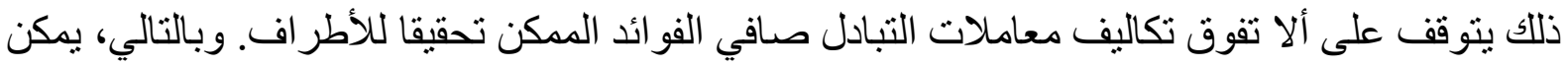

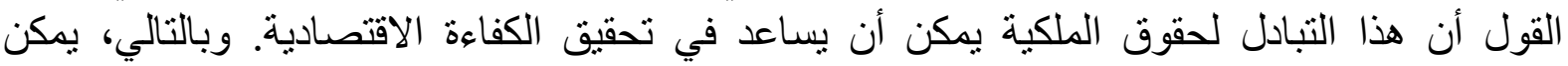

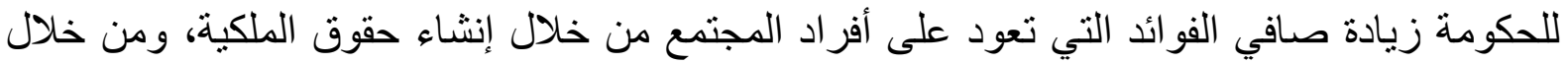

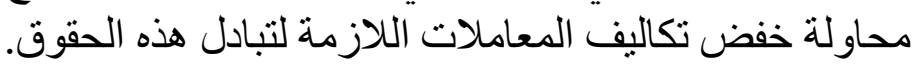

وتتص نظرية كواس على أن الحكومات، بمجرد إنثاء حقوق استخدام الموارد الاقتصادية، يمكنها

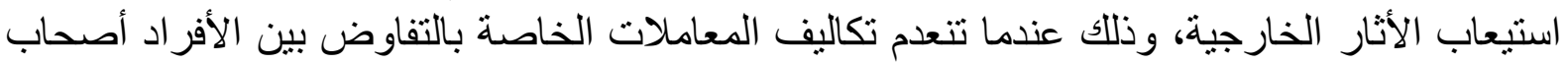

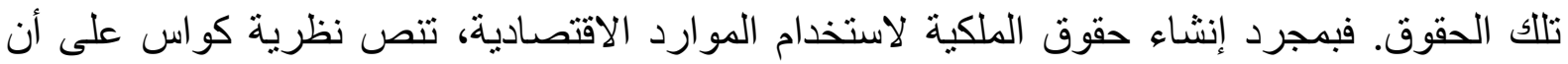

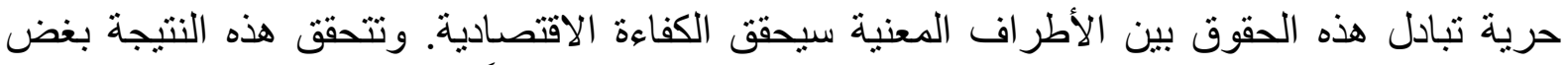
النظر عن الطرف الذي خُصص لهُ لهن حق استخدام المورد الاقتصادي بدايةً 343

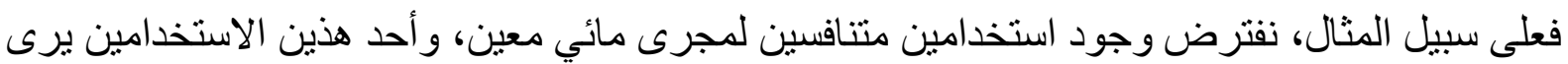

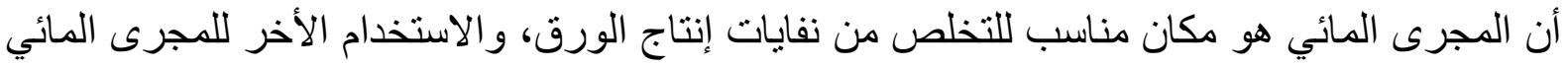

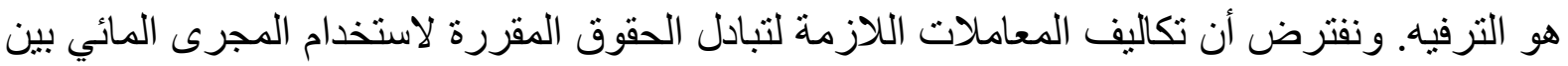

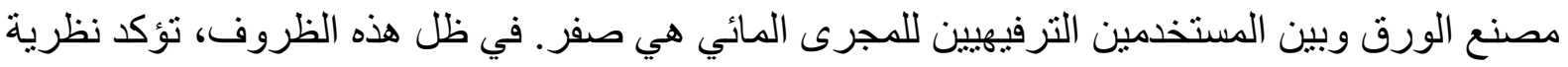

342 Polinsky, A. Mitchell., (1979). “Controlling Externalities and Protecting Entitlements: Property Right, Liability Rule, and Tax-subsidy Approaches." Journal of Legal Studies 8 (1), PP. 1 - 48.

${ }^{343}$ Meade, J. E., (1973). The Theory of Economic Externalities: The Control of Environmental Pollution and Similar Social Costs. Leiden: Sijthoff, P.81. 
كو اس أنه لا يوجد فرق بين ما إذا تم منح المصنع الحق في تلويث المجرى المائي وبين منح المستخدمين

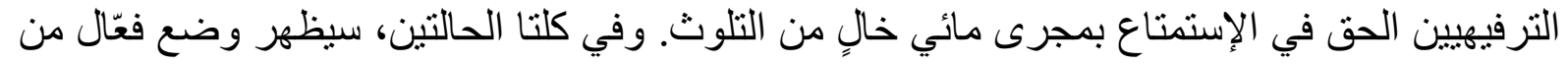

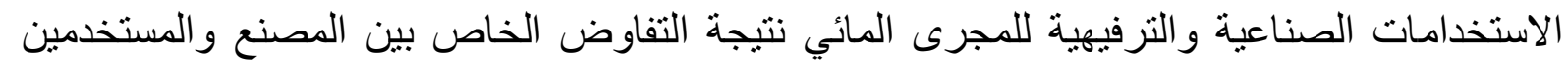

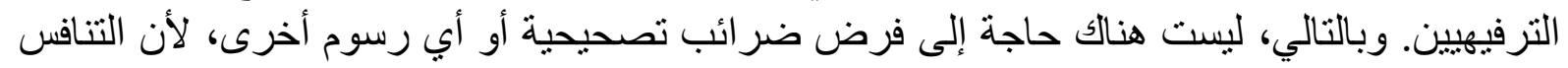
على استخدام المجرى المائي من قبل الأطر اف المعنية سيؤدي إلى استيعاب الأثار الخارجية.

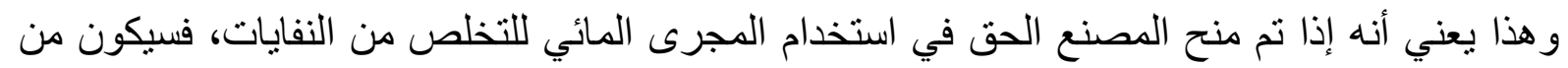

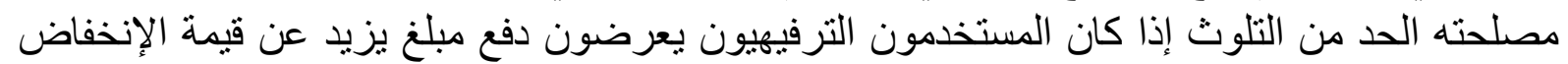

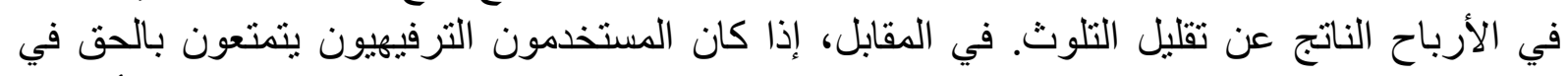

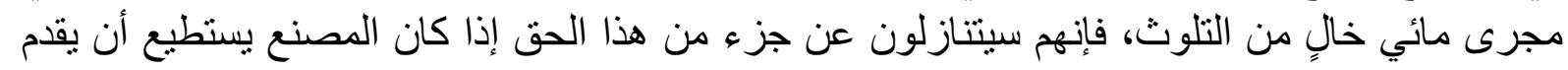

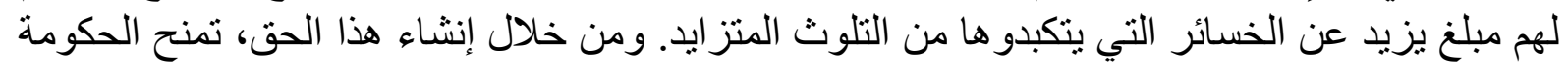

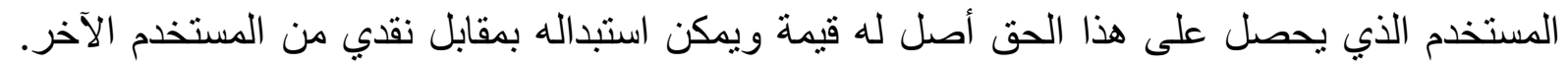

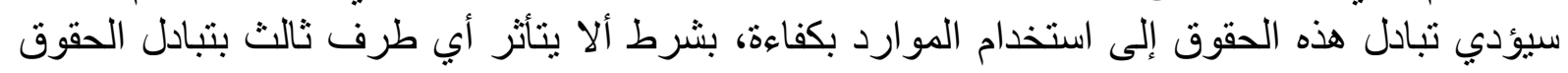
التي أنشأتها الحكومة.

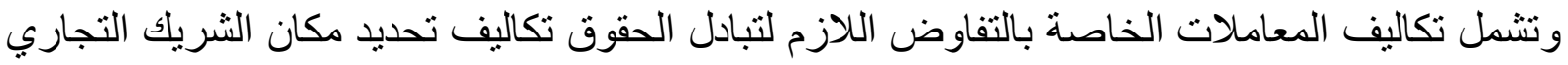

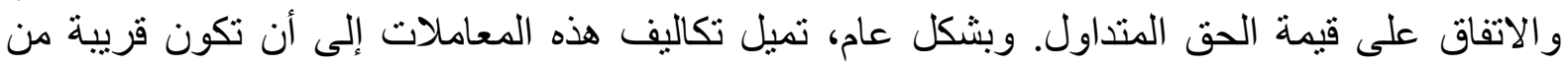

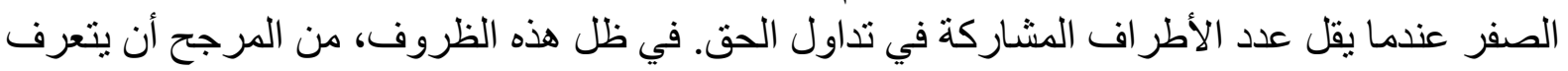

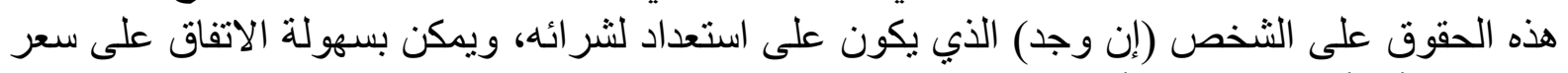

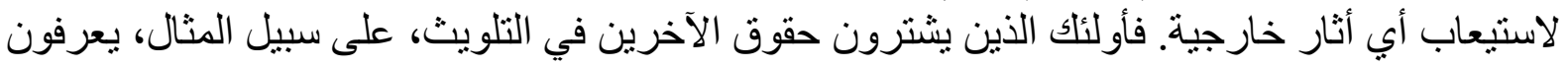

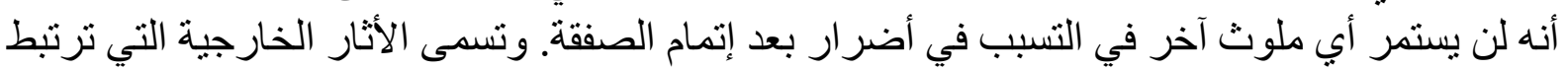

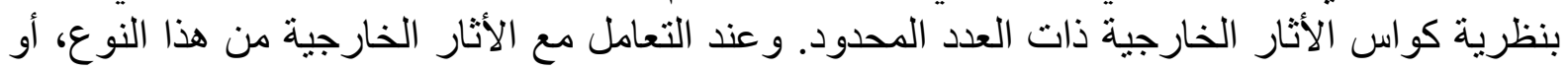

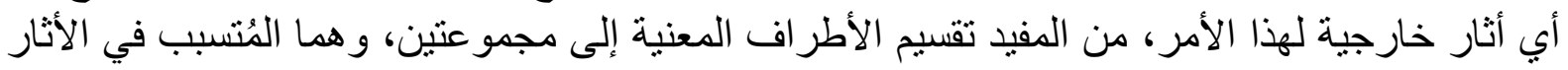

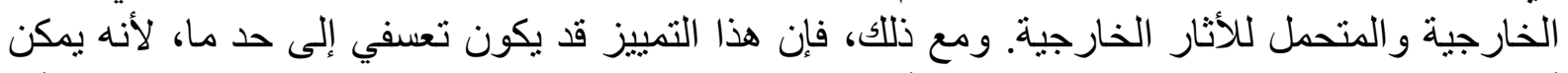

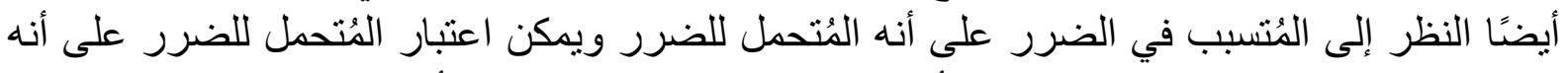

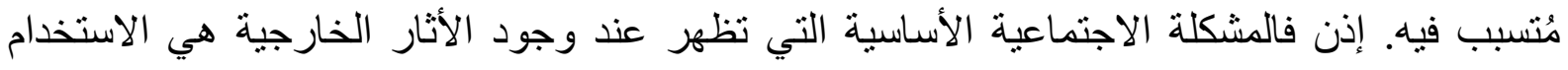
المتناز ع عليه لمورد إنتاجي. فالمئ.

\section{أولاً: تبادل حقوق الملكية لاستيعاب الأثار الخارجية السلبية}

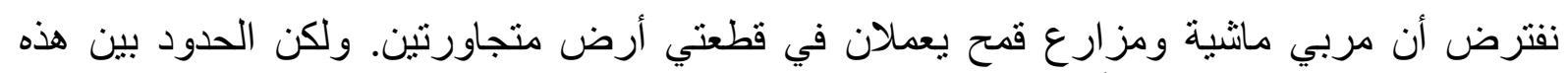

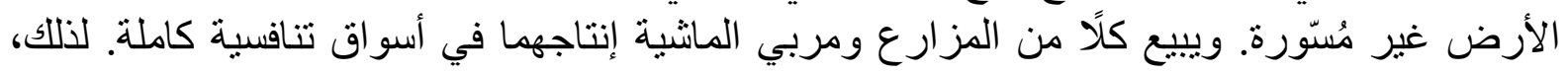

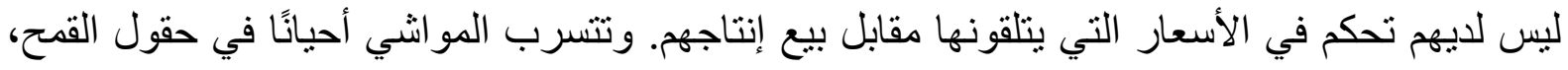

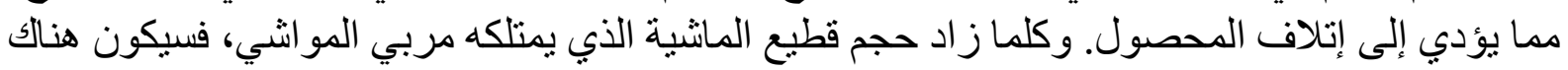

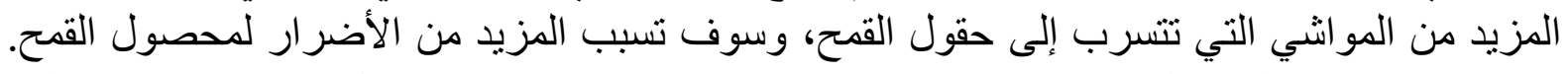

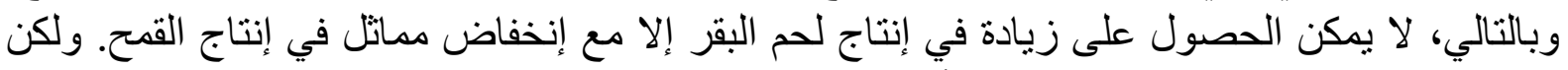

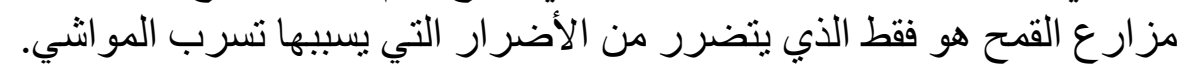

لنفترض أن السلطات الحكومية تمنح منتج القمح الحق في أن تكون أرض خالية من تسرب أب مواشي الثي

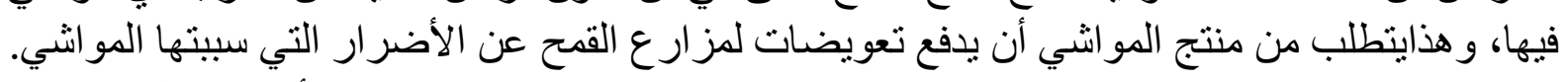
و هذا يجبر منتج الموانتي على مراعاة التكلفة الخارجية، والتي تساوي حجم الأضرار التعن التي سبيتها 
المو اشتي لمحصول القمح. في الواقع، يعمل القانون على استيعاب الأثار الخارجية بطريقة تزيد من التكلفة

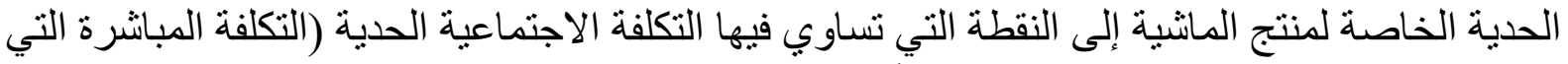
يتحملها منتج المواثي، بالإضافة إلى قيمة الأضر ار التي لحقت بمحصول القمح).

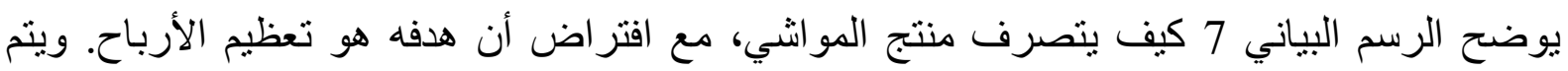

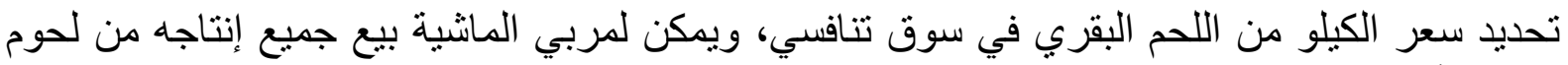

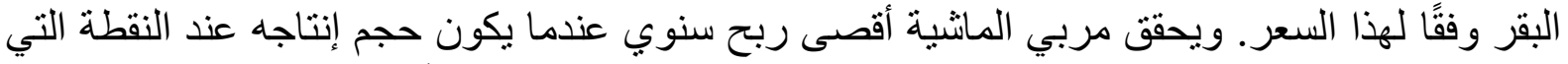

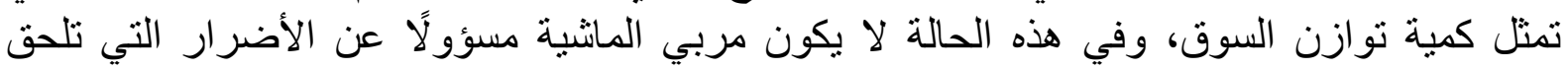

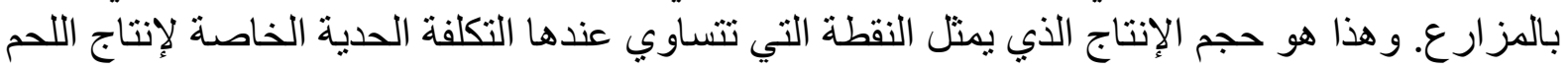

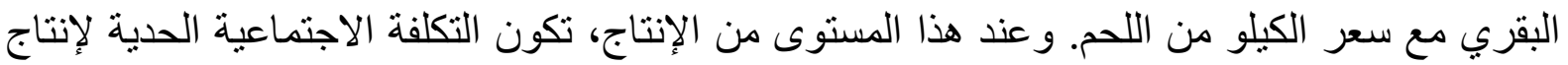

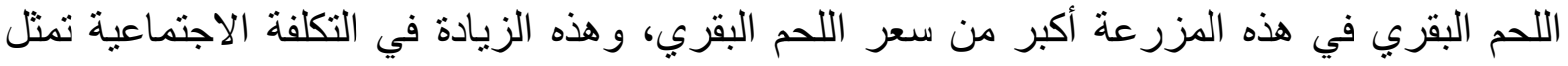

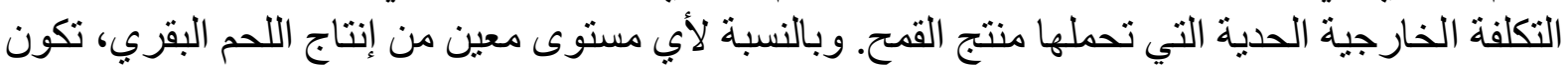

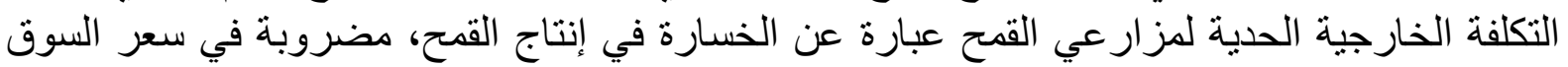

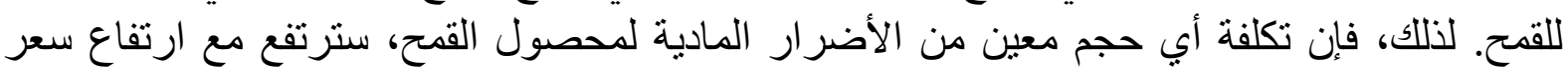
القمح.234 (ل)

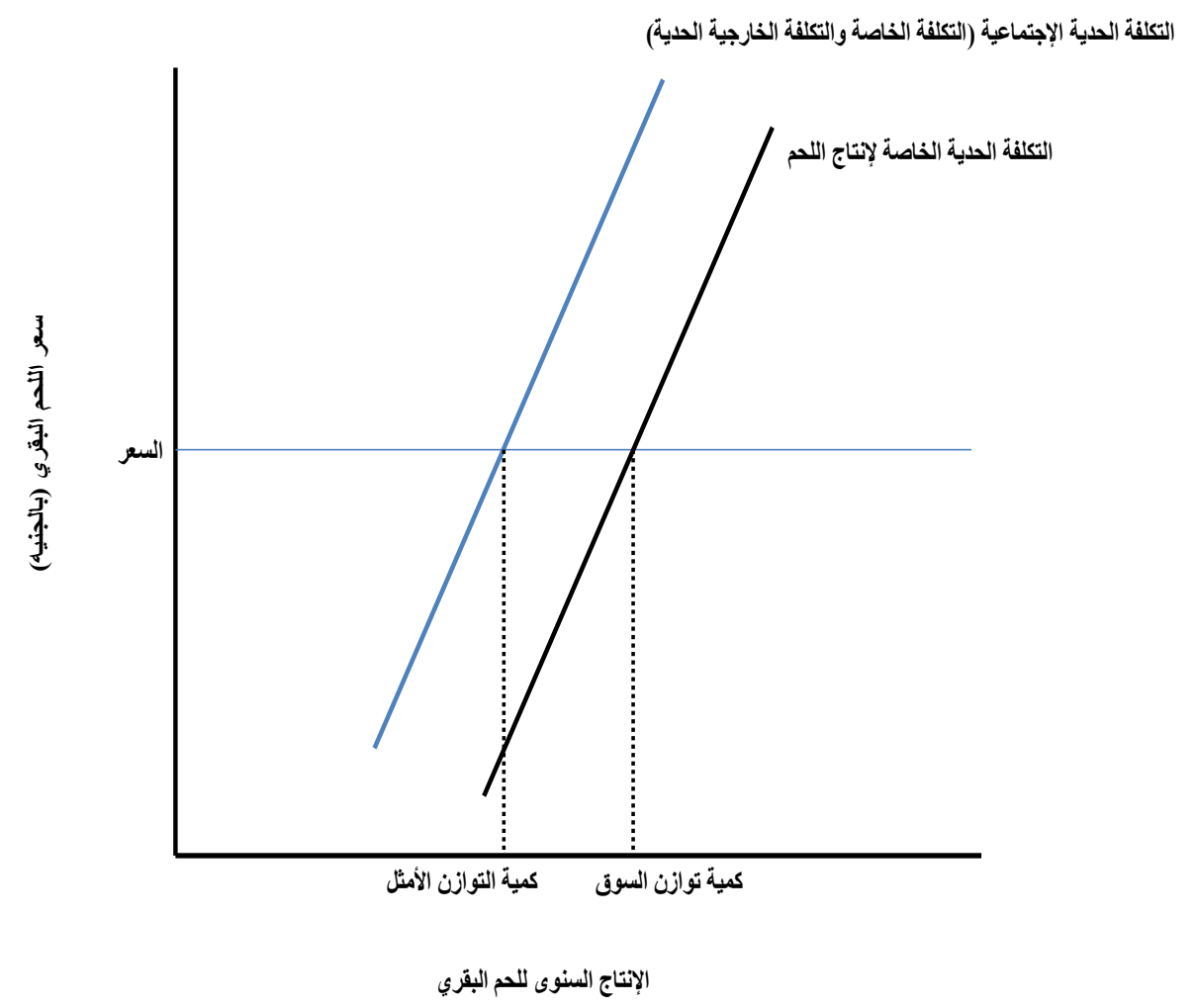

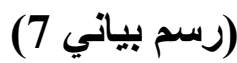

${ }^{344}$ Polinsky, A. Mitchell., (1979). “Controlling Externalities and Protecting Entitlements: Property Right, Liability Rule, and Tax-subsidy Approaches.” Journal of Legal Studies 8 (1), P. 20. 


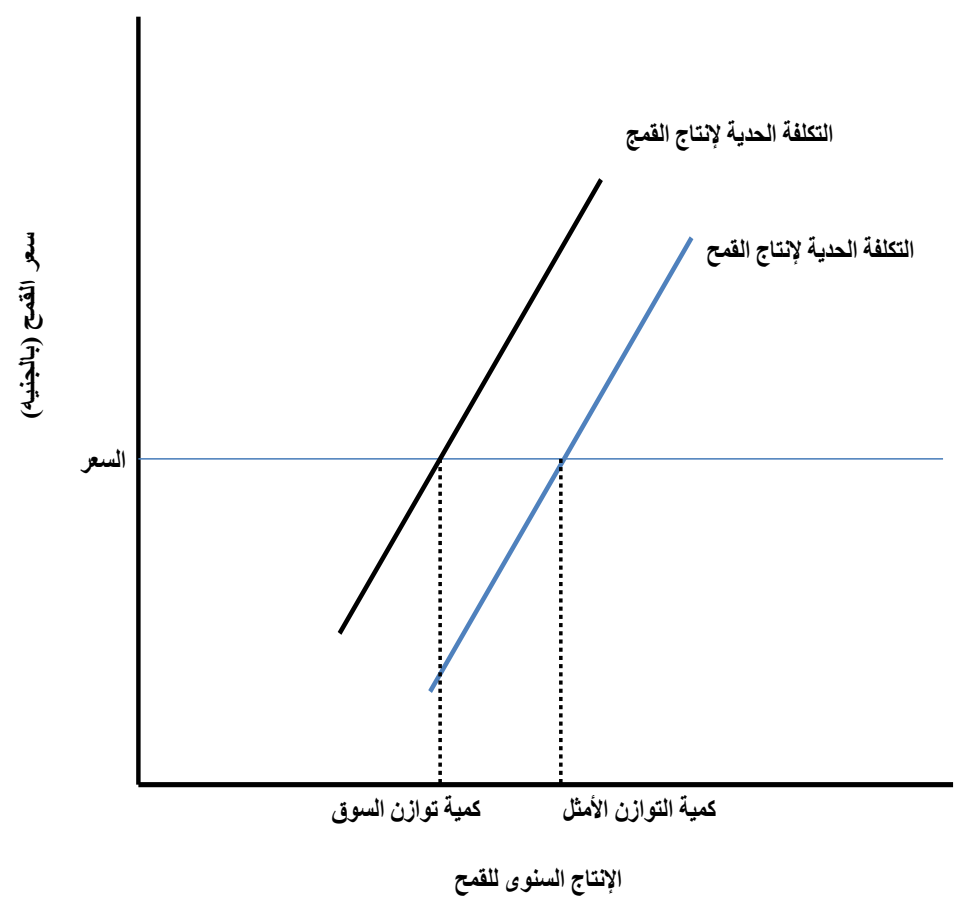

\section{(رسم بياني 8 )}

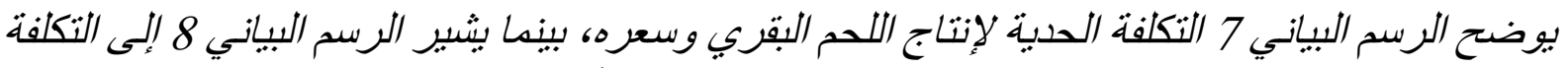

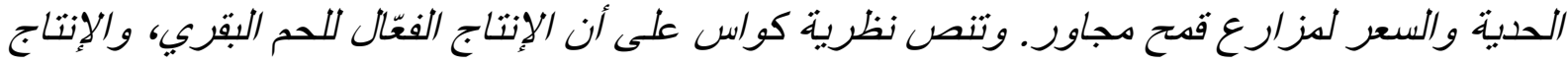

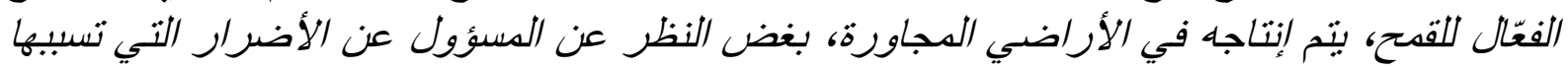

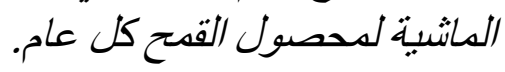

وفي (الرسم البياني7)، تكون التكلفة الاجتماعية الحدية لإنتاج اللحم البقري عبارة عن التكلفة الخاصة

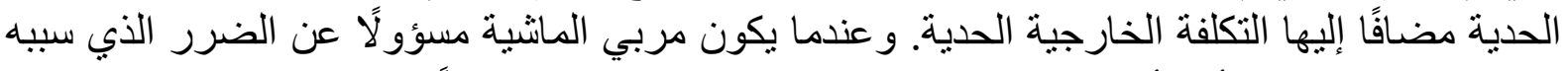

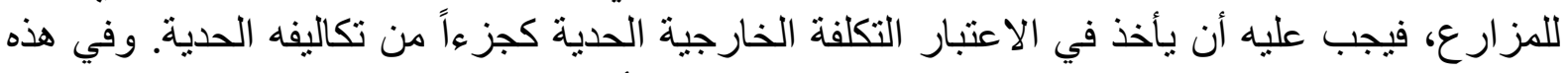

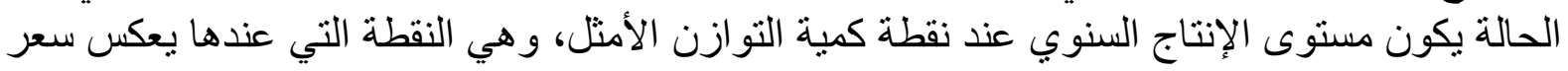

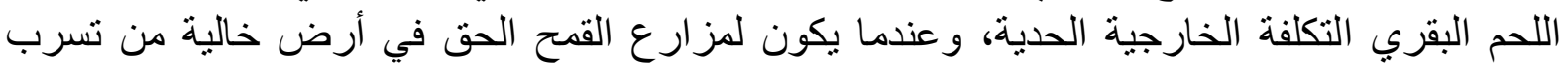

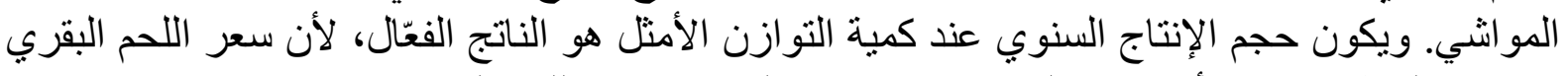

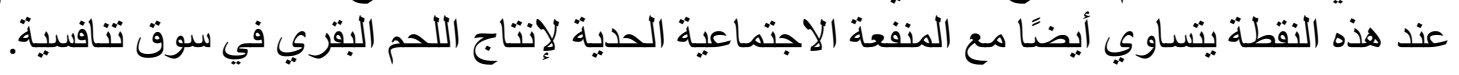
إذا كان الحد الأقصى للإِير ادات التي يمكن أن يحققه مربي الماثشية عندما يكون حجم الإنتاج السنوي عند الإند

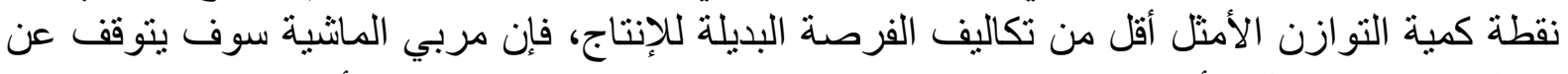

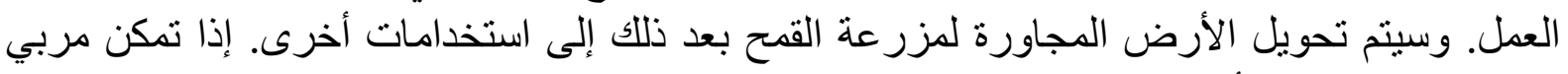

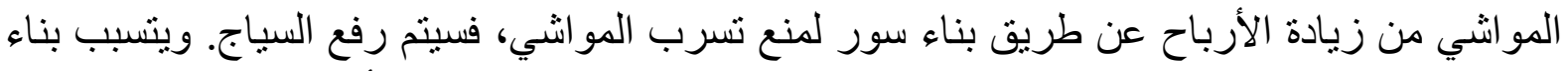

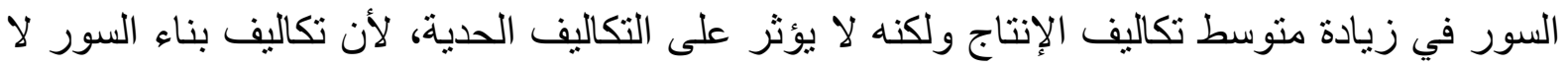

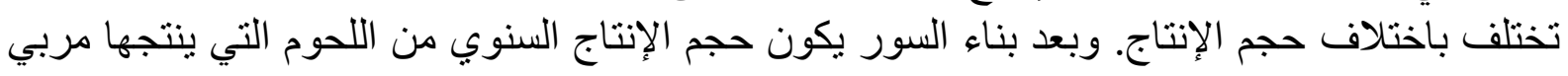


الماثية عند نقطة كمية التوازن، وذلك لأن التكلفة الخارجية الحدية تكون صفر عند أي مسنوى من الإنتاج بعد بناء السور.

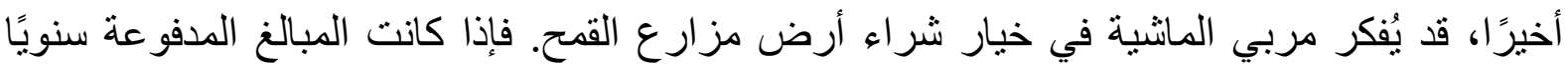

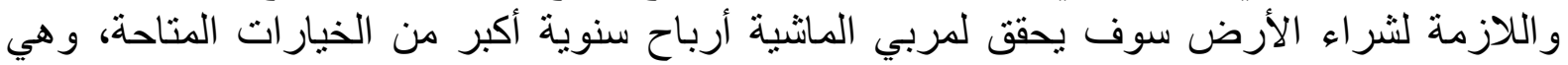

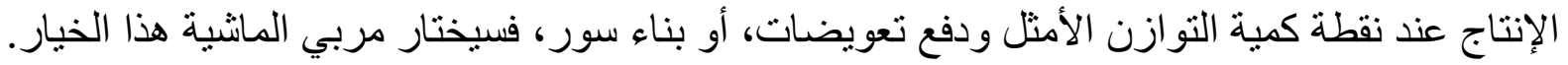

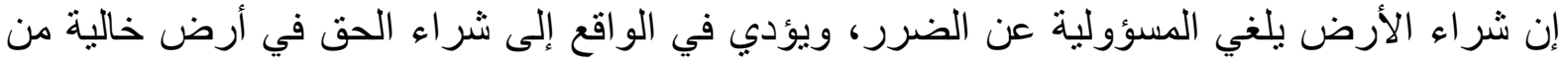

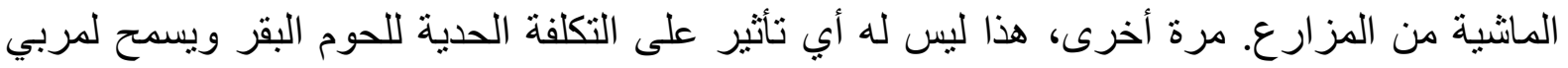

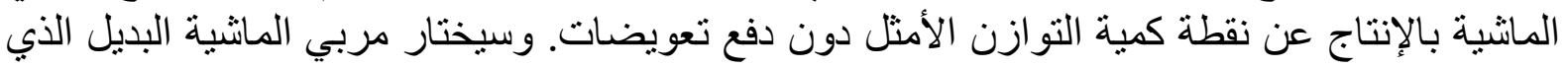
يحقق له أكبر ربح ممكن.

\section{ثانيًا: التنازل عن حق الملكية البديلة}

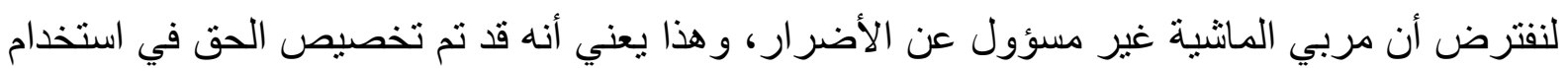

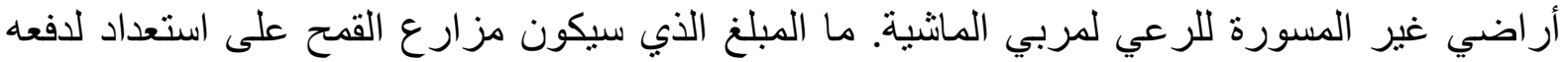

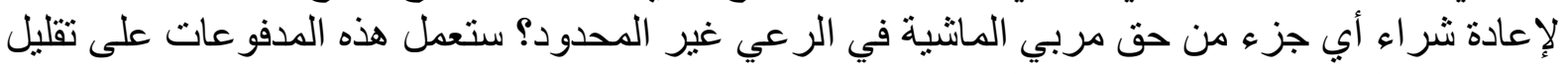
حجم قطيع المواثني الخاص بمربي المانشية.

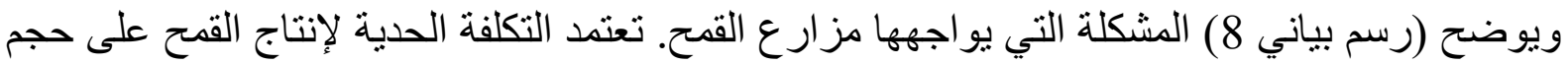

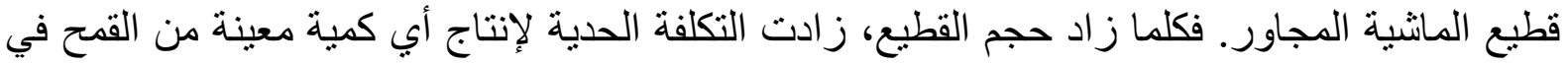

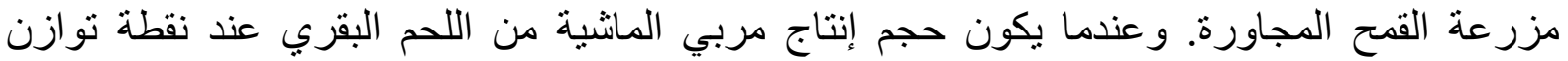

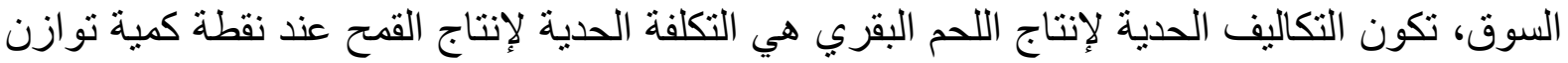

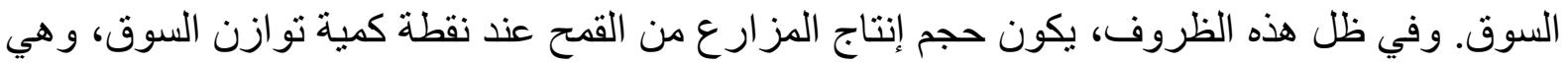

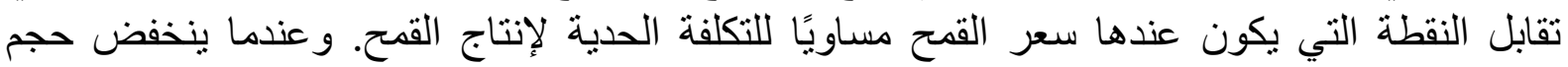

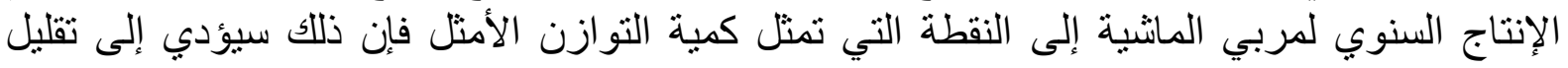

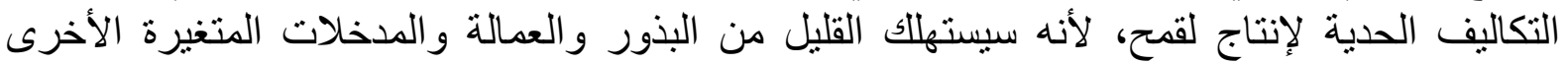

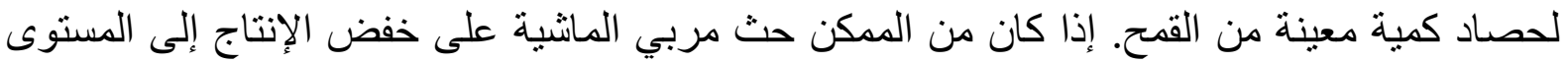

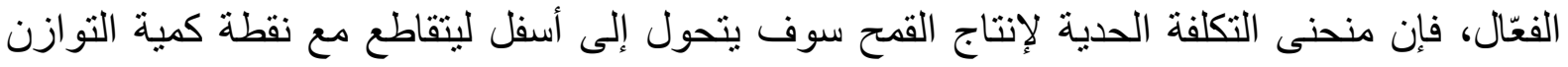

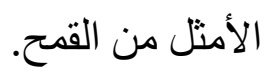

سيقبل مربي الماثية دفع بعض المبالغ لتقليل الإنتاج السنوي من اللحم البقري، إذا كان ذللك سيحقق له له

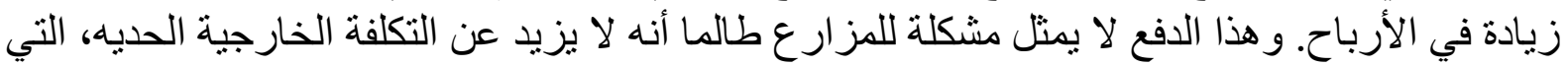

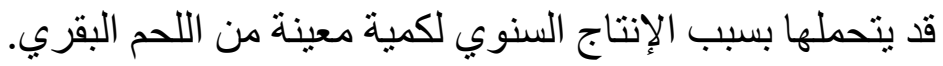

و الحد الأقصى للمبلغ الذي سيدفعه المزارع لكل وحدة تخفيض في إنتاج اللحم البقري من قبل المبل المربي

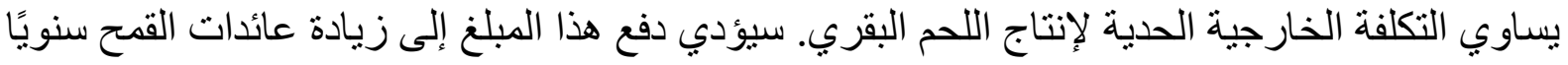

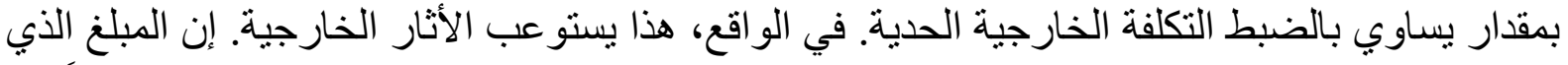

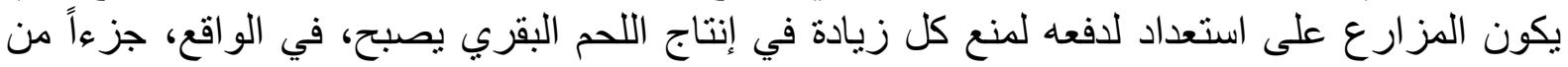

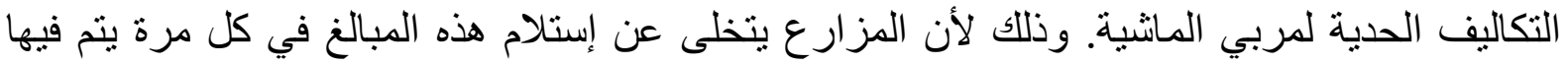

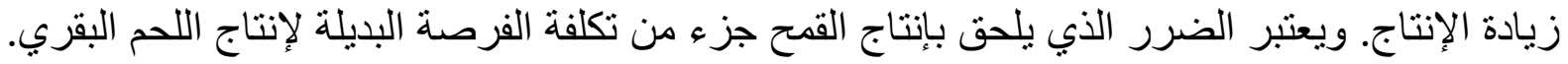

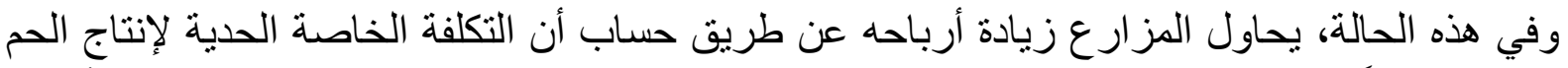

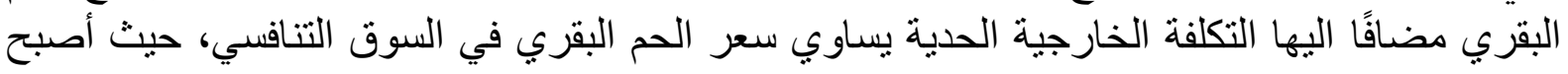




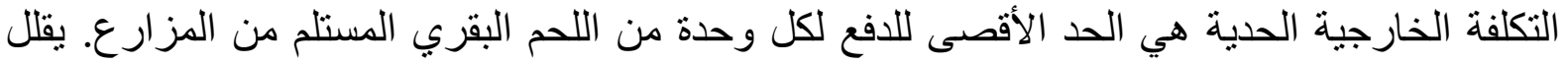

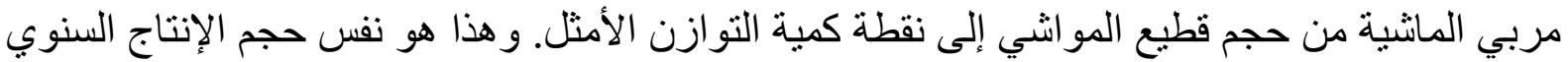

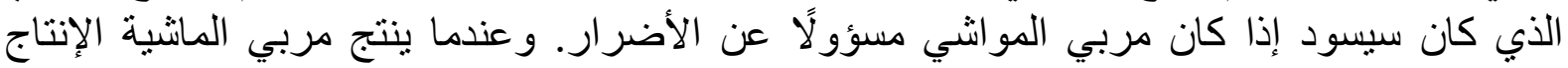

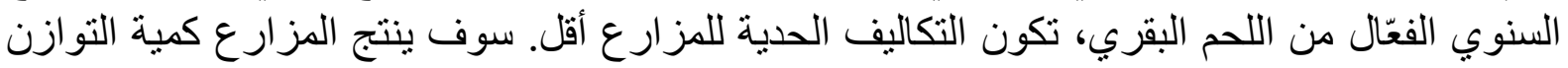
الأمثل من القمح، والتي تقابل النقطة التي يتساوى عندها التكلفة الحدية لإنتاج القمح مع سعر القمح.

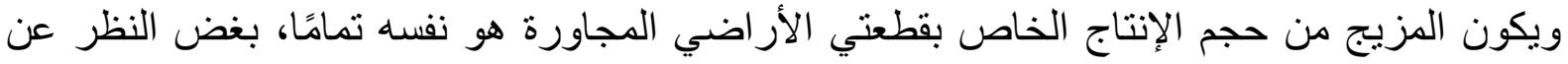

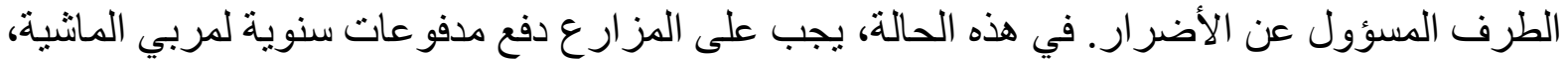

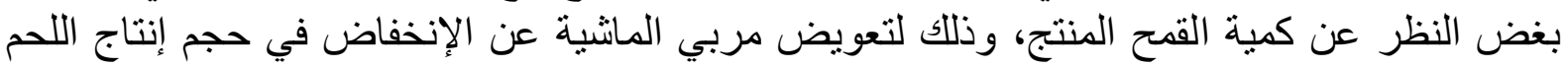

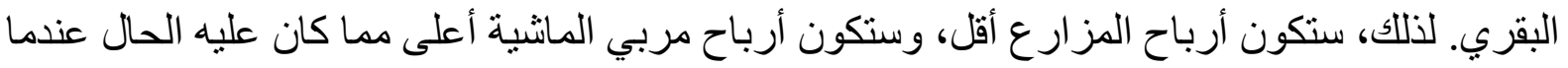
كان للمز ارع الحق في المطالبة بتعويضات من مربي المانشية.

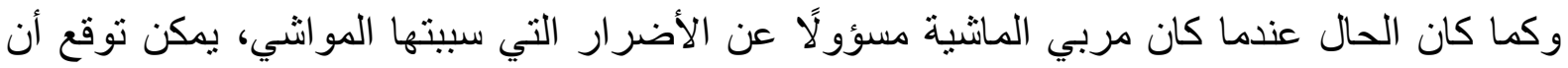

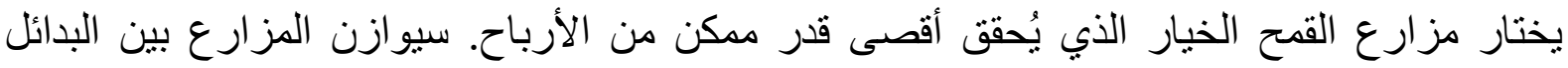

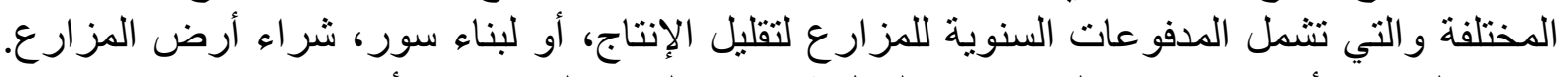
سيفكر المزارع أيضًا في خيار التوقف عن العمل ثم يختار الخيار الذي يزيد الأنيأ الأرباح. ثالثًا: تطبيق نظرية كواس: حقوق التلوث

يتمثل أحد حلول ألية السوق المدكنة لمشكلة التحكم في التلوث في إنشاء تصاريح قابلة للتناول بشأن فئان

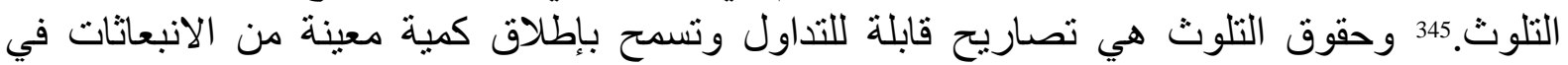

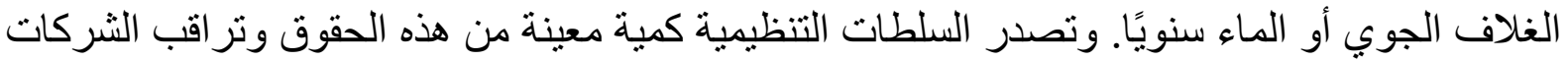

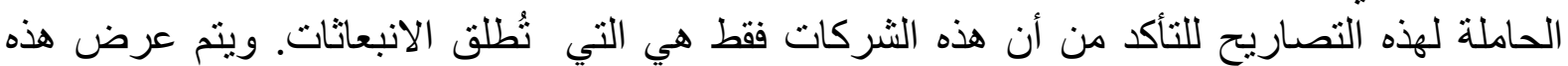

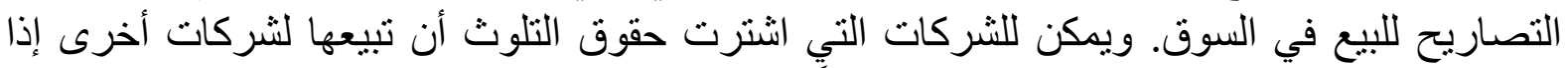

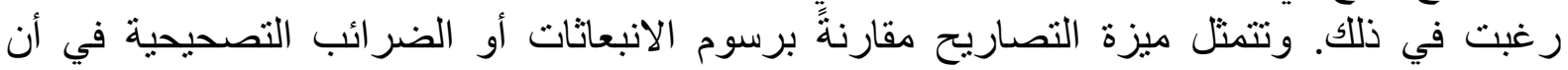

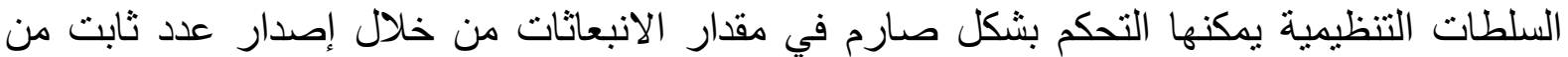

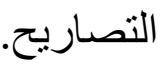

لنفترض، على سبيل المثال، في حالة عدم وجود أي لوائح أو رسوم، أن الكمية الحالية للانبعاثات السنوية

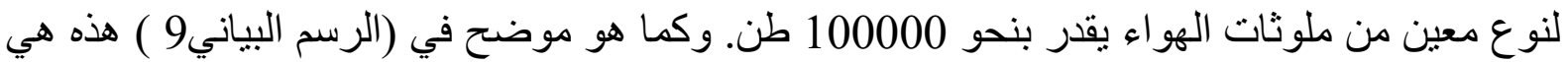

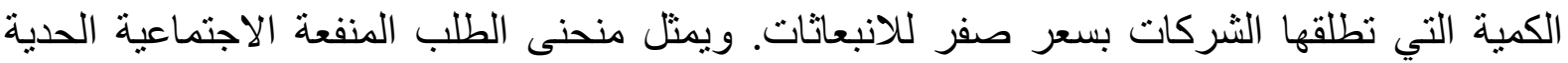

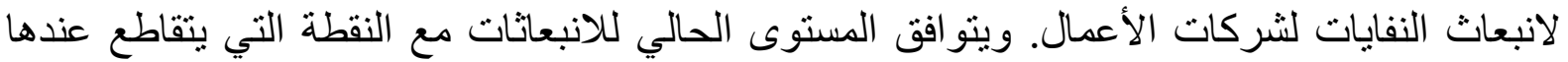
منحنى الطلب مع المحور الأفقي.

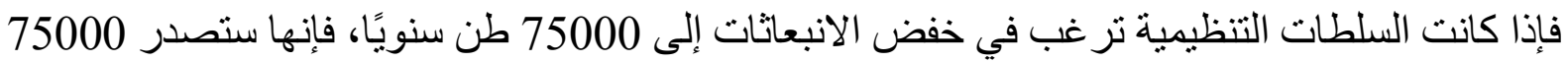

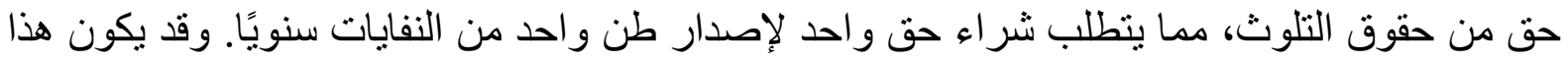

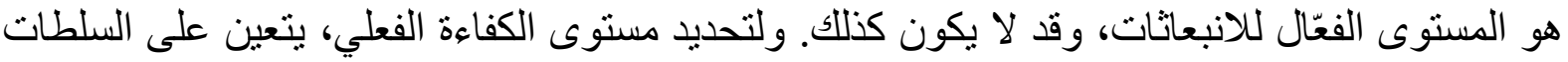

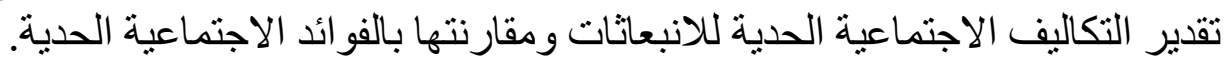

345 J. H. Dales. See J. H. Dales, (1970). Pollution, Property, and Prices (Toronto: University of Toronto Press Toronto. 
ستقوم لجنة مكافحة التلوث بعرض حقوق التلوث بالمز اد العلني لتللك الثركات التي ترغب في انبعاث

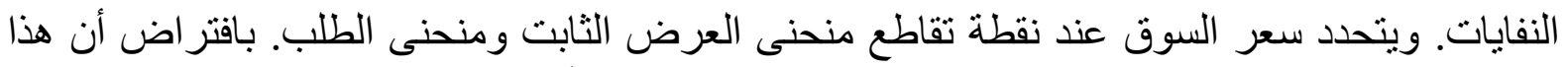

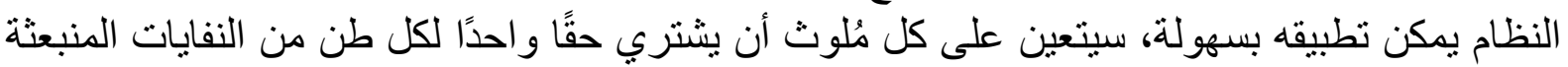

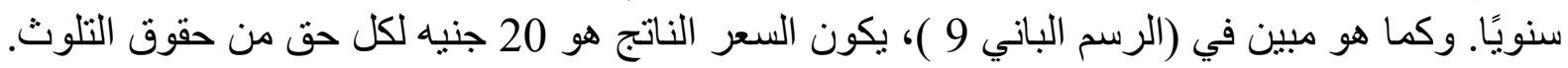

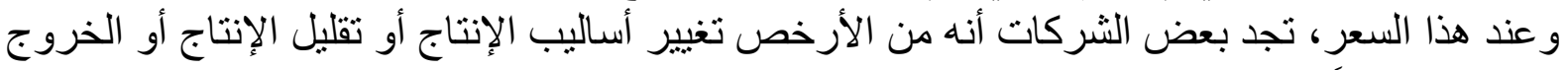

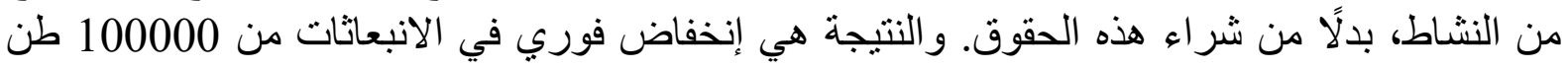
سنويًا إلى الى 75000 طن سنويًا.

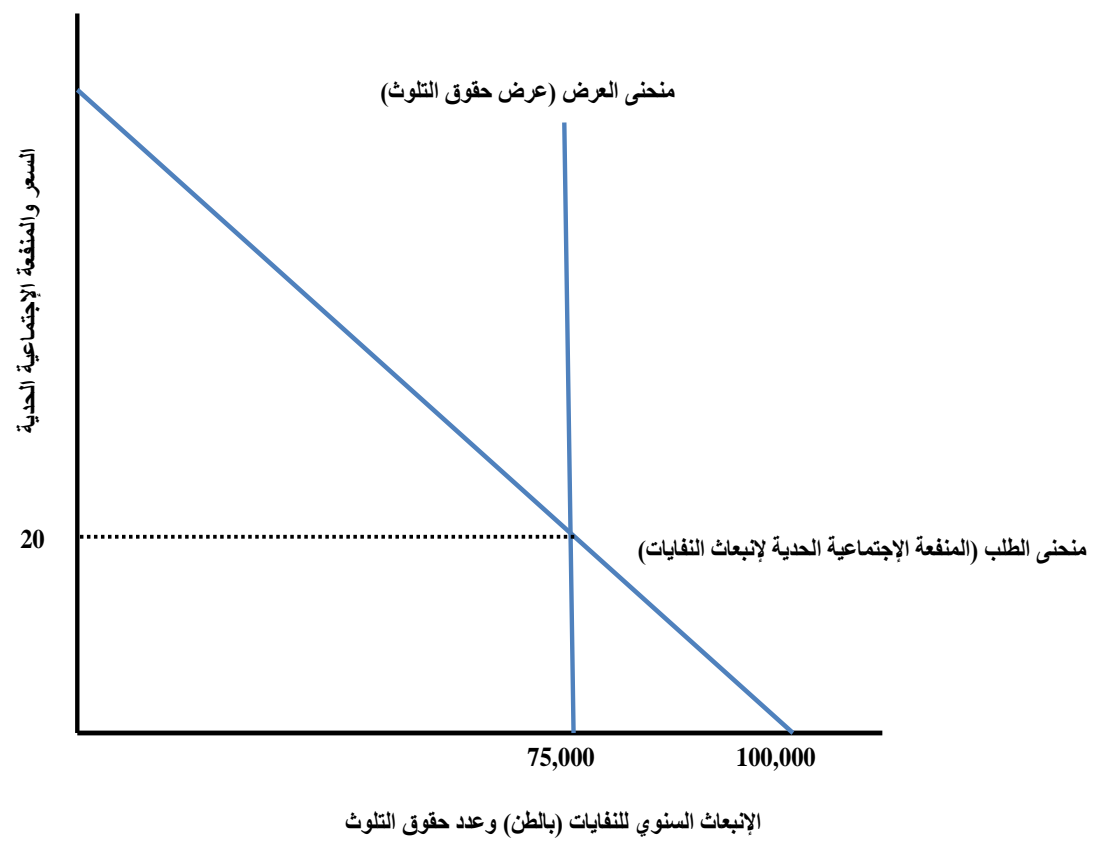

(رسم بياني 9) حقوق التلوث والانبعاثات

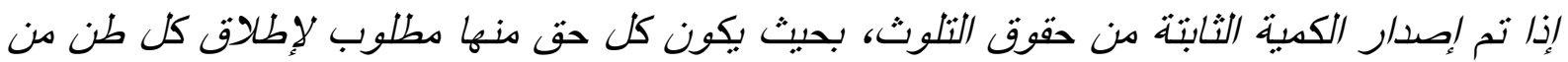

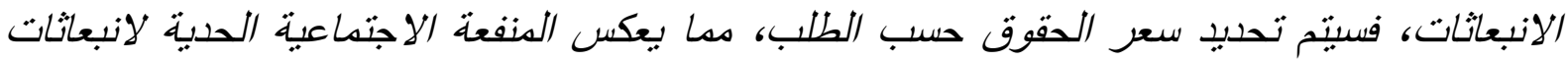

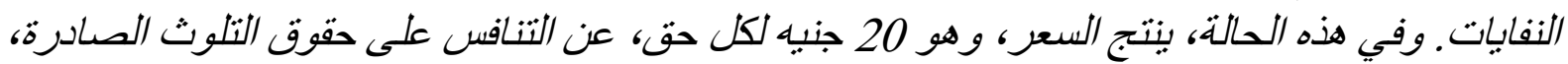
وهي

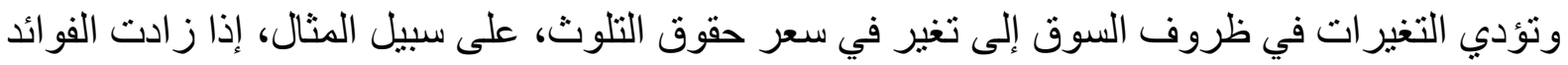

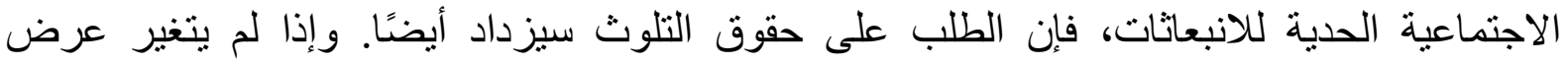

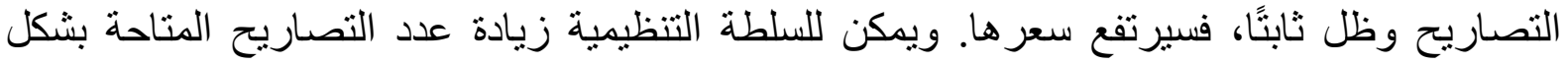

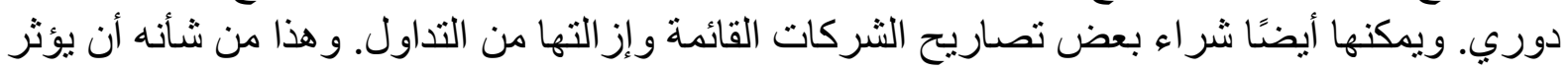

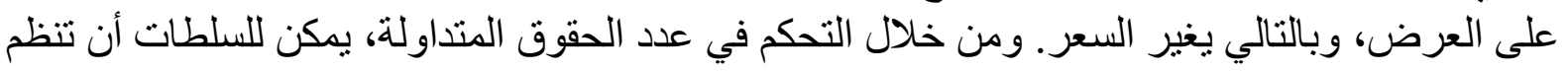

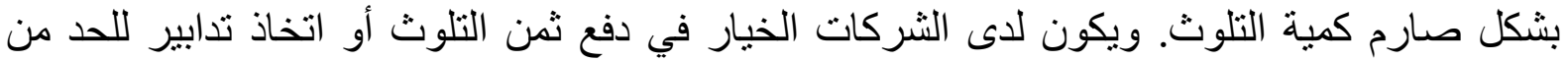
الانبعاثات. وتُشتخدم حقوق التلوث اليوم في الو لايات المتحدة للتحكم في انبعاثات ثناني أكسيد الكبريت. 


\section{1. كفاعة مستويات الحد من التلوث}

ويثار التساؤل عن مقدار التحكم في التلوث الكافي. يوضح (الرسم البياني 10) الفوائد الاجتماعية الحدية

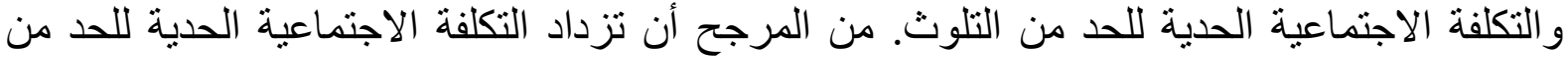
التلوث، مع زيادة الحد من التلوث.

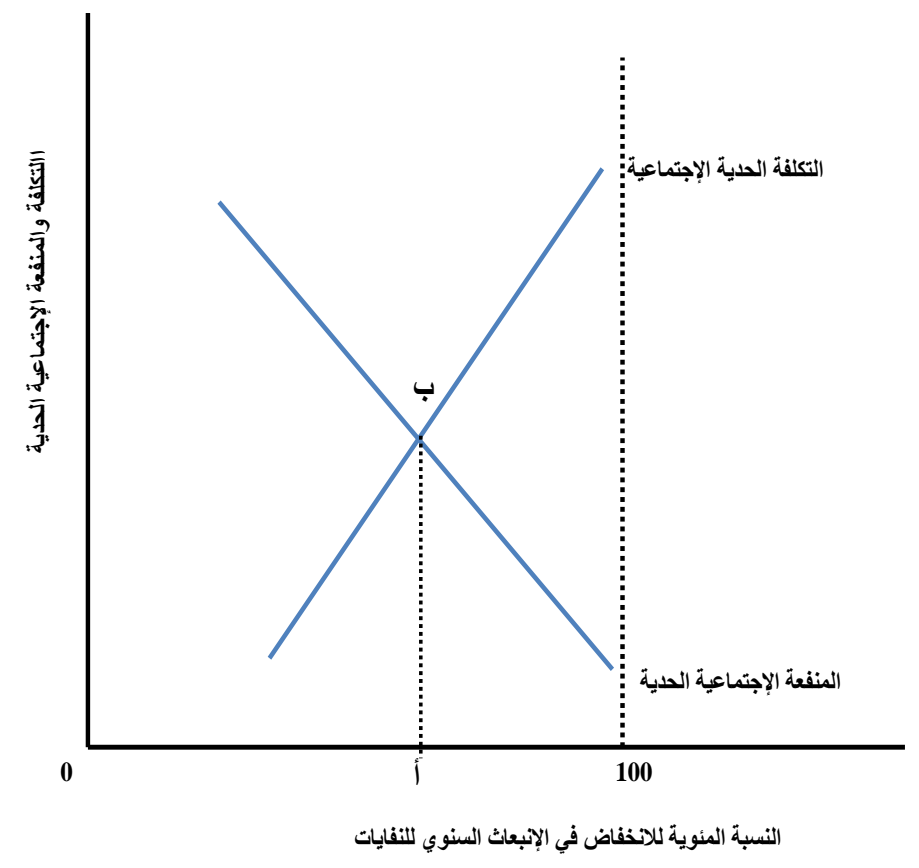

\section{(رسم بياني 10) المستوى الفمّال للحد من التلوث}

من المرجح أن يكون تحقيق كل خفض منتالي بنسبة واحد في المائة في النفايات المنبعثة سنويًا أكثر تكلفة

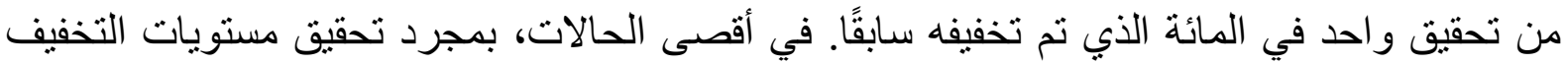

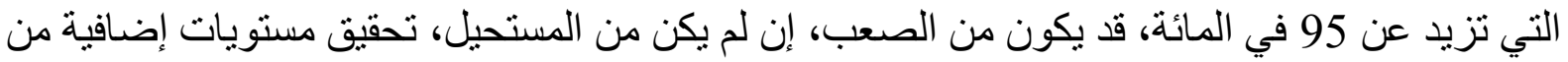
الجودة البيئية المحسنة باستخدام تقنية معينة لإعادة التدوير أو التنظيف أو جمع منتجات التين النفايات قبل التبل التخلص منها في بيئة. 346

وبالمثل، من المرجح أن تنخفض الفائدة الاجتماعية الحدية لزيادة الحد من التلوث مع تخفيف المزيد من

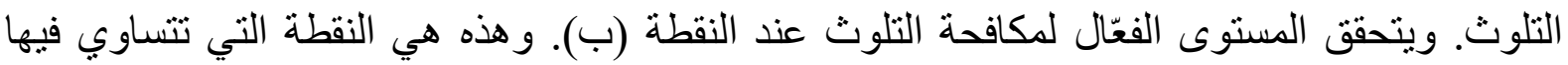

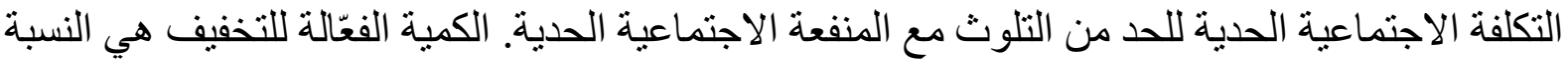

المؤية لتخفيض الانبعاث السنوي من النفايات التي تتحقى عند النقة التهة ( أ).

346 A. Myrick Freeman III, (2002). "Environmental Policy Since Earth Day I: What Have We Gained?" Journal of Economic Perspectives 16, 1, P. 125. 
لذللك، فإن السياسة المثالية لمكافحة التلوث هي تلك التي توازن بين الناتج الضائع، و الذي ينتج عن زيادة تكلفة الحد من التلوث مع الفائدة الإضافية التي تتمنل في تحسين جودة البيئة. ويمكن أن بؤدي التي عدم التفكير في تكلفة الفرصة البديلة لبيئة أنظف إلى الكى حل أكثر ضررًا من المشكلة. 347

\section{المبحث الرابع: دور السياسة العامة في منع الأثار الخارجية للوضع الاستهلاكي}

تظهر الأثار الخارجية للوضع الاستهلاكي عندما تُغير عمليات الشراء الجديدة سياق الاستهلاك ذات

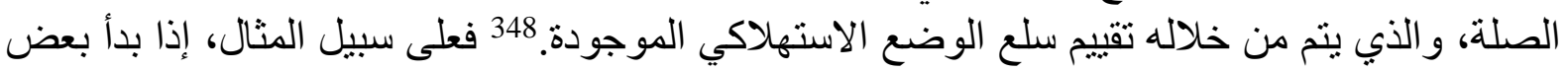

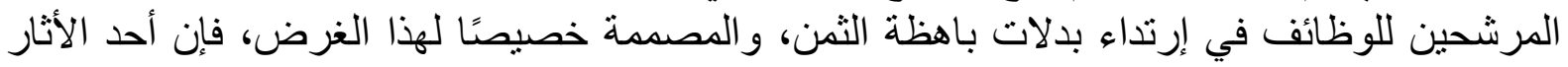
الخارجية لهذا التصرف هو أن المرشحين الآخرين قد يصبحوا أقل احتمالية لإعطاء إنطباعات إيجابية عند اختيار هم للوظيفة. ومن وجهة نظر أي شخص يسعى للحصول على هذه الوظيفة، قد يكون أفضل رد الته

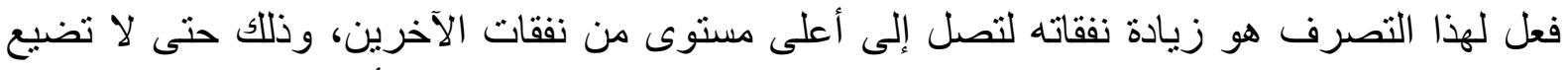

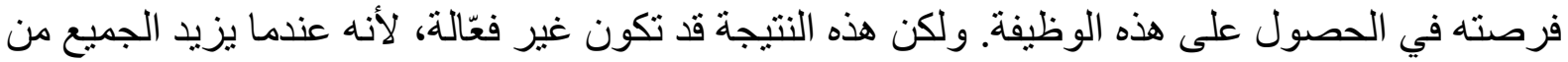

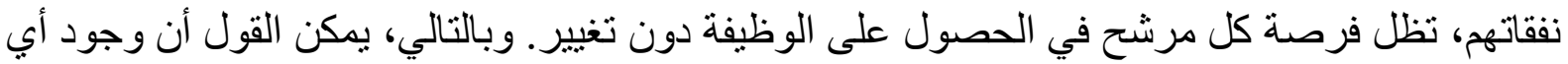
شكل من أثكال القيود الجماعية على هذا النوع من الإنفاق قد يساهم في الحد من ظهور الون الأثار الخارجية للوضع الاستههلاكي.

ولكن، في مثل هذه الحالات، غالبًا ما يكون من غير العملي التفاوض بين هذه الأطر اف على حلول

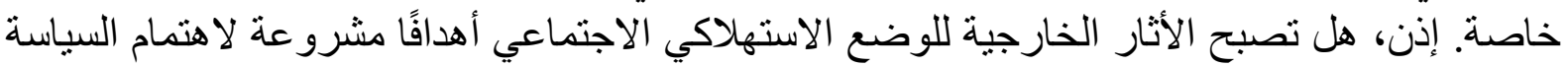

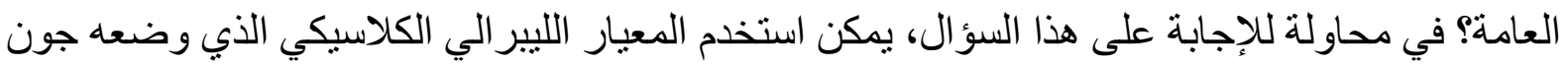

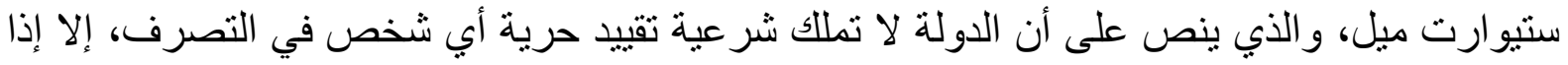

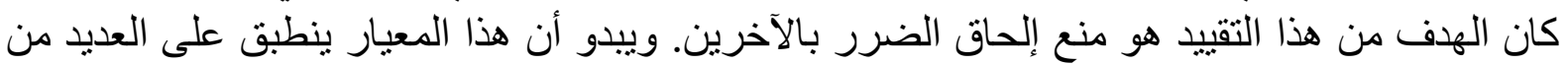

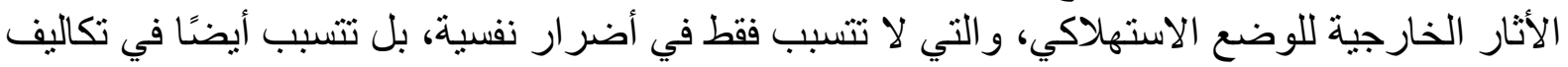

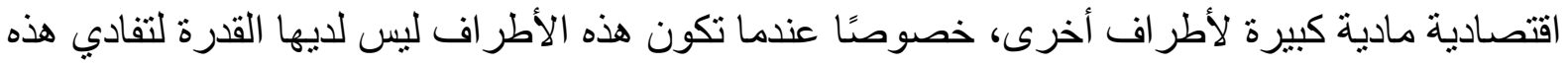

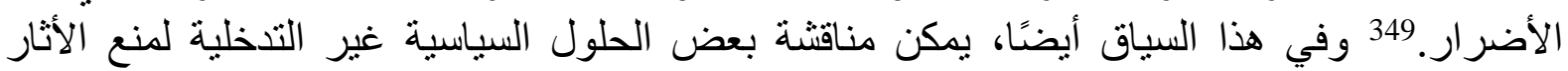
الخارجية للوضع الاستهلاكي الاجتماعي، وأحد هذه الحلول هو الذي يمكن استخدامه على غرار استخدام

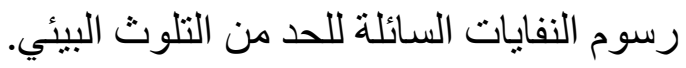

\section{أولاً: حدود سياسة عدم التلخل في النشاط الاقتصادي}

عموما، يرى الفكر الاقتصادي الليبر الي أن الدولة قد تقيد حرية الشخص في التصرف فقط لمنع إلحاق الأذى بالآخرين. دن الواضح أن الأثار الخارجية للوضع الاستهلاكي قد تسبب ضررًا للآخرين. فالآباء

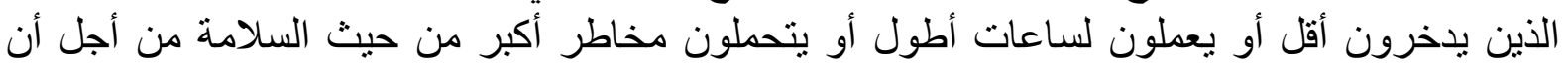

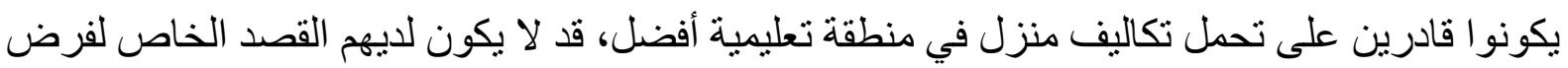

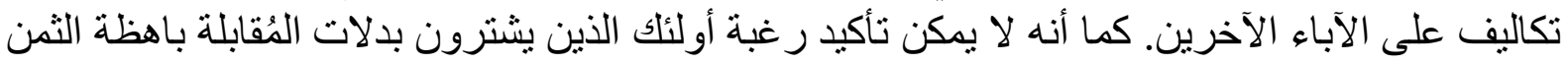

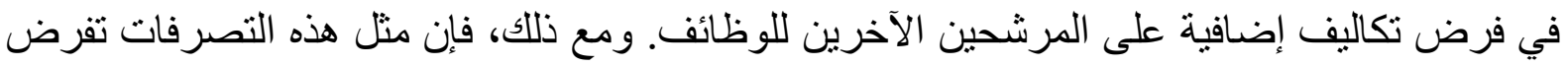

${ }^{347}$ Barthold, Thomas A., (1994). "Issues in the Design of Environmental Excise Taxes." Journal of Economic Perspectives 8, 1, P. 133.

${ }^{348}$ Frank, Robert H., (1991). Positional externalities. In: Zeckhauser, Richard (Ed.), Strategy and Choice: Essays in Honor of Thomas C. Schelling. MIT Press, Cambridge, MA, P. 25.

${ }^{349}$ Mill, John Stuart, (1982). On Liberty. Viking, New York. 
تكاليف على الآخرين، وتجبر هم على إنفاق أكثر بكثير مما قد يكون ضروريًا لتحقيق أهداف الحياة

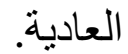

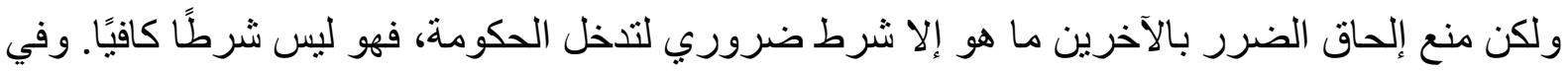

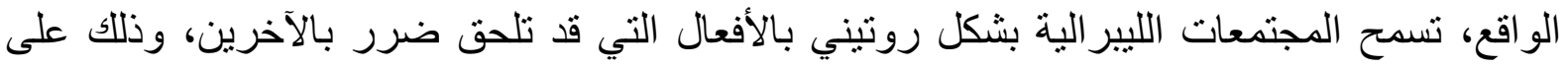

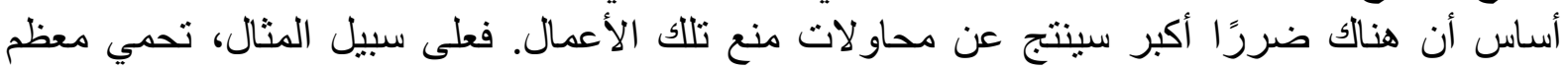

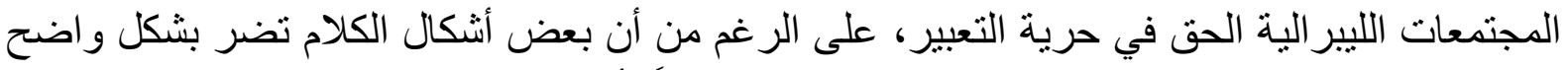

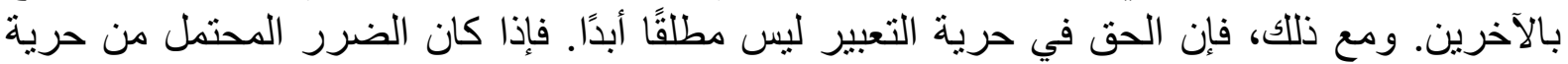

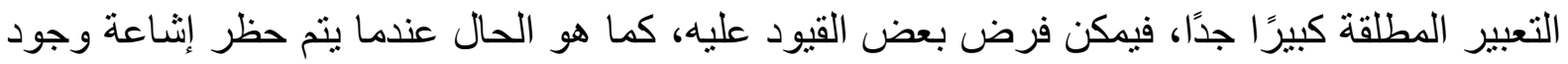

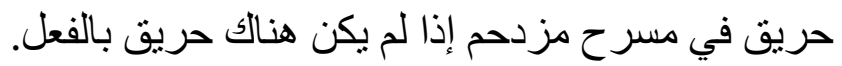

تتطلب مسألة تقييد التصرفات التي تسبب ضررًا للآخرين تقييمًا دقيقًا للضرر الناجم عن الأفعال نفسها

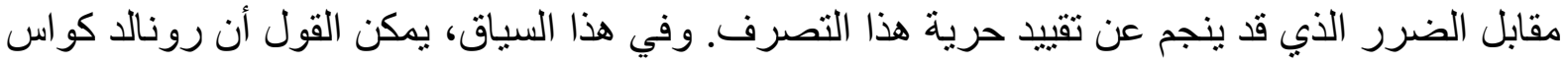

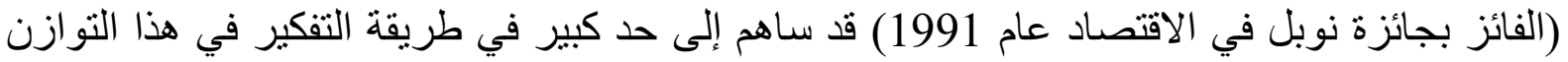
الدقيق. والهدف هنا هو تحديد مدى الإستفادة من نظرية كواس في تشكيل الإنيل السياسة العامة تجاه الأثار الخارجية للوضع الاستهلاكي 350.

قبل ظهور الفكر الاقتصادي لكواس، كان من الثائع أن تُصاغ المناقثات السياسية حول الأثار الخارجية

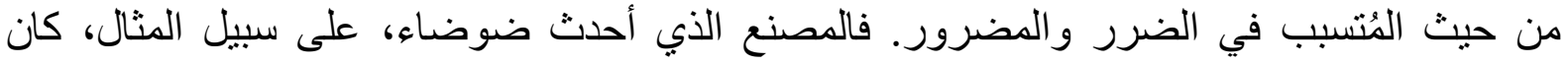

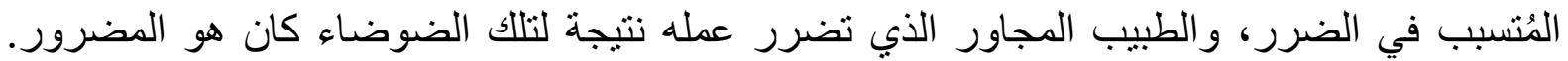

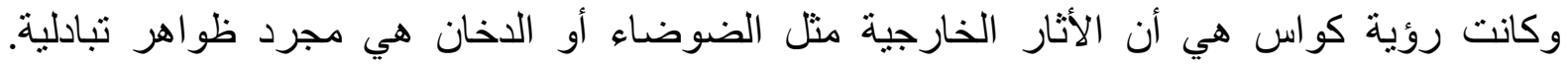

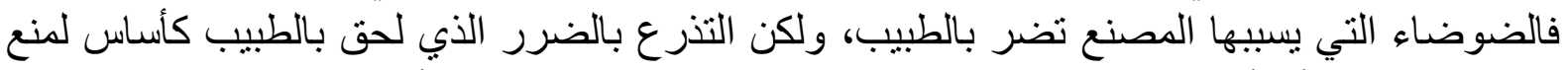

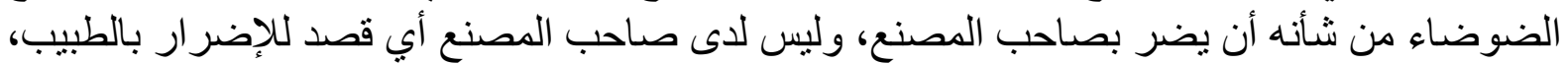

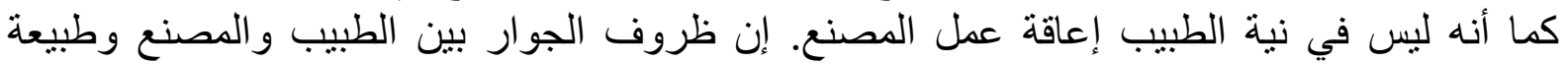

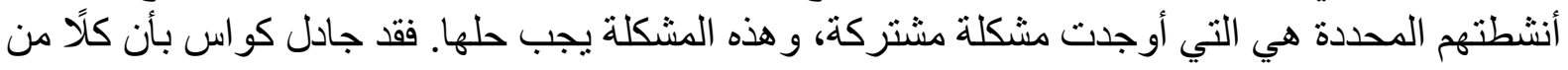

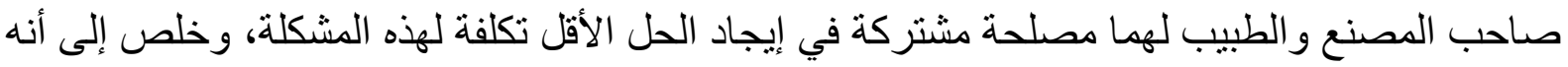

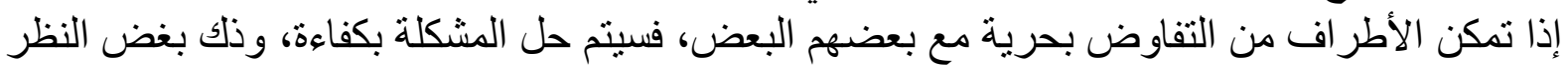

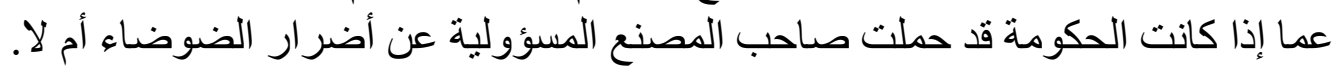

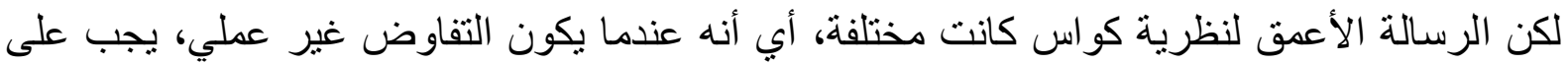

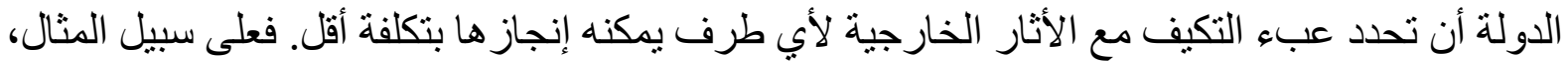

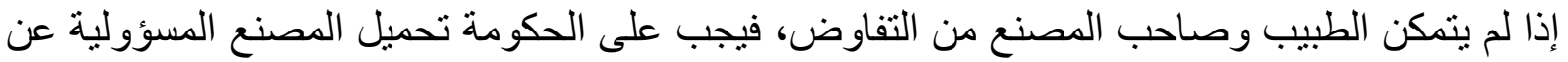

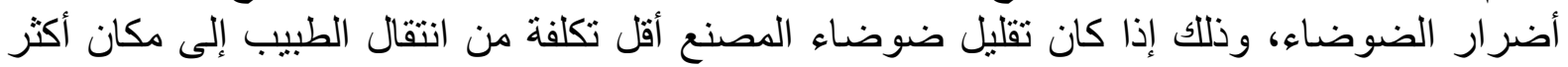

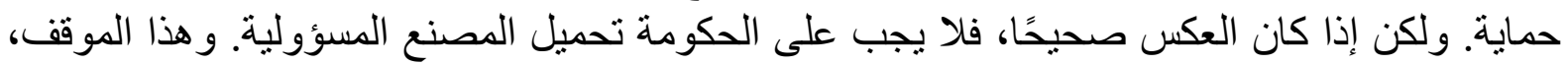

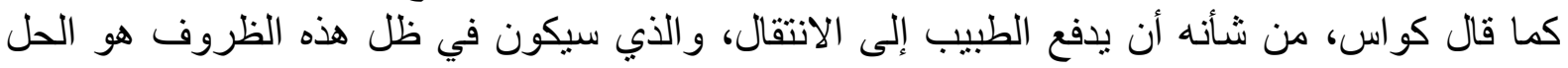

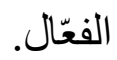

ولكن ماذا عن دور نظرية كو اس في حل مشكلة الأثار الخارجية للوضع الاستهلاكي. للمساعدة في تأطير

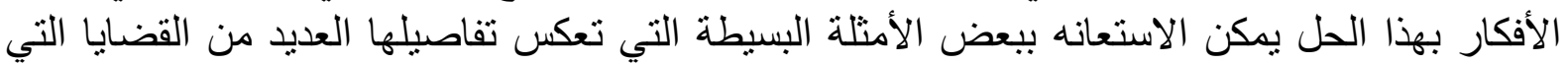

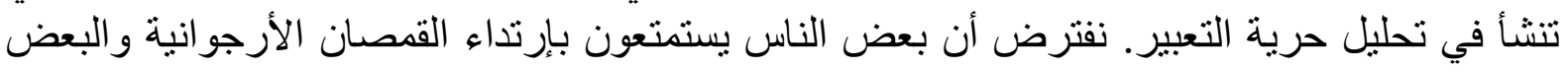

${ }^{350}$ Coase, Ronald, (1960). The problem of social cost. Journal of Law and Economics 3, P. 144. 


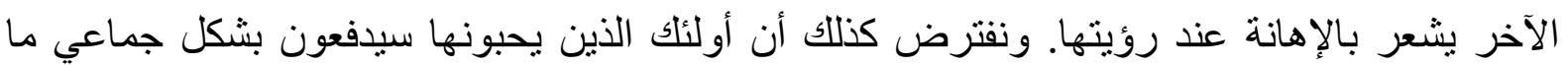

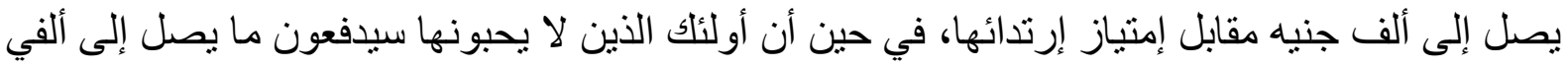

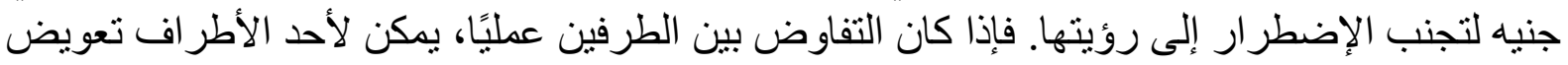
أولئك الذين يفضلون القصدان الأرجو انية مقابل مو افقتهم على عدم إرتدائها.

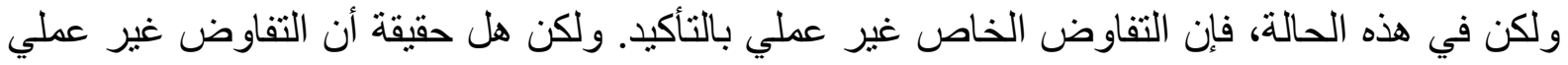

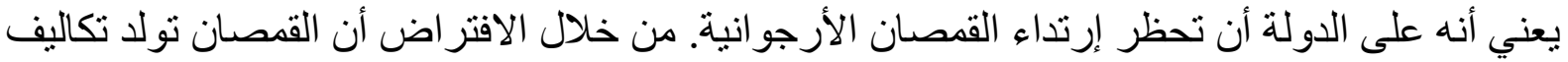

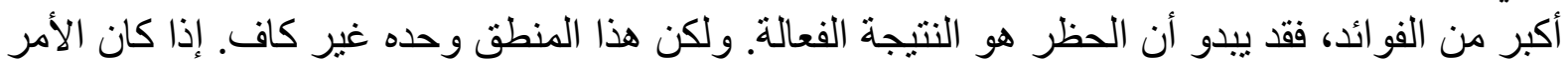

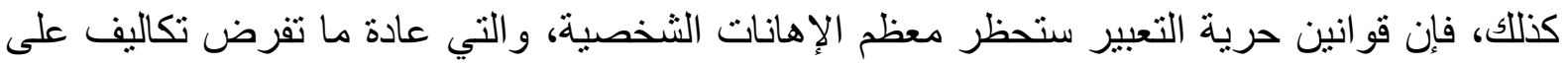

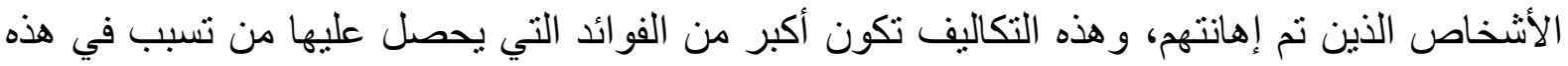

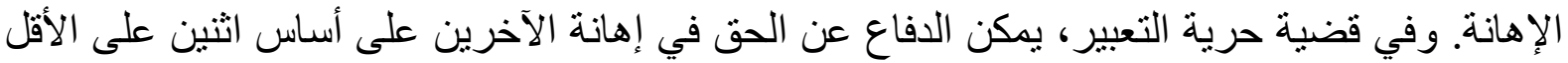

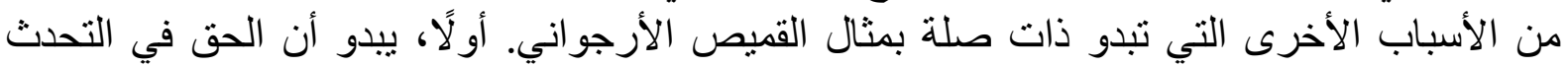

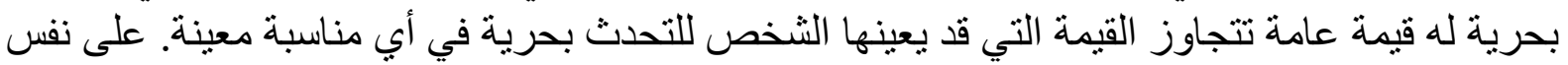

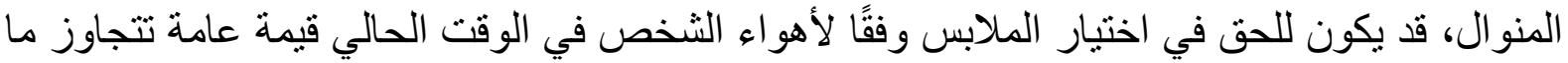

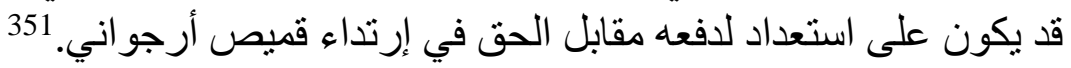

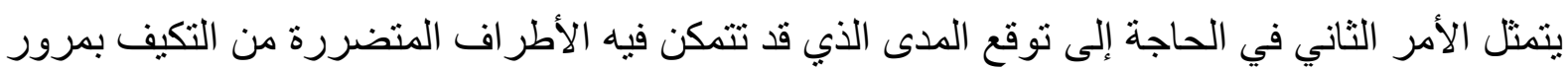

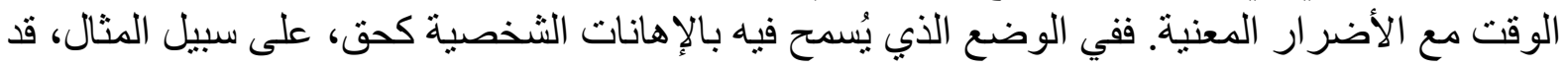

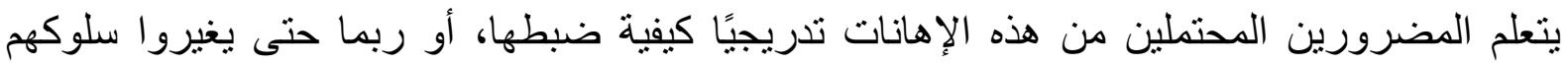

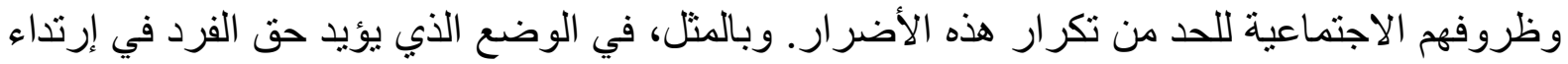

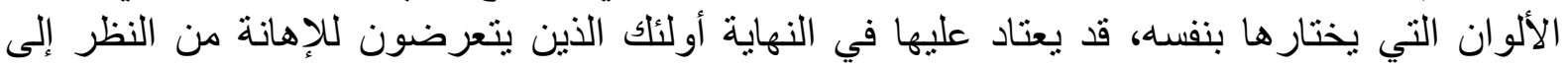

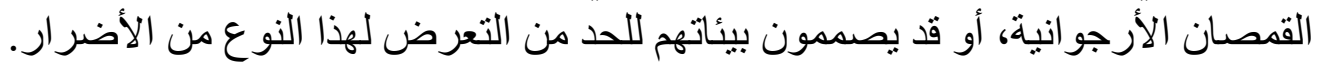

إن الدفاع عن أي حق يستلزم الموازنة بين كلًا من التكاليف و الفو ائد. وفي النهاية، فإن الإثكالية المتعلقة

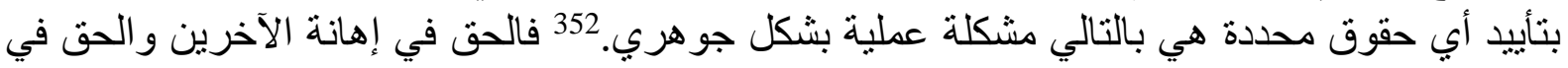

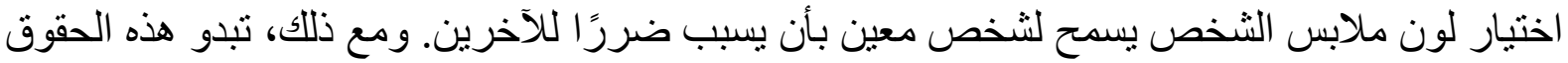

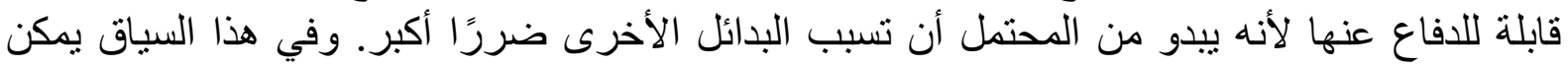

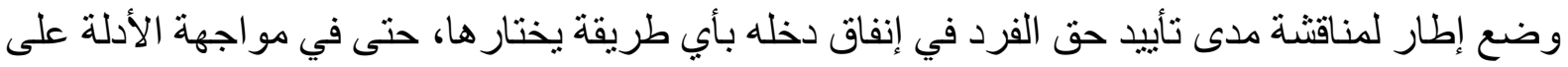
أن بعض أنشكال الإنفاق قد تفرض تكائ نقاليف على الآخرين.

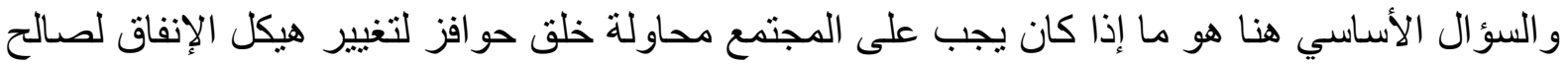

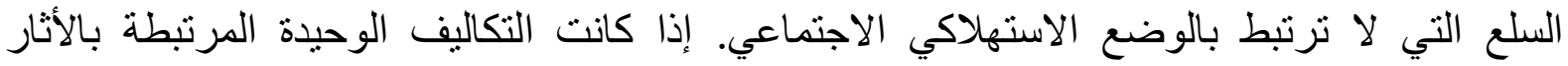

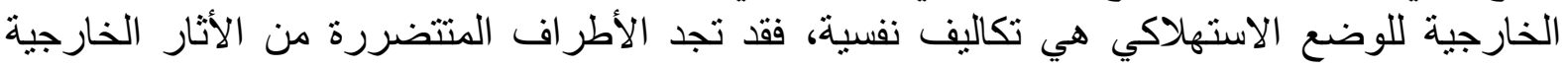

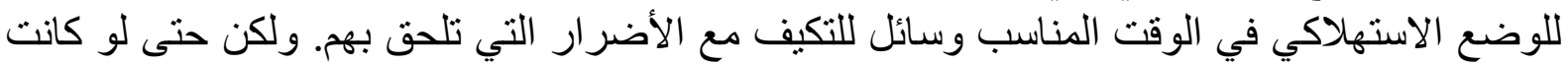

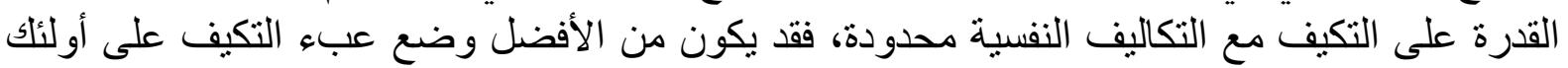
الذين يعانون من هذه التكاليف، حيث يمكن تفسير البديل على أنه دعوة ضمنية الألفية للثكوى.

${ }^{351}$ Frank, R. (2005). Positional Externalities Cause Large and Preventable Welfare Losses. The American Economic Review, 95(2), PP. 137-141.

${ }^{352}$ Holmes, Stephen, Sunstein, Cass, (2000). The Cost of Rights: Why Liberty Depends on Taxes. W. W. Norton, New York, P.83. 
ولكن الأثار الخارجية للوضع الاستهلاكي في سوق الإسكان مثلًا تنطوي أيضًا على تكاليف مادية أكثر

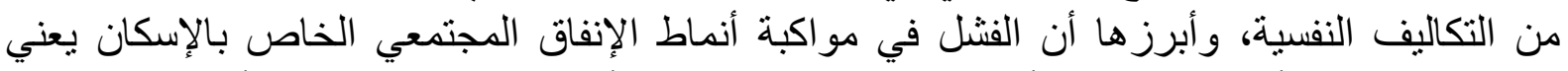

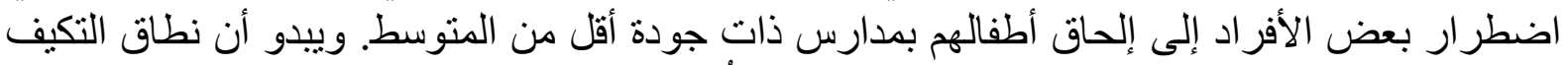

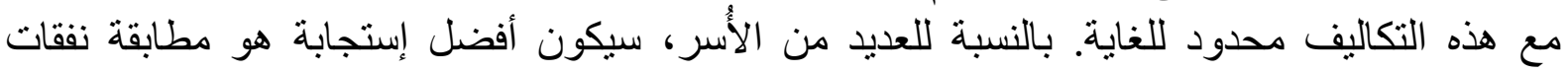

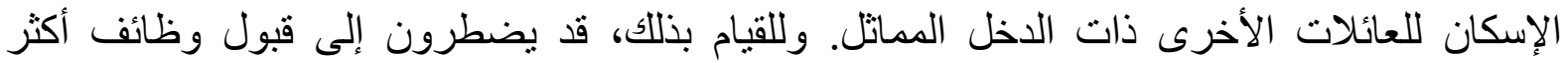

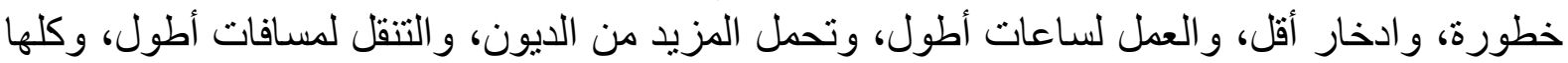
مرتبطة بمستويات منخفضة من الرفاهية الذاتية.

\section{ثانيًا: الضرائب والأثار الخارجية للوضع الاستهلاكي}

لقد نجح الاقتصاديين أخيرًا في إقناع محللي السياسة والمشرعين بالإبتعاد عن التنظيم البيئي المبانشر

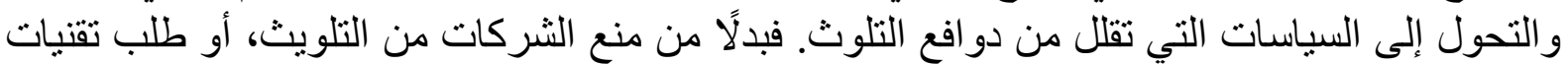

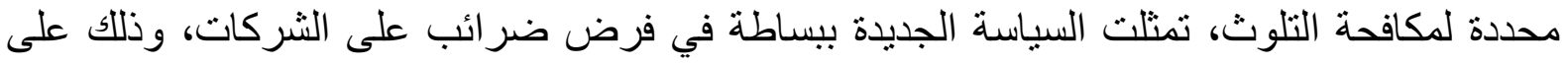

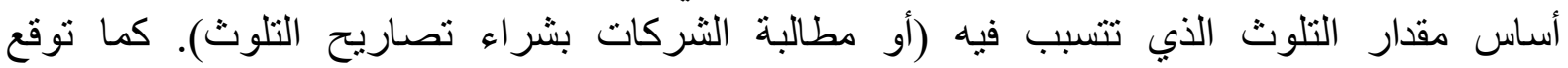

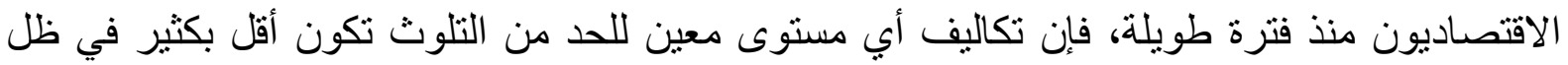
الأنظمة القائمة على الحو افز عنها في ظل اللو ائح التنظيمية. 354

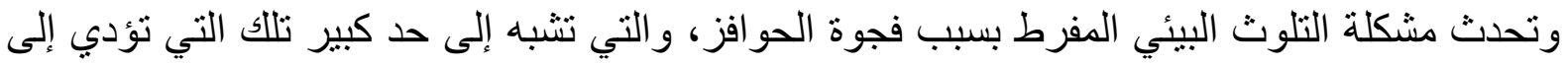

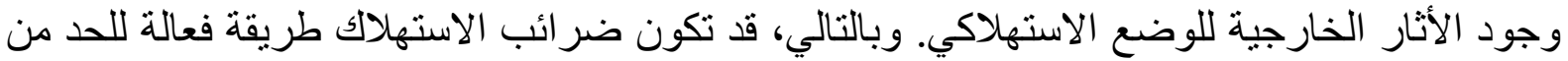

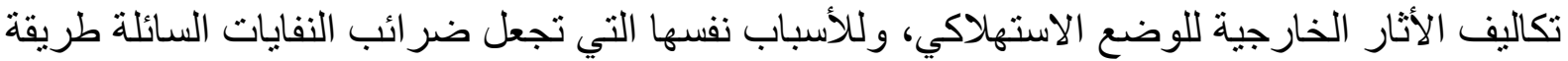

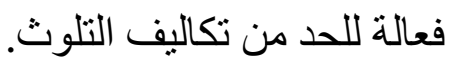

في عالم المعلومات الكاملة والحكومة المثالية، سيكون الحل هو تحديد معدل ضريبة مختلف لكل سلعة الحكا

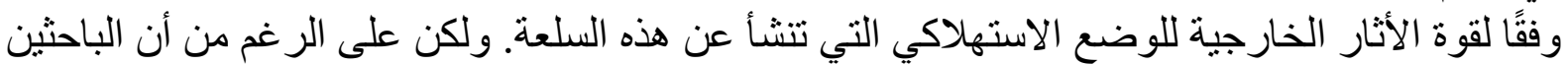

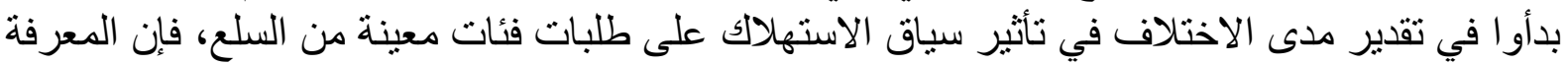

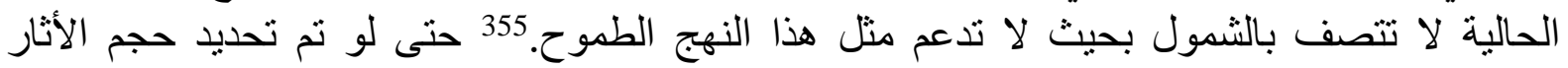

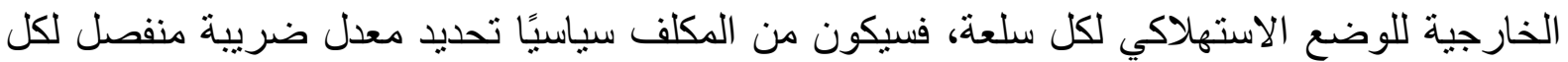

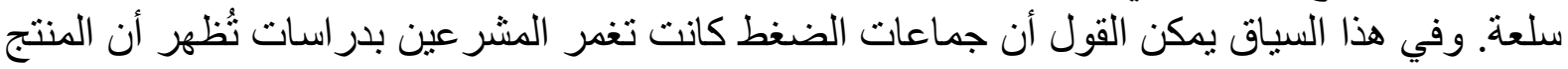

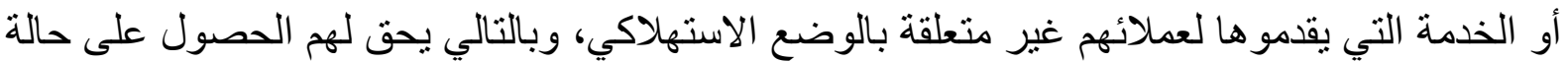
الإعفاء الضريبي.

ومع ذلك، فإن الضريبة المحددة على السلع المتعلقة بالوضع الاستهلاكي تثثير العديد من المشاكل. أولَا،

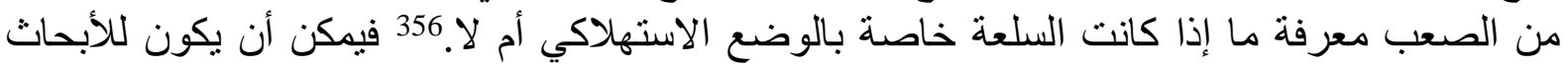

${ }^{353}$ Frank, Robert H., (1999). Luxury Fever: Why Money Fails to Satisfy in an Era of Excess, The Free Press, New York, P.326.

${ }^{354}$ Dorris, Gary W., (1996). Redesigning Regulatory Policy: a case study in urban smog, $\mathrm{PhD}$ dissertation. Cornell University.

355 Solnick, S.J., Hemenway, D., (1998). Is more always better?: a survey on positional concerns. Journal of Economic Behavior and Organization 37, PP. 373-383: Kerwin, Charles, Hurst, Erik, Roussanov, Nick, (2009). Conspicuous consumption and race. The Quarterly Journal of Economics. Vol. CXXIV, Issue 2, P.425.

356 Mason, R., (2000). Conspicuous Consumption and the Positional Economy: Policy and Prescription since 1970. Managerial and Decision Economics. 21 (3), P. 123. 


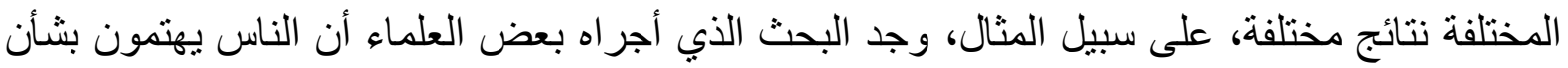

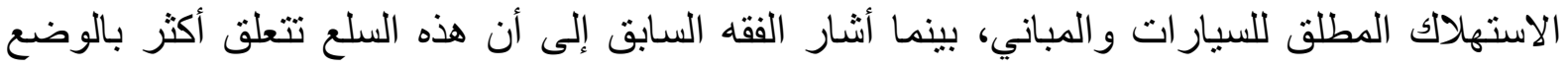

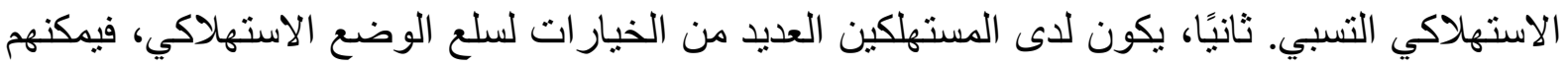

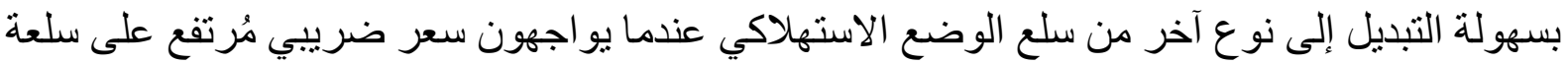
وضع استهلاكي و احدة.

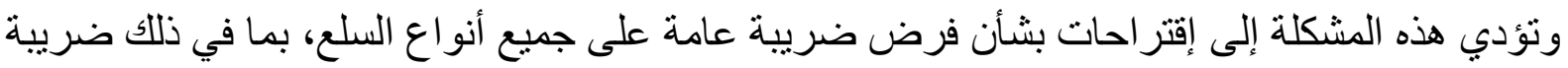

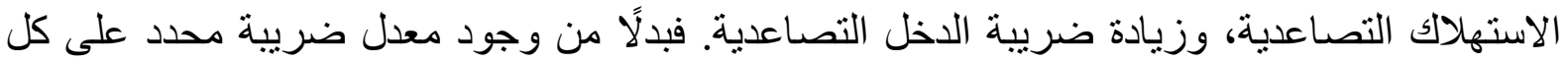

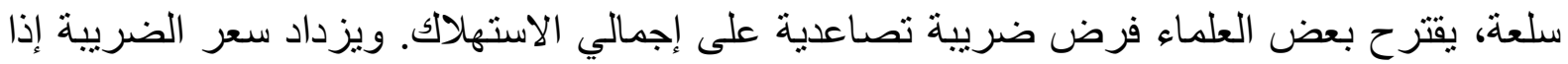

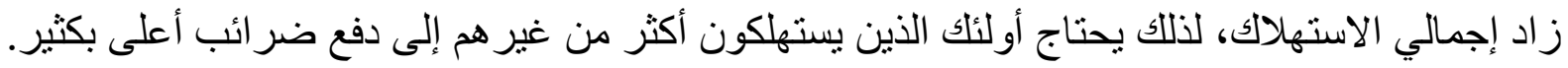

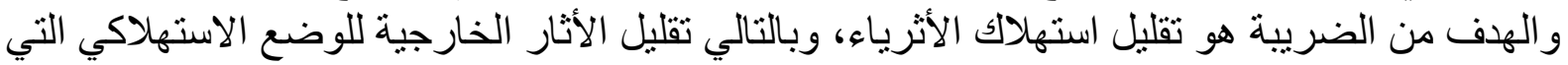

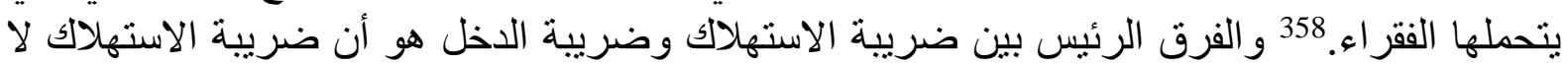
تؤُثر سلبًا على الادخار، مما سيساعد الاقتصاد على النمو بشكل أسر ع في المستقبل.

و هنا يمكن القول بأن النهج الأبسط والأكثر واقعية هو التخلي عن ضريبة الدخل التصاعدية الحالية

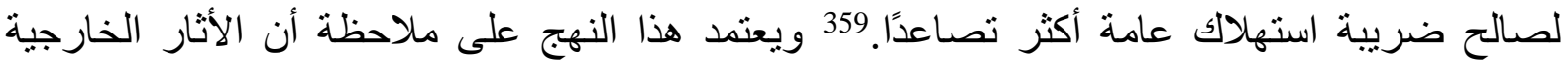

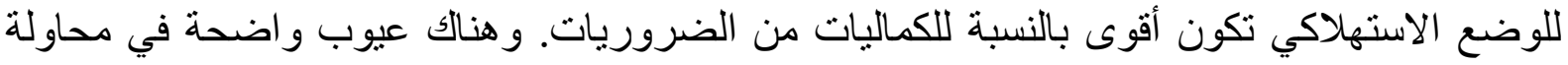

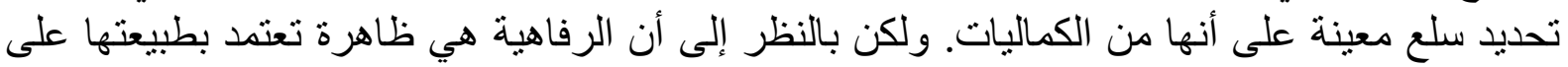

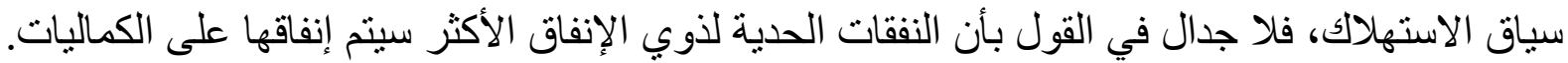

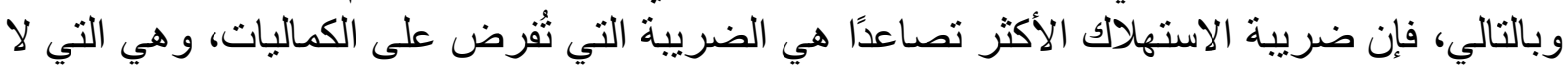
تحتاج إلى تحديد سلع معينة على أنها من الكماليات. 360

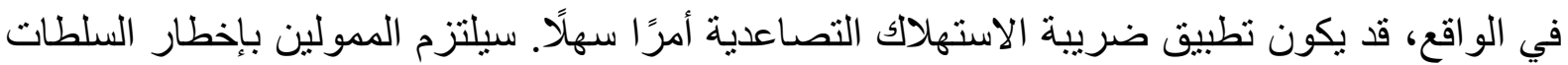

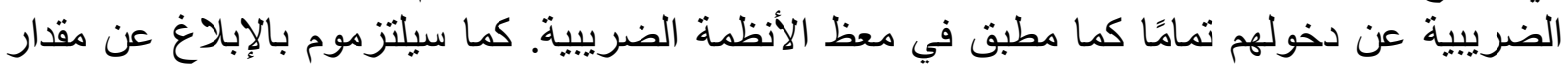

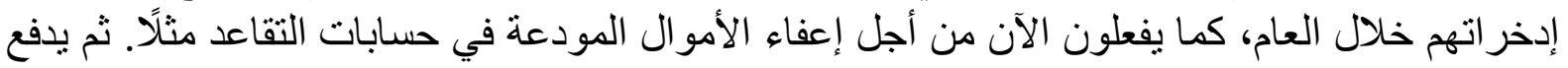

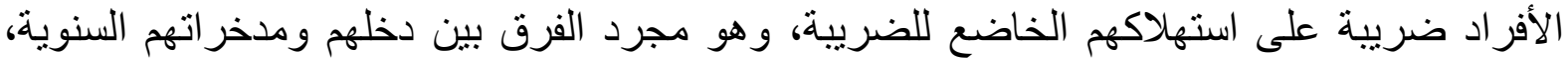

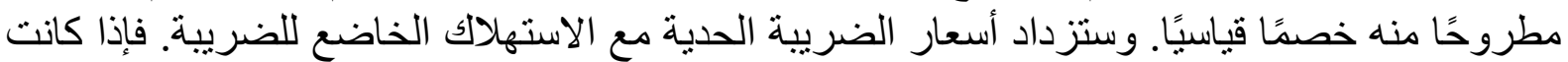

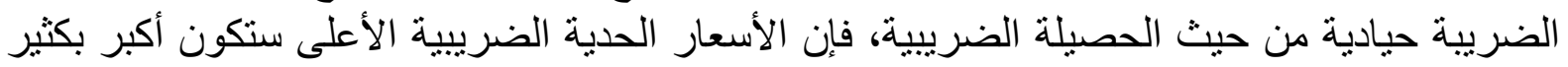

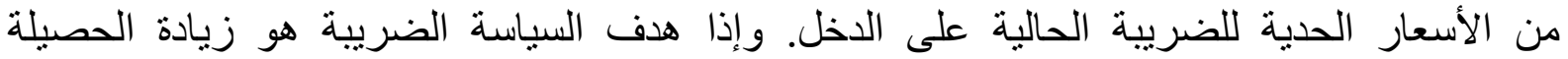

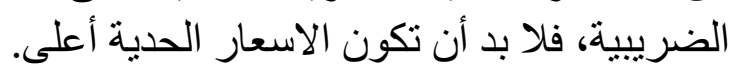

إن المقترحات الخاصة بزيادة الحصيلة الضريبية من ضريبة الدخل عن طريق زيادة الأسعار الضريبية

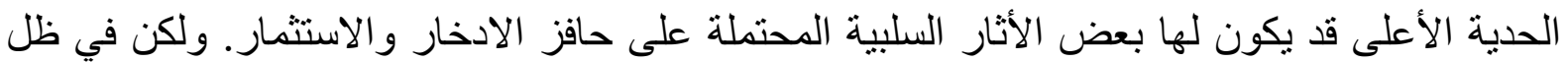

${ }^{357}$ Alpizar, F., Carlsson, F., \& Johansson-Stenman, O., (2005). How Much do we Care about Absolute Versus Relative Income and Consumption? Journal of Economic Behavior \& Organization. 56 (3), P.405.

${ }^{358}$ Frank, R. H.. (1997). The Frame of Reference as a Public Good. The Economic Journal. 107 (445), P.1832.

${ }^{359}$ Frank, Robert H., (1985). Choosing the Right Pond. Oxford University Press, New York; Frank, Robert H., (2007). Falling Behind: How Rising Inequality Harms the Middle Class. University of California Press, Berkeley, CA, P.77.

${ }^{360}$ Ireland, Norman, (1998). Status seeking, income taxation, and efficiency. Journal of Public Economics 70, P. 99. 
ضريبة الاستهلاك التصاعدية، سيكون هناك حافز أكثر لدى الأفر اد على الادخار والاستثمار، حتى لو لو الإلي كانت الأسعار الضريبية الحدية الأعلى على الاستهلاك مرتفعة للغاية. 361

كنلك من شأن ضريبة الاستهلاك التصاعدية أن تُغير أيضًا الأسعار النسبية الأخرى التي تؤثر على التى التئ

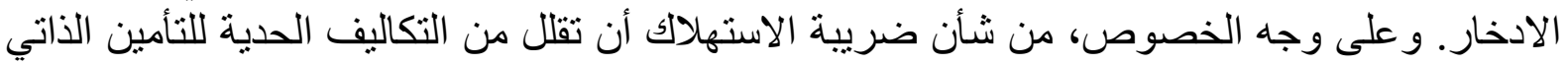

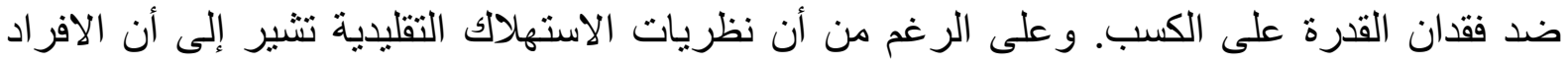

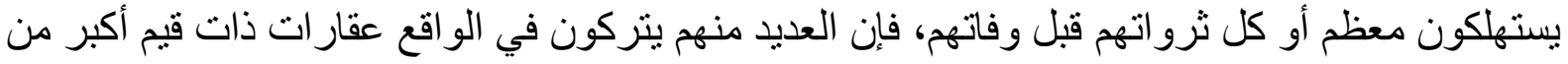

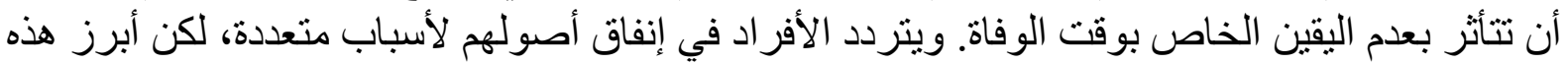

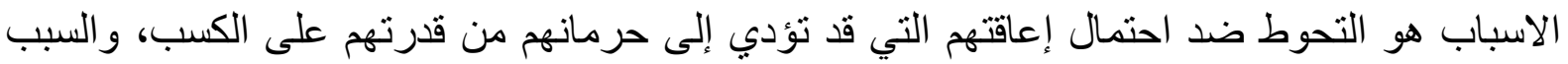

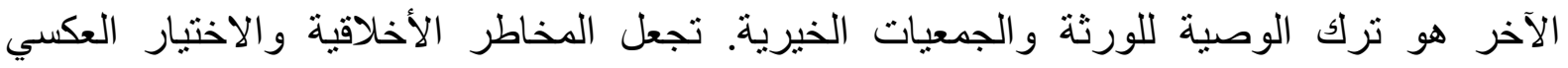

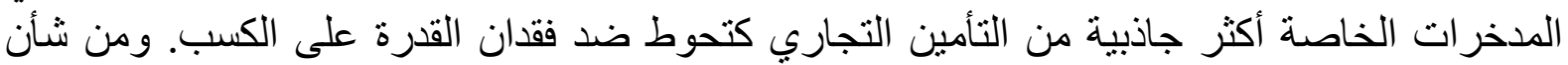
ضريبة الاستهلاك التصاعدية أن تقلل من تكلفة التأمين الذاتي، كما أنها ستقلل من تكلفة ترك التهان الوصايا. 362

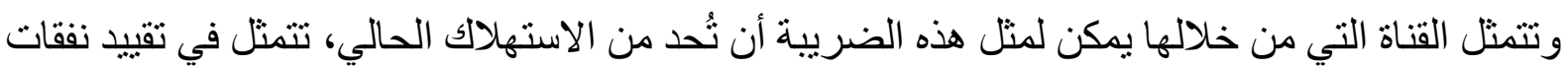

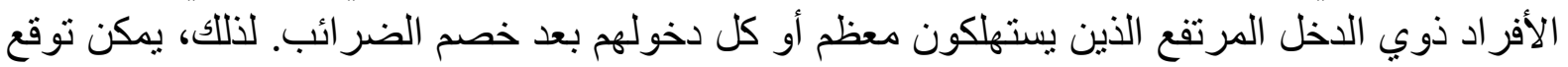
أن تؤدي ضريبة الاستهلاك التصاعدية إلى تحفيز الادخار. 363

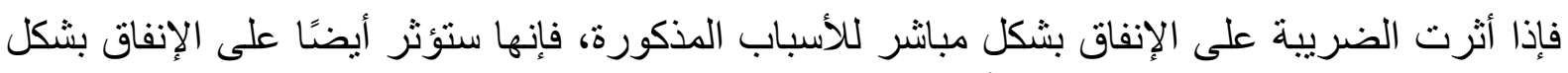

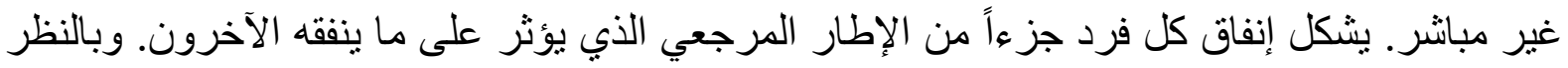

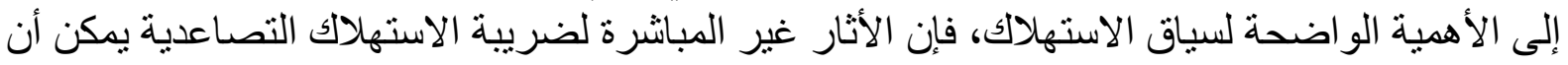

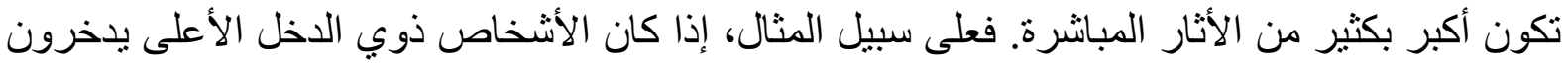

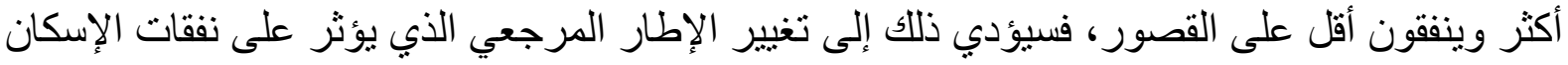

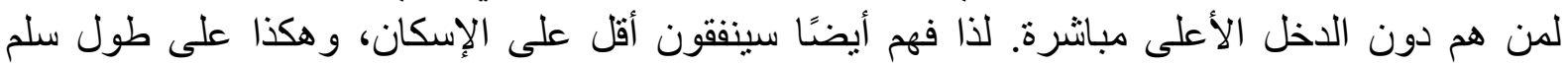

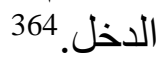

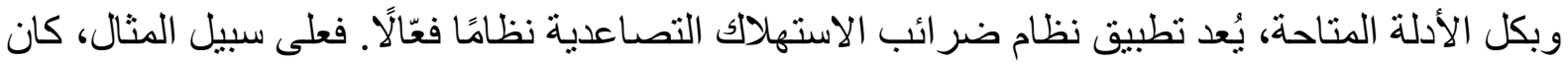

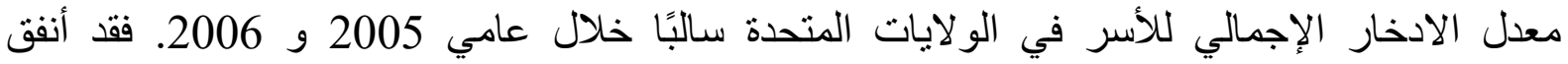

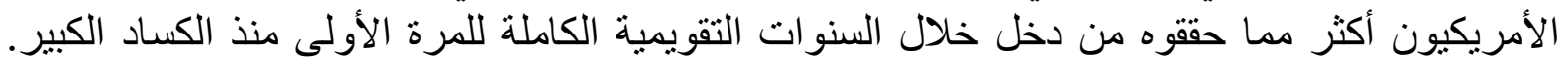

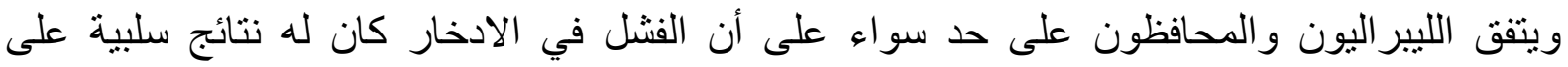

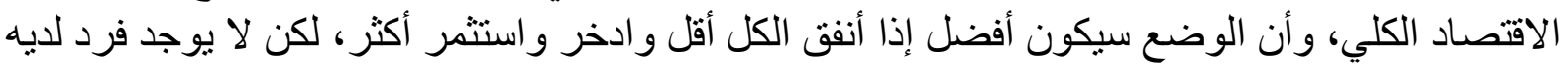

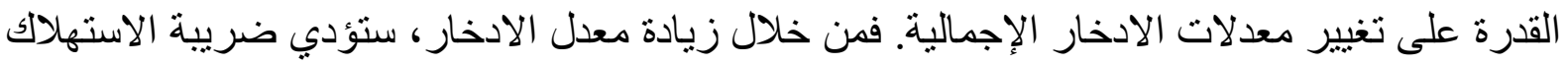

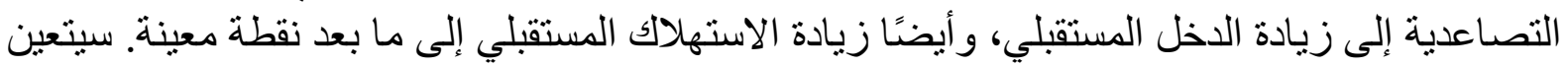

361 Boskin, Michael, Sheshinski, Eytan, (1978). Optimal redistributive taxation when individual welfare depends on relative income. Quarterly Journal of Economics 92 (4), P. 589.

362 Aronsson, T., Johansson-Stenman, O. (2017). Genuine saving and positional externalities. International Economic Review, 58(4), P. 1155.

${ }^{363}$ Alpizar, F., F. Carlsson, AND O. Johansson-Stenman, (2005). How Much Do We Care about Absolute versus Relative Income and Consumption? Journal of Economic Behavior and Organization 56, P. 405.

${ }^{364}$ Hopkins, Ed, Kornienko, Tatiana, (2004). Running to keep in the same place: consumer choice as a game of status, with Ed Hopkins. American Economic Review 94, P. 1085. 
على الأفر اد في نهاية المطاف تلبية استهلاك أعلى مما هي عليه الآن، ولكن سيكون لايهم أيضًا الدخل الأعلى اللازم لتلبية هذا المعيار.

وتتمثل الميزة الأساسية للنهج الضريبي الذي يطبق في كلًا من الهجال البيئي و الاستهلاكي في مرونة هذا

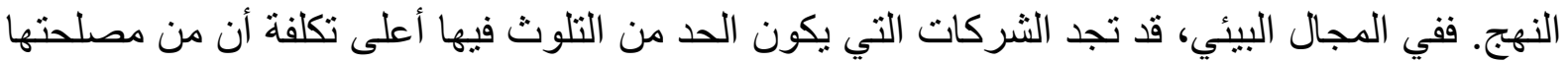

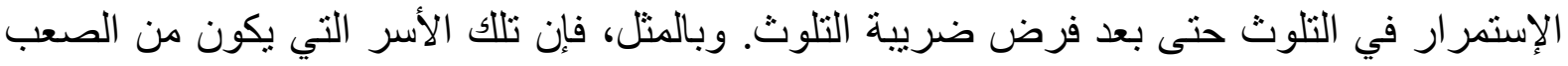

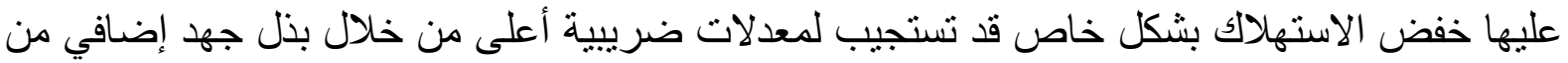

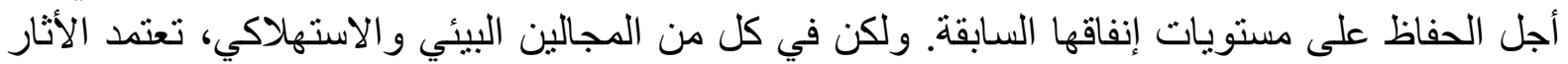

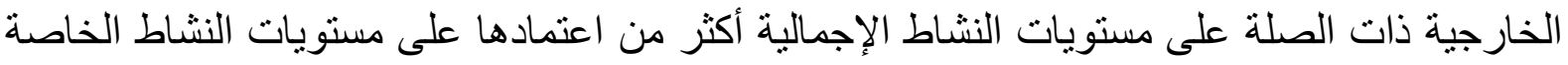

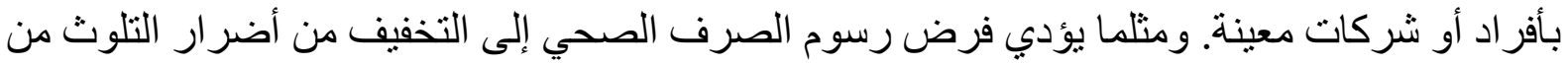

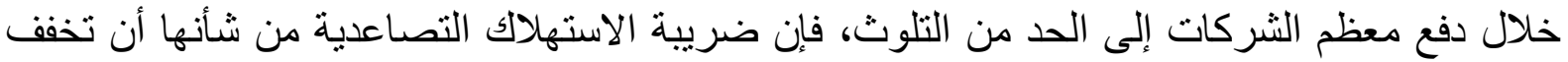

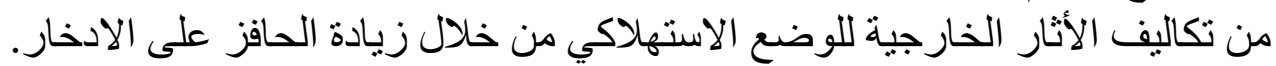

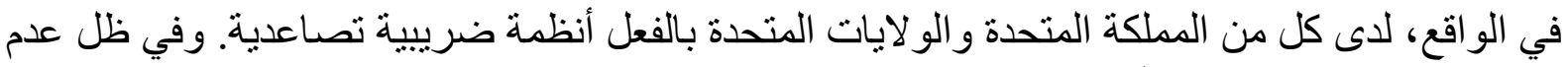

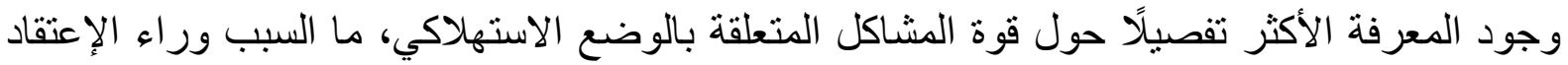

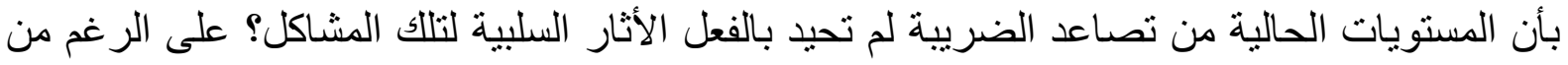

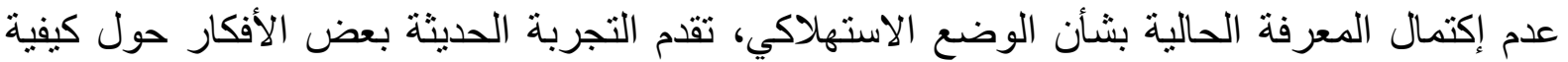

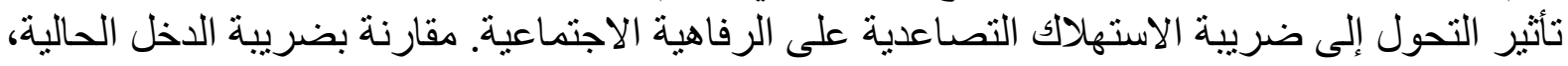

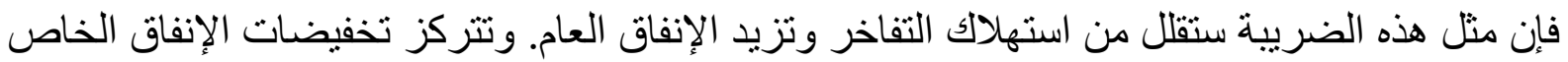

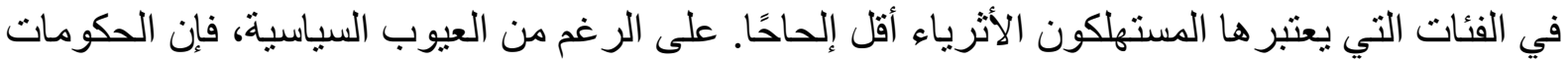

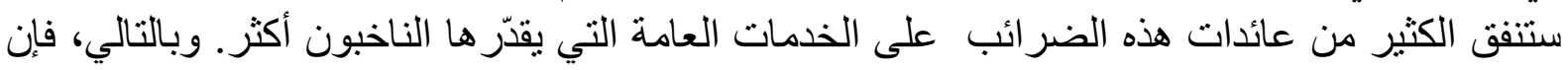

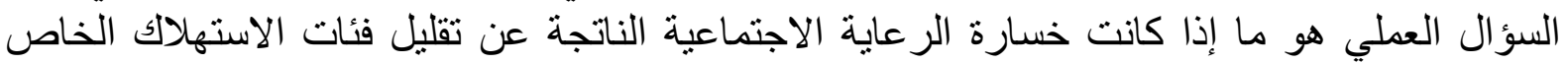

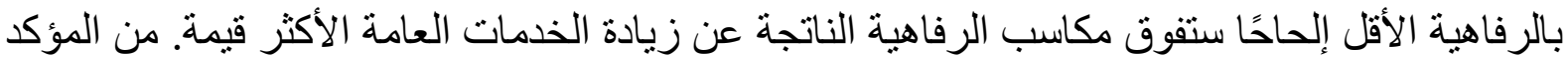

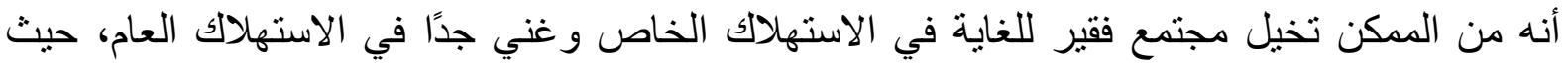

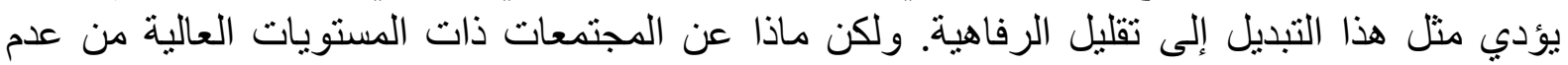

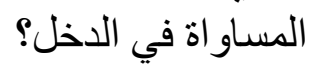

في ظل عدم وجود دليل عملي مفصل، فإن الاستنتاج المنطقي هو أن النفقات الأولية التي سيخفضها

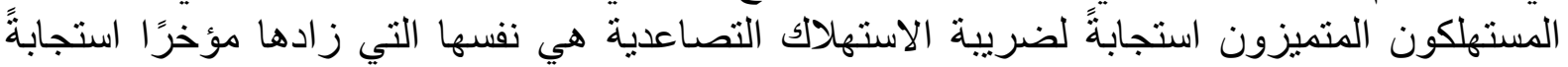

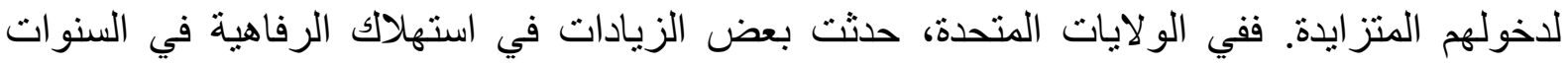

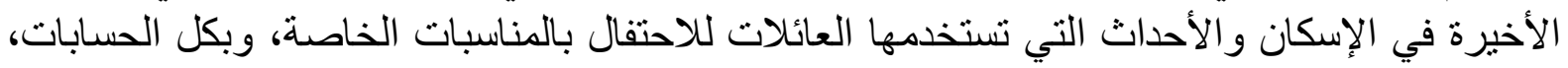
تتعلق هذه النفقات بالوضع الاستهلاكي النسبي.

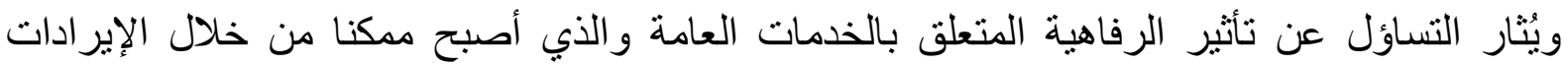

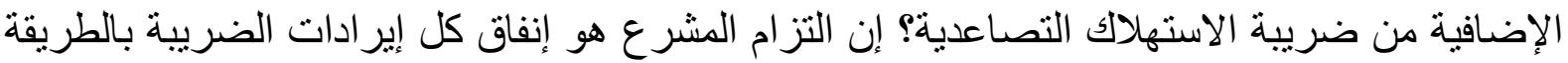

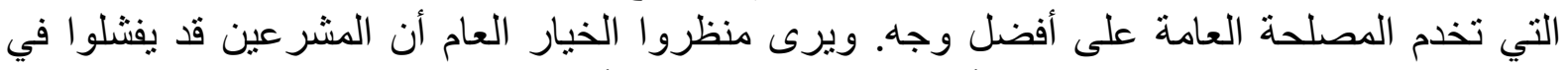

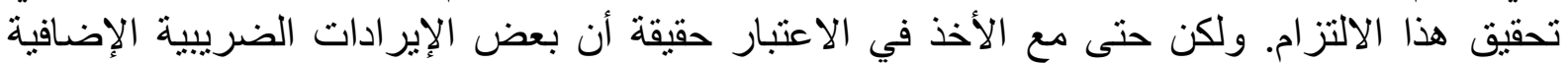

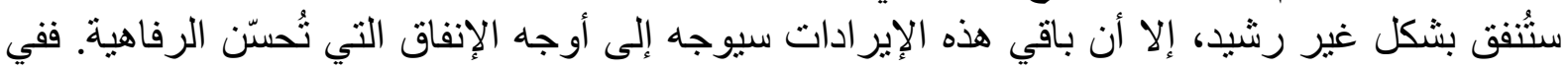

${ }^{365}$ Frank, R., (2005). Positional Externalities Cause Large and Preventable Welfare Losses. The American Economic Review, 95(2), P. 137. 


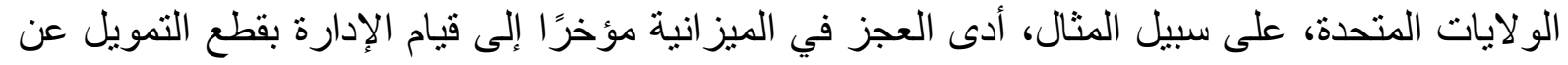

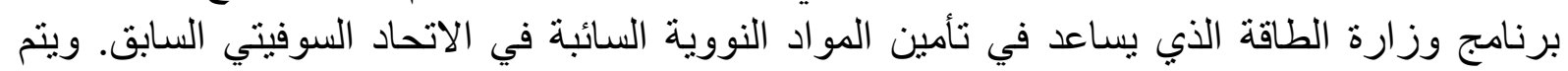

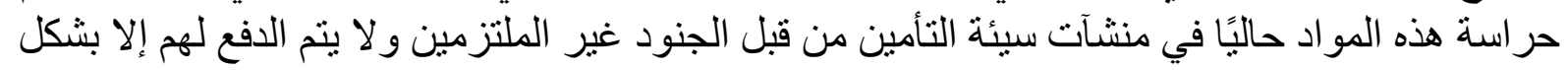

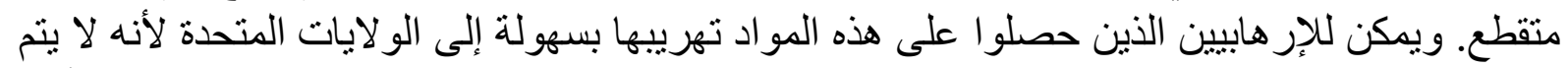

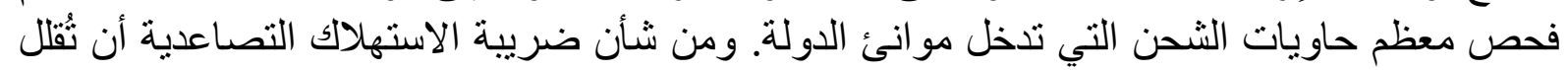
من احتمالات حدوث مثل هذه النتائج.

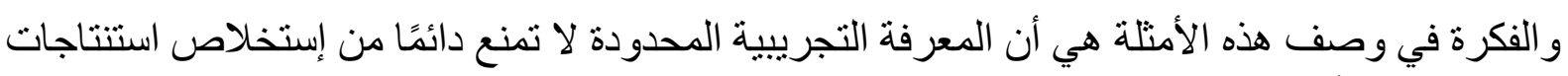

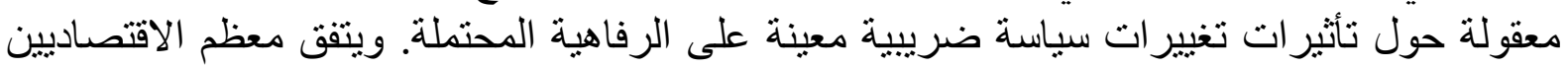

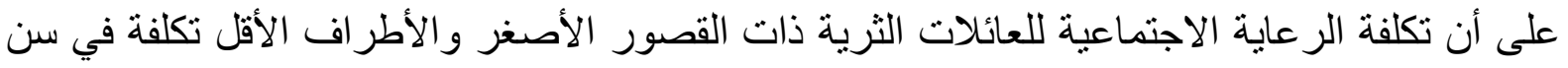

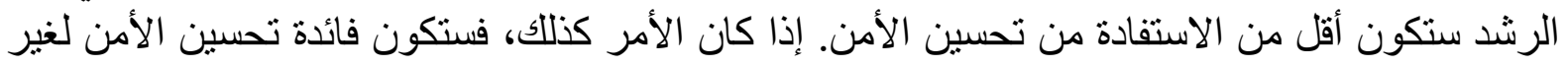

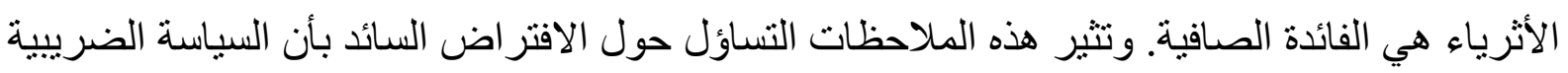

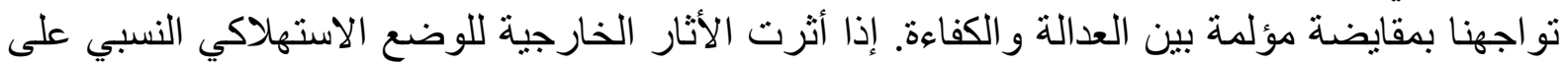

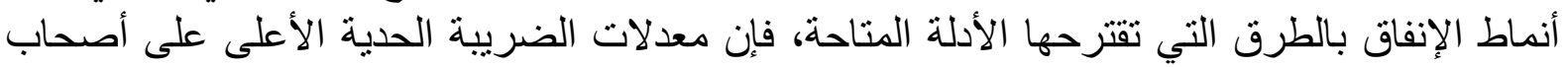

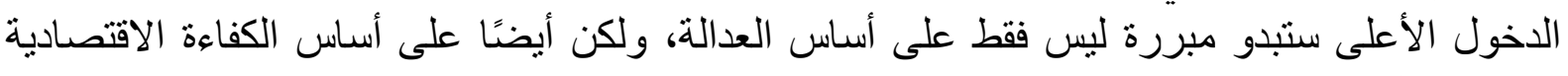
بمفهومها الضيق.

${ }^{366}$ Frank, Robert H., (2008). Should public policy respond to positional externalities? Journal of Public Economics, Elsevier, vol. 92(8-9), August, P. 1782. 
من الناحية الاقتصادية، ظهر مفهوم فثل السوق في البداية كوسيلة لتبرير النفقات الحكومية أو زيادتها.

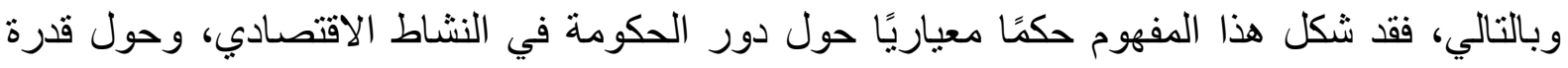

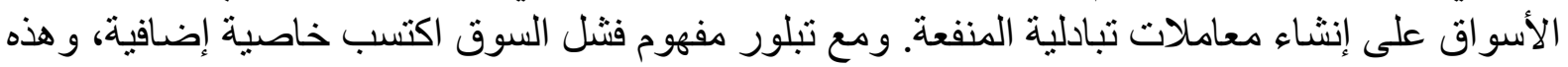

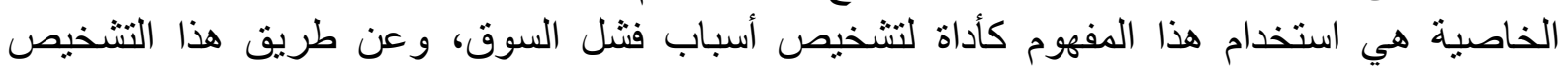

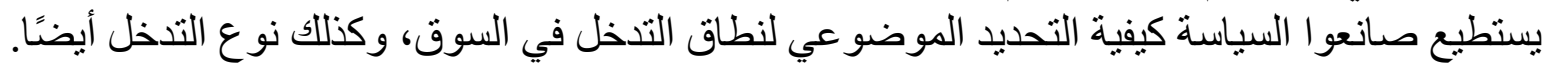
ويُعرَّف فثنل السوق على أنه عبارة عن خلل في نظام الأسعار، بحيث يُشنكل هذا الخلل عائقًا أمام

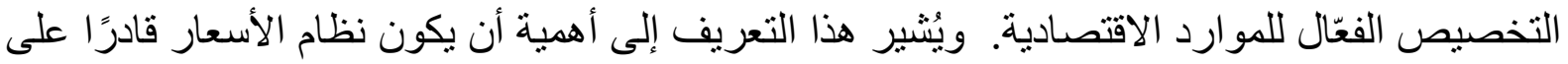

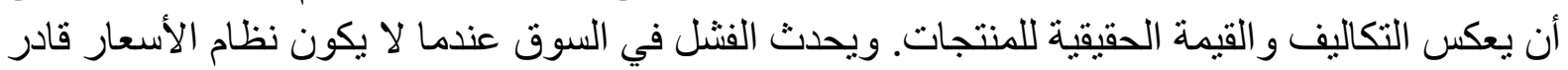

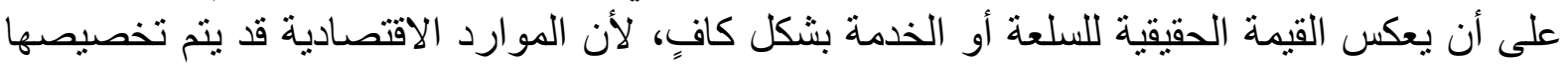

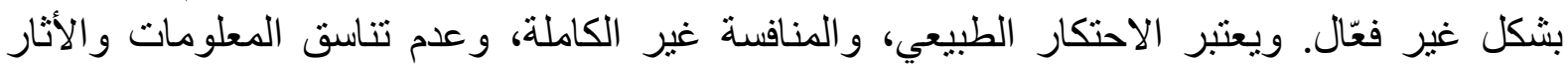

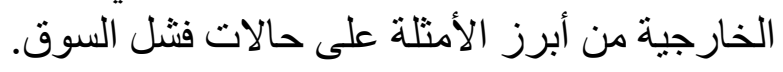

وفي هذا السياق، يندرج فثنل السوق ضمن فئة عامة من أسباب فنثل السوق تسمى الأثار الخارجية

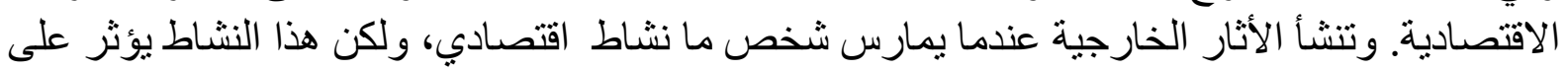

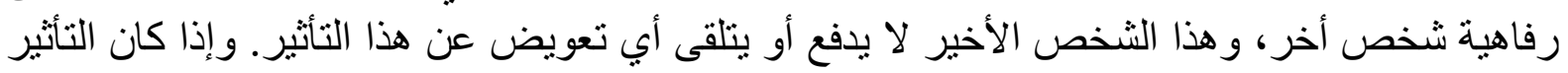

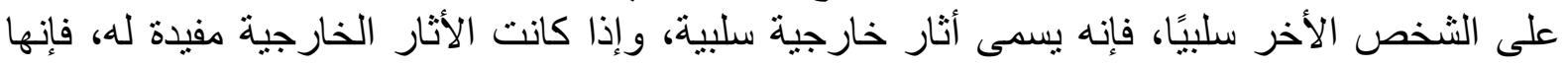

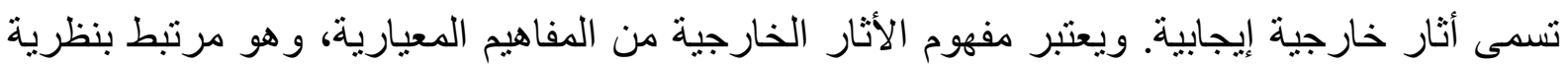

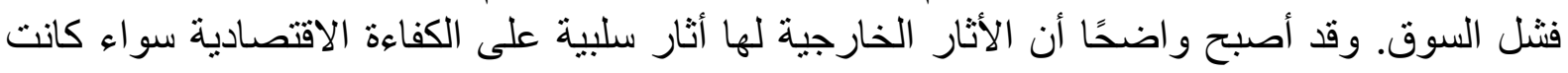
كفاءة الإنتاج أو الاستهلاك أو التوزيع.

وبعد تعريف فثل السوق بصفة عامة والأثار الخارجية كسبب لفثل السوق، وبعد دراسة وتحليل

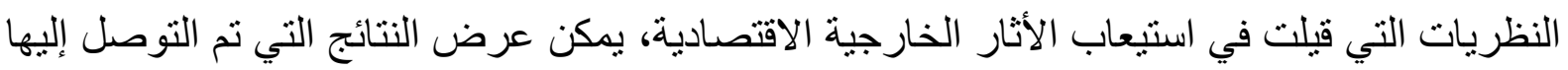

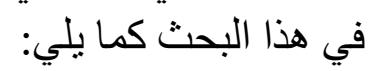

لا لا يمكن استيعاب كل الأثار الخارجية الاقتصادية باستخدام الإجراءات الحكومية التصحيحية،

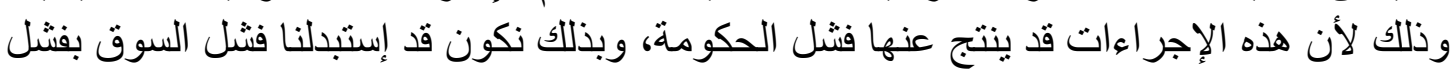

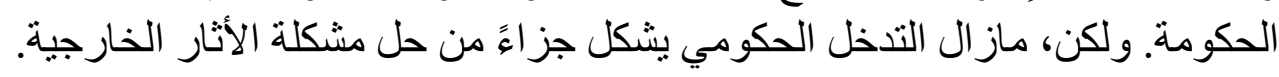

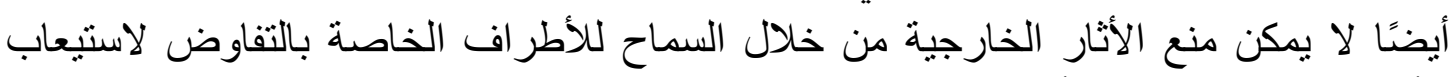

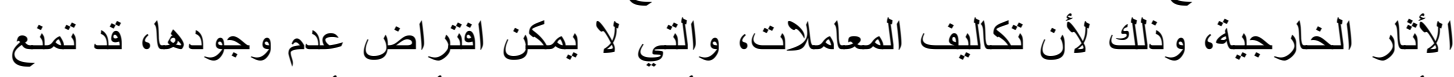

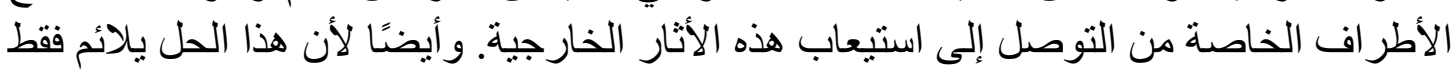

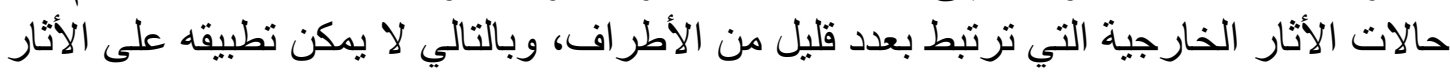

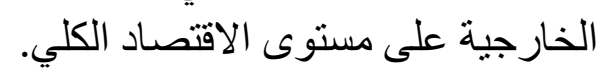

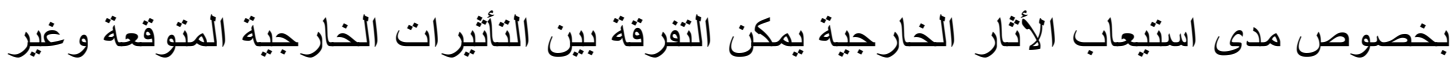

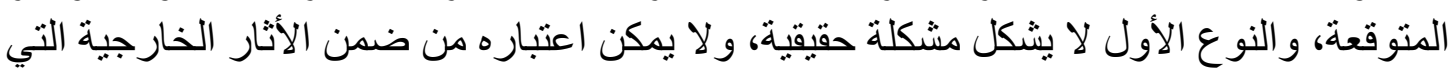

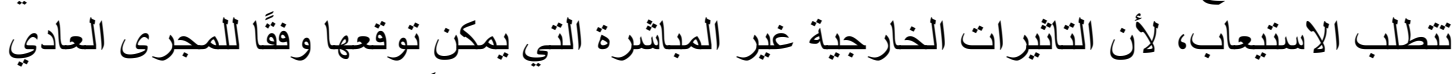

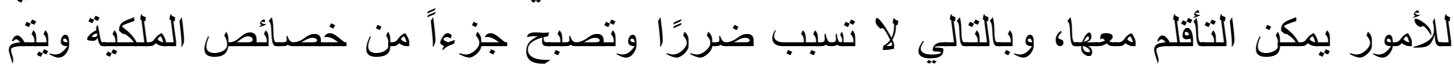

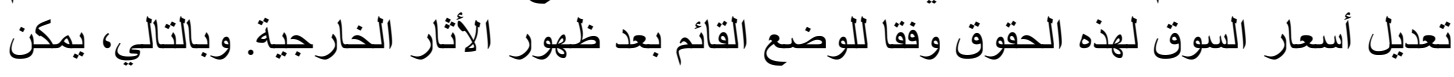


القول أن الأثار الخارجية المنوقعة تخضع لأسعار السوق و لا تحتاج إلى أي إجراءات لاستيعابها.

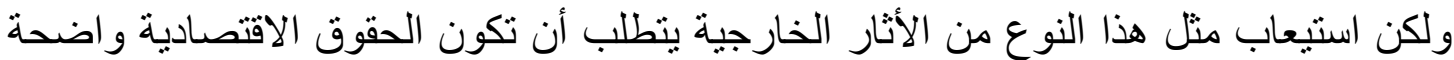

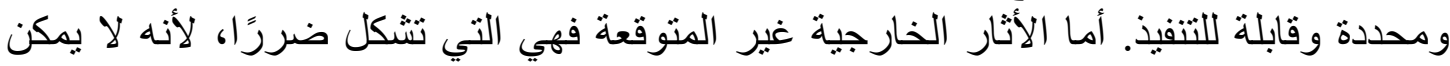

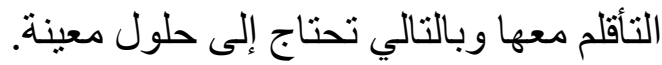

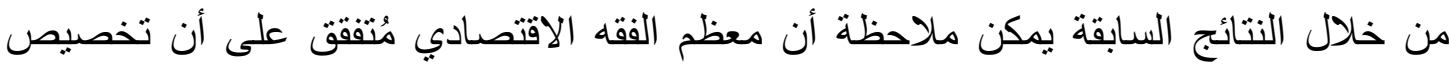

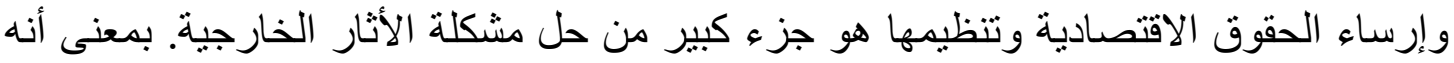

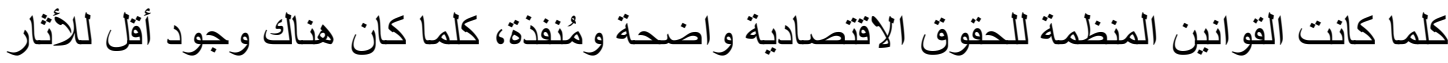

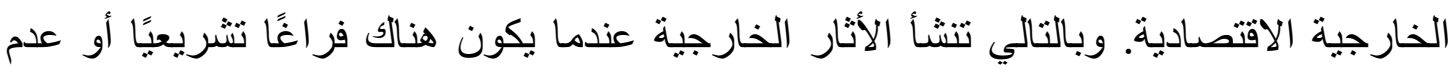

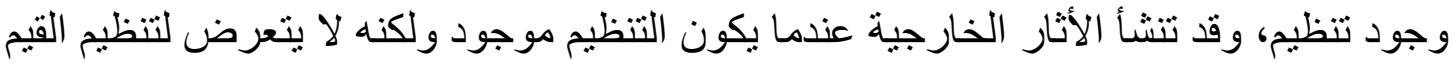

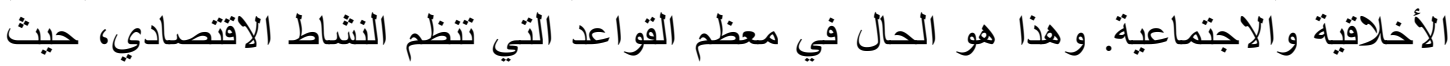

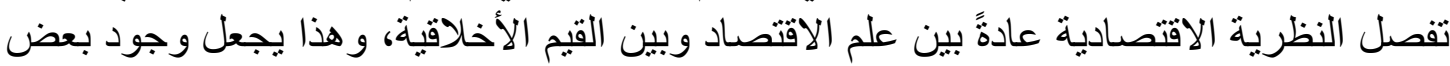

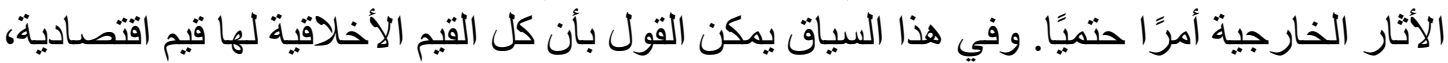

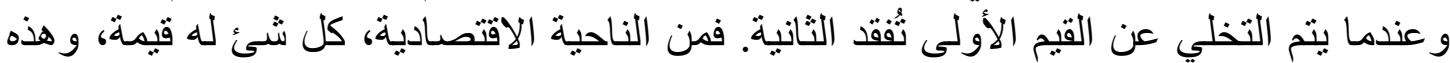

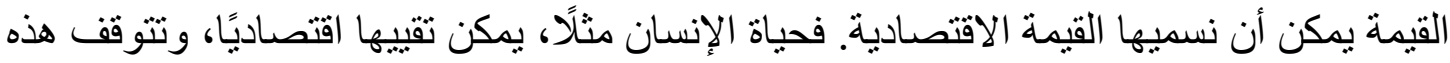

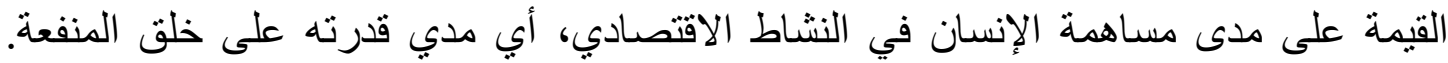

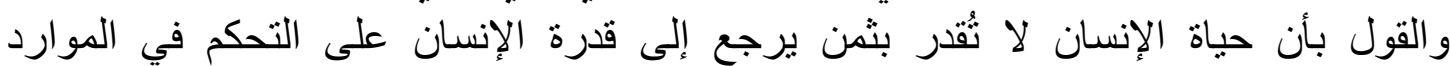

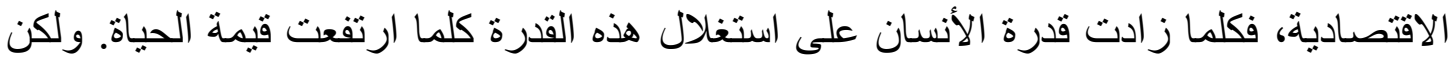

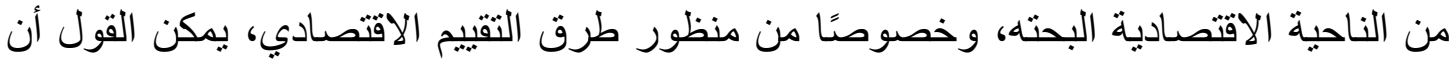

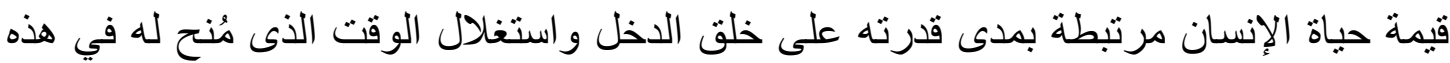

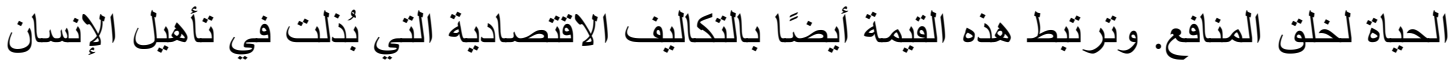

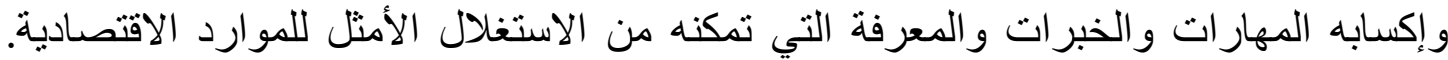

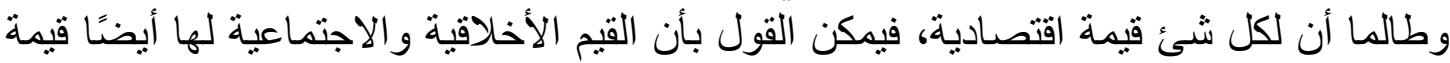

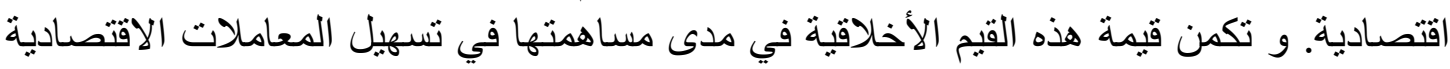
وفي تقليل تكاليف هذه المعاملات، فمثلًا، الصدق له قيمه اقتصادية وكذلك الوفاء بالوعود غير الألير

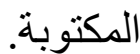
إضافة إلى ذلك، تظهر الأثار الخارجية الاقتصادية لأن المعايير القانونية التي يتم الإستناد اليها

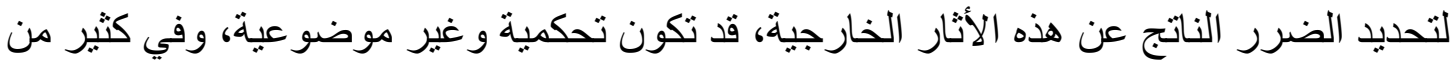

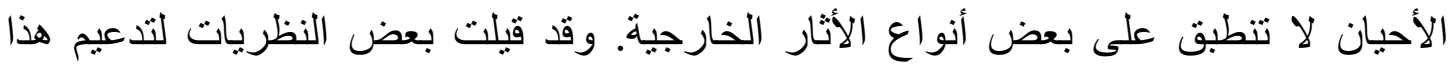

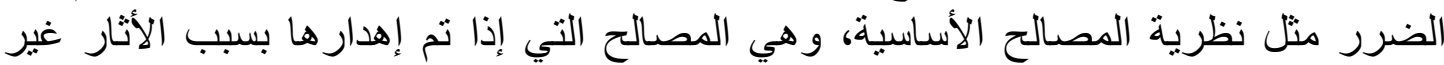

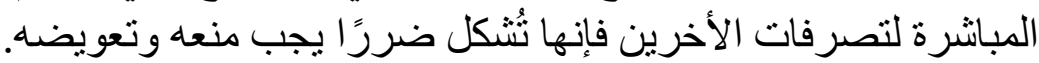

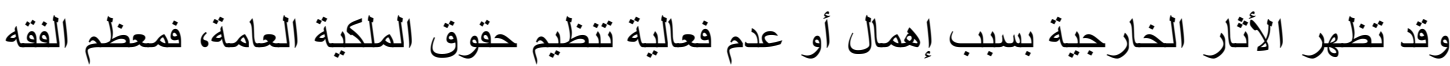

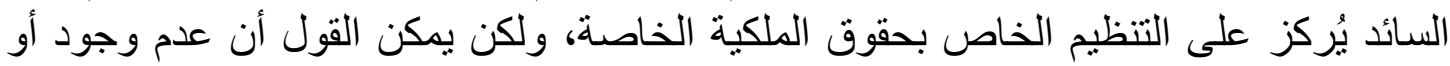

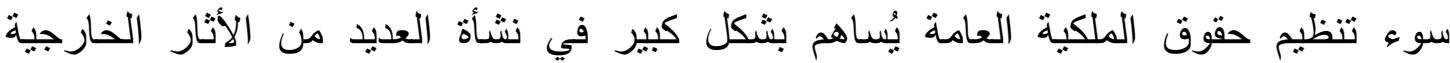

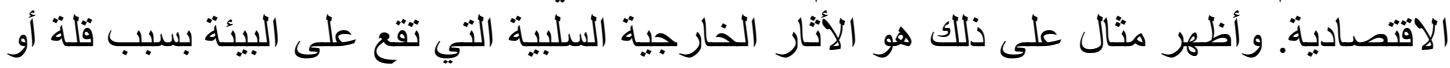

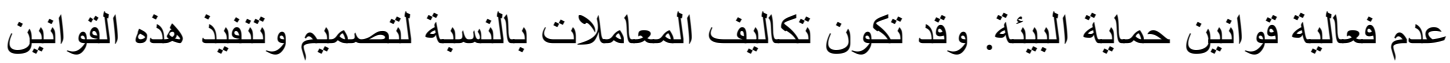

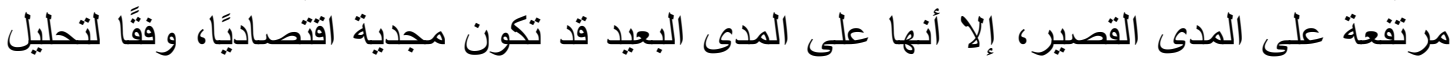

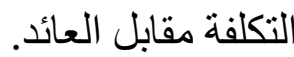

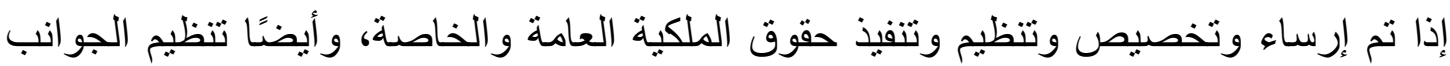

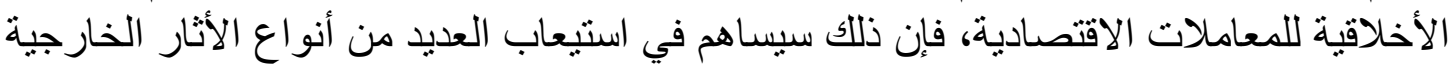




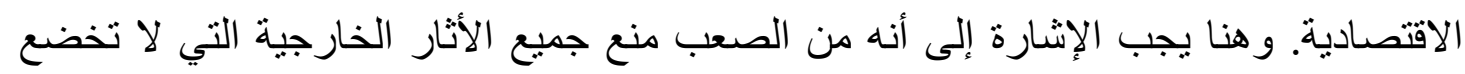

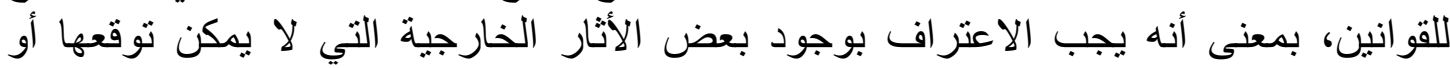

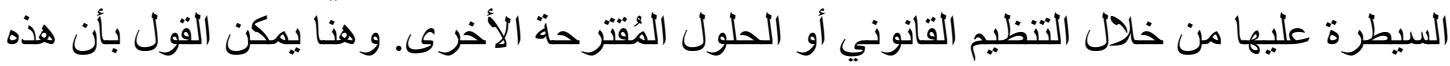

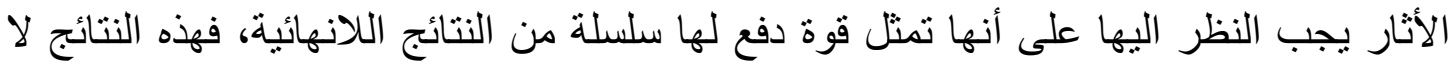

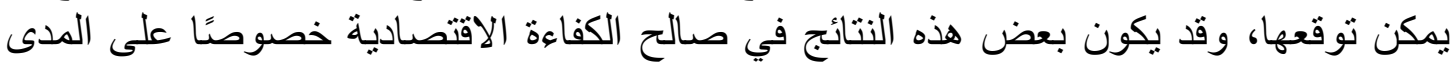

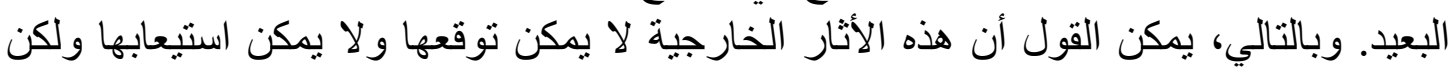

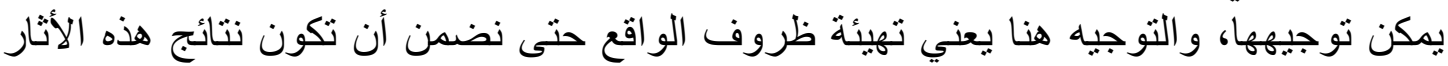

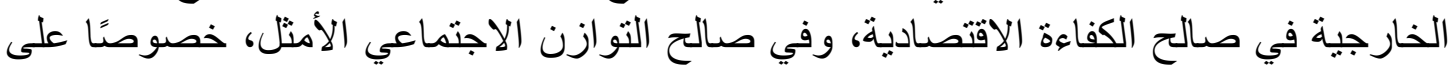

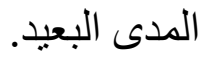


بناءً على النتائج السابقة يمكن تقديم بعض التوصيات التهات التي يمكن أن تساهم في استيعاب الأثار الخارجية

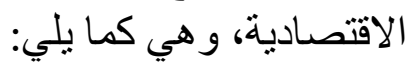

هنبغي العمل على تخصيص وتتظيم وحماية وتنفيذ حقوق الملكية العامة و الخاصة على حد سواء، ونهاء ويجب أن يكون هذا التنظيم واضح وشامل.

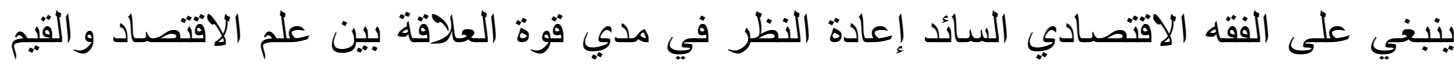

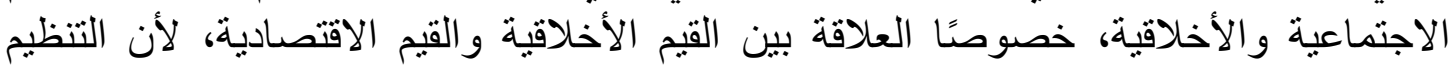

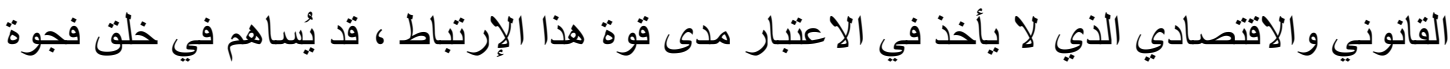
كبيرة تسمح بظهور الأثار الخارجية الاقتصادية. لألفائ.

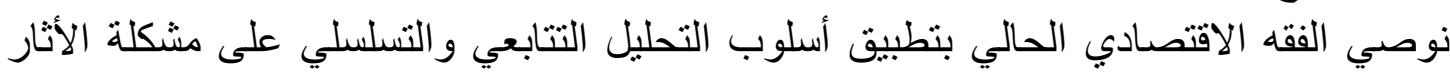

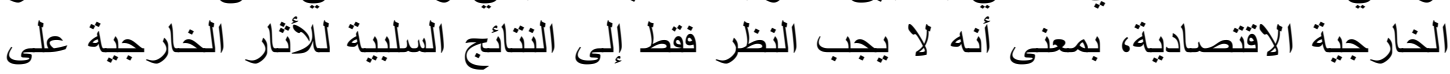

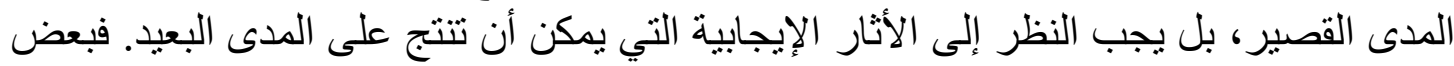
الأثار الخارجية السلبية قد تتحول إلى إيجابية على المدى البعيد. 
A. Myrick Freeman III, (2002). 'Environmental Policy Since Earth Day I: What Have We Gained?' Journal of Economic Perspectives 16, 1, PP. 125-146.

Abilene, Texas. N. Edward Coulson \& Robin M. Leichenko, (2001). 'The Internal and External Impact of Historical Designation of Property Values', 23 J. REAL EST. FIN. \& ECON.

Alain Marciano \& Steven G. Medema, (2015). 'Market Failure in Context: Introduction,' History of Political Economy, Duke University Press, vol. 47(5), PP. 1-19.

Alan Randall, (1983). 'The Problem of Market Failure', 23 Nat. Resources J. 131.

Alfred Marshall, (1920). Principles of Economics 266 (8th ed).

Allen, D., (1999). 'Transactions costs'. In S. Medema, G. Bouckaert, \& G. DeGeest (Eds.), Encyclopedia of law and economics. Aldershot, UK: Edward Elgar.

Allen, D.W., (1991). 'What are transaction costs?' In R.O. Zerbe and V.P. Goldberg (Eds.), Research in law and economics, Greenwich, CN: JAI Press, Vol. 14, PP. 1-8.

Allen, Douglas W., (1991). 'What are transaction costs?' Research in Law and Economics, 14.

Allen, Douglas W., (1998). 'Property Rights, Transaction Costs, and Coase: One More Time'. In Coasean Economics: Law and Economics and the New Institutional Economics, pp. 105-18. Steven G. Medema (ed.). Kluwer.

Alpizar, F., Carlsson, F., \& Johansson-Stenman, O., (2005). 'How Much do we Care about Absolute Versus Relative Income and Consumption?' Journal of Economic Behavior \& Organization. 56 (3), PP.405-421.

Alvin Roth, (2007). Repugnance as a Constraint on Markets, 21 J. ECON. PERSP. 37, P. 42

Andersson, F. W., (2008). Is concern for relative consumption a function of relative consumption? The Journal of Socio-Economics 37, PP. 353-364.

Andrew Narwold, (2008). Estimating the Value of the Historical Designation Externality, 1 INT'L J. HOUSING MKTS. \& ANALYSIS 288.

Armstrong, Mark, (1998). Network interconnection in telecommunications. Econ. J.108, PP. $545-564$.

Arnold, N. S., (2009). Imposing Values. An Essay on Liberalism and Regulation, Oxford: Oxford University Press, PP. 28-36.

Aronsson, T., Johansson-Stenman, O., (2017). Genuine saving and positional externalities. International Economic Review, 58(4), PP. 1155-1190. 
Arrow, K., (1999). Knowledge as a factor of production. In Annual World Bank Conference on Development Economics. Stiglitz, J.E. \& Pleskovic, B. (Eds.), Washington, DC: The World Bank, PP: 15-20.

Arthur Cecil Pigou, (1932). The Economics of Welfare (4th ed.), P. 130.

Ayres, Robert U., and Allen V. Kneese., (1969)."Production, Consumption, and Externalities.” American Economic Review 59 (3), PP. 282-97.

Baake, Pio, Boom, Anette, (2001). Vertical product differentiation, network externalities, and compatibility decisions. Int. J. Ind. Organ.19, PP. 267-284.

Bailey, Martin J., (1954). "The Interpretation and Application of the Compensation Principle." Economic Journal 64 (253), PP. 39-52.

Banerji, A., Dutta, Bhaskar, (2009). Local network externalities and market segmentation. Int. J. Ind. Organ.27, PP. 605-614.

Barry, B., (1986). 'Lady Chatterley's lover and doctor Fischer's bomb party: liberalism, Pareto optimality, and the problem of objectionable preferences', in J. Elster and A. Hylland (eds.) Foundations of Social Choice Theory, New York: Cambridge University Press.

Barthold, Thomas A., (1994). "Issues in the Design of Environmental Excise Taxes." Journal of Economic Perspectives 8, 1, PP. 133-151.

Barzel, Yoram., (1985). 'Transaction costs: are they just costs?' Journal of Institutional and Theoretical Economics, 141, PP.4-16.

Baumol, W. J., Panzar, J. C. and Willig, R. D., (1982), Contestable Markets and the Theory of Industrial Structure, (New York, Harcourt Brace).

Baumol, W.J., \& Oates, W.E., (1975). The theory of environmental policy. Englewood Cliffs, NJ: Prentice Hall.

Baumol, William J., (1972). "On Taxation and the Control of Externalities." American Economic Review 62 (3), PP. 307-22.

Berta, Nathalie, and Elodie Bertrand., (2014). "Market Internalization of Externalities: What Is Failing?" Journal of the History of Economic Thought 36 (3), P. 331-57.

Berta, Nathalie., (2017). "On the Definition of Externality as a Missing Market." European Journal of the History of Economic Thought, 24 (2), PP. 287-318.

Boadway, R.W., \& Wildasin, D.W. (1984). Public sector economics (2nd ed.). Toronto: Little Brown and Company, P. 61.

Boardman, A.E., Greenberg, D.H., Vining, A.R., \& Weimer, D.L. (1996). Cost-benefit analysis: Concepts and practice. Upper Saddle River, NJ: Prentice Hall, P. 99. 
Boskin, Michael, Sheshinski, Eytan, (1978). Optimal redistributive taxation when individual welfare depends on relative income. Quarterly Journal of Economics 92 (4), PP. 589-601.

Bourdieu, P., (1984). Distinction: A social critique of the judgment of taste. Cambridge, Mass.: Harvard University Press

Brennan, Geoffrey and James Buchanan. (1985). The Reason of Rules. Cambridge: Cambridge University Press.

Bryan Caplan, Externalities, LIBR. ECON. \& LIBERTY, available at: <https://www.econlib.org/library/Enc/Externalities.html?highlight=\%5B \%22externality \%22 $\% 5 \mathrm{D}>$.

Buchanan, James M., (1986). 'Rights, Efficiency, and Exchange: The Irrelevance of Transactions Cost'. In J. M. Buchanan, Liberty, Market and the State: Political Economy in the 1980s, New York University Press.

Calabresi, G., (1970). The Costs of Accidents: A Legal and Economic Analysis, New Haven, CT: Yale University Press, P.151.

Cantner, Uwe; Vannuccini, Simone, (2016). Innovation and lock-in, Jena Economic Research Papers, No. 2016-018, Friedrich Schiller University Jena, Jena.

Carl Dahlman, (1979). The Problem of Externality, 22 J. L. \& ECON., 141.

Carlsson, F., Johansson-Stenman, O., \& Martinsson, P. (2007). Do You Enjoy having More than Others? Survey Evidence of Positional Goods. Economica. 74 (296), PP. 586-598.

Chris Warhurst et al., (2009). Lookism: The New Frontier of Employment Discrimination?, 51 J. INDUS. REL. 131.

Claassen, R., (2011). 'Making Capability Lists. Philosophy versus Democracy', Political Studies, 59(3), PP. 491-508.

Claassen, Rutger, (2016). Externalities as a basis for regulation: a philosophical view. Journal of Institutional Economics. -1, PP. 1-23.

Clark, Andrew, Oswald, Andrew, (1996). Satisfaction and comparison income. Journal of Public Economics 61, PP. 359-381.

Coase, R. H., (1960). 'The Problem of Social Cost', The Journal of Law and Economics, 3, PP. 1-44.

Coase, R. H., (1990). "The Firm, the Market, and the Law," University of Chicago Press Economics Books, University of Chicago Press, 26-27, P.20.

Coase, R.H., (1937). The nature of the firm. Reprinted in R. Coase, The firm, the market, and the law. Chicago: University of Chicago Press, 1988. 
Coase, Ronald H., (1960). "The problem of social cost'. Journal of Law and Economics, 3, PP.1-44.

Coase, Ronald H., (1993). 'Law and Economics at Chicago'. Journal of Law and Economics, 36, PP. 239-54.

Cohen, G.A., (1995). Self-Ownership, Freedom, and Equality, Cambridge: Cambridge University Press, P.67.

Congleton RD., (1989). Efficient status seeking: externalities and the evolution of status games, Journal of Economic Beha6ior and Organization 11, PP. 175-190.

Cornes, Richard, and Todd Sandler., (1996). The Theory of Externalities, Public Goods and Club Goods. Second edition. New York: Cambridge University Press.

Cunningham, S. (2011). Understanding Market Failures in an Economic Development Context. Pretoria, South Africa: Mesopartner Monograph 4.

Cunningham, S., (2009). The role of market failure in the utilisation of Quality Management services by the tooling industry. Ph.D. Thesis, North West University.

Dahlman, C.J., (1979, April). The problem of externality. Journal of Law and Economics, 22, PP. 141-162.

Daniel S. Hamermesh \& Jeff E. Biddle, (1994). Beauty and the Labour Market, 84 AM. ECON. REV. 1174.

David Parrish \& William Stockwell, (Jan. 8, 2015). Urbanization and Air Pollution: Then and Now, EOS EARTH \& SPACE SCI. NEWS.

David, Paul., (2007). Path Dependence: A Foundational Concept for Historical Social Science. Cliometrica, Journal of Historical Economics and Econometric History. 1. 91-114.

De Alessi, L., (1996, Spring/Summer). Error and bias in benefit-cost analysis: HUD's case for the wind rule. Cato Journal, 16, 129-147.

De Soto, H., (2000). The mystery of capital: why capitalism triumphs in the West and fails everywhere else. New York, NY: Basic Books.

Demsetz, H., (1996). 'The Core Disagreement between Pigou, the Profession, and Coase in the Analysis of Externalities', European Journal of Political Economy, 12(4), PP. 565-579.

Diener, Ed, Ed Sandvik, Larry Seidlitz, and Marissa Diener, (1993). The Relationship between Income and Subjective Well-Being: Relative or Absolute? Social Indicators Research, 28, PP. 195-223.

Don Lavoie, (1985). Rivalry and Central Planning: The Socialist Calculation Debate Reconsidered, New York: Cambridge University Press. 
Donald Boudreaux, Roger Meiners \& Todd Zywicki, (1999). Talk Is Cheap: The Existence Value Fallacy, 29 ENVTL. L. 765.

Donald J. Boundreaux \& Roger Meiners, (2019). Externality: Origins and Classifications, 59 Nat. Resources J. 1 ,P.22.

Dorris, Gary W., (1996). Redesigning Regulatory Policy: a case study in urban smog, $\mathrm{PhD}$ dissertation. Cornell University.

Douglas M, Isherwood B., (1978). The World of Goods. Penguin Books: London.

Easterlin, R. A., (1974). Does Economic Growth Improve the Human Lot? Some Empirical Evidence.' Nations and Households in Economic Growth [Online], PP. 89-125.

Easterlin, Richard, (1995). Will raising the incomes of all increase the happiness of all? Journal of Economic Behavior and Organization 27, PP. 35-47.

Edward L. Glaeser \& Joshua D. Gottlieb, (2009). The Wealth of Cities: Agglomeration Economies and Spatial Equilibrium in the United States, 47 J. ECON. LITERATURE 983, 1014-15.

Edwin S. Mills \& Philip E. Graves, (1986). The Economics of Environmental Quality, 2 (2d ed.).

Edwin S. Mills \& Philip E., (1986).Graves, The Economics of Environmental Quality, 2 (2d ed.).

Ellis, Howard S., and William Fellner. (1943). "External Economies and Diseconomies." American Economic Review 33 (3): 493-511.

Epstein, R.A., (1995). 'Are values incommensurable, or is utility the ruler of the world?' Utah Law Review, PP. 683-715, P.700.

Eytan Shekhinski, (2002). On Atmosphere Externality and Corrective Taxes, 88 J. PUB. ECON. 727.

F.A. Hayek, (1973). Law, Legislation, and Liberty: Rules and Order. Vol. 1, University of Chicago Press.

F.A. Hayek, (2014). Competition as a Discovery Procedure, in the market and other orders (Bruce Caldwell ed.), PP. 304-13.

Farrell, Joseph., (1987). "Information and the Coase Theorem." Journal of Economic Perspectives 1 (2), PP. 113 - 129.

Feinberg, J., (1984). Harm to Others, Oxford: Oxford University Press, P.115.

Ferrer-i-Carbonell, A., \& Frijters, P., (2004). 'How Important is Methodology for the Estimates of the Determinants of Happiness?' The Economic Journal. 114 (497), PP. 641659. 
Festinger, L., (1954). 'A Theory of Social Comparison Processes.' Human Relations [Online]. 7 (2), PP. 117-140

Finnis, J., (2011). Natural Law and Natural Rights, Oxford: Oxford University Press.

Fligstein, N., (2001). The architecture of markets: an economic sociology of twenty-first century capitalist societies. Princeton, NJ: Princeton University Press.

Francis M. Bator, (1958). The Anatomy of Market Failure, 72 Q.J. ECON. 351, P. 354.

Frank H. Knight, (1924).Some Fallacies in the Interpretation of Social Cost, 38 Q.J. ECON. 582.

Frank RH., (1985). Choosing the Right Pond: Human Beha6ior and the Quest for Status. Oxford University Press: New York.

Frank RH., (1997). The frame of reference as a public good, Economic Journal 107, PP. $1832-1847$.

Frank, R., (2005). Positional Externalities Cause Large and Preventable Welfare Losses. The American Economic Review, 95(2), PP. 137-141.

Frank, R., (2008), 'Should Public Policy Respond to Positional Externalities?', Journal of Public Economics, 92(8-9): 1777-1786.

Frank, R. H., (1985). 'The Demand for Unobservable and Other Non-positional Goods.' The American Economic Review. 75 (1), PP. 101-116.

Frank, R. H., (1997). The Frame of Reference as a Public Good. The Economic Journal [Online]. 107 (445), PP.1832-1847.

Frank, R. H., (2005). 'Positional Externalities Cause Large and Preventable Welfare Losses.' The American Economic Review. 95 (2), PP.137-141.

Frank, R. H., (2008). Should Public Policy Respond to Positional Externalities? Journal of Public Economics. 92 (8), PP.1777-1786.

Frank, R. H., (2010). Luxury fever: Weighing the cost of excess. New Jersey: Princeton University Press.

Frank, R., (2005). Positional Externalities Cause Large and Preventable Welfare Losses. The American Economic Review, 95(2), PP. 137-141.

Frank, Robert H., (1985). Choosing the Right Pond. Oxford University Press, New York.

Frank, Robert H., (1985). The demand for unobservable and other non-positional goods. American Economic Review 75, March, PP. 101-116. 
Frank, Robert H., (1991). Positional externalities. In: Zeckhauser, Richard (Ed.), Strategy and Choice: Essays in Honour of Thomas C. Schelling. MIT Press, Cambridge, MA, PP. 2547.

Frank, Robert H., (1999). Luxury Fever. The Free Press, New York.

Frank, Robert H., (2007). Falling Behind: How Rising Inequality Harms the Middle Class. University of California Press, Berkeley, CA.

Frank, Robert H., (2008). Should public policy respond to positional externalities? Journal of Public Economics, Elsevier, vol. 92(8-9), August, PP. 1777-1786.

Frankel, T., (1995, Fall). Foreword. Symposium: A recipe for effecting institutional changes to achieve privatization. Boston University International Law Journal, 13, 295-311. P. 295.

Friedman, D.D., (2000). Law's Order: What Economics Has to Do with Law and Why It Matters, Princeton, NJ: Princeton University Press, P.40.

Galbraith JK., (1958). The Affluent Society. Houghton Mifflin: Boston.

Gardner, J. and Shute, S., (2000). 'The wrongness of rape', in J. Horder, Oxford Essays in Jurisprudence: Fourth Series, Oxford: Oxford University Press, P. 216.

George J. Stigler, (1976). The Xistence of X-Efficiency, 66 AM. ECON. REV., PP. 213- 216.

Grossman GM, Shapiro C., (1988). Foreign counterfeiting of status goods, Quarterly Journal of Economics 102, PP. 79-100.

Harford, T., (2006). The undercover economist. London: Little Brown Book Group.

Harold Demsetz, (1996). The Core Disagreement between Pigou, the Profession, and Coase in the Analyses of the Externality Question, 12 EUR. J. POL. ECON. 565, PP. 569-70.

Harold Demsetz, (2011). The Problem of Social Cost: What Problem? A Critique of the Reasoning of A.C. Pigou and R.H. Coase, 7 REV. L. \& ECON. 1, P. 3.

Hatzis, A., (2015), 'Moral Externalities: An Economic Approach to the Legal Enforcement of Morality', in A. Hatzis and N. Mercuro (eds.), Law and Economics: Philosophical Issues and Fundamental Questions, Oxon/New York: Routledge, PP. 226-244.

Hatzis, Aristides N., (January 1, 2015). Moral Externalities: An Economic Approach to the Legal Enforcement of Morality, Law and Economics: Philosophical Issues and Fundamental Questions. Edited by Aristides N. Hatzis \& Nicholas Mercuro. London/New York: Routledge, PP. 226-244.

Hausman, D., (1992). 'When Jack and Jill Make a Deal', Social Philosophy and Policy, 9(1): 95-113.P, 103. 
Hausman, Daniel M., (2008). "Market Failure, Government Failure, and the Hard Problems of Cooperation," Ethics and Economics, CREUM, Université de Montréal, vol. 6(1), PP. 1-6.

Hausman, Daniel., (1992). "When Jack and Jill Make a Deal," Social Philosophy and Policy 9: $95-113$.

Hausmann, R. \& Rodrik, D., (2003). Economic development as self-discovery. Journal of Development Economics, 72(2):603-633, P.10.

Hawk, Barry E., (2018) .English Competition Law Before 1900 (February 2,). Antitrust Bulletin, Fordham Law Legal Studies Research Paper.

Heath, J., (2005). 'Liberal Autonomy and Consumer Sovereignty', in J. Christman and J. Anderson (eds.), Autonomy and the Challenges to Liberalism. New Essays, Cambridge: Cambridge University Press, PP. 204-225.

Heller, Walter P., and David A. Starrett, (1976). "On the Nature of Externalities." In Steven A. Y. Lin, ed., Theory and Measurement of Economic Externalities. New York: Academic Press, PP. 9 - 21.

Henry E. Smith, (2004).Exclusion and Property Rules in the Law of Nuisance, 90 VA. L. REV. 965.

Henry Mohrman, (2015). Coase on the Coase Theorem, 'The Social Cost Controversy, 2 MAN \& ECON. 215, P.221.

Herzog, D., (2000), 'Externalities and Other Parasites', The University of Chicago Law Review, 67(3), PP. 895-923.P, 912.

Hirsch F., (1976). Social Limits to Growth. Harvard University Press: Cambridge, MA, PP. 179-180.

Holderness, C.G., (1985). 'A legal foundation of exchange', Journal of Legal Studies 14, PP. 321-344, P. 326.

Holderness, C.G., (1989) 'The assignment of rights, entry effects, and the allocation of resources', Journal of Legal Studies 18, PP. 181-189, P.184.

Hollingsworth, R., (2000). Doing institutional analysis: implications for the study of innovations. Vienna: Austrian Academy of Sciences. Research Unit for Institutional Change and European Integration - ICE, P. 61.

Holmes, Stephen, Sunstein, Cass, (2000). The Cost of Rights: Why Liberty Depends on Taxes. W. W. Norton, New York.

Holtug, N., (2002), 'The Harm Principle', Ethical Theory and Moral Practice, 5(4), PP. 357389. 
Hopkins, E., \& Kornienko, T., (2004). 'Running to Keep in the Same Place: Consumer Choice as a Game of Status.' The American Economic Review. 94 (4), PP. 1085-1107.

Hosseini, H., (2001). Uncertainty and perceptual problems causing government failures in less advanced nations. The Journal of Socio-Economics, 33(2001):263-271

Hovenkamp, Herbert J., (1990). 'Marginal utility and the Coase Theorem'. Cornell Law Review, 75, PP.783-810.

Hoxby, Caroline, (2000). Peer effects in the classroom: learning from gender and race variation. NBER Working Paper No. W7867 August.

Hunt A., 1996. Governance of the Consuming Passions. Macmillan Press: London.

Hyman, D.N., (1990). Public finance: A contemporary application of theory to policy. Chicago: Dryden Press.

Hyman, David N., (2011). Public Finance: A Contemporary Application of Theory to Policy, (10ed) South-Western, Cengage Learning, P. 98.

Ireland, Norman, (1998). Status seeking, income taxation and efficiency. Journal of Public Economics 70, PP. 99-113.

J. H. Dales, (1970). .Pollution, Property, and Prices (Toronto: University of Toronto Press Toronto.

Jackson, T., (2009). Prosperity without growth. London: Earthscan.

Jacob Viner, (1931). Cost Curves and Supply Curves, 3 ZEITSCHRIFT FÜR NATIONALÖKONOMIE 23, 36.

James Buchanan, (1959). Positive Economics, Welfare Economics, and Political Economy, 2 J. L. \& ECON. 124,PP. 126-37.

James E. Meade, (1952). External Economies and Diseconomies in a Competitive Situation, 62 ECON. J. 54, 56.

James M. Buchanan, (1962). Politics, Policy and the Pigouvian Margins, 29 ECONOMICA 17.

James M. Buchanan, (1969). External Diseconomies, Corrective Taxes, and Market Structure, 59 AM. ECON. REV. 174, P. 177.

James M. Henderson \& Richard E. Quandt, (1971). Microeconomic Theory: a Mathematical approach 111 ( $2 \mathrm{~d}$ ed.).

Johnson, Marianne. (2015). "Public Goods, Market Failure, and Voluntary Exchange." In Market Failure in Context, edited by Alain Marciano and Steven G. Medema. History of Political Economy 47: 174-98. 
Joseph E. Stiglitz, (1989). Markets, Market Failures, and Development, 79 AM. ECON. REV., P. 197.

Julian Le Grand, (1991). The Theory of Government Failure. British Journal of Political Science, 21, PP 423-442.

Kahneman, Daniel, Diener, Ed, Schwartz, Norbert (Eds.), (1999). Understanding WellBeing: Scientific Perspectives on Enjoyment and Suffering. Russell Sage, New York.

Kahneman, Daniel, Krueger, Alan B., Schkade, David, Schwartz, Norbert, Stone, Arthur B., (2006). Would you be happier if you were richer? A focusing illusion. Science 312, June 30, PP. 1908-1910.

Kapferer, J., \& Michaut, A., (2015). 'Luxury and Sustainability: A Common Future? The Match Depends on how Consumers Define Luxury.' Luxury Research Journal. 1 (1), PP. 3-17.

Kashdan, A. and D. Klein, (2006). 'Assuming the Positional: Comment on Robert Frank', Economic Journal Watch, 3(3), PP. 412- 434.

Kerwin, Charles, Hurst, Erik, Roussanov, Nick, (2007). Conspicuous consumption and race. University of Chicago, mimeo.

Klaus Mathis, (2009). Efficiency instead of justice: Searching for the Philosophical Foundations of the Economic Analysis of Law, Springer Science Business Media B.V.

Klinger, B. \& Lederman, D., (2006). Diversification, innovation, and imitation inside the global technological frontier. Policy Research Working Paper Series. World Bank Policy Research Discussion Paper No. 3872, Washington, DC: The World Bank, P.2.

Kneese, A. and R. Ayres., (1969). "Production, Consumption, and Externalities, " American Economic Review 59: 282-97.

Kolm, S. C. (1977), Modern Theories of Justice, (Cambridge, MIT Press).

Lagueux, M., (2010). 'The Residual Character of Externalities', European Journal of the History of Economic Thought, 17(4), PP. 957-973.

Lagueux, Maurice., (2010). "The Residual Character of Externalities." The European Journal of the History of Economic Thought, 17 (4), PP. 957 - 973.

Lancaster K., (1971). Consumer Demand. Columbia University Press: New York, P. 174.

Landes, William M. and Richard A. Posner, (1983). 'Causation in tort law: an economic approach'. Journal of Legal Studies, 12, P.109

Landis, B., \& Gladstone, J. J., (2017). 'Personality, Income, and Compensatory Consumption: Low-Income Extraverts Spend More on Status.' Psychol Sci. 28 (10), PP. 1518-1520

Layard, Richard, (2005). Happiness: Lessons from a New Science. Penguin, London. 
Lewinsohn-Zamir, D., (1998). 'Consumer Preferences, Citizen Preferences, and the Provision of Public Goods', The Yale Law Journal, 108(2), PP. 377-406.

Lindblom, C.E., (2001). The market system: what it is, how it works, and what to make of it. New Haven, CT: Yale University Press.

Lines, D., Marcouse, I. \& Martin, B., (2006). The complete AZ business studies handbook. 5th ed. London: Hodder Arnold.

Lipsey, R. G. and Lancaster, K., (1956). The General Theory of the Second Best, Review of Economic Studies, Vol.24 (1), PP.11-23.

List F., (1841). The National System of Political Economy. Reprinted 1965 (5th edn). Augustus M. Kelley: New York;

M. Olson, Jr. and R. Zeckhauser, (June, 1970). "The Efficient Production of External Economies," American Economic Review LX, PP. 512-17.

M. Rahmatian \& L. Cockerill, (2004). Airport Noise and Residential Housing Valuation in Southern California: A Hedonic Pricing Approach 1 INT'L J. ENVTL. SCI. \& TECH. 17, 18.

Malthus, Thomas Robert., (1798). An Essay on the Principle of Population. London: Joseph Johnson.

Mandeville B., (1714). The Fable of the Bees: or, Private Vices, Public Benefits. Clarendon Press: Oxford.

Mankiw, N. G., (2002). Principles of microeconomics. Toronto: Nelson Thomson Learning, P. 120.

Mankiw, N. G., \& Taylor, M. P., (2014). Economics. (3rd ed.).

Mason R., (1985). Ethics and the supply of status goods. Journal of Business Ethics, 4, PP. 457-464.

Mason R., (1998). The Economics of Conspicuous Consumption. Edward Elgar: Cheltenham. PP. 157-159.

Mason, R., (2000). Conspicuous Consumption and the Positional Economy: Policy and Prescription since 1970. Managerial and Decision Economics. 21 (3), PP. 123-132.

Mazzoleni, R. \& Nelson, R.R., (1998). Economic theories about the benefits and costs of patents. Journal of Economic Issues, 32(4):1031-1052.

Mcmillan, J., (2002). Reinventing the bazaar: a natural history of markets. 1st Ed. New York, NY: Norton.

Meade, J. E., (1973). The Theory of Economic Externalities: The Control of Environmental Pollution and Similar Social Costs. Leiden: Sijthoff, P.15. 
Medema, S.G., \& Zerbe, R.O. Jr., (1999). The Coase theorem. In S. Medema, G. Bouckaert, \& G. DeGeest (Eds.), Encyclopedia of law and economics. Aldershot, UK: Edward Elgar.

Medema, Steven G., (2009). The Hesitant Hand: Taming Self-Interest in the History of Economic Ideas. Princeton, N.J.: Princeton University Press.

Medema, Steven G. and Richard O. Zerbe, Jr., (1999). "The Coase Theorem'. In The Encyclopaedia of Law and Economics. Boudewijn Bouckaert and Gerrit De Geest (eds.). Edward Elgar Publishing.

Medema, Steven G., (2009). The Hesitant Hand: Taming Self-Interest in the History of Economic Ideas. Princeton University Press, JSTOR.

Mestelman, S., (1982). 'Production externalities and corrective subsidies: a general equilibrium analysis.' Journal of Environmental Economics and Management 9, PP. 186-93.

Michael A. Lewis, (2012). The Spending Explosion: Positional Externalities and Exponential Consumption Growth, 7 J. Applied Quantitative Methods, 25.

Michael L. Katz and Carl Shapiro, (Jun., 1985). Network Externalities, Competition, and Compatibility, The American Economic Review, Vol. 75, No. 3, PP. 424- 440.

Mill, J. S., (1991). 'On Liberty', in J. Gray (ed.), On Liberty and Other Essays, Oxford: Oxford University Press, PP. 5-12, P. 14.

Mill, John Stuart., (1848). Principles of Political Economy. London: Longmans, Green and Co.

Miller E., (1975). Status goods and luxury taxes. American Journal of Economics and Sociology 34, PP. 141-154.

Mishan, E J., (1969). "The Relationship between Joint Products, Collective Goods, and External Effects," Journal of Political Economy, University of Chicago Press, vol. 77(3), May/June, PP. 329-348, P. 342.

Moher, P. \& Fourie, L., (2007). Economics for South African students. 4th ed. Pretoria: Van Schaik, P. 243.

Nathalie Berta and Elodie Bertrand, (2014). Market Internalisation of Externalities: What is the falling? Journal of the History of Economic Thought, 36, PP. 331-357.

Nelissen, R. M. A., \& Meijers, M. H. C., (2011). 'Social Benefits of Luxury Brands as Costly Signals of Wealth and Status.' Evolution and Human Behavior [Online]. 32 (5), PP.343-355.

Nelson, R., (1987, summer). Roles of government in a mixed economy. Journal of Policy Analysis and Management, 6, PP. 541-557. 
Nelson, R.R., (2003). The advance of technology and the scientific commons. Philosophical Transactions: Mathematical, Physical and Engineering Sciences, 361(1809):1691-1708.

North, Gary, (1992.). The Coase Theorem: A Study in Economic Epistemology, Tyler, TX: Institute for Christian Economics.

Nussbaum, M., (2000). Women and Human Development. The Capabilities Approach, Cambridge: Cambridge University Press.

Oates, W. E., (1972), Fiscal Federalism, (New York, Harcourt Brace Jovanovich).

Ostrom, E., (1990). Governing the Commons: The Evolution of Institutions for Collective Action (Political Economy of Institutions and Decisions). Cambridge: Cambridge University Press.

Papandreou, Andreas A., (1994). Externality and Institutions. Oxford: Oxford University Press.

Papandreou, Andreas., (2000). Externality, convexity and institutions. Economics and Philosophy. 19. 281309.

Paul A. Samuelson, (1954). The Pure Theory of Public Expenditure, 36 REV. ECON. \& STAT. 387.

Paul Eckerstorfer \& Ronald Wendner, (2013). Asymmetric and Non-Atmospheric Consumption Externalities, and Efficient Consumption Taxation, 106 J. PUB. ECON. 42.

Paul Samuelson, (1955). Diagrammatic Exposition of a Theory of Public Expenditure, 37 REV. ECON. \& STAT, P. 350.

Pearce, D.W., (1986). Market Failure. In Macmillan dictionary of modern economics. Pearce, D.W. (Ed.).

Perez-Truglia, R., (2013). 'A Test of the Conspicuous-consumption Model using Subjective Well-being Data.' The Journal of Socio-Economics [Online]. 45, PP.146-154.

Pigou, A.G., (1932). The economics of welfare (4th ed.). London: Macmillan, P. 173.

Polinsky, A. Mitchell., (1974). 'Economic analysis as a potentially defective product: a buyer's guide to Posner's Economic Analysis of Law'. Harvard Law Review, 87, P.1655.

Polinsky, A. Mitchell., (1979). "Controlling Externalities and Protecting Entitlements: Property Right, Liability Rule, and Tax-subsidy Approaches." Journal of Legal Studies 8 (1), PP. $1-48$.

Posner, R.A., (1997). 'Should there be homosexual marriage? And if so, who should decide?’ Michigan Law Review 95, PP. 1578-1587. 
Posner, R.A., (1983). The Economics of Justice, 2nd edition, Cambridge, MA: Harvard University Press, P.72.

Posner, R.A., (2003). 'Wedding bell blues', New Republic, December 22.

Prahalad, C.K., (2005). The fortune at the bottom of the pyramid. Upper Saddle River, NJ: Wharton School Publishing.

Randall G. Holcombe \& Russell S. Sobel, (2001). Public Policy Toward Pecuniary Externalities, 29 PUB. FIN. REV. 304, 307.

Raz, J., (1986). The Morality of Freedom, Oxford: Clarendon Press.

Raz, J., (1987). 'Autonomy, Toleration, and the Harm Principle', in R. Gavison (ed.), Issues in Contemporary Legal Philosophy. The Influence of H.L.A. Hart, Oxford: Clarendon Press, PP. 313-333.

Richard Bishop et al., (2017). Putting a Value on Injuries to Natural Assets: The BP Oil Spill, 356 SCI. 253, 254.

Richard G. Lipsey and Kelvin Lancaster, (1956). "The General Theory of Second Best," Review of Economic Studies 24, PP.11-32.

Robert H. Frank, (2008). Should Public Policy Respond to Positional Externalities?, 92 J. PUB. ECON. 1777.

Robert U. Ayres and Allen V. Kneese, (Jun., 1969), Production, Consumption, and Externalities, The American Economic Review, Vol. 59, No. 3, PP. 282-297.

Roberta Mann, (2017). Controlling the Environmental Costs of Obesity, 47 ENVTL. L. 697.

Rodrik, D., (2000). Institutions for high-quality growth: What they are and how to acquire them. Studies in Comparative International Development, 35(3), PP.3-31.

Rodrik, D., (2008). Second-best institutions. Working Paper 14050, Cambridge: National Bureau of Economic Research (NBER).

Rodrik, D., (2007). Industrial policy for the twenty-first century. In One economics, many recipes: globalisation, institutions, and economic growth. Rodrik, D. (Ed.), Princeton, NJ: Princeton University Press.

Roger Meiners \& Rafal Czajkowski, (2014), Making Cost-Benefit a Political Tool, 3 LA. ST. U. J. ENERGY L. RESOURCES 225, PP. 226, 247.

Roger Meiners, (2017). Externalities: Bad Economics, Good Law, in Exploration in public sector economics: Essays by prominent economists 61-91 (J. Hall ed.).

Ronald H. Coase, (1937). The Nature of the Firm, 4 ECONOMICA 386. 
Williamson, O. E., (1985). The economic institutions of capitalism: Firms, markets, relational contracting. New York: Free Press.

Ronald H. Coase, (1959). The Federal Communications Commission, 2 J. L. \& ECON. 1, P.12.

Ronald H. Coase, (1960). The Problem of Social Cost, 3 J. L. ECON. 1, P.29.

Ronald H. Coase, (1974). The Lighthouse in Economics, 17 J. L. \& ECON. 357.

Ronald H. Coase, (1988). The Firm, The Market, and the Law 26-27.

Herbert Hovenkamp, (2009). The Coase Theorem and Arthur Cecil Pigou, 51 ARIZ. L. REV, PP.634:635.

Ronald H. Coase, (2015). Testimony to the Federal Communications Commission, 2 MAN \& ECON. 1, P.22.

Roscher W., (1854). Principles of Political Economy. Reprinted 1878 (translated by JJ Lalor). Henry Holt and Co: New York.

Roy E. Cordato, (1998). Time Passage and the Economics of Coming to the Nuisance: Reassessing the Coasean Perspective, 20 CAMPBELL L. REV. 273, P. 273.

S. J. Liebowitz \& Stephen E. Margolis, (1994). Network Externality: An Uncommon Tragedy, 8 J. ECON. PERSP. 133, 133-34.

Samuelson, P.A. \& Nordhaus, W.D., (1992). Economics. 14th ed. New York, NY: McGraw-Hill.

Samuelson, P.A., (1954, November). The pure theory of public expenditure. Review of Economics and Statistics, 36, 386-389.

Satz, D., (2010), Why Some Things Should Not Be for Sale: The Moral Limits of Markets, New York: Oxford University Press, P.32.

Schweizer, Urs., (1988). "Externalities and the Coase Theorem: Hypothesis or Result?" Journal of Institutional and Theoretical Economics 144 (2), PP. 245 - 266.

Shavell, S., (2002). 'Law versus morality as regulators of conduct', American Law \& Economics Review 4, PP. 227-257.

Shiffrin, S. V., (2000). 'Paternalism, Unconscionability Doctrine, and Accomodation', Philosophy \& Public Affairs, 29(3), PP. 205-250.

Sidgwick, H., (2011). The Principles of Political Economy (Cambridge Library Collection Philosophy). Cambridge: Cambridge University Press.

Sidgwick, Henry. (1901). Principles of Political Economy, 3rd ed. London: Macmillan. 
Skaggs, N.T., \& Carlson, J.L., (1996). Microeconomics: Individual choice and its consequences (2nd ed.). Cambridge, MA: Blackwell Publishers, P. 543.

Smith, A., (1776) 1976. An Inquiry into the Nature and Causes of the Wealth of Nations. General editors: R. H. Campbell and A. S. Skinner. Textual editor: W. B.Todd. Oxford: Oxford University Press.

Smith, Adam., (1982). An Inquiry into the Nature and Causes of the Wealth of Nations. 1776. Rpt. Oxford: Oxford University Press.

Solnick, S. J., \& Hemenway, D., (2009) 'Do Spending Comparisons Affect Spending and Satisfaction?' The Journal of Socio-Economics. 38 (4), PP. 568-573.

Solnick, S.J., Hemenway, D., (1998). Is more always better?: a survey on positional concerns. Journal of Economic Behaviour and Organization 37, PP. 373-38.

Solomon MR, Assael H., (1987). The forest or the trees: a gestalt approach to symbolic consumption. In Marketing and Semiotics: New Directions in the Study of Signs for Sale, Umiker-Sebeok J (ed.). Mouton de Gruyter: Berlin, PP. 189-217.

Stephen N. S. Cheung. Stephen N. S. Cheung, (1973). The Fable of the Bees: An Economic Investigation, 16 J. L. \& ECON. 11, 12.

Steven G. Medema, (1999). Symposium on the Coase Theorem: Legal Fiction: The Place of the Coase Theorem in Law and Economics. Economics and Philosophy, 15, PP. 209-233.

Stigler, G.J., (2002). Monopoly. In The Concise Encyclopaedia of Economics. Henderson, D.R.E. (Ed.).

Stigler, George J., (1966). The Theory of Price. 3rd edn. Macmillan, P.113.

Stiglitz, J.E., (1998). Markets, market failures and development. Perspectives on economic development. American Economic Review, 79(2):197-203.

Thomas Aronsson \& Olof Johansson-Stenman, (2015). Keeping Up with the Joneses, the Smiths, and the Tanakas: On International Tax Coordination and Social Comparisons, $131 \mathrm{~J}$. PUB. ECON. 71.

Tibor Scitovsky, (Apr., 1954), Two Concepts of External Economies, Journal of Political Economy, Vol. 62, No. 2, PP. 143-151.

Tran Xuan Thang, (2019). Negative positional externality of conspicuous and positional goods on society: An empirical analysis on income and clothing consumption for 9 EU countries, Aalto University, P.4.

Trebilcock, M., (1993). The Limits of Freedom of Contract, London: Harvard University Press, P. 65. 
Trebilcock, M.J., (1993). The Limits of Freedom of Contract, Cambridge, MA: Harvard University Press, P.75.

Trigg, A. B., (2001). Veblen, Bourdieu, and Conspicuous Consumption. Journal of Economic Issues. 35 (1), PP. 99-115.

Tyler Cowen, Public Goods and Externalities, LIBR. ECON. \& LIBERTY, <http://www.econlib.org/library/Enc1/PublicGoodsandExternalities.html >.

Veblen, T., (1899). The theory of the leisure class: An economic study of institutions. New York: Macmillan Co.

Veljanovski, Cento G., (1982). "The Coase Theorems and the Economic Theory of Markets and Law." Kyklos, 35 (1), PP. 53 - 74.

Von Hayek, F.A., (1944), reprinted 2001. The road to serfdom. London: Routledge Classics.

Weimer, D. L. and Vining, A. R., (1999). Policy Analysis (third edition), (Upper Saddle River, N. J., Prentice Hall), P.134.

Weimer, D.L., \& Vining, A.R., (1992). Policy analysis: Concepts and practice (2nd ed.). Englewood Cliffs, NJ: Prentice Hall, P. 13.

Wen-Fang Liu, Stephen J. Turnovsky, (2005). Consumption externalities, production externalities, and long-run macroeconomic efficiency, Journal of Public Economics 89, PP. $1097-1129$.

Wertheimer, A., (2002). 'Liberty, Coercion, and the Limits of the State', in Robert Simon (ed.), The Blackwell Guide to Social and Political Philosophy, Malden, MA \& Oxford: Blackwell Publishers, PP. 38-59.

White, H.C., (2002). Markets from networks: socioeconomic models of production. Princeton, NJ: Princeton University Press.

William J. Baumol, (1972). On Taxation and the Control of Externalities, 62 AM. ECON. REV. 307, PP. 307: 308.

William Meckling \& Armen A. Alchian, (1960). Incentives in the United States, 59 AM. ECON. REV. 55, 59.

Winston, C., (2006). Government Failure versus Market Failure: Macroeconomics Policy Research and Government Performance. AEI-Brookings Joint Centre for Regulatory Studies, the American Enterprise Institute for Public Policy Research, Washington, D.C., and the Brookings Institution, Washington, D.C.

Wolf, C., (1979). "A Theory of Nonmarket Failure: Framework for Implementation Analysis". Journal of Law and Economics, Vol. 22(April), PP. 107-139. 
Wolf, C., (1987). Market and Non-Market Failures: Comparison and Assessment. Journal of Public Policy 7(1), PP. 43-70.

Zerbe, Richard \& McCurdy, Howard., (1999). The Failure of Market Failure. Journal of Policy Analysis and Management. 18, PP. 558-578. 
10 منهج البحث

13 الفصل الأول

43

65

$$
65 .
$$$$
\text { مفهوم وأنواع الأثار الخارجية الاقتصادية... }
$$
الفصل الثالث

66 المبحث الأول: مفهوم الأثار الخارجية الأنار الخار

$$
109 .
$$



المبحث الأول: الضر ائب التصحيحية واستيعاب الأثار الخارجية السلبية...

141

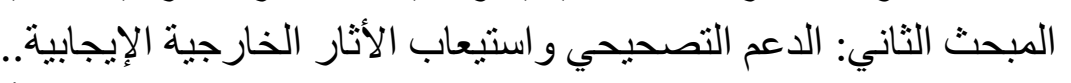

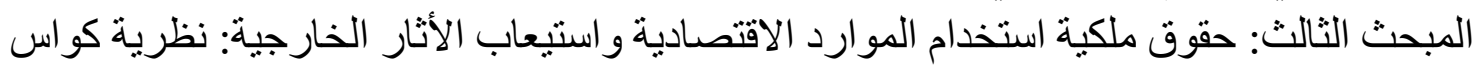
143.

151. المبحث الر ابع: دور السياسة العامة في منع الأثار الخارجية للوضع الاستهلاكي.

159 النتائج والتوصيات

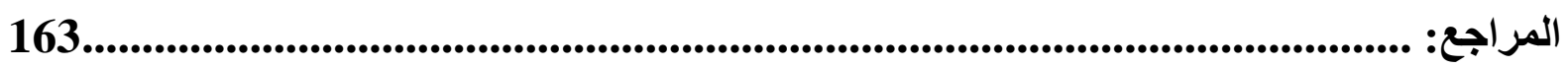
181 